Interim Consequence

Management Guidance for a

Wide-Area Biological Attack

E. Raber, R. Kirvel, D. MacQueen, A. Love, M. Dombroski, T. McGrann, J. Richards, C. Melius, T. Bunt, W. Hibbard, R. Greenwalt, R. Miles, M. Dillon, S. Mancieri, S. Harris, R. Michalik, R. Wheeler, B. Hoppes, M. Tucker, P. Krauter, R. Knowlton, L. Yang, D. Franco, W. Einfeld, J. Brockman, R. Betty

May 24, 2011 
This document was prepared as an account of work sponsored by an agency of the United States government. Neither the United States government nor Lawrence Livermore National Security, LLC, nor any of their employees makes any warranty, expressed or implied, or assumes any legal liability or responsibility for the accuracy, completeness, or usefulness of any information, apparatus, product, or process disclosed, or represents that its use would not infringe privately owned rights. Reference herein to any specific commercial product, process, or service by trade name, trademark, manufacturer, or otherwise does not necessarily constitute or imply its endorsement, recommendation, or favoring by the United States government or Lawrence Livermore National Security, LLC. The views and opinions of authors expressed herein do not necessarily state or reflect those of the United States government or Lawrence Livermore National Security, LLC, and shall not be used for advertising or product endorsement purposes.

This work performed under the auspices of the U.S. Department of Energy by Lawrence Livermore National Laboratory under Contract DE-AC52-07NA27344. 


\section{Interim Consequence Management Guidance for a Wide-Area Biological Attack}

May 17, 2011 


\section{DISCLAIMER}

This document was prepared as an account of work sponsored by an agency of the United States government. Neither the United States government nor Lawrence Livermore National Security, LLC, nor any of their employees makes any warranty, expressed or implied, or assumes any legal liability or responsibility for the accuracy, completeness, or usefulness of any information, apparatus, product, or process disclosed, or represents that its use would not infringe privately owned rights. Reference herein to any specific commercial product, process, or service by trade name, trademark, manufacturer, or otherwise does not necessarily constitute or imply its endorsement, recommendation, or favoring by the United States government or Lawrence Livermore National Security, LLC. The views and opinions of authors expressed herein do not necessarily state or reflect those of the United States government or Lawrence Livermore National Security, LLC, and shall not be used for advertising or product endorsement purposes.

This work performed under the auspices of the U.S. Department of Energy by Lawrence Livermore National Laboratory under Contract DE-AC52-07NA27344. 


\section{List of Contributors}

This document is the result of a multi-agency collaboration. Participants include the following:

U.S. Environmental Protection Agency (OEM, OHS, OPPTS, ORD, OSC RI)

U.S. Department of Homeland Security

Department of Health and Human Services (ASPR, CDC, FDA)

White House, HSC

Department of Defense/USN Interagency Operations JTF Civil Support

Department of Defense/USARNORTH

J-8 Joint Requirements Office, CBRND

Pierce County (State of Washington) Emergency Management

City of Seattle Emergency Management

King County (State of Washington) Office of Emergency Management

Defense Threat Reduction Agency Contractors: Cubic Applications, Inc., Tauri Group

$\begin{array}{ll}\text { Lawrence Livermore } & \text { National Laboratory } \\ \text { Ellen Raber } & \text { Wilthea Hibbard } \\ \text { Robert Kirvel } & \text { Robert Greenwalt } \\ \text { Don MacQueen } & \text { Robin Miles } \\ \text { Adam Love } & \text { Michael Dillon } \\ \text { Matthew Dombroski } & \text { Sav Mancieri } \\ \text { Thomas McGrann } & \text { Steve Harris } \\ \text { John Richards } & \text { Richard Michalik } \\ \text { Carl Melius } & \text { Richard Wheeler } \\ \text { Thomas Bunt } & \text { Bill Hoppes }\end{array}$

Sandia National Laboratories

Mark Tucker

Dave Franco

Paula Krauter Wayne Einfeld

Robert Knowlton

Lynn Yang John Brockman

Rita Betty

We thank the numerous individuals who reviewed this document and provided valuable input. 


\section{Contents}

\section{Table of Contents}

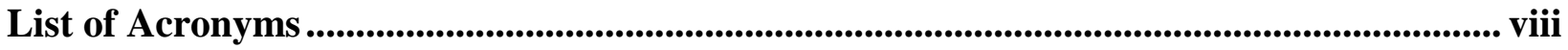

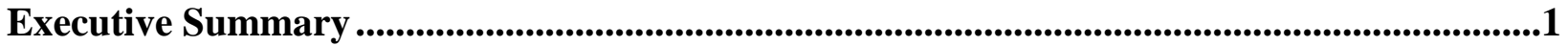

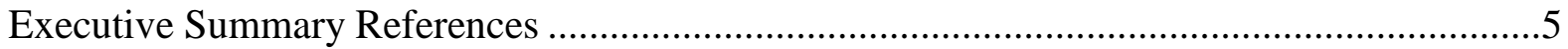

Part I: Introduction and Response Structure .....................................................................6

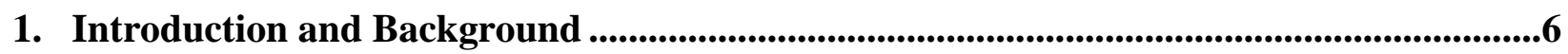

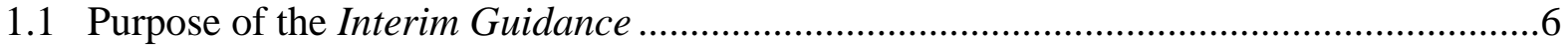

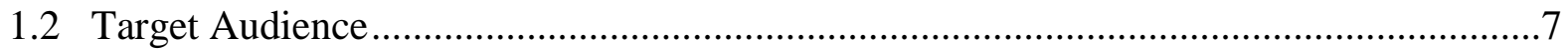

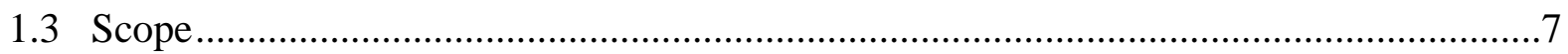

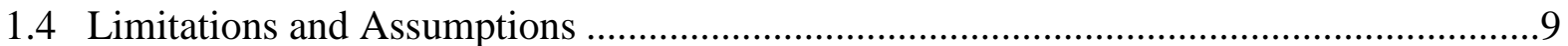

1.5 Authorities, Governance, and References............................................................. 10

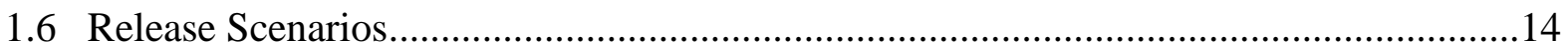

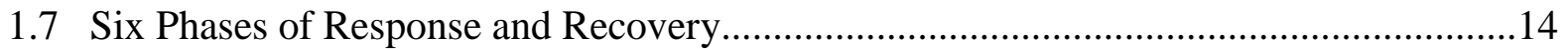

1.8 Organization and Content of the Interim Guidance .....................................................17

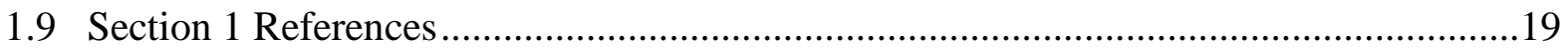

2. Response and Recovery Structure...........................................................................................21

2.1 Unified Command for a Wide-Area Incident ...........................................................21

2.2 Other State and National Components and Communication Paths ..............................34

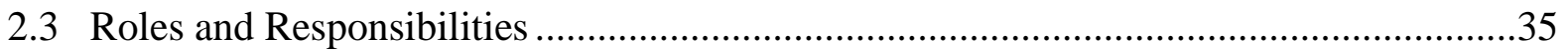

2.4 Interim Recommendations for Pre-Incident Planning ............................................37

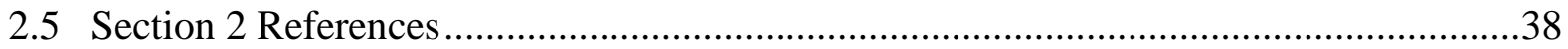

Part II: Response.............................................................................................................................40

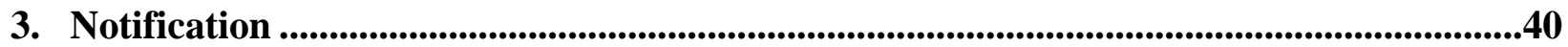

3.1 Receiving and Assessing Information (Boxes 100, 101) ..........................................41

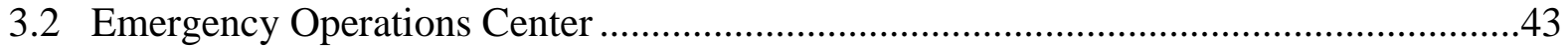

3.3 Disseminating Key Information (Boxes 102, 103) ................................................43

3.4 Interim Recommendations for Notification ...........................................................45

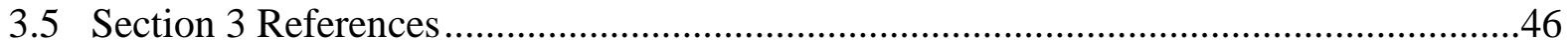

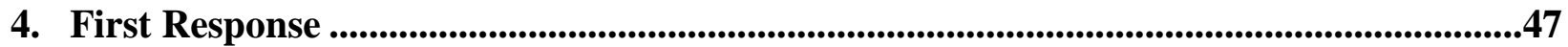

4.1 Activate and Deploy Resources and Capabilities ..................................................4 47

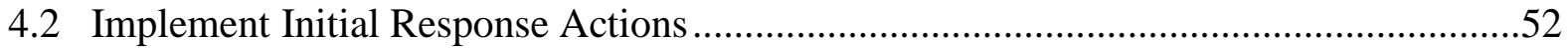

4.3 Assess the Interface of Initial Response Activities to Remediation Activities...............64

4.4 Section 4 Summary of Actions ........................................................................65

4.5 Interim Recommendations for First-Response Phase Protocols ...................................66

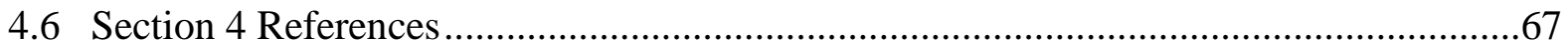

Part III: Transition to Remediation ..........................................................................................69

5. Prioritization of Essential Areas, Facilities, and Functions ..........................................69

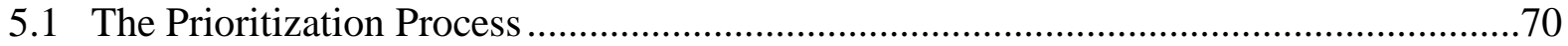




\section{Contents}

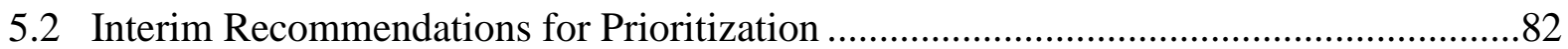

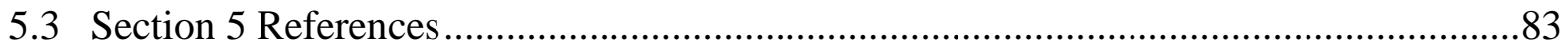

6. Risk-Based Remediation Decisions .........................................................................................84

6.1 Overall Risk Assessment and Management Methodology ............................................85

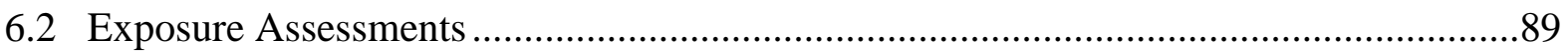

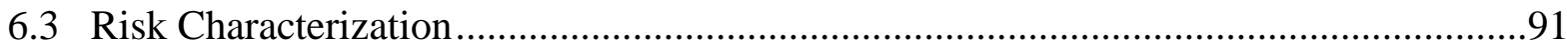

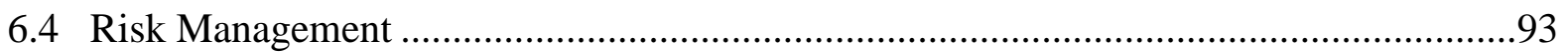

6.5 Establishing Clearance Goals .................................................................................96

6.6 Example: Applying the Methodology for a Wide-Area B. anthracis Attack ...............101

6.7 Section 6 Summary of Actions ....................................................................... 108

6.8 Interim Recommendations for Clearance Goals .......................................................109

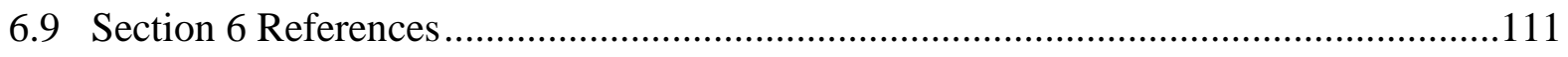

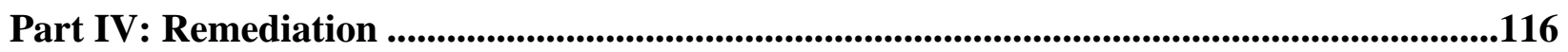

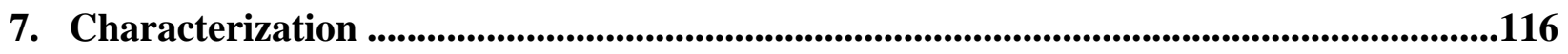

7.1 Identify Characterization Priorities (Boxes 300, 301) .............................................123

7.2 Begin Detailed Characterization Process (Box 302) .................................................124

7.3 Acquire Site-Specific Characteristics to Help Assess Contamination (Box 303) .........131

7.4 Review Existing Containment (Box 304) ..............................................................135

7.5 Develop Comprehensive Characterization Sampling Strategies ..............................137

7.6 Address Health Measures, and Provide for Worker Decontamination........................154

7.7 Conduct Characterization Environmental Sampling, Evaluate Results (Box 305-3) ....155

7.8 Conduct Environmental Risk Assessment for Remediation (Box 306)........................155

7.9 Establish Clearance Goals (Box 307) .....................................................................156

7.10 Reassess Public Health and Medical Options (Boxes 308-313, 315) ........................157

7.11 Reassess Risk Management and Communication (Box 316) ....................................157

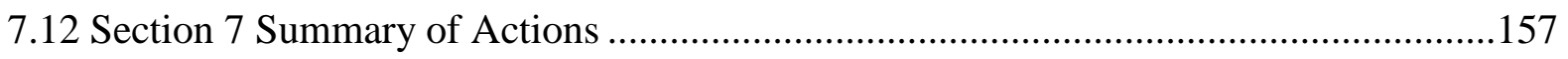

7.13 Interim Recommendations for Characterization .................................................159

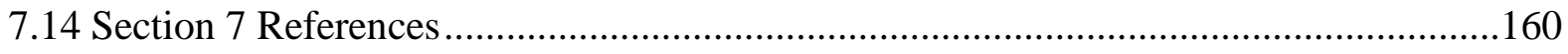

8. Decontamination .......................................................................................................165

8.1 Evaluate Options and Prioritize Decontamination Areas (Box 400) ..........................168

8.2 Evaluate Monitored Natural Attenuation vs Engineered Decontamination ................171

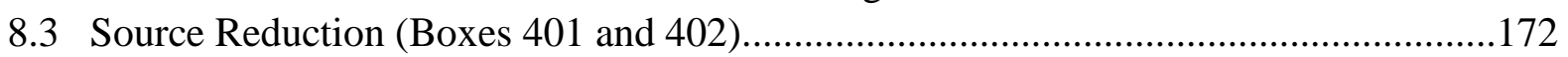

8.4 Select Decontamination Technologies (Box 403-1) ..............................................175

8.5 Select Waste-Management and Waste-Disposal Strategies (Boxes 404 and 405) ........190

8.6 Verify Decontamination Processes (Boxes 406 and 408).........................................196

8.7 Identify Civilian and Military Assets Needed to Implement Decontamination ............197

8.8 Prepare Site-Specific Remediation Action Plan(s) (Box 406)...................................198

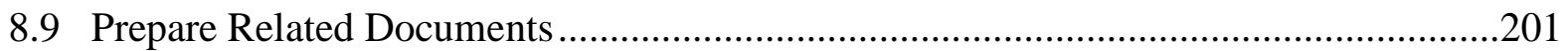

8.10 Perform Decontamination (Box 407) ....................................................................202

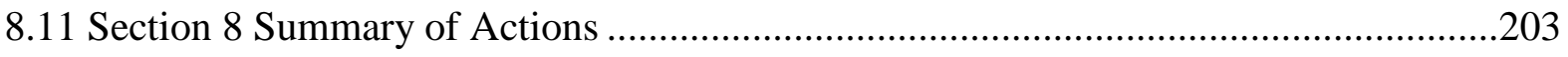

8.12 Interim Recommendations for Decontamination ...................................................204 


\section{Contents}

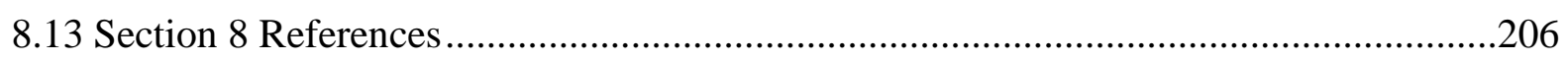

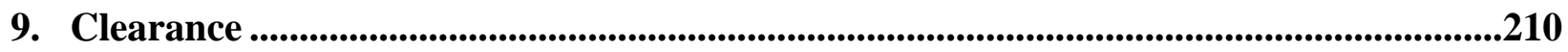

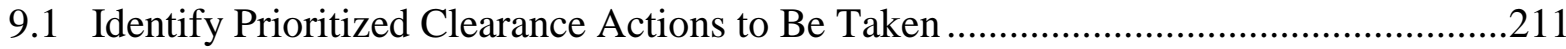

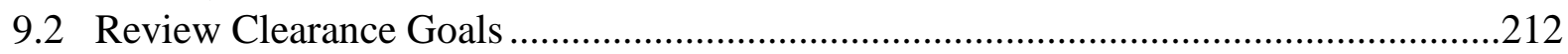

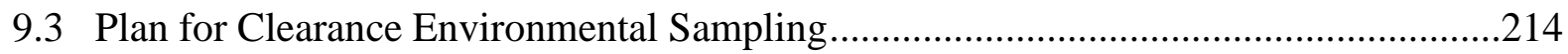

9.4 Review Data Management, Visualization, and Analysis ..............................................22

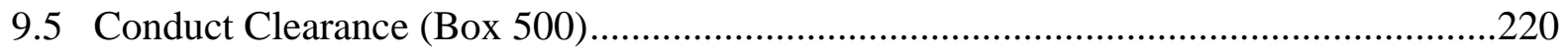

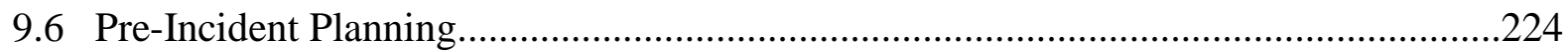

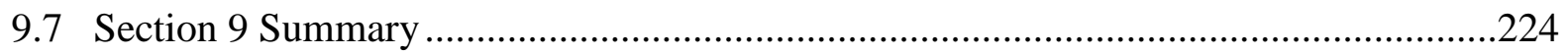

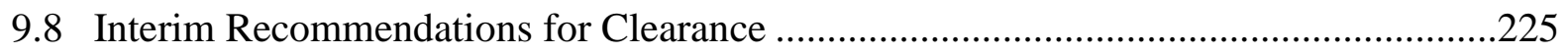

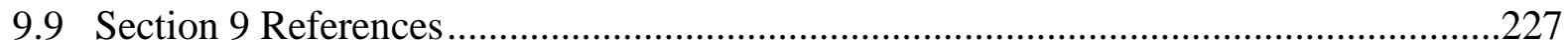

10. Restoration/Reoccupancy .....................................................................................................229

10.1 Review Reoccupancy Considerations (Boxes 600-603) …………………….............229

10.2 Evaluate Long-Term Medical Monitoring (Box 604) ……..........................................230

10.3 Initiate Post-Clearance Environmental Monitoring (Box 604).....................................231

10.4 Repopulate through Public Reassurance and Incentives ............................................232

10.5 Address Remaining Stakeholder Issues, Concerns (Box 605).....................................23

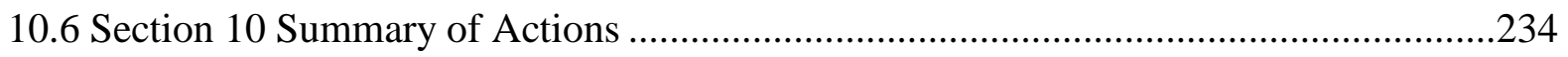

10.7 Interim Recommendations for Restoration ...............................................................235

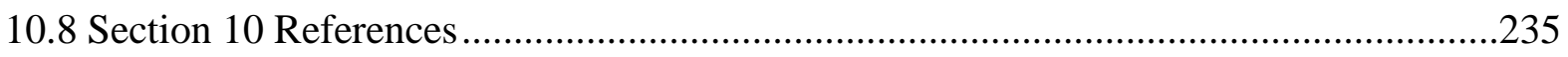

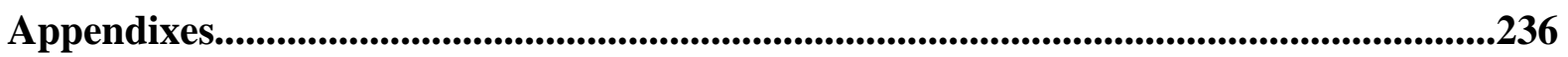

11 Checklist for Planning Wide-area Remediation …….................................................236

12 Expanded Operational Decision Framework ………...............................................242

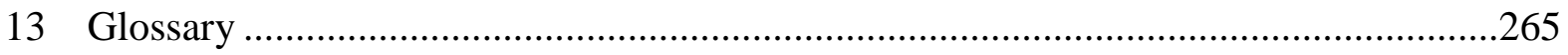




\section{Contents}

\section{Tables}

Table 2-1. Areas of expertise and organizations providing subject-matter experts ................... 26

Table 2-2. Examples of military support capabilities............................................................... 33

Table 2-3. Potential agency representatives within the IC or UC structure .............................. 36

Table 2-4. Interim recommendations for ConOps-related actions ........................................... 37

Table 3-1. Interim recommendations for notification protocols and procedures ....................... 45

Table 4-1. Risk communication and education of the public: recommended procedures.......... 63

Table 4-2. CDC example of a short public health message about anthrax exposure................... 64

Table 4-3. Summary of first-response actions in approximate order of unfolding events. ........ 65

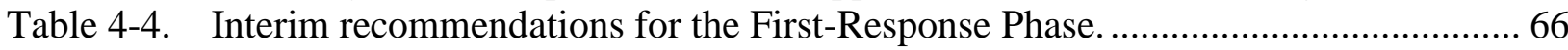

Table 5-1. Types of critical infrastructure assets listed in the National Asset Database ........... 74

Table 5-2. Example: Assign value to assets requiring remediation.............................................. 76

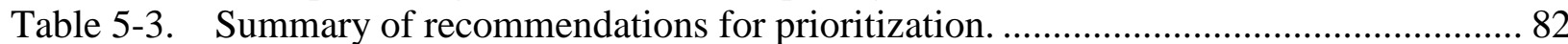

Table 6-1. Example cleanup strategies comparing cost and health risks.................................. 96

Table 6-2. Remediation alternatives and associated qualitative costs....................................... 105

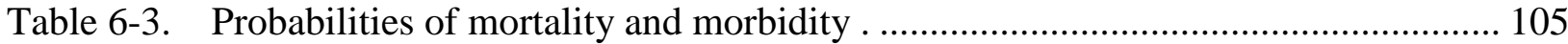

Table 6-4. Summary of risk assessment and risk management actions................................... 108

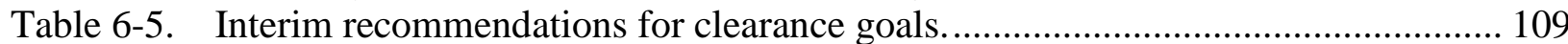

Table 7-1. Common types of biological agent fate and transport models. ${ }^{a}$.............................. 130

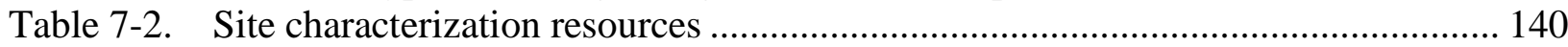

Table 7-3. Number of samples required for simple discovery sampling................................ 145

Table 7-4. Estimated limits of detection for selected surface sampling methods..................... 152

Table 7-5. Current environmental sample-processing capacities of analytical labs ................ 153

Table 7-6. Summary of characterization actions in approximate order of unfolding events... 158

Table 7-7. Summary of interim recommendations for characterization................................. 159

Table 8-1. Criteria for selecting a decontamination reagent................................................. 178

Table 8-2. Decontamination technology options for consideration .............................................. 182

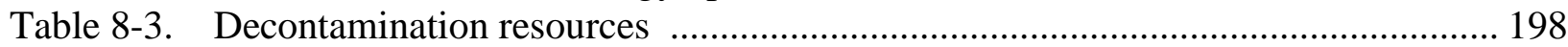

Table 8-4. Summary of decontamination actions in order of unfolding events ...................... 203

Table 8-5. Summary of recommended strategies for decontamination.................................. 204

Table 9-1. Summary of clearance actions to be taken prior to a biological attack. ................. 224

Table 9-2. Summary of clearance actions in approximate order of unfolding events. ............ 224

Table 9-3. Summary of interim recommendations for clearance. ........................................... 226

Table 10-1. Summary of restoration actions in approximate order of unfolding events. .......... 234

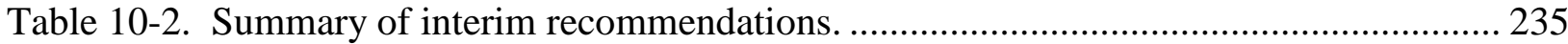




\section{Figures}

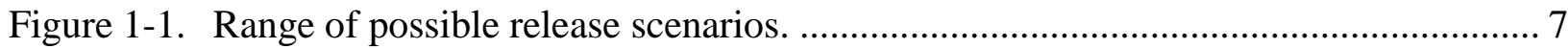

Figure 1-2. Influences of national preparedness initiatives to emergency planning ................... 11

Figure 1-3. Response and recovery phases to wide-area biological contamination .................... 15

Figure 1-4. Principal operational phases of response and recovery .......................................... 18

Figure 2-1. Notional command structure for a biological release............................................. 23

Figure 2-2. Possible components of the command structure for remediation ............................. 24

Figure 2-3. Components of the Technical Working Group. ..................................................... 25

Figure 2-4. Components of an Environmental Clearance Committee. ...................................... 27

Figure 2-5. National Guard and Active Force response timelines for civil response. ................ 28

Figure 2-6. Example of the civil response process................................................................. 29

Figure 2-7. National Guard and USNORTHCOM CBRNE response force packages. ............... 30

Figure 2-8. Example DOD command and control structure for DSCA. .................................... 33

Figure 3-1. Principal activities associated with the Notification Phase ...................................... 40

Figure 3-2. Expanded steps for Box 100: activate an Emergency Operations Center................. 42

Figure 4-1. Principal activities association with the First-Response Phase. ................................ 48

Figure 4-2. Expanded Box 204: define and establish preliminary hot and warm zones............. 56

Figure 4-3. Expanded Box 208: perform additional sampling and analysis ..............................59

Figure 4-4. Expanded Box 215: implement additional emergency-response actions ................... 61

Figure 5-1. Recommended 5-step prioritization methodology. .................................................. 71

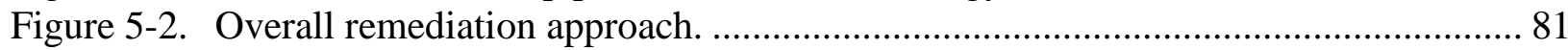

Figure 6-1. Risk assessment and risk management .............................................................. 86

Figure 6-2. Approach to characterize risk and develop risk-based remediation guidance . ........8 88

Figure 6-3. Two images of the same contaminated area after the Chernobyl disaster .............. 91

Figure 6-4. Cumulative inhaled exposure for an individual over an 8-hr period ...................... 102

Figure 6-5. Assumed dose-response relation for inhaled anthrax exposure ............................ 103

Figure 6-6. Probability of lethality and infection over an 8-hr period ........................................... 104

Figure 6-7. Comparison of cost and expected mortality. ....................................................... 106

Figure 6-8. Revised comparison of alternatives with error bars ............................................... 107

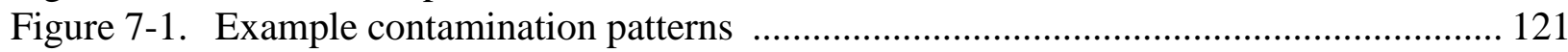

Figure 7-2. Principal activities association with the Characterization Phase............................ 122

Figure 7-3. Expanded Box 301: identify and prioritize areas for detailed characterization. .... 123

Figure 7-4. Expanded Box 302: assess all collected information to identify data gaps............ 125

Figure 7-5. Expanded Box 303: determine site-specific characteristics................................... 132

Figure 7-6. Expanded Box 304: review and improve containment.......................................... 136

Figure 7-7. Expanded Box 305: conduct characterization environmental sampling ................ 138

Figure 7-8. Example of grid/transect layout of sample locations. .......................................... 147

Figure 7-9. Expanded Box 306: conduct environmental risk assessment ............................... 156

Figure 8-1. Principal activities associated with the Decontamination Phase............................. 167

Figure 8-2. Expanded Box 400: Evaluate decontamination options........................................... 169

Figure 8-3. Expanded Box 403: develop decontamination strategy. ....................................... 176

Figure 8-4. Box 404 expanded: determine strategy for waste to be recycled or reused. ........... 191

Figure 8-5. Box 405 expanded: determine strategy for waste to be disposed........................... 192

Figure 8-6. Box 406 expanded: develop RAP and clearance SAP. ........................................... 199 


\section{Contents}

Figure 9-1. Principal activities associated with the Clearance Phase. ................................. 212

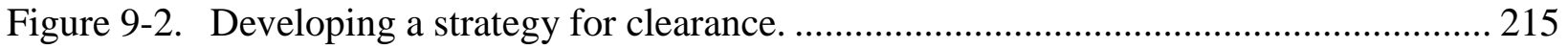

Figure 9-3. Box 500 expanded: conduct clearance environmental sampling. ....................... 222

Figure 10-1. Principal activities associated with the Restoration/Reoccupancy Phase. ............ 230

Figure 10-2. Box 604 expanded: consider long-term environmental monitoring...................... 231 


\section{Acronyms}

\section{List of Acronyms}

\begin{tabular}{|c|c|}
\hline AAMI & Association for Advancement of Medical Instrumentation \\
\hline AAMP & Ambient Air Monitoring Plan \\
\hline ACAMS & Automated Critical Asset Management System \\
\hline ACIP & Advisory Committee on Immunization Practices \\
\hline AHU & air handling unit \\
\hline AML & Area Medical Laboratory (Department of Defense) \\
\hline ARAR & applicable or relevant and appropriate requirement \\
\hline ARNORTH & U.S. Army North \\
\hline ASPR & Assistant Secretary for Preparedness and Response \\
\hline ATSDR & Agency for Toxic Substances and Disease Registry \\
\hline AVA & Anthrax Vaccine Absorbed \\
\hline AWARE & Analyzer for Wide-Area Restoration Effectiveness \\
\hline BAC & BioWatch Advisory Committee \\
\hline BADD® & Biowarfare Agent Detection Devices \\
\hline B. anthracis & Bacillus anthracis (causative agent of the disease anthrax) \\
\hline BAR & BioWatch Actionable Result \\
\hline BASIS & Biological Aerosol Sentry and Information System \\
\hline BDS & Biohazardous Detection System \\
\hline $\mathrm{BI}$ & biological indicator \\
\hline BROOM & Building Restoration Operations Optimization Model \\
\hline BSA & Base Support Area \\
\hline BSI & Base Support Installation \\
\hline BSL & Biohazard Safety Level \\
\hline BWA & biological warfare agent \\
\hline CARA & CBRNE Analytical and Remediation Activity \\
\hline CBIRF & Chemical, Biological, Incident Response Force (U.S. Marine Corps) \\
\hline CBRNE & chemical, biological, radiological, nuclear, or high-yield explosive \\
\hline CCMRF & CBRNE Consequence Management Response Force \\
\hline $\mathrm{CDC}$ & Centers for Disease Control and Prevention \\
\hline CERCLA & Comprehensive Environmental Response, Compensation, and Liability Act \\
\hline CERFP & CBRNE Enhanced Response Force Package \\
\hline CFD & computational fluid dynamics \\
\hline CFM & cubic feet per minute \\
\hline $\mathrm{ClO}_{2}$ & chlorine dioxide \\
\hline CMAT & Consequence Management Advisory Team \\
\hline ConOps & concept of operations \\
\hline CONUS & continental United States \\
\hline COOP & Continuity of Operations Plan \\
\hline CSM & conceptual site model \\
\hline CST & Civil Support Team \\
\hline CWA & chemical warfare agent \\
\hline DCO & Defense Coordinating Officer \\
\hline DHHS & U.S. Department of Health and Human Services \\
\hline DHS & U.S. Department of Homeland Security \\
\hline DNA & deoxyribonucleic acid \\
\hline
\end{tabular}




\section{Acronyms}

\begin{tabular}{|c|c|}
\hline DOD & Department of Defense \\
\hline DOE & Department of Energy \\
\hline DEOC & Director's Emergency Operations Center (of the CDC) \\
\hline DOI & U.S. Department of Interior \\
\hline DOT & U.S. Department of Transportation \\
\hline DSCA & Defense support of civil authorities \\
\hline DTRA & Defense Threat Reduction Agency \\
\hline ECBC & Edgewood Chemical Biological Center \\
\hline ECC & Environmental Clearance Committee \\
\hline ECH & ethylene chlorohydrin \\
\hline EMAC & Emergency Management Assistance Compact \\
\hline EMG & Emergency Management Group (DHHS) \\
\hline EMS & Emergency Management Services \\
\hline EOC & Emergency Operations Center \\
\hline EPA & Environmental Protection Agency \\
\hline ERLN & Environmental Response Laboratory Network \\
\hline ESF & Emergency Support Function (of the National Response Framework) \\
\hline EtO & ethylene oxide \\
\hline EU & Environmental Unit \\
\hline FBI & Federal Bureau of Investigation \\
\hline FAA & Federal Aviation Administration \\
\hline FCO & Federal Coordinating Officer \\
\hline FDA & Food and Drug Administration \\
\hline FEMA & Federal Emergency Management Agency \\
\hline FIELDS & Fully Integrated Environmental Location Decision Support \\
\hline FIFRA & Federal Insecticide, Fungicide, and Rodenticide Act \\
\hline GAO & U.S. Government Accounting Office \\
\hline GIS & Geographic Information System \\
\hline GPS & Global Positioning System \\
\hline HASP & Health and Safety Plan \\
\hline HazMat & hazardous materials \\
\hline HAZWOPER & Hazardous Waste Operations and Emergency Response \\
\hline HEPA & high-efficiency particulate air \\
\hline HHS & Department of Health and Human Services (also referred to as DHHS) \\
\hline HMRU & Hazardous Materials Response Unit \\
\hline HSIP & Homeland Security Infrastructure Program \\
\hline HSPD & Homeland Security Presidential Directive \\
\hline HTP & high throughput \\
\hline HVAC & heating, ventilation, and air conditioning \\
\hline IAP & Incident Action Plan \\
\hline IBRD & Interagency Biological Restoration Demonstration (Program) \\
\hline IC & Incident Command \\
\hline $\mathrm{ICP}$ & Incident Command Post \\
\hline ICS & Incident Command System \\
\hline ID & infectious dose \\
\hline IDQTF & Intergovernmental Data Quality Task Force \\
\hline IMAAC & Interagency Modeling and Atmospheric Assessment Center \\
\hline IMT & Incident Management Team \\
\hline IPS & Integrated Planning System \\
\hline IRCT & Incident Response Coordination Team \\
\hline
\end{tabular}




\section{Acronyms}

IRF

ISSA

IT

JCCSE

JFHQ

JFLCC

JFO

$\mathrm{JIC}$

$\mathrm{JOC}$

JTF

JTF-CM

JTF-CS

LBL

LD

LFA

LLNL

LOD

LRN

MAA

MAUT

MCL

MEI

MOA

MOU

NARAC

NAS

NAU

NBFAC

NCP

NCR

NCTC

NDMS

NEMA

NEPA

NGRF

NHSRC

NIOSH

NIMS

NISAC

NMRC

NOAA

NOC

NPDWR

NRC

NRCC

NRF

NRT

OCP

ORNL

OSC
Initial Response Force

Inter Service Support Agreement

information technology

Joint CONUS Communications Support Environment

Joint Force Headquarters

Joint Force Land Component Commander

Joint Field Office

Joint Information Center

Joint Operations Center

Joint Task Force

Joint Task Force-Consequence Management

Joint Task Force-Civil Support

Lawrence Berkeley Laboratory

lethal dose

Lead Federal Agency

Lawrence Livermore National Laboratory

limit of detection

Laboratory Response Network

Mutual Assistance Agreement

multi-attribute utility theory

maximum contaminant level

minimum essential infrastructure

memorandum of agreement

memorandum of understanding

National Atmospheric Release Advisory Center

National Academy of Sciences

negative air unit, also known as negative air machine, or NAM

National Bio-Forensic Analysis Center

National Contingency Plan

National Capitol Region

National Counterterrorism Center

National Disaster Medical System

National Emergency Management Association

National Environmental Policy Act

National Guard Response Force

National Homeland Security Research Center

National Institute for Occupational Safety and Health

National Incident Management System

National Infrastructure Simulation and Analysis Center

Naval Medical Research Center

National Oceanic and Atmospheric Administration

National Operations Center

National Primary Drinking Water Regulations

National Research Council

National Response Coordination Center

National Response Framework

National Response Team

operational command post

Oak Ridge National Laboratory

On-Scene Coordinator; also Federal On-Scene Coordinator (FOSC) 


\section{Acronyms}

OSHA

OSTP

PAHPA

PCR

PEP

PFO

PNNL

POD

POTW

PPE

ppm

PSU

QA/QC

RAP

RCRA

RM

RODAC

RPIN

RV-PCR

SADA

SAM

SAP

SARA

SBAC

SCC

SFO

SIOC

SMART

SMC

SME

SNL

SNS

SOC

SQL

TSA

TWG

UC

UFP-QAPP

USACE

USAMRIID

USC

USDA

USGS

USNORTHCOM

UTM

VPHP

VSP

WSVA

WMD
Occupational Safety and Health Administration

Office of Science and Technology Policy

Pandemic and All-Hazards Preparedness Act

polymerase chain reaction

post-exposure prophylaxis

Principal Federal Official

Pacific Northwest National Laboratory

Points of Dispensing

publicly owned treatment works

personal protective equipment

parts per million

portable sampling unit

quality assurance and quality control

Remediation Action Plan

Resource Conservation and Recovery Act

Response Manager

replicate organism detection and counting

Regional Public Information Network

rapid-viability polymerase chain reaction

Spatial Analysis and Decision Assistance

standard analytical method

Sampling and Analysis Plans

Superfund Amendments and Reauthorization Act

solid block activated carbon (filter)

Scientific Support Coordinator

San Francisco International Airport

Strategic Information and Operations Center

Specialty Medical Augmentation Response Team

Seattle Municipal Code

subject-matter expert

Sandia National Laboratories

Strategic National Stockpile

Secretary Emergency Operations Center (DHHS)

Structured Query Language

Transportation Security Administration

Technical Working Group

Unified Command

Uniform Federal Policy for Quality Assurance Project Plans

U.S. Army Corps of Engineers

U.S. Army Medical Research Institute for Infectious Diseases

United States Code

Department of Agriculture

United States Geological Survey

U.S. Northern Command

universal transverse Mercator

vapor-phase hydrogen peroxide

Visual Sampling Plan

Water System Vulnerability Assessment

weapon of mass destruction 


\section{Summary}

\section{Executive Summary}

The Interagency Biological Restoration Demonstration (IBRD) program is a collaborative, interagency effort co-chaired by the Department of Homeland Security and Department of Defense aimed at improving the nation's ability to respond to and recover from a large-scale, wide-area, domestic attack involving the release of an environmentally persistent biological warfare agent. The program is focused on understanding interactions between the civilian and military sectors, and in building mutual support to carry out such remediations.

This Interim Consequence Management Guidance document provides guidance for decisionmakers in executing activities required to respond to and recover from a biological incident affecting a wide urban area insofar as information is currently available. The spore-forming bacterium Bacillus anthracis is discussed as the biological agent of primary concern because it is the most difficult of known bioterrorism agents to inactivate and is considered to be one of the key threat agents. Most other biological threat agents are much easier to remediate, and in many cases, inactivation would occur naturally within days as a result of environmental exposure; however, the framework and operational questions that need to be addressed are expected to remain the same.

The guidance in this document is applicable to (1) enclosed facilities, such as commercial, residential, and continental U.S. military facilities; (2) semi-enclosed facilities, such as subways and public transit facilities; (3) outdoor areas (both localized and wide area), such as building exteriors, streets, parks, and other open spaces; (4) drinking water facilities; and (5) drinking water sources.

This document follows an interagency framework [Planning Guidance for Recovery Following Biological Incidents (DHS and EPA 2009)] — which considered Raber et al. (2002) in its development - but takes the framework to a more operational level and provides guidance at key action and decision points. The information in this Interim Guidance serves as a current baseline and can be used to develop a comprehensive roadmap outlining key science and technology areas as well as preplanning priorities for a wide-area biological incident. Any framework will not necessarily be followed sequentially, and tasks and decisions will occur in parallel.

Section 1 summarizes the document's purpose, audience, scope, and organization. It addresses important limitations, largely imposed by knowledge and capability gaps, enumerated throughout the document by topic. Governing authorities for plan implementation are identified.

Section 2 identifies the response and recovery structure and defines roles and responsibilities as envisioned today following wide-area biological contamination. The structure and recommendations conform to the National Response Framework (NRF) (DHS 2008), guidance on language contained in the Integrated Planning System (DHS 2009), and implementation of the National Incident Management System (NIMS 2008). A key concept is that of an Incident Command evolving into a Unified Command, which would be formed to direct cleanup jointly and to take ultimate responsibility for cleanup decisions. In some facilities and jurisdictions, additional response plans or procedures (such as BioWatch or other regional emergency response plans or protocols) may govern notification and first response. 


\section{Summary}

During several indoor cleanups, which included fumigations following the anthrax attacks of 2001 in the U.S., a Technical Working Group of multi-agency, multi-disciplinary experts was convened to evaluate data and make recommendations on technical aspects of the response. A separate Environmental Clearance Committee was also convened at most of the sites to independently review pre- and post-decontamination sampling data and data on decontamination parameters, to evaluate whether the decontamination was effective, and to provide recommendations on whether or not the facilities were safe for re-use, thus adding credibility to decisions about reoccupying indoor decontaminated areas. Use of specialized technical expertise is recommended in this Interim Guidance, although such expertise would now operate within the construct of the NIMS Incident Command System.

Subsequent sections of the Interim Guidance are structured around the principal phases of response and recovery. However, the first two phases, Notification (Section 3) and First Response (Section 4), are treated relatively briefly. These two phases relate to many initial and transitional activities - such as initial public health assessments and environmental samplingthat may, in turn, affect subsequent phases of response and recovery that are the main focus of the document. This document does not describe in detail all the public health responses to release of a biological warfare agent. If the presence of a viable biological agent were confirmed, likely by public health personnel, then the responsible public health agencies would commence appropriate actions, such as treatment and decontamination of potentially contaminated individuals, distribution of prophylaxis, vaccination, and medical examinations.

Before wide-area cleanup begins in earnest, it is necessary to identify and prioritize essential areas and facilities in affected regions. The proposed five-step prioritization process (Section 5) begins by setting remediation objectives and concludes by optimizing remediation resources to clean up rank-ordered assets. As part of an interative prioritization process, this Interim Guidance advocates the rapid and complete (to the extent possible) remediation of outdoor areas in contaminated (hot) zones first, before proceeding to prioritized interior spaces to minimize the likelihood of recontamination and health risk and to maximize access by remediation personnel.

It is essential to apply the principles of sound risk management and to develop risk-based clearance goals, which inform subsequent decisions. Section 6 describes a risk assessment and management methodology, discusses the difficulties of setting clearance goals for B. anthracis, shows how the methodology would be applied to a wide area, and concludes with interim recommendations regarding risk assessment and management according to our knowledge of the science today. Any approach would be incident- and site-specific, and any decisions must address both scientific and political considerations.

Sampling would occur throughout a response and recovery, including screening environmental sampling (Section 4), characterization environmental sampling (Section 7), sampling to support decontamination (both environmental sampling and decontamination verification sampling; Section 8), clearance environmental sampling (Section 9), post-clearance environmental sampling (long-term monitoring; Section 10), and BioWatch sampling if an incident were to occur in a BioWatch city. In addition, sampling would be done to support public health assessments and actions. Where practical, sampling can serve both public health and remediation planning objectives; however, this document focuses on sampling for remediation.

Characterization (Section 7) is an iterative process of gathering information needed to understand health risks and the options to mitigate the risks. Preliminary assessments of the hazard involve 


\section{Summary}

evaluating the screening environmental sampling data collected by first responders, forensic data, initial targeted environmental sampling and analysis data as well as health assessments conducted by public health, and all other sources of data, such as plume modeling, to approximate the locations of contamination. Confirmation of agent type and viability is obtained from Laboratory Response Network or other qualified laboratories. The steps to develop comprehensive characterization sampling strategies are described, leading to zone-specific Characterization Sampling and Analysis Plans with all goals identified. Upon approval of such plans by the Incident or Unified Command, characterization commences.

Characterization assessments should identify "hot" zones, in which some type of action needs to be taken, "cold" zones in which decision-makers are willing to assert no action is needed, and "warm" zones that separate the two for staging and personnel or equipment decontamination. Remaining indeterminate areas will require some degree of characterization. Principal tools for characterization are environmental sampling, laboratory analysis of agent properties, fate and transport models, and epidemiology data. Characterization activities are aimed at determining the extent of contamination. Such determination will involve the collection and analysis of surface and bulk samples as well as Interagency Modeling and Atmospheric Assessment Center models to refine the area quickly with minimum samples. Although the results will indicate the extent of residual contamination and potential areas that may pose a health risk, inhalation risk should also be determined by characterizing the amount of respirable viable spores present in a person's breathing zone. The dermal and ingestion risks must also be evaluated (e.g., from contaminated water and soil).

The choice of decontamination method depends on characteristics of the agent, the nature and extent of contamination, and other site-specific parameters identified during characterization. Decontamination-related decisions can have a major impact on waste-disposal costs, so it is necessary to develop a disposal plan that identifies the means of disposal, approvals, transportation, and other details. Clearance goals drive decontamination requirements, and after reviewing the prioritization scheme together with the results of characterization, Remediation Action Plans specifying the chosen decontamination methods are developed (Section 8). Under NIMS, such plans are implemented through a series of standardized, shorter-term Incident Action Plans, which describe activities to take place during a specified period. For some biological warfare agents that do not remain viable in the environment for long, monitored natural attenuation may be an adequate decontamination option. However, for $B$. anthracis spores that are known to be capable of remaining viable in the environment (such as in soil) for many years, and when time is of the essence for economic and other reasons, monitored natural attenuation may not always be realistic. It is expected that liquid reagents and foams will be used for equipment, limited surface cleanup and hot spot decontamination will be done on nonporous surfaces indoors and outdoors, and water and wastewater will be decontaminated. Both technology development and validation testing are limited with respect to outdoor decontamination of $B$. anthracis spores, thus any strategy must be tested at smaller scale and evaluated for effectiveness before large-scale application. If wide-area outdoor decontamination is necessary, several strategies could be evaluated for application. Strategy options are discussed involving the use of reagents to be dispersed over large areas, and all requiring efficacy testing.

For extensive contamination at indoor locations by agents that may remain viable for extended times (months or years), engineered processes such as fumigation might be necessary. Both vaporous hydrogen peroxide and gaseous chlorine dioxide were used successfully to fumigate 


\section{Summary}

building interiors after the 2001 anthrax attacks and should be considered as the standard approaches along with other options. Following a wide-area attack, it is recommended that as few materials as possible (namely, extremely high-value items, contaminated perishables such as foodstuffs, and items that cause difficulty for engineered decontamination processes) be removed from contaminated facilities before decontamination because costs would otherwise be prohibitive, space and disposal options are expected to be limited, and time is of the essence. A cost-benefit analysis should be incorporated in decisions concerning decontamination of items in situ for retention or ultimate disposal as solid waste, versus transportation to an off-site facility for disposal as regulated medical waste. The enormous waste stream arising from wide-area contamination would be highly problematic.

Section 9 addresses clearance. A clearance strategy is developed to ensure that after decontamination, agreed-on risk levels are met or optimized, and risks understood. A clearance sampling plan is developed, which sets clearance criteria for outdoor, indoor, and water facilities, specifies how to determine whether the criteria have been met, and describes how and where to collect clearance samples after decontamination. For purposes of clearance, high-volume air sampling is recommended for consideration for both outdoor and indoor areas along with other factors for success, such as verification that fumigation parameters are met, if fumigation is used. Aggressive air sampling may also be considered indoors (NRT 2005, p. 50; ATSDR 1994). Targeted surface sampling is recommended for contaminated indoor facilities, but only limited outdoor surface samples are expected to be taken.

Clearances goals recommended for consideration are discussed in Sections 6 and 9. For the anthrax incidents to date, indoor cleanup was considered successful only when there was no growth of $B$. anthracis cultured from any indoor environmental samples taken after decontamination. No codified clearance goals for outdoor $B$. anthracis remediation exist at present. A clearance goal recommended for consideration is, "no viable B. anthracis spores detected above background levels from any high-volume (and possibly aggressive) air sampling." Some surface sampling may also be necessary to understand whether a health risk for cutaneous anthrax is present even though the case-fatality rate of cutaneous anthrax is less than $1 \%$ with antibiotic treatment. Section 6 identifies two levels of $B$. anthracis spore contamination in drinking water deemed by the U.S. Army to cause illness, depending on amount of water consumption, and such values might be used as starting points for discussion. Any clearance goals for outdoor areas and water, in particular drinking water, would need buy-in from area decision-makers and stakeholders. The Unified Command makes the final decision that an area, resource, or facility is acceptable for reoccupancy.

Section 10 addresses the Restoration/Reoccupancy Phase, which consists of assisting individuals, businesses, and critical infrastructure in meeting basic needs and returning to self-sufficiency. Whereas a detailed account of long-term restoration is outside the scope of this Interim Guidance, Section 10 briefly reviews some recovery considerations that must be addressed by urban-area decision-makers. Effective communication with the media and public is an essential component through all phases of wide-area response and recovery. Section 11 is a checklist for planning wide-area remediation. A glossary of terms is located at the end of the document, and Interim Guidance recommendations are made in final tables for each phase of response and recovery. 


\section{Summary}

Response and recovery following the wide-area release of a biological agent is certain to be a complex and resource-intensive undertaking involving unprecedented challenges arising from the many unknowns, resource limitations, and current knowledge gaps as well as areas of disagreement and uncertainty. High-priority gaps are identified in this Interim Guidance in the context of specific remediation actions. Nevertheless, much has been learned from indoor cleanups following the anthrax attacks of 2001 in the U.S. Several pertinent interagency guidance documents on the topic of decision-making and indoor biological remediation are in the final stages of preparation or have been released in recent years (see subsequent references), and new work is underway to identify technologies and procedures to enhance response and recovery processes.

\section{Executive Summary References}

ATSDR (1994), U.S. Department of Health and Human Services, Public Health Service, Agency for Toxic Substances and Disease Registry, Division of Health Assessment and Consultation, Environmental Data Needed for Public Health Assessments, A Guidance Manual; available at <http://www.atsdr.cdc.gov/ednpha.html\#ambient $>$, accessed May 4, 2009.

DHS (2008), Department of Homeland Security, National Response Framework; documents available at $<$ http://www.fema.gov/emergency/nrf/> .

DHS (2009), Department of Homeland Security, Integrated Planning System; available at <http://www.hlswatch.com/wp-content/uploads/2009/01/dhs-integrated-planning-system-january-2009.pdf $>$.

DHS and EPA (2009), Department of Homeland Security and Environmental Protection Agency, Planning Guidance for Recovery Following Biological Incidents, National Science and Technology Council, Biological Decontamination Standards Working Group.

NIMS (2008), National Incident Management System, document available at: <http://www.fema.gov/pdf/emergency/nims/NIMS_core.pdf>.

NRT (updated July, 2005), National Response Team, Technical Assistance for Anthrax Response, Interim-Final Draft; available at $<$ http://www.nrt.org/production/NRT/NRTWeb.nsf/PagesByLevelCat/Level2TA?Opendocument $>$.

Raber, E., J. M. Hirabayashi, S. P. Mancieri, A. L. Jin, K. J. Folks, T. M. Carlsen, and P. Estacio (2002), "Chemical and Biological Agent Incident Response and Decision Process for Civilian and Public Sector Facilities," Risk Analysis 22(2), 195-202. 


\section{Part I: Introduction and Response Structure}

\section{Introduction and Background}

In the event of a large-scale, wide-area, domestic terrorist attack involving a release of biological warfare agent (BWA), decision-makers will need to make important choices concerning how to respond and recover. This Interim Consequence Management Guidance for a Wide-Area Biological Attack identifies the issues that must be addressed and activities to be carried out following such an attack. The document discusses resources that are available and procedures that could be implemented today should such an incident occur in a major metropolitan area.

This Interim Guidance is funded by, and developed as part of, the Interagency Biological Restoration Demonstration (IBRD) program - a collaborative effort among Department of Homeland Security (DHS), Department of Defense (DOD), and numerous other Federal, state, and local agencies - to improve the nation's ability to respond and recover following a wide-area biological incident. The Homeland Security Council recommended developing an interim product to provide guidance for plan development using current knowledge and capabilities (the "as-is" state of affairs). Accordingly, the objective of this interim product is to provide guidance if such an attack were to happen tomorrow, and it fills a short-term need until the final product is developed. The information in this Interim Guidance serves as a current baseline and can be used to develop a comprehensive roadmap outlining key science and technology areas as well as preplanning priorities for a wide-area biological incident.

\subsection{Purpose of the Interim Guidance}

The purpose of this document is to provide current knowledge and best practices for biological remediation planning and execution at all levels. Such guidance is designed to assist localities in developing their own regionally specific, operational plans that address the unique challenges associated with a biological terrorism attack over a wide urban area. As such, the document serves as a bridge between an overall Federal framework, under the recent Integrated Planning System (IPS; see DHS 2009), and the eventual development of regional operational plans.

As Danzig (1999, p. 5) has suggested, if it is unlikely that all BWA attacks can be thwarted or deterred, then "What is more believable is that success will come by managing the consequences of an attack and limiting its effects." One of the principal recommendations contained in The Report of the Commission on the Prevention of WMD Proliferation and Terrorism (Graham, et al. 2008) is that the United States should undertake to "...enhance the nation's capabilities for rapid response to prevent biological attacks from inflicting mass casualties."

The Interim Guidance provides a set of procedures and coordinated operational approaches for response and recovery, with a focus on remediation aspects. The guidance is designed to facilitate and enhance stakeholder and interagency coordination at Federal, regional, state, and local levels, and to address the social, economic, and operational interdependencies and current limitations that affect remediation actions. More specifically, it clearly sets forth strategies and offers recommendations for consideration that may ultimately reduce the time required to recover from the effects of a BWA release by implementing a decision framework that should 


\section{Introduction}

allow for optimization of key parameters on a site- and incident-specific basis. To reduce remediation times and costs - thus facilitate a return to functionality - the principal challenges highlighted in this document are to pre-plan actions to the extent possible and to understand and address the important resource, technology, and knowledge gaps underlying wide-area biological remediation. This guidance is primarily provided to aid emergency planners in developing their own area- and scenario-specific plans under the IPS scheme; however, in the absence of such specific plans addressing a wide-area BWA release, it could serve as interim operational guidance.

\section{$1.2 \quad$ Target Audience}

The primary audience for the Interim Guidance is emergency planners at the Federal, state, and local levels. The audience also includes elected and appointed leaders (such as state governors, mayors, and city and county officials); other local, tribal, state, and Federal government officials; and those in the chain of command who are involved in conducting or overseeing response and recovery operations at one or more sites contaminated by a BWA. This document is intended to serve as generic guidance to be used by jurisdictions when their own specific plans are created. It will then be necessary to describe the local environment each jurisdictional plan encompasses, including details on population, geographic area, local laws, and local and regional regulations. The Interim Guidance is also useful at the Federal level when planning for how Federal assets can be best leveraged to provide aid and support.

\subsection{Scope}

In general, this Interim Guidance covers urban areas (see Figure 1-1), but it might apply to rural areas as well and addresses how the country as a whole would respond to a wide-area aerosolized

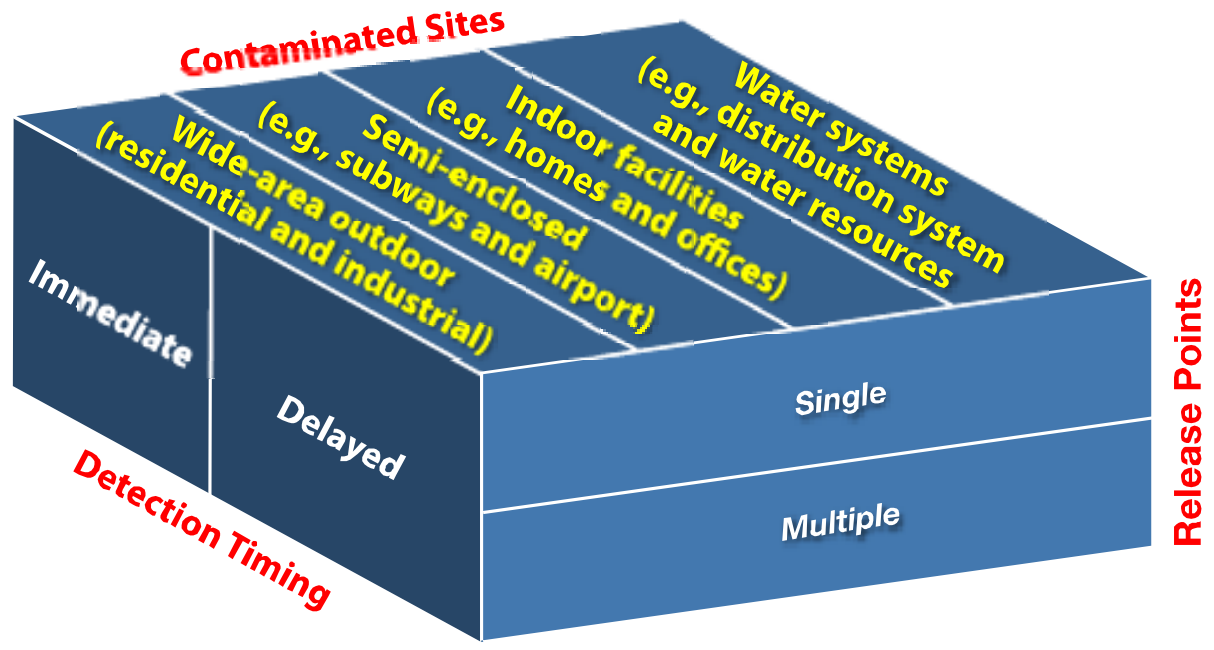

Figure 1-1. Range of possible release scenarios. 
attack. The types of attack addressed (see Section 1.6) would result in widespread contamination of outdoor and indoor areas as well as water-distribution systems. Thus, the guidance applies to single and multiple release points as well as incidents that may involve either immediate or delayed detection. The following types of contamination and cleanup are addressed:

- Enclosed facilities, such as commercial and residential buildings, outbuildings, and other enclosed structures.

- Semi-enclosed facilities, such as subways and public transit facilities.

- Outdoor areas - both localized and wide area — such as building exteriors, streets, parks, agricultural land, forests, and other open spaces.

- Drinking water facilities, including water-distribution systems and open water sources.

The primary focus of the guidance is on noncontagious and environmentally persistent biological agents, such as Bacillus anthracis (B. anthracis) spores. An attack involving $B$. anthracis represents a difficult, long-term remediation problem because the agent is the most difficult of known BWAs to decontaminate, B. anthracis spores remain viable for lengthy periods, and the spores can reaerosolize both indoors and outdoors. Different approaches required to counter contagious versus noncontagious BWAs would arise predominantly during initial response activities, which are not the focus of this document.

Whereas an overall risk- and decision-management framework covers all phases of response to and recovery from a biological incident, this document emphasizes guidance for remediation activities (specifically the Characterization, Decontamination, and Clearance Phases, as defined in Section 1.7) rather than initial phases of response (Notification and First-Response Phases). Nevertheless, because the transition from First Response to Remediation/Cleanup is a key component of effective recovery, response issues are addressed in that context. Aspects of Restoration/Reoccupancy, which includes facility renovation, reoccupancy, and long-term monitoring, are given limited coverage.

Any response and recovery approach for a large-scale BWA incident will involve an overall optimization approach, which will be both site- and incident-specific. Although this document provides basic guidance and identifies recommended actions utilizing current technology, a catastrophic biological contamination incident must be evaluated for site-, area-, and incidentspecific parameters to determine the best options for response and recovery in a given situation.

This document applies to the civilian sector and does not specifically address unique requirements that may be associated with remediation of military bases or other military facilities, although much of the guidance can be applied to Continental U.S. (Conus) military bases. The guidance does identify military resources that can be applied to the civilian sector following a BWA attack, and it reviews the important civilian and military roles and responsibilities at Federal, state, and local levels.

Guidance is presented in the context of currently available scientific and technological information, some of which is limited. As new data are obtained, that information will be incorporated into a final Consequence Management Guidance document. The guidance herein is not intended to discourage or prevent the development and use of novel or practical approaches if such approaches can be implemented safely and effectively. 


\section{$1.4 \quad$ Limitations and Assumptions}

Wide-area biological remediation is an extremely complex problem with many unknowns. Whereas Section 1.3 defined the scope of guidance, this section addresses additional limitations, assumptions, and issues. Consequence management actions following a biological attack take place in parallel with public safety and public health activities. This document does not describe in detail public health responses (e.g., evacuation or specific medical countermeasures) following the release of a BWA. If laboratory analytical results confirm the presence of a viable BWA, the responsible public health agencies involved in a response will commence appropriate public health actions, such as isolating people, decontamination of potentially contaminated individuals, medical examinations, treatment, and distribution of prophylaxis, including mass vaccination. For further information, see:

- $\quad$ NRF Biological Incident Annex, available at <http://www.fema.gov/pdf/emergency/nrf/nrf_BiologicalIncidentAnnex.pdf $>$.

- HHS/ASPR ESF-8 Aerosolized Anthrax Playbook, which provides strategic guidance for the Federal Emergency Support Function (ESF) 8 response and is available at $\langle\underline{\mathrm{http}: / /}$ www.hhs.gov/disasters/discussion/planners/playbook/anthrax/aerosolized/index.html >).

- Brookmeyer et al. (2004), "Public Health Vaccination Policies for Containing an Anthrax Outbreak," Nature 432, 901-904, available at <http://www.nature.com/nature/journal/v432/n7019/index.html>.

Responding to an intentional release of an infectious BWA differs in important ways from responding to a release of a chemical warfare agent (CWA), hazardous material, or radiological material. Although many elements of consequence management may be similar following releases of nonbiological contamination, this document addresses only biological remediation.

Implementation of some elements of the Interim Guidance is limited by capability (e.g., trained personnel and resources) and knowledge gaps in addressing the likely requirements facing incident commanders who will manage remediation. In addition, unique issues associated with outdoor, wide-scale contamination are not completely understood. Important gaps, uncertainties, and challenges include, but are not limited to:

- Local and national response and recovery capabilities (such as competent manpower, equipment, and other potential shortages).

- Prioritization and resource-planning and allocation tools and methods.

- The need for improved, fundamental, risk-assessment and risk-management approaches, including a better understanding of health-risk-based, dose-response information.

- The need for improved environmental characterization and long-term monitoring options.

- Identification of decontamination technologies, especially for wide-scale outdoor areas on previously untested surfaces and media.

- Effective data management and analysis tools for a wide-area contamination incident.

- Understanding the dynamic and continuing meteorological effects on transport and spread of an aerosol-deposited agent outdoors and the continued threat of migration from outside to inside.

- The need for outdoor and water-associated clearance goals and remediation approaches.

- Potentially overwhelming waste-management and disposal issues. 
Gaps are further identified in subsequent sections of this document. Because of current gaps, one of the purposes of the Interim Guidance is to identify the best available "as-is" technologies and associated limitations for use should such an incident occur today in the U.S.

Any biological incident will have unique, site- and organism-specific characteristics associated with remediation, thus final decision-making must be done on a case-by-case basis and should include an optimization process. Examples of earlier conceptual decision-making frameworks designed to specify initial and follow-up actions - including decontamination - and to address long-term health and environmental issues following the release of a BWA are available in the literature (e.g., Raber et al. 2002). The six-stage framework for risk management, published by the Presidential/Congressional Commission (1997), was designed to be "general enough to work in a wide variety of situations" and addresses technical and policy issues as well as stakeholder involvement. The National Response Team's Technical Assistance for Anthrax Response (NRT 2005), which has been updated twice, is a valuable source of information derived from the 2001 B. anthracis cleanups. A newly established interagency document, Planning Guidance for Recovery Following Biological Incidents (DHS and EPA 2009), which considered Raber et al. (2002) in its development, serves the present document as the higher-level framework from which operational-level decisions and guidance has been developed (several flowcharts from the interagency document are reproduced herein).

\subsection{Authorities, Governance, and References}

Remediation activities must be implemented under applicable legislation and governing authorities. Decision-makers are to apply this Interim Guidance as a supplement to, and in the context of, existing Federal, state, regional, and local laws and regulations. The National Response Framework (NRF; DHS 2008) establishes a comprehensive, all-hazards approach to enhance the ability of the United States to manage domestic incidents (see Biological Incident Annex). Under the NRF, technical and policy issues are addressed at the lowest possible organizational level. It is expected that, for large-scale incidents that affect the public, the Domestic Readiness Group, Federal agency heads, high-level elected officials, and the Homeland Security Council will be involved in decisions related to priorities and clearance goals. This document is expected to aid decision-makers and help focus their decisions. Figure 1-2, taken from the Federal Emergency Management Agency (FEMA) Comprehensive Preparedness Guide 101 <http://www.fema.gov/about/divisions/cpg.shtm>, illustrates the relationships among national policies, regulations, standards, and other initiatives at various state and local levels that would need to be coordinated during remediation.

\subsubsection{National Policy}

Guidance in this interim Consequence Management Guidance document conforms to, and is a supplement to, the following national-level policies:

- National Preparedness Guidelines (DHS 2007).

- National Strategy for Homeland Security (DHS 2002). 


\section{Introduction}

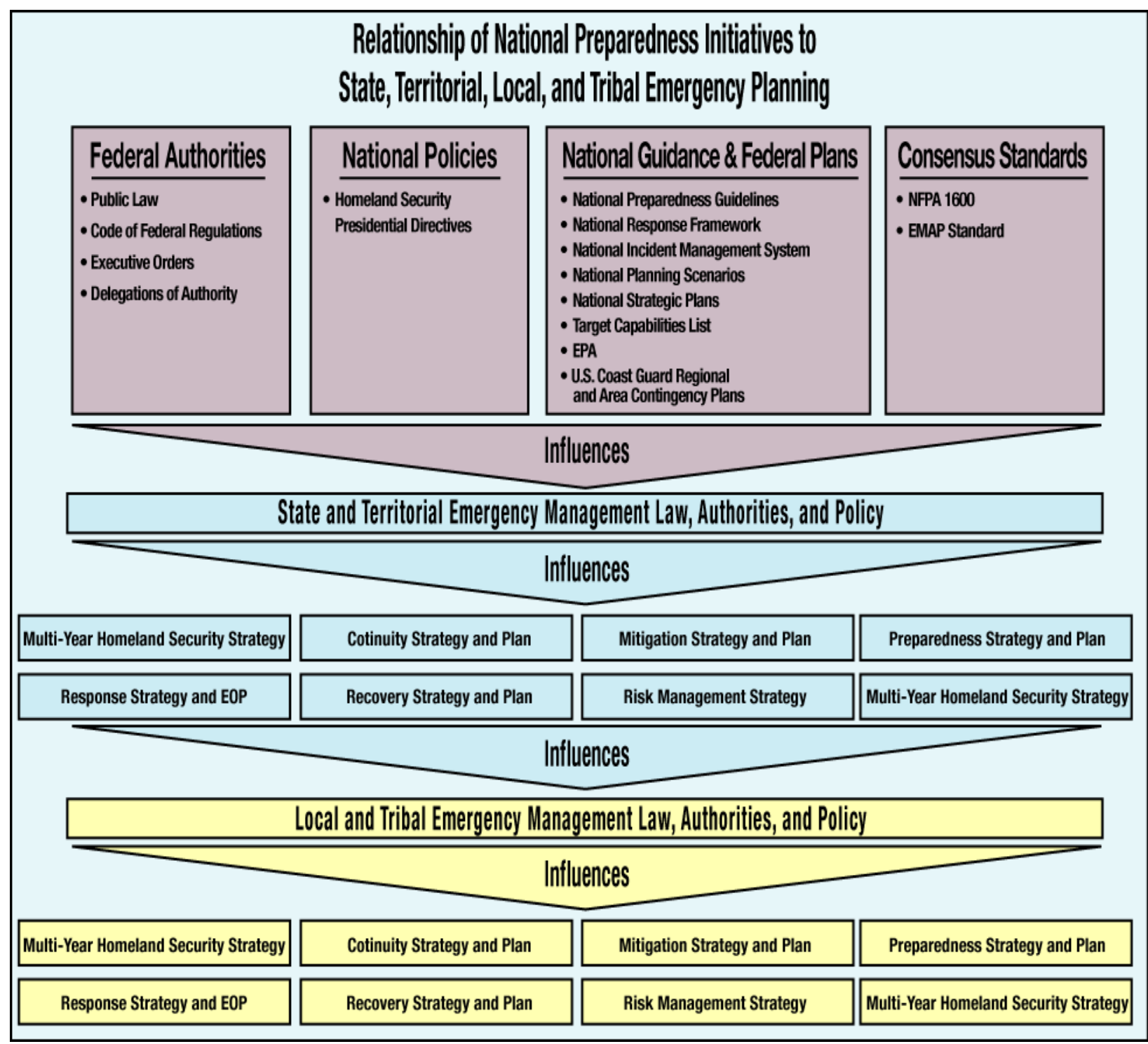

Figure 1-2. Influences of national preparedness initiatives to emergency planning at state and local levels.

- National Response Framework (DHS 2008) - in particular Emergency Support Function Annexes \# 8 and \#10.

- Integrated Planning System (DHS 2009).

- U.S. Environmental Protection Agency's (EPA's) National Oil and Hazardous Substances Pollution Contingency Plan (NCP) (40 CFR 300) (EPA 2000).

- $\quad$ National Incident Management System (NIMS 2008).

- Pandemic and All-Hazards Preparedness Act (PAHPA), Public Law No. 109-417 (December 2006).

- Homeland Security Act of 2002 (6 U.S.C. 101).

- Homeland Security Presidential Directive (HSPD) 5.

- Robert T. Stafford Disaster Relief and Emergency Assistance Act (Stafford Act 2007). 
- National Environmental Policy Act (NEPA 1969).

- Comprehensive Environmental Response, Compensation, and Liability Act (CERCLA 1980).

- Superfund Amendments and Reauthorization Act (SARA 1986).

- DOD Strategy for Homeland Defense and Civil Support (DOD 2005a)

A concise statement of the core preparedness goal for the nation is provided in the National Preparedness Guidelines (DHS 2007). Goal 3 from the National Strategy for Homeland Security (DHS 2002) is to "Respond to and recover from incidents that do occur." The NRF (DHS 2008) is a "guide to how the nation conducts all-hazards incident response." Additional policies at the national level include the Federal Insecticide, Fungicide, and Rodenticide Act (FIFRA), the Clean Air Act, the Clean Water Act, and the Resource Conservation and Recovery Act. Although some portions of these and other acts apply and are relevant, most such high-level documents contain little specific guidance for conducting the numerous activities associated with remediation following biological contamination.

The EPA's National Contingency Plan (NCP: see EPA 2000) is a Federal regulation governing environmental planning and response, and it provides "the organizational structure and procedures for preparing for and responding to discharges of oil and releases of hazardous substances, pollutants, and contaminants." The concept of operations described in this Interim Guidance for response and recovery (Section 2) conforms to existing regulations including the NRF; policies and procedures outlined in the Emergency Support Function Annex (ESF) \#8, Public Health and Medical Services Annex; ESF \#10, Oil and Hazardous Materials Response Annex; the Biological Incident Annex of the NRF; and implementation of the National Incident Management System (NIMS 2008), including direction therein to implement a Unified Command model.

Pursuant to the Homeland Security Act of 2002 (6 U.S.C. 101) and Homeland Security Presidential Directive (HSPD) 5, the Secretary of Homeland Security is the Principal Federal Official (PFO) for domestic incident management. The HSPD-5 defines the situations for which DHS shall assume overall Federal incident-management coordination responsibilities within the NRF. Among other things, the Homeland Security Act of 2002, Section 2, defines first responders as primarily local police, fire, and emergency personnel who, during the early stages of an incident, are responsible for public safety as well as protecting and preserving life, property, evidence, and the environment (including emergency response providers as well as emergency management, public health, clinical care, public works, and other skilled personnel who provide immediate support services).

Among the laws and authorities most relevant to wide-area remediation is the Robert T. Stafford Disaster Relief and Emergency Assistance Act (Stafford Act 2007). Its purpose is to "provide an orderly and continuing means of assistance by the Federal Government to State and local governments in carrying out responsibilities to alleviate the suffering and damage which result from ... disasters." Two titles are particularly relevant: Title III: Major Disaster and Emergency Assistance Administration and Title IV: Major Disaster Assistance Programs.

The National Environmental Policy Act (NEPA 1969) requires evaluation of the environmental consequences of alternative ways to solve a defined problem. NEPA is usually required if Federal funds are used, or a Federal agency is involved, or action occurs on Federal property. 


\section{Introduction}

However, under Section 316 of the Stafford Act, any action that restores a facility "substantially to its condition prior to a disaster or emergency" is exempt from NEPA requirements.

Furthermore, under NEPA, emergency or major disaster responses requiring immediate action are exempt from the regulatory provisions regardless of whether the actions have the potential for significant impact (Luther 2005).

The Comprehensive Environmental Response, Compensation, and Liability Act (CERCLA, 1980), commonly referred to as Superfund, was enacted to provide response authorities to actual or potential threats of releases of hazardous substances that may endanger public health or the environment. CERCLA's implementing regulation is the National Oil and Hazardous Substances Pollution Contingency Plan (NCP, 40 CFR Part 300). CERCLA also provides authorities for response to pollutants or contaminants that pose an imminent and substantial threat to human health or the environment. BWAs would be considered pollutants or contaminants under CERLCA and the NCP. The key Federal environmental responder with tactical emergency response authorities is the On-Scene Commander (OSC). The authorities enable the EPA OSC to participate in an Incident Command System (ICS) response management structure (see Sections 2 and 4) as an Incident Commander or provide EPA decision-making representation in a Unified Command.

When the President declares a major Federal disaster, the EPA generally carries out its work under Mission Assignments as set forth in the Stafford Act, and the EPA has discretion in determining the appropriate response activities. In situations in which the Stafford Act is not invoked and the EPA is conducting a CERCLA response action, the statute and regulations also provide the EPA with discretion as to the appropriate cleanup response action. Responses under CERCLA are carried out in accordance with the National Oil and Hazardous Substances Pollution Contingency Plan (NCP) as stated above; however, during a large-scale Federal disaster, although the NCP is generally in effect, it does not compel the EPA to undertake any specific response action, and several provisions are not applicable.

The Superfund Amendments and Reauthorization Act (SARA 1986) amended CERCLA to reflect the EPA's experience in administering the Superfund program and made important changes and additions to the program. Among other changes, SARA stresses the importance of permanent remedies and innovative treatment technologies in cleaning up hazardous waste sites, provides new enforcement authorities, increases state involvement, increases the focus on human health problems posed by hazardous waste sites, and encourages greater citizen participation in making decisions on how sites should be cleaned up.

\subsubsection{State and Local Policy}

Understanding exactly how issues related to biological cleanup will be coordinated across various levels of city, county, state, and Federal government is an important component of widearea remediation planning and execution (see Figure 1-2) and a complex topic in itself. Policies and assigned roles and responsibilities vary among states in many important respects. States and local jurisdictions have emergency plans in place to which any wide-area remediation plans must conform or serve as a supplement. Existing plans generally include public health, emergency management, environmental protection, transportation control and management, agriculture and animal disease control, business continuity, and continuity of government. Because local plans 
vary widely across regions, a generic interim guidance document cannot address them in detail. Locals authorities are ultimately responsible for managing local response actions.

\subsubsection{Military Policy}

The DOD Strategy for Homeland Defense and Civil Support (DOD 2005a) states that one of its "paramount objectives" is to "support civil authorities in minimizing the damage and recovering from domestic ... Chemical, Biological, Radiological, Nuclear, or high-yield Explosive (CBRNE)... mass casualty attacks." Defense support of civil authorities (DSCA), often referred to as civil support, is "DOD support, including Federal military forces, the Department's career civilian and contractor personnel, and DOD agency and component assets, for domestic emergencies and for designated law enforcement and other activities. The DOD provides defense support of civil authorities when directed to do so by the President or Secretary of Defense." DSCA resources and roles and responsibilities are discussed in more detail in Section 2. The following instructions and directives are among the most relevant:

- CJCSI 3125.01 Military Assistance to Domestic Consequence Management Ops in Response to a CBRNE Situation (CJCSI 2007).

- CJCS CBRNE CM EXORD (June 2008).

- DOD Directive 3025.1 Military Support to Civil Authorities.

- DOD Directive 3025.15 Military Assistance to Civil Authorities.

\subsection{Release Scenarios}

Throughout this document, the spore-forming bacterium B. anthracis is discussed as the biological agent of concern because it is considered the most difficult of known bioterrorism agents to inactivate and is one of the agents most likely to be used as a biological weapon. The document is aimed at providing recovery applicable to National Planning Scenario \#2 and widearea outdoor release of $B$. anthracis spores in an urban area. There are many possible ways a wide-area biological response and recovery effort could unfold (see e.g., Danzig 2003). For example, a biological release could be recognized promptly, as with a white powder release, or recognition could be delayed 8 to 32 hours as would be the case in a BioWatch detection. This document represents our best understanding of how to approach either type of release with existing technologies and in light of key gaps, which are identified in the context of each phase of recovery. For regional planning applications, any hypothetical scenarios could be adjusted for dispersion method, efficiency, and meteorology, among other factors.

\subsection{Six Phases of Response and Recovery}

Actions following a bioterrorism incident can be categorized into six principal phases. The sixphase diagram for responding to and recovering from a biological contamination incident shown in Figure 1-3 is a consensus scheme developed after multi-agency review and approval [slightly modified from Planning Guidance for Recovery Following Biological Incidents (DHS and EPA 2009), Figure 3]. 


\section{Introduction}

\begin{tabular}{|c|c|c|c|c|c|}
\hline \multicolumn{6}{|c|}{ Response and Recovery* } \\
\hline \multirow[b]{2}{*}{ Notification } & \multirow{2}{*}{$\begin{array}{c}\text { First } \\
\text { Response }\end{array}$} & \multicolumn{3}{|c|}{ Remediation/Cleanup } & \multirow{2}{*}{$\begin{array}{l}\text { Restoration/ } \\
\text { Reoccupancy }\end{array}$} \\
\hline & & Characterization & Decontamination & Clearance & \\
\hline $\begin{array}{c}\text { Receive } \\
\text { information } \\
\text { on biological } \\
\text { incident } \\
\text { Identification } \\
\text { of suspect } \\
\text { release sites } \\
\text { Notification } \\
\text { of } \\
\text { appropriate } \\
\text { agencies }\end{array}$ & $\begin{array}{c}\text { Initial threat } \\
\text { assessment } \\
\text { HazMat and } \\
\text { emergency } \\
\text { actions } \\
\text { Forensic } \\
\text { investigation } \\
\text { Public health } \\
\text { actions } \\
\text { Screening } \\
\text { sampling } \\
\text { Determination } \\
\text { of agent type, } \\
\text { concentration, } \\
\text { and viability } \\
\text { Risk } \\
\text { communication }\end{array}$ & $\begin{array}{c}\begin{array}{c}\text { Characterization } \\
\text { of biological } \\
\text { agent }\end{array} \\
\text { Characterization } \\
\text { of affected site(s) } \\
\text { Site containment } \\
\text { Continue risk } \\
\text { communication } \\
\text { Characterization } \\
\text { environmental } \\
\text { sampling and } \\
\text { analysis } \\
\text { Initial risk } \\
\text { assessment } \\
\text { Clearance goals }\end{array}$ & $\begin{array}{c}\begin{array}{c}\text { Decontamination } \\
\text { strategy }\end{array} \\
\begin{array}{c}\text { Remediation } \\
\text { Action Plan }\end{array} \\
\begin{array}{c}\text { Worker health } \\
\text { and safety }\end{array} \\
\text { Site preparation } \\
\text { Source reduction } \\
\text { Waste disposal } \\
\text { Decontamination } \\
\text { of sites or items } \\
\text { Decontamination } \\
\text { verification }\end{array}$ & $\begin{array}{c}\text { Clearance } \\
\text { environmental } \\
\text { sampling and } \\
\text { analysis } \\
\text { Clearance } \\
\text { decision }\end{array}$ & $\begin{array}{l}\text { Renovation } \\
\text { Reoccupation } \\
\text { decision } \\
\text { Long-term } \\
\text { environmental } \\
\text { and public } \\
\text { health } \\
\text { monitoring }\end{array}$ \\
\hline
\end{tabular}

Figure 1-3. Response and recovery phases to a wide-area biological contamination incident. The content of this illustration was developed with interagency cooperation. The focus of this Interim Guidance is on characterization, decontamination, and clearance (areas shaded in blue). 


\section{Introduction}

The six principal phases can be briefly described as follows:

- Notification Phase. One or more Emergency Operations Centers (EOCs) identifies an incident or has knowledge of a threat regarding an incident. Information gathering and dissemination to all relevant agencies are the main tasks.

- First-Response Phase. Central concerns are containing areas of contamination to the extent possible and the crime scene; rescuing, decontaminating, evacuating, and, if needed, isolating or quarantining or otherwise managing affected persons (for isolation and quarantine, see DHHS/CDC 2006; see also NRF Biological Incident Annex, Public Health Service Act, 42 USC 264); mitigating conditions that pose an immediate threat to human health (such as explosion in the case of an explosive release); and minimizing the spread of contamination. This phase begins by activating a Unified Command, law enforcement and emergency operations personnel [e.g., security, medical, and hazardous materials (HazMat) teams, as needed], and continues as long as emergency personnel are present. The agent is identified and assessed for viability, toxicity, infectiousness, and other characteristics using a reliable [e.g., Laboratory Response Network (LRN)] laboratory. Initial public health assessment can assist in identifying potential sources of contamination, locations of contaminants, contaminated media, and exposure scenarios.

- Characterization Phase. The focus is on performing characterization environmental sampling to determine the extent and levels of contamination, and on assessing environmental characteristics of the BWA that affect its subsequent spread, such as its survivability on surfaces and potential for reaerosolization. Potential health consequences to humans and harm to the environment are evaluated. An environmental risk assessment for remediation purposes is conducted. Collected information is evaluated to determine what types and degrees of decontamination are needed indoors and outdoors and what public health measures are necessary for persons who were potentially exposed.

- Decontamination Phase. The focus is on preparing and implementing detailed plans for decontaminating those contaminated items, areas, and facilities deemed suitable for such treatment. Outdoor and indoor areas are likely to be addressed separately. Because of critical access issues and the likelihood of recontamination, certain outdoor areas may be treated first. For some biological agents that do not remain viable for lengthy periods in the environment, monitored natural attenuation may be an adequate decontamination option. In cases where contamination is not extensive or the agent is not environmentally persistent, application of surface decontaminants or other methods of medical infection control may be effective. For extensive contamination, especially in indoor areas by agents such as $B$. anthracis, fumigation is an option. In those cases, source reduction is considered, which involves removing salvageable and nonsalvageable items, and precleaning surfaces to reduce contaminant load. Scenario- and site-specific decontamination reagents and delivery systems are selected, and all systems are pre-tested before carrying out chemical treatments.

- Clearance Phase. The focus is on determining whether to reoccupy an area or facility and re-establish normal activities. Appropriate experts review and evaluate key data, such as characterization and clearance environmental sampling results; decontamination process parameters and results from the culture of biological indicators that may have been used indoors; quality assurance and quality control (QA/QC) data; and other relevant information. Clearance goals are likely to be set separately for indoor facilities, outdoor 


\section{Introduction}

areas, and water-distribution systems. Clearance criteria are applied to judge the effectiveness of any decontamination processes that may have been used. Final decisions on clearance are made by local, state, or Federal public health officials, or government agencies, depending on site-specific jurisdictional authorities.

- Restoration (Reoccupancy) Phase. The focus is on preparing an area or facility for reoccupancy, reuse, or refurbishment, such as renovating indoor areas that have undergone fumigation. Restoration can include upgrading equipment in critical infrastructure to mitigate the effect of possible future attacks. The phase also involves decisions regarding long-term environmental and public health monitoring.

\subsection{Organization and Content of the Interim Guidance}

Figure 1-3 provides the overarching framework for this guidance document. Key operational decisions are identified for each of the six principal phases, and supporting information is provided to allow decision-makers to address a wide-area incident in a systematic way. The format is intended to allow risk-based decisions to be identified, and actions optimized, to best meet the site- and incident-specific needs of all stakeholders.

This Interim Guidance is organized into 11 major sections encompassing all anticipated operational decisions and actions. The document first outlines the concept of operations and related background information. It then generally follows the six principal phases by describing operational capabilities and response options at a detailed level. As shown in Figure 1-4, the key operational phases are notification and first response (collectively referred to as the response); characterization, decontamination, and clearance (collectively referred to as remediation); and reoccupancy (also known as restoration). Although the phases are shown sequentially in Figure 1-4, the steps can overlap, with some activities taking place concurrently; the steps are iterative; and multiple areas or facilities can be addressed either independently or simultaneously. The timeframes to complete each phase are very incident- and site-specific and depend on available resources as well as the specific remediation approaches used. However, relative order of magnitude estimates have been included in Figure 1-4. In addition to the six principal phases of response and recovery, relevant and necessary topics -including risk-based decision-making to establish clearance goals, and prioritization of essential facilities and infrastructure - are addressed in this document at the point that the topics are most pertinent to planning and execution. 
Introduction

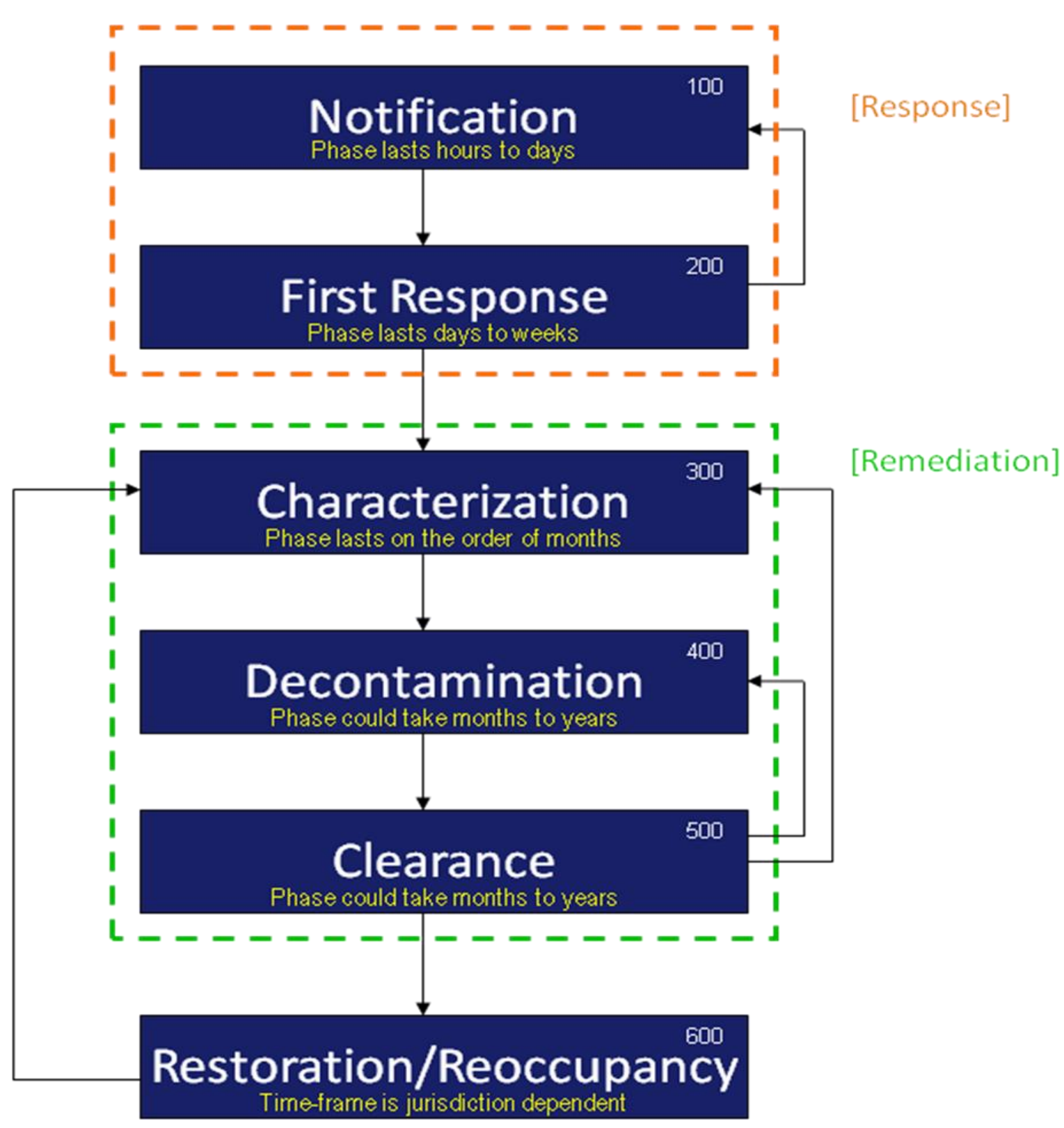

\section{Steps can proceed in parallel, \\ are iterative and multiple \\ areas or facilities can be addressed \\ Independently or simultane ously}

Figure 1-4. Principal operational phases of response and recovery with estimates of duration. 


\section{Introduction}

\subsection{Section 1 References}

Brookmeyer R. E. Johnson, and R. Bollinger (2004), "Public Health Vaccination Policies for Containing an Anthrax Outbreak," Nature 432, 901-904, available at http://www.nature.com/nature/journal/v432/n7019/index.html.

CERCLA (1980), Comprehensive Environmental Response, Compensation, and Liability Act, Title 42-The Public Health and Welfare, Chapter 103; available at <http://www.access.gpo.gov/uscode/title42/chapter103_html >.

CJCSI (2007), Chairman of the Joint Chiefs of Staff Instruction, CJCSI 3125.01 Military Support to Domestic Consequence Management Operations in Response to a Chemical, Biological, Radiological, Nuclear, or High Yield Explosive Situation; OUO, but available at $\langle$ https://ca.dtic.mil/cjes_directives/cdata/limited/3125_01.pdf $>$.

Danzig, R. J. (1999), "It Can Happen Here," Hoover Digest 2; adapted from a speech given at the Hoover Institution on November 17, 1998.

Danzig, R. (2003), Catastrophic Bioterrorism-What Is To Be Done? Center for Technology and National Security Policy, National Defense University, Washington DC.

DHHS/CDC (2006), Department of Health and Human Services and Centers for Disease Control and Prevention, Fact Sheet: Legal Authorities for Isolation and Quarantine; available at

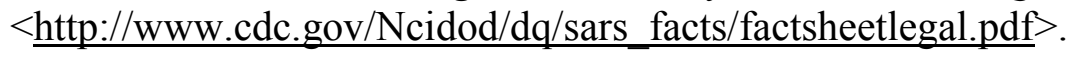

DHS (2002), Department of Homeland Security, National Strategy for Homeland Security; available at $<$ http://www.whitehouse.gov/homeland/book/>.

DHS (2007), Department of Homeland Security, National Preparedness Guidelines; available at $<$ http://www.dhs.gov/xlibrary/assets/National_Preparedness_Guidelines.pdf $>$.

DHS (2008), Department of Homeland Security, National Response Framework; documents available at <http://www.fema.gov/emergency/nrf/> .

DHS (2009), Department of Homeland Security, Integrated Planning System; available at $<$ http://www.hlswatch.com/wp-content/uploads/2009/01/dhs-integrated-planning-systemjanuary-2009.pdf>.

DHS and EPA (2009), Department of Homeland Security and Environmental Protection Agency, Planning Guidance for Recovery Following Biological Incidents, National Science and Technology Council, Biological Decontamination Standards Working Group.

DOD Directive 3025.1 Military Support to Civil Authorities; available at <http://www.dtic.mil/whs/directives/corres/pdf/302501p.pdf $>$.

DOD Directive 3025.15 Military Assistance to Civil Authorities: available at <http://www.dtic.mil/whs/directives/corres/pdf/302515p.pdf $>$.

DOD (2005a), Department of Defense, Strategy for Homeland Defense and Civil Support; available at <http://www.defenselink.mil/news/Jun2005/d20050630homeland.pdf>.

EPA (Revised July 2000), U.S. Environmental Protection Agency, National Oil and Hazardous Substances Pollution Contingency Plan (NCP) (40CFR300); available at $<\underline{\text { http://www.epa.gov/oilspill/ncpover.htm }>\text {. }}$ 


\section{Introduction}

FEMA Comprehensive Preparedness Guide 101; available at <http://www.fema.gov/about/divisions/cpg.shtm>, accessed 30 October 2008.

Graham, B., J. Talent, G. Allison, R. Cleveland, S. Rademaker, T. Roemer, W. Sherman, H. Sokolski, and R. Verma, (2008), World At Risk: The Report of the Commission on the Prevention of Weapons of Mass Destruction Proliferation and Terrorism, Vintage Books, New York.

Luther, L. (2005), NEPA and Hurricane Response, Recovery and Rebuilding Efforts, Congressional Research Service Report for Congress, p. i.

NEPA (1969), The National Environmental Policy Act of 1969, see Public Law 91-190, 42 U.S.C. 4321-4347, January 1, 1970, as amended by Public Law 94-52, July 3, 1975, Public Law 94-83, August 9, 1975, and Public Law 97-258, Section 4(b), Sept. 13, 1982; available at <http://ceq.eh.doe.gov/nepa/regs/nepa/nepaeqia.htm>.

NIMS (2008), National Incident Management System; document available at <http://www.fema.gov/pdf/emergency/nims/NIMS_core.pdf>.

NRT (updated July, 2005), National Response Team, Technical Assistance for Anthrax Response, Interim-Final Draft; available at http://www.nrt.org/production/NRT/NRTWeb.nsf/PagesByLevelCat/Level2TA?Opendocument.

Presidential/Congressional Commission on Risk Assessment and Risk Management (1997), Final Report, Volume 1, Framework for Environmental Health Risk Management and Volume 2, Risk Assessment and Risk Management in Regulatory Decision-Making; (Presidential/ Congressional Commission on Risk Assessment and Risk Management, Washington, D.C.); available at <http://www.riskworld.com/Nreports/nr7me001.htm>.

Raber, E., J. M. Hirabayashi, S. P. Mancieri, A. L. Jin, K. J. Folks, T. M. Carlsen, and P. Estacio (2002), "Chemical and Biological Agent Incident Response and Decision Process for Civilian and Public Sector Facilities," Risk Analysis 22(2), 195-202.

SARA (1986), Superfund Amendments and Reauthorization Act, Title 42-The Public Health and Welfare, Chapter 103; available at 〈http://www.epa.gov/superfund/policy/sara.htm>.

SNL and LLNL (2008), Sandia National Laboratories and Lawrence Livermore National Laboratory, IBRD Task 1 Systems Analysis Report (same document published separately at both laboratories as report SNL2008-1349 and report LLNL-AR-401510).

Stafford Act (2007), see Public Law 93-288, as amended, 42 U.S.C. 5121 et seq. and related authorities. U.S.C. Title 42-The Public Health and Welfare, Chapter 68-Disaster Relief. Robert T. Stafford Disaster Relief and Emergency Assistance Act, as amended, and related authorities. FEMA 592, April 2007; available at <http://www.fema.gov/about/stafact.shtm>. 


\section{Response and Recovery Structure}

In the context of this Interim Guidance document, a concept of operations (ConOps) is the formal plan that describes the roles, responsibilities, and relationships of organizations involved in responding to a contaminated area or facility. A ConOps addresses Federal, state, local, and Tribal agencies and how they should interact when responding to a potential or actual terrorist threat or incident. In addressing the criteria for successful planning, the NRF states that response planning meets the "adequacy" criteria if the ConOps "identifies and addresses critical tasks specific to the plan's objectives." (DHS 2008, p. 74.)

According to many high-level national plans, and in particular the National Strategy for Homeland Security, "One of the fundamental response principles is that all incidents should be handled at the lowest jurisdictional level possible." (DHS 2002, p. 33.) However, "there are special circumstances (e.g., catastrophic incidents and terrorist incidents) during which the Federal Government exercises a larger and more proactive role.” (SNL and LLNL 2008, p. 17.) Roles and responsibilities for wide-area remediation have not been fully defined, but the principles contained in the NRF and NIMS should apply, with the Federal government providing assistance when requested by state authorities.

\subsection{Unified Command for a Wide-Area Incident}

Per the NRF (DHS 2008), effective unified command (UC) is indispensable to response activities and requires a clear understanding of the roles and responsibilities of each participating organization. This section describes the civilian and military components of a UC to address wide-area biological contamination.

Clear communication is essential throughout all phases of response and recovery. Lines of communication during initial and continuing phases may include mechanisms stipulated through existing memoranda of understanding (MOUs), memoranda of agreement (MOAs), mutual aid agreements (MAA), mutual assistance agreements, and other protocols.

A UC is formed when more than one agency has incident jurisdiction or when incidents cross different political jurisdictions. A designated agency official from the government who serves on the UC, for example, is an individual who has jurisdictional authority and functional responsibility under statute or ordinance to manage a specific aspect of an emergency. The designated agency official's position and command authority are stipulated by law, ensuring that the UC consists of individuals who can make high-level decisions in a crisis situation on behalf of an agency or organization without relying on approval from superiors, when such approval might delay critical actions. Representatives must be able to commit resources to support the incident response, if needed. They must work cooperatively with other agencies and organizations to establish objectives and strategies, identify priorities, and develop Incident Actions Plans (IAPs), as defined in the National Incident Management Structure (NIMS 2008).

Members of the UC would include representatives from state and local health, emergency management, and environmental agencies as well as the EPA. The Secretary of Homeland Security will designate a Principal Federal Official (PFO) under the NRF, who may also serve on the Unified Coordination Group, facilitate Federal support to the overall response, or both. The 


\section{Response and Recovery Structure}

PFO is responsible for coordinating all domestic incidents requiring multi-agency Federal response (DHS 2008). The Secretary may elect to designate a single individual to serve as his or her primary representative to ensure consistency of Federal support. Federal assistance for incidents that do not require DHS coordination may be led by other Federal departments and agencies, consistent with their authorities.

Under the NRF, an Area Command is established to oversee the management of large or multiple incidents that are each being handled by an Incident or Unified Command using the Incident Command System (ICS). Each Incident or Unified Command is staffed by Incident Management Team (IMT) members. An IMT is an incident command organization made up of the command, general staff members, and appropriate functional units of an ICS organization. Wide-area biological contamination involving both civilian and military locations may result in establishment of an Area Command.

As part of the Federal response, a Joint Field Office (JFO) would be established quickly to coordinate all Federal support. Senior officials from each Federal agency with primary statutory or jurisdictional responsibility and significant operational responsibility for the incident assemble at the JFO. The JFO will be staffed, organized, and managed in a manner consistent with NIMS structure. The governor of the state in which contamination is located may also request that the U.S. President make a Presidential Disaster Declaration under the Stafford Act (2007).

An Emergency Operations Center (EOC) is the location at which command, control, and coordination functions are performed regionally. In the language of the NRF, the field location for primary, tactical-level functions is referred to as the Incident Command Post (ICP). In a wide-area attack, multiple EOCs and ICPs may be stood up and used. Because EOCs are fixed locations, they might be located within a contamination zone following a wide-area biological release. In such cases, the EOCs would have to be relocated, which emphasizes the need for emergency planners to identify alternative facilities and relocation plans.

\subsubsection{Civilian Components of the Command Structure}

Figure 2-1 shows a notional civilian command structure, highlighting the relationships among organizations involved in responding to and recovering from a wide-area BWA release. The relationships among organizations involved in remediation conform to the NRF (DHS 2008) and implementation of NIMS (2008), but they are updated with components that may play a role in wide-area response and recovery. Figure 2-2 identifies some specific entities that would likely make up the command, though the composition would evolve over time.

Under current laws and regulations, some IC or UC responsibilities are clearly delineated, whereas others are not. For example, under the Stafford Act, state governors are responsible for requesting Federal emergency assistance for communities within their jurisdiction. In contrast, some responsibilities are held in common among different organizations or agencies-civilian, military, or both. Examples include saving lives, protecting property, protecting the environment, preserving the social and economic structure of the jurisdiction, and meeting basic human needs. 


\section{Response and Recovery Structure}

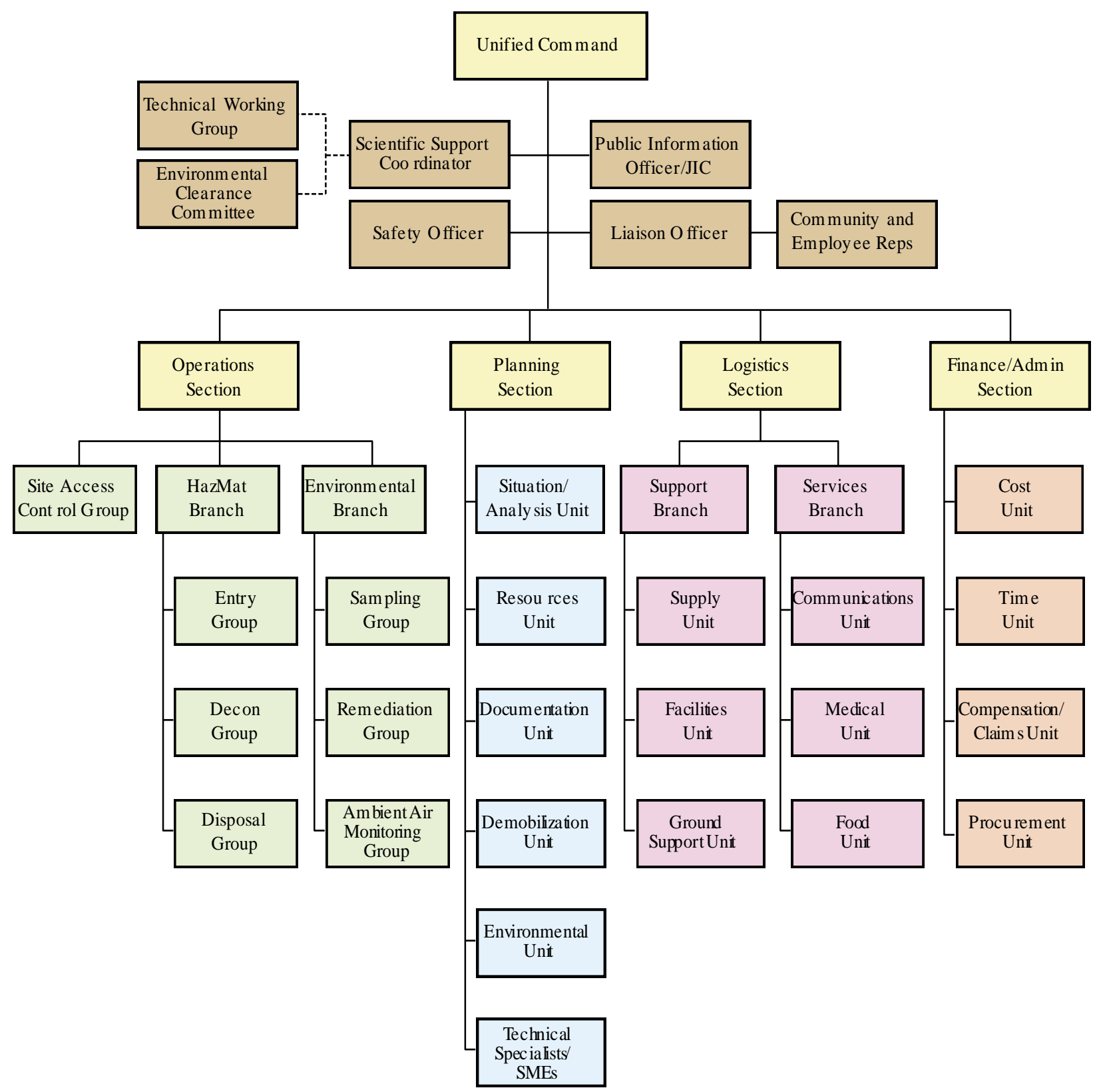

* At the discretion of the IC or UC, a Scientific Support Coordinator (SCC) can assemble an Environmental Clearance Committee that would report to the SSC. A Technical Working Group may also be established and report to the SSC.

Figure 2-1. Notional command structure for a biological release. 


\section{Response and Recovery Structure}

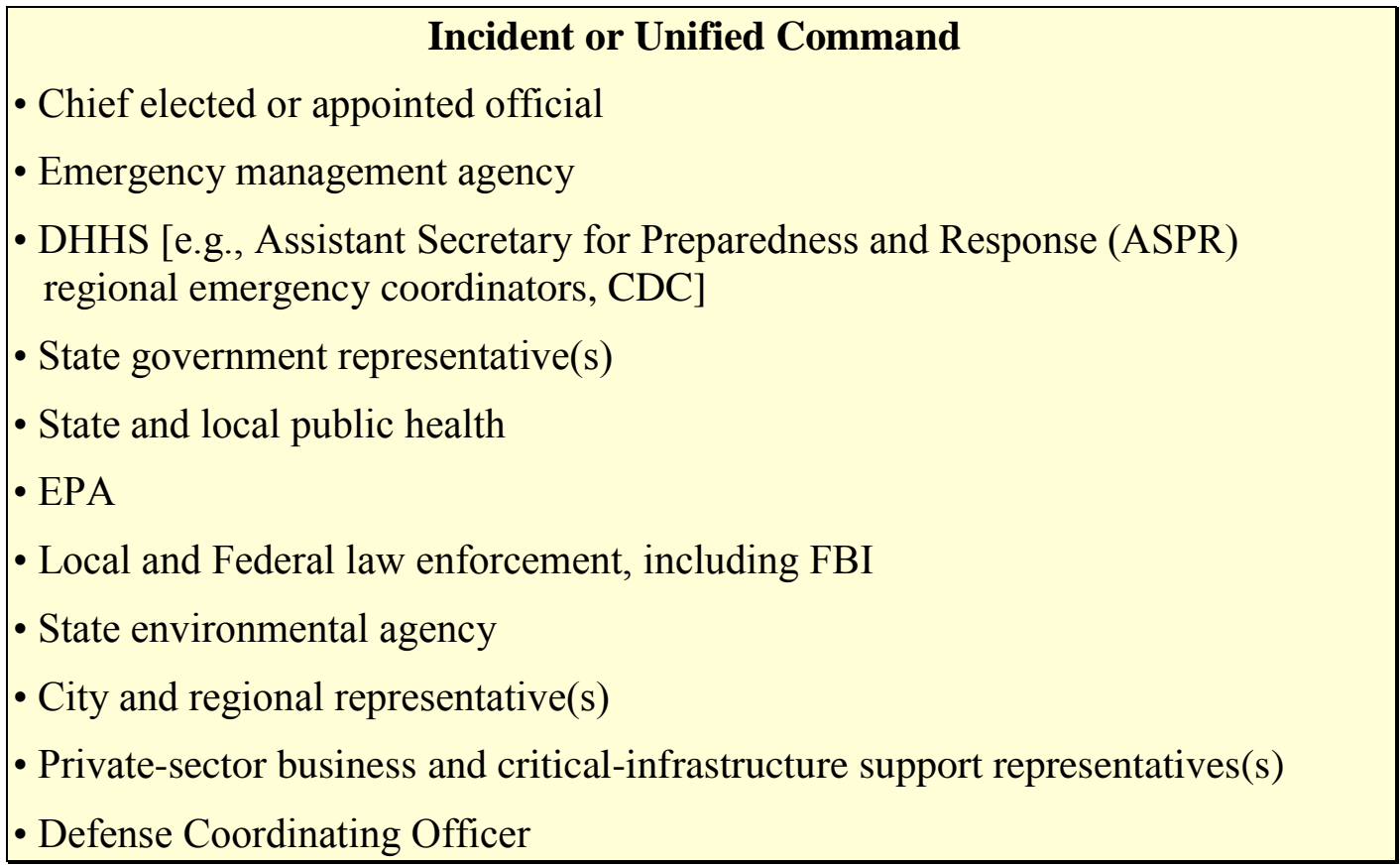

Figure 2-2. Possible components of the command structure for remediation, as specified in the NRF (2008).

Per the NRF, key partners in a response include:

- The chief elected or appointed official (which may be a mayor, city manager, or county manager as a jurisdiction's chief executive officer).

- The local emergency manager.

- Local department and agency heads (such as those representing firefighting, law enforcement, emergency medical services, public works, and environmental agencies).

- Private-sector organizations that may become involved (such as hospitals, critical infrastructure, and telecommunications).

- State government representatives, such as the Governor, State Homeland Security Advisor, Director of the State Emergency Management Agency, and other state agencies.

- Federal Government agencies, including the FBI, DHS, and Secretary of Homeland Security as the PFO.

\subsubsection{Technical Working Group}

In most cases, the Scientific Support Coordinator (SCC) within the ICS structure would recommend to the IC or UC that it assemble an advisory group of outside technical experts to function as an independent body in reviewing all relevant data (EPA 2009). Such experts form a Technical Working Group (TWG) supporting the IC or UC. A TWG is not required but is highly recommended as an effective and efficient way to plan for remediation operations. Some jurisdictions may want to identify potential members of the TWG in advance. If so, members 


\section{Response and Recovery Structure}

should meet periodically and should review this Interim Guidance before an incident occurs. The TWG should be activated as soon as feasible following first-response activities.

A TWG is also involved with the optimizing remediation activities. Stakeholder working groups, consisting of Federal, state, local individuals with expertise in relevant topics, would be assembled to assist the TWG with the optimization process.

Figure 2-3 identifies some of the entities that would likely make up the TWG.

\begin{tabular}{|l|}
\hline Technical Working Group \\
Areas of Required Expertise \\
- Microbiology \\
- Sterilization science \\
- Waste disposal (Federal and state) \\
- Ambient air monitoring \\
- Environmental sampling \\
- Chemical engineering \\
- Decontamination methods \\
- Toxicology \\
- Risk assessment \\
- Water and wastewater specialists \\
Representatives from \\
- Facilities involved \\
- DHHS (e.g., CDC, NIOSH) \\
- State and local public health, analytical labs \\
- Other affected public health agencies \\
- OSHA \\
- DOD (civilian or military representatives) \\
- Private sector \\
- Universities \\
\hline
\end{tabular}

Figure 2-3. Components of the Technical Working Group.

Table 2-1 identifies various areas of expertise and the types of organizations that can provide specialists and subject-matter experts who may advise the IC or UC. Such experts should be identified in advance, meet periodically, and should review any appropriate documentation before an incident occurs. The TWG and such specialists or experts can be a single entity or separate entities, depending on the size and specific needs of an incident. 


\section{Response and Recovery Structure}

Table 2-1. Areas of expertise and organizations providing subject-matter experts who may advise the IC or $\mathrm{UC} .^{\text {a }}$

\begin{tabular}{|l|l|}
\hline \multicolumn{1}{|c|}{ Areas of required expertise } & \multicolumn{1}{c|}{ Agencies and organizations providing experts } \\
\hline Federal and state waste-disposal requirements & Facility at which an incident occurs \\
Ambient air monitoring & DHHS (e.g., CDC, NIOSH) \\
Environmental sampling & EPA and state environmental agency \\
Biological analysis & State and local public health, analytical laboratories \\
Chemical engineering & Other affected public health agencies \\
Decontamination methods & DOD (e.g., DTRA Consequence Management Advisory Team) \\
& Private sector \\
& Universities \\
\hline
\end{tabular}

a The EPA's document, Environmental Unit in an ICS Structure-Guidance Document (EPA July 2009) assigns the areas of expertise within the Environmental Unit to the following functional groups: (1) analytical team, (2) response and cleanup technologies specialists, (3) ecological and health assessment team, (4) modeling interpretation team, (5) data interpretation team.

\subsubsection{Environmental Clearance Committee}

The IC, UC, or organization in charge of remediation (i.e., characterization, decontamination, and clearance) may instruct the SCC to assemble an Environmental Clearance Committee (ECC). Following the $2001 \mathrm{~B}$. anthracis attacks, at most of the indoor sites that used fumigation as the decontamination method, ECCs consisting of subject-matter experts in relevant scientific disciplines were established. An ECC functions as an independent body reviewing all data relevant to the remediation process. Important data for evaluation are initial and characterization environmental sampling data; data on the efficacy of fumigation processes, including monitoring results of key decontamination process variables (relative humidity, temperature, fumigant concentration, and time of treatment) and results from biological indicators positioned prior to fumigation(s); and assessing the nature, placement, and results of clearance environmental sampling. An ECC then makes recommendations on whether facilities are effectively decontaminated and safe for reuse. Establishing an ECC is not mandated in the event of widearea contamination but is highly recommended as an effective way to make sound clearance decisions and add credibility to the determination that a decontaminated zone or facility may be recommended for reoccupation. Members of an ECC should be identified in advance and should review this document before an incident occurs. It is highly recommended that the ECC be convened at the initiation of cleanup activities. It would be useful for the ECC to be briefed on decontamination activities by relevant members of the IC or UC and to be asked to review the concept for clearance environmental sampling prior to the initiation of such sampling. The briefing and review would help ensure that the ECC finds the clearance sampling approach acceptable when it reviews remediation data after the process is completed. The makeup and functions of an ECC are discussed in more detail in Section 8. Figure 2-4 identifies some of the entities that would likely make up an ECC. 


\section{Response and Recovery Structure}

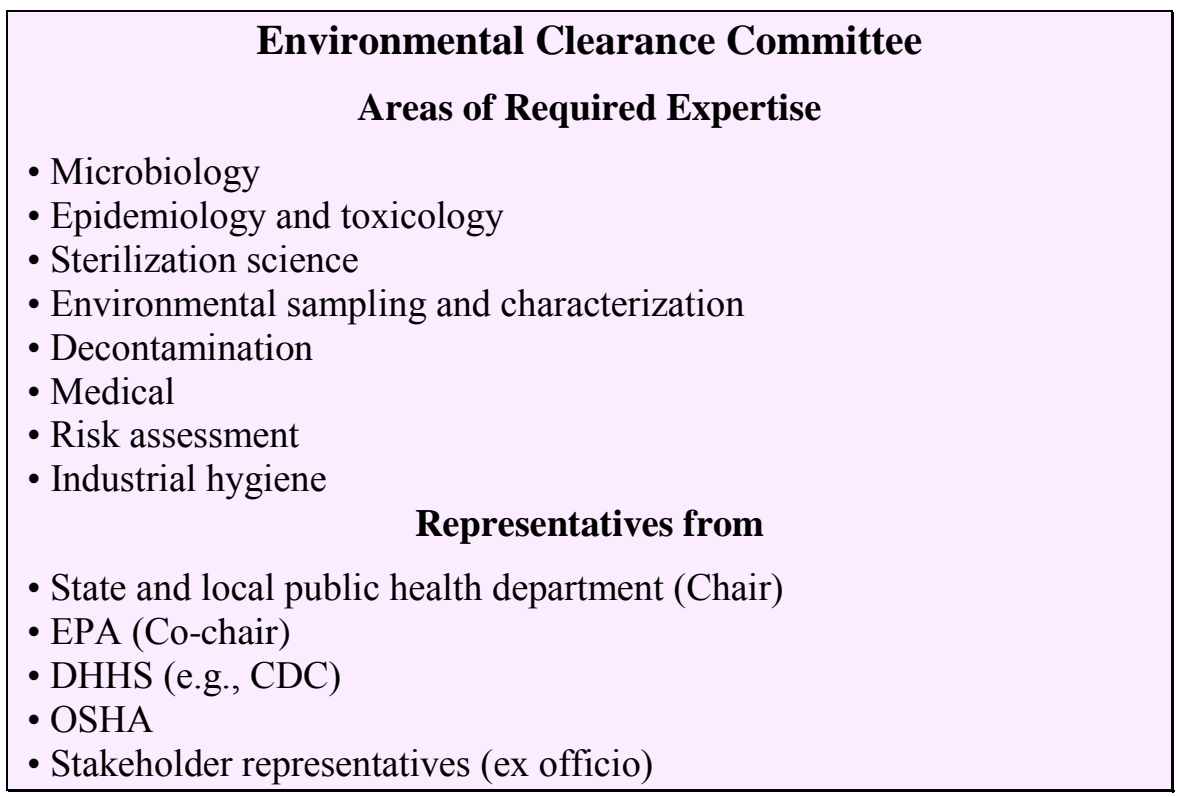

Figure 2-4. Components of an Environmental Clearance Committee.

\subsubsection{Military ConOps and Coordination with Civilian Efforts}

In the event of a wide-area BWA attack, or the warning of such an attack, the military is prepared to respond with graduated, reinforcing response packages drawn from both the National Guard and Active Force under the umbrella of Defense Support of Civil Authorities (DSCA). DSCA encompasses support provided by Federal military forces, DOD civilians and contract personnel, DOD agencies and components for emergencies, designated law enforcement (such as the FBI), and other activities. National Guard forces can operate under state control [Title 32 United States Code (USC)] or be federalized and operate under Federal control (Title 10 USC). "Support provided by National Guard forces performing duty in accordance with Title 32 is considered DSCA, but is conducted as a state-directed action." (DODD 5111.13).

\subsubsection{DOD CBRNE Response Force Capabilities}

Figure 2-5 shows a notional progression of DOD response forces in the event of a biological incident. The actual response structure is still evolving. National Guard units directed by a state or territory under Title 32 USC form the backbone of initial response. Such forces include:

- Weapons of Mass Destruction (WMDs) Civil Support Teams (CSTs). There are currently 55 CSTs established nationwide and servicing every state (CA has two) as well as Federal territories (see: 〈http://c21.maxwell.af.mil/wmd-cst.htm\#fedteams $>$, website updated March 11, 2009; accessed January 20, 2010). CSTs conduct preliminary testing as needed to supplement other hazmat responses. Information on CST organization, mission, command and control, and operations can be found in the Army Field Manual 3-11-22, Weapons of Mass Destruction-Civil Support Team Operations; available at <http://www.fas.org/irp/doddir/army/fm3-11-22.pdf>. 


\section{Response and Recovery Structure}

- Chemical, Biological, Radiological, Nuclear, or high-yield Explosive (CBRNE) Enhanced Response Force Packages (CERFP) consisting of 200 to 400 personnel. Twelve packages currently exist nationwide, at least one for each FEMA region (NGB 2008 \#4). See <http://www.ngb.ngb.army.mil/features/HomelandDefense/cerfp/factsheet.html>.

- A company-sized (75 to 125 personnel) National Guard Response Force (NGRF), one per state (NGB 2008 \#5).

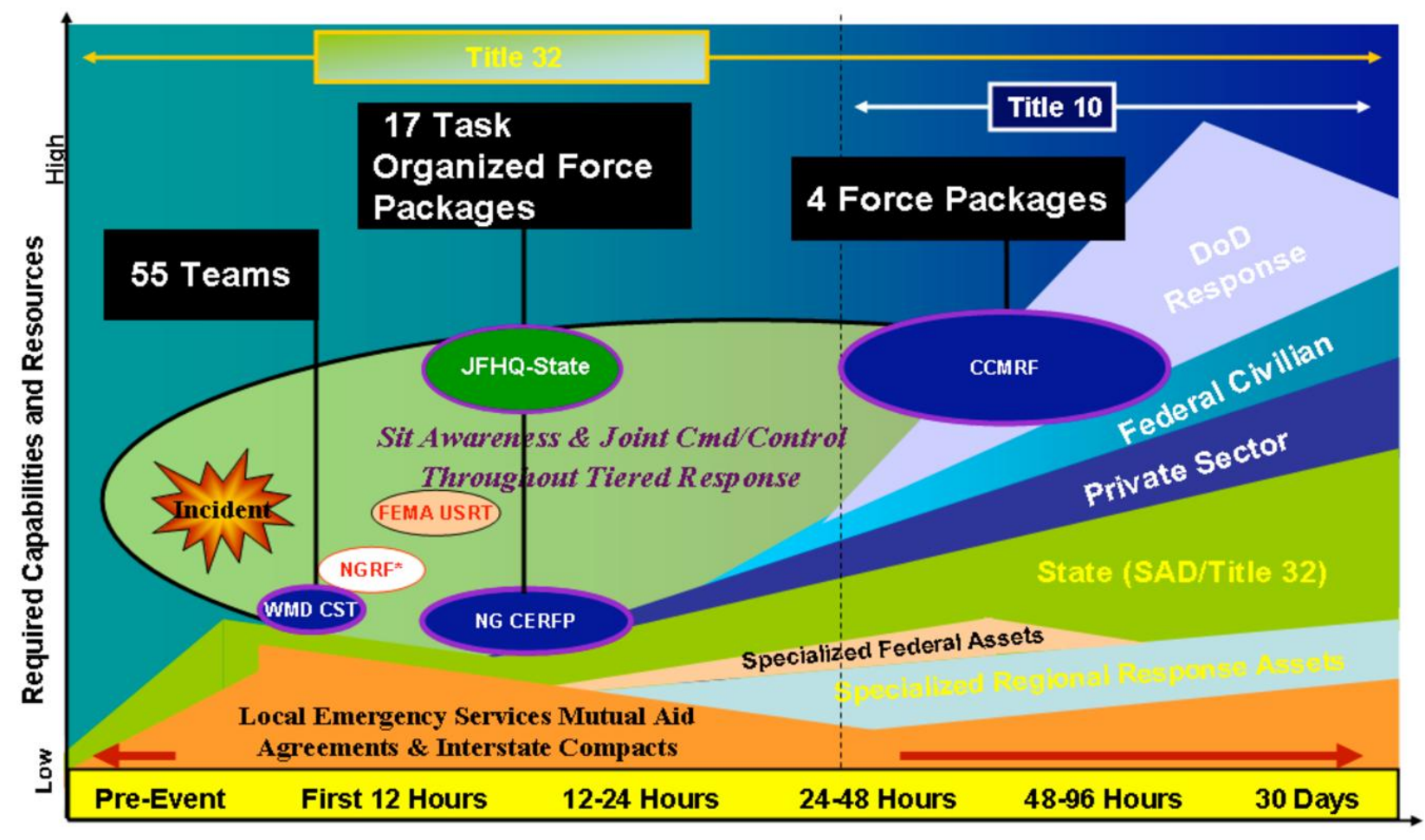

Source: NC CCMRF Briefing

Figure 2-5. National Guard and Active Force response timelines for civil response.

States and territories can also gain immediate access to local DOD Title 10 assets under DOD's Immediate Response Authority. This authority authorizes local military commanders or responsible officials of other DOD agencies to respond to civil authorities' requests for emergency DSCA support to save lives, prevent human suffering, or mitigate great property damage under imminently serious conditions when time does not permit approval from a higher authority or there has been no Presidential declaration of emergency. DOD support under immediate response authority is limited to the time that local or state authorities can resume control (generally $72 \mathrm{hr}$ or less per DODD 3025.1, DODD 3025.15, and JP 3-28, Ch 2.) If an incident overwhelms state and local capabilities, state governors can request the U.S. President to make a major disaster declaration under the Stafford Act (2007) (see Figure 2-6). 


\section{Response and Recovery Structure}

With such a declaration, broad Federal support can be requested through the designated Lead Federal Agency (LFA). If the LFA's Federal Coordinating Officer (FCO), after examining existing resources, decides there is insufficient capability to assist and DOD support is warranted, the FCO then contacts the Defense Coordinating Officer (DCO) to solicit DOD support through the U.S. Northern Command (USNORTHCOM).

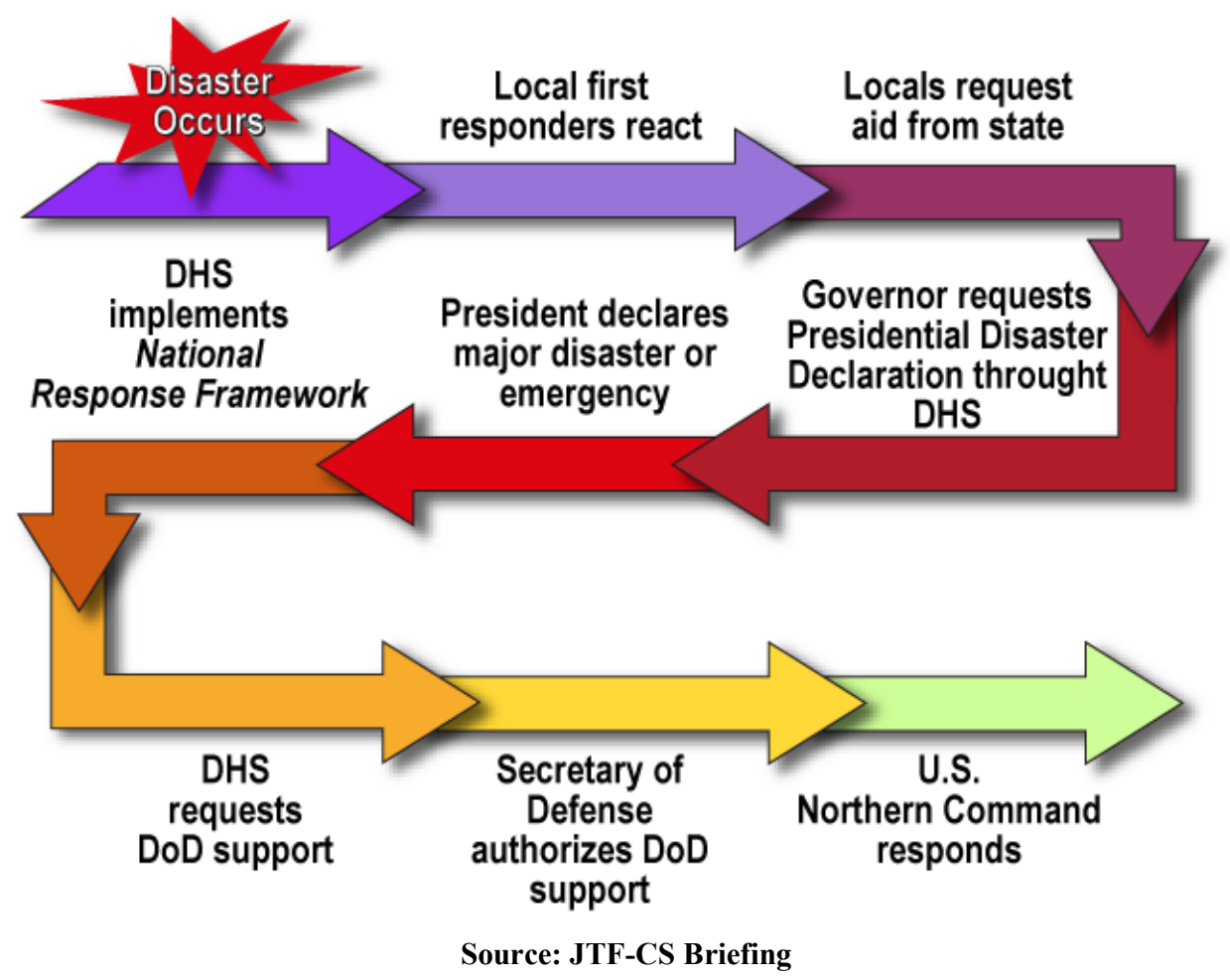

Figure 2-6. Example of the civil response process.

DCOs play the key role in coordinating DSCA provided by the DOD under any crisis scenario. At least one DCO is attached to each FEMA region, where they maintain offices in the FEMA regional headquarters and interact with FEMA regularly (FEMA 2008). When required, the DCO will deploy as part of the Joint Field Office. The DCO's team analyzes all requests from the LFA and recommends approval or denial. If a request is approved by USNORTHCOM, a mission assignment is created and given to the military unit with the capability of accomplishing it.

Key among USNORTHCOM's major response elements is the CBRNE Consequence Management Response Force (CCMRF), a team of 4,700 joint personnel that is organized, trained, and equipped to respond within $48 \mathrm{hr}$ to a large-scale CBRNE event, as directed by the Secretary of Defense. Its capabilities include search and rescue, agent detection, decontamination, medical support, aviation, force protection, communications, and logistical support. Depending on mission requirements and the mission commander's priorities, each CCMRF consists of three functional sub-task forces for operations, medical, and aviation support. USNORTHCOM will be able to draw on three CCMRFs by 2011. (USNORTHCOM PAO 2008.) Figure 2-7 summaries the capabilities of CBRNE response forces. 


\section{Response and Recovery Structure}

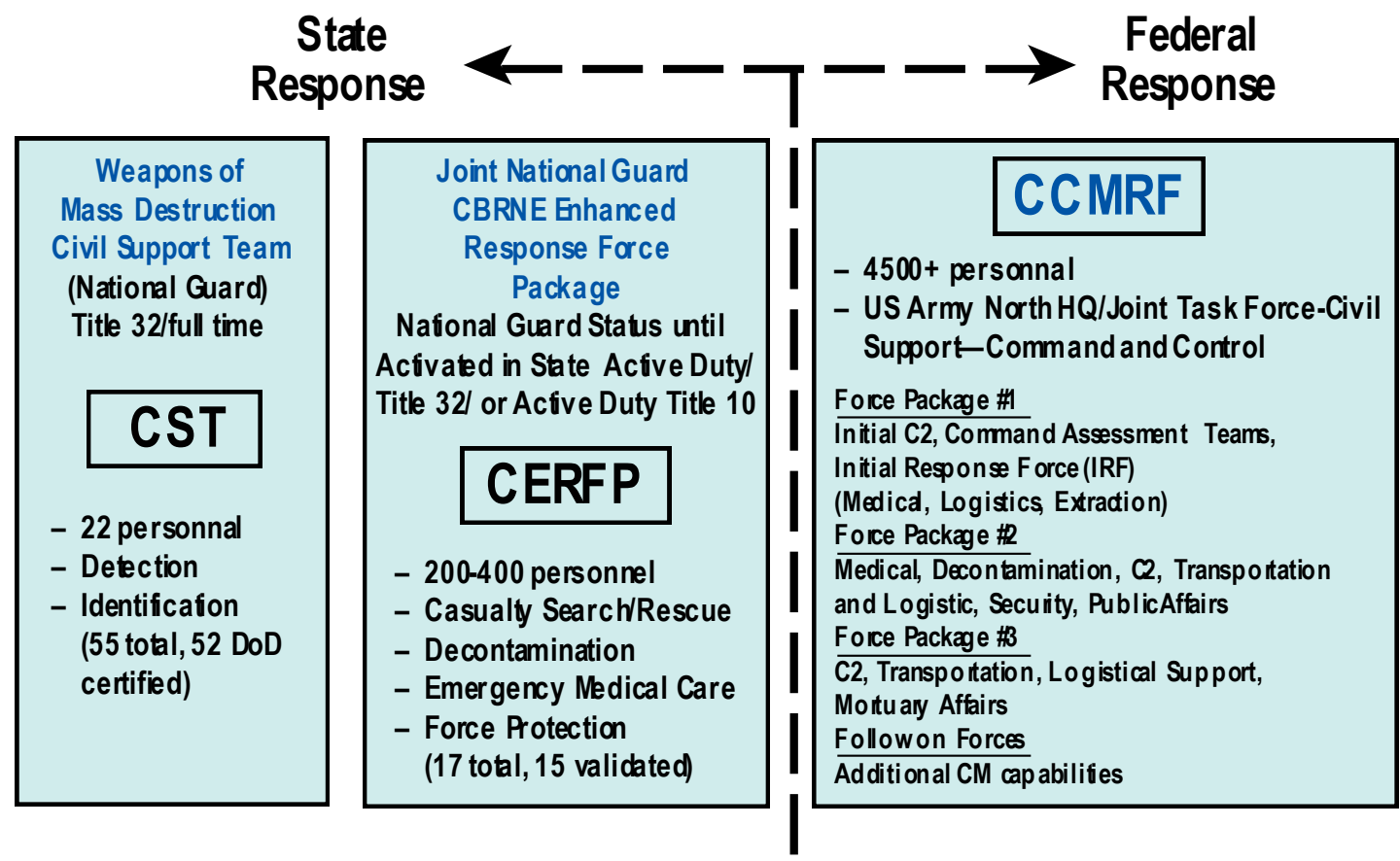

Source: NC CCMRF Briefing

Figure 2-7. National Guard and USNORTHCOM CBRNE response force packages.

\subsubsection{Local or Limited Attack on Civilian Infrastructure}

In the event of a biological attack or warning of such an attack within a state, the governor supports local EOCs with state emergency-response assets and oversees the execution of local emergency-services mutual aid agreements and essential interstate compacts. The governor can also activate National Guard response packages under USC Title 32 authority for employment at the direction of the state adjutant general (USC Title 32). National Guard assets available to state control under Title 32 USC are:

- State Joint Force Headquarters (JFHQ-State). State JFHQs provide command and control of all National Guard forces in the state or territory for the governor and can act as a jointservices headquarters for national-level response efforts. In the District of Columbia, the Secretary of the Army acts in this role (NGB 2008 \#1).

- Joint Task Force State (JTF-State). Upon attack or warning, a state can stand up a JTFState to provide command and control of all state and military assets deployed in support of civil authorities or a specific incident and facilitate the flow of information between the JFHQ-State and its deployed units (NGB 2008/2).

- National Guard Civil Support Teams (CSTs). CSTs assess suspected WMD attacks, advise civilian responders on appropriate actions through preliminary onsite testing and expert consultation, and facilitate the arrival of additional state and Federal military forces (NGB 2008 \#3).

- CBRNE Enhanced Response Force Package (CERFP). CERFPs respond to CBRNE incidents and support local, state, and Federal agencies managing the consequences of an 


\section{Response and Recovery Structure}

event. The CERFP has four elements: search and extraction, casualty and patient decontamination, medical support, and command and control. The CERFP search and extraction mission is assigned to an Army National Guard Engineering Battalion; the decontamination mission is assigned to an Army National Guard Chemical Battalion; and the medical mission is assigned to an Air National Guard Medical Group. The CERFP command and control team directs overall activities of the CERFP and coordinates with JTF-State and the Incident Commander (NGB 2008 \#4).

- National Guard Reaction Force (NGRF) provides force protection and security for WMD CSTs and CERFP teams. Reaction Forces provide every state with a combat-ready force capable of delivering, at the request of the governor or U.S. President, an initial force package of 75 to 125 personnel who can arrive on scene within 24 to $36 \mathrm{hr}$ at the request of the governor. Their missions include site security, establishing roadblocks or checkpoints, assisting civil authorities in controlling civil disturbances, and protecting DOD critical infrastructure (NGB 2008 \#5).

- Joint CONUS Communications Support Environment (JCCSE). JCCSEs encompass all of the vital organizations and supporting net-centric information technology (IT) capabilities required by the National Guard to support USNORTHCOM, USPACOM, USSTRATCOM, and other Homeland Defense and DSCA mission partners by extending interagency trusted-information sharing and collaboration capabilities to and from the national level, the 54 states and territories, and local incident sites (NGB 2008 \#6).

\subsubsection{Local Attack on a DOD Installation or Facility and Local Civilian Infrastructure}

In the event of a biological attack on DOD-owned or leased facilities, or affecting nearby civilian infrastructure, the DOD will take the lead as the On-Scene Coordinator to "protect personnel on the installations... to respond to the attacks with trained and equipped emergency responders, and to ensure installations are able to continue critical operations during an attack and to resume essential operations after an attack" (DOD 2005). DOD is required to assume this role under the NCP as well as an Executive Order providing emergency response to releases on their facilities or from their facilities.

In most anticipated situations, however, DOD installations will not have sufficient resources to continue long-term efforts to return affected facilities to pre-incident conditions. Installations would rely primarily on the Service Components, Inter-Service Support Agreements (ISSA), and the USNORTHERN Command for consequence management and recovery missions. Installations will also seek support from local agencies for emergency response via Mutual Assistance Agreements (MAAs), Memoranda of Understanding (MOUs), and Memoranda of Agreement (MOAs). Each state and county has unique interfaces with their DOD military installations and facilities, depending on mutual aid agreements and available resources. DOD installations have been instructed to identify and determine the capabilities of their applicable civilian response agencies that would be available should CBRNE incidents occur. Their instructions state that formal "Agreements between installations and local agencies are a critical step in response operations," and that "to ensure successful operations, these agreements require interoperability of standards and equipment" (DOD 2005). During wide-area remediation, installations will also rely on other Federal agencies, such as the EPA for large-scale cleanups. 


\section{Response and Recovery Structure}

\subsubsection{Catastrophic Wide-Area Attack}

In the event of a catastrophic, wide-area biological attack that overwhelms state and local capabilities, a governor may request that the U.S. President make a Major Disaster Declaration under the Stafford Act. However, the response to a human disease outbreak of known or unknown origin requiring Federal assistance may take place with or without a Presidential Stafford Act declaration or a public health emergency declaration by the DHHS Secretary. The DHS coordinates nonmedical support and response actions across all Federal departments and agencies, and the DHHS leads public health and medical emergency-response efforts across all Federal departments and agencies. Once all appropriate Federal response organizations are activated, the LFA issues mission assignments to the appropriate Federal agencies for support during the emergency.

Requests for DOD support from the LFA are generated through the Joint Field Office and coordinated with the DCO. The DCO retains responsibility for coordinating all DOD support to meet Federal and state needs as a situation evolves. After receiving an assessment of the situation from the DCO, USNORTHCOM submits a "Request for Forces" to the Joint Director of Military Support. The Joint Staff then issues orders to initiate the movement of DOD forces to support local responders. DOD forces entering an area are located in a separate Base Support Installation (BSI) initially under the command of the DCO, and later under the JTF Commander if a Joint Task Force is created.

A major USNORTHCOM response to a crisis will take the form of task-organized forces under the direction of the Joint Force Land Component Commander (JFLCC), which is U.S. Army NORTH. Under most CBRNE situations, this task force will be the Joint Task Force-Civil Support (JTF-CS; see Figure 2-8) commanded by an Army Major General. JTF-CS will determine the proper mix of personnel and equipment needed, request the appropriate organizations and people from the JFLCC, and provide essential detection, decontamination, medical, aviation, and logistical support. Table 2-2 lists examples of some of the types of support that the military can provide.

If a situation requires additional assistance, the JFLCC can stand up two operational command posts from ARNORTH. Those headquarters would organize, by task, their additional assigned forces under the umbrella of a Joint Task Force. If the situation so requires, USNORTHCOM can stand up a larger JTF-CM commanded by an Army Lieutenant General or equivalent commander (JTF-CS 2007). 


\section{Response and Recovery Structure}

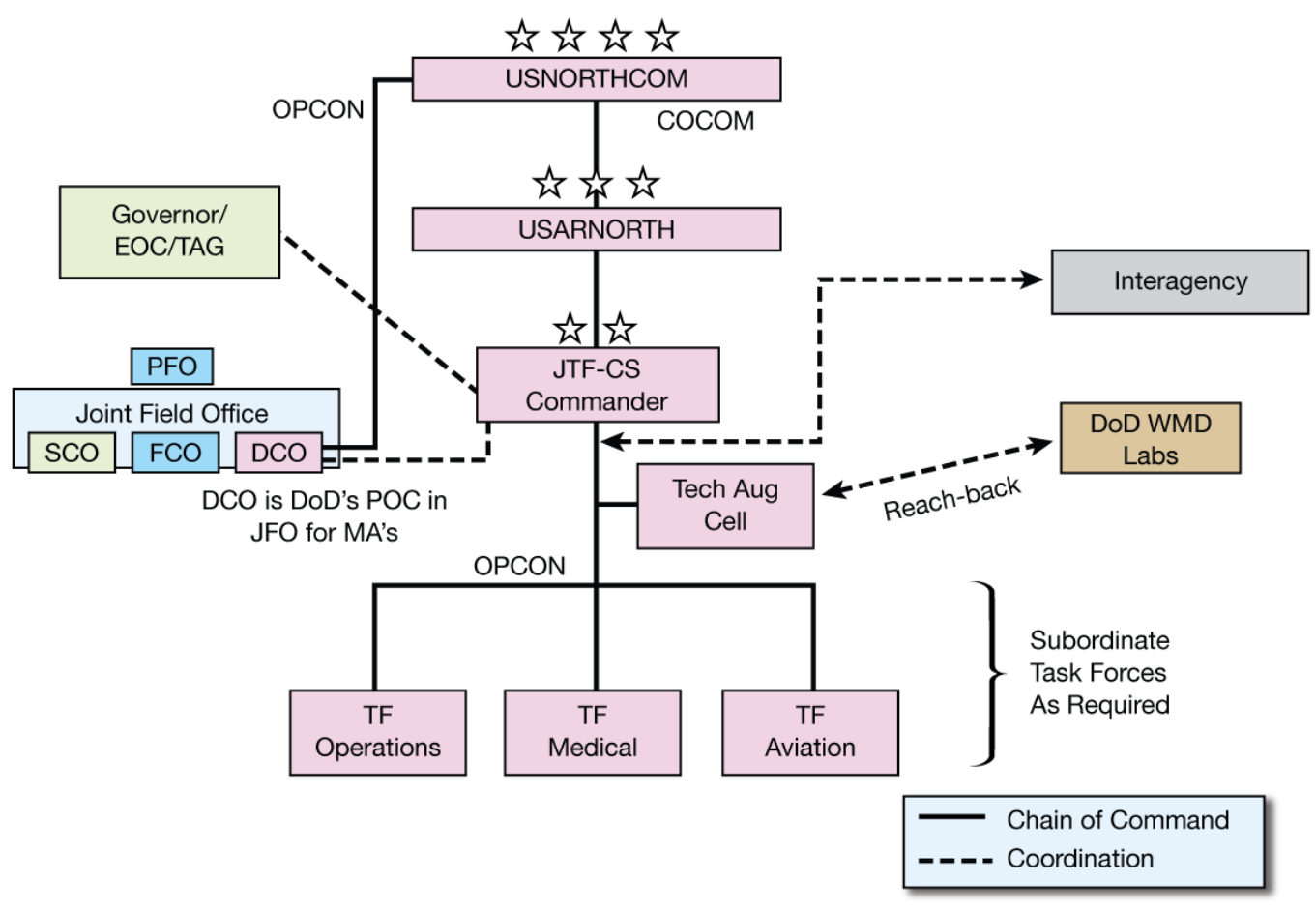

Source: JTF-CS Briefing

\section{Figure 2-8. Example DOD command and control structure for DSCA.}

Table 2-2. Examples of military support capabilities.

\begin{tabular}{|c|c|}
\hline $\begin{array}{l}\text { Cargo storage facilities (covered storage for emergency } \\
\text { supplies) }\end{array}$ & Cargo shipment facilities \\
\hline Communications & $\begin{array}{l}\text { Construction support (carpentry, earthmoving, electrical, } \\
\text { plumbing, high-voltage power) }\end{array}$ \\
\hline Decontamination stations (personnel and equipment) & $\begin{array}{l}\text { Emergency medical response (medics, physician's } \\
\text { assistants, ground and air ambulances) }\end{array}$ \\
\hline $\begin{array}{l}\text { Field hospitals (including emergency rooms, wards, } \\
\text { surgeries, ICU, labs, pharmacies) }\end{array}$ & Field sanitation \\
\hline Field power generation & Firefighting teams \\
\hline Food (including field kitchens and food distribution) & Fuel distribution \\
\hline GIS support (maps, overlays, map reproduction) & Graves registration (recovery and transport of deceased) \\
\hline Imagery (such as aerial photography) & Medical evacuation \\
\hline Organized labor force & Potable water \\
\hline Prime power (facility size) & Reconnaissance (ground, water, air, underwater) \\
\hline $\begin{array}{l}\text { Refugee camps (tent cities, sanitary facilities, lighting, } \\
\text { security, food service, recreational facilities) }\end{array}$ & Search and rescue (ground, water, and air) \\
\hline Security & Traffic control \\
\hline Transportation (people, equipment, supplies & Underwater construction and salvage \\
\hline Vehicle and equipment recovery and repair & Veterinary medicine \\
\hline
\end{tabular}




\section{Response and Recovery Structure}

Interim Consequence Management Guidance

\subsubsection{Specialized DOD CBRNE Response Elements}

The DOD has two other major CBRNE response elements that - although focused on overseas contingencies and war-fighting operations - can be called on for domestic operations if needed. The U.S. Army $20^{\text {th }}$ Support Command (CBRNE $20^{\text {th }}$ SUPCOM) can serve as the overall headquarters for a CBRNE Joint Task Force. The $20^{\text {th }}$ SUPCOM is an Army expeditionary unit designed to combat WMDs, counter CBRNE threats, and defeat all types of improvised explosive devices both within and outside the continental U.S. Capabilities include agent detection and identification; casualty search, rescue, and personnel decontamination; and medical care and stabilization of contaminated personnel. Details on unit missions, capabilities, and equipment are available at <http://www.cbrne.army.mil/info/factsheets/factsheets.html $>$.

A second major CBRNE response element is the U.S. Marine Corp's Chemical, Biological, Incident Response Force (CBIRF). This element can assist local, state, or Federal agencies and USNORTHCOM in the conduct of consequence management operations and may function independently under an established JTF or as part of CCMRF.

Other specialized response elements include:

- The Defense Threat Reduction Agency's (DTRA's) Consequence Management Advisory Team (CMAT). The CMAT is a task-organized team of 2 to 20 personnel who provide CBRNE advice and assistance. Their military backgrounds include explosive ordnance disposal operations and nuclear, biological, and chemical operations. Modelers are trained in CBRNE modeling tools, weather phenomenology, and communications. The CMAT uses DTRA's CBRNE computer modeling programs to predict the effects of an incident. CMAT is supported with reach-back capability to the DTRA Operations Center, which provides CBRNE technical reference material, CBRNE situational awareness, and agency command and control.

- The U.S. Army Medical Command's Specialty Medical Augmentation Response Teams (SMARTs) are designed to provide focused assistance in one of more than 10 specialized areas. The U.S. Army Center for Health Promotion and Preventive Medicine is responsible for the SMART-Preventive Medicine team, which tailors each team to the specific mission request. A team roster could include physicians, epidemiologists, environmental scientists, health physicists, industrial hygienist, medical entomologists, public health nurses, and other public health professionals.

\subsubsection{Conclusion of DOD Support}

DOD assets remain in an affected area to support the Lead Federal Agency that is conducting operations to stabilize an emergency situation by saving lives and preventing further injury. As directed, the DOD can provide services such as decontamination, medical assistance, and temporary critical life support for the local population. Once a situation stabilizes, DOD elements withdraw because they are not a rebuilding or restoration force.

\subsection{Other State and National Components and Communication Paths}

Additional state or national components that may come into play in a wide-area biological response include entities such as the Coast Guard, National Guard, Federal Aviation 


\section{Response and Recovery Structure}

Administration (FAA), Transportation Security Administration (TSA), U.S. Army Corps of Engineers (USACE), Red Cross, Salvation Army, and other volunteer organizations. Among their roles, the National Guard may be employed to help establish initial hot zones. The Coast Guard can provide a strike team, often within a few hours, to assist the UC; could be involved in port and coastal cleanup operations; and under the authority of the Captain of the Port, can issue an order to close a port to keep people from contaminated areas. The TSA might order the FAA to carry out a ground stop (no movement of aircraft out of or into an airport) or reroute scheduled flights in the event of contamination at an airport.

A state can request assistance under Emergency Management Assistance Compacts (EMACs) that are established with other EMAC member states. The National Emergency Management Association (NEMA) administers the day-to-day operation of EMAC. Once a governor has declared a state of emergency, the governor can issue a request to NEMA for support from other EMAC members. NEMA works with the affected state to identify needed resources and communicates the request for assistance to other EMAC members. EMAC member states can supply medical, water, food, energy, and fuel resources; search and rescue aid; and other emergency response resources.

Volunteer organizations would likely help provide refugee support, including food and shelter, among other services. Communication among such components and all other IC or UC entities is coordinated throughout all phases of response and recovery through a Joint Information Center (JIC) established by the IC or UC, as discussed in Section 3.3. In addition, a Public Information Officer (Section 4.2.7) is appointed to ensure that information about an incident is communicated to all the organizations involved. Some of the assets belonging to these entities for each phase of remediation are identified in Sections 7-9.

\subsection{Roles and Responsibilities}

Although roles and responsibilities during a wide-area response have not been fully worked out in detail, and the response organization is at the discretion of the Incident Commander and is scalable and flexible under NIMS (2008), Table 2-3 identifies many of the civilian and military organizations that would be involved at local, state, and Federal levels during consequence management. 


\section{Response and Recovery Structure}

\section{Table 2-3. Potential agency representatives within the IC or UC structure during consequence management.}

\begin{tabular}{|c|c|}
\hline Position in theCommand & Agency Representatives \\
\hline $\begin{array}{l}\text { Incident Command or Unified } \\
\text { Command }\end{array}$ & $\begin{array}{l}\text { Chief elected or appointed official, emergency management agency, DHHS/CDC, state } \\
\text { government representative, state and local public health, EPA and state environmental department, } \\
\text { city and regional representative, local and Federal law enforcement including the FBI, fire } \\
\text { department, private-sector business and critical infrastructure support representative, and DCO }\end{array}$ \\
\hline Safety Officer & Local public health and safety officer \\
\hline Public Information Officer & Public relations \\
\hline Operations Section & Section Leader: EPA \\
\hline HazMat Branch & EPA; state environmental department \\
\hline Entry Group & $\begin{array}{l}\text { Local fire department HazMat team; hired contractors; state National Guard Civil Support Team; } \\
\text { U.S. Coast Guard Strike Team }\end{array}$ \\
\hline Decontamination Group & EPA; hired contractors; local fire department \\
\hline Disposal Group & EPA; state environmental department; hired contractors \\
\hline Environmental Branch & EPA; state environmental department \\
\hline Sampling Group & $\begin{array}{l}\text { EPA; state environmental department, state National Guard Civil Support Team; hired } \\
\text { contractors; U.S. Coast Guard Strike Team; local fire department }\end{array}$ \\
\hline Remediation Group & EPA; state environmental department; hired contractors \\
\hline $\begin{array}{l}\text { Ambient Air Monitoring } \\
\text { Group }\end{array}$ & Air Quality Management District; EPA \\
\hline Site Access Control Group & Local police department \\
\hline Planning Section & Section Leader: EPA \\
\hline Situation and Analysis Unit & EPA; state environmental department; local public health; local fire dept.; hired contractors \\
\hline Resources Unit & FEMA; EPA; state environmental department \\
\hline Document Unit & EPA; hired contractors \\
\hline Demobilization Unit & EPA; state environmental department; hired contractors \\
\hline Environmental Unit & $\begin{array}{l}\text { EPA; state environmental department; local air quality management district; state department of } \\
\text { public health; local public health }\end{array}$ \\
\hline Technical Working Group & $\begin{array}{l}\text { Facilities involved, state and local departments of public health, analytical labs, other affected } \\
\text { health agencies, state environmental department, CDC, local fire department health HazMat } \\
\text { division, DOE national laboratories, EPA, OSHA Health Response Team, National Guard, } \\
\text { military, local fire department, private sector, and academia }\end{array}$ \\
\hline \multicolumn{2}{|l|}{ Logistic Section } \\
\hline Supply Unit & FEMA; EPA; DTSC; state OES; state environmental dept.; hired contractors \\
\hline Facilities Unit & Facility management \\
\hline Ground Support Unit & Local police department; local fire department; hired contractors \\
\hline Communications Unit & State National Guard Civil Support Team; local fire department; local police department \\
\hline Medical Unit & Local public health; local health services \\
\hline Food Unit & FEMA; state emergency mgmt.; local fire dept.; local police dept.; all agency representatives \\
\hline Finance and Admin Section & Section Leader: FEMA, State Emergency Management \\
\hline Cost Unit & All response agencies \\
\hline Time Unit & All response agencies \\
\hline Compensation/Claims & All response agencies \\
\hline Procurement Unit & FEMA; EPA; state emergency management; local authorities \\
\hline
\end{tabular}




\section{Response and Recovery Structure}

\subsection{Interim Recommendations for Pre-Incident Planning}

During pre-incident planning, local, state, and Federal agencies that have jurisdictional authority during an incident need to identify appropriate individuals who can serve on the IC or UC. Preplanning should address potential changes in command because the makeup of the IC or UC may change as response to an incident shifts from one phase to another.

Reducing the time required to re-establish functionality following wide-area contamination is a major goal of remediation planning. Decision-makers can address some issues in advance of a biological contamination incident. Table 2-4 identifies essential pre-incident planning activities related to the cleanup response structure.

Table 2-4. Interim recommendations for ConOps-related actions to be taken prior to a biological attack.

\begin{tabular}{|c|c|}
\hline Responsible Personnel & Recommended Pre-Incident Actions \\
\hline $\begin{array}{l}\text { City, county, state, regional, } \\
\text { or Federal decision-makers }\end{array}$ & $\begin{array}{l}\text { - Identify members of the command structure early in the pre-planning process. } \\
\text { Determine which agencies contribute tactical or service resources versus those } \\
\text { that supply technical assistance or special expertise. Members of the command } \\
\text { structure should review this Interim Guidance document. } \\
\text { - Identify alternative locations for Emergency Operations Centers (EOCs) in the } \\
\text { event that one or more EOCs are contaminated with a biological agent. } \\
\text { - Identify tools and resources needed to support planning, characterization, } \\
\text { decontamination, and clearance efforts, including sample analysis. } \\
\text { - Identify medical stockpile resources within the urban area; determine distribution } \\
\text { paths and options for treatment. } \\
\text { - Identify potential members of a Technical Working Group (TWG). The TWG } \\
\text { should review this document. } \\
\text { - Identify potential technical specialists needed to support the Planning and } \\
\text { Operations Sections. } \\
\text { - Identify potential members of an Environmental Clearance Committee (ECC). } \\
\text { The ECC should review this document. } \\
\text { - Conduct periodic training exercises with likely command personnel, including } \\
\text { TWG members, and other responder and agency representatives. Ensure they } \\
\text { have appropriate health and safety training. } \\
\text { - Identify liaison to the Joint Field Office. } \\
\text { - Prepare decision tree to determine need for expanding an IC into Area Command. } \\
\text { - Establish a process to integrate multi-jurisdictional agencies into a Unified } \\
\text { Command. }\end{array}$ \\
\hline
\end{tabular}




\section{Response and Recovery Structure}

\subsection{Section 2 References}

CERFP (2007), National Guard Fact Sheet (U), Chemical, Biological, Radiological/Nuclear, and Explosive (CBRNE)-Enhanced Response Force Package (CERFP), available at <www.jsoh.org/fs/CBRNE FS.doc> (accessed April 2007).

DHS (2002), Department of Homeland Security, National Strategy for Homeland Security; available at

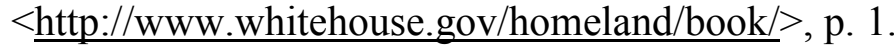

DHS (2008), Department of Homeland Security, National Response Framework; documents available at <http://www.fema.gov/emergency/nrf/> .

DoD (2005), Department of Defense, DoD Interim CONOPS for CBRNE Defense Supporting U.S. Military Installations and Facility Preparedness.

EPA (2007), U.S. Environmental Protection Agency_Incident Management Handbook;

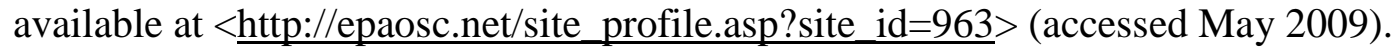

EPA (July 2009), Environmental Protection Agency Incident Command System, Environmental Unit Leader Job Aid; available at <http://epaosc.net/doc_list.asp?site_id=963>.

EPA (July 2009), Environmental Unit in an ICS Structure-Guidance Document; available at <http://www.epaosc.org/site/doc_list.aspx?site_id=963>.

FEMA (2008), FEMA Fact Sheet (U), Defense Coordinating Officer (DCO)/Defense Coordinating Element (DCE); available at <http://www.fema.gov/about/regions/regionv/dco/dce.htm> (accessed April 2008).

JTF-CS (2007), Joint Task Force-Civil Support, Command Briefing, OUO, March 2007.

NGB (2008), National Guard Bureau, The National Guard Bureau Fact Sheet, The National Guard's Role in Homeland Defense; available at

<http://www.ngb.army.mil/features/HomelandDefense/index.html> (accessed December 2008).

1. Joint Force Headquarters-State (JFHQ-State); available at <http://www.ngb.army.mil/features/HomelandDefense/jfhq/factsheet.html $>$.

2. Joint Task Force - State (JTF-State); available at <http://www.ngb.army.mil/features/HomelandDefense/jtf/factsheet.html >

3. Civil Support Teams (CST); available at <http://www.ngb.army.mil/features/HomelandDefense/cst/factsheet.html >.

4. CBRNE Enhanced Response Force Package (CERFP); available at <http://www.ngb.army.mil/features/HomelandDefense/cerfp/factsheet.html $>$.

5. National Guard Reaction Force (NGRF); available at <http://www.ngb.army.mil/features/HomelandDefense/ngrf/factsheet.html $>$.

6. Joint CONUS Communications Support Environment (JCCSE); available at <http://www.ngb.army.mil/features/HomelandDefense/jccse/factsheet.html >.

NGRF (2008), National Guard Response Force (NGRF), National Guard Bureau Public Affairs Release (U), May 2007. 


\section{Response and Recovery Structure}

NIMS (2008), National Incident Management System, document available at: <http://www.fema.gov/pdf/emergency/nims/NIMS_core.pdf>.

OSD/Policy, OASD for Homeland Defense and America's Security Affairs FAQs: Defense Support to Civil Authorities; available at <http://www.defenselink.mil/policy/sections/policy_offices/hd/faqs/defenseSupport/index.html> (accessed January 2009).

Raber, E., J. M. Hirabayashi, S. P. Mancieri, A. L. Jin, K. J. Folks, T. M. Carlsen, and P. Estacio (2002), "Chemical and Biological Agent Incident Response and Decision Process for Civilian and Public Sector Facilities," Risk Analysis 22(2), 195-202.

SNL and LLNL (2008), Sandia National Laboratories and Lawrence Livermore National Laboratory, IBRD Task 1 Systems Analysis Report (same document published separately at both laboratories as report SNL2008-1349 and report LLNL-AR-401510).

Stafford Act (2007), see Public Law 93-288, as amended, 42 U.S.C. 5121 et seq. and related authorities. U.S.C. Title 42-The Public Health and Welfare, Chapter 68-Disaster Relief. Robert T. Stafford Disaster Relief and Emergency Assistance Act, as amended, and related authorities. FEMA 592, April 2007; available at <http://www.fema.gov/about/stafact.shtm $>$.

USA20Spt Cmd, U.S. Army 20th Support Command web portal; available at <http://www.cbrne.army.mil/aboutus/aboutus.html> (accessed January 2009).

USC Title 32, Chapter 9. Homeland Defense Activities.

USMC CBIRF mission, available at <https://www.iimefpublic.usmc.mil/public/infolinemarines.nsf/(ArticlesDocuments)/7841ced4ae 7542ee8525721100505e64/\$file/cbirf mission.pdf openelement>.

USNC CCMRF (2006), USNORTHCOM Final Operational Capabilities Briefing (OUO), Chemical, Biological, Radiological, Nuclear and Explosive (CBRNE) Mission Response Force (CCMRF), June 2006.

USNC PAO (2008), USNORTHCOM Public Affairs Office Release, U.S. Northern Command Gains Dedicated Response Force, 30 September 2008.

The following sources contain more information relevant to topics discussed in this section.

Stand-To (2008), Stand-To Fact Sheet (U), Defense Support of Civil Authorities-Defense Coordinating Officer/Defense Coordinating Elements.

USCG (April 2001), Incident Management Handbook, U.S. Coast Guard, Washington D.C.; available at <homelandsecurity.tamu.edu/framework/dhls/coastguard/u-s-coast-guard-incidentmanagement-handbook/>. 


\section{Notification}

\section{Part II: Response}

\section{Notification}

This section outlines basic considerations pertaining to the Notification Phase. Notification is the process of communicating the occurrence, or potential occurrence, of a biological incident to designated authorities who then initiate first-response actions. The process occurs as the first step in response to a suspected or actual biological incident. Principal activities during the Notification Phase are:

- Receiving and assessing information pertaining to a wide-area biological attack.

- Identifying suspected release sites.

- Disseminating information to appropriate agencies and stakeholders.

- Alerting or standing up additional resources.

Notification activities summarized in Figure 3-1 do not necessarily occur in strict sequential order but may start at different times, run concurrently, or continue beyond the Notification Phase.
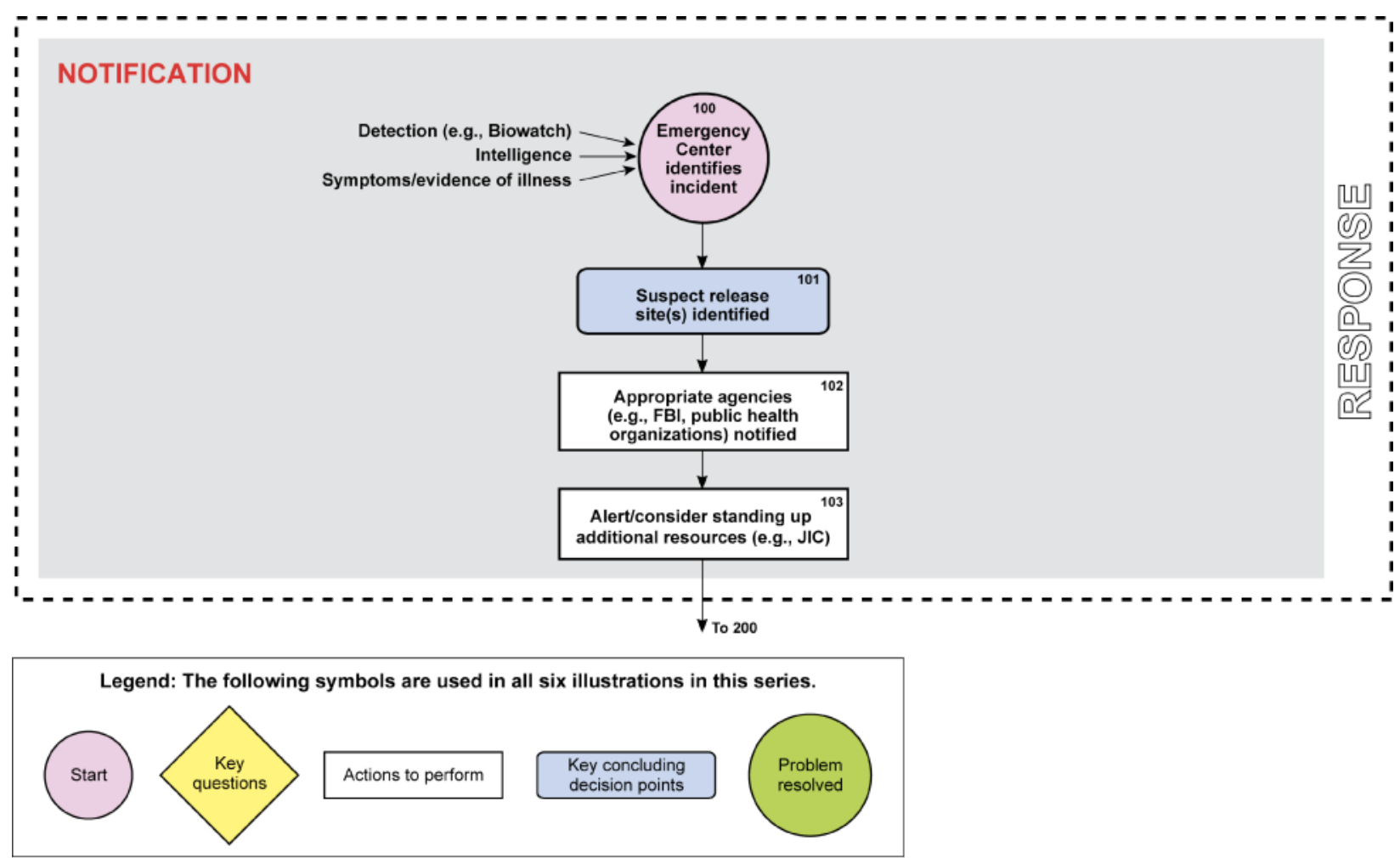

Figure 3-1. Principal activities associated with the Notification Phase. This is the first in a series of six high-level flowcharts that provide an overview of steps for biological response and recovery. Steps are continued in subsequent sections. 
At the national level, the National Contingency Plan (EPA 2000, 40 CFR Part 300.4) contains general information and regulatory mandates about the discovery of a release and notification, and the NRF (DHS 2008) contains notification information as well. Additional references regarding Federal, state, regional, and local notification procedures are provided in this section. Across all levels of response, initial actions include activating people and teams, and establishing incident management and response structures to organize and coordinate an effective response. According to the NRF (2008, p.35), "All responders should maintain and regularly exercise notification systems and protocols."

\subsection{Receiving and Assessing Information (Boxes 100, 101)}

Initial information about a potential or actual wide-area biological release can come from various sources (Figure 3-1, Boxes 100 and 101). In a domestic, civilian setting, a biological incident can be detected (Figure 3-2, Box 100-1) or suspected by an individual at the scene, an active detection system, [e.g., BioWatch network (Shea and Lister, 2003); U.S. Postal Service Biohazard Detection System for Bacillus anthracis spores (Noller, 2005; McBride et al., 2003); see also Meehan 2004], images from cameras or other surveillance equipment, intelligence information, medical surveillance (e.g., clinical cases), epidemiologic investigation, or notification from military authorities. Information about a potential or actual incident will likely be received by a Federal, state, or local organization, such as an emergency management or public health office. The responsible person(s) at the receiving location assesses the credibility of information (Box 100-2) and the degree to which a response is needed. If incoming information about a possible biological incident appears credible and requires a response, the responsible receiving person relays information to appropriate agencies, such as police, fire, public health, HazMat teams, the Federal Bureau of Investigation (FBI), and DHS (Box 102). Because each agency, in turn, has predetermined notification or "call-down" lists, notification is likely to be redundant in many instances.

Initial information (Boxes 100 and 101) about a potential or actual biological release on or affecting a military installation can likewise come from direct observation by one or more individuals, an active detection system (such as Guardian, if one is in place), cameras, medical surveillance, epidemiological investigation, or notification by civilian authorities. A military installation would follow a pre-established notification protocol. The DOD may elect to designate a JTF to command Federal (Title 10) military activities in support of incident objectives. The JTF Commander exercises operational control of Federal military personnel and most defense resources in a Federal response.

The details of how initial notification takes place would vary, depending on the trigger event, its location, and other factors. For example, immediately after declaration of a BioWatch Actionable Result (BAR) from the BioWatch system, the BioWatch notification protocol would be executed. The BioWatch Advisory Committee (BAC) is convened within two hours of a BAR and begins to collect data, interpret the data, and participate in bioterrorism threat and public health risk assessments. Members of the BAC can include the LRN laboratory director, epidemiological investigations team leader, modeling and data visualization team leader, local FBI WMD coordinator, regional EPA representative, state epidemiologist, emergency response coordinator, and other experts. Furthermore, representatives from Federal partnering agencies (including the DHHS, EPA, and DHS) participate in BAC meetings. The affected region, tribe, territory, or 


\section{Notification}

state would contact the CDC's Director's Emergency Operations Center (DEOC) and individuals on the BAC about the pending conference call. Once the DHHS Secretary Emergency

Operations Center (SOC) is advised of the call by the DEOC, watch officers would notify other Federal agencies, including the DHS and the FBI WMD Coordinator. Phase I and II sampling would likely be conducted by local sampling team(s) to begin characterization of the incident. Results from Phase I and II sample collection and analysis would be reviewed as they become available and used to evaluate the extent of contamination. Additional responders and capabilities (Box 103) could be requested through mutual aid and assistance agreements, the state, or the Federal Government.

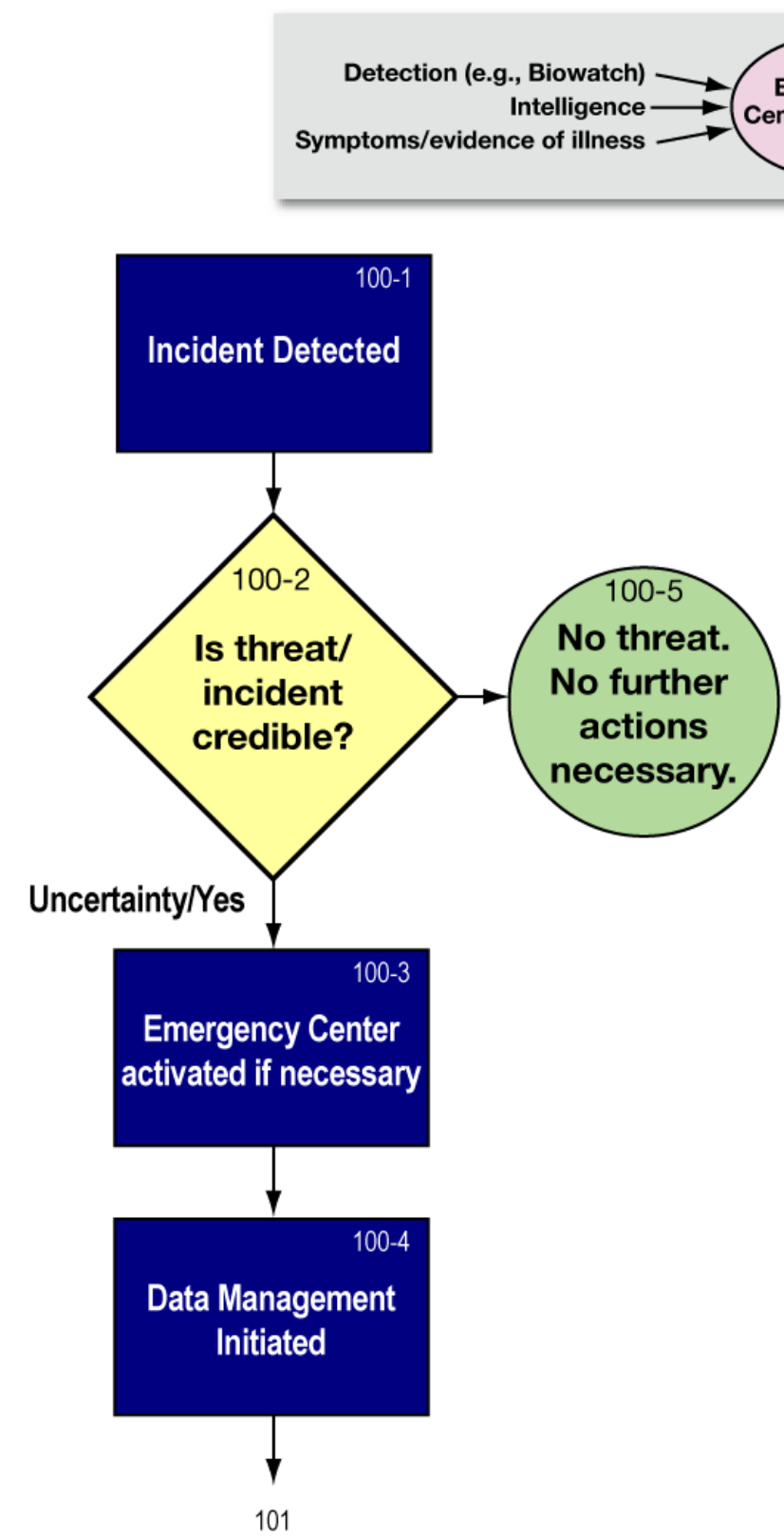

Figure 3-2. Expanded steps for Box 100: activate an Emergency Operations Center. 
Notification

\subsection{Emergency Operations Center}

An Incident Command is typically established with the arrival on-scene of the first person of authority (e.g., fire department or police department representative). In the case of a wide-area incident, a UC would likely be established quickly — depending on what is initially known about the type and scale of incident - with arrival of representatives from other agencies (e.g., public health and FBI). The coordination of information and resources to support domestic incident management activities generally takes place, at least initially, at an EOC (Boxes 100-3 and 1004), which may be a temporary or a permanently established facility. More than one EOC would almost certainly be involved in a wide-area incident because of the different agencies involved. EOCs may be organized by major functional disciplines (e.g., fire, law enforcement, and medical services), by jurisdiction, or some combination. Per the NRF (2008, p. 35), every EOC "should have standard procedures and call-down lists to notify department and agency points of contact."

\subsection{Disseminating Key Information (Boxes 102, 103)}

At the national level, when notified (Box 102) of a threat or incident that potentially requires a coordinated Federal response, the National Operations Center (NOC) "evaluates the information and notifies appropriate senior Federal officials and Federal operations centers: the National Response Coordination Center (NRCC), the FBI Strategic Information and Operations Center (SIOC), the National Counterterrorism Center (NCTC), and the National Military Command Center. The NOC serves as the primary coordinating center for these and other operations centers.” (See NRF 2008, p. 34.) Furthermore, “...the Secretary of Homeland Security coordinates with other appropriate departments and agencies to activate plans and applicable coordination structures of the Framework, as required." Thus, the NOC would maintain the common operating picture providing overall situational awareness of information about an incident. Some Federal departments or agencies may deploy to an incident under their own authorities.

DOD T10 forces would only respond if requested to do so by local authorities under an existing MOU or through an approved mission assignment from the Lead Federal Agency. Such forces may deploy to a nearby DOD installation under their own authorities and at their own expense.

The DHHS and its SOC (see Section 3.1) play a pivotal role in coordinating the medical response and disseminating public health information. Once the DHHS Secretary, Assistant Secretary for Preparedness and Response (ASPR), and other relevant Federal agencies are notified, the SOC would commence its internal notification procedures, alerting, among others, the DHHS Emergency Management Group (EMG). In consultation with the Secretary and after an update from the SOC, the ASPR directs the DHHS to transition from normal operations to coordinated departmental emergency response operations, with each division activating its Emergency Operations Center. The SOC identifies liaison officers needed at other Federal agencies, establishes an EMG, and alerts an Incident Response Coordination Team (IRCT), augmenting the team with subject matter experts on epidemiological investigations and related operations. The SOC also alerts its ESF-8 partners and contacts regional, tribal, territorial, state, and local public health officials managing the response, closely monitoring activities such as epidemiological investigations, environmental sampling results, and data visualization and computer modeling efforts. The SOC establishes communications with the CDC DEOC, which brings together experts for analysis and planning for the incident. The alert notification includes 


\section{Notification}

Interim Consequence Management Guidance

the Strategic National Stockpile (SNS). In coordination with other officials and agencies, the SOC publishes a schedule listing key daily events during the response, including conference calls, briefings, and press conferences.

DHHS coordinates with state and local officials to review emergency management plans and procedures for making assistance requests to the Federal government. Working with all relevant public health officials, DHHS explores methods of increasing the effectiveness of healthcare and emergency response operations. Such efforts can include deployment of Federal assets, such as epidemiological and laboratory support (for the expected surge of LRN work), National Disaster Medical System (NDMS) teams for critical-care capability, and Points of Dispensing (PODs) capabilities. DHHS also coordinates with other Federal agencies, including the DOD, for potential support in the event that numerous patients develop inhalation anthrax. The ASPR directs the CDC to prepare to deploy appropriate countermeasures and supplies, such as those from the SNS. DHHS begins consultations with all relevant officials and manufacturers as to the availability of, safety of, and rapid manufacturing capabilities of inhalation anthrax-related countermeasures, such as vaccines and antibiotics. DHHS would also begin its implementation of communications and media campaigns designed specifically for responding to an anthrax attack.

Effective public information strategies are essential during all phases of an incident. A UC would elect to establish a JIC in a wide-area incident (Box 103), which is a physical location where the coordination and dissemination of information for the public and media are managed. JICs can be established locally, regionally, or nationally depending on the size of an incident, and the NRF (2008, p. 65) encourages co-location of Federal, state, tribal, and local JICs. The JIC staff facilitates the dissemination of accurate, consistent, accessible, and timely public information to numerous audiences (see Section 4). For example, information about where to receive assistance is communicated directly to victims and families in accessible format and appropriate languages. 


\subsection{Interim Recommendations for Notification}

Table 3-1 summarizes the currently expected principal actions that would take place during notification for a wide-area biological incident.

\section{Table 3-1. Interim recommendations for notification protocols and procedures in approximate order of unfolding events.}

\begin{tabular}{|c|c|}
\hline Responsible Personnel & Recommended Actions \\
\hline \multirow[t]{4}{*}{$\begin{array}{l}\text { Emergency management } \\
\text { organization and law } \\
\text { enforcement or other } \\
\text { response and public } \\
\text { health organizations }\end{array}$} & $\begin{array}{l}\text { Emergency manager, public health, and law enforcement representatives receive } \\
\text { notification that: } \\
\text { - A biological incident has been detected, or } \\
\text { - A biological incident is suspected, or } \\
\text { - Information about a credible threat is received as the result of a detection system such as } \\
\text { BioWatch, medical surveillance, or epidemiologic investigation. }\end{array}$ \\
\hline & $\begin{array}{l}\text { - Gather information, and continue to assess incident credibility, status, potential effects on } \\
\text { a facility or urban area, and the degree to which a response is needed. } \\
\text { - Implement standard EOC communication protocols, including information dissemination } \\
\text { via Fax, Web-EOC, or other Internet communication tools. }\end{array}$ \\
\hline & $\begin{array}{l}\text { Emergency manager, public health, and law enforcement representatives initiate } \\
\text { notification, as appropriate, by: } \\
\text { - Following previously established notification protocols tailored to specific triggers at } \\
\text { each stage of a developing incident by alerting responders (Federal, state, and local) or } \\
\text { acting on direction from them. } \\
\text { - Disseminating information, including preliminary risk communication and public health } \\
\text { directives. }\end{array}$ \\
\hline & $\begin{array}{l}\text { Establish an Incident Command at the scene initially, and coordinate information at EOCs. } \\
\text { Alert and consider standing up additional resources, such as the JIC and Federally managed } \\
\text { JFO. } \\
\text { Anticipate establishing an ICP for the tactical management of a wide-area biological } \\
\text { incident by the IC or UC. }\end{array}$ \\
\hline
\end{tabular}




\section{Notification}

\subsection{Section 3 References}

DHS (2008), Department of Homeland Security, National Response Framework; documents available at $\langle$ http://www.fema.gov/emergency/nrf/> .

EPA (Revised July 2000), U.S. Environmental Protection Agency, National Oil and Hazardous Substances Pollution Contingency Plan (NCP) (40CFR300); available at <http://www.epa.gov/oilspill/ncpover.htm>.

McBride, M. T. et al. (2003), Autonomous detection of aerosolized Bacillus anthracis and Yersinia pestis, Anal. Chem. 75(20), 5293-9.

Meehan, P., N. Rosenstein, M. Gillen, R. Meyer, M. Kiefer, S. Deitchman, R. Besser, R. Ehrenberg, K. Edwards, and K. Martinez (June, 2004), "Responding to Detection of Aerosolized Bacillus anthracis by Autonomous Detection Systems in the Workplace," Morbidity and Mortality Weekly Report, 53(7).

Noller, A. (2005), "US Postal Service Bio-Detection System," National Homeland Security Consortium Meeting, Monterey, CA, May 24-25, 2005 (National Emergency Management Association, Lexington, KY); available at: <http://www.nemaweb.org/?1381 >; see also National Association of Letter Carriers (2005), USPS Biohazard Detection System (BDS); available at <http://www.nalc.org/depart/safety/USPSBDS.html> (accessed 9/30/2005).

Shea, D. A. and S. A. Lister (2003), The BioWatch Program: Detection of Bioterrorism, Congressional Research Service, Washington, D.C., Report No. RL 32152. 


\section{First Response}

A discussion of the First-Response Phase is included in this Interim Guidance because early actions and information obtained during initial response, such as sampling results, affect subsequent remediation activities. Initial response to a wide-area biological attack is likely to begin with emergency actions - probably by local police and fire personnel at or near the scene of a release. Other emergency operations personnel (e.g., HazMat teams, public health, and security) would be quickly called in, and their roles would continue as long as an emergency is in effect. Some response missions may still continue long after that. In addition to initial search and rescue, perimeter control, site security, and law-enforcement activities, initial responses include containing the area(s) of contamination to the extent possible; protecting the crime scene(s); carrying out public health actions, such as treating potentially exposed persons, decontaminating people, and mitigating any conditions that pose an immediate threat to human health; and continued environmental sampling and analysis.

As discussed in two scenarios presented in Section 1 and in Section 3, initial information about a biological attack can range from incident-specific details obtained during an observed release to epidemiological evidence of infection reported days to weeks after a release. The response will likewise vary, depending on scene features (e.g., port, airport, tunnel, bridge, or road closures) and the type and timing of information. The deposition of a released BWA is not likely to be static; rather, deposited material will be subject to relocation by weather (wind and rain), human activity (vehicle and pedestrian traffic), and a combination of reaerosolization or fomites (e.g., tracking). Identification of contaminated areas will be an ongoing process requiring a wide-area sampling strategy given the possible mechanisms for contaminant transport.

\subsection{Activate and Deploy Resources and Capabilities}

HazMat and emergency actions take place when first responders arrive on-scene to address immediate threats (Figure 4-1, Box 200) to life or property and to establish control. Responders set up a command post, initiate the ICS, establish perimeter controls and site security, conduct evacuation, execute shelter-in-place orders if applicable, initiate any needed rescue operations, mitigate any life-threatening or hazardous conditions (e.g., fire or explosion), and conduct preliminary tests [often referred to as "screening" environmental sampling or assessment; see for example NRT (2005, p. 49)] to determine whether the threat substance is biological in nature (Boxes 201 and 202) or likely to be a hazard (Box 203). See Section 4.2.3 for information regarding appropriate analyses of such samples. First responders communicate with command personnel to activate and deploy additional support personnel and resources, as needed. 


\section{First Response}

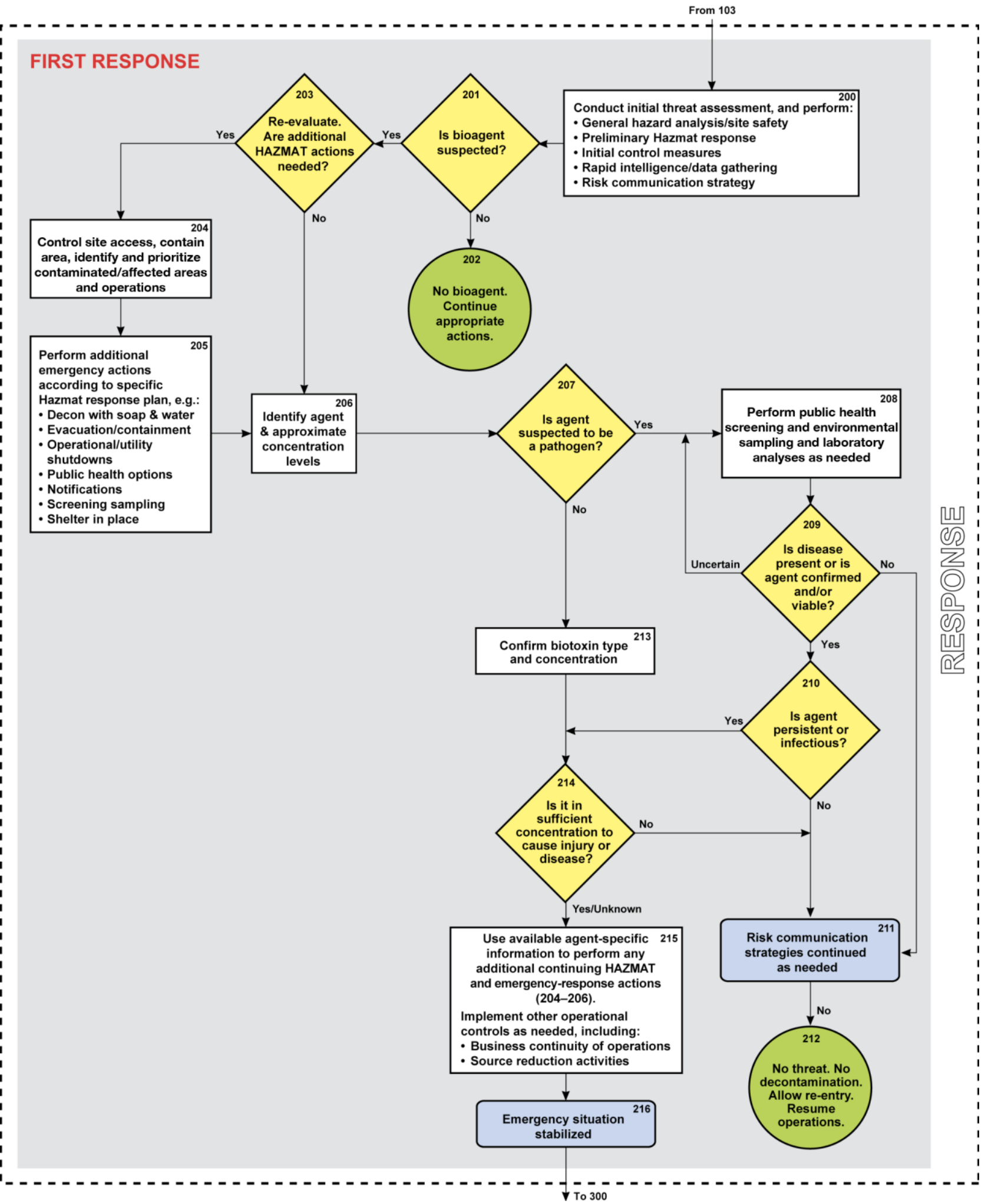

Figure 4-1. Principal activities association with the First-Response Phase. 


\subsubsection{Local Response}

The coordination of information and resources for the ICP is through individual agency EOCs, each of which uses call-down lists or other mechanisms to notify relevant agencies and points of contact. For the coordinated response required after a wide-area biological attack, agencies work together through the designated members of the IC or UC. Incident Management Teams (IMTs; see Section 2.1) and specialized response teams, such as search and rescue, HazMat response teams, and public health specialists, are activated as required. Experts on various topics, such as public health, make and deliver initial situation assessments to the IC or UC.

Incident objectives are based on incident-specific priorities, and in most cases the command organization (IC or UC) develops Incident Action Plans (IAPs) to guide daily actions. In a widearea incident, local responders would request additional resources by activating mutual aid and assistance agreements, and states can similarly request assistance from other states by using the agreements already in place, such as Emergency Management Assistance Compacts (EMACs).

\subsubsection{Federal Response}

Pursuant to the Homeland Security Act of 2002, the Secretary of Homeland Security is responsible for coordinating Federal operations within the United States to prepare for, respond to, and recover from terrorist attacks, major disasters, and other emergencies, including biological incidents. The Secretary is the Principal Federal Official (PFO) for domestic incident management. The DHS coordinates overall nonmedical support and response actions across all Federal departments and agencies.

The EPA is the primary agency that addresses environmental response to threats involving human health or the environment. The NCP provides for an OSC to receive notifications of environmental releases. An EPA OSC is responsible for assessing the need for Federal response and carrying out response actions deemed appropriate. An OSC can support a response at the local or state level, assimilating into the Incident Command Structure as part of a UC, or an OSC can implement response actions to protect public health and the environment as deemed necessary in an emergency situation within the delegated authorities. The OSC has the authority to provide for an Incident Command System, to assume the incident command role if the state or locals are unable to perform the responsibilities, and to support or conduct site characterization and integrate EPA emergency response assets into the IC or UC.

The Biological Incident Annex of the NRF outlines the actions, roles, and responsibilities associated with response to a human disease outbreak of known or unknown origin requiring Federal assistance. Actions described in this annex can take place with or without a Presidential Stafford Act declaration or a public health emergency declaration by the Secretary of DHHS. This annex outlines Federal-level biological incident response actions, including threat assessment notification procedures, laboratory testing, joint investigative and response procedures, and activities related to recovery. The DHHS leads public health and medical emergency response efforts across all Federal departments and agencies.

The FBI coordinates the investigation of criminal activities if such activities are suspected. Upon notification of a known or suspected bioterrorism attack by any source, the FBI will be deployed 
to the site during the First Response Phase and continue the forensic investigation for whatever time period is necessary. The FBI does not need to receive a request to go to the scene of a terrorist attack to conduct its law enforcement mission. The appropriate Hazardous Materials Response Unit (HMRU) from the FBI laboratory will be deployed to the site, as well as other response units as required. Such units must be in transit to an affected site anywhere in the world within $2 \mathrm{hr}$ of notification. The FBI team will fold into the NIMS structure at the site and report to the IC or UC. They will work with the IC or UC but manage the forensic investigation. After the FBI completes its forensic investigation, should additional source material be found or other possible evidence identified during ongoing site activities, it will be necessary for the UC or IC to cease all activities in the affected area(s) and alert relevant FBI staff to return to the site to perform an additional forensic investigation.

DHHS provides guidance to state, tribal, territorial, and local authorities and collaborates closely with the FBI in the proper handling of any materials that may have evidentiary implications (e.g., LRN samples) associated with disease outbreaks suspected of being terrorist or criminal in nature. If the incident response progresses such that it requires multiagency participation, DHS serves as the Incident Coordinator. DHHS serves as the coordinating agency for public health issues as do other agencies for their area of technical expertise. If there is potential for environmental contamination, DHHS collaborates with the EPA in developing and implementing sampling strategies and sharing results.

In the event of an outbreak of an agriculturally significant zoonotic disease or human food-borne pathogen, the DHHS collaborates with the Department of Agriculture (USDA) during the preparation, planning, or response processes. The USDA is the Government's primary agency for outbreaks or attacks that involve animals used in the commercial production of food. The USDA may also serve as the Government's primary agency for attacks on food-processing and slaughtering facilities under its regulatory purview. In the event of biological attack affecting food or animals, the DHHS may provide additional public health and veterinary epidemiological assistance to the USDA. Wildlife impacts would be under the purview of the Department of the Interior (DOI), whereas those involving marine animals would be managed and monitored by the Department of Commerce.

For an incident requiring coordinated Federal response, the NOC, often acting through the National Response Coordination Center, notifies other Federal departments and agencies and specifies the level and type of activation required. Field deployment may initially be to a Joint Field Office (JFO), which is a central coordination point among local, tribal, state, and Federal governments, or a Joint Operations Center (JOC), which is an interagency command post established by the FBI. Reach-back resources, including the Interagency Modeling and Atmospheric Assessment Center (IMAAC), BioWatch, and others, may be mobilized to promptly begin analyzing the problem. It is not yet clear how a BioWatch Advisory Committee would evolve from a planning to a response body within the ICS structure, but see Section 3.1 for a description of the likely range of members from various agencies constituting a BAC.

A State Governor can also request Federal assistance (funds, resources, and critical services) by several means including the Stafford Act, which is triggered by a Presidential declaration of a major disaster or emergency. Declaration of a major disaster by the President results in long-term Federal recovery programs, whereas an emergency declaration is more limited in scope. The affected state(s) and the Federal Government may also take more proactive measures to mobilize 


\section{First Response}

and deploy assets in anticipation of a formal request. A mechanism called "Proactive Response to Catastrophic Incidents" (DHS 2008) is designed to ensure that resources reach the scene in a timely manner.

\subsubsection{Military Response}

The DOD provides defense support of civil authorities when directed to do so by the President or Secretary of Defense. See Section 2.1.4 for more details. Military response also includes "immediate response authority," which occurs in the absence of an Emergency Declaration or direction from the Secretary of Defense for the purpose of saving lives. [Note: DSCA, which is defined in the NRF, involves the assignment and allocation of DOD resources (Federal military forces, DOD civilians, contract personnel, and DOD agencies and components) to support civil authorities during civil emergencies, such as terrorist threats or attacks and major disasters when DOD assistance is requested. However, Federal law restricts the use of Title $\mathrm{X}$ forces to support civil law enforcement.]

\subsubsection{Types of Response Missions}

Any or all of the following response missions and actions may be designated during the FirstResponse Phase by command personnel. Some of the missions continue well past the FirstResponse Phase.

- Search and rescue.

- Citizen shelter-in-place or evacuation.

- Perimeter control, site security, crowd control, and crowd management.

- Forensic investigation.

- Isolating people and quarantine.

- Mass care (sheltering, feeding, and related services).

- Emergency triage and pre-hospital treatment.

- Mass prophylaxis.

- Medical surge and fatality management.

- EOC management.

- Onsite incident management.

- Critical-resource logistics and distribution.

- Emergency public safety and security response.

- Emergency public information and warning.

- Environmental sampling.

- Agent characterization.

- Citizen-performed decontamination options.

- Responder safety and health.

- Animal health emergency support.

- Volunteer management and donations. 
First Response

\subsection{Implement Initial Response Actions}

\subsubsection{Initial HazMat Response (Boxes 200-205)}

An initial threat assessment is made of the situation with the objective of stabilizing the emergency. Activities carried out at this early stage would likely include making a rapid hazard and site-safety analysis, performing preliminary HazMat responses that are appropriate, putting into place initial control measures, and ensuring rapid intelligence and data gathering (Box 200). Emergency personnel initially focus on health-protective actions in an effort to save lives. Initial HazMat actions can include any or all of the following:

- Access control to affected area(s) (Boxes 204 and 204-1).

- Performing initial containment to prevent the further spread of contaminant (Box 204).

- Identifying and prioritizing contaminated or affected areas and operations (Box 204).

- Mitigating any life-threatening or hazardous conditions (e.g., fire or explosion) (Box 205).

- Employing immediate decontamination with soap and water (Box 205).

- Addressing any other immediate threats to life or property (Box 205).

- Initiating evacuation and any needed rescue operations (Box 205).

- Providing shelter options (Box 205).

- Shutting down building utilities and affected operations where appropriate (Box 205).

- Setting up a command post and making additional notifications (Box 205).

- Performing screening sampling to determine if a threat substance is a likely hazard (Box 205).

It is possible that a wide-area BWA incident might not be detected until several days or weeks after a covert attack. However, once an incident is recognized, the situation needs to be evaluated and handled as an emergency until the emergency is stabilized. It will be important to quickly assess the extent of contamination, which entails a wide-area sampling plan that rapidly identifies all contamination boundaries, but not necessarily uncontaminated areas.

\subsubsection{Personal Decontamination and Prophylaxis}

If personal decontamination is deemed appropriate (Boxes 201, 203-5), according to the CDC (1999), persons should remove their clothing and personal effects, place all items in plastic bags, and shower using copious quantities of soap and water. Plastic bags with personal effects should be labeled with the owner's name, contact telephone number, and inventory of contents. Personal items may be kept as evidence in a criminal trial or returned to the owner if the threat is unsubstantiated. Evidence or personal items should be double-bagged and decontaminated on the outside with an appropriate sporicide prior to removal from the hot zone.

Post-exposure prophylaxis (PEP) for persons exposed to aerosolized $B$. anthracis spores is discussed in the HHS/CDC's Advisory Committee on Immunization Practices (ACIP) Summary Report (2008), which is available at <http://www.cdc.gov/vaccines/recs/acip/downloads/minoct08.pdf > . In brief, the recommendation by the CDC and ACIP for PEP is administration of a three-dose series of Anthrax Vaccine Absorbed (AVA, which is the only FDA-approved product to prevent anthrax pre-exposure) at weeks 0,2 , and 4 , in conjunction with a 60 -day course of antimicrobial therapy. 
The CDC and other offices in HHS are working with state and local health departments, Federal agencies, and nongovernmental organizations to improve the public health capacity to address bioterrorism and develop locality-specific response plans. The CDC can assist public health officials with decision-making if a threat occurs alleging the use of a BWA. Decisions regarding the use of antibiotics are made at state and local levels.

\subsubsection{Evacuation versus Shelter-In-Place Decision}

A key decision with important implications (Box 205) is whether or not to order an evacuation of the affected area or to implement a shelter-in-place directive together with instructions regarding protective measures and personal self-decontamination. Among other named "critical challenges," inadequate evacuation procedures was identified as one of the major gaps in the report prepared for the White House entitled, The Federal Response to Hurricane KatrinaLessons Learned (February 2006, p.51), available at <http://www.whitehouse.gov/reports/katrina-lessons-learned/>.

Evacuation - if deemed advisable — presents additional potential problems for Home-Rule States, because there is no such thing as mandatory evacuation in those states. The term "Home Rule" has various meanings, depending on a given state and municipality, but it usually connotes some form of self-government by the constituent parts of a state. Only six states (Alabama, Idaho, Indiana, Mississippi, Virginia, and Vermont) do not provide for some form of municipal Home Rule. For example, in Seattle the Washington State Department of Health would make the decision to evacuate or shelter-in-place, but that department is essentially in the position of only offering advice. Furthermore, implementing an evacuation plan would be geographically difficult in Seattle because mountains and the Puget Sound are located to the east and west, respectively, of the affected urban area in the Seattle scenario. In the case of New York City, the orderly evacuation of an estimated 8 to 16 million residents and commuters who might be present in Manhattan on a workday could present insurmountable challenges.

Thus, during the First-Response Phase careful consideration must be given to the options of evacuation versus shelter-in-place. Neither choice is without risk, both entail costs and decisions are made at state and local levels. Self-evacuation and mass exodus could take place, which would need to be addressed at the local level as well. If the agent is known and determined to be one that can remain viable in the environment for extended times, and secondary resuspension is likely, and medical countermeasures are either unavailable or inadequate to treat all of the potentially exposed population in timely fashion, then evacuation of some or all affected individuals will likely be necessary. On the other hand, a shelter-in-place decision might be recommended if the pathogen is sensitive to antibiotics, adequate medical countermeasures are available, and such measures can be implemented (including the dispensation of prophylactic antibiotics within the first 48 to $72 \mathrm{hr}$ and possible mass vaccination over the longer term), along with guidance issued to the public on self-protective measures. A shelter-in-place decision includes the assumption that all persons in an affected zone will receive antimicrobial prophylaxis. Related considerations are whether adequate facilities and supplies are immediately available to house and sustain the potentially affected population, whether a mass-evacuation plan can be implemented without causing undue confusion, and whether evacuation will result in bottlenecks that obstruct the movement of emergency vehicles. 
After reviewing the numerous pros and cons associated with evacuation versus shelter-in-place, this Interim Guidance document recommends a hybrid approach (given a hybrid approach, further review by the DHHS would be needed). For example, those who are determined to leave the affected area regardless of official advice, and those at significant risk of contracting anthrax and refusing prophylaxis, would be among the individuals permitted or encouraged to depart. Plans for the orderly evacuation of such individuals should be developed in advance-if they are not already available for specific jurisdictions - with the overriding objective of keeping transportation routes open for emergency vehicles and supplies. For those willing to remain in mass shelters or inside homes, assurances from officials must be provided that medical care is available and likely to be effective (see risk communication in Section 4.2.7). Both city residents and nonresidents must be given equal access to prophylaxis. Authorities could also provide public guidance on techniques such as expedient masking (e.g., use of appropriate filter masks dispensed by authorities or purchased by individuals, which may help to reduce the inhalational risk; see Section 6), home decontamination (see Section 8), avoidance of contamination to the extent possible, decontamination of companion animals, and available PEP and treatment options. Incentives could be given to those individuals willing to accept the risks, incur the costs associated with remaining in a contaminated area, and help in the overall remediation process, as needed. Examples of Federal incentives might include tax benefits, government subsidized rent or mortgage payments, free or subsidized medical follow-up, and shared decontamination expenses.

The Federal Government can institute restrictions of movement if there is a risk of inter-state spread of disease. Per the NRF Biological Incident Annex, "The Governor of an affected state implements isolation and/or social-distancing requirements using State/local legal authorities. To prevent the interstate spread of disease, DHHS may take appropriate Federal actions using the authorities granted by U.S.C. title 42, 42 CFR parts 70 and 71, and 21 CFR 1240. State, local, and tribal assistance with the implementation and enforcement of isolation and/or quarantine actions is utilized if Federal authorities are invoked."

\subsubsection{Preliminary Determination of Zones}

As soon as possible after determining that a BWA release has occurred and emergency public health issues are addressed, it is necessary to distinguish among, and set boundaries for, three preliminary zones (Figure 4-2, Boxes 204-2 through 204-4). The following standard zone designations [see <http://www.epa.gov/emergencies/content/hazsubs/safety.htm>] are used to guide subsequent cleanup and environmental sampling activities and to reduce contamination as well as the likelihood of recontamination of already cleared areas:

- Exclusion zones (or hot zones) are areas where contamination is either known or expected to occur and where the greatest potential for future exposure exists. Access to and egress from an exclusion zone should be restricted to access control points. All persons who enter an exclusion zone must wear the appropriate level of personal protective equipment (PPE) for the degrees and types of hazards present (per OSHA guidance).

- Contamination-reduction zones (or warm zones) are areas surrounding a hot zonelikely quite large in extent in a wide-area attack - that may pose low, but some potential health risk. Here, decontamination takes place of personnel, equipment, and items coming 


\section{First Response}

out of the hot zone. Such zones are the transition area between an exclusion zone and support zone (see below). The purpose of a contamination-reduction zone is to reduce the possibility that a support zone will become contaminated or affected by site hazards.

- Support zones (or cold zones) are the uncontaminated areas that may be safely used as planning and staging areas where workers are unlikely to be exposed to biological agents or dangerous conditions. Because support zones are free from contamination, personnel working within them wear normal work clothes. Support zones are designated as such from all available site characterization data and should be located upwind from exclusion zones. Cold zones may change in response to environmental conditions, such as wind and rain, and must be monitored over time.

It is also important to define areas where people were initially exposed versus those where a current hazard exists or is expected to be located in the future. Beyond obvious public health reasons for quickly delineating zones following a wide-area release, such delineation is important for HazMat teams, the FBI, and other responders as they establish standard work zones at a contaminated area and make efforts to reduce the likelihood of spreading a contaminant.

The first set of zones is defined through screening environmental sampling and analysis, as discussed in Section 4.2.3 (see Box 205), with refinement through a process of continued sampling and laboratory analysis (Box 208), and as discussed in Section 7. The definition of zones will proceed over time as more information is obtained, particularly following a covert release. Law enforcement and intelligence information may also provide insight into the degree of contamination. Information on contaminated areas will initially be sketchy, requiring confirmatory environmental samples to fill in the details. Such information is important not only for defining zones and associated actions but also for identifying the potentially exposed population. Once a contaminated site is identified - and there may be more than one contaminated location - determining the extent of contamination will proceed from there. 


\section{FIRST RESPONSE (204 Expanded)}

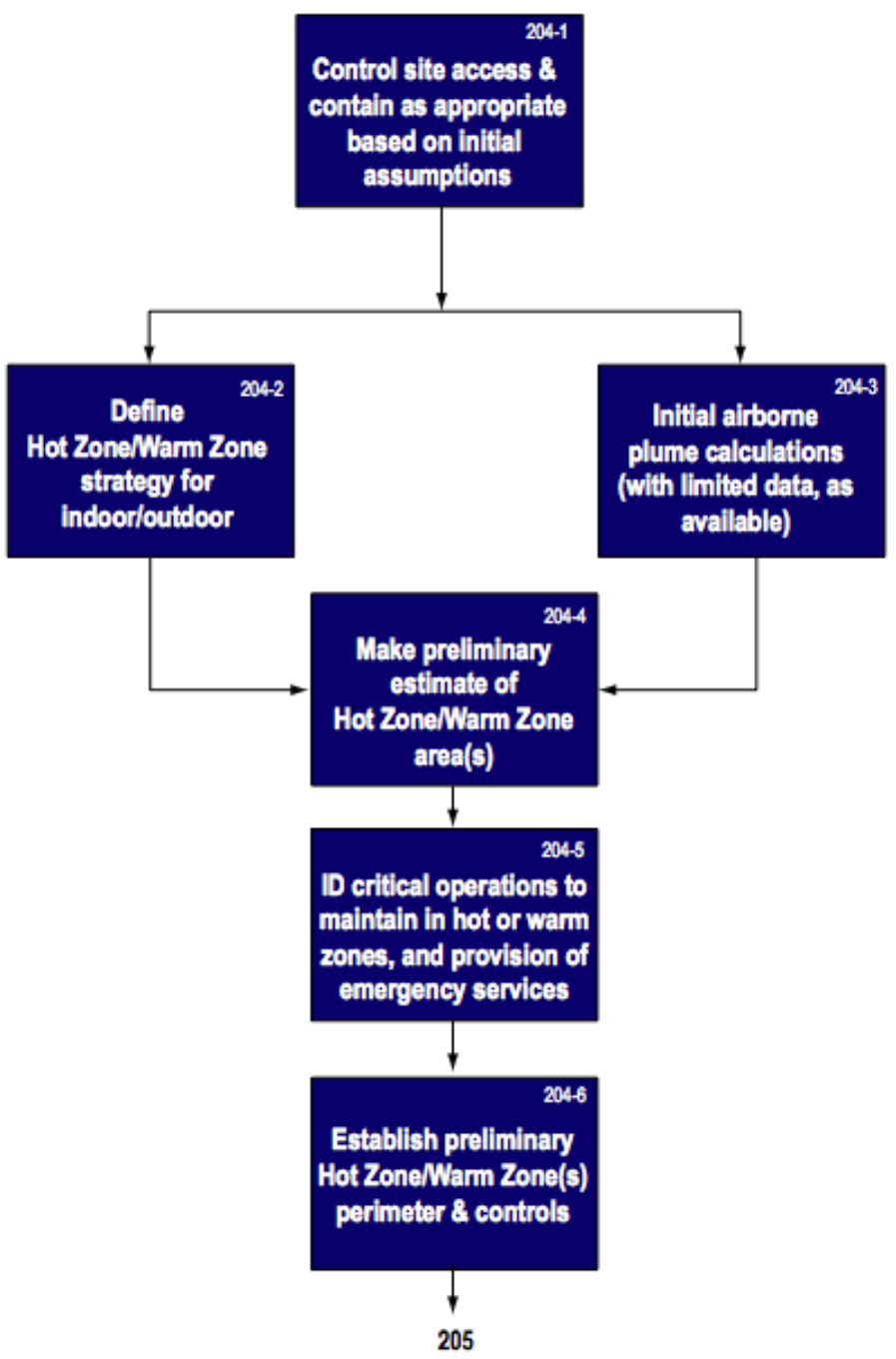

Figure 4-2. Expanded Box 204: define and establish preliminary hot and warm zones.

Over time, the results of surface sampling, air monitoring (which detects re-aerosolized particles), the results of fate and transport models (Box 204-3) (e.g., IMAAC modeling), and any epidemiological data for which exposure can be traced to a sufficiently well-defined location are used to update and redefine the hot zones boundaries, as necessary (see Section 7). In addition to analyzing samples from existing BioWatch collectors and planned sampling in areas identified by epidemiological evidence, "found samples" may be an important source of information. Such 
samples are referred to by Durbin et al. $(2006,2007)$ as "native air samples." They could include data from environmental aerosol monitoring stations (operated by the EPA, state and local agencies, and possibly others), building HVAC filters, and selected vehicle air filters.

Initial work zones should be monitored through ongoing quality-assurance environmental sampling and predictive models to determine if they are adequate for continued agent containment and the safety of workers and others in the vicinity of a release. From the results of additional environmental sampling or other data (Boxes 206-208), the boundaries of zones may need to be adjusted over time. To the extent possible, responders must take care throughout the response to limit fomite transport and avoid redistributing the agent, which could make the problem worse (e.g., cross-contamination from tracking).

\subsubsection{Screening Environmental Sampling and Analysis (Boxes 205-214)}

Screening environmental sampling (Box 205) is the initial collection of a limited number of environmental samples to determine the identity, concentration (Box 206), viability, and approximate location of contamination by a suspected biological agent, and for informing the IC/UC for decision-making on appropriate public health and subsequent remediation actions. Results from screening environmental sampling along with other data inputs, including epidemiological data, intelligence data, and modeling data, help to inform early decisions regarding both public health actions and environmental remediation. In a wide-area catastrophic biological incident, such as the one posed in this Interim Guidance document, environmental sampling during first response will proceed at a faster pace than normal following BioWatch detection, and would ideally return analytical laboratory results within the first $12 \mathrm{hr}$. Under the NIMS, the ICS Planning Section would help devise sampling plans through the Environmental Unit.

The nature of screening environmental sampling depends on how an incident is discovered. Following an overt release, a release device might be recovered, or there might be visible "white powder" to sample. In such cases, screening environmental sampling is likely to begin with first responders following pre-existing protocols that might include field-screening methods. If incident discovery were through a BioWatch Actionable Result (BAR), sampling would begin with BioWatch protocols, and screening environmental sampling can focus on areas suggested by the location(s) of the BAR(s). If a release were covert and discovered indirectly (for example, from epidemiological investigation of disease outbreak), the identification of area(s) to be sampled would be guided by epidemiological information (i.e., probable locations of exposure). In all cases, characterization environmental sampling (Section 7) should begin, or be planned, as soon as there is credible evidence of a wide-area release of a viable, infectious pathogen (Boxes 208, 209, and 210).

Appropriate experts (e.g., from the FBI, CDC, and analytical laboratories) must address a series of questions to determine whether an agent is an organism or whether it may actually be a chemical or toxin (Box 213) (assuming such information is unknown at first). For example, if the agent is an organism, but the organism is not viable, then no immediate threat exists (Box 212), and normal activity can resume. If a pathogen is suspected (Box 207), both public health screening and environmental sampling with laboratory analyses (Box 208) are indicated. Such additional environmental sampling would require appropriate, but rapid, systematic planning. Such sampling should help determine whether the agent is viable (Box 209), persistent, or 
infectious (Box 210), or present in sufficient concentration to cause injury or disease (Box 214). It may take several days to obtain definitive answers to the questions. The minimal infectious dose for many biological agents, and B. anthracis in particular, is not well established (see Section 6). In such cases, and if the agent is viable, a judgment must be made about whether to proceed with emergency response and subsequent actions as though the agent poses a threat (Box 207). If any identified agent is present in sufficient concentration to cause injury or disease, then agent-specific information is used as a basis for performing initial or continuing HazMat and emergency response actions. If those evaluations indicate the likely presence of a hazardous biological substance, the FBI will likely commence a forensic investigation to identify the agent and determine its genetic, physical, and chemical properties (such properties also have value in managing a response); search for other types of evidence; establish a possible source of the contamination; and attempt to determine the responsible party.

The number of samples taken during initial response is determined by available resources (collection personnel, equipment, and laboratory surge capacity) and the size and type of release. Response time is generally within the first 24 to $48 \mathrm{hr}$. Responders in appropriate PPE (DHHS 2008) collect at least the initial sample(s) from any discrete material found and from other locations according to the information available. Because the size and type of release may not be known, sampling may also need to be conducted in locations not immediately suspected.

Following notification of a presumptive positive result from screening environmental sampling - possibly from field tests - first responders, industrial hygienists, or others collect additional environmental samples (Box 208 and Figure 4-3; Box 208-1). Hand-held field sampling devices might be used during first response or subsequently, but there is debate about the specificity and sensitivity of detection results from field devices in general, and results are not public health actionable. Other sampling methods used are appropriate to the site or medium from which samples are taken, such as wet wipes or wet swabs from hard, nonporous surfaces and high-efficiency particulate air (HEPA) vacuum samples from porous surfaces within the affected areas, water samples from drinking water, and solid samples from food. Found samples, such as aerosol monitoring samples and building or vehicle air filters should also be considered together with methods that sample over large areas or consolidate samples. Current information on environmental sampling methods can be obtained from Emmanuel et al. (2008) and the CDC website, available at <http://www.bt.cdc.gov/agent/anthrax/ environmental-samplingapr2002.asp>.

Samples are sent to a Laboratory Response Network (LRN) (CDC 2005) laboratory for analysis to confirm the identity of the contaminant (Box 208-2) and to obtain results that are public health actionable. The meaning of analytic test results depends on the type of test conducted. For example, the first laboratory test run on a suspected sample of B. anthracis spores is typically a polymerase chain reaction (PCR) test to determine the presence or absence of DNA. A PCR test does not provide information about viability. A follow-up, culture-based test together with confirmatory biochemical, molecular, or antigenic testing provides confirmation as to whether spores are capable of producing viable, vegetative bacteria, as well as other information, such as strain and susceptibility to antibiotics. See Section 7 for more discussion of both sampling and analysis methods. If laboratory analytical results confirm the presence of a viable BWA, the responsible public health agencies commence appropriate epidemiological investigations and public health actions in light of that knowledge (Boxes 208-3 and 208-5). Actions can include 
treatment and decontamination of potentially contaminated individuals, medical examinations, and distribution of prophylaxis.

FIRST RESPONSE (208 Expanded)

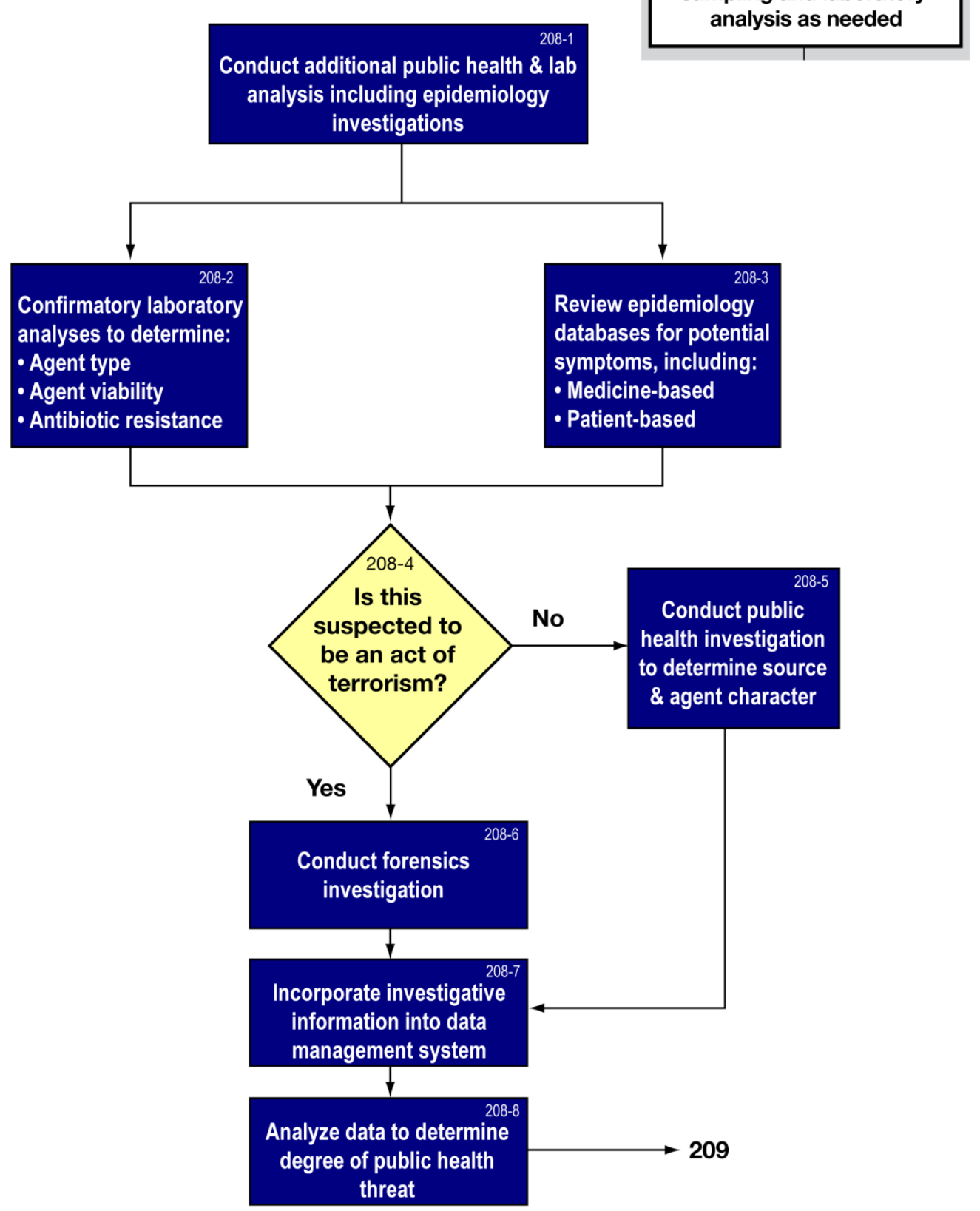

Figure 4-3. Expanded Box 208: perform additional sampling and analysis and epidemiological investigations to determine public health threat. 
First Response

\subsubsection{Forensic Investigation and Attribution}

If preliminary screening tests indicate the likely presence of a bioterrorism agent, the FBI will promptly commence a forensic investigation (Box 208-6) to identify the agent and determine its genetic, physical, and chemical properties; search for other evidence; establish a possible source of the contamination; and attempt to determine the responsible party. The FBI begins its law enforcement activities as soon as it arrives at the site unless victims and other exposed persons are still being evacuated. In that event, FBI agents will wait until the evacuation is completed.

FBI staff will collect environmental samples using techniques comparable to those used for determining the nature and extent of contamination, but such samples will be collected strictly to produce evidence for prosecution. The FBI may share some or all of the results of its sampling activities with the organization charged with performing the cleanup, if it concludes that sharing data will not compromise its criminal case. Future coordination between public health and law enforcement is essential during the First-Response Phase (see U.S. Department of Justice, Federal Bureau of Investigation, and U.S. Army Soldier Biological Chemical Command, Criminal and Epidemiological Investigation Handbook, 2003, available at <www.edgewood.army.mil/downloads/mirp/ECBC_ceih.pdf >). If a crime scene is established, environmental sampling must be done with explicit approval from the FBI.

The FBI would likely release the site to the EPA OSC when the crime scene investigation is completed. Following a wide-area release, however, the FBI might need additional time to process forensic samples. A possible option would be for the EPA to initiate characterization environmental sampling (Section 7) in areas judged not to be critical to the ongoing FBI investigation. Such cooperation could expedite remediation but must not interfere with the FBI criminal investigation.

\subsubsection{Immediate Decontamination (Box 215)}

Given a preliminary designation of hot zone(s), presumably the region(s) of greatest risk, Incident Command might decide to perform some immediate decontamination on a limited scale. For example, if obvious source material were visible either outdoors or indoors, that surface contamination would be physically collected and removed as soon as possible before detailed environmental sampling takes place (Box 215). However, such actions would be delayed until the FBI had completed any forensic activities associated with such material and granted permission to proceed. It might also be necessary or expedient to clear a clean path (e.g., access route) to critical infrastructure and buildings associated with essential services and then perform more detailed sampling afterward. Immediate decontamination could involve the application of soap and water for limited areas of contamination, or the use of water hoses, fire trucks, or similar truck-mounted water spraying systems to wash down larger outdoor areas. However, see the discussion in Section 8, especially regarding concerns about potential reaerosolization. Immediate source reduction and containment actions, if done properly, could help limit the spread of contamination, but could also worsen the situation if done improperly.

\subsubsection{Implement Additional HazMat Actions, Emergency-Response Actions, and Operational Controls (Boxes 215, 216)}

From all available, current information about the identified agent, it may be necessary to perform additional HazMat actions, redefine the hot zone (Figure 4-4, Box 215-1), and implement further 


\section{First Response}

public health actions for special populations of individuals or the affected population at large (Box 215-2). Such actions could include further evacuations (Boxes 215-3 through 215-8), as discussed in Section 4.2.1.2. Additional operational controls, such as business continuity-ofoperations plans, are implemented as the emergency situation is stabilized (Box 216).

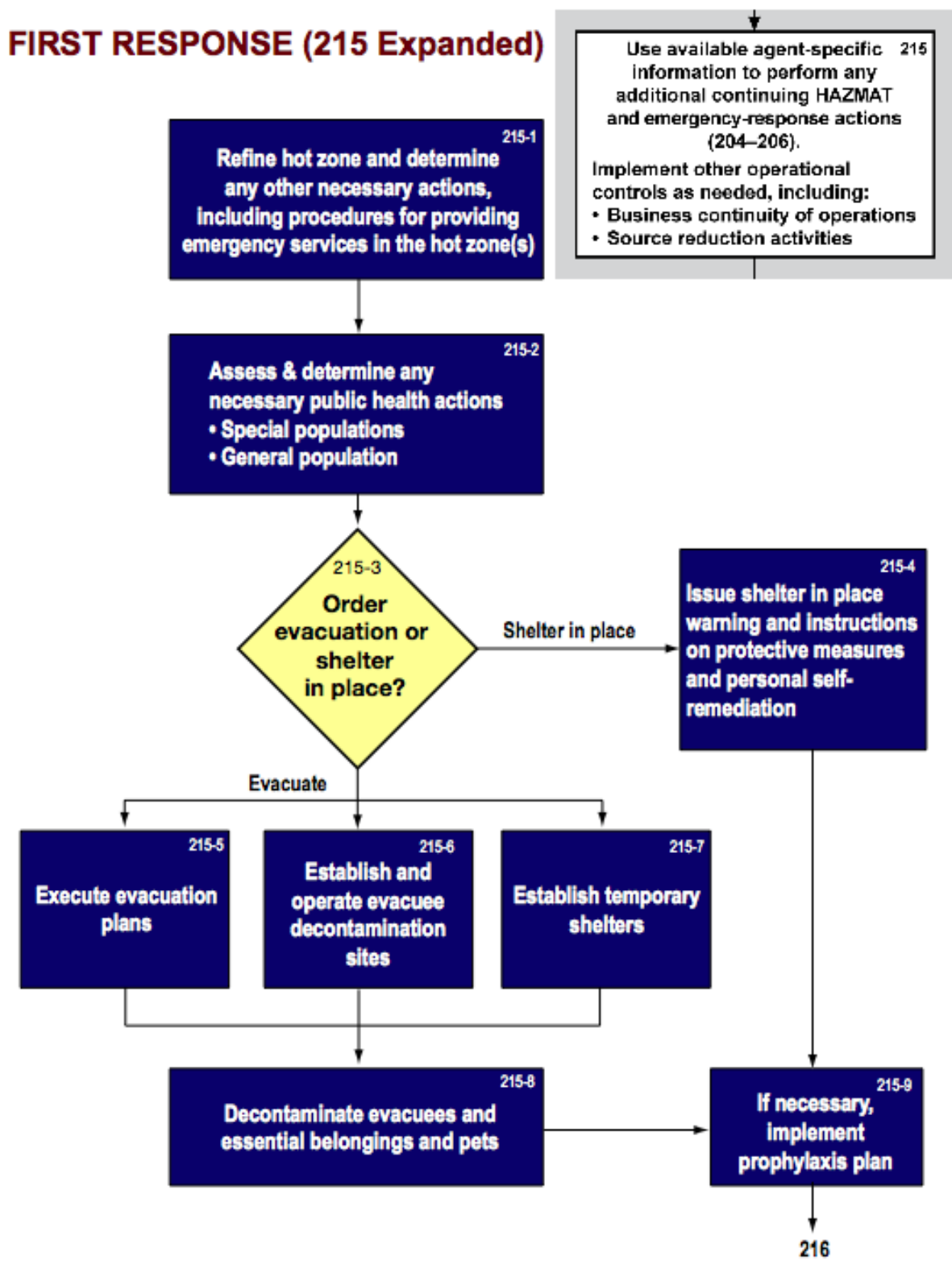

Figure 4-4. Expanded Box 215: implement additional emergency-response actions and operational controls. 
First Response

\subsubsection{Public Relations and Risk Communication Strategies}

Casualties and public fear are likely following a wide-area biological attack, especially in view of the fact that information is instantly transmitted $24 \mathrm{hr}$ a day by the media. Effective national response relies on disciplined processes, procedures, and systems to communicate timely, accurate, and accessible information on an incident's cause, size, and current situation to the public, responders, and others (NRF 2008, p. 11).

Many state and local agencies have developed and implemented processes for exchanging information and communicating risk (Boxes 200 and 211). Operations centers at virtually every level maintain active situational awareness and communication with regional counterparts. At the state level, public safety and welfare are fundamental responsibilities of every governor, whose roles include communicating to the public the consequences of a major incident.

Among other centers for assimilating and distributing information, the FBI's Strategic Information and Operations Center (SIOC), which is located at FBI Headquarters, serves as a clearinghouse to help collect, process, vet, and disseminate information relevant to law enforcement and a criminal investigation. At the national level, the Principal Federal Official (PFO), who is appointed by the Secretary of Homeland Security, acts as the primary Federal spokesperson for coordinated media and public communications.

As discussed in Sections 2 and 3, the tactical ICS/UC should establish a JIC to communicate emergency public information for the UC, conduct public affairs activities, and manage media releases. A JIC may be established locally, regionally, or nationally. For example, if there are multiple incident commands over one or more jurisdictions, an Area Command may be formed to support those commands, and an Area Command could have a JIC formed to support all the ICPs in communicating information to the public. Multiple JICs need to be coordinated through the communication links established through NIMS. The JIC staff should be familiar with the basic tenets of emergency risk communication and with the unique information requirements of each phase of activity. The operational requirements of each phase will vary according to the nature and longevity of a crisis. A Public Information Officer (PIO) who reports to the Command Staff (NRF 2008, p. 50) is appointed to develop and communicate information about the incident to the public, media, and all organizations involved. Targeted communication must evolve in synchrony with the phases of response and needs to be directed toward phase-specific activities.

Among various sources of information regarding risk communication and public education following a wide-area biological attack, the Homeland Security Institute's Wide-Area Biological Restoration Final Report (HSI 2005) states that, “...psycho-social resilience engenders economic resilience. Therefore, establishing public trust and confidence is likely to be one of the greatest cost-saving measures we can employ." DiGiovanni et al. (2003) and others recommend that messages should be coordinated among local government and nongovernment sources along with Federal officials, with trusted locals - supported by Federal health authorities - taking the lead in delivering the messages. Table 4-1 summarizes key HSI recommendations for how to communicate with the public, along with recommendations from other sources.

The CDC's National Center for Health Marketing has published both short and extended messages containing health and safety information to help minimize immediate risk to the public from a biological attack. Table 4-2 reproduces one of the CDC's anthrax-exposure short messages that can be used by spokespersons during the first hours after a suspected or confirmed 
release. As part of pre-planning, decision-makers should either adopt such pre-scripted messages or draft their own area-tailored statements on topics that can range from immediate protection and prevention to prophylaxis and vaccination, along with options such as mass sheltering or evacuation.

Table 4-1. Risk communication and education of the public: recommended procedures.

\begin{tabular}{|c|c|}
\hline Recommended procedure & Considerations for guidance \\
\hline $\begin{array}{l}\text { Cultivate a trusting relationship with the } \\
\text { broadcast media before an incident. Conduct } \\
\text { training programs with the media for dealing with } \\
\text { bioterrorism information, the incident itself, and } \\
\text { risk communication through all phases of activity. }\end{array}$ & $\begin{array}{l}\text { Discuss with the media the exchange of accurate, timely, and } \\
\text { appropriate information should an incident occur. } \\
\text { Communication is a two-way street. Establish clear lines of } \\
\text { communication for input from the Command Staff, in } \\
\text { particular, the PIO. Providing correct information to the } \\
\text { media is as important in preventing misunderstanding as the } \\
\text { media's role in disseminating information to the public. }\end{array}$ \\
\hline $\begin{array}{l}\text { Educate the public. Education reduces fear by } \\
\text { helping people become aware of their } \\
\text { responsibilities and informing them about BWAs. }\end{array}$ & $\begin{array}{l}\text { Consider backgrounds and community traditions during risk } \\
\text { communication. Public perception of an affected area or } \\
\text { facility may dictate its future use. Once priorities are set, } \\
\text { enlist the broadcast and other media to help manage public } \\
\text { perceptions through educational advisories, warnings, and } \\
\text { alerts. }\end{array}$ \\
\hline $\begin{array}{l}\text { Determine the most influential authorities in the } \\
\text { community. }\end{array}$ & $\begin{array}{l}\text { Enlist local officials to assist in communicating news and } \\
\text { health information to constituents, supported by Federal } \\
\text { authorities. Local sources tend to be trusted more by different } \\
\text { members of the community (DiGiovanni 2003). Respected } \\
\text { community leaders should be trained in the strategies and } \\
\text { tactics of risk communication. }\end{array}$ \\
\hline $\begin{array}{l}\text { Employ all available methods to communicate } \\
\text { information to the widest possible audience. }\end{array}$ & $\begin{array}{l}\text { Include releases designed for television, radio, the internet, } \\
\text { newspapers, and the mass distribution of printed material. }\end{array}$ \\
\hline Provide information about prevention. & $\begin{array}{l}\text { Use town hall meetings, community counselors, and } \\
\text { intervention specialists to diffuse conflicts. }\end{array}$ \\
\hline $\begin{array}{l}\text { Explain the importance of prophylaxis } \\
\text { (antibiotics), vaccination, or any other medical } \\
\text { countermeasures that may be recommended. }\end{array}$ & $\begin{array}{l}\text { Risk communicators must pay special attention to the families } \\
\text { of first responders and journalists. Tailor the message to the } \\
\text { audience (DiGiovanni et al. 2003). Crucial differences exist in } \\
\text { risk communication needs associated with responders, the } \\
\text { media, and the general public. }\end{array}$ \\
\hline $\begin{array}{l}\text { During the different phases of remediation } \\
\text { (characterization, decontamination, and } \\
\text { clearance) and restoration, foster involvement by } \\
\text { and cooperation of the public. Involve } \\
\text { stakeholders in the decision-making process. }\end{array}$ & $\begin{array}{l}\text { Recognize that communication must continue throughout all } \\
\text { phases of an attack, including restoration. Invite citizen } \\
\text { involvement during recovery, with an emphasis on } \\
\text { establishing trust and keeping people informed. Ministers, } \\
\text { physicians, and other authority figures can facilitate } \\
\text { communication at familiar gathering places (e.g., schools, } \\
\text { community centers, and churches). }\end{array}$ \\
\hline $\begin{array}{l}\text { Eliminate communication system failures and } \\
\text { security breaches. }\end{array}$ & $\begin{array}{l}\text { Provide security and backup protection for the } \\
\text { communication infrastructure. }\end{array}$ \\
\hline
\end{tabular}




\section{Table 4-2. CDC example of a short public health message about anthrax exposure.}

This is an urgent health message from the U.S. Department of Health and Human Services (HHS). Public health officials believe than the spores that cause anthrax may have been deliberately released in the $x x x$ area.

At this time, we do not know the extent or source of the anthrax release. Local, state, and Federal officials, including HHS, FBI, and Homeland Security, are working together.

Anthrax is a disease that affects both humans and animals. In people, it can be caused by spores that are released as a powder or into the air. The spores are not known to spread from person to person. Based on what we know now, only those people who were in the $x x x$ area on $x x x$ date are at risk for getting sick. After contact with the anthrax spores, symptoms of anthrax usually develop within 7 days. Depending on how a person comes into contact with the spores, three types of illness can occur.

1. When a person breathes in the anthrax spores, the first symptoms are like those of the flu. Later symptoms may include severe breathing problems.

2. When anthrax spores enter a cut on the skin, symptoms include sores or blisters and may look like an insect bite.

3. When a person eats or drinks anthrax spores, symptoms include nausea, loss of appetite, and diarrhea. There are treatments for anthrax, and HHS is working to get these treatments to the people who need them We have challenges ahead, and we are working to find out more about this outbreak. By staying informed and following instructions from health officials, you can protect yourself, your family, and the community against this public health threat.

Go to [insert local media information here] to hear the latest information from local officials. For more information about anthrax, visit the HHS website at http://www.hhs/gov, the CDC's anthrax page at http://www.bt.cdc.gov/agent/anthrax/, or call the CDC Hotline at 1-800-CDC-INFO for the latest updates.

Reproduced from the CDC's website (last modified May 14, 2007), entitled Communicating in the First Hours, Anthrax: Short and Extended Messages, CDC Emergency Communication System, Division of Health Communication and Marketing, National Center for Health Marketing. For other short and extended messages, see http://emergency.cdc.gov/firsthours/anthrax/messages.asp.

\subsection{Assess the Interface of Initial Response Activities to Remediation Phase Activities}

To facilitate a smooth transition from emergency response to remediation, initial response actions and related information that could impact subsequent remediation activities (those performed during characterization, decontamination, and clearance) should be documented and evaluated. For example, the results of initial environmental sampling may provide a baseline and be crucial for evaluating the spread of contamination or natural attenuation monitored over time. The Situation Unit within the Planning Section (see Table 2-2 in Section 2) should develop a process for capturing, evaluating, and passing along actions conducted and results obtained during the initial response as such information relates to remediation. The interface of firstresponse activities to remediation activities needs to be fluid as identification and redefinition of hot zones continues over time, with new zones emerging and old ones being remediated. The interface includes FBI and law enforcement personnel providing information to the EPA and the 
ICS/UC regarding characteristics of the bioagent that may facilitate environmental response and help protect responders.

\subsection{Section 4 Summary of Actions}

Table 4-3 summarizes the likely actions and responsible entities for making decisions or performing actions during the First-Response Phase following a wide-area biological release.

Table 4-3. Summary of first-response actions in approximate order of unfolding events.

\begin{tabular}{|c|c|}
\hline Responsible Personnel & Action \\
\hline \multirow[t]{9}{*}{$\begin{array}{l}\text { Incident Command or } \\
\text { Unified Command, if } \\
\text { established at this early } \\
\text { stage }\end{array}$} & $\begin{array}{l}\text { Continue to activate personnel, as necessary. Coordinate with local security, FBI, local law } \\
\text { enforcement departments, fire departments, public health and medical personnel, HazMat } \\
\text { teams, and local EPA On-Scene Coordinator(s). Integrate into ICS as UC if not done } \\
\text { already. }\end{array}$ \\
\hline & $\begin{array}{l}\text { Perform screening environmental sampling and analysis to form a preliminary estimate of } \\
\text { contaminated areas. However, depending on the scenario, qualitative guidance may be } \\
\text { available (e.g., regional wind patterns, forecasts of high reaerosolization conditions) with no } \\
\text { or minimal sampling. }\end{array}$ \\
\hline & $\begin{array}{l}\text { Activate IMAAC modeling capabilities, and consider initiating modeling for preliminary } \\
\text { estimates of contaminated areas using current meteorological and environmental conditions. }\end{array}$ \\
\hline & Continue to inform responders and agencies about developing details of the incident. \\
\hline & $\begin{array}{l}\text { Control access and egress to affected areas; contain contamination as much as possible; and } \\
\text { establish hot, warm, and cold zones. }\end{array}$ \\
\hline & Continue risk communication. \\
\hline & Transition to an Area Command if needed and not already done. \\
\hline & Start to prioritize potentially contaminated or affected areas and operations. \\
\hline & Plan and conduct initial screening environmental sampling for biological threat agent. \\
\hline $\begin{array}{l}\text { DHHS/CDC and local } \\
\text { public health } \\
\text { departments }\end{array}$ & $\begin{array}{l}\text { Perform public health screening and laboratory environmental sampling and analysis to } \\
\text { determine risk to public health. Consider agent viability, antibiotic resistance, and so forth. }\end{array}$ \\
\hline $\begin{array}{l}\text { Planning Section: } \\
\text { Environmental Unit }\end{array}$ & Update initial hot, warm, and cold zones as a function of incoming information. \\
\hline \multirow{4}{*}{$\begin{array}{l}\text { Incident Command or } \\
\text { Unified Command, if } \\
\text { established }\end{array}$} & Rescue, evacuate, shelter-in-place, or isolate persons, as needed. \\
\hline & Control access routes, and develop population-movement plans, as appropriate. \\
\hline & $\begin{array}{l}\text { Mitigate any conditions posing immediate threat to human health. Consider decontamination } \\
\text { of individuals, medical interventions, temporary shelters, immediate area decontamination, } \\
\text { source reduction, and veterinary and agricultural interventions. }\end{array}$ \\
\hline & $\begin{array}{l}\text { Determine if any facilities or operations should be sustained, diverted, or suspended. } \\
\text { Implement appropriate actions, considering continuity of operations. }\end{array}$ \\
\hline
\end{tabular}




\subsection{Interim Recommendations for First-Response Phase Protocols}

Among the most relevant critical gaps relevant to the First Response Phase and the content of Section 4 are inadequate evacuation plans and support for evacuees, including the distribution and availability of medical countermeasures; poor understanding of a host of hot-zone issues; and a lack of understanding of spore fate and transport, especially how B. anthracis spores are spread by humans, vehicles, and other modes of transportation. Table 4-4 summarizes Interim Guidance recommendations for actions to be taken during initial response.

Table 4-4. Interim recommendations for the First-Response Phase.

\begin{tabular}{|c|c|}
\hline Recommended action & Comments and approaches \\
\hline $\begin{array}{l}\text { Initiate collection and analysis of screening } \\
\text { environmental samples as quickly as possible }\end{array}$ & $\begin{array}{l}\text { - Purposes of sampling include determination of the agent's identity, viability, } \\
\text { and susceptibility to antibiotics; area of contamination; exposure scenarios; } \\
\text { appropriate public health measures; and subsequent remediation actions. } \\
\text { - Initial sampling to be done by local response teams. Sample collection } \\
\text { assets vary as a function of local HazMat and biohazard response planning. } \\
\text { - Sample analysis to be conducted by local LRN capabilities, supplemented as } \\
\text { needed by other laboratories geared to handling LRN surge capacity. } \\
\text { - BioWatch has a mobile BSL-2+ laboratory that could be deployed and made } \\
\text { operational within } 24 \text { hr to provide sample surge support (100s of samples } \\
\text { per day, operated by } 2 \text { to } 3 \text { people). Throughput varies by sample type. }\end{array}$ \\
\hline $\begin{array}{l}\text { Perform transport modeling to the extent } \\
\text { possible. Update transport information as } \\
\text { additional data are available to map extent of } \\
\text { contamination and likely population exposures. }\end{array}$ & $\begin{array}{l}\text { - Use IMAAC and BioWatch 24/7 capabilities, per the NRF. } \\
\text { - Continue to update results as more sampling data become available. }\end{array}$ \\
\hline $\begin{array}{l}\text { Apply initial personnel protection, } \\
\text { decontamination, or mitigation methods to avoid } \\
\text { the spread of contamination. }\end{array}$ & $\begin{array}{l}\text { - Issue guidance to individuals in the plume to use available masks (i.e., N95 } \\
\text { or better). } \\
\text { - Instruct individuals to bag clothing and shower. } \\
\text { - Reduce immediate potential for reaerosolization by instructing fire } \\
\text { department(s) to wet down areas, as feasible. } \\
\text { - Direct homeowners to turn on sprinklers and keep grounds moist until } \\
\text { further notice. } \\
\text { - Provide guidance on decontamination of companion animals. }\end{array}$ \\
\hline $\begin{array}{l}\text { Consider a hybrid scheme of shelter-in-place and } \\
\text { evacuation tailored to the specifics of a release } \\
\text { location and the populations potentially affected } \\
\text { by a biological release. Augment with medical } \\
\text { countermeasures for those remaining in place and } \\
\text { those who evacuated or left the scene. } \\
\text { (Such an approach assumes that medical } \\
\text { countermeasures will be effective. If the strain is } \\
\text { antibiotic-resistant, an overall evacuation will } \\
\text { probably be needed, and casualties will be far } \\
\text { greater.) }\end{array}$ & $\begin{array}{l}\text { - Make plans to provision locations used as mass shelters. } \\
\text { - Implement a strategy for the orderly evacuation of those at high risk for } \\
\text { anthrax, those who may refuse antibiotics, and those determined to leave } \\
\text { the city. } \\
\text { - Implement a plan for distributing medical countermeasures using postal } \\
\text { service options, distribution centers, or both. }\end{array}$ \\
\hline $\begin{array}{l}\text { Ensure that information is communicated to } \\
\text { stakeholders and the public in an accurate, } \\
\text { timely, and consistent fashion. }\end{array}$ & $\begin{array}{l}\text { - Follow the guidance in Table 4-1. } \\
\text { - Deliver consistent messages via coordination among local government and } \\
\text { nongovernment sources along with Federal officials. } \\
\text { - Have trusted locals, supported by Federal health authorities, take the lead in } \\
\text { delivering health-risk-related and educational messages. }\end{array}$ \\
\hline
\end{tabular}




\subsection{Section 4 References}

CDC (1999), Centers for Disease Control and Prevention, Morbidity and Mortality Weekly Report 48(04), 69-74 (February 5, 1999).

CDC (2005), Centers for Disease Control and Prevention, The Laboratory Response Network: Partners in Preparedness; available at <http://www.bt.cdc.gov/lrn/> (accessed 12/07/2008).

CDC (2007), Centers for Disease Control and Prevention, CDC Emergency Communication System, Division of Health Communication and Marketing, National Center for Health Marketing. website entitled Communicating in the First Hours, Anthrax: Short and Extended Messages (last modified May 14, 2007); available at

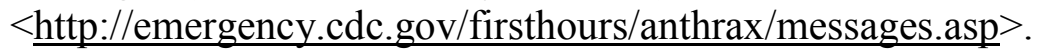

DHS (2008), Department of Homeland Security, National Response Framework; documents available at $<$ http://www.fema.gov/emergency/nrf/> .

DHHS (June 2008), Department of Health and Human Services, Guidance on Emergency Responder Personal Protective Equipment (PPE) for Response to CBRN Terrorism Incidents, DHHS (NIOSH) Publication No. 2008-132; available at 〈www.cdc.gov/niosh>.

DiGiovanni, Jr., C., Reynolds, B., Harwell, R., Stonecipher, E. B., and Burkle, F. M. (2003), "Community Reaction to Bioterrorism: Prospective Study of Simulated Outbreak," Emerging Infect. Dis. 9(6), 708-712.

Durbin, T. L., J. E. Brockmann, and G. Brown (2006), "Evaluation of Native Air Samples: Proof of Concept," Presentation by Brockmann to 2nd National Conference on Environmental Sampling and Detection for Bio-Threat Agents, New York City, October 24-26, 2006, SAND2006-6877C, Sandia National Laboratories, Albuquerque, NM.

Durbin, T. L., J. E. Brockmann, D. A. Lucero, T. Rudolph, G. Brown, J. Leonard, C. A. Souza, and T. H. West (2007), "Evaluation of Native Air Samples for Augmenting the BioWatch System: Proof of Concept," SAND2007-0099, Sandia National Laboratories, Albuquerque, NM.

Emanuel, P. et al. (2008), Sampling for Biological Agents in the Environment, ASM Press, Washington, DC.

EPA (2006), U.S. Environmental Protection Agency, Data Quality Objectives, EPA QA/G4.

Friedlander, A. M., S. L. Welkos, M. L. M. Pitt, et al. (1993), "Postexposure Prophylaxis against Experimental Inhalation Anthrax," J. Infect. Dis. 167, 1239-43.

HHS/CDC (2008), Department of Health and Human Services, Centers for Disease Control and Prevention, Advisory Committee on Immunization Practices (ACIP) Summary Report (October 22-23, 2008), Atlanta, Georgia, available at $<$ http://www.cdc.gov/vaccines/recs/acip/downloads/min-oct08.pdf $>$.

HSI (2005), Homeland Securities Institute, Wide-Area Biological Restoration Final Report, prepared for the Department of Homeland Security, Science and Technology Directorate, Programs, Plans, and Requirements, Biological Countermeasures Program. 


\section{First Response}

NRT (updated July, 2005), National Response Team, Technical Assistance for Anthrax Response, Interim-Final Draft; available at http://www.nrt.org/production/NRT/NRTWeb.nsf/PagesByLevelCat/Level2TA?Opendocument.

SNL and LLNL (2008), Sandia National Laboratories and Lawrence Livermore National Laboratory, IBRD Task 1 Systems Analysis Report (same document published separately at both laboratories as report SNL2008-1349 and report LLNL-AR-401510).

The Federal Response to Hurricane Katrina-Lessons Learned (February 2006); available at $<$ http://www.whitehouse.gov/reports/katrina-lessons-learned/>. 


\section{Part III: Transition to Remediation}

\section{Prioritization of Essential Areas, Facilities, and Functions}

This section describes the importance of, and specifies a methodology for, prioritizing areas and facilities to be remediated following wide-area biological contamination. Because it is impossible to clean everything at once following BWA contamination, prioritization becomes essential. Whereas a general rank ordering of areas, facilities, and functions is necessary before remediation commences, prioritization must also be done iteratively as events unfold over each of four phases, that is, during characterization, decontamination, clearance, and restoration/reoccupancy. As remediation progresses, prioritization should be revisited to take into consideration issues such as shifts in objectives, the availability of additional resources, and creation of new work-arounds. Different areas or facilities are likely to be at different stages of remediation at any given time following first response, thus the process may become complex. Nevertheless, creating and updating a workable prioritization scheme is essential to planning for efficient wide-area remediation because of the limited availability of resources, potentially long delays associated with characterization and cleanup, the critical nature of certain disrupted functions, dependence of virtually all critical operations on infrastructure, and competing requirements among a host of sectors and interests.

The National Asset Database, (see for example the Report for Congress by Moteff 2007; available at <http://www.fas.org/sgp/crs/homesec/RL33648.pdf >) identifies critical infrastructure across the U.S., but a method for prioritizing the listed assets for a given urban area has not been established. Likewise, there is as yet no officially recognized method to prioritize the remediation of essential areas, facilities, and functions following a wide-area BWA attack. However, if such an incident were to occur today, the method discussed in this section can be applied to set priorities for achieving remediation objectives and then for allocating and managing resources to meet those objectives.

A wide-area BWA incident could involve the loss of access to many critical infrastructure systems (e.g., highways, water, power, airports, and seaports), will make apparent the extremely limited availability of remediation resources, and will have severe socio-economic impacts locally, regionally, and nationally. Such complexities, combined with intense public and congressional scrutiny, require that a defensible method be applied to prioritize systems and critical infrastructure.

A prioritization methodology must address at least four major objectives: (1) minimizing health effects, (2) minimizing socio-economic disruption, (3) minimizing costs, and (4) maximizing public satisfaction (Wide-Area Biological Restoration Final Report, HSI 2005, p. 27). These four objectives are also consistent with those in the Federally mandated planning literature, such as the National Contingency Plan (EPA 2000). Applying a formal method that prioritizes assets in light of remediation objectives, while factoring in operational constraints, is an important part of an optimized wide-area remediation effort. 


\section{Prioritization}

Establishing priorities for a wide urban area would be complicated further if biological contamination extended across multiple jurisdictions. Among the many factors to be considered as part of prioritization are political considerations, the perceived importance of assets associated with specific areas and facilities, the degree of biological contamination at a given location, and related socio-economic issues. The process will inevitably involve trade-offs among the conflicting values and concerns of stakeholders as well as an understanding of the ramifications of selecting certain candidate locations for priority remediation while delaying others. A regional working group that includes local political leaders from affected jurisdictions should be appointed for prioritization purposes during a real incident. Furthermore, a formal process should be established that allows additional stakeholders (e.g., Federal officials and key local industry representatives) to provide information and their viewpoints. The political nature of trade-offs requires not only their participation but also the use of a transparent and accountable scheme.

It is obvious that prioritization is a complicated problem. In some jurisdictions, decision-makers will request that all appropriate stakeholders prepare lists of priorities, which will be combined into a consolidated list. When complex projects are planned by industry, many prioritization tools and analyses are employed, usually by experts, and such an approach is currently employed in some jurisdictions to help with emergency recovery. Because major emergencies are infrequent, specific models or tools designed in advance will likely be out of date and inappropriate when needed; therefore, this section describes a general methodology to be applied for prioritization purposes.

\subsection{The Prioritization Process}

Figure 5-1 summarizes the recommended five-step, wide-area prioritization process. Steps 1 through 4 identify assets and facilities to be remediated and place them in rank-order according to the function(s) they provide; step 5 weighs the rank-ordered list against available resources to produce a strategy for remediation.

Step 1 identifies and sets high-level objectives for remediation. Objectives will likely include, but are not limited to, minimizing adverse health effects, minimizing socio-economic impacts, maintaining national-defense capabilities, and minimizing impacts on the environment. Specifying the objectives at the outset reinforces the importance of broad and overriding concerns and places a focus on the relative importance of each remediation objective. However, as progress is made toward cleanup over time, and as political considerations evolve, the relative importance of individual objectives may change. For example, at the start of remediation, minimizing adverse public health effects will likely trump all other objectives, but as areas with high levels of contamination are remediated and the healthcare system becomes operational, reducing economic impacts will likely increase in importance.

Step 2 consists of identifying the geographical areas, facilities, assets, and infrastructure requiring remediation. This step involves listing assets in a contaminated area and identifying the critical infrastructure, major lifelines, and minimum essential infrastructure (MEI) within the area that must be remediated to restore essential functions to the area. Assets are identified from the sources described in Section 5.1.2.

Step 3 involves defining metrics that can be used to determine an asset's value to each remediation objective. From the metrics, an asset's contribution toward achieving the 


\section{Prioritization}

remediation objectives can be quantified. Determining the appropriate metrics to apply is a nontrivial task but enables comparisons among multiple asset types.

Step 4 consists of developing a ranked list of assets to be remediated in order of priority. Stakeholders and emergency managers are key decision-makers in assigning the weighting of various factors considered as part of the ranking process. Factors include an asset's contribution to remediation objectives (Step 3), the availability of work-arounds for a given asset, and dependencies among different assets. Tools are available to help in the rank ordering.

Step 5 yields an operational plan for the remediation work by applying resource constraints to the rank-ordered list of assets. The plan will be the result of balancing the need for rapid remediation with the realities of resource and manpower limitations. In certain cases, a lowerpriority task could be executed before a higher-priority task because of the unavailability of particular resources. Considerations such as resource availability, ownership, and effectiveness must be taken into account during this step.

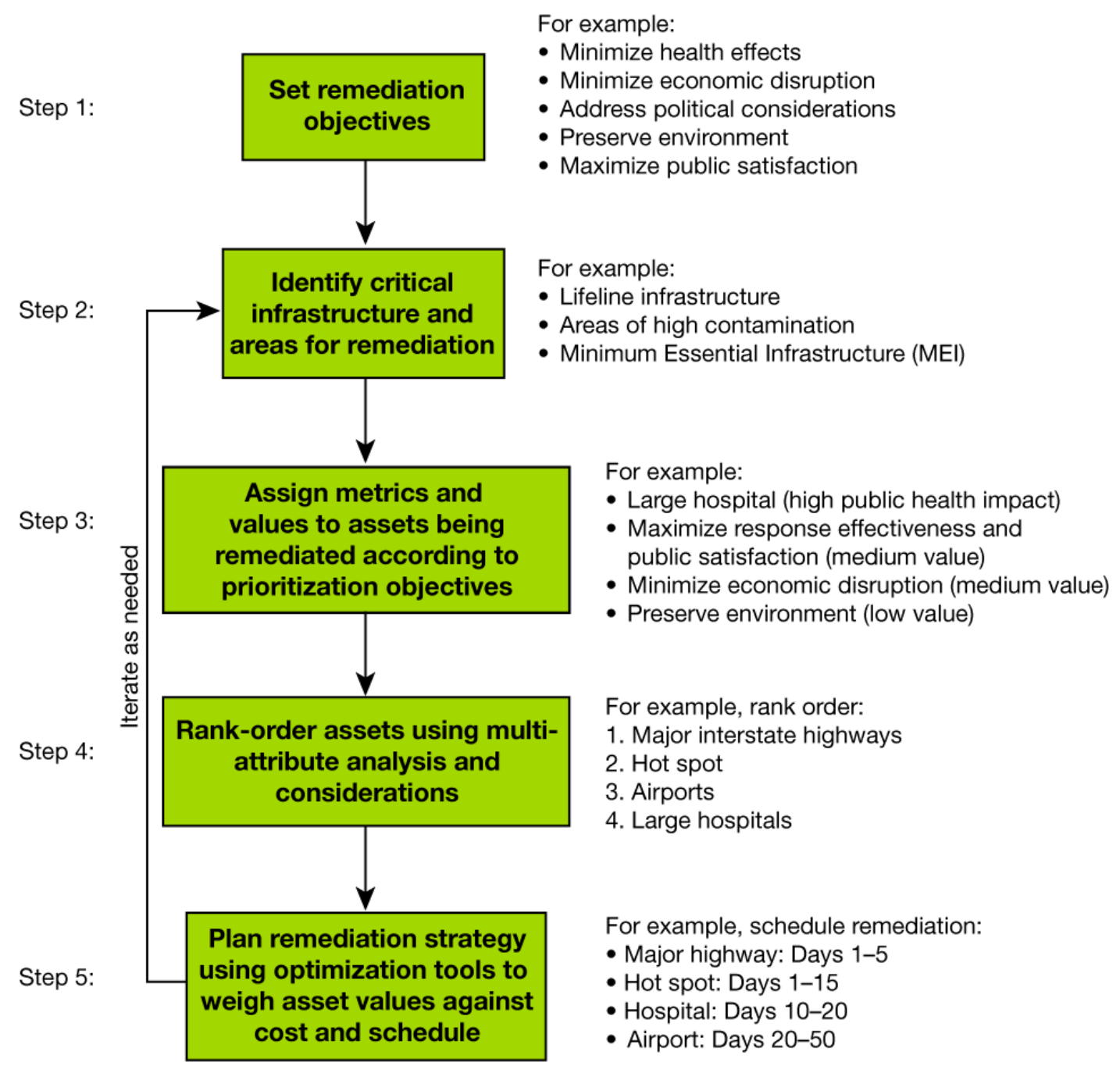

Figure 5-1. Recommended 5-step prioritization methodology. 


\section{Prioritization}

As remediation progresses, changes can occur in any one of several inputs to the prioritization process, including assets or areas to be remediated, values assigned to assets that affect its priority rank, and the availability of resources, such as decontamination reagents or technologies. Remediation planning is an iterative effort from beginning to end, and it must be adaptable to changing conditions.

\subsubsection{Step 1: Set Remediation Objectives}

To begin to determine priorities, it is necessary to establish the highest-level objectives that must be achieved by remediation. The NRF (DHS 2008) states that decontamination priorities, in order of importance, must be to ensure: (1) life safety, (2) incident stabilization, and (3) property conservation. Other high-level documents are in general agreement with NRF priorities, thus objectives stipulated by the NRF and other guidance documents are a starting point for setting incident-specific objectives. Step 1 involves developing more detailed objectives that are appropriate to the affected region yet in keeping with the NRF approach. Step 1 includes establishing the relative importance of each objective.

Health and safety concerns are paramount, especially at early times following a release of BWA when the probability of exposure through secondary mechanisms, such as reaerosolization and tracking, is greatest. Time and environmental conditions may reduce the risk to the public, but public health risk must always be assessed in formulating remediation objectives.

Economic impact and public satisfaction are also high on the list of objectives, but both are likely to involve conflicting stakeholder interests. Because of the many different ways to assess economic impacts (e.g., impacts to the wide range of business types affected, or to governments and their tax bases, to name a few), it will be difficult to determine which considerations are most important. Economic value can be assessed using total asset value of a company, annual sales figures, number of employee, number of customers, or some other metric. Public satisfaction is a reflection of the quality of life as well as confidence in the government's response, and the factors key to maximizing public satisfaction must be identified for the affected region. Stakeholder involvement is clearly an essential part of the process.

Matters related to national security after a biological attack involve the impacts of contamination on, and possible disruption to, military facilities and functions, the military-industrial complex, strategic national networks, and critical knowledge centers. Although the NRF does not specifically identify national security considerations as a priority, such issues have the potential to impact other major priorities, including life safety, incident stabilization, and property conservation.

Another important objective is to minimize impacts to the environment arising from decontamination methods and materials. Trade-offs may be necessary between decontamination methods and materials that are highly effective but also hazardous to the environment. Environmental preservation must be considered when developing remediation objectives.

Stakeholders may identify many other issues of local, regional, or national concern. For example, a single facility that supports not only local interests but also many other facilities and people in a wider region may be viewed as more important than one that does not. How long a particular facility can remain inoperative before it is abandoned and replaced by another outside the area is another consideration. Perceived values may also change over time, depending on the rate of 
progress of remediation. The drivers for objectives are not merely local, but state and Federal. Some contaminated facilities or areas, such as defense facilities, may be perceived locally as relatively low-priority assets; however, they may be deemed critical to decision-makers at regional or Federal levels. At the regional level, there may also be other issues that would profit from prioritization, such as where to deploy public health assets. Resolving issues and possible conflicts of interest requires the incorporation of stakeholders and political leaders when setting high-level remediation objectives. Prioritization should thus be done by including decisionmakers at both regional and local levels. We recommend that the Planning Section of the ICS/UC provide recommendations to the Operations Section Chief and UC within the ICS tactical response-management structure.

\subsubsection{Step 2: Identify Areas for Remediation and Critical Infrastructure}

After first specifying the areas and geographical extent of contamination, Step 2 consists of identifying all highly contaminated locations, critical and supporting infrastructure, and other facilities or items of concern within those areas. It is useful to categorize the affected areas by type of use, such as agricultural, industrial, residential, commercial, and recreational. Following such categorization, the important infrastructure components in the areas are identified. The identification of infrastructure that must be restored should be informed by what critical functions are disrupted and need to be returned to service.

\subsubsection{Highly Contaminated Locations}

The first task in Step 2 is to identify those areas with such high levels of contamination that they must be given priority for cleanup regardless of whether or not they contain critical infrastructure or other key assets. Highly contaminated areas must be given priority primarily because of the threat of ongoing cross-contamination and dispersal to other locations.

\subsubsection{Critical Infrastructure}

Critical infrastructure has been defined as "the assets of physical and computer-based systems that are essential to the minimum operations of the economy and government" (Radvanovsky 2006). The National Strategy for Homeland Security (DHS 2002) lists critical infrastructure sectors as: agriculture, food, water, public health, emergency services, government, defense industrial base, information and telecommunications, energy, transportation, banking and finance, chemical industry, and postal and shipping.

The National Asset Database assembled by the DHS catalogs critical infrastructure under 15 sectors. The list tends to place assets into two broad categories: (1) fixed assets, which include the defense industrial base and key industries whose disruption would have long-term impacts; and (2) lifelines, which are the underlying infrastructure necessary to sustain human activity. Lifelines include information and communications; electrical power systems; gas and oil production, storage, and transportation; banking and finance; transportation; water-supply systems; emergency services; and continuity of essential government services. 


\section{Prioritization}

Interim Consequence Management Guidance

\subsubsection{Minimum Essential Infrastructure}

A sub-set of critical infrastructure referred to as minimum essential infrastructure (MEI) can be identified at national or regional levels. National MEI consists of "critical organizations, personnel, systems, and facilities that provide a flow of goods and services that are absolutely essential to the economic operational success, as well as national security of the United States" (Radvanovsky 2006). National MEI is of such importance that its disruption would have a severe effect on operations in the rest of the nation. Regional MEI consists of assets critical to the economy and security of a particular region. Examples of regional MEI are major highways, shipping ports, airports, major power plants, and major water-reclamation plants in a given area. As part of pre-planning, MEI should be clearly identified at the regional and local levels.

\subsubsection{Federal Databases and Supporting Capabilities}

Several databases and capabilities can be adapted for application to Step 2 if a wide-area biological release were to happen today. They include databases of information on land use and critical infrastructure, as well as decision and planning tools.

The DHS National Asset Database is a compilation of critical infrastructure throughout the country. The database can be used to identify the number and types of critical infrastructure and land-use designations for a given geographical area. As an example, Table 5-1 summarizes eight lifeline-sector categories of critical infrastructure extracted from the DHS National Asset Database for Seattle. Whereas hundreds of critical infrastructure assets are listed in the database, no indicator is provided for the volume of use associated with many of the categories. In many instances where such an indicator is available, the information was omitted from the database. Therefore, there is no mechanism currently in the database to differentiate between critical infrastructures of greater or lesser importance. This database could be improved for application to a wide-area release by specifying the value of assets to aid in their prioritization for remediation purposes.

Table 5-1. Types of critical infrastructure assets listed in the DHS National Asset Database for downtown Seattle and Fort Lewis. ${ }^{\text {a }}$

\begin{tabular}{|c|}
\hline Lifeline sector of critical infrastructure \\
\hline Information and communications \\
\hline Electrical power systems \\
\hline Gas and oil production, storage, and transportation \\
\hline Banking and finance \\
\hline Transportation \\
\hline Water-supply systems \\
\hline Emergency services \\
\hline Continuity of government services \\
\hline
\end{tabular}




\section{Prioritization}

Additional Federal critical infrastructure databases include Homeland Security Infrastructure Program (HSIP) Gold and HSIP Freedom. These sources provide a common store of data on domestic critical infrastructure that agencies can use in developing and exercising response plans to acts of terrorism, natural disasters, and other homeland security events. Local critical infrastructure management systems, such as the Automated Critical Asset Management System (ACAMS), can be used for obtaining and sharing information. Another possible source of information is the prioritized lists for restoring electric power that many power companies already have in place.

The National Infrastructure Simulation and Analysis Center (NISAC) (see for example <http://www.libertysecurity.org/article1086.html >) is a program of the DHS Office of Infrastructure Protection. The center provides advanced modeling and simulation capabilities for the analysis of critical infrastructure and its interdependencies, vulnerabilities, consequences of disruption, and other complexities. NISAC can provide the following information quickly and in standardized format:

- Information on infrastructure assets.

- Information on the interrelations among infrastructure assets.

- Analysis of national economic consequences after the loss of an infrastructure element.

NISAC can also provide a more in-depth analysis to answer more economic-policy-related questions such as:

- Which industries and economic regions are affected most by an infrastructure disruption?

- How do infrastructure or industry constraints prolong economic recovery?

- Are small firms hurt more than large firms? Which are most influential on economic stability?

\subsubsection{Step 3: Assign Metrics and Values To Assets}

With respect to every objective identified in Step 1, each asset (essential area, facility, or function) identified in Step 2 will have a certain value. Step 3 assigns the value. Appropriate metrics need to be first identified then used to quantify an asset's value with respect to one or more remediation objectives. Metrics should be logical and consistent with available information.

One way to determine value is to construct a matrix containing all assets on one axis and each objective on the other, as shown in Table 5-2. By referring to a checklist of key considerations (see below) and factoring in the dependencies of facilities on each other, each asset can be assigned a value with respect to each objective to fill out the matrix. Trade-offs, redundancies, and work-arounds should be considered as part of the process. A simple analysis can be used to identify assets that contribute to multiple, high-priority remediation objectives. Step 3 thus prompts decision-makers to prioritize across remediation objectives and quantify the relative value of remediating each of the assets. The process provides a context and transparency for prioritization discussions and negotiations.

In Table 5-2, the assets and objectives are listed. The metrics chosen for each cell depend on the asset type and remediation objective. The method enables easy comparison of assets of similar type (e.g., prioritizing power plant X because it serves more residences and employs more people 


\section{Prioritization}

than a competing power plant.) In addition, assets of different types can be compared. For example, in this case the hospital is prioritized above the power plant because of the importance placed on minimizing health impacts. However, if all objectives were weighted equally, then the power plant would likely be prioritized above the hospital because it has considerable impacts on many objectives. Whereas Table 5-2 assigns values to assets for specified remediation objectives, many other considerations (see Step 4) may cause the priorities to shift.

Table 5-2. Example: Assign value to assets requiring remediation.

\begin{tabular}{|c|c|c|c|c|c|}
\hline \multirow[b]{2}{*}{ Assets } & \multicolumn{5}{|c|}{ Objectives } \\
\hline & $\begin{array}{c}\text { Health } \\
\text { impact } 5 x\end{array}$ & $\begin{array}{l}\text { Socio- } \\
\text { economic } \\
\text { value } 1 \times\end{array}$ & $\begin{array}{l}\text { National } \\
\text { security 1× }\end{array}$ & $\begin{array}{c}\text { Public } \\
\text { satisfaction 1× }\end{array}$ & $\begin{array}{l}\text { Environmental } \\
\text { impact } 1 \times\end{array}$ \\
\hline $\begin{array}{l}\text { Downtown } \\
\text { outdoor area }\end{array}$ & - & - & - & High (subjective) & Low \\
\hline Hospital A & $\begin{array}{l}\text { High (> 300 } \\
\text { staffed beds) }\end{array}$ & $\begin{array}{l}\text { Medium ( } 4000 \\
\text { employees) }\end{array}$ & - & Low (subjective) & Low \\
\hline Port B & - & $\begin{array}{l}\text { High (1000 } \\
\text { employees, } \\
\text { critical } \\
\text { economic node) }\end{array}$ & $\begin{array}{l}\text { Medium } \\
\text { (receives }>50 \% \\
\text { of supplies for } \\
\text { local military } \\
\text { base) }\end{array}$ & - & Medium \\
\hline Power plant X & $\begin{array}{l}\text { Medium } \\
(10000 \\
\text { residences } \\
\text { served })\end{array}$ & $\begin{array}{l}\text { Low (1000 } \\
\text { employees) }\end{array}$ & $\begin{array}{l}\text { Medium (powers } \\
>50 \% \text { of } \\
\text { facilities on local } \\
\text { military base) }\end{array}$ & $\begin{array}{c}\text { High }(40000 \\
\text { people impacted) }\end{array}$ & Medium \\
\hline
\end{tabular}

Decision-makers who participate in assigning value to assets will have a large impact on outcomes, and Federal stakeholders may have perspectives quite different from those of local stakeholders. Objective or subjective considerations may apply. Socio-economic value may be ascribed in a more deterministic way by calculating the cost of losing a given asset (opportunity cost), whereas maximizing public satisfaction is clearly a subjective evaluation. Health-based value can be determined through a risk-assessment approach. By referring to a checklist of key considerations (see below) and factoring in the dependencies of facilities on each other, each asset can be assigned a value with respect to each objective to fill out the matrix.

\subsubsection{Checklist of Considerations}

The following checklist (considerations are not listed in rank order) can be used to help assign values to individual assets:

\section{- What is the loss or degradation of capability?}

For a BWA scenario in which worker access is delayed or denied, some systems may suffer short- or long-term physical or functional degradation. The type and extent of degradation can depend on the asset involved, the number of personnel normally required to operate that asset, the ability to execute operations remotely, the amount and schedule of required maintenance, and a host of other factors. Certain activities may become 


\section{Prioritization}

operational more quickly by providing workers with post-exposure prophylaxis and the first course of anthrax vaccine.

- If a capability is degraded, can it be made operational in the short or long term? Following the completion of first-response activities, it is likely the regional population will decrease, and goods and services will be reduced. Requirements for commodities such as power, waste management, and broadband access will be reduced accordingly. Certain assets, though partially compromised, may still be able to meet the lessened demand. As requirements change over time and people return to the area, to what extent can a given asset meet demand?

- Are there possible work-arounds?

A work-around is an alternative - usually temporary-way to restore some capability. If a work-around is available, and some level of functionality is maintained, the asset may not need to be restored immediately. In some cases, a work-around may become the long-term status quo; in others, the alternative may only suffice for a limited time before the asset must be restored.

- What are the metrics for prioritization?

Different metrics drive different priorities, which are likely to change over time. For example, if restoring lifelines is most important at the outset, then providing medical treatment might be assigned the highest priority. Once sufficient medical treatment capability is created, minimizing economic disruption might become the focus, in which case other elements of the infrastructure might be given higher priority.

- What are the dependencies within the system; across other systems; and across local, regional, and national areas?

A major complexity in modeling critical infrastructure arises from the interdependencies among assets within systems and across other systems. Dependencies can involve issues such as location, proximity to and availability of goods and services, and how the use of one facility depends on another. For example, many systems, including healthcare depend on roads, power, and water to operate. To fully restore a hospital's capabilities, it must be decontaminated, regional access must be provided, skilled workers and supplies must be available, and power and water restored, among other considerations.

- What is the asset's ability to self-restore?

Facilities that have resources available for self-remediation will likely not be prioritized ahead of (i.e. given additional resources) those assets that are resource-constrained.

- Is a capability location-specific?

A question related to the one immediately above is: which region does the asset serve? If a typically high-priority asset (e.g., power plant) serves a low-priority area, then the asset may be deemed less critical and prioritized lower.

- Is the asset or capability unique?

An asset may serve a function or provide a capability that cannot be replicated. If so, and the capability is critical to remediation objectives, it would be given high priority.

- Will the asset help to restore public confidence? 
Benefits may be derived from restoring certain assets that are simply quicker or easier to restore (e.g., require fewer resources). Such an approach could have political benefits and inspire public confidence in decision-makers and the remediation effort.

- Will the asset enhance the overall remediation strategy?

An asset or area may be given higher priority because it allows for more effective remediation. For example, characterizing and initially remediating outdoor areas reduces the spread of agent, reduces health hazards and other constraints in traveling through hazardous areas, and allows access to facilities needing cleanup.

- What are the political or social considerations?

Public perception of an asset influences its value. For example, the Empire State Building in New York City and the Space Needle in Seattle are icons that may be given greater value as representations of a city's robustness and progress towards normalcy.

The FBI's InfraGard program is a Federal resource that can be useful for acquiring critical infrastructure information. InfraGard is a government and private-sector alliance that was developed by FBI Cleveland in 1996 to promote protection of critical information systems. The program has grown into a FBI-Headquarters-supported program, and all 56 field offices support at least one InfraGard chapter within each territory through the assignment of one or more Special Agent InfraGard Coordinators. InfraGard provides formal and informal channels for the exchange of information about the nation's critical infrastructures and key resources. The mission of the InfraGard program is to increase information and intelligence sharing between the FBI and InfraGard members to strengthen the defense of the nation's critical infrastructures and key resources across FBI priority programs.

\subsubsection{Step 4: Rank-Order the Assets}

Ranking should be conducted by the tactical UC based on management objectives provided by political leadership. Because of the unique perspectives of various stakeholders, possible involvement of many jurisdictions, special political interests, and potential emotional considerations, deciding on the rank order of assets across a wide area can be difficult. Assets may be interconnected in complex ways. For example, assets deemed relatively unimportant to one group of stakeholders may affect a different asset that is critical to another stakeholder group. Thus, to develop an accurate list, rank ordering must be done across multiple stakeholders with an understanding of the potential interconnections and implications. A more formal, objective, and internally consistent approach that takes into account the competing priorities of stakeholders is recommended. One science-based analysis technique that is well suited for prioritization is multi-attribute analysis. A multi-attribute prioritization process involves developing tradeoff curves (utility functions) to generate a single rank-ordered list. If such an approach is used, assistance by an individual experienced in the practice of expert elicitation is advised.

Multi-attribute utility (MAU) models are a set of mathematical tools developed to help decisionmaking across multiple objectives, especially when groups of stakeholders with competing interests are involved. The models provide a formal framework for quantifying tradeoffs between attributes and apply the concept of utility, which seeks to infer subjective value (utility) from the choices of decision-makers. Utility theory is used to rescale the numerical value of a measure of interest onto a scale of 0 to 1 so that direct comparisons between and among measures can be 


\section{Prioritization}

developed and an overall preference rating determined. The shape of utility curves depends on a decision-maker's preferences as well as perception of risk and uncertainty. Commercial MAU packages, such as Logical Decisions, are available to streamline the structuring of a problem, assess utilities, and understand the impact of tradeoffs on prioritization.

If decision-makers must prioritize without the benefit of technical analysis, a simpler but possibly less-effective process can be used in which emergency managers rank order the asset list according to values collectively determined in Step 3. For example, the availability of a short-term work-around may be paramount over all other considerations. The logic behind such an approach would be that as long as an asset's function is carried out well enough to meet the region's immediate needs, then there is no urgent need for immediate remediation of that asset. Regardless of the method applied, logical reasoning must prevail during prioritization to instill confidence in the process and to justify final choices to the public and other stakeholders.

\subsubsection{Step 5: Plan For and Optimize Remediation}

The final step in prioritization is to develop the overall remediation strategy. An optimization process is used to apply time and resource constraints (a trade-off analysis on the use of limited resources) to the rank-ordered list of assets from Step 4 to develop the treatment order and yield an optimized cleanup strategy. Here, time and resource constraints are assessed separately from the other variables previously considered. This means that some lower-valued assets requiring little in the way of resources may be decontaminated before higher-valued assets that require more or specialized resources. Thus, the final prioritization scheme for remediation may be quite different from the rank-ordered list of assets derived from Step 4.

Step 5 could be accomplished by applying time and resource requirements to each asset in the prioritized list, then using scheduling techniques, such as project planning, to determine the order of remediation. However, wide-area remediation is comparable in complexity to a massive construction project, such as building the Golden Gate Bridge, in which planning and prioritization are both extremely important and difficult. Decision-makers should make use of tools and expert help to reach an optimal solution. Operations research experts can provide expertise in elicitation to aid in understanding decision-makers' preferences, multi-attribute analysis to adjudicate several factors when ranking priorities, scheduling, and optimization of resource allocations. Expert help is required throughout all phases of biological remediation, and prioritization is no exception.

\subsubsection{The Overall Decontamination Approach}

In applying resource and time constraints to the rank-ordered assets derived from Steps 1 through 4, an overarching remediation approach must also be considered, as it should be throughout the 5-step process. The approach recommended in this Interim Guidance, which is to clean outdoor areas first, will obviously affect prioritization. Moreover, all outdoor areas are not equal; in particular, those areas surrounding priority assets will likely assume increased importance for priority cleanup.

Any BWA that does not rapidly degrade in the environment and has not yet agglomerated into an immobile form can be re-suspended by wind, or relocated by tracking, and be transported into uncontaminated or previously cleaned areas. The characterization and removal of potential sources of exposure and recontamination is an imperative. This overriding consideration 


\section{Prioritization}

necessitates the remediation of outside areas before the insides of buildings, and areas with high probability of contamination before areas with low probability of contamination. The timing and extent of outdoor remediation will depend on the assessment of associated health risks, outdoor remediation techniques applied, and costs, all of which are knowledge gaps at this time. Although the strategy of decontaminating outdoor areas before indoor facilities is recommended to prevent reintroducing contamination to clean or decontaminated facilities, access to certain priority facilities (such as hospitals, police stations, and fire stations) may be required even before outdoor areas are addressed. After they are cleaned up, methods to isolate essential facilities from outdoor contamination will be necessary.

To minimize the impact of a wide-area BWA release, nationally and regionally important MEI must be restored as quickly as possible. An approach for restoring such infrastructure in the midst of an otherwise contaminated area includes cleaning transportation access routes, remediating critical buildings, and providing immunization and hazardous material suits for workers at MEI facilities. MEI, such as highways typically used by the general public, will likely require full remediation before use. Characterization steps, including ongoing air monitoring, can help assess the danger of continued exposure, but immediate mitigation measures including the removal of known deposits of BWA and general decontamination of outdoor areas surrounding the release site(s), will probably rank high on the list of priority remediation activities.

Figure 5-2 shows a general remediation strategy for wide-area contamination considering the hazards associated with tracking and reaerosolization of $B$. anthracis spores together with the importance of critical lifelines, MEI, and critical economic infrastructure supporting a region. First, outdoor remediation proceeds quickly and completely throughout a contaminated (hot) zone. Access is then available to infrastructure within the area. Contamination-free buildings can be used immediately, and contaminated buildings can be remediated in prioritized order, with critical infrastructure remediated before noncritical. The advantages are that the approach reduces potential sources of recontamination and health risk, and allows for the parallel remediation of privately and publicly funded buildings. Once access routes to buildings slated for remediation have been cleared, characterization and remediation of contaminated buildings within a hot zone can proceed in order of priority. 


\section{Prioritization}

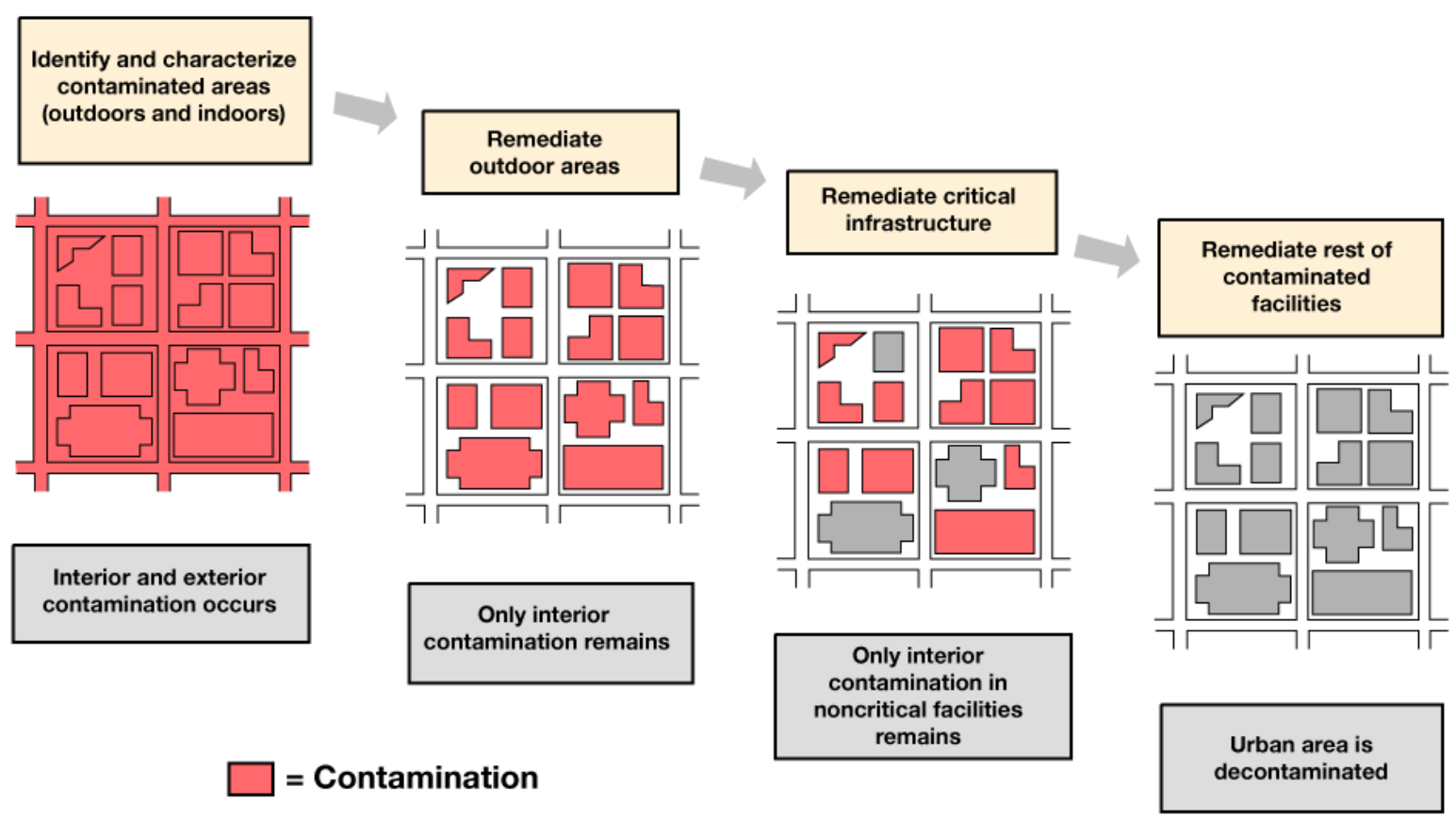

Figure 5-2. Overall remediation approach.

\subsubsection{Optimization Tools CPLEX and COIN-OR}

Optimal scheduling of projects can be formulated as an integer programming problem in which the problem is defined by an objective function and set of constraints. The objective function defines the costs and benefits associated with undertaking a set of projects in a particular order, and the constraints define the limitations under which the projects can be scheduled. For example, resource requirements (e.g., staffing and equipment) will constrain the number of projects that can be undertaken simultaneously or a set of projects that need to be undertaken sequentially. Because problem formulations can be quite large, the use of mathematical programming software can be used to find an optimal solution. Packages available for solving the set of linear equations developed by an analyst include CPLEX (a commercial package) and COIN-OR (an open-source package). Such tools are best used with expert assistance.

\subsubsection{Other Supporting Tools}

Additional decisions affecting prioritization include the best application of laboratory-analysis resources and the most effective use of limited and trained personnel across all other remediation functions. To assist with resource planning and allocation, a tool known as Analyzer for WideArea Restoration Effectiveness (AWARE) is being developed as part of the IBRD project. AWARE lists the detailed steps in the remediation process, is populated with preliminary estimates of resources, times, and costs. Key parameters are included as default values that can be changed to represent local and unique conditions. AWARE is an example of a tool that can be used during prioritization to assess process trade-offs; however, the tool has not yet been validated (Einfeld 2008). AWARE also allows testing of different strategies to compare the allocation of resources across various tasks and determine the optimal application of resources for Step 5. 


\section{Prioritization}

\subsection{Interim Recommendations for Prioritization}

Table 5-3 summarizes recommended actions for prioritizing critical infrastructure in preparation for remediation. It is expected that the actions would be carried out by members of the UC.

\section{Table 5-3. Summary of recommendations for prioritization.}

\begin{tabular}{|c|c|}
\hline Recommended item, action, or process & $\begin{array}{c}\text { Comments, qualifications, responsible entity } \\
\text { or specific approach/tools }\end{array}$ \\
\hline $\begin{array}{l}\text { Identify outdoor areas with potential for continued exposure to } \\
\text { the public by particle resuspension or other means. }\end{array}$ & Use available characterization tools. See Section 7. \\
\hline $\begin{array}{l}\text { Collect information about affected critical infrastructure and } \\
\text { determine the sub-set of critical infrastructure referred to as } \\
\text { minimum essential infrastructure (MEI). }\end{array}$ & $\begin{array}{l}\text { Use the DHS National Asset Database, NISAC, and } \\
\text { other sources to identify critical infrastructure. }\end{array}$ \\
\hline $\begin{array}{l}\text { Form a prioritization working group of government, business, } \\
\text { military, health officials, and stakeholders. }\end{array}$ & $\begin{array}{l}\text { Assign metrics and value to affected assets } \\
\text { considering remediation objectives. Provide } \\
\text { continued input to the IC or UC throughout the } \\
\text { remediation process. }\end{array}$ \\
\hline $\begin{array}{l}\text { Prioritize areas and infrastructure to be remediated in terms of } \\
\text { asset value, availability of work-arounds, critical timelines, } \\
\text { dependencies, and political considerations. }\end{array}$ & $\begin{array}{l}\text { Use available tools such as multi-attribute utility } \\
\text { theory (MAUT); however, recognize that they have } \\
\text { not been used for this type of catastrophic incident. }\end{array}$ \\
\hline $\begin{array}{l}\text { Set remediation objectives based on public health issues, } \\
\text { economic considerations, and national security implications. }\end{array}$ & See Section 6. \\
\hline $\begin{array}{l}\text { Use an optimization-planning tool to develop the remediation } \\
\text { strategy, considering available resources, costs, and asset } \\
\text { values. }\end{array}$ & $\begin{array}{l}\text { Consult experts. Consider using planning tools such } \\
\text { as CPLEX (commercially available), COIN-OR } \\
\text { (commercially available), or AWARE (available } \\
\text { through IBRD); however, recognize that they have } \\
\text { not been used for this type of catastrophic incident. }\end{array}$ \\
\hline $\begin{array}{l}\text { Commence remediation of outdoor areas that remain } \\
\text { hazardous to health. Proceed in order of prioritized assets. }\end{array}$ & See Section 8. \\
\hline
\end{tabular}




\section{Prioritization}

\subsection{Section 5 References}

Conference Proceedings (in press), Chemical and Biological Defense Physical Sciences and Technology Conference, November, 2008.

DHS (2002), Department of Homeland Security, National Strategy for Homeland Security; available at $\langle$ http://www.whitehouse.gov/homeland/book/>.

DHS (2008), Department of Homeland Security, National Response Framework; documents available at $\langle$ http://www.fema.gov/emergency/nrf/> .

Einfeld, W., D. M. Edwards, D. O. Franco, J. Fruetel, and L. I. Yang (2008), “AWARE: A Planning and Response Tool for Wide-Area Military or Civilian Contamination Events," EPA (Revised July 2000), U.S. Environmental Protection Agency, National Oil and Hazardous Substances Pollution Contingency Plan (NCP) (40CFR300); available at < $\underline{\text { http://www.epa.gov/oilspill/ncpover.htm>. }}$.

HSI (2005), Homeland Securities Institute, Wide-Area Biological Restoration Final Report, prepared for the Department of Homeland Security, Science and Technology Directorate, Programs, Plans, and Requirements, Biological Countermeasures Program.

Moteff, J. (2007), Critical Infrastructure: The National Asset Database, Congressional Research Service Report for Congress, Order Code RL33648; available at 〈http://www.fas.org/sgp/crs/homesec/RL33648.pdf>.

Radvanovsky, R. (2006), Critical Infrastructure: Homeland Security and Emergency Preparedness, Taylor and Francis, New York, New York.

SNL and LLNL (2008), Sandia National Laboratories and Lawrence Livermore National Laboratory, IBRD Task 1 Systems Analysis Report (same OUO document published separately at both laboratories as report SNL2008-1349 and report LLNL-AR-401510, respectively). 


\section{Risk-Based Remediation Decisions}

This section addresses risk assessment and management issues along with approaches to be implemented in the context of a wide-area biological attack. The purpose of risk assessment is to provide the IC or UC with science-based measurements or estimates of the potential level of risk associated with different levels of exposure of humans (and animal populations) to a hazardous substance. Risk management in this context refers to a decision-making process that combines risk-related information with other considerations - such as economic, social, or political concerns - to determine what level of risk is acceptable or tolerable, and to analyze and compare alternatives designed to reduce risk (EPA/IRIS 2008). Together, these processes provide the IC or UC with a basis for decisions about what the clearance goal(s) and criteria for measuring them should be. For such purposes, a clearance goal is defined as an amount of residual contamination for a specific contaminant in or on an area or item that, once achieved following decontamination, provides acceptable protection to human health and the environment [Planning Guidance for Recovery Following Biological Incidents (DHS and EPA 2009)]. Clearance goals can be established for each potential exposure pathway, including indoor or outdoor surfaces, items such as equipment or personal belongings, the air in rooms or open spaces, soil, vegetation, or water. Clearance goals should also take into consideration cumulative risk from all exposures. Clearance goals are best set early because they should be initially incorporated into remediation activities. However, the goals may be revised, if appropriate, as part of a remediation approach that incorporates a continually updated assessment of risk as a key input. An interagency Microbial Risk Assessment Guidelines document is currently under development, and any recommendations from that source will need to be considered when the document is released.

Scientifically appropriate exposure guidelines must be used to ensure that human health is safeguarded without defaulting to overly conservative actions that would divert limited resources without major benefits. For an actual wide-area incident, site- and incident-specific factors would need to be considered, and a risk-based decision process must involve key stakeholders. In all cases, final risk management decisions are those made by responsible site-specific authorities and would reflect multiple operational factors as well as subjective considerations of risk acceptance and socioeconomic concerns.

Risk assessment and risk management are usually viewed as components of a broader process known as risk analysis, which includes risk assessment, risk management, and risk communication (Haimes 1998; Haas et al. 1999). Risk communication is a field in the area of environmental health through which a communicator hopes to provide the receiver with information about the expected type and magnitude of an outcome. Risk communication (see more detail in Sections 5, 7, and 8) is typically a discussion about adverse outcomes and the probability of a particular outcome occurring to assist others in making informed judgments (Morgan et al. 2002; Reynolds 2002).

Determining how many biological organisms of a given type constitute an actual infectious dose (risk assessment) is a science issue. However, establishing what decision-makers and stakeholders are willing to accept in terms of health risks is a social (risk management) issue. Successful wide-area remediation requires both science and stakeholder inputs, and past experience suggests that public perceptions often determine cleanup requirements although 
economics and inconvenience can persuade stakeholders to accept higher risks. In other words, a balance needs to be found among health concerns, safety issues, cost of cleanup, and other economic and national security issues that would arise from loss of access to facilities and resources following wide-area incident. Current policies regarding risk and clearance decisions related to $B$. anthracis reflect a mix of scientific, social (public perception), bureaucratic (regulatory and legal), and practical (cost and time) considerations (Raber et al. 2008a).

To address such important issues, a broadly applicable risk-assessment methodology is required to translate environmental sampling data obtained during characterization into estimates of public health risk and provide the ability to objectively compare risk management alternatives (Raber 2002). Long after initial exposures to wide-area B. anthracis contamination occur, it is anticipated that people will continue to be at risk of getting sick and possibly dying from exposure to residual spores. Risk in this context is defined as the danger to public health (morbidity or mortality potential) of people coming in contact with and being exposed to a persistent environmental agent or set of agents (EPA/IRIS 2008). Risk assessment during the Remediation Phase is done to characterize that risk using a quantitative approach, assess whether remediation is necessary, and if so, evaluate and optimize remediation options using an objective set of risk-based criteria. This section describes such a quantitative risk assessment approach and applies it to an example $B$. anthracis contamination incident.

Figure 6-1 shows where risk assessment and risk management fit into the operational phases that were defined in Section 1. As indicated, the risk assessment and management tools presented in this section assist with evaluating and implementing public health and medical options as a part of response and recovery. The tools go hand in hand with an evaluation of regulatory and other requirements leading to the choice of decontamination strategies and the final determination of whether cleanup goals have been achieved.

Many different definitions of risk assessment and its current limitations appear in the recent literature (NRC 2005, pp 16-17). In a human health context, risk assessment is the evaluation of scientific information on (1) the hazardous properties of environmental agents (hazard identification), (2) extent of human exposure to those agents (exposure assessment), and (3) the dose-response relationship (dose-response assessment) associated with those agents. Each of these topics is addressed in turn in this section. The product of a risk assessment is risk characterization, a statement integrating information from the three factors, above, to estimate the probability and degree to which exposed populations of individuals will be harmed (EPA/IRIS 2008) as a function of environmental levels. Although characterizing human health risks associated with residual $B$. anthracis remains problematic today, it is necessary to come up with consensus-based clearance goals for indoor, outdoor, and water environments following a wide-area attack involving $B$. anthracis spores.

\subsection{Overall Risk Assessment and Management Methodology}

To make an effective risk management decision, risk managers and other stakeholders need to know what potential harm the situation poses and how likely it is that people or the environment will be harmed. This is accomplished through the risk assessment process. The overall goal for a site-specific environmental risk assessment after a BWA release is to collect and evaluate all relevant information about the biological agent, its characteristics, and potential or measured exposure, and then provide decision-makers with scientifically reliable human, animal, or 


\section{Risk Decisions}

environmental estimates of risks. The goal of risk management is scientifically sound, costeffective, and integrated actions that reduce or prevent risks while taking into account social, cultural, ethical, political, economic, and legal considerations [Planning Guidance for Recovery Following Biological Incidents (DHS and EPA 2009)]. As part of a risk management paradigm, potential risks posed by a BWA following a wide-area release need to be assessed to help decision-makers set clearance goals (Section 6.5), formulate a decontamination strategy (Section 8), develop a Remediation Action Plan (Section 8), and formulate a clearance plan (Section 9).

\section{Operational Phases for Response and Consequence Management}

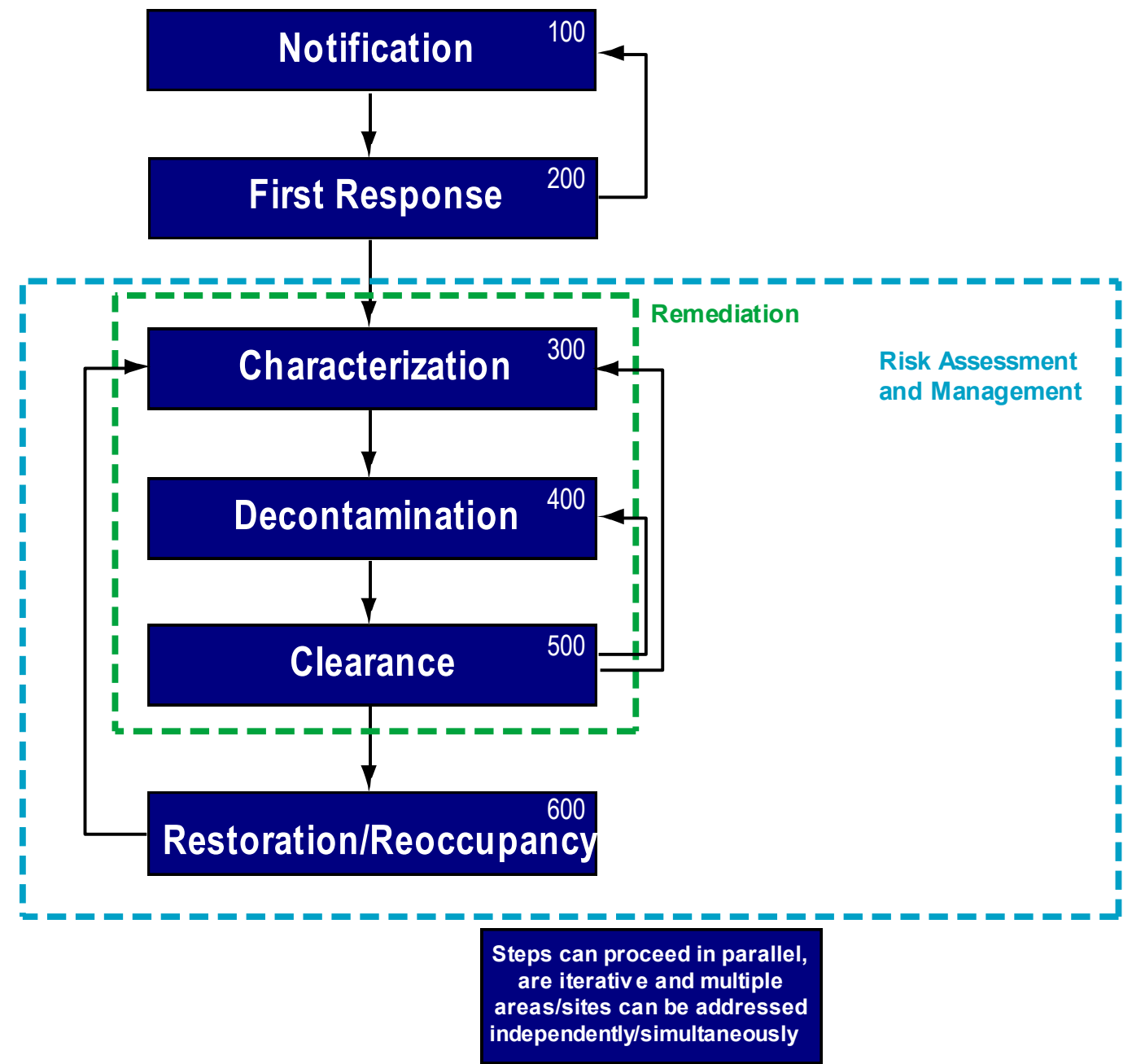

Figure 6-1. Risk assessment and risk management are key for determining and optimizing overall strategies for response and recovery. 
The risk assessment and management methodology recommended in this Interim Guidance addresses potential health risk to people who might use or otherwise occupy indoor or outdoor areas or facilities, including water facilities, following remediation. The recommendations are derived from presently available information and may change as more research and new information become available. However, it is important to recognize that risk characterization is needed to serve as a baseline from which decisions are made regarding whether corrective action is necessary, and if so, which corrective action(s) should be taken. The risk assessment methodology presented here is general and can be applied to any contamination zone within a wide area as long as the zone can be characterized. If contamination levels, population characteristics, or both were to change, the methodology would still apply, but the outcome of risk assessment would likely change. Overall, the methodology consists of:

- Translating exposure assessment(s) into expected exposure levels.

- Translating expected exposure levels into public health risk.

- Determining whether or not remediation is necessary.

- Generating risk management (mitigation) alternatives.

- Evaluating public health impacts of alternatives using objective risk metrics.

- Generating risk-based guidance for decision-makers.

Figure 6-2 shows different components of the risk assessment and management methodology and how they relate to one another. Here, a distinction is made between information gathered during initial response and that gathered to help make follow-on remediation decisions. Even though initial exposure assessment and risk characterizations inform the latter, the two are shown as distinct to emphasize the iterative nature of risk assessment and characterization. Because it is unlikely that all uncertainty will be resolved through initial environmental sampling and before remediation decisions are made, uncertainty is an inherent component of the problem and should be managed to the extent possible. In zones where uncertainty is considerable and the uncertainty can affect future decisions, iterative sampling, risk assessments, and risk characterizations may be necessary to reduce uncertainty and accurately characterize public health risk.

Once a zone is characterized, the question of whether a risk associated with that zone is acceptable must be addressed. If the risk is unacceptable, then risk management alternatives are developed and assessed. Plans involving a biological hazard should rely on relevant infectious disease or biological safety recommendations by the CDC (see for example

<http://emergency.cdc.gov/bioterrorism>) and other expert bodies including first responders, law enforcement, and public health officials. Possible actions include prophylaxis and vaccination for people living or working in contaminated areas, the use of respiratory protection or other protective equipment (depending on agent type and many other incident-specific variables), waiting for natural attenuation to have its effects, physical decontamination (cleanup), medical monitoring of individuals in the area, the remediation and restoration of designated facilities, or some combination of those approaches. Standardized risk-based metrics (e.g., expected infections or expected mortalities) provide objective criteria to evaluate each risk management alternative. After alternatives are evaluated, they can be compared and used to develop riskbased guidance, from which recommended actions can be further developed for decision-makers. Before taking action in a wide-area incident, however, the actions recommended for a given contamination zone should be evaluated against recommended actions for other zones or areas 
because they may be interconnected. After recommended actions are taken, the effectiveness of those actions must be evaluated and additional actions implemented, as appropriate.

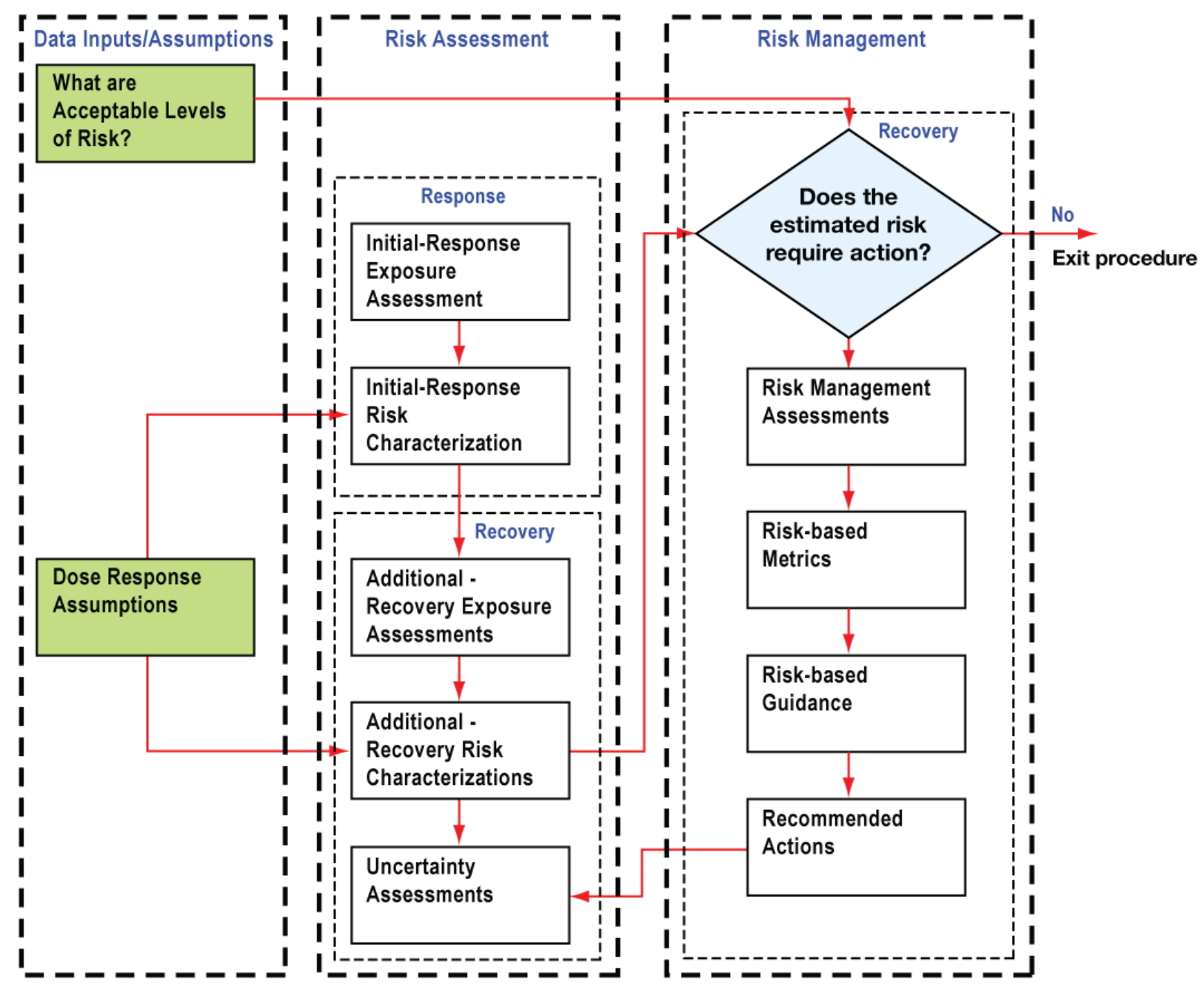

Figure 6-2. Approach to characterize risk and develop risk-based remediation guidance for a given contaminated area.

The components shown in Figure 6-2 are consistent with the six-stage framework for environmental health risk management published by the Presidential/Congressional Commission (PCCRARM 1997), which was designed to be "general enough to work in a wide variety of situations" and to address technical and policy issues as well as stakeholder involvement. The most salient risk analysis principles from the 1997 Commission report that need to be considered by decision-makers as they plan and carry out actions to address a biological incident are to:

- Clarify the factual and scientific basis of risks posed by the problem, treating health and ecological risks both qualitatively and quantitatively where possible.

- Describe the nature, severity, reversibility, or preventability of adverse effects.

- Identify who is at risk and when they are at risk; explain the possibility of multiple effects. 
- Evaluate the weight of scientific evidence, and identify the primary sources of uncertainty.

- Place specific risks posed by the problem into their multi-source, multimedia, and multirisk contexts.

- Identify stakeholder perceptions of the risks posed by the problem (Till and Meyer 2001).

- Combine information on scientific and contextual aspects of risks posed by the problem into a characterization of the problem's risks to human health or the environment.

The principles are explicitly incorporated, or can be easily incorporated, into the risk assessment and risk management process described in this section. The remainder of this section describes each component of the risk assessment and management methodology.

\subsection{Exposure Assessments}

As the first step of risk assessment for a BWA, hazard assessments identify and characterize the agent that has been confirmed to be present in a contaminated area. Among the most important characteristics to ascertain are the length of time the agent can survive in the contaminated setting (environmental persistence), whether the agent is present in a form that easily disperses or reaerosolizes, likely routes of exposure, and the degree of resistance to inactivation.

A site-specific exposure assessment is performed by integrating the results of both environmental sampling conducted to date (Section 3 ) and any additional characterization environmental sampling (Section 7). Sampling data (Section 7.5) may also be used to document the amounts (if quantitative analyses were performed) and locations of biological agent. An evaluation of site characteristics gives an indication of site or area structure, the presence of conditions that can spread an agent, and types of items and environmental matrices at the site. Modeling might also be done to assess the potential movement of biological agent from one location to another, which is part of exposure assessment. Some models have not been adequately tested; however, several models can be useful for estimating the extent of contamination. Information from the initial public health assessment typically conducted in the first 24 to $48 \mathrm{hr}$ in the First Response Phase can contribute to understanding the degree of contamination.

Exposure assessments are important inputs when characterizing risk. In the context of a widearea biological attack, the hot zone can be defined as an area that is contaminated or potentially contaminated and, as a result, might pose a danger to human health. The purpose of an exposure assessment is to clearly define the degree of contamination within a given area (i.e., contamination per square meter for the ground or surfaces, or contamination per cubic meter for air). It is important to identify the spatial resolution of the problem and to perform assessments on a scale that allows for a relatively constant or uniform environment, such as specific buildings, blocks of buildings, or outdoor areas with common environmental parameters. The results of local assessments must then be incorporated into the wide-area assessment, where each local area is prioritized for remediation (Section 5) according to its risk assessment together with political, social, security, economic, or other concerns.

Contamination estimates derived from environmental sampling (air, surface, or water, depending on the actual risks associated with the nature of the agent) are crucial to support decision-making geared towards protecting populations at risk. From a remediation standpoint, however, initially sampled areas may require more detailed sampling over time to fully understand the potential risks. As the operation shifts from response to recovery, it is likely that subsequent 
environmental sampling will need to be targeted to reduce uncertainty associated with the initial exposure assessment. However, some uncertainty will always remain, and eventually decisions must be made with the best available information.

Although the 1986 nuclear plant disaster at Chernobyl was a radiological incident rather than biological, it illustrates some of the complexities associated with wide-area contamination and the need for reliable, timely, and accurate information to make decisions. Even though radiation may be easier to measure than spores, and validated sampling methods exist for radiation, Chernobyl represents one of closest examples we can examine of an actual incident entailing a wide-area release of contamination posing human health hazard where the source term is known.

Figure 6-3 shows how an assessment of contamination can change as additional information becomes available through iterative environmental sampling. If remediation decisions for Chernobyl were made using only the contamination information shown in Figure 6-3(a), it is likely that most of the highly contaminated areas would be contained, but many mistakes might be made. Figure 6-3(b) shows a more complete and accurate assessment of contaminated areas from which remediation decisions would also be more accurate. Unfortunately, decision-makers might not have the luxury of waiting for accurate contamination assessment information before decisions had to be made for a wide-area incident. Although remediation decisions should ideally be made quickly, the choices would also involve considerable uncertainty. It might be unfeasible or exorbitantly expensive to wait months for a full exposure assessment with near-zero uncertainty. Thus, from both practical and economic perspectives, decisions may need to be made from an incomplete exposure assessment [in the case of the Chernobyl incident, using an incomplete assessment such as that in Figure 6-3(a) instead of a more complete one such as that in Figure 6-3(b)].

An additional complication is that the location(s) at which individual exposures to $B$. anthracis spores occur can shift after initial plume deposition as a result of wind (resuspension), precipitation, tracking, fomites, and other environmental processes. As a result, the locations of risk might not match the location(s) of the source. Fate and transport models of aerosols can be useful tools for exposure assessment to interpolate between empirical sampling data (which will not be available at every point in space and time). However, it is important to understand the limitations associated with using models results. Models do not incorporate all of the complexities of the real-world environment and might not include relevant transport and degradation processes. Even with such limitations, models can be useful to guide future sampling efforts or provide estimates of contamination levels in areas where sampling is not feasible. In such situations, modeling should be used along with empirical sampling data to build as accurate a picture of the affected areas as possible. 


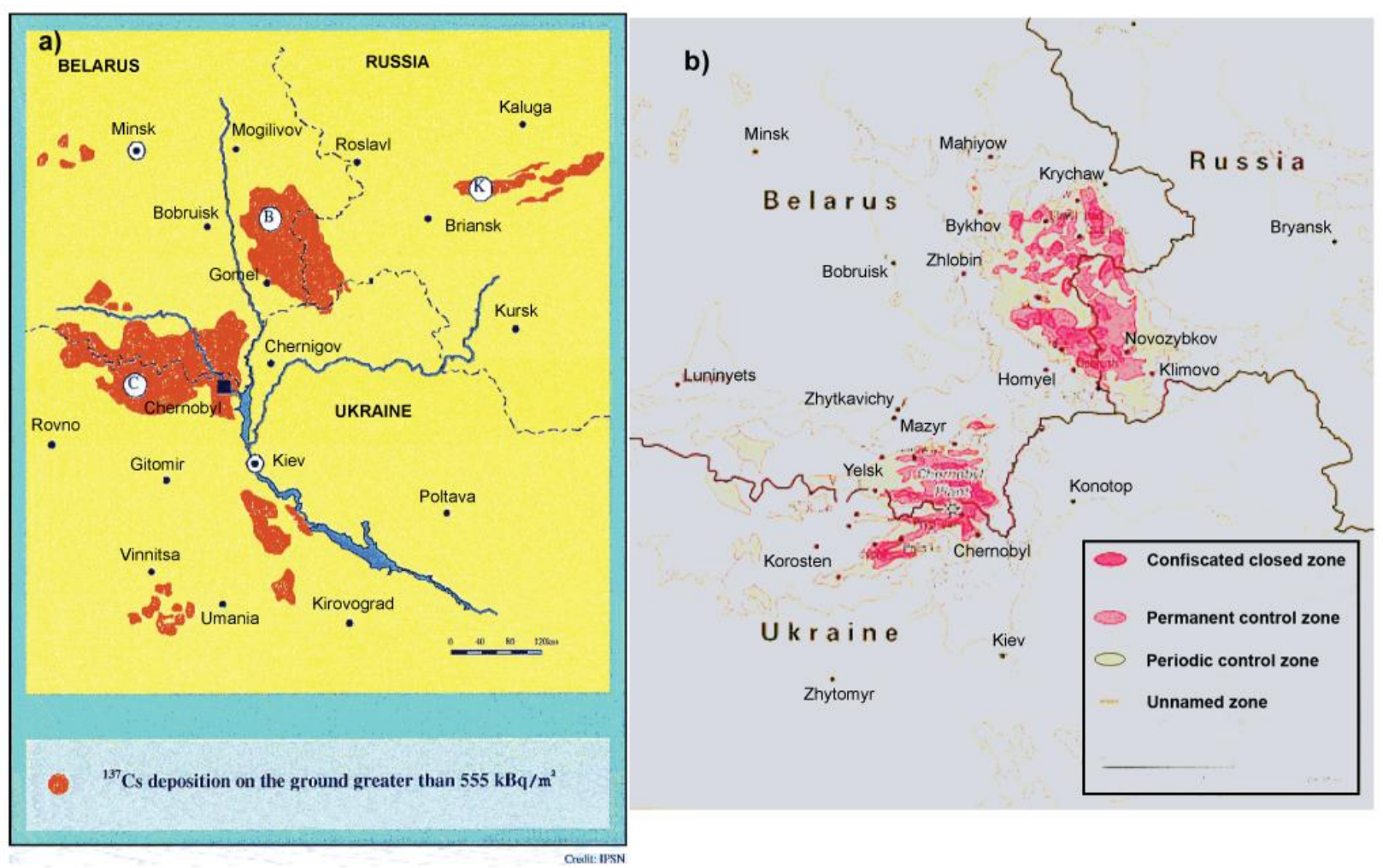

Figure 6-3. Two images of the same contaminated area after the Chernobyl disaster in 1986. (a) Only limited contamination information may be available the first few days. (b) With more sampling, a fully characterized region may emerge CIA 1996).

\subsection{Risk Characterization}

Whereas an exposure assessment might produce an estimate of the level of contamination in a given area, the risk characterization calculation translates that estimate into an expected number of illnesses, mortalities, or both (EPA/IRIS 2008). Risk characterization provides a baseline assessment indicating whether a given area needs remediation. Because of the uncertainties and difficulties in establishing infectious doses for most biological pathogens, a structured quantitative risk characterization may be difficult to develop. Nevertheless, a qualitative risk characterization also has value and needs to be provided to decision-makers. Such a characterization is instrumental in helping decision-makers determine clearance goals and a decontamination strategy. For example, risk characterization that concludes that the biological agent at a particular site is environmentally persistent, easily aerosolizes, and presents a significant risk of disease to humans from inhalation would promote the selection of stringent clearance goals and an aggressive decontamination strategy.

During risk characterization, assumptions must be made about exposure and behaviors that could lead to a dose. Dose-response is an assessment that must be conducted before risk characterization to determine the effects from exposure to a specific dose of pathogen. Doseresponse assumptions developed from the assessment are an important input to risk characterization. Because different behaviors lead to different degrees of exposure, consideration must be given to accurately modeling those behaviors that affect exposures. For example, if a 
sensitive subpopulation (e.g. immuno-compromised) frequents a particular contamination zone, their behavior and characteristics should be considered for risk characterization rather than the population as a whole. Similarly, zones might need to be distinguished in terms of land use (e.g., residential, commercial, or industrial) because different behaviors in such zones affect exposures.

Although determining the dose-response of biological agents is a difficult and often controversial science, a dose-response assessment is necessary to translate expected exposures into public health risk. Therefore, estimates of dose-response relationships for morbidity and mortality are inputs to a risk characterization so that risk can be expressed as an expected number of sick individuals and fatalities. A dose-response assessment usually includes a review of available animal and human toxicology or human epidemiological data along with medical incidence data. A frequently cited infectious dose is the $\mathrm{ID}_{50}$ or the number of organisms that would cause illness in $50 \%$ of the exposed population. A minimum infectious dose is the smallest number of organisms administered to an individual (or animal), or calculated to have been present in an exposure in an epidemiological study, that resulted in illness in at least one individual. Any given individual exposed to a number of organisms less than the established minimum infectious dose still may become infected if that individual is more susceptible than those in the study population, if the exposure is different [i.e., inhaled in an aerosol (1- to 10- $\mu \mathrm{m}$ particles, or larger liquid or solid particles)], or if the organisms were more virulent (either a different strain or prepared with virulence-enhancing materials). A recent review by the National Research Council (NRC) of the National Academy of Sciences (NAS) concluded that infectious doses for pathogenic biological agents cannot be determined with confidence because the infectivity and virulence of pathogens can vary by strain, within species, and by the type of preparation used in biological weapons (NRC 2005).

Analysts can use either most-likely or worst-case assumptions for behavior and dose-response. Regardless of what assumptions are adopted, they should be well documented and consistent across all assessments to ensure transparency and objectivity.

Major uncertainties associated with both exposure assessment and risk characterization should be documented and reviewed before assessing what can be done to mitigate risk. Uncertainties should be categorized into those that could be managed if more information were available and those that are simply unmanageable because of a lack of relevant knowledge and research. Identifying the relative magnitude of impact of an uncertainty factor is also helpful. Because the range of uncertainty is important, to the extent possible, uncertainties should be quantified in the form of error bars for the risk estimate (an example is provided below). If the range of uncertainty is great enough to alter important decisions, then at least one more iteration of sampling and risk assessment may be required. Uncertainties in all phases of a risk assessment should be reduced as much as practicable. 


\subsection{Risk Management}

Once public health risk has been characterized, the focus shifts from assessing to managing risks. Risk characterization and risk management are treated separately because sound risk management decisions depend on accurate observations and characterizations as well as best professional judgement. The steps of risk management include:

1. Determining whether remediation and risk management are necessary.

2. Determining what risk management alternatives are available (and how to optimize the options, if possible).

3. Estimating the risk reduction of each option using objective criteria, called risk metrics.

4. Comparing alternatives and providing risk-based guidance to decision-makers.

Before developing and assessing risk management alternatives, careful consideration should be given to whether the risks actually warrant action or not. Doing nothing can be a viable risk management alternative if the outputs of risk characterization indicate that public health is not in danger.

\subsubsection{Establish Whether Remediation Is Necessary}

An important question that must be addressed is whether an estimated risk is great enough to warrant the cost and time of remediation. The first major decision that the IC/UC (the risk managers) faces is where to establish the boundaries for the hot zone(s) based on the results of the initial screening environmental sampling, physical evidence if any, and hazard identification information about the specific bioagent. Once the boundaries of the hot zone(s) are drawn, the IC/UC (potentially with TWG input) then faces the next question of whether monitored natural attenuation will be effective or whether other remediation methods need to be applied. These concepts are important and are covered in detail in Section 7 and Section 8, but will be ultimately based on identifying "how clean is clean enough?" and will rely heavily on being able to set incident- and site-specific clearance goals.

Considerable research has been conducted on identifying suitable standards for cleanup and reoccupancy following a B. anthracis attack (Raber 2001, 2004; Simpson 2005; Canter 2005; see also Section 6.5). If risk is framed in terms of expected illnesses or deaths, then it should be straightforward to examine the risk and determine whether remediation is necessary. In cases where risk is extremely low, a different standard might be necessary according to empirical evidence of dose-response at low exposures. Whatever standard is chosen for a particular location or area, it should be defensible, and residual levels of contamination should be consistent with broader considerations for the wide-area effort.

\subsubsection{Generate Management Alternatives}

If corrective action is necessary, then analysts must generate risk management alternatives. Such alternatives in the context of wide-area biological contamination include:

- Natural attenuation combined with long-term environmental and public health monitoring.

- Cleanup, such as the application of bleach, foam, fumigant, or other means to meet a clearly defined clearance goal (Canter 2003). 


\section{Risk Decisions}

- Repopulation with controls (e.g., admit people for a specified number of hours/day).

- Repopulation with medical monitoring.

- Repopulation with prophylaxis, vaccination, or both.

- Possible use of protective equipment (such as N-100 masks) as an option, and based on incident-specific hazard assessment, for those who refuse to leave or are determined to return despite hazards.

- Facility destruction, disposal, and rebuilding for some indoor contaminated areas, might be considered as a last resort.

- Evacuation and abandonment, which is probably an unacceptable political option.

Decision-makers should not be limited to a small subset of options, such as only considering cleanup alternatives. At first glance, some alternatives may seem unreasonable; however, the estimate of risk characterization together with how an area will be used should be evaluated before eliminating any options. Less conventional options might be feasible if an area is to have limited use or costs are prohibitive for more conventional alternatives. For example, it would be unreasonable and prohibitively expensive to repopulate areas and mandate that the public wear Level A or Level B PPE (see DHHS 2008) in some areas. Although protective masks offer limited protection against some inhalation hazards, they are better than wearing no protection at all, and it is reasonable to assume that the use of such masks might be a rule that many people would follow. However, PPE recommendations, such as respiratory protection, would depend on details associated with the type of BWA and site-specific considerations. If an area is to have only limited use, it might be reasonable to mandate that people who must use the area only enter it if they are wearing some form of protection to limit inhalation exposure.

To facilitate decision-making, analysts should consider many factors specific to each management alternative that might affect acceptance, including:

- Social issues.

- Political considerations.

- Security.

- Psychological concerns or effects.

- Resources available.

- Economic costs.

Resource requirements and cost estimates associated with alternatives should be generated, and cost uncertainties should be quantified to provide error ranges. Over time, uncertainties can be reduced when resource constraints become more apparent. Cost is a major factor in wide-area remediation decisions; therefore, it is important that the costs of alternatives be objectively and consistently measured across the wide area. Guidance might be necessary on whether to include both direct and indirect costs, such as lost economic productivity. Because any risk management decision implemented for a small contaminated area will be part of a broader assessment for the wide area, consistency in cost-benefit estimates is essential for objective comparisons. 


\subsubsection{Evaluate Alternatives Using Risk Metrics}

An essential task associated with risk management is to effectively communicate the tradeoffs among management alternatives (Haimes 1998). Thus, the next step involves estimating the likely health impacts associated with management alternatives and drawing a clear connection between those impacts and available options. This Interim Guidance recommends that objective risk metrics be expressed as:

- Expected exposures to spores post-remediation.

- Expected illnesses from disease post-remediation.

- Estimated hospitalizations post-remediation.

- Probable number of mortalities post-remediation.

- Time that an area will be unusable for normal activity.

Analysts must assess impacts on the environment as if each alternative were implemented. For behavioral-management or medical-related alternatives, the environment will not change; however, with cleanup alternatives, the environment will be less contaminated after remediation. This new environment then becomes an input to an individual risk characterization calculation conducted on that alternative. The risk calculation includes the dose-response and behavioral assumptions used in the baseline assessment, along with any potential changes to account for use of protective equipment, vaccinations, prophylaxis, behavioral restrictions, or medical monitoring that might be components of a broader management strategy. It is also possible that remediation alternatives might be combined, for example, by limiting access to the area until monitored natural attenuation lowers risk, then cleaning up to some defined standard. In such cases, a combined strategy can be treated in the analysis as a single alternative for comparison with others.

Each alternative should have an associated public health risk. The difference between the baseline risk and the risk associated with a given alternative is the benefit of that alternative. Uncertainties should be documented and quantified to the extent possible to provide error ranges. Analysts should ensure consistency, transparency, and objectivity in assessing every alternative.

\subsubsection{Build Risk-Based Guidance}

Once the management alternatives have been assessed, risk-based guidance must be provided to objectively compare the alternatives. Ultimately, such guidance is a multi-objective optimization problem in which the metrics on each alternative, such as cost and health risk, are compared.

One form of guidance (referred to as choosing Pareto optimal solutions) applies the principle that one objective function can only be improved at the expense of another objective function (Haimes 1998). In the example shown in Table 6-1, decision-makers must consider the tradeoffs between costs and the number of expected illnesses. Cleanup strategy $\mathrm{C}$ costs $\$ 25,000$ less than strategy B and results in 10 fewer illnesses. If the goal is to minimize both objectives, strategy B is dominated by strategy $\mathrm{C}$ and, considering only these two criteria, strategy $\mathrm{B}$ can be discarded from consideration. Strategy $\mathrm{A}$ is expensive relative to $\mathrm{C}$, but it has less health impact and therefore can still be considered. It is up to decision-makers to make the tradeoff decision between cost and public health risk and assess whether strategy A is worth the reduced risk. 


\section{Risk Decisions}

Table 6-1. Example cleanup strategies comparing cost and health risks.

\begin{tabular}{|c|c|c|}
\hline Cleanup strategy & Cost $\mathbf{( \$ )}$ & Expected illnesses \\
\hline A & 2 million & 5 \\
\hline B & 100 thousand & 50 \\
\hline C & 75 thousand & 40 \\
\hline
\end{tabular}

Another common method to support decision-making is multi-attribute utility theory (MAUT; see for example, Keeney 1993). Here, the preferences among objective functions are explicitly represented using utility theory, and results are expressed as an overall score for each alternative according to the scores of each objective function. In effect, the alternative with the highest score is the most preferred. This approach requires close interaction between an analyst and decisionmakers to accurately identify preferences. The MAUT approach can become cumbersome if the numbers of functions and alternatives are large. It can also be difficult to reconcile utility functions between many decision-makers with different preferences, but approaches have been developed to reconcile such problems (Morgan 1990, 2002; Fischbeck 2001).

Both approaches - choosing Pareto optimal solutions and MAUT - have been successfully applied to complex, real-world problems. The choice between the options for a wide-area contamination problem would depend on local conditions and preferences among decisionmakers and analysts, but a quantitative approach to compare alternatives and select a subset for evaluation and implementation is an integral part of providing guidance to decision-makers.

\subsection{Establishing Clearance Goals}

If cleanup is a recommended action emerging from risk-based guidance, clearance goals need to be evaluated and established to select optimal remediation options. Although the evaluation of risk associated with a given alternative is a technical problem, determining whether a given clearance goal is acceptable is a social and political problem. Furthermore, the choice(s) of clearance goal(s) can have a large impact on the time and cost of remediation, especially for a wide-area incident (e.g., more stringent clearance goals are likely to take more time and cost more to meet). A risk-based approach in this context means that cleanup guidelines should be based on a defined, "acceptable," or "tolerable" level of risk to health (see previous section). Clearly, many factors must be considered in developing standards and realistic clearance goals to protect health, property, and resources.

The challenges associated with setting an "acceptable cleanup level" leading to clearance following a biological attack are discussed in many reports (see for example PCCRARM 1997; Raber et al. 2001 and 2004; GAO 2003a and b; Simpson 2005; and Canter 2005). Most researchers writing on the topic agree that there is currently insufficient information to develop an "infectious dose" and to quantify a "safe" amount of residual biological agent in a decontaminated facility or outdoor environment (see for example Rubin 1987; Haas et al. 1999, 2002; Meselson 2001; Peters and Hartley 2002; Johnson 2003; NRC 2005; Raber et al. 2004; and Lucey 2005). In the event of wide-area biological contamination, any clearance goal will need to address and incorporate incident- and site-specific parameters and conditions. 
On the question of how clean is safe, the Catastrophic Incident Supplement to the NRF states, "Due to the site-specific nature of many cleanup issues..., a determination of 'how clean is safe' for returning residences and resumption of business is a risk management decision based on the selection and site-specific application of such values. As such, cleanup levels will be determined on a site-by-site basis by local governments working in tandem with Federal and State technical experts in accordance with NRF/NIMS decision-making processes." (DHS, Catastrophic Incident Supplement to the National Response Framework, p. 96.) This statement may also be expected to apply to outdoor areas in a wide-area biological incident.

\subsubsection{Indoor Clearance Goal}

A host of papers were published on the topic of clearance goals for indoor cleanup after the 2001 anthrax attacks in the U.S. In general the collective, professional judgment of technical experts, within the context of the concerns of stakeholders, is used to set clearance goals (NRC 2005; Raber et al. 2001) appropriate to site-specific circumstances. The goals may also be influenced by national security, economic, sociological, psychological, and political considerations, as well as available resources given competing remediation priorities following multiple or wide-area attacks. In cases where contamination is extensive, intermediate goals may be set, complemented by other interventions, such as prophylaxis, vaccination, shelter-in-place advisories, medical monitoring, wearing protective equipment, and other ESF \#6 mass-care considerations.

For the 2001 U.S. anthrax cleanups, successful indoor decontamination was defined as no growth of $B$. anthracis spores on all clearance samples (GAO 2003a). In 2003, a NAS committee likewise found that there was no scientific basis for establishing a level of residual B. anthracis contamination that could be safely left behind for indoor locations. A separate review was made during preparation of this Interim Guidance of approximately 50 research papers published since the late 1990s on the topic of "How Clean Is Clean Enough?" following contamination by $B$. anthracis spores. The principal conclusion of that review, which focused on indoor cleanup, is that no statement on B. anthracis indoor clearance goals in the literature that was accessed by the literature search and published since 2005 counters the policy position of "no growth on all postremediation environmental samples" (see also NRC 2005; Canter 2005). Although no-growth is an expensive option, there is little evidence at present that supports an alternative and lessstringent standard for weaponized or terrorist-related incidents. Despite historic and current indoor clearance goals for $B$. anthracis and the foregoing discussion, final recommendations regarding such goals following an unprecedented wide-area incident will be site-specific and entail the consideration of risks to guide decision-making. That is, it is possible that a no-growth standard might not be feasible following a wide-area contamination, and a risk-management optimization approach might be applied to relax such a goal.

\subsubsection{Outdoor Clearance Goal}

Current knowledge gaps related to clearance goals are even greater for outdoor than indoor environments. Knowledge of the fate and transport of spores in environmental conditions will be valuable to setting a reasonable clearance goal. Over time, spores could adhere to soil or undergo viability attenuation through exposure to environmental factors and become less of an inhalation hazard, but such attenuation is at present theoretical. The NRT Quick Reference Guide: Bacillus anthracis (Anthrax) (2008) states that spores are "highly persistent/stable $>40$ years in soil."

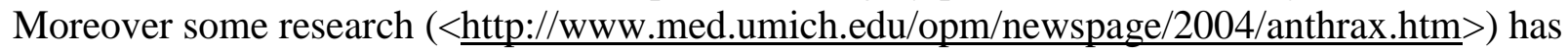


shown that $B$. anthracis can complete its full life cycle in soil and without a mammalian host. Although data are being gathered by the BioWatch program for major metropolitan areas, we also do not yet know what natural background levels of $B$. anthracis might be expected in different environments around the U.S., and spore resuspension variables outdoors are not well understood.

Because inhalation represents a major health risk associated with a wide-area biological release, high-volume and possibly aggressive air sampling will be needed to understand the hazard associated with a specific incident (ATSDR 1994; Lorber et. al. 2007). If such an incident were to happen today, air sampling would be necessary to understand the potential inhalation health risk. For example, "In the days following the collapse of the World Trade Center (WTC) towers on September 11, 2001 (9/11), the U.S. Environmental Protection Agency (EPA) initiated numerous air monitoring activities to better understand the ongoing impact of emissions from that disaster. Using these data, EPA conducted an inhalation exposure and human health risk assessment to the general population." (Lorber et al. 2007). Furthermore, according to the NRT (2005, p.50), "Aggressive sampling techniques should be used to maximize the possibility of detecting spores on surfaces and in the air. Aggressive sampling techniques are modeled on EPA's guidance for clearing facilities for re-occupancy after asbestos decontamination. While the [indoor] area is under negative pressure, all surfaces are aggressively agitated and air is continuously disturbed while samples are collected. Aggressive sampling techniques (using fans and leaf blowers) should be done only within the confines of the exclusion zone...." See DHHS (1994) for additional discussion and recommendations associated with aggressive air sampling. See EPA (2009; Part F, Section 7) for further recommendations related to sampling to determine contaminant concentrations in air for the purpose of inhalation risk assessment. Whereas recommendations for aggressive air sampling have historically been made in the context of indoor contamination, such sampling is suggested for consideration outdoors as well in the case of a wide-area biological attack.

Quantitative risk assessment has a key role in explicitly representing the tradeoffs between different clearance goals that might be appropriate and establishing "acceptable" clearance goals outdoors. Such an assessment must be informed by fate and transport models and air sampling, which could predict where outdoor hazard zones are located at different times. Although very little data were found as part of a recent review (Turtletaub and Raber 2008), B. anthracis resuspension appears likely, depending on particle size (and other key parameters), on what surface the spores are deposited, the weather, and human activity in the contamination zone (Krauter and Biermann 2007; Thatcher and Layton 1995). The extent of resuspension outdoors needs additional research to model what proportion of spores would actually be available for inhalation. Some data suggest that very large numbers of spores on a surface would constitute small risk from resuspension (Inglesby et al. 2002). However, this subject remain controversial.

One possible approach for setting outdoor clearance goals - similar to the EPA-adopted policy for indoor clearance levels - that could be used is "no viable anthrax spores detected above background levels from any high-volume (and possibly aggressive) air sampling." Whereas such a highly conservative goal might be desirable and could be used initially, it is problematic until more biological and efficacy data become available to make a better-informed decision (Turtletaub and Raber 2008, p. 60). The lack of viable spores in a limited number of air samples does not imply that viable spores are not present anywhere in the air. More thorough sampling 
would help decide whether such is the case, but extensive sampling could be prohibitive in a wide-area release scenario. Moreover, even extensive air sampling would not preclude spores present on the ground that could be resuspended to pose an inhalation hazard. An alternative approach is to base clearance goals on risk rather than an absolute goal of "no spore growth on all post-remediation environmental samples." Such an approach would use the methodology described in Section 6 as a whole and is illustrated in Section 6.6. At its core, the rationale behind the approach is that it is impractical to manage to zero risk, and that a low, but not zero, residual risk may be acceptable.

The above discussion does not address the issue of cutaneous anthrax for which we currently have no infectious dose numbers. Although not directed specifically at assessing inhalation hazard, some outdoor surface sampling may be necessary in hot zones to better understand whether a public health risk for cutaneous anthrax is present and to gain stakeholder acceptance of such a risk even though the case-fatality rate associated with cutaneous anthrax is less than $1 \%$ with antibiotic treatment (<http://www.cdc.gov/vaccines/pubs/pinkbook/downloads/anthrax$\underline{508 . p d f}>$ ). Whereas information from surface sampling by itself does not inform us about the potential for resuspension of spores from surfaces and into the air, it would provide some data relevant to assessing potential cutaneous, as well as gastrointestinal (Beatty et al. 2003), risks. Ultimately, it may be necessary to establish a separate clearance goal for outdoor surfaces, coupled with long-term monitoring of the population at risk.

\subsubsection{Water Clearance Goal}

Whereas nearly all BWAs are intended for aerosol application, many "have strong potential as waterborne threats" and could inflict heavy casualties when ingested (Burrows and Renner 1999, p. 975). The NRT Quick Reference Guide: Bacillus anthracis (Anthrax) (2008) states that "B. anthracis is a probable water threat," and USACHPPM (2008) also identifies it as a water threat. Even though the principal risk associated with the consumption of water containing B. anthracis spores would be an ingestion hazard, water used for bathing, showering, or recreational purposes may also pose inhalational and cutaneous exposure hazards. There is controversy regarding the life cycle of $B$. anthracis in water, and actual experimental evidence is very limited, but according to a review (see Sinclair et al. 2008, Table 7) of nonkinetic studies on survival of virulent strains in the environment, $B$. anthracis spores can survive from 2 to 18 years in pond water and 20 months in seawater or distilled water. USACHPPM (2008) identifies B. anthracis spores as "stable in water" for 2 years.

Scientific investigations have led to recommended guidelines in water for only some of the BWAs that have been identified by the CDC (Rotz et al. 2002) as priority microbes and by Haas et al. (1999) or others (Burrows and Renner 1999) as microbes of medical importance in water. For many other BWAs, including B. anthracis, no consensus water guidelines are established for civilian purposes (Raber and Kirvel, 2008b, Table 6).

Even though the U.S. National Primary Drinking Water Regulations (NPDWRs) are enforceable and must be health protective (Macler and Regli 1993), some have argued that in light of new epidemiological evidence, water-quality guidelines for pathogenic microorganisms have not kept pace with microbiological risk assessments, and that a new framework linking assessment of risks with health targets and outcomes should be used to converge on what constitutes a "tolerable risk" of infection from water (Bartram et al. 2001). 
It is possible that, in the event of a biological attack that extends to water supplies or resources, a conservative clearance goal (similar to that for indoor environments) may need to be implemented (Raber and Kirvel 2008b). However, current methods used to monitor environmental samples, particularly BWAs in water, do not always provide the levels of sensitivity required to ascertain the efficacy of treatment processes (Hass et al. 1999).

Chapter 3 of the USACHPPM (2008) Technical Guide 188 is a Water System Vulnerability Assessment (WSVA) “... based upon the best available information from various Federal agencies and professional associations.” A WSVA “...is defined as a mechanism for evaluating a water system's susceptibility to adversarial actions and provides a prioritize approach for reducing or mitigating the risks associated with those identified adverse actions" (page 3-2). Table 3-7 of the Guide (page 3-32) identifies the level in drinking water of B. anthracis spores deemed by the WSVA to cause illness. The specified levels of contamination are 57 spores per liter with the consumption of 15 liters of water per day, or 171 spores per liter with the consumption of 5 liters of water per day for 7 days. Although Technical Guide 188 is written to address American military personnel and their families, these published levels of B. anthracis spores in drinking water deemed to cause illness may be useful as a starting point for discussions of clearance goals. Clearly, any clearance goal for public drinking water would need buy-in from area decision-makers and stakeholders.

The balancing of chemical risks associated with decontamination, potential cancer risks arising from treatment byproducts that might be formed, and the risks from BWAs themselves in water needs to be addressed and cannot be solved without an appropriate risk assessment (Hass et al. 1999, p 100.) Clearly, risk trade-offs must be considered as part of the decision-making process whereby monitored natural attenuation versus other treatment methods are evaluated to minimize microbial risks, but approaches to strictly limit or prevent secondary contamination of water systems should be incorporated into remediation planning. This is especially important when considering water resources, such as reservoirs, lakes, and streams (Section 8).

\subsubsection{Additional Considerations for Clearance Goals}

If a wide-area $B$. anthracis attack were to happen tomorrow, the luxury of focusing on a specific number of spores in indoor or outdoor settings, or in drinking water sources, may not be feasible, and other options may need to be considered. For example, decision-makers could consider assessing the incidence of disease as a criterion rather than focusing exclusively on some number of viable spores or on "no spore growth on all post-remediation environmental samples" as the goal. If no disease were found, additional monitoring might be considered as a better use of limited resources, and stringent clearance goals might be relaxed. Another option would be to state that the clearance goal is: "doing the best that can be done with the best practices available." In this case, using the best engineering practices available, along with additional operational and process controls, might be considered. Clearly, the consequences of any alternative clearance goal to some specified level of viable spores must be weighed carefully by decision-makers. For example, if a decision were made to use long-term antibiotics on an entire population, then decision-makers would need to evaluate the possibility of rendering individuals more susceptible to other highly contagious microorganisms that are extremely difficult to treat. 


\subsection{Example: Applying the Methodology for a Wide-Area B. anthracis Attack}

How should the components of risk assessment methodology actually be put into practice to address wide-area contamination? Consider a scenario in which $B$. anthracis spores are released with an aerosolization efficiency of $1 \%$ in the city of Seattle during the morning, resulting in a release of 1 trillion weaponized spores. Furthermore, assume that by several days after the initial release, the immediate emergency response phase is over, initial environmental sampling is complete, the spores are confirmed to be $B$. anthracis, and officials are entering the remediation phase. Let us further assume that the environmental exposure assessment is essentially complete, and there is little uncertainty in that assessment. The following analysis focuses on an outdoor contamination zone covering an area of $10,000 \mathrm{~m}^{2}$ where contamination in the zone is found to be relatively uniform and constant.

\subsubsection{Example Exposure Assessment}

Several existing models can be applied to evaluate how deposited spores are likely to resuspend and move through the environment under different conditions (Sehmel 1980, Nicholson 1988, Garger et al. 1998, Sextro et al. 2002, Loosmore 2003, and Ferro et al. 2004). Models used for estimating exposure have important limitations. Many do not have the fidelity to accurately predict exposures because they do not incorporate all environmental variables that could affect exposure levels. Furthermore, models produce approximations of contamination levels and have some error in predictions. If models are integrated into an exposure assessment, care should be taken to select models that minimize potential errors. However, contamination prediction models will likely play a beneficial role in filling gaps in sampling data and identifying sample readings that might be outside the bounds of what is expected. To the extent possible, models should incorporate and be used with empirical data that are available from sampling, rather than in lieu of sampling data. Any models will need to address both acute exposure risk and cumulative exposures. Both types of exposures would be important in assessing public health risk.

After selecting one of the models, let us assume that an analysis of modeling and sampling data for the contamination zone under consideration shows an expected average air concentration at 1 to 2 meters above ground of 10 spores per cubic meter, which is expected to last for at least the next $24 \mathrm{hr}$. Officials are concerned whether or not that concentration poses an acute health risk to adults who might repopulate the area during working hours and, if so, what can be done about it.

\subsubsection{Example Risk Characterization}

The risk to public health depends on how inhabitants are likely to behave in the area. The following calculation assumes the area is only populated during working hours, and that a susceptible adult spends 8 continuous hours in the contamination zone, with a breathing rate of $20,000 \mathrm{~cm}^{3} / \mathrm{min}$ (Till and Meyer 1983). Each adult operates independently throughout the region, and air concentration is uniformly mixed, so exposures are uniformly distributed. In calculating the inhalation risk, the particle-size distribution of agglomerated spores is in the inhalable region (i.e., between 1 and 10 micrometers in diameter), and the assumption is made that there is little risk of cutaneous or gastrointestinal exposures. From all the foregoing assumptions, Figure 6-4 shows the inhaled exposure for one individual over $8 \mathrm{hr}$. Other exposure durations could be evaluated as a function of a specific incident. 


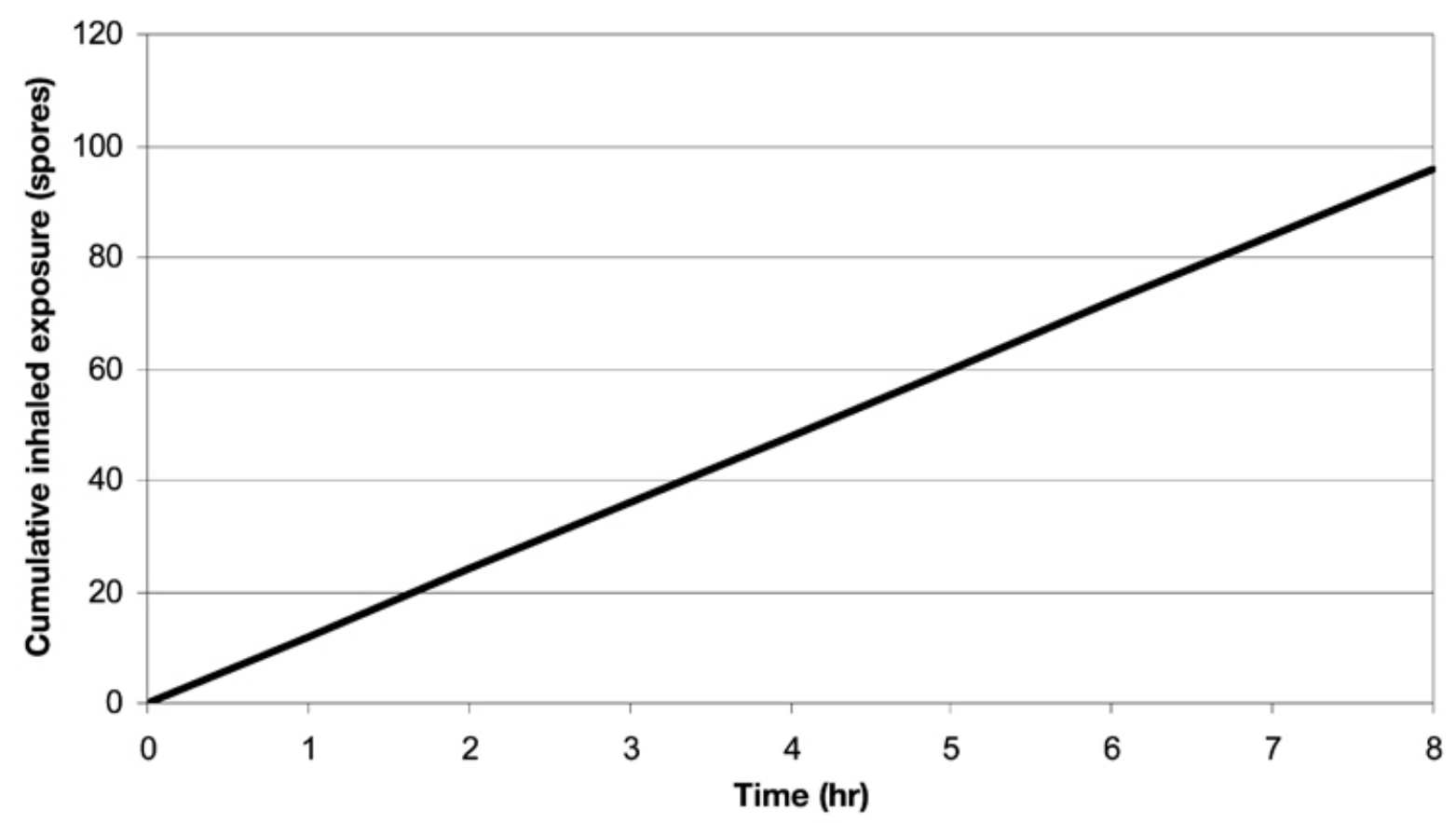

Figure 6-4. Cumulative inhaled exposure for an individual over an 8-hr period.

Although the data indicate that an individual would receive a total dose of about 96 spores after $8 \mathrm{hr}$, the calculation does not reveal an individual's risk. A dose-response assessment is necessary to indicate morbidity and mortality potential, and here we have a problem. Studies suggest a wide range in possible infectious doses from inhaled anthrax, but empirical evidence indicates that an infection could occur with a very small dose (1 to 100 spores) (Meselson 2001; Peters and Hartley 2002; Haas 2002; and Fennelly et al. 2004). Inhaled anthrax dose-response characteristics have been described generally in several papers (Lucey 2005, Inglesby et al. 2006), and primate tests provide some information, but it is unclear whether primate responses can be extrapolated to human responses (Haas 2002, Bartrand et al. 2008). Much of what is known about human anthrax response comes from the release in Sverdlovsk, Russia, in 1979; however, some medical data from the incident are incomplete, missing, or inaccurate (Abramova et al. 1993, Wilkening 2006). Thus, anthrax dose-response is highly uncertain at present, and responses depend on the strain and aerosolization efficiency. The numbers used in the following example are for illustration only.

Our example uses a lethal dose-response curve based on monkey tests conducted by the U.S. Army, suggesting an LD $_{50}$ of 8,000 spores (Meselson 2001; Peters and Hartley 2002). Response for other doses was modeled as a lognormal relation, with a probit slope of 0.7 probits per log dose (Glassman 1966; Meselson 2001). This dose-response relation is shown in Figure 6-5. A similar curve for infection is also shown, which has an $\mathrm{ID}_{50}$ of 4,100 spores. The curves produce an $\mathrm{ID}_{10}$ of 65 spores and an $\mathrm{LD}_{10}$ of 120 spores. $\mathrm{ID}_{1}$ and $\mathrm{LD}_{1}$ are estimated to be between 1 and 3 spores. The curves in Figure 6-5 are consistent with empirical observations that some infections 
Risk Decisions

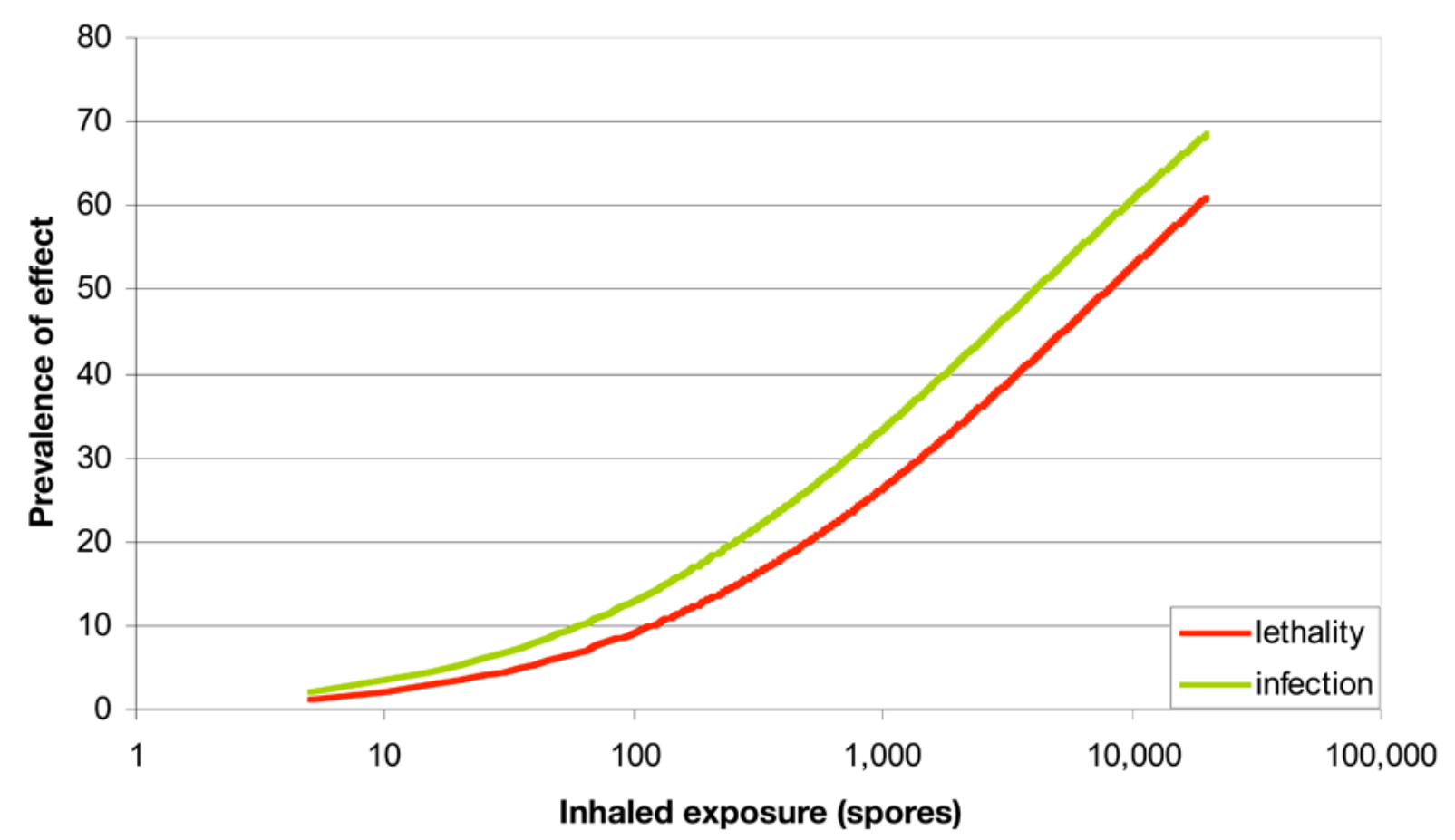

Figure 6-5. Assumed dose-response relation for inhaled anthrax exposure. Inhaled exposure is plotted as a logarithmic scale on the $x$ axis.

occur at low doses (1 to 100 spores) (Glassman 1966; Haas 2002; Fennelly et al. 2004; Lucey 2005), but once again, they are applied here only for purposes of illustration. The methodology is such that if more accurate dose-response relationships were to become available, they could be inserted into the analysis.

The likelihood that an individual will become infected or die can be predicted by combining the exposure assessment with the dose-response assessment, and Figure 6-6 shows the results of such a combination. Over an 8-hr period, the example scenario results in a probability of lethality approaching 0.09 and a probability of infection approaching 0.13 . This means that if 1,000 people were to repopulate the contamination zone, the calculation shows that 10 spores per cubic meter would lead, on average, to 90 mortalities and 130 infections from B. anthracis exposure over an 8-hr period. If victims were to begin arriving at medical facilities 1 to 7 days after exposure in such a situation, it might be too late to save them (Lucey 2005).

With respect to uncertainty, issues such as changes in the exposure (e.g., settling out of spores), agglomeration of spores into un-inhalable particles, static charge of particles affecting air concentrations, and the type of anthrax spores released are all important factors that can affect potential risk. Additional uncertainties might include the ages of susceptible people, total number of people exposed, and number of sensitive subpopulations. Although such uncertainties are important in terms of recommendations, they in no way preclude a risk management process, and they are unlikely to significantly reduce the risk as characterized in Figure 6-6. 


\section{Risk Decisions}

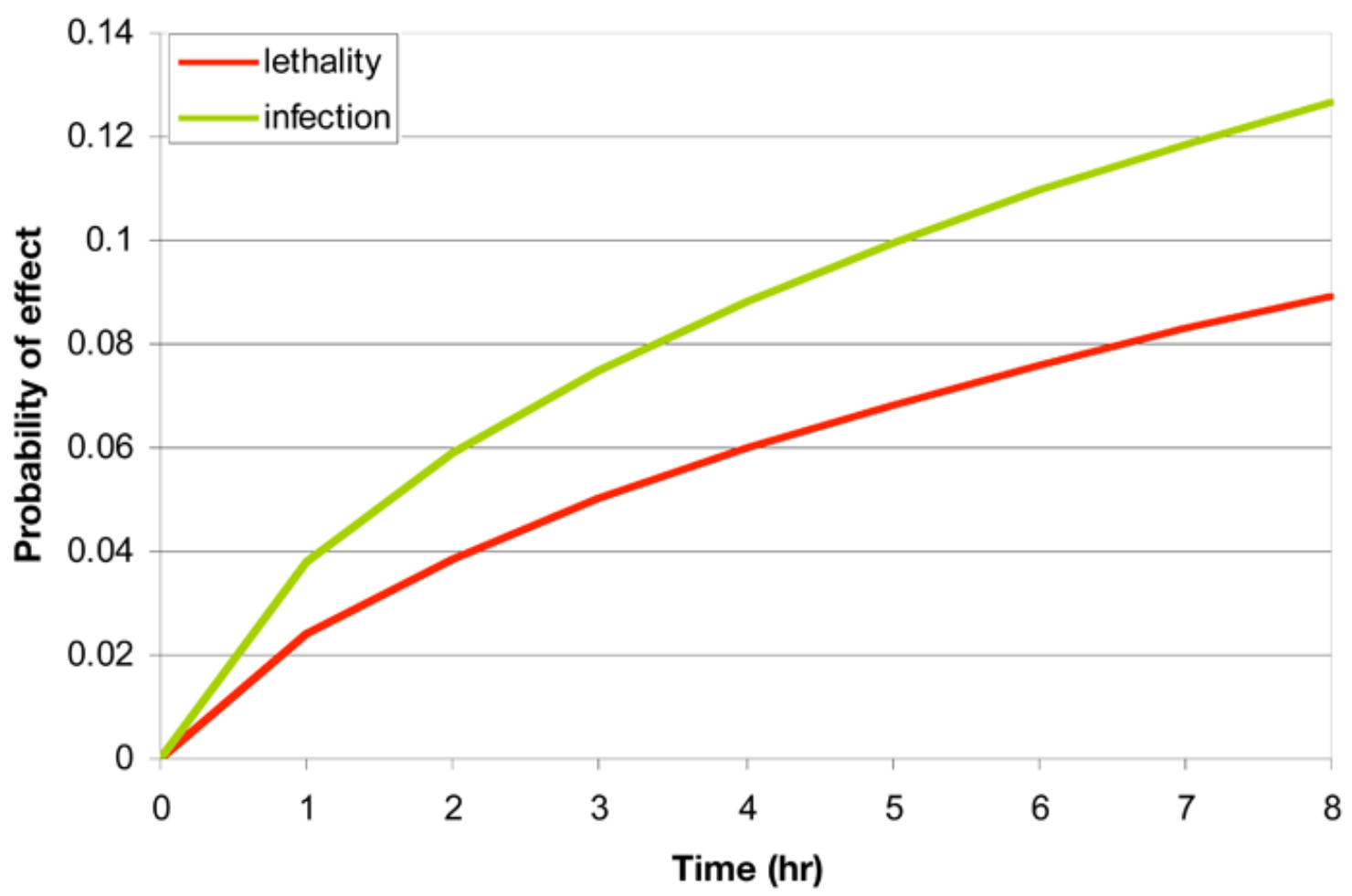

Figure 6-6. Probability of lethality and infection over an 8-hr period across the selected contamination zone.

\subsubsection{Example Risk Management}

An important step for risk management is to determine whether remediation is necessary. From the previous estimate of risk to human health in our example, and by all current standards, the risk is significant and unacceptable (PCCRARM 1997, GAO 2003a, Simpson 2005, Canter 2005). Furthermore, no remediation action is without risk. Therefore, remediation alternatives must be developed and evaluated. Table 6-2 lists some remediation alternatives and qualitative direct and indirect costs associated with the contaminated area being unusable for some time. Estimates of costs shown here do not reflect a complete or site-specific analysis, which would be required during a real recovery operation. Cleanup effectiveness was assigned arbitrarily using simple assumptions on effectiveness of various cleanup techniques. Values are applied here only for illustrative purposes. 


\section{Risk Decisions}

Table 6-2. Remediation alternatives and associated qualitative costs.

\begin{tabular}{|c|c|c|}
\hline $\begin{array}{l}\text { Remediation } \\
\text { alternative }\end{array}$ & Cost & Notes \\
\hline Do nothing & None & \\
\hline Light cleanup & Low & Objective is to reduce contamination to attain $1.3 \mathrm{spores} / \mathrm{m}^{3}$ \\
\hline Medium cleanup & Low & Objective is to reduce contamination to attain to attain $0.3 \mathrm{spores} / \mathrm{m}^{3}$ \\
\hline Mid-heavy cleanup & Mid & Objective is to reduce contamination to attain $0.001 \mathrm{spores} / \mathrm{m}^{3}$ \\
\hline Heavy cleanup & High & Objective is to reduce contamination to attain 0 spores $/ \mathrm{m}^{3}$ \\
\hline PPE & Mid & Repopulate, but require people to use PPE, such as respiratory protection \\
\hline $\begin{array}{l}\text { Medical monitoring/ } \\
\text { medical countermeasures }\end{array}$ & High & $\begin{array}{l}\text { Repopulate, but require people to undergo regular medical monitoring to } \\
\text { treat conditions early. Offer vaccinations. }\end{array}$ \\
\hline Remove soil and rebuild & Very high & Dispose of all contaminated land in area; regrade and rebuild \\
\hline
\end{tabular}

The next step requires an estimation of risk metrics to objectively compare the remediation alternatives. Table 6-3 shows the probabilities of mortality and morbidity over an 8-hr period, derived from Figures 6-5 and 6-6 for dose-response, if proposed clearance goals for each cleanup strategy were achieved. Table 6-3 assumes that cleaning to 0 spores $/ \mathrm{m}^{3}$ results in zero probability of mortality and morbidity. In truth, any mitigation option will introduce some risk (e.g., re-aerosolization and worker exposure). Such risks are not considered here, but are estimated in the uncertainty assessment later in the example problem.

Table 6-3. Probabilities of mortality and morbidity associated with each clearance goal for proposed cleanup strategies using the assumptions from risk characterization.

\begin{tabular}{|c|c|c|}
\hline Clearance goal $\left(\mathbf{s p o r e s} / \mathbf{m}^{\mathbf{3}}\right)$ & Probability of mortality & Probability of morbidity \\
\hline 1.3 & 0.025 & 0.039 \\
\hline 0.3 & 0.008 & 0.014 \\
\hline 0.001 & $1.7 \times 10^{-5}$ & $4.1 \times 10^{-5}$ \\
\hline 0 & 0 & 0 \\
\hline
\end{tabular}

For the remaining remediation alternatives that do not entail cleanup (e.g., use of PPE such as respiratory protection), and for illustrative purposes, we arbitrarily assign values to the probabilities of morbidity $\left(P_{\text {morbidity }}\right)$ and mortality $\left(P_{\text {mortality }}\right)$. For example, we might assume that the use of PPE would only reduce mortality by $50 \%$ because people might not use the equipment properly (thus, $P_{\text {mortality }}=0.05 ; P_{\text {morbidity }}=0.1$ ). Medical monitoring might be effective for reducing mortalities $\left(P_{\text {mortality }}=0.005\right)$, but it would be less effective at reducing morbidity $\left(P_{\text {morbidity }}=0.05\right)$. Removing the soil and rebuilding would be effective at reducing 
the likelihood of morbidity and mortality, but because of resuspension during demolition and disposal of contaminated waste, there would be a slight likelihood of both mortality and morbidity $\left(P_{\text {mortality }}=0.001 ; P_{\text {morbidity }}=0.01\right)$. For a population of 1,000 people in the contaminated area, Figure 6-7 shows relative cost versus expected mortality. The Pareto optimal frontier, which consists of cleanup options, is the solid blue line.

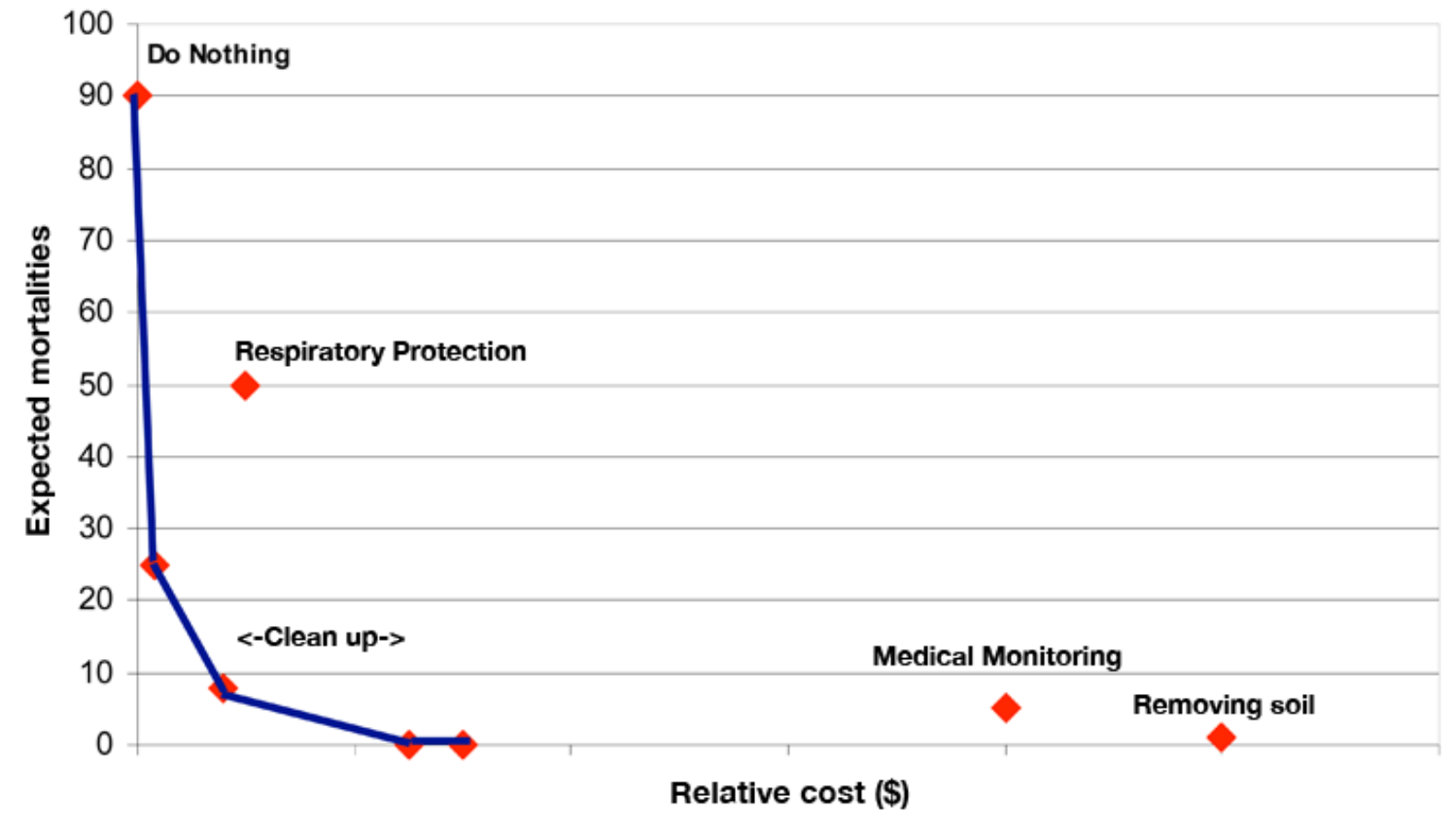

Figure 6-7. Comparison of cost and expected mortality out of 1,000 people for each alternative.

Figure 6-7 shows that cleaning up to a given clearance goal or doing nothing are the only Pareto optimal alternatives for this example (i.e., a lower value on one objective function could only be achieved by increasing the value on the other objective). Other alternatives might achieve a cost savings or a risk-reduction benefit, but at the expense of increasing the other objective function; therefore, they are sub-optimal. To take the example one step further, uncertainty can be superimposed on both axes of Figure 6-7 to show how it affects the results. The outcome is shown for illustrative purposes in Figure 6-8.

The data in Figure 6-8 could be used to communicate some important and potentially problematic uncertainties in the risk assessment. For example, as cleanup alternatives become more invasive and clearance goals become more stringent (i.e., risk decreases), the uncertainty in cost increases because it is more difficult to estimate what is necessary to reach a more stringent clearance goal. Similarly, medical monitoring is a highly uncertain alternative because its effectiveness and cost are both highly variable. Rebuilding is highly uncertain in both dimensions because razing an area could create a hazardous plume that could affect many people if the soil disposal and rebuilding effort were not done carefully. Costs of respiratory protection are fairly certain, but the effectiveness is highly variable because it is not known to what extent people who repopulate the area would use protection. All alternatives, including cleanup, carry 


\section{Risk Decisions}

certain risks. The vertical error bars in Figure 6-8 include both uncertainty in the effectiveness of the alternatives and the potential additional risk that could be introduced as a result of implementing the alternatives, for example, through resuspension of materials and poor decontamination practices.

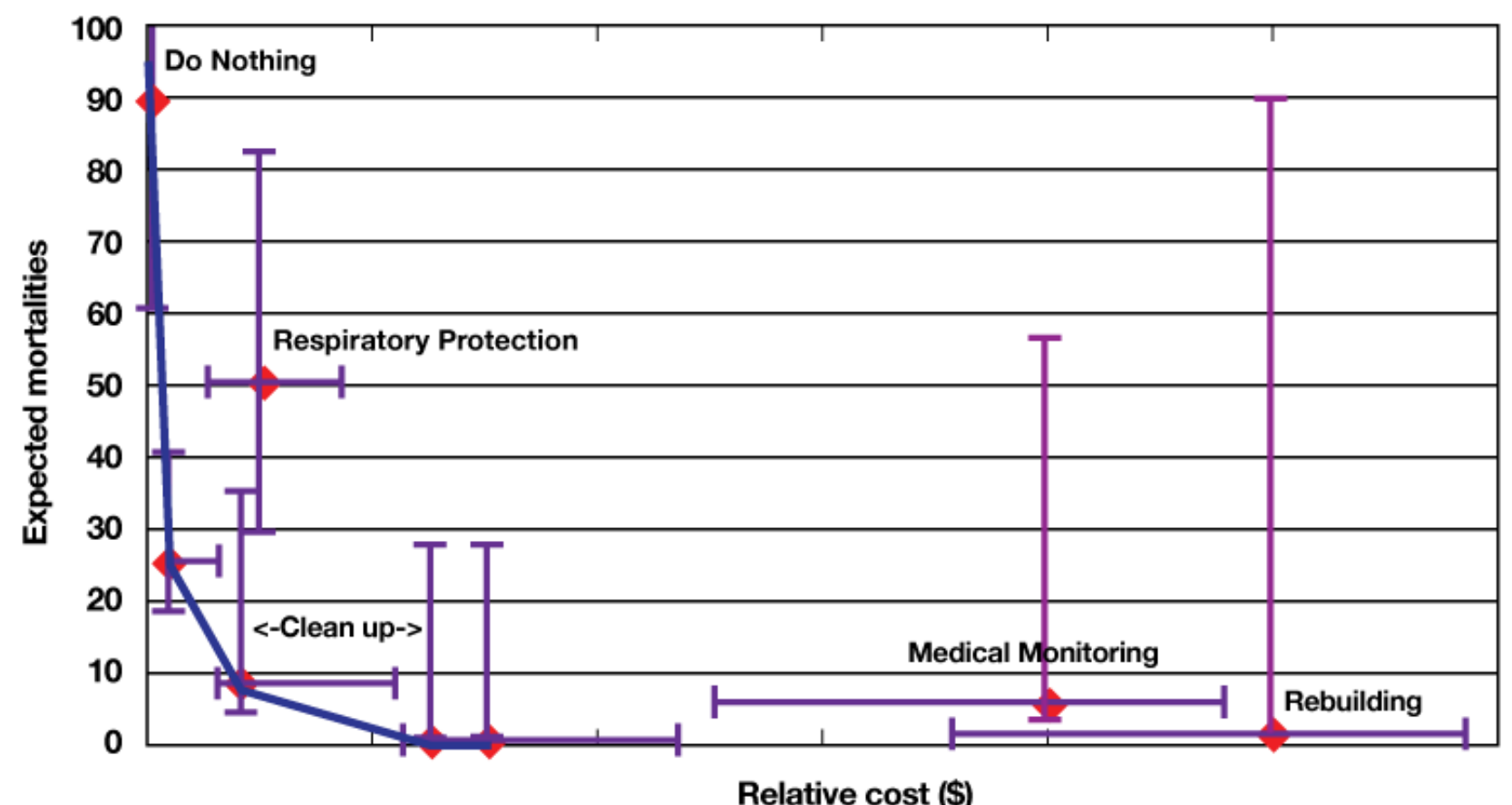

Figure 6-8. Revised comparison of alternatives with error bars (uncertainty) superimposed on cost and risk axes.

The 10,000- $\mathrm{m}^{2}$ contamination zone under consideration would be only one of many contamination zones in a wide-area incident. It is possible to superimpose the results from other contamination zones onto Figure 6-8. However, when comparisons are made among different contamination zones, new objective functions must be considered (e.g., critical infrastructure in each zone, number of people, susceptible populations expected in each zone, economic impacts, and variations between zones). Rather than combining all the risk assessments from various contamination zones into one quantitative analysis, the output of risk analysis should be part of a broader political deliberation that includes risk assessments from other contamination zones and a consideration of remediation resources. Meetings may be held with stakeholders to prioritize contamination zones for remediation (Section 5) using the risk assessment results as well as political, social, infrastructure, security, and economic concerns unique to each zone along with consideration of limited remediation resources. Thus risk assessment is one aspect-albeit an important one — of a broader decision framework involving many competing objectives. 


\section{Risk Decisions}

\subsection{Section 6 Summary of Actions}

The objectives of risk assessment and risk management in a wide-area biological incident are to combine contamination estimates with public behavior assumptions to assess public health risk and objectively evaluate options to reduce risk. Table 6-4 identifies the principal actions that take place during risk assessment and risk management to determine appropriate clearance goals.

Table 6-4. Summary of risk assessment and risk management actions.

\begin{tabular}{|c|c|}
\hline Step & Action \\
\hline $\begin{array}{l}\text { Step 1. Gather relevant } \\
\text { information. }\end{array}$ & $\begin{array}{l}\text { To objectively measure public health risk in a wide-area biological contamination } \\
\text { incident, several pieces of information are needed: } \\
\text { - List of experts to contact for assistance. } \\
\text { - Exposure assessment information (output of response and characterization phases). } \\
\text { - Environment use, land use, and population characteristics of affected areas, } \\
\text { including animal populations. } \\
\text { - A priori assessments of infrastructure and its importance in affected zones. } \\
\text { The affected area should be divided into contamination zones exhibiting relatively } \\
\text { constant contamination levels, population characteristics, and infrastructure. The } \\
\text { ordering of risk assessments for the zones should be guided by preparedness } \\
\text { assessments of infrastructure. }\end{array}$ \\
\hline $\begin{array}{l}\text { Step 2. Assess public } \\
\text { health risk. }\end{array}$ & $\begin{array}{l}\text { Risk analysts and experts can estimate baseline public health risk in a given } \\
\text { contamination zone by implementing a quantitative risk assessment methodology } \\
\text { using the inputs above. Oversight should ensure that assumptions are clear and } \\
\text { baseline risk levels can be objectively compared. Uncertainty should be accounted for } \\
\text { wherever possible. Cleanup options and standards for outdoor areas will be different } \\
\text { from options and standards for indoor areas. }\end{array}$ \\
\hline $\begin{array}{l}\text { Step 3. Prioritize } \\
\text { contamination zones for } \\
\text { risk management. }\end{array}$ & $\begin{array}{l}\text { If the baseline risk estimate is high enough to warrant management, relevant } \\
\text { stakeholders may be gathered to prioritize contamination zones. Decision-makers } \\
\text { should deliberate using: } \\
\text { - Health risk estimates. } \\
\text { - Political, economic, and social concerns. } \\
\text { - A priori prioritizations of affected areas. }\end{array}$ \\
\hline $\begin{array}{c}\text { Step 4. Assess risk } \\
\text { management alternatives. }\end{array}$ & $\begin{array}{l}\text { Risk analysts and policy makers should identify a set of risk management alternatives } \\
\text { that could reduce risk in a high-priority contamination zone. Risk management } \\
\text { alternatives include: } \\
\text { - Cleanup. } \\
\text { - Repopulation with protective actions, such as medical monitoring. } \\
\text { - Limiting access to contaminated areas. } \\
\text { - Soil removal and rebuilding. } \\
\text { Objective criteria should be used to compare alternatives, including estimated cost } \\
\text { and reduced risk of a given alternative. Results can be folded into a broader set of } \\
\text { decision-making guidance. }\end{array}$ \\
\hline $\begin{array}{l}\text { Step 5. Perform risk } \\
\text { communication. }\end{array}$ & $\begin{array}{l}\text { See Table 4-1 for recommendations on how expert communicators are employed to } \\
\text { discuss the probability of a particular outcome occurring and assist individuals in } \\
\text { making informed judgments }\end{array}$ \\
\hline
\end{tabular}




\section{Risk Decisions}

\subsection{Interim Recommendations for Clearance Goals}

Several gaps related to risk assessment are discussed in this section. Although much has been learned from the indoor contamination incidents of 2001, significant gaps exist in the data needed to derive an acceptable risk. In particular, disagreement exists on whether a threshold exists or whether one spore can cause disease, although current opinion tends towards the nothreshold assumptions. Data are needed on the survivability of weaponized spores in the environment; on factors that affect resuspension; on the dose-response for inhalational, cutaneous, and gastrointestinal anthrax for humans; and on the levels of B. anthracis naturally present across the country. Reliance on assumptions for such variables results in the propagation of uncertainties throughout the risk assessment process. Table 6-5 summarizes Interim Guidance recommendations related to risk assessment and management, and clearance goals.

Table 6-5. Interim recommendations for clearance goals.

\begin{tabular}{|c|c|}
\hline Recommended action & Comments and approaches \\
\hline $\begin{array}{l}\text { Perform a quantitative microbial risk assessment to the extent } \\
\text { possible using all applicable resources, and utilize the } \\
\text { principles and processes established by the six-stage } \\
\text { framework for environmental health risk management } \\
\text { published by the Presidential/Congressional Commission } \\
\text { (PCCRARM 1997). Provide the assessment to the IC or UC, } \\
\text { and the TWG to help establish and approve clearance goals. }\end{array}$ & $\begin{array}{l}\text { - Risk assumptions should be incident- and site- } \\
\text { specific. } \\
\text { - All assumptions need to be clearly identified. } \\
\text { - Qualitative assessments may be necessary if data } \\
\text { are limited or nonexistent. } \\
\text { - Results of the assessment may allow for a less } \\
\text { conservative approach than otherwise possible. }\end{array}$ \\
\hline $\begin{array}{l}\text { Establish whether conventional remediation is necessary by } \\
\text { understanding the risks (see above) and associated costs, or } \\
\text { consider other management options, or incorporate a } \\
\text { combination of both. }\end{array}$ & $\begin{array}{l}\text { Other management options to evaluate include: } \\
\text { - Monitored natural attenuation combined with long- } \\
\text { term environmental and public health monitoring. } \\
\text { - Repopulation with controls (e.g., people admitted } \\
\text { for a specified number of hours/day). } \\
\text { - Repopulation with medical monitoring. } \\
\text { - Repopulation with prophylaxis, vaccination, or } \\
\text { both. } \\
\text { - Repopulation with PPE (e.g., respiratory } \\
\text { protection). } \\
\text { - Long-term evacuation or abandonment (probably } \\
\text { an unacceptable political option). }\end{array}$ \\
\hline $\begin{array}{l}\text { The IC or UC, TWG, and other key stakeholders must agree } \\
\text { on the risk metrics. }\end{array}$ & $\begin{array}{l}\text { Recommended risk metrics are: } \\
\text { - Expected exposures to spores post-remediation. } \\
\text { - Expected illnesses from anthrax disease post- } \\
\text { remediation. } \\
\text { - Estimated hospitalizations post-remediation. } \\
\text { - Probable number of mortalities post-remediation. } \\
\text { - Time area will be unusable for normal activity. }\end{array}$ \\
\hline
\end{tabular}


Indoor clearance goal: Use the current clearance goal for building interiors, namely, "no growth of spores from any clearance samples taken" unless other data become available showing that a less conservative approach can be taken, or if the risk assessment for a site-specific incident justifies a less conservative value.
- Same as the EPA cleanup clearance goal used for 2001 anthrax-contaminated buildings (GAO 2003a).

- 2003 NAS committee found no scientific basis for establishing a level of residual $B$. anthracis contamination that could be safely left behind for indoor facilities.

- Consider alternatives, such as assessing the incidence of disease as a criterion or using the best engineering practices and operational controls.

- The primary goal is based on understanding and eliminating inhalation risk only, thereby requiring high-volume aggressive air sampling for verification (see Sections 7 and 9).

- The primary clearance goal assumes some surface samples can be positive and that monitoring for cutaneous anthrax will be done and additional actions taken, as appropriate.

- It may be necessary to set an additional surface clearance goal for cutaneous anthrax although there currently are no infectious dose numbers. The goal should take into account whether anthrax is indigenous to the area under consideration.

- Consider alternatives, such as assessing the incidence of disease as a criterion or using the best engineering practices and operational controls.

It is anticipated that methods other than natural attenuation are either impractical or will cause undue harm to the environment.
- Risk trade-offs must be considered as part of the decisionmaking process for natural attenuation versus other treatment methods. Natural attenuation is the recommended option for consideration.

- Approaches to strictly limit or prevent secondary contamination of water systems should be incorporated into remediation planning.

\section{Drinking water distribution systems:}

- As a starting point, refer to USACHPPM Technical Guide 188 for levels of $B$. anthracis spores in drinking water that cause illness (57 spores/L for drinking $15 \mathrm{~L} /$ day; 171 spores/L for drinking $5 \mathrm{~L} /$ day for 7 days).

- Point-of-use water treatment options (see Section 9.2.3) may need to be considered for implementation.
Individual states have drinking water regulations based on stakeholders' requirements, and this fact must be taken into account when determining water guidelines related to an unnatural incident. Reuse of a previously contaminated drinking water distribution system must be approved by the appropriate agency, which varies from state to state. 


\subsection{Section 6 References}

Abramova, F. A., L. M. Grinberg, O. V. Yampolskaya, and D. H. Walker (1993), "Pathology of Inhalational Anthrax in 42 Cases from the Sverdlovsk Outbreak of 1979," Proc. Nat. Acad. Sci. 90, 2291-2294.

ATSDR (1994), U.S. Department of Health and Human Services, Public Health Service, Agency for Toxic Substances and Disease Registry, Division of Health Assessment and Consultation, Environmental Data Needed for Public Health Assessments, A Guidance Manual; available at 〈http://www.atsdr.cdc.gov/ednpha.html\#ambient〉, accessed May 4, 2009.

Bartram, J., L. Fewtrell, and T. A. Stenstrom (2001), "Harmonised Assessment of Risk and Risk Management for Water-Related Infectious Disease: An Overview," in L. Fewtrell and J. Bartram, eds., in Guidelines, Standards and Health: Assessment of Risk and Risk Management for Water-Related Infectious Disease, World Health Organization and IWA Publishing, London, pp. 1-16.

Bartrand, T. A., M. H. Weir, and C. N. Haas (2008), "Dose-Response Models for Inhalation of bacillus Anthracis Spores: Interspecies Comparisons," Risk Anal. 28(4), 1115-1124.

Beatty, M. E., D. A. Ashford, P. M. Griffin, R. V. Tauxe, and J. Sobel (2003), “Gastrointestinal anthrax: Review of the Literature," Arch. Intern. Med. 163(20), 2527-31.

Burrows, W. D. and S. E. Renner (1999), "Biological Warfare Agents as Threats to Potable Water," Env. Health Perspectives 107(12), 975-984.

Canter, D. A. (2005), "Addressing Residual Risk Issues at Anthrax Cleanups: How Clean Is Safe?” J. Toxicol. Env. Health, Part A 68, 1017-1032.

Canter, D. A. (2003), "Remediating Sites with Anthrax Contamination: Building on Experience," Proc. 2003 AWMA/EPA Indoor Air Quality Problems and Engineering Solutions Specialty Conference and Exhibition, RTP, NC.

CIA (1996), Central Intelligence Agency, Handbook of International Economic Statistics 1996, Directorate of Intelligence, DIANE Publishing Company, BPI Information Services.

DHHS (1994), Department of Health and Human Services, Agency for Toxic Substances and Disease Registry, Environmental Data Needed for Public Health Assessments; A Guidance Manual; available at <http://www.atsdr.cdc.gov/ednpha.html\#ambient>.

DHHS (June 2008), Department of Health and Human Services, Guidance on Emergency Responder Personal Protective Equipment (PPE) for Response to CBRN Terrorism Incidents, DHHS (NIOSH) Publication No. 2008-132; available at <www.cdc.gov/niosh〉.

DHS and EPA (2009), Department of Homeland Security and Environmental Protection Agency, Planning Guidance for Recovery Following Biological Incidents, National Science and Technology Council, Biological Decontamination Standards Working Group.

EPA (1986), U.S. Environmental Protection Agency, Bacteriological Ambient Waste Quality Criteria for Marine and Fresh Recreational Water. 
EPA (2009), U.S. Environmental Protection Agency, Office of Superfund Remediation and Technology Innovation, Risk Assessment Guidance for Superfund, Volume I: Human Health Evaluation Manual (Part F, Supplemental Guidance for Inhalation Risk Assessment), EPA-540R-070-002, ASWER 9285.7-82 (January 2009).

EPA/IRIS (2008), U.S. Environmental Protection Agency, Integrated Risk Information System (IRIS) Glossary; available at <http://www.epa.gov/ncea/iris/help_gloss.htm> .

Fennelly, K. P., A. L. Davidow, S. L. Miller, N. Connell, and J.J. Ellner (2004), “Airborne Infection with Bacillus anthracis—-from Mills to Mail," Emerging Infect. Dis. 10(6), 996-1001.

Ferro, A. R., R. J. Kopperud, and L. M. Hildemann (2004), "Source Strengths for Indoor Human Activities That Resuspend Particulate Matter," Environ. Sci. Technol. 38, 1759-1764.

Fischbeck, P. S. and R. S. Farrow (2001), Improving Regulation: Cases in Environment, Health, and Safety, Resources for the Future, Washington, D.C.

GAO (2003a), General Accounting Office, Capitol Hill Anthrax Incident: EPA's Cleanup was Successful; Opportunities Exist to Enhance Contract Oversight, Report to the Chairman, Committee on Finance, U.S. Senate, GAO-03-686.

GAO (2003b), General Accounting Office, U.S. Postal Service: Issues associated with anthrax testing at the Wallingford facility, Testimony before the subcommittee on National Security, Emerging Threats, and International Relations, Committee on Government Reform, GAO-03$787 \mathrm{~T}$.

Garger, E. K., H. G. Paretzke, and J. Tschiersch (1998), "Measurement of Resuspended Aerosol in Chernobyl Area, Part III: Size Distribution and Dry Deposition Velocity of Radioactive Particles During Anthropogenic Enhanced Resuspension,” Rad. Environ, Biophys. 37, 201-208.

Glassman, H. N. (1966), “Discussion,” Industrial Inhalation Anthrax 30, 657-659.

Haas, C. N., J. B. Rose, and C. P. Gerba (1999), Quantitative Microbial Risk Assessment, John Wiley and Sons, Inc., New York.

Haas, C. N. (2002), "On the Risk of Mortality to Primates Exposed to Anthrax Spores," Risk Anal. 22(2), 189-193.

Haimes, Y. Y. (1998), Risk Modeling, Assessment, and Management, John Wiley \& Sons, New York, NY.

Inglesby, T. V. et al. (2002), “Anthrax As a Biological Weapon, 2002: Updated Recommendations for Management," JAMA 287(17), 2236-2252.

Johnson, B. (2003), “OSHA Infectious Dose White Paper,” App. Biosafety 8(4), 160-165.

Keeney, R. L. and H. Raiffa (1993), Decisions with Multiple Objectives-Preferences and Value Tradeoffs, Cambridge University Press, Cambridge, UK.

Krauter, P. and A. Biermann (2007), "Reaerosolization of Fluidized Spores in Ventilation Systems," Appl. Environ. Microbiol. 73(7), 2165-2172.

Loosmore, G. A. (2003), "Evaluation and Development of Models for Resuspension of Aerosols at Short Times after Deposition," Atmospheric Environ. 37, 639-647. 
Lorber, M. et al. (2007), "Assessment of Inhalation Exposures and Potential Health Risks to the General Population that Resulted from the Collapse of the World Trade Center Towers," Risk Analysis 27(5).

Lucey, D. (2005), Chapter 205: Bacillus anthracis (Anthrax), in G. L. Mandell, J. E. Bennett, and R. Dolin (Eds.), Principals and Practice of Infectious Diseases: Part III-Infectious Diseases and their Etiologic Agents, $6^{\text {th }}$ Ed., Churchill Livingstone, Philadelphia, PA.

Macler, B. A. and S. Regli (1993), "Use of Microbial Risk Assessment in Setting United States Drinking Water Standards," Int. J. Food Microbiol. 18(4), 245-56.

Meselson, M. (2001), Note regarding source strength, The ASA Newsletter; available at <http://www.asanltr.com/newsletter/01-6/articles/016a.htm>.

Morgan, G., B. Fischhoff, A. Bostrom, and C. J. Atman (2002), Risk Communication: A Mental Models Approach, Cambridge University Press, Cambridge, UK.

Morgan, G. and M. Henrion (1990), Uncertainty, Cambridge University Press, Cambridge, UK.

NRC (2000), National Research Council of the National Academies, Natural Attenuation for Groundwater Remediation, The National Academies Press, Washington, D.C.

NRC (2005), National Research Council of the National Academies, Reopening Public Facilities After a Biological Attack: A Decision Making Framework, The National Academies Press, Washington, D.C.

NRT (updated July, 2005), National Response Team, Technical Assistance for Anthrax Response, Interim-Final Draft; available at $<$ http://www.nrt.org/production/NRT/NRTWeb.nsf/PagesByLevelCat/Level2TA?Opendocument $>$.

NRT Quick Reference Guide: Bacillus anthracis (Anthrax) (2008); available at 〈http://yosemite.epa.gov/sab/sabproduct.nsf/5AC43A81439F12A1852574D6004FC77C/\$File/HSAC+Anthrax+12+20.pdf〉.

Nicholson, K. W. (1988), “A Review of Particle Resuspension,” Atmospheric Environ. 22(12), 2639-2651.

Peters, C. J. and D. M. Hartley (2002), “Anthrax Inhalation and Lethal Human Infection,” The Lancet 359, 710.

PCCRARM (1997), Presidential/Congressional Commission on Risk Assessment and Risk Management, Framework for Environmental Health Risk Management: Volume 1, Washington, D.C.; available at <http://www.riskworld.com/Nreports/nr7me001.htm>.

Raber, E., A. Jin, K. Noonan, R. McGuire, and R. D. Kirvel (2001), "Decontamination Issues for Chemical and Biological Warfare Agents: How Clean Is Clean Enough?” Internat. J. Environ. Health Res. 11, 128-148.

Raber, E., J. M. Hirabayashi, S. P. Mancieri, A. L. Jin, K. J. Folks, T. M. Carlsen, and P. Estacio (2002), "Chemical and Biological Agent Incident Response and Decision Process for Civilian and Public Sector Facilities, Risk Analysis 22(2), 195-202.

Raber, E., T. M. Carlsen, K. J. Folks, R. D. Kirvel, J. I. Daniels, and K.T. Bogen (2004), "How Clean Is Clean Enough? Recent Developments in Response to Threats Posed by Chemical and Biological Warfare Agents," Internat. J. Environ. Health Res. 14(1), 31-41. 
Raber, E., T. Carlsen, and R. Kirvel (2008a), "Remediation Following Chemical and Biological Attacks," in WMD Terrorism: Science and Policy Choices, S. M. Maurer and C. Hartmann Siantar, Eds., MIT Press (in press).

Raber, E. and R. Kirvel (2008b), "Health Risk Assessment for Radiological, Chemical, and Biological Attacks," in Handbook of Science and Technology for Homeland Security, John Wiley and Sons, Inc., New York (in press).

Reynolds, B. (2002), Crisis and Emergency Risk Communication, Centers for Disease Control and Prevention; available at 〈http://www.maxwell.af.mil/au/awc/awcgate/cdc/cerc_book.pdf $>$.

Rotz, L. D., A. S. Khan, S. R. Lillibridge, S. M. Ostroff, and J. M. Hughes (2002), "Public Health Assessment of Potential Biological Terrorism Agents," Emerging Infectious Diseases 8(2), 225-230.

Rubin, L. G. (1987), "Bacterial Colonization and Infection Resulting from Multiplication of a Single Organism," Rev. Infectious Dis. 9(1), 488-93.

Sehmel, G.A. (1980), "Particle Resuspension: A Review,” Environ. Internat. 4, 107-127.

Sextro, R. G., D. M. Lorenzetti, M. D. Sohn, and T. L. Thatcher (2002), Modeling the Spread of Anthrax in Buildings, Proceedings: Indoor Air 2002; available at <http://eetd.lbl.gov/IED/APT/pubs/Anthrax_in_Bldgs.pdf >.

Simpson, M. M. (2005), Anthrax-Contaminated Facilities: Preparations and a Standard for Remediation, Congressional Research Service, Library of Congress, RL33191.

Sinclair, R., S. A. Boone, D. Greenberg, P. Keim, and C. P. Gerba (2008), "Persistence of Category A Select Agents in the Environment," App Env. Microbiol. 74(3), 555-563.

SNL and LLNL (2008), Sandia National Laboratories and Lawrence Livermore National Laboratory, IBRD Task 1 Systems Analysis Report (same OUO document published separately at both laboratories as report SNL2008-1349 and report LLNL-AR-401510).

Thatcher, T. L. and D. W. Layton (1995), "Deposition, Resuspension, and Penetration of Particles Within a Residence,” Atmospheric Environ. 29(13), 1487-1497.

Till, J. E. and H. R. Meyer (Eds.) (1983), Radiological Assessment: A Textbook on Environmental Dose Analysis, U.S. Nuclear Regulatory Commission, Report NUREG/CR-3332.

Till, J. E. and K. R. Meyer (2001), "Public Involvement in Science and Decision Making," Health Phys. 80(4), 370-8.

Turtletaub K., and E. Raber (2008), "Outdoor Biological Agent Risk Analysis and Assessment," in Technical Gap Analysis for Wide Area Biological Incidents, Lawrence Livermore National Laboratory, UCRL-TR 401133.

Wilkening, D. A. (2006), "Sverdlovsk Revisited: Modeling Human Inhalation Anthrax," Proc. National Academy Sci., 103(20), 7589-7594.

USACHPPM (2008), U.S. Army Center for Health Promotion and Preventive Medicine, Technical Guide 188: U.S. Army Food and Water Vulnerability Assessment Guide; July 2008 revision available for official use by contacting USACHPPM. 


\section{Risk Decisions}

Yong, R. N., A. M. O. Mohamed, and B. P. Warkentin (1992), "Principles of Contaminant

Transport in Soils," in Developments in Geotechnical Engineering, Vol. 73, Elsevier, Netherlands. 


\section{Characterization}

\section{Part IV: Remediation}

\section{Characterization}

Characterization is the process of gathering information needed to develop plans for decontamination and to make clearance decisions. Although there may be many ways to go about decontamination, ultimately there are only two options: to decontaminate or not to decontaminate. Thus, the end result of characterization should be a complete delineation of which outdoor areas will be decontaminated (if any) and which will not, and a list of facilities (enclosed, semi-enclosed, and water) that will be decontaminated. All available and applicable methods and approaches to making these determinations should be evaluated and used as appropriate, and to their fullest extent. Criteria for determining whether decontamination is necessary should be based on risk (Section 6). Results from prioritization (Section 5) may indicate regions and facilities that should have priority for characterization. Section 7 begins with an overview of a suggested characterization strategy followed by discussions of elements of that strategy.

An overall characterization strategy is guided by some basic assumptions. The assumptions represent, in effect, a pre-incident conceptual site model (CSM) because they are intended to approximate what a CSM might look like as characterization begins and before much incidentspecific information has been gathered.

An aerosol release of $B$. anthracis spores would immediately be followed by an airborne plume of spores, and people and animals within the plume would inhale the spores. Spores can enter buildings and other facilities, transportation systems, and vehicles by a wide variety of pathways, such as open doors and windows, ventilations systems, and fomite transport. Spores also settle on surfaces of all types, such as streets, lawns, trees, shrubs, walls and roofs of buildings, exposed surface water, crops if farming areas are within the plume, and so on. Larger spores would settle closer to the release location. Spores are likely to enter the storm drain system as a function of water runoff, and spores may also enter water distribution systems if reservoirs or other sources are exposed. Initially, the plume extent would be unknown, and any estimates of its size would likely be highly uncertain (with the possible exception of a release that is witnessed). Symptoms from exposure to the initial plume would begin to appear within about a week of exposure (see <http://www.bt.cdc.gov/agent/anthrax/anthrax-hcp-factsheet.asp>).

Over time, the initial plume would dissipate. Spores that had settled on surfaces would be available for resuspension, the amount of which would vary by surface type, spore properties, meteorological conditions, fomite interaction, and other variables. As spores settle during the initial plume passage, resuspension would also be taking place, resulting in a gradual transition from air concentrations arising from the initial plume to air concentrations as a function of resuspension. As time passes, resuspension would continue as would fomite transport. Spores that settle on water surfaces would travel with the water as it flows to new locations. Thus, the spatial distribution of spores would continually change, with the rate of change varying according to meteorological conditions, fomite activity, and other unforeseen factors. Eventually 


\section{Characterization}

rates of change would likely slow as spores either become bound to surfaces and materials or leave the area and become so dilute as to be undetectable.

The foregoing discussion assumes that when spores resuspend, they travel. However, it is also possible that spores might not travel far and, instead, "recirculate" by traveling back and forth within the same general area. In any event, resuspension and fomite transport can be expected to spread contamination outside the area covered by the initial plume, and initial estimates of the extent will be highly uncertain. Even after the distribution of spores has become generally stable, future changes can still be expected. For example, extreme weather such as high winds may occur, or human activities such as construction might well release spores previously bound to a surface or material. Thus, new cases of illness from exposure could well occur during an extended post-plume period. Moreover, particles could be carried to great distances beyond the original plume by people traveling to other cities, rendering the problem practically infinite. However, such considerations are outside the scope of this Interim Guidance, which focuses on cleaning up only the "wide-area" in which a release occurred.

Wide-area remediation can have no effect on exposures to an initial plume because such exposures would occur well before wide-area remediation can take place. Therefore wide-area remediation activities are directed at reducing exposures from post-plume sources to acceptable levels for all exposure pathways identified as being of concern and whatever those levels may be (see Section 6). Characterization for the purpose of decontamination, the primary focus of Section 7, must identify areas where decontamination can reduce post-plume exposure to acceptable levels (below clearance goals) while taking into account the changing spatial extent of contamination. Characterization to assist the public health response should take place in parallel with, and be coordinated with, characterization for decontamination.

Because initial information will be limited, it will not be possible at the beginning of an incident to determine with confidence throughout a wide area whether decontamination is needed in a given location. Therefore initial assessments should focus on two steps:

1. Making an initial estimate of an outer boundary of the affected area. Ultimately, the criterion for "contaminated zones" should be the presence of detectable levels of residual agent - the overall extent of contamination. Here, "residual agent" refers to any agent remaining after the initial release, whether viable or not; see Section 7.5.3.2. Initially however, there will probably not be enough information to identify the boundary of residual contamination with confidence, in which case planners should make a conservative estimate.

2. Making an initial estimate of boundaries of areas for which residual levels of viable agent present an unacceptable health risk, that is, exceed clearance goals. Such areas will need decontamination throughout and may be called "remediation zones." Risk management principles are used to determine what actions to take and ultimately to determine clearance goals according to site-, area-, and incident-specific characteristics (Section 6.4).

Initial estimates are updated and improved as additional information is gathered, become part of an initial CSM of the contamination, and guide subsequent work (EPA 2006). Because initial information is likely to be limited, an initial estimate of the contaminated zone should probably be highly conservative, and the initial size of the zone will likely be a judgment call. From public health and public relations points of view, it is better to move areas from "possibly 


\section{Characterization}

contaminated" to "not contaminated" than the opposite. If a release were overt and witnessed, then the vicinity of the release location would be a good candidate for an initial remediation zone, but there would be little basis for estimating its size. If a release were detected by environmental monitoring (e.g., BioWatch), then the initial remediation zone might include the detector location(s) and some distance in directions upwind during the sampling period; however, once again, there would be little basis for estimating its size. For a covert release, there may be no information whatsoever with which to estimate initial remediation zone boundaries, in which case an estimate would have to be made later. Initial estimates of both zones are preliminary and expected to change over time, but ultimately the problem must be bounded (EPA 2006, Data Quality Objectives, step four, "Define the Boundaries of the Study").

If no outdoor remediation zone can be identified, then there would presumably be no further outdoor work anywhere, but such a conclusion would need to be reached with high confidence, especially if there is evidence that clearance goals have been exceeded (e.g., cases of anthrax arise resulting from post-plume exposure). To have high confidence, evidence for such a decision would likely be required to meet applicable clearance decision criteria.

Information from the First-Response Phase, especially environmental sampling results, if any, is used to estimate initial boundaries. If, and only if, sufficient information is available to generate a credible air-dispersion model, its output can also be used (see Section 7.2.2 for information about modeling requirements). Surface sampling is the primary sampling method contributing to estimates of the outer boundary of the contaminated zone because surface samples can measure residual contamination remaining after initial plume passage. Initial clearance goals will identify the exposure pathways that remediation should address and that are therefore used to determine the remediation zone. For inhalation risk, air sampling is primary because air samples can be used to estimate inhalation risk. Surface samples are less useful because it is difficult to use surface concentrations to estimate inhalation exposure (ATSDR 1994). If other exposure pathways are to be controlled, then sampling methods appropriate to such pathways would also be used.

A potential complication in applying environmental sampling results to estimate boundaries is the possible presence of natural background levels of a biological agent. If sample analyses can easily distinguish genetic variations or differences in physical characteristics between endemic spores and those released, then a background correction would not be necessary. Otherwise, some adjustment would be necessary (see also Sections 6.5.2 and 9.2.1). In any event, the actual risk of contracting the disease anthrax is the key consideration for characterization.

Following initial zone boundary estimates, the Characterization Phase consists of gathering additional information with which to iteratively update and validate zone boundaries until the outdoor yes-or-no decontamination decision can be made throughout the area. This iterative process represents the development of a CSM (EPA 2006), which describes an understanding of where the contamination is, or will be, present and likely to pose a hazard. The tools by which a CSM is developed are likely to include environmental sampling to assess current conditions; statistical analyses of environmental sampling results (e.g., interpolation, geostatistics); fate and transport modeling to predict concentrations in unmeasured locations and in the future; and epidemiological data and risk assessment modeling to predict and validate human health impacts. For example, environmental sampling data could be used to validate the contamination distribution CSM. Where the CSM and data comparison is not sufficiently accurate, fate and 


\section{Characterization}

transport models would be updated to more accurately reflect the actual event. The models would be used to update the CSM and guide further sampling efforts to reduce the CSM uncertainty further (Sections 7.2.2, and 7.5.3 through 7.5.4). Geostatistical models could be used to suggest new sampling in locations that will best reduce mapping uncertainty. Additional CSM validation could occur by comparing CSM risk-assessment predictions with obtained epidemiological data. Regardless of the methodologies used, the goal is to develop a map that delineates with confidence what areas will be decontaminated and what areas will not.

At the same time, assessments of enclosed facilities, semi-enclosed facilities, and water systems should be conducted. It may be appropriate to characterize high-priority critical infrastructure facilities as soon as possible (even before initial zone boundaries are established), especially if they are needed for continuity of operations or continuation or resumption of lifeline critical infrastructure. Otherwise, once initial boundaries are established for outdoors zones (and subsequently updated), facilities can begin to be characterized on a priority basis (Sections 5 and 7.1). Facility characterization entails two steps: (1) deciding which facilities to characterize, and (2) deciding how to characterize them.

The contaminated zone of a wide-area urban release is likely to include numerous facilities with a potential for indoor contamination, probably too many for all to be characterized with the same thoroughness as was used after the 2001 anthrax contamination. At one extreme, the approach would be to characterize every indoor facility within some defined area. In some facilities, a few correctly placed judgmental samples would find contamination above acceptable levels, and those facilities would immediately be moved in the "needs remediation" category. Otherwise, additional indoor characterization would continue until either contamination is found or the sampling is sufficient to confidently declare the facility is not contaminated (amounting to clearance sampling during the Characterization Phase). This approach has the potential of minimizing the number of facilities needing decontamination, but at the cost of a substantial sampling effort. The opposite extreme would be to assume all facilities within some defined area are contaminated, and to do no characterization whatsoever, proceeding directly to decontamination. The latter approach minimizes the time and cost of characterization but at the potential cost of unnecessary decontamination. In both of these extreme cases, identifying "some defined area" could be difficult, but at a minimum should include the outdoor remediation zone.

An intermediate strategy with the potential to optimize facility characterization, would be to first group facilities according to the prioritization analysis of Section 5, and then within priority groups classify facilities according to the expected likelihood of migration of BWA from the outside to the inside. A random and representative set of facilities within each class would be characterized, and the results considered representative of all facilities in the class. The expected level of contamination would likely be assessed according to outdoor contamination levels to which a facility was exposed, and the potential for intrusion of BWA into interior spaces. Facility-specific information is essential to the classification process. For example, modern highrise office buildings and 50-year old wood-frame residences are likely to have different means and rates of air exchange with the outside. Facility use, the typical number of occupants, and how much entering and exiting took place since the release are also important. If any facilities were identified that might not be contaminated at all indoors (e.g., because of the type of construction, operation of HVAC systems, and use or disuse at the time or release), then they should be quickly screened and protected via access controls to ensure they do not subsequently 


\section{Characterization}

become contaminated. Given that a facility has been selected for characterization, a quick characterization with only a few samples can give a "yes, decontamination is needed" answer if any samples confirm contamination above clearance goals. However, a limited characterization with just a few samples does not yield a confident "no" answer (Section 7.5.3.4).

Characterization entails addressing at least four important challenges. First, zone boundaries are expected to evolve - perhaps substantially - over time. Changes will occur as a result of more accurate characterization, updating of the limited information from preliminary assessments used to define initial zone boundaries, and the potential for an agent to move or change in other ways. For example, BWAs can degrade following direct UV exposure. Alternately, dry and windy conditions or human activity may cause a previously fixed deposit of BWA to migrate to a formerly clean area, depending on surface type and the specific biological agent. Migration pathways include air (e.g. resuspension), water (e.g. rain), or fomite (e.g. vehicle) transport. Such changes may render sample data "perishable" in the sense that future conditions may not be well reflected by prior measurements.

Second, small-scale variability is likely. Numerous studies have shown that environmental concentrations of contaminants can vary more than an order of magnitude over distances of a few meters (Crumbling et al. 2003). For B. anthracis spores, surface contamination may vary widely by surface type (e.g., carpet versus hard surfaces) and orientation (e.g., vertical versus horizontal), and small hot spots can be created by a variety of processes (tracking and electrostatic charges on surfaces, among them). Thus, measurements with small sample support (those with surface area coverage that is smaller than the scale of surface variability; see Section 7.5.3) should be performed and interpreted carefully, or sampling may overlook or overestimate regions of contamination (Crumbling et al. 2003).

Third, the total number of samples that can be processed will be limited, especially if some laboratories are also being sent numerous clinical samples. Therefore, it will be important to use techniques that optimize the process of determining zone boundaries (Section 7.5.3).

Fourth, the precision to which zone boundaries need to be drawn is unknown. Precision will ultimately be determined in consultation with decontamination planners who must weigh the relative costs of an anticipated decontamination method versus the characterization process. Imprecise boundaries could be addressed by establishing buffer zones beyond estimated boundaries and decontaminating within both buffer and remediation zones.

Figure 7-1 shows examples of four potential contamination patterns to illustrate trade-offs that may be necessary to optimize characterization and decontamination. The boundaries of the remediation zone(s) need to be identified with enough precision that decontamination is not done unnecessarily, yet confidence remains high that decontamination is unnecessary outside the zones. Figure 7-1a shows a pattern for the task at its simplest: a single remediation zone within a wide area. Figure 7-1b shows a pattern that is somewhat more challenging: two discontinuous zones, each needing decontamination. Here, the trade-off is between the additional time and cost of correctly identifying each zone, leading to a reduced decontamination effort, versus surrounding both zones with a single and larger zone and decontaminating everything within, leading to some unnecessary decontamination. In Figure 7-1c, identifying the outer boundary of the remediation zone should be no more difficult than for the case of Figure 7-1a; however, identifying the interior sub-zone that does not need decontamination would take extra effort. The trade-off is similar to that of Figure 7-1b; increased characterization effort verses increased 


\section{Characterization}

decontamination effort. Figure 7-1d combines the patterns of 7-1b and 7-1c, showing the potential for more complex patterns. Optimization will be challenging because of the likelihood of imperfect knowledge about whether there are discontinuous zones needing decontamination or sub-zones that do not, and their relative sizes and shapes.

The approach to facility characterization described above would have a similar trade-off. One could characterize a relatively small set of representative facilities and use the results to make the "decontaminate" versus "do not decontaminate" decision for a many facilities. This would reduce the time and cost of characterization at the potential cost of performing unnecessary decontamination. If the time and effort of characterizing a single facility can be made small enough, then more facilities can be characterized, leading to reduced decontamination efforts.

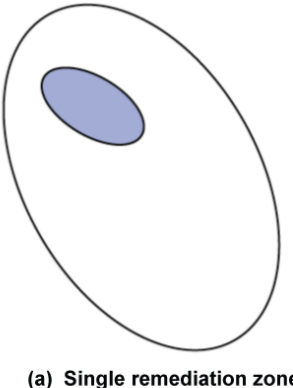

within the wide area

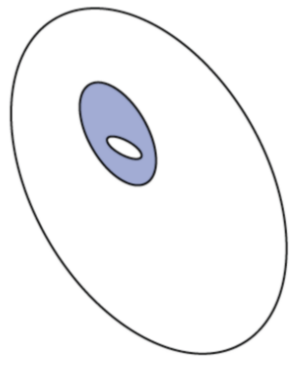

(c) Single remediation zone, with embedded "clean" zone

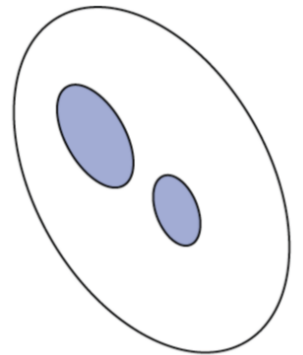

(b) Two remediation zones within the wide area

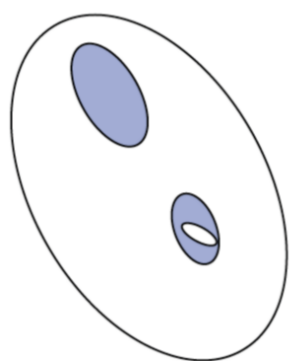

(d) Combination of $b$ and $c$

Figure 7-1. Example contamination patterns to illustrate characterization trade-offs. Outer ovals represent the wide area. Shaded areas need decontamination; white areas do not. Areas are not to scale, and shapes of zones would vary.

The remainder of Section 7 discusses existing tools and approaches available today to identify, monitor, and update remediation zone boundaries for outdoor areas, and to characterize indoor facilities and water systems. The principal activities are environmental sampling, qualitative and statistical interpretation of sampling results, laboratory analysis of agent properties, and fate and transport models (e.g., air-dispersion modeling, including assessments of agent resuspension and degradation).

Figure 7-2 is an overview of the principal activities associated with characterization. A summary of characterization actions in the approximate order in which they are expected to occur, along with the personnel responsible for specific actions taken during the Characterization Phase, is provided toward the end of Section 7. 


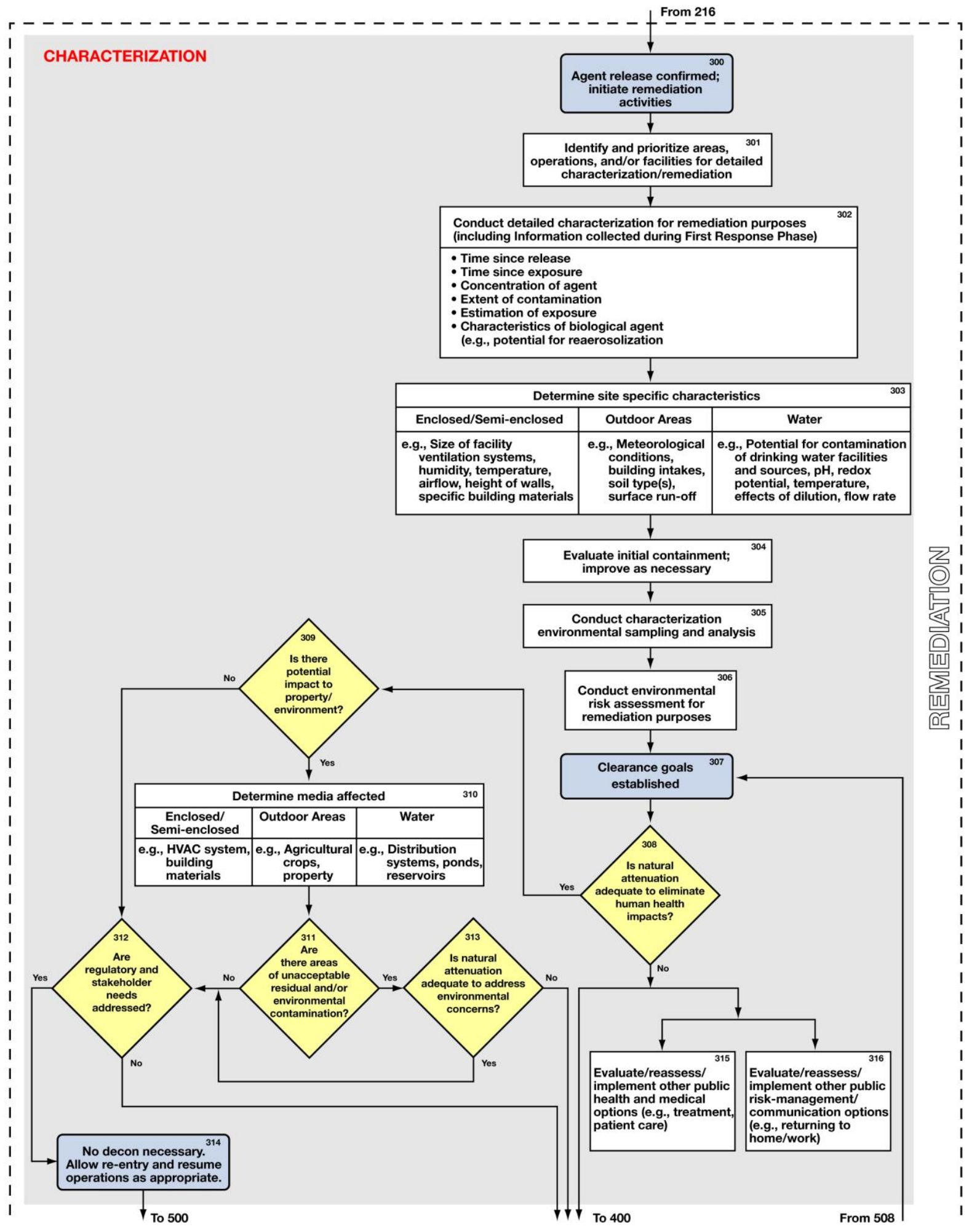

Figure 7-2. Principal activities association with the Characterization Phase. 


\section{Characterization}

\subsection{Identify Characterization Priorities (Boxes 300, 301)}

Resources, including trained sampling personnel and possibly environmental sampling equipment, will be limited for a wide-area characterization effort. Moreover, the size of a contamination plume(s) and number of structures affected will be daunting. Decision-makers will need to apply the results of the prioritization approach (Figure 7-3) to allocate available resources to the affected region according to their assigned importance or urgency. The prioritization results will indicate the areas in which it is important to have more precise zone boundaries. As remediation zone boundaries become refined, the prioritization results should indicate what buildings or facilities should be characterized first, and then subsequently decontaminated first. For example, MEI can be designated for immediate characterization and decontamination according to the priorities set by stakeholders.

\section{CHARACTERIZATION (301 expanded)}
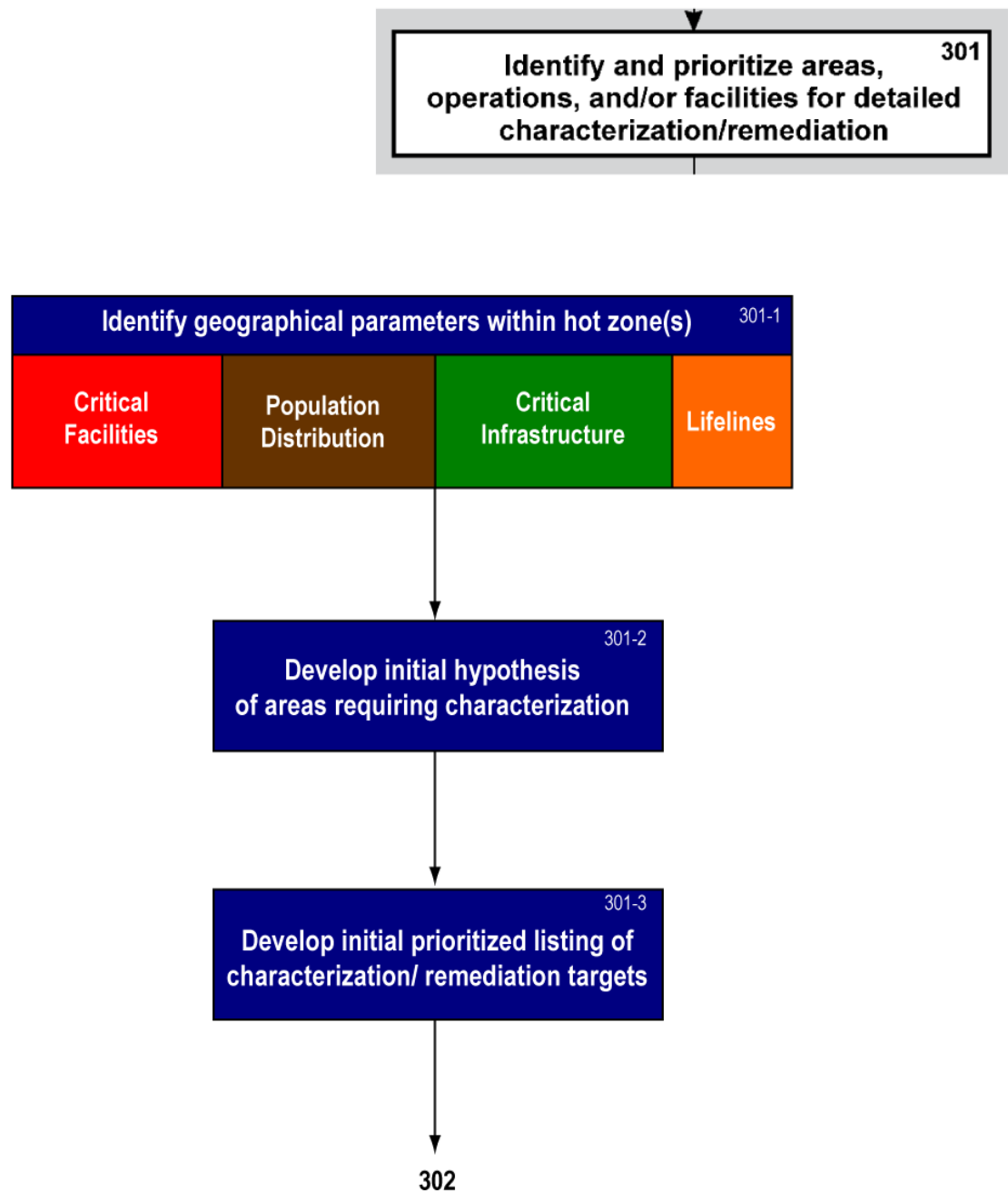

(OSTP Draft Guidance)

Figure 7-3. Expanded Box 301: identify and prioritize areas for detailed characterization. 


\section{Characterization}

Prioritization is discussed in detail in Section 5. In brief, Box 301-1 refers to identifying the facilities, infrastructure, and lifelines in the area for which prioritization is needed. Population distribution information is important because it affects priorities. The initial hypotheses of Box 301-2 are the initial estimates of the contamination and remediation zones described earlier in Section 7, and Box 301-3 refers to the initial results of the prioritization process.

\subsection{Begin Detailed Characterization Process (Box 302)}

The planning team will typically begin by developing a conceptual model of the problem, which summarizes the key environmental release, transport, dispersion, transformation, deposition, uptake, and behavioral aspects of the exposure scenario that underlies the problem. The conceptual model is an important tool for organizing information about the current state of knowledge and understanding the problem, as well as for documenting key theoretical assumptions underlying an exposure assessment. This includes identifying (1) known or expected locations of contaminants, (2) potential sources of contaminants, (3) media that are contaminated or may become contaminated, and (4) exposure pathways, including the locations of human or ecological receptors (US EPA 2006). Figure 7-4 shows how information is collected during characterization to identify what is actually known and not yet known.

\subsubsection{Collect and Evaluate Information From First Response (Box 302-1)}

Decision-makers need to make judgments about how much confidence to place in answers derived from information collected during first response (Box 302-1) and what data gaps (Box 302-4) must be filled. Initial assessments must be updated throughout the remediation process because of the limited information likely to be available during an initial determination, the expected stream of environmental data acquired during characterization, and the potential for contamination to evolve and move within the environment. The end result of the preliminary assessment should include estimated boundaries of the remediation zone(s) and an outer boundary of the contaminated zone.

Data collected during first response (Box 302-1), including the results from any initial environmental sampling, should be compiled by the Planning Section's Situation Unit and turned over to the Environmental Unit (EU) for use in planning subsequent cleanup. Because the release of a BWA is a crime, it is assumed that the FBI will maintain control of the identified area until it has completed its criminal investigation. The FBI coordinates the release of the site, when possible, to allow remediation and recovery activities to occur. When public safety needs arise, the FBI shares relevant criminal investigative information, including initial environmental sampling data, with appropriate and authorized individuals within the Unified Command and those located at the JFO.

The kinds of information available at the beginning of characterization will depend on how an incident evolves, choices made at times when information is extremely limited, and whether a release is overt or covert. In the former case, the time, location, and mechanism of release will likely be known with some confidence. Release parameters from a covert release might be derived through sampling devices, if the location is a BioWatch city, or through epidemiological investigation of unusual cases of suspected BWA exposure that reveals a place where presenting patients were located during the expected exposure period, or from the results of modeling analysis. 


\section{Characterization}

\section{CHARACTERIZATION (302 expanded)}

Conduct detailed characterization for remediation purposes (including Information collected during First Response Phase)

- Time since release

- Time since exposure

- Concentration of agent

- Extent of contamination

- Estimation of exposure

- Characteristics of biological agent

(e.g., potential for reaerosolization)

Gather/collect information from first response (e.g., time since release, concentration maps,

characteristics of agent)

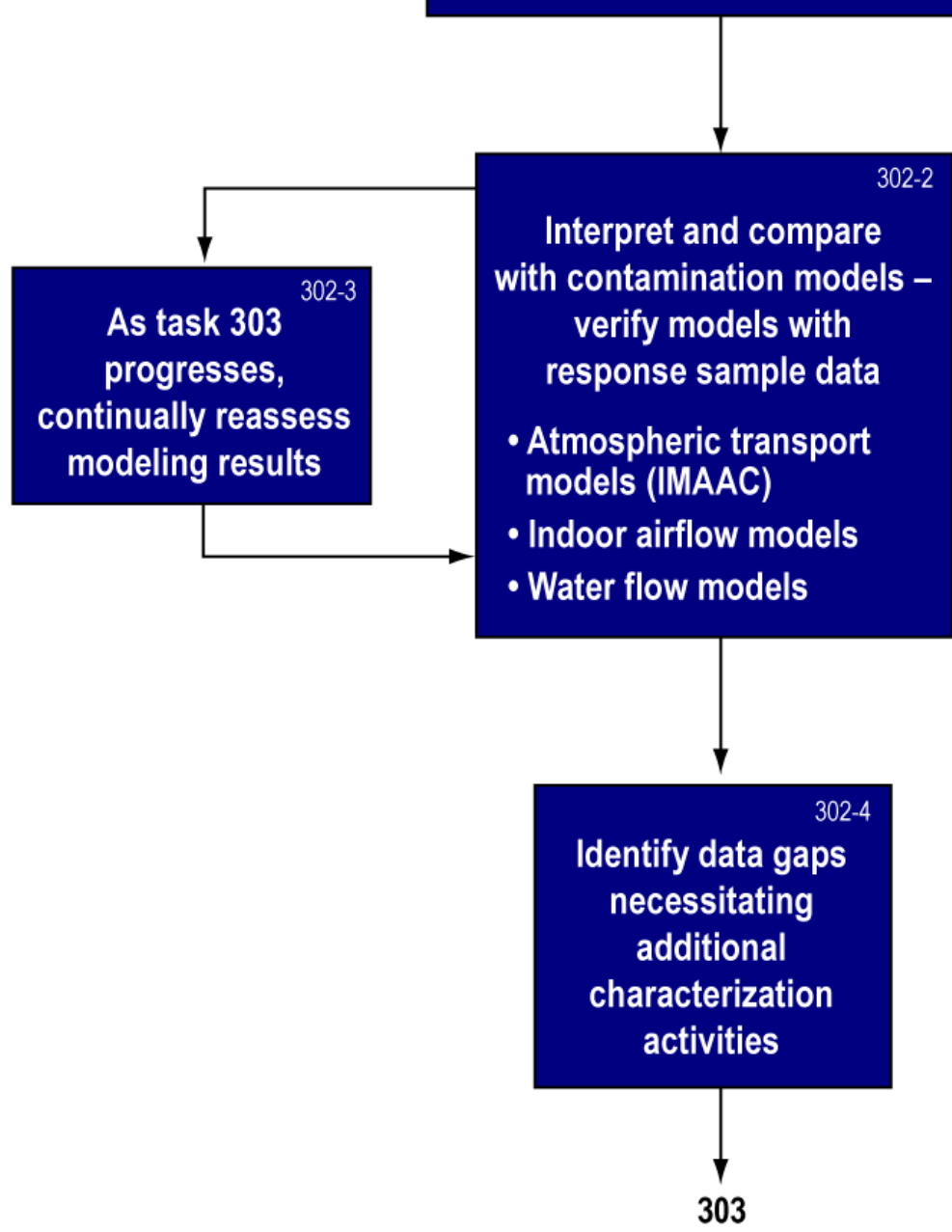

Figure 7-4. Expanded Box 302: assess all collected information to identify data gaps. 


\section{Characterization}

In most BioWatch cities, first responders will have collected and analyzed samples and confirmed the release (Box 300) of a viable or infectious organism. (If the organism is not viable, then no immediate threat exists, and there will have been no need to begin a characterization phase.) See Section 4.2.3 for additional discussion of sampling during first response.

Under ideal circumstances, first response activities will have included analyses of the BWA characteristics, producing information relevant to fate and transport and the potential health threat (Section 6). Otherwise, agent characteristics must be determined as soon as possible. Such measurements are made with particular attention to properties that affect its movement and evolution within the environment, together with health implications (e.g., dose-response relation). Does the agent have the potential to reaerosolize both indoors and outdoors? Will it agglomerate quickly and pose a reduced health hazard? What are its adherence properties? Will it degrade in areas of moderate UV exposure? Analyses of agent properties take place within a laboratory setting, and confirmatory testing by an LRN laboratory is recommended. Cities that participate in the BioWatch program have pre-identified sites for post-BioWatch detection environmental sampling, and sampling results should be obtained from them.

Meteorological data, including wind speed and direction, temperature, relative humidity, precipitation, and cloud cover, must be collected during first response and continue to be collected. Other types of useful information that may be collected include, but are not limited to, population movement (including pedestrian traffic, vehicular traffic, and known wild and domestic animal pathways), land cover (e.g., amounts and types of vegetation, locations and types of urban surfaces, soil types, and soil conditions), and key agent properties (e.g., environmental persistence and susceptibility to inactivation of spores with respect to sunlight or chemicals). Security camera recordings, eyewitness accounts, the results of epidemiological investigations, or a combination of such information may help to identify the release time and location, especially for an overt attack. The EPA or a local air-quality monitoring agency may have a collection of archived ambient-monitoring samples that would be a potential source of information about natural background levels of a BWA such as B. anthracis.

\subsubsection{Employ Fate and Transport Models (Box 302-2)}

Modeling to estimate the extent of contamination and potential associated health impacts is a key tool for characterization. Abbot (1999) contains an example of the use of air-dispersion models at a CERCLA Superfund site to "prioritize soil sampling locations, site air monitors, ... and to help develop remediation plans." Here, the contaminant of interest was lead in blowing dust that presented a human health threat through the inhalation and ingestion of contaminated dust. The use of air-dispersion models for a variety of air-quality and regulatory purposes is well established (40 CFR Part 51; NRC 2007).

Health impacts and associated risk-assessment modeling are addressed in Section 6. In a widearea application, fate and transport models would be used to integrate available data and describe how contaminants enter and move within the environment and where human and animal exposures may occur. Models can have many different forms, including written descriptions, source-receptor flowcharts, physical replicas, statistical (empirical) data analyses, and computer programs. Modeling support has the potential to improve confidence, reduce costs, and speed characterization (to yield better, cheaper, and faster results) over a purely empirical approach by providing: 


\section{Characterization}

- A physically justified basis to categorize regions requiring decontamination by estimating current and future contamination levels and the risk of contaminant spread.

- The means to characterize uncertainty and identify actions needed to reduce uncertainty.

- A means to identify worker and general population exposure pathways and forecast conditions when risk of infection is high, such as during dry periods.

Fate and transport models will likely be used for event reconstruction to understand what release scenarios are consistent with available data, and then to estimate contamination patterns (interpolated contamination maps). Release scenarios (which are model input parameters) include the release amount, release location and pattern (e.g., point and line), release method, and meteorology during the time of interest. The basic process of event reconstruction consists of selecting plausible input parameters, running the model to get predictions, comparing predictions with data, and then adjusting input parameters to obtain a better match between model and data. The process is then repeated. Consult with a modeling expert for more complete information. The release scenarios and contamination patterns can then be used to assist prioritization decisions and guide further characterization (sampling guidance) and decontamination actions. For example, predicted contamination levels, projected health risks, and the likelihood of contamination spread could be used to categorize potential remediation sites into groups that would then be sampled to determine whether or not a given group requires decontamination. The ability to use the output of models is directly correlated with the accuracy of measurement data and an understanding of the dynamic physical processes by which contamination moves in the environment, especially meteorological data and resuspension rates. The accuracy of model estimates depends on variability of weather conditions within the window of the estimated release, the accuracy of the quantification of surface deposits and air sampling measurements, and an understanding of the dynamic physical processes by which contamination moves in the environment. Efforts to pinpoint the exact time of release help to maximize the usefulness of model estimates (SNL and LLNL, 2008, p. 37).

Following a covert release, it is unlikely that initial data will be sufficient to identify a specific release scenario. Thus, an initial modeling task following covert release is to find one or more sets of plausible release scenarios consistent with available data, i.e., reconstruct the event. From an estimated initial starting point, the model then works forward to predict where deposits will be found. This process currently relies heavily on subject-matter expert judgment and experience along with available data, modeling tools, and exploratory model runs to identify parameters such as source locations, timing, and magnitude. Recent progress has been made in mathematical and statistical algorithms that assist in event reconstruction, but current capabilities do not completely solve the problem. For event reconstruction from a covert release, multiple release scenarios may fit initially available measurements. If all reasonable release scenarios result in essentially the same delineation of remediation zones, then ensuring the accuracy of any single release scenario has little impact on the primary goal of characterization. Otherwise, additional data must be collected and used to refine release scenarios.

The use of models for interpolation and extrapolation of available measurements generally produces a map showing the expected distribution of surface contamination. The map is generated from the set of reasonable event parameters developed as part of event reconstruction. If maps of contamination distribution from modeling are relied on to delineate remediation zones (i.e., estimates of potential health risk), then it is especially important to refine the model until 


\section{Characterization}

planners are satisfied with the quality (Section 7.5.3.1). By defining the objective of modeling as predicting remediation zone boundaries, rather than contamination levels throughout an entire urban area, the required sampling and modeling resources can be reduced.

Model output may also indicate regions of the greatest expected contamination levels, which could be sampled for the purpose of risk assessment (Section 7.5.3.2). Model output combined with information on population distribution may indicate areas of greatest potential exposure, as well as areas that could be sampled for risk assessment. Indoor models may be used to help estimate the extent of contamination within a facility, provided the necessary facility-specific model already exists or can be developed. HVAC operational parameters from the time of the incident forward will be essential. Surface deposition models are typically built into airdispersion models. Building infiltration modeling is a relatively new area, and although researchgrade capability exists (Chan et al. 2007a and b), operational capability is extremely limited. Such models could be used, but results must necessarily be interpreted carefully and should not be used in the absence of sampling data. Event-specific models have been shown to be effective in predicting resuspension rates for outdoor, indoor, and subway environments (Droppo 2006; Loosmore 2003; Loosmore and Hunt 1998; Nicholson 1988; and Sehmel 1980).

The Interagency Modeling and Atmospheric Assessment Center (IMAAC) “...provides a single point for the coordination and dissemination of Federal dispersion modeling and hazard prediction products that represent the Federal position" (NRF 2008) during actual or potential incidents. The National Atmospheric Release Advisory Center (NARAC) at Lawrence Livermore National Laboratory (LLNL) serves as the primary IMAAC operations center. The IMAAC is supported by a Memorandum of Understanding signed by eight Federal agencies [DHS, Department of Energy (DOE), DOD, EPA, DHHS, National Aeronautics and Space Administration (NASA), National Oceanic and Atmospheric Administration (NOAA), and the Nuclear Regulatory Commission]. IMAAC draws on plume modeling and data capabilities from all supporting agencies to provide the best analysis of an event.

IMAAC predicts locations where contamination might occur by performing modeling plume transport and fate analyses. Model runs use information on the location, time, and quantity of material released, as well as meteorological (e.g., winds) and geographical (e.g., terrain and landuse) data for the area of interest. IMAAC personnel work closely with field assets and help to guide sampling plans and to refine modeling analyses according to sampling data. IMAAC uses a wide range of modeling tools for event reconstruction (estimation of key release scenario parameters, such as the location and quantity of material). The accuracy of such estimates depends on the variability of weather conditions and the quantity and quality of available measurements. Information that limits the potential time, location, or quantity of a release simplifies the IMAAC analysis (SNL and LLNL, 2008, p. 37; Chow et al. 2008).

A common classification scheme for atmospheric dispersion models is summarized here and in Table 7-1:

- Gaussian plume models are extremely fast, taking only a few seconds or less, and allow for the rapid assessment of numerous scenarios. They are attractive for their relative simplicity (both the underlying mathematics and limited inputs required) and computational speed. Such models are reliable up to 1 to $10 \mathrm{~km}$ downwind when winds are steady and unidirectional, and the plume moves over a relatively flat terrain. They are 


\section{Characterization}

often used for regulatory applications and to conduct risk assessments from the statistical averaging of numerous weather conditions and release scenarios.

- Gaussian puff models are fast, taking only seconds to minutes, and they capture temporal, horizontal, and vertical variations in weather conditions. Such models can be used over a larger range of distances and scales than Gaussian plume models. Most such models can consider a wide range of release scenarios and can model urban effects in a general sense, but not down the level of individual buildings. Gaussian puff models are often designed as stand-alone models requiring only event-specific weather data.

- Lagrangian models typically require a few minutes to an hour of simulation time, depending on the complexity of a release scenario and the computational platform used. Lagrangian models provide a more detailed resolution of the atmosphere and plumes moving within it than Gaussian models. Like Gaussian puff models, Lagrangian models can model complex source terms (e.g., spray from moving vehicles), environmental transformations (e.g., biological decay), deposition, and degradation and resuspension processes. Lagrangian models can be applied to problems ranging from 10 to 100 meters for extremely homogenous conditions, and out to global scales. Lagrangian models often model urban effects in a general sense, but not down to the level of individual buildings.

- Empirical urban models are designed to run quickly, in seconds to minutes. Using empirical relations derived from wind tunnel and field experiment, these models resolve plumes as they moves around individual buildings.

- Computational fluid dynamics (CFD) models have the potential to provide the highestfidelity transport and fate simulations (Chan and Leach 2007). Such models solve fluid dynamics equations from first principles and appropriate physics submodels for turbulence, radiation, surface heat budgets, and other processes. CFD models are the most demanding in terms of user expertise, data requirements, and computational resources, taking minutes to days to set up and minutes to hours to run. However, CFD models are able to capture great detail, such as plume arrival and departure times and peak concentrations. CFD models are unlikely to be used during initial assessments, but they are valuable for pre-planning and might be needed to model complex urban areas, such as downtown areas with numerous tall buildings, to guide detailed surface sampling plans. CFD models can be applied to indoor spaces as well.

- Multi-zone indoor models are designed to run quickly, within seconds, and resolve the plume as it moves within an individual building. Although quick running, such models require an expert user and information on the building being modeled. Thus, the setup can be demanding.

- Subway models are designed to run quickly, within minutes, and resolve the plume as it moves within an underground subway system. Such models require expert user, detailed information on the subway system being modeled, and are not widely available.

The models identified in Table 7-1 are representative examples of available models. Content is not intended as an exhaustive list of all modeling capabilities. 


\section{Characterization}

\section{Table 7-1. Common types of biological agent fate and transport models.}

\begin{tabular}{|c|c|c|c|}
\hline Model category & Advantages & Disadvantages & Examples \\
\hline $\begin{array}{l}\text { Gaussian plume } \\
\text { models }\end{array}$ & $\begin{array}{l}\text { Fast desktop software. } \\
\text { Limited inputs required. } \\
\text { Designed for general user. }\end{array}$ & $\begin{array}{l}\text { Only applies for short } \\
\text { distances and for limited } \\
\text { weather conditions. }\end{array}$ & $\begin{array}{l}\text { No widely available } \\
\text { model for bioagents }\end{array}$ \\
\hline $\begin{array}{l}\text { Gaussian puff } \\
\text { models }\end{array}$ & $\begin{array}{l}\text { Fast desktop software. } \\
\text { Uses realistic meteorology and a } \\
\text { range of source scenarios. } \\
\text { Typically designed for the } \\
\text { general user. }\end{array}$ & $\begin{array}{l}\text { Less detailed resolution of the } \\
\text { atmosphere and plumes than } \\
\text { Lagrangian particle models. }\end{array}$ & $\begin{array}{l}\text { HPAC JEM }^{\mathrm{b}} \\
\text { (DOD/DTRA) }\end{array}$ \\
\hline Lagrangian models & $\begin{array}{l}\text { Desktop or Linux cluster } \\
\text { software. } \\
\text { Real-time applications for local } \\
\text { to continental scale. } \\
\text { Higher fidelity than Gaussian } \\
\text { puff models. } \\
\text { Uses realistic meteorology and a } \\
\text { wide range of source scenarios. }\end{array}$ & $\begin{array}{l}\text { Require greater computing } \\
\text { resource than Gaussian puff } \\
\text { models. }\end{array}$ & $\begin{array}{l}\text { ADAPT/LODI } \\
\text { (IMAAC/NARAC) }^{\mathrm{c}}\end{array}$ \\
\hline $\begin{array}{l}\text { Empirical urban } \\
\text { models }\end{array}$ & $\begin{array}{l}\text { Desktop software. } \\
\text { Treats individual buildings in an } \\
\text { urban environment. } \\
\text { Much faster than CFD models }\end{array}$ & $\begin{array}{l}\text { Less fidelity than CFD } \\
\text { models. } \\
\text { Requires building-specific } \\
\text { data. } \\
\text { Designed for expert user. }\end{array}$ & $\begin{array}{l}\mathrm{QUIC}^{\mathrm{d}}(\mathrm{LANL}) \\
\mathrm{UDM}^{\mathrm{e}}(\text { Dstl })\end{array}$ \\
\hline $\begin{array}{l}\text { Computational } \\
\text { fluid dynamics } \\
\text { (CFD) models }\end{array}$ & $\begin{array}{l}\text { Highest fidelity model. } \\
\text { Resolves individual buildings } \\
\text { and building features. } \\
\text { Full physics models solving } \\
\text { first-principles, fluid-flow } \\
\text { equations. }\end{array}$ & $\begin{array}{l}\text { Requires high-performance } \\
\text { computing resources or cluster } \\
\text { computing. } \\
\text { Requires building-specific } \\
\text { data. } \\
\text { Requires expert user. }\end{array}$ & $\begin{array}{l}\text { FEM3MP }^{\mathrm{f}}(\mathrm{LLNL}) \\
\text { FLUENT }^{\mathrm{g}} \\
\text { (Ansys, Inc.) }\end{array}$ \\
\hline $\begin{array}{l}\text { Multi-zone indoor } \\
\text { models }\end{array}$ & $\begin{array}{l}\text { Fast desktop software for indoor } \\
\text { modeling only. }\end{array}$ & $\begin{array}{l}\text { Requires information on } \\
\text { building being modeled. } \\
\text { Designed for expert user. }\end{array}$ & CONTAM (NIST) \\
\hline Subway models & $\begin{array}{l}\text { Desktop to workstation } \\
\text { computing. }\end{array}$ & $\begin{array}{l}\text { Requires detailed information } \\
\text { on the subway being modeled. } \\
\text { Designed for expert user. } \\
\text { Not widely available. }\end{array}$ & CB-EMIS (ANL) \\
\hline
\end{tabular}

a Sources of information for this table include: Office of the Federal Coordinator for Meteorological Services and Supporting Research (2002), Atmospheric Modeling of Releases from Weapons of Mass Destruction: Response by Federal Agencies in Support of Homeland Security, FCM-R17-2002; National Research Council (2003), Tracking and Predicting the Atmospheric Dispersion of Hazardous Material Releases, Committee on the Atmospheric Dispersion of Hazardous Material Releases, ISBN: 0-309-08926-3; and National Research Council (2007), Protecting Building Occupants and Operations from Biological and Chemical Airborne Threats: A Framework for Decision Making, Committee on Protecting Occupants of DOD Buildings from Chemical and Biological Release, ISBN: 0-309-10956-6.

Footnotes for Table 7-1 continue on the next page. 


\section{Characterization}

Footnotes for Table 7-1, continued.

b JEM (Joint Effects Model) is the only DOD-accredited model, replacing HPAC (Hazard Prediction and Assessment Capability), VLSTRACK (Vapor, Liquid, Solid Tracking Computer Model), and D2PUFF.

c ADAPT/LODI are Lawrence Livermore National Laboratory's (LLNL's) coupled meteorological data-assimilation and Lagrangian particle-dispersion models that form the core of the IMAAC/NARAC operational model system.

d QUIC (Quick Urban and Industrial Complex) is developed by Los Alamos National Laboratory (LANL).

e UDM (Urban Dispersion Model) is developed by the Defence Science and Technology Laboratory (Dstl), Ministry of Defence, U.K and is used by DOD/DTRA.

f FEM3MP (Finite Element 3 Massively Parallel) model is from LLNL, and it is used for NARAC/IMAAC planning and research.

g FLUENT is an example of a commercial CFD model from ANSYS, Inc.

\subsection{Acquire Site-Specific Characteristics to Help Assess Environmental Contamination (Box 303)}

Site-specific characteristics (Figure 7-5) are needed for two tasks. First, limited analytical resources are expected to prevent the full characterization of contamination at all locations of interest. Therefore we recommend grouping areas and facilities that are similar with regard to their likelihood of being contaminated above clearance levels, and likelihood of spreading contamination to other areas. To determine the appropriate groups, site-specific information must be acquired. Second, once a decontamination decision is made, site-specific information is required to perform the decontamination.

The information needed to group regions and buildings, and then guide sampling efforts to categorize the group as either needing or not needing decontamination, will vary with the details of the release scenario, particular site being assessed, and grouping method applied. In general, however, contamination levels will depend on the site- and scenario-specific mechanisms by which a BWA is transported from the release site. Health risks will depend on the contamination levels and available exposure pathways. The risk of further spread will depend on the properties of materials, soils, surfaces, or water at a given location as well as current and future environmental conditions such as temperature, wind speed, and humidity (Figure 7-5, Box 3031). For a given geographical location (Box 303-2), maps must be developed showing potentially contaminated sites, lifelines, and associated population distributions (Box 303-3). Such information, either generated or corroborated by updated model results (Box 302-4), is used to coordinate characterization priorities in outdoor areas, enclosed facilities, and semi-enclosed facilities (Box 303-5). 


\section{Characterization}

\section{CHARACTERIZATION (303 expanded)}

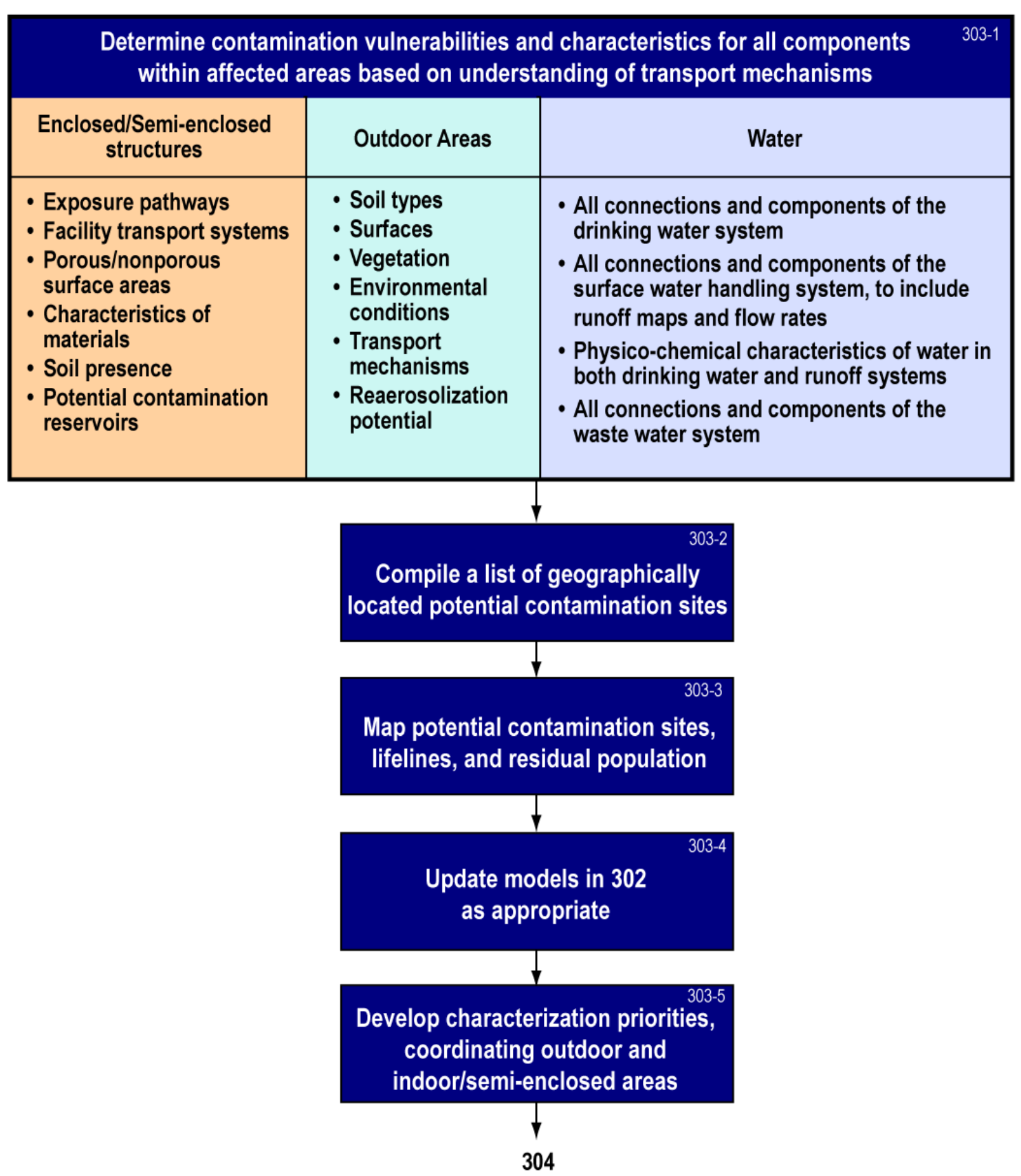

Figure 7-5. Expanded Box 303: determine site-specific characteristics. 


\section{Characterization}

The following is a summary of site-specific information necessary to assess the contamination at a given site and, for sites needing decontamination, to support decontamination activities.

Characterization activities that apply to all types of sites (outdoor areas, enclosed facilities, semienclosed facilities, and drinking water facilities and water sources) are listed first, followed by activities specific to subsets of site categories.

\subsubsection{Generic Characterization for All Site Categories}

Given the likelihood that cleanup activities will take place in phases (different areas at different times according to prioritization), it may be useful for operational and management purposes to define additional subzones:

- A characterization zone is any discrete sub-area viewed as a unit for the purpose of characterization.

- A decontamination zone is any area within a remediation zone viewed as a unit for the purpose of decontamination, potentially including an entire remediation zone.

- A clearance zone is any discrete sub-area viewed as a unit for the purpose of making a clearance decision.

- Sampling zone is used when it makes sense to organize sampling activities into smaller physical units than an entire characterization or clearance zone. For example, if "downtown" is a characterization zone, then "the first floor inside City Hall," or "outdoor surfaces along Pine Avenue between Sixth and Seventh Streets" could be sampling zones.

Decision-makers will work from the prioritization framework to review and update as necessary the assignment of the entire contaminated zone into prioritized sub-areas. Then, starting with the highest-priority areas, they would establish characterization zones or sampling zones, as appropriate. Because of the possibilities of reaerosolization and recontamination, together with the need for clean access routes, Section 5 recommends, in general, conducting necessary outdoor decontamination before decontaminating indoor facilities within the contamination footprint.

For remediation zone sites, estimate the surface area and volume of materials and surfaces (both contents and structure) that may be potentially contaminated. Maps or floor plans of facilities, areas, and water systems will be required to categorize the contents and attributes of a contaminated site (LBL 2004; NRC 2005, p. 161). Consult with public works departments and other agencies that understand the affected utility, sewer, and water systems.

\subsubsection{Enclosed and Semi-Enclosed Facilities}

For all potentially contaminated enclosed and semi-enclosed facilities:

- Collect information about HVAC systems (DHHS 2002) or other systems that might spread an airborne BWA. Such information, coupled with estimates of outdoor BWA concentrations, can be used to estimate interior contamination levels. Accurate models can require several man-months per facility, and it may not be feasible to validate them postevent. For high-value infrastructure, development and validation of detailed fate and transport models prior to an event is recommended. Models may be available for certain BioWatch facilities. 


\section{Characterization}

- Determine potential routes of exposure, such as inhalation or skin contact, and biological agent reservoirs unique to the affected site. For example, desktop computers and other objects with internal fans that draw in air might act as a reservoir of contamination. Other potential reservoirs include water, soil, damp organic materials, fountains, pools, atria, crawl spaces, plants, animals, and insects. Such information is used to estimate the health risk associated with a facility and to guide sampling efforts.

- For remediation zone sites, identify the size of facilities, surfaces of structures, and contents. Surfaces generally fall into one of two categories-hard and nonporous (e.g., walls, hard flooring, and metal surfaces) and porous (e.g., ceiling tile, upholstery, and carpet). The presence of soil or other organic material on surfaces should be recorded because it could decrease the effectiveness of decontamination. The composition of treated material needs to be evaluated for compatibility because of the potential for interference with a decontaminant (chemical reagent), possible production of hazardous byproducts that remain after treatment, and potential effects of decontaminant or byproducts on sensitive equipment.

\subsubsection{Outdoor Areas}

For all potentially contaminated outdoor areas:

- Document environmental conditions during and after the (estimated) release time as well as climatological characteristics, including ambient temperature, humidity, exposure to sunlight, cloud cover, wind speed and direction, rate and directional flow of water, and precipitation.

- Document environmental characteristics such as land cover; vegetation and soil type, location, and density; and building geometry, location, and construction.

- Document activities that contribute to the spread of contamination, including surface properties that affect resuspension, road traffic, wild animal movements and congregation sites, construction or agricultural activities, and surface water transport routes.

\subsubsection{Water Facilities and Outdoor Water Sources}

For all potentially contaminated drinking water facilities and outdoor water sources of concern:

- Obtain maps of all connections and components of water-distribution systems. Identify potential points of entry for a contaminant, such as water sources exposed to atmosphere.

- Review the age and construction of the water system, especially for the existence of locations with a potential for the buildup of biofilms or other organic matter.

- Measure residual disinfection levels at or near the point of entry, estimate the transit time to the most distant downstream customer (to determine if the agent has already cleared the system), and look for storage vessels that may have greater water age or residence time than the rest of the system.

- Document physico-chemical characteristics of the water. Water can have a range of physical and chemical characteristics (e.g., pH), some of which can affect the environmental persistence or detectability of pathogens. Information such as metal-ion content, presence or absence of disinfectant residuals, and temperature should be collected 


\section{Characterization}

if possible. For example, heavy metals can interfere with PCR analysis (Emmanuel et al. 2008, p. 101).

For wastewater treatment facilities, it will be necessary to evaluate the need for characterization using some or all of the above items, as appropriate, and the potential for impact arising from ultimate use.

\subsection{Review Existing Containment (Box 304)}

After an initial release, B. anthracis spores can spread through the movement of people and reaerosolization (Weis et al., 2002), and it is important that the spread be limited as much as possible. Measures to prevent spread are referred to as containment (Figure 7-6, Box 304). (To avoid confusion, "isolation" in this Interim Guidance refers to measures taken to prevent the release and spread of fumigant or other decontamination reagent into unwanted areas).

Some containment actions take place as soon as a BWA incident is confirmed, such as cordoning off areas to prevent entry (which could lead to additional spread by tracking), but early during remediation, the EU should review any such measures and decide whether additional containment is necessary. Aside from establishing and updating standard work zones in all areas (Boxes 304-1, 304-2, and 304-7), it may be necessary to take other measures, which can include:

\section{Outdoor Areas}

- Excluding pedestrians and animals from areas of known contamination (Box 304-3).

- Grounding or rerouting vehicles, aircraft, ships, subway cars, trains, and the like because of the potential for cross-contamination (Box 304-3).

- $\quad$ Considering the potential spread of BWA to surrounding populations of susceptible animals because many BWAs are zoonotic pathogens.

- Implementing vector-control measures if the agent is vector-borne.

- Implementing methods to minimize outdoor reaerosolization (Box 304-5, Section 8.3).

\section{Semi-Enclosed and Indoor Facilities:}

- $\quad$ Restricting entry of unauthorized personnel by installing perimeter fencing, posting signs, installing physical barriers, posting guards, or applying other controls (Box 304-3).

- $\quad$ Halting HVAC operation, if deemed appropriate.

- $\quad$ Sealing off with 6-mil polyethylene sheeting air ducts, windows, doors, conduits, and other vents that might allow contaminants to enter or escape a facility (Box 304-4).

- Shut down equipment that may cause particles to move about, such as computers or other equipment with internal fans. 


\section{Characterization}

\section{CHARACTERIZATION (304 expanded)}
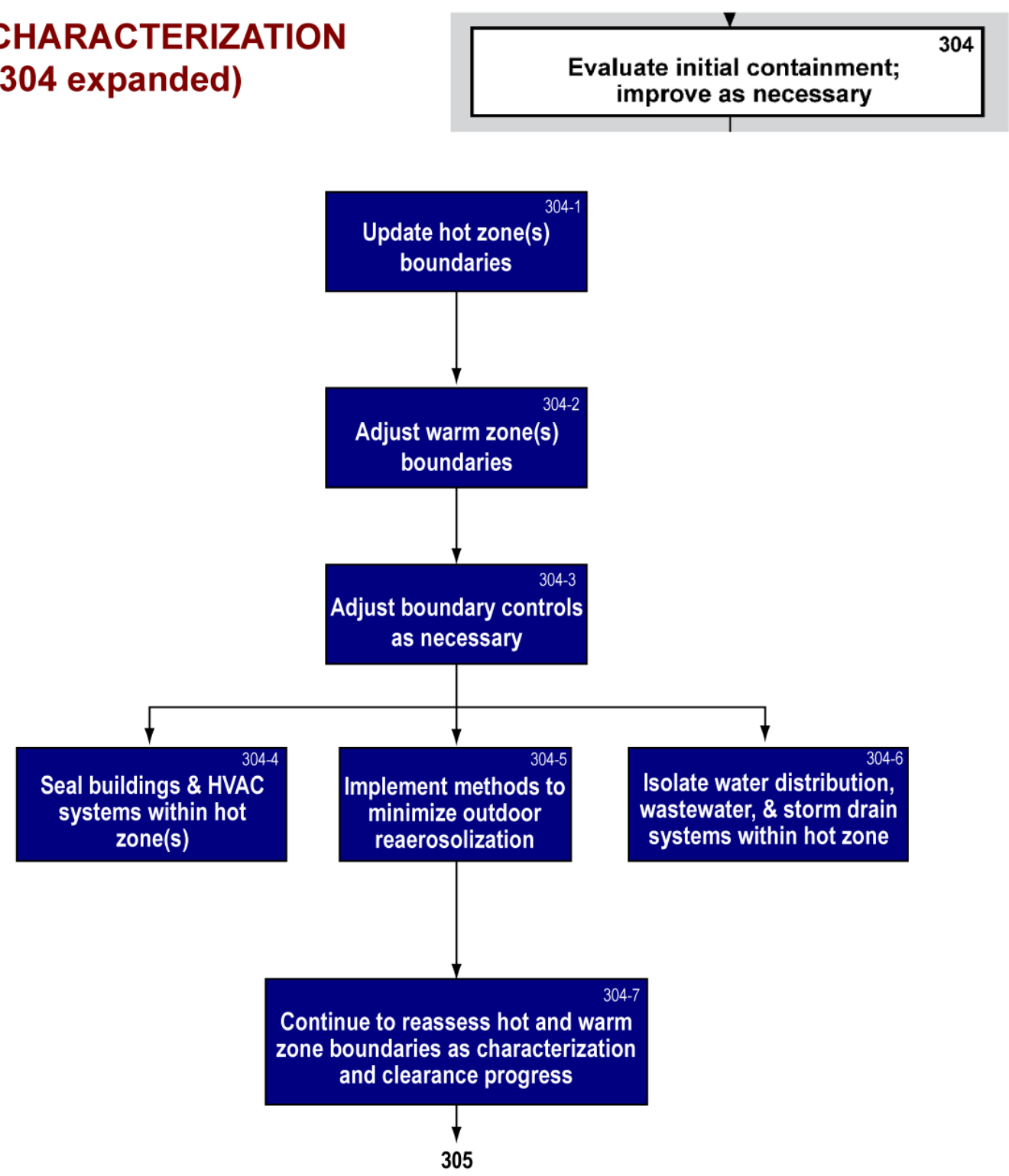

Figure 7-6. Expanded Box 304: review and improve containment.

\section{Water Distribution Systems:}

- Closing valves or segregating stand-alone portions of a water distribution system known to be contaminated (e.g., isolating pressure zones, storage tanks, pump houses, and the like) (Box 304-6). Experts in the operation of water distribution systems should be consulted to avoid unintended side effects.

\subsubsection{Consider Immediate Source Reduction}

Because $B$. anthracis spores can be reaerosolized or otherwise spread, prompt reduction of the concentration of spores in high contamination areas may reduce the scale and complexity of the 


\section{Characterization}

problem. Source reduction may have taken place to some extent during first response with the removal of source material by HazMat responders or by the FBI. If not, opportunities for source reduction should immediately be sought. Localized areas with especially high levels of contamination could be apparent, particularly in the vicinity of a release. If so, prompt and localized decontamination by qualified personnel using appropriate techniques should be considered. For example, if dense deposits of B. anthracis are present on the street or floors surrounding a release device, they could be treated by a surface application of diluted, $\mathrm{pH}$ adjusted bleach or other reagent solution then physically removed (see Section 8 for more detail and cautions) before more thorough decontamination.

More broadly, source reduction can include actions taken to prevent or reduce secondary dispersion, and opportunities for such actions should be sought continuously. Methods for dust suppression and soil stabilization could be considered for this purpose, particularly for open fields of bare dirt and especially if hot, dry weather is forecast (Sackschewsky and Becker 2001; see also <http://www.epa.gov/etv/vt-apc.html\#dsssp>).

Planners may consider implementing a small sampling program to test whether containment and source reduction measures to date have been effective. The program might include surface sampling of any treated surfaces, or air sampling within treated areas. Air sampling would have to be designed to be sensitive, as much as possible, to resuspension from the treated area only.

\subsection{Develop Comprehensive Characterization Sampling Strategies (Boxes 305-1, 305-2)}

Characterization (Figure 7-7; Boxes 304-3, 305-1, and 305-2) must be thorough, well documented, and provide sufficient data to support decisions. An overall characterization plan for a wide-area release should document the sampling and modeling strategies to be employed and reflect the iterative nature of the effort. It is unrealistic to expect that a single sampling plan, followed by a one-time execution of that plan, would be sufficient to support all necessary decisions. Separate sampling plans can be written (Box 305-2), for example, for outdoor areas containing high-priority critical infrastructure, the interiors of critically important buildings, water-distribution systems, and then later, other areas and facilities in order of decreasing priority. Such plans describe the sampling strategies (Box 305-1) that are selected, specify where and how to sample, and include supporting information, such as the laboratories that will analyze samples; procedures and protocols to be followed in transporting, handling, processing, and analyzing samples; the laboratory's quality-assurance procedures; and how to document and report the results. Suggested sampling strategies for various characterization purposes are described in Section 7.5.3. 


\section{Characterization}

\section{CHARACTERIZATION (305 expanded)}
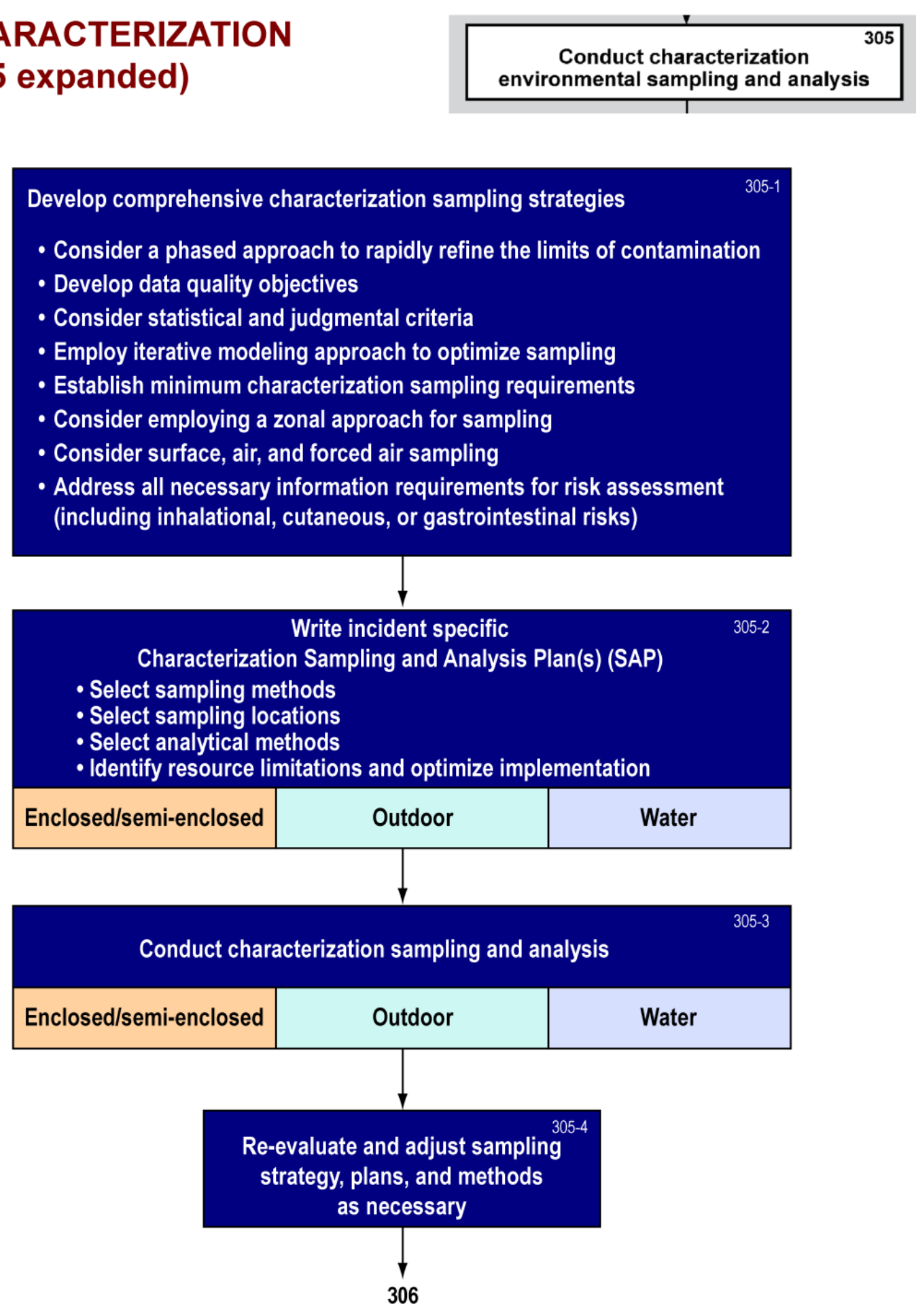

Figure 7-7. Expanded Box 305: conduct characterization environmental sampling and analysis.

Sampling plans must include adequate attention to quality assurance and should meet requirements in the Uniform Federal Policy for Quality Assurance Project Plans [(UFP-QAPP; 


\section{Characterization}

see Intergovernmental Data Quality Task Force (IDQTF 2005)]. The EPA regional offices can be expected to have sampling plan templates that conform to the UFP-QAPP that might be used, although they may need to be adapted for sampling plans that are intended to coordinate with both indoor and outdoor dispersion modeling.

\subsubsection{Identify Assets Needed to Implement Characterization}

Characterization activities can begin before first-response activities are complete. The UC or Area Command identifies and mobilizes as quickly as possible personnel and equipment needed for characterization. Personnel who should be ready to respond on short notice include:

- Sampling teams with up-to-date training.

- Analytical laboratory personnel from the LRN and other qualified laboratories, including mobile laboratories. To the extent available, laboratories able to provide rapid analyses are preferred because the number of samples may be large.

- Facility personnel or city planners with architectural drawings of affected structures.

- Fate and transport modeling and sampling-design experts.

- Data-management tools and data-management and documentation specialists.

- Agency experts who can provide support (e.g., the National Counterterrorism Evidence Response Team, National Decontamination Team, and Environmental Response Team).

- DSCA personnel and associated resources that can provide support, if requested.

Members of an ECC (Section 2) should be available for consultation. To maintain independence, it is best if ECC personnel are not members of teams actually planning or performing characterization work; however, the ECC should be informed of the plans and work.

Staging areas from which sampling contractors enter an affected area will need to be established. Considering the potential size of the affected area, it may be necessary to locate staging areas on all sides; however, the potential for staging areas to become contaminated by future migration of the agent should be considered. Personnel designated to perform sampling must have specialized training in collection techniques to ensure that samples are useful for laboratory analysis. Incident-specific analytical requirements (including methods, detection limits, and QA/QC procedures) should be developed using a data-quality objectives process, and all laboratories providing analyses should have procedures that meet incident-specific requirements.

The startup time for characterization will be reduced if resources are identified in advance. Most EPA regional offices maintain a list of qualified environmental remediation contractors, and OSCs have access to pre-negotiated response contractors able to perform environmental sampling. The EPA National Decontamination Team is a valuable source of information. Planners should be familiar with resources available through their local EPA offices and should establish a working relationship with personnel at those offices before an incident. Planners should contact the nearest LRN laboratory, as well as other LRN laboratories that can analyze additional samples. DHS should be contacted to coordinate the use of its fixed and mobile assets, including the LLNL National Capitol Region (NCR) and west coast BioWatch laboratories that are available to provide additional surge capacity to meet national needs. Additional expertise may be drawn from the U.S. Department of Health and Human Services (DHHS), including CDC/NIOSH, the Agency for Toxic Substances and Disease Registry (ATSDR), and military 


\section{Characterization}

organizations including, but not limited to, the U.S. Army Medical Research Institute for Infectious Diseases (USAMRIID), the Department of Defense Area Medical Laboratory (AML) mobile laboratories, the Edgewood Chemical Biological Center (ECBC), the Defense Threat Reduction Agency (DTRA) Consequence Management Advisory Teams (CMAT), and the CBRNE Analytical and Remediation Activity (CARA) under the U.S. Army $20^{\text {th }}$ Support Command (U.S. Army 2007). The DHHS will also mobilize its response assets to assist local responders in evaluating health risk and contamination pathways. Table 7-2 is a summary of characterization resources to be mobilized rapidly. When using this Interim Guidance to prepare specific urban-area plans, local authorities should make adjustments as appropriate. For planning purposes, phone numbers and contacts should be verified and updated at least once a year.

Table 7-2. Site characterization resources that should be identified in advance. (Local authorities adjust as appropriate, fill in, and maintain.)

\begin{tabular}{|l|l|l|}
\hline \multicolumn{1}{|c|}{ Resource } & Contact & Phone \\
\hline Members of Unified Command or organization in charge & & \\
\hline Members of Technical Working Group & & \\
\hline Members of Environmental Clearance Committee & & \\
\hline $\begin{array}{l}\text { Primary LRN or Environmental Response Laboratory Network } \\
\text { (ERLN) analytical laboratory (list methods and capacity) }\end{array}$ & & \\
\hline $\begin{array}{l}\text { Secondary LRN or ERLN, or deployable (e.g., mobile) } \\
\text { laboratory support (list methods and capacity) }\end{array}$ & & \\
\hline U.S. Environmental Protection Agency (EPA) & & \\
\hline U.S. Department of Health and Human Services (DHHS) & & \\
\hline Centers for Disease Control and Prevention (CDC) & & \\
\hline National Institute for Occupational Safety and Health (NIOSH) & & \\
\hline Agency for Toxic Substances and Disease Registry (ATSDR) & & \\
\hline DSCA (See Section 1.5.3) & & \\
\hline National Guard Civil Support Teams & & \\
\hline Sampling team(s) and contractor(s) & & \\
\hline Data management and documentation specialists & & \\
\hline Agent environmental monitoring team and contractor & & \\
\hline Personal protective equipment (PPE) rental suppliers & & \\
\hline Facility engineering and construction team(s) & & \\
\hline $\begin{array}{l}\text { Fate, transport, and exposure pathway modeling team and } \\
\text { contractor }\end{array}$ & & \\
\hline Decontamination and fumigation teams & & \\
\hline Waste-disposal resource personnel & & \\
\hline Wastewater management authorities & & \\
\hline
\end{tabular}




\section{Characterization}

\subsubsection{Review Data Management, Visualization, and Analysis Systems}

Data management systems must be in place as soon as possible, and especially before large numbers of samples are collected. It is imperative to use a data-collection, processing, storage, and reporting system that provides rapid and efficient data entry, allows for convenient access to data (including metadata, such as location coordinates photos, and field notes), helps assess whether data meet measurement-quality objectives, ensures data integrity and documentation, and can be managed effectively. This is especially important when many sampling teams from more than one organization (contractors) collect the samples, or more than one laboratory is used, as will likely be the case for a wide-area incident. It will be best if all sampling organizations use a common and consistent data management system and if all the laboratories involved deliver data electronically in a format compatible with that system. The value of sampling is undermined if the sampling is not well documented. All samples must be labeled with a unique identifier, and the specific location, date, and time of each sample should be recorded so that analytical results can be used to direct decontamination activities, update models, and revise fate and transport models. Sampling contractors are experienced with sample documentation requirements, so additional detail is not included here.

If a wide-area incident were to happen today, the official EPA data management tool would be EPA SCRIBE. Another option would be EPA Region 6 Response Manager.

- SCRIBE runs on a local desktop computer. When multiple teams are operating, each could run SCRIBE locally, receiving and reviewing data locally. After data quality has been confirmed, data would be uploaded to "Scribe.Net," then to a centralized EPA database, from which it would be available for planning, review, and reporting, including sharing with the general public. It would also be available for transfer to Geographic Information Systems (GISs) and statistical analysis systems. The system is available today for managing analytical data, but it has limited capability for storing and managing metadata, such as photographs. SCRIBE is linked with an additional capability called "Scribelets" that enables SCRIBE to link to PDAs. A limitation of SCRIBE is that geocoordinates must be entered by hand.

- EPA Region 6 Response Manager (RM) and associated data management software consist of a suite of applications that collect, manage, and display data from environmental response activities. The suite includes web-based interfaces to data management and appears to be particularly well suited to managing data from a large geographical area. RM can manage metadata as well as analytical data. It includes interfaces with SCRIBE, VSP, and FIELDS (see below), as well as GPS systems (EPA 2007). RM did quite well at managing data from the Hurricane Katrina incident for operational uses, but it was not as effective for use by higher-level decision-makers or sharing with the public. At present, the RM central server resides on a server belonging to an EPA contractor. Although RM was developed for Region 6, other regions have received training, and it is available for use should a wide-area incident occur today.

- EPA is also developing an emergency management portal that could replace or supplement the SCRIBE and RM tools.

Decision-support and sample planning tools are interactive software tools used by decisionmakers to help answer questions, solve problems, and support conclusions and develop sampling plans (EPA 2005). In the context of wide-area remediation, the following tools should be 


\section{Characterization}

considered as valuable assets in identifying appropriate sampling schemes, estimating the necessary number of samples to collect, locating hot spots, and directing additional sample collection:

- Building Restoration Operations Optimization Model (BROOM) was developed by Sandia National Laboratories (SNL) for both indoor and outdoor data acquisition, data management, and data analysis. The tool has both hardware and software to facilitate paperless data acquisition. A barcode reader is used to uniquely and efficiently identify all samples. It has both GPS and laser-positioning capabilities for real-time identification of sampling locations. It has the ability to take photos and preserve them in the data matrix. A SQL database allows efficient management of data and sharing across secure networks. A GIS engine allows management of map information. A suite of geostatistical tools provides visualization capabilities that account for spatial variability, including uncertainty and probability plots. BROOM has been integrated with VSP (see below) and SCRIBE (see above).

- Visual Sampling Plan (VSP), developed by Pacific Northwest National Laboratory (PNNL-Battelle), is a free statistical software program that estimates sample sizes for given probabilities of detection using estimated population variability. The software is compatible with BROOM.

- Spatial Analysis and Decision Assistance (SADA), developed at the University of Tennessee with assistance from Oak Ridge National Laboratory (ORNL), is similar to VSP, but focuses on cost-benefit analysis and sampling location, as opposed to comparison of means in VSP. SADA has been incorporated into FIELDS (see below) focusing on 3D visualization tools.

- Fully Integrated Environmental Location Decision Support (FIELDS) was developed for the EPA and combines GIS, Global Positioning System (GPS), database, analysis, and imaging technologies to assist in environmental cleanup efforts.

- $\quad$ F/S Plus, provided by the EPA, is a combination of FIELDS and SADA.

At present, the tools most likely to be used during wide-area remediation are those with which local responders are most familiar, and choices will depend on where an incident occurs.

\subsubsection{Select Characterization Approaches}

As described in the introduction to this section, the overall outdoor characterization strategy consists of first making initial estimates of (1) the outer boundary of the contaminated zone and (2) the boundaries of remediation zones in which environmental concentrations of the BWA exceed clearance goals and therefore need remediation. Zone boundaries are then iteratively updated and refined until there is sufficient confidence in the zones to begin decontamination. Boundaries must be monitored over time because they may move or evolve.

Within a remediation zone, sampling should focus on gathering information specific to developing a decontamination strategy, including decisions about what decontamination methods to use and what materials, equipment, items, and surface types require decontamination in place versus removal and disposal, or removal and treatment. The specific type of information needed is identified in consultation with decontamination planners.

In general, there are three strategies for selecting sampling locations and evaluating the data. 


\section{Characterization}

Judgmental samples are selected on the basis of experience and expert knowledge; locations are selected because they have specific desirable properties. Suggestions for judgmental sampling are included below. Systematic samples are placed in a grid pattern or along a transect. Statistical samples involve some form of random selection of locations (Gilbert 1987; EPA 2002). EPA (2002) describes additional sampling strategies, including adaptive cluster sampling, which may be optimal when the characteristic of interest is sparsely distributed but highly aggregated. Generally included in the "statistical" category is geostatistical analysis of sampling results. Geostatistical methods can be used with either grid sampling or random sampling. A number of tools exist to facilitate the use of geostatistical analyses, including the EPA's Geostatistical Environmental Assessment Software (Geo-EAS) (EPA 1992).

Geostatistical modeling can assist with numerous decisions necessary after wide-area contamination. A geostatistical modeling analysis can provide maps of the distribution of BWA contamination based on sampling results, uncertainty assessments, probability maps, and optimal sampling design for characterization activities. The methods do not account for transport mechanisms or reaerosolization. Therefore, geostatistical models provide a basis for evaluating the spatial distribution of contaminants at a given time but not event reconstruction or transport per se.

A geostatistical modeling approach provides a way to estimate the spatial distribution of contamination (e.g., a contour map of surface contaminant concentrations). Sample data are fit to a spatial correlation model that, in turn, is used to predict contaminant concentrations throughout an area of interest. A geostatistical model can provide quantitative estimates of uncertainty in contaminant distribution and produce a probability map. For instance, a map showing the probability of exceeding a defined concentration threshold (e.g., a zone boundary) would be useful for planning the decontamination strategy. Geostatistical models provide a more rigorous interpretation of spatial distribution than contouring algorithms that use simple interpolation by accounting for spatial correlation and uncertainty. EPA has used geostatistical modeling to delineate the spatial distribution of contamination for remediation purposes (Englund and Heravi, 1994).

Geostatistical models are also coupled with optimization routines to provide an alternative sampling design method. Traditional statistical approaches do not account for spatial variability in the manner of geostatistical models and may lead to larger numbers of samples to obtain desired confidence goals. An approach that combines geostatistical modeling with optimization has the potential to reduce the number of samples required for characterization compared to more conventional methods. With this type of method, the proposed sample design is optimized to delineate the area where concentrations are nearly at the risk-based cleanup guideline, so locations with a high probability of being either below or above the guideline would not be sampled, thereby reducing the number of samples. Geostatistical models are readily available but not computationally burdensome, and they can provide near-real-time analysis when used in a decision-support tool (Section 7.5.2). Such models require each sample to have well-defined spatial coordinates and are therefore well suited to surface sampling results.

Numerous incident-specific details determine the number of characterization samples required. If statistical sampling designs are used, the number of samples will depend, at a minimum, on desired confidence levels, type of statistical analysis performed, and the variability of agent concentrations in the environment. For any statistical analysis using average concentrations, the 


\section{Characterization}

number of samples depends on the desired precision with which the average is to be estimated, the desired confidence level associated with that precision, variability of concentrations relative to the average concentration, and statistical distribution of that variability (e.g., symmetric or skewed). None of those elements can be known in advance of an incident. Following an attack, a small first round of sampling could be done to estimate the variability for use in subsequent statistical sample planning, but such estimates would probably be valid only within a relatively limited spatial extent.

For statistical analyses based on presence versus absence of surface contamination at detectable levels, the number of samples can be determined in advance for certain narrowly defined questions. Suppose there is a large and open area with upward facing surfaces all of the same type (a large parking lot, for example), and it is unknown that spores reached the area. If samples are collected on such surfaces, and at least one sample contains spores, then the question is answered in the affirmative. If no sample contains spores, the question is not answered in the negative. If deposition is heavy and uniform, it should not be difficult to sample and discover its presence, and only a few samples would be needed. However, if deposition is light and patchy, discovery is less likely, and the more patchy, the less likely. Suppose the decision is made that if spores have reached the area, and deposition is such that $5 \%$ or more of the surface area available for sampling is contaminated at detectable levels, then there should be a $99 \%$ probability of discovering the fact that spores reached the area. In this case, Table 7-3 shows that 90 randomly placed samples meet the design criteria. This type of strategy is well known in industrial qualitycontrol applications under the name of acceptance sampling (Montgomery 1997).

The most extreme example in Table 7-3, namely a 99\% probability of discovering contamination present at detectable levels in only $1 \%$ of the area, illustrates a basic truth about discovery sampling: many samples are required to find something rare (the needle in the haystack effect). Furthermore, the example applies only to a single, defined area. Defining the boundaries of areas is not necessarily easy, and if such an approach were used following wide-area contamination, there would be many areas. In addition, relatively few outdoor sites are as physically simple and nearly homogenous as a large parking lot consisting principally of upward-facing concrete or asphalt.

The phrase "at detectable levels" is key to the example statistical approach. At low environmental levels, collection and extraction efficiencies of the sampling and analytical methods come into play, and any agent that is present might not be detected. Failure to detect is one of the challenges of agent discovery, and although more sophisticated statistical models can take the challenge into account (by requiring more samples), the present example was kept simple, and does not lead to more samples. For such reasons, a simple strategy is not likely to be practical if high confidence levels are required, and alternate strategies would need to be identified [for example, combined judgmental random sampling; see Section 9.3.2 (Sego et al. 2010)]. 


\section{Characterization}

Table 7-3. Number of samples required for simple discovery sampling.

\begin{tabular}{|c|c|c|c|c|}
\hline \multirow{2}{*}{$\begin{array}{c}\text { Surface area with } \\
\text { detectable levels }\end{array}$} & \multicolumn{4}{|c|}{ Desired probability of discovery } \\
\cline { 2 - 5 } & $\mathbf{8 0 \%}$ & $\mathbf{9 0 \%}$ & $\mathbf{9 5 \%}$ & $\mathbf{9 9 \%}$ \\
\hline $1 \%$ & 161 & 230 & 299 & 459 \\
\hline $5 \%$ & 32 & 45 & 59 & 90 \\
\hline $10 \%$ & 16 & 22 & 29 & 44 \\
\hline $15 \%$ & 10 & 15 & 19 & 29 \\
\hline
\end{tabular}

The simple statistical approaches just described are based on relatively simple mathematical (probability) models and the sampling process, and they consider only information derived from sampling. Substantial reduction in the number of samples may be possible by taking into account other information. In the parking lot example, there might be locations where particles are more likely to settle or remain after settling. If such locations could be identified, it might be possible to answer the question about the presence of BWA in the affirmative with only a few judiciously located samples. Such a possibility would require scientific knowledge of fate and transport indicating the nature of the locations. Other approaches to estimating the number of required samples depend even more on incident specifics. Additional model assumptions, such as geostatistical models described above, or fate and transport models described in Section 7.2.2, provide information that can be used to guide the selection of sample locations, reducing the need to densely blanket an entire area with samples.

Sampling strategies for various purposes are discussed in the next few sections. In addition to choosing sampling locations, sampling methods must be selected. In general, sampling methods should be those with the best ability to detect spores if they are in the area. For surface samples, detection is affected by small-scale heterogeneity of deposition (EPA 2003, Figure 6). To compensate for small-scale heterogeneity, surface samples should sample as large a surface area as possible, composite samples should be collected, or both (NRT 2005, Section 6.2.2).

\subsubsection{Sampling to Refine Outdoor Fate and Transport Models}

Outdoor sampling to refine fate and transport models consists of comparing model results with environmental sample results and then adjusting the model parameters (the model inputs) to optimize the correlation between them. To do so, it is necessary to collect and analyze samples using the same contamination characteristic as that used in model predictions.

Air sampling can be used for this purpose because the concentration data can be directly compared with predictions from atmospheric dispersion modeling of contamination. For example, model predictions of a 24-hr average air concentration at a given location can be directly compared to a 24 -hr air sample collected at that location. Air concentrations can vary with time; therefore, the 24-hr period(s) used for sampling should correspond with the $24 \mathrm{hr}$ for which the model is predicting air concentration. If an incident were to occur in a BioWatch city, air samples collected during the suspected time of the incident could be quite useful in quickly understanding the general extent of the contaminant plume. Similarly, if a model predicts average surface deposition over, say, an area of a few hundred square meters, then individual surface samples should be collected in an area of that size, and the results averaged. The amount 


\section{Characterization}

of heterogeneity from surface samples compared to the model uncertainty may indicate that the scale at which characterization is being performed is, or is not, appropriate for model refinement. Whether to use air samples, surface samples, or both in model refinement is an operational decision for fate and transport modeling experts.

A simple strategy for selecting sample locations with which to update a model is to collect samples along transects that extend to both sides of contours of interest. For example, if a model is used to predict the boundary of a remediation zone, then samples should be collected at intervals along a line (transect) extending beyond both sides of the predicted boundary. More generally, samples could be located in a grid pattern encompassing the entire predicted boundary. A grid pattern allows geostatistical methods to be applied to sampling results. Figure 7-8 shows an example transect/grid strategy. Irregular sample locations (i.e., not a perfect grid) would occur if an urban landscape prevents the use of a perfectly regular grid.

\subsubsection{Outdoor Sampling to Determine the Contaminated Zone}

When sampling surfaces to determine the boundary of a contaminated zone, it is appropriate to sample on both sides of an estimated boundary. Outside the boundary, there should be no detection of agent; inside, agent should be detected. However, deciding that contamination is present is easier than deciding it is not. Even a single positive sample can confirm that a BWA is present, but a single negative sample is not enough to decide with confidence that none is present. Therefore, sampling should be designed to have a high probability of detecting the biological agent if it is present.

A key question is whether or not to determine the boundaries of contamination zones according to viability (in contrast to remediation zones, the determination of which should be based on viability). B. anthracis spores only pose a health risk if they are viable, which would suggest the advisability of sampling followed by an analysis that determines spore viability. However, to the extent that viability analyses take substantially longer, using viability as a criterion will slow the determination of zone boundaries. Therefore, a suggested approach is to base the boundary determination primarily on PCR analyses, with a subset of samples also analyzed for viability. If many samples yield nonviable results, it may indicate that natural attenuation is taking place. In addition, the term "contaminated zone" is used here to refer to the entire affected area, that is the area within which spores from the original release are present. If spores are found, they are from the original release whether or not they are viable, unless there is a natural background of spores. 


\section{Characterization}

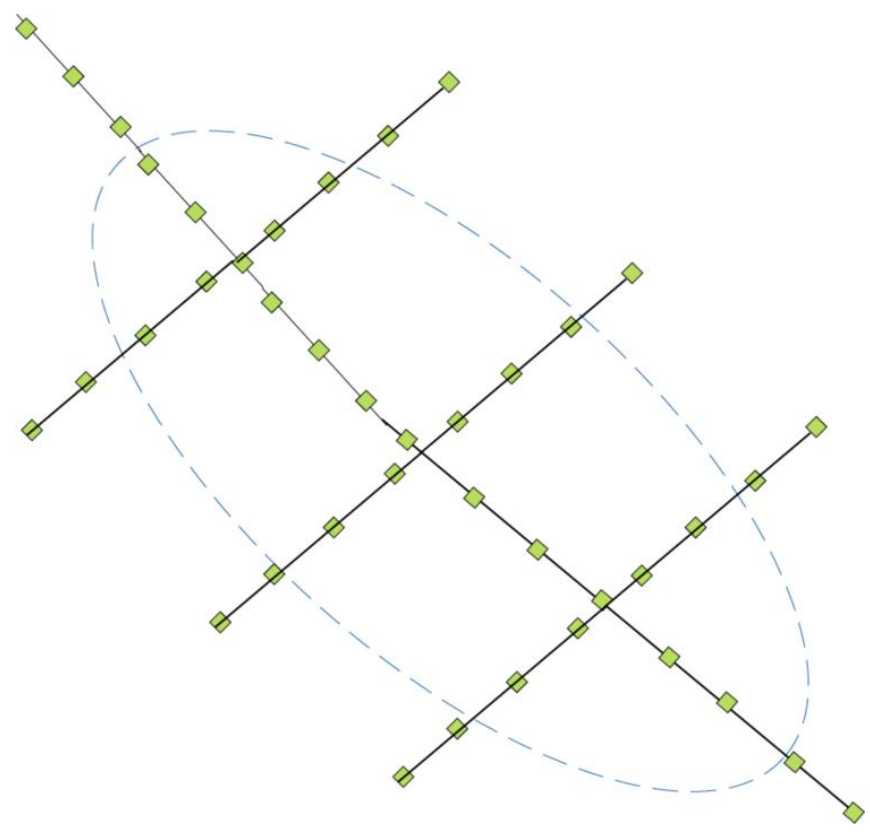

Figure 7-8. Example of grid/transect layout of sample locations to help refine a modeled concentration contour.

Ideal judgmental sampling locations are those that meet two criteria: (1) the agent is most likely to be deposited through atmospheric, fomite, or water-transport mechanisms; and (2) the agent is least likely to be removed through resuspension, fomite or water transport, biological decay, or other mechanisms. When particles arrive via atmospheric transport, the first criteria is satisfied by horizontal surfaces, such as roofs, and elevated objects with large surface areas, such as trees. In contrast, vertical surfaces including building walls and smooth surfaces such as sheet metal typically collect less material. The second criterion is met by "sticky" surfaces, such as corners and regions sheltered from wind or surfaces where electrostatic forces hold an agent on the surface (e.g., ATM screens). Judgment, guided by model predictions and an understanding of how material is deposited and moves in the environment, are applied to identify sampling locations. Among other considerations, selections would reflect meteorological data and identification of locations where an agent is easy to detect with available assay methods.

Random sampling can also be used to ensure a high probability of detecting the agent if it is present. For example, decision-makers might require a $95 \%$ probability of discovering the presence of the agent if it is present in 5\% or more of the available surface (see the discussion associated with Table 7-3). Geostatistical methods can be used with surface sampling to help locate the outer boundary of the contaminated zone.

If it is suspected that there may be hot spots (relatively small areas with relatively high concentration) and it is necessary to find them, a sampling grid can also be designed to yield a high probability of discovering a hot spot. The TWG would need to specify the size of the hot spot and desired probability of its discovery. 


\section{Characterization}

In addition to samples collected at pre-planned locations as part of a sampling plan, the use of native air samples, such as samples from air filters taken from major buildings, automobiles, buses, or trains should be considered. However, such sampling has yet to be validated for a widearea incident.

\subsubsection{Sampling for Risk Assessment}

Because inhalation represents the major health risk associated with a wide-area, biological, aerosolized release, high-volume air sampling must be done to understand actual risks associated with a specific incident (Section 6.5.2). Such sampling should collect breathable air at appropriate heights above ground. Although this method is recommended for use outdoors, highvolume air sampling could also be considered for use indoors to assess risk. It is important to ensure that an air sampling method maintains the viability of the BWA in the course of sample collection. It would also be appropriate to collect surface samples nearby and upwind of air sample locations and analyze them for viability if air sampling yields results that indicate the potential for inhalation risk.

Air sampling, especially high-volume air sampling, draws air from an area surrounding the sampler, including potentially some distance upwind. Therefore, it may not represent local environmental contamination, and cannot by itself determine a remediation zone boundary to within a distance less than the area from which the air is drawn. This is one reason that air dispersion models and environmental sampling are used jointly.

Sampling to assess health risk should include

- Identifying areas with the greatest predicted or confirmed air concentrations.

- Identifying areas with the greatest potential for exposure.

The two areas may not be the same, and the potential for exposure may differ for different agents. For example, dry and dusty areas outdoors may pose a substantial reaerosolization potential, whereas the greatest agent concentration may be on wet grass. High-traffic locations, such as entrances to subway stations or outdoor plazas where people congregate, are examples of areas with significant exposure potential. Other large-volume facilities, such as stadiums, may warrant this approach as well. Personnel from a local or regional air-quality management district should be consulted for information about suitable locations.

If initial risk assessments (Section 6) indicate that gastrointestinal or cutaneous disease risks are of concern, then sampling at locations associated with those exposure pathways should be included as well. Surface sampling is appropriate for cutaneous disease risk; samples should be collected at locations and on surfaces where transfer from the surface to skin is most likely to occur. Sampling for gastrointestinal disease risks should focus on materials likely to be ingested, which could include drinking water and consumable crops (especially those consumed without processing that would destroy spores).

Nasal swab screening of potentially exposed persons can be used with environmental sampling and an epidemiologic analysis of the nasal screening results to help determine the extent of exposure and to characterize for the purpose of remediation. Such screening would be especially helpful if exposure to residual contamination can be distinguished from exposure that took place during initial plume passage because the former can reveal areas where spores have traveled outside the original plume area. Similarly, an epidemiological analysis of disease cases, where 


\section{Characterization}

the timing of disease onset indicates post-plume exposure, could reveal post-plume spread beyond the original plume area.

\subsubsection{Sampling for Indoor Characterization}

Indoors, characterization should be just sufficient to support the anticipated or selected decontamination procedures. For example, suppose that the size of a building is such that if any part needs fumigation, then the entire building will be fumigated. In that case, the fumigation decision depends only on the presence of contamination somewhere in the building. It is unnecessary to determine that some portion is contaminated and another portion is not. In other words, the question of extent is simplified: as soon as BWA is discovered anywhere in a building, the decision is made, and sampling can stop. In this case, judgmental surface sampling at locations believed most likely to have the BWA present at detectable levels is appropriate. Examples include surfaces immediately inside entrances and exits, at HVAC system intake filters, and on electrostatic surfaces.

In contrast, if there is reason to suspect one or more unknown hot spots inside a facility, and it is judged worthwhile to bleach or tent and fumigate hot spots before fumigating the entire building, then characterization sampling must be designed to yield a high likelihood of discovering the hot spots. Therefore, an early characterization priority is to determine the likely decontamination method(s) and strategy.

If a first set of samples does not find contamination, it will be necessary to perform a more thorough characterization, or to decide that decontamination is not necessary. The latter choice would be essentially equivalent to deciding that the first characterization is also adequate for clearance. Such a decision is almost certainly untenable within the remediation zone or for any facility in which spore intrusion is considered likely. Either a more thorough characterization will be needed, or additional judgmental assumptions will be required.

\subsubsection{Sampling for Surface Water, Water Distribution Systems, and Wastewater Treatment Systems}

In consultation with area water authorities who know the water-distribution system, along with water-sampling experts and members of the TWG, if such as group is assembled, an assessment of the risk posed by water contamination should be performed, and, if necessary, a water sampling strategy devised. The strategy should specify (1) exact locations where water samples are to be taken from the water-distribution system, (2) frequency of sampling over time, (3) estimated duration of sampling, (4) types of analytical tests to be performed, and (5) analytical laboratories that perform the tests.

Drinking water sampling can include the following types of locations:

- Locations where surface water could have been exposed to the plume.

- Surface water locations used for drinking water storage.

- Existing locations in a water distribution system used for routine water-quality sampling.

- Locations where there is a buildup of biofilms or other organic matter that may trap spores.

- Locations where water exits the system, such as outdoor faucets. 


\section{Characterization}

- Key outdoor wastewater system sampling locations, such as secondary or tertiary treatment ponds.

\subsubsection{Select Sampling and Analysis Methods}

For each sample location and sample type (air, surface, bulk, or water), planners must select a specific sampling and analysis method. Validated methods are preferred, but few if any such methods currently exist for $B$. anthracis (Emanuel et al. 2008, Ch. 10; NRT 2005). The selection of sampling method(s) should be done by a qualified industrial hygienist or someone with appropriate training. Characterization planners should ideally select from standard analytical methods (SAMs) for environmental restoration following homeland security events. Planners should also seek sampling guidance from authorized laboratories that will carry out sample analysis to coordinate sampling procedures and volumes.

The following summary of sampling and analysis methods is adapted from Appendix $\mathrm{C}$ of LLNL, SNL, and LBL (2008). Emanuel et al. (2008) should also be consulted. The principal sample collection techniques currently available can be grouped into four categories.

- Air techniques, including dry and wet collection. High-volume air samplers such as the Portable Sampling Unit (PSU) typically collect 1,000 liters of air per minute (100 times the amount a typical person breathes in the same time) onto dry filter material. Air is typically collected over 12 to $24 \mathrm{hr}$. Air samplers such as the AGI-30 collect a low volume of air (12.5 L/min, 2-hr collection period) directly into a volume of liquid. The main advantage of this collection technique is that the liquid keeps cells viable for culture analysis. Trace-evidence vacuum samplers of the type employed by law enforcement agencies can be used. Agar plate air samplers can provide time-resolved air sampling measurements, and cascade impacters can be used for particle-size-distribution.

- Surface techniques, including swab, wipe, RODAC plates, and vacuum. Wipes can be used on hard, nonporous surfaces. Swabs, also recommended for nonporous surfaces, can be used to sample nooks, crannies, joints, and seams. To increase the ability to locate sparse contamination, the use of large-area samples (Buttner et al. 2004) with wipes is recommended, or HEPA vacuuming. Vacuum samples are recommended because they have the largest sample area. HEPA vacuuming can be used on asphalt, brick, and concrete; on porous materials, such as carpets and certain types of furniture; and on HVAC filters. The direct sampling method using RODAC agar plates (Becton-Dickinson, Franklin Lakes, NJ) is recommended for detecting and enumerating microorganisms on surfaces of sanitary importance. Swab and wipe materials available include cotton, polyester/nylon blends, and macrofoam (polyurethane). Vacuum attachment types in use are cardboard tube sock, high-efficiency nozzle sock, microvacuum filter cassette, and 3M trace-evidence filter (used by the forensic community). Some techniques are superior for small, directed sampling $\left(\mathrm{swab}=100 \mathrm{~cm}^{2} ;\right.$ RODAC $\left.=10 \mathrm{~mm}^{2}\right)$; others for larger-area sampling (wipes $=1 \mathrm{~m}^{2}$; vacuum $=1$ to 2 tablespoons of vacuumed debris).

- Bulk techniques for soil, water, and vegetation. Bulk samples can be collected from soil, water, and vegetation, and they are best collected in moist or wet areas without direct sunlight where spores might remain viable. For water, a sterile pipette is typically used to collect $5 \mathrm{ml}$ of water into a standard, sterile, capped, conical test tube. 


\section{Characterization}

- Aerial-based collection. Methods from the air pollution and climate research fields, such as the relaxed eddy-flux correlation technique (Nie et al. 1995), directly measures net resuspension and deposition. The technique can be mobile (via airplane) and can work with the filter and polyurethane foam collection methods used for biological sampling (Zhu et al. 1998). Such methods have the potential to provide regional estimates of concentration, resuspension, or deposition with a reduced number of samples.

Planners should contact analytical laboratories for specific recommendations about sampling methods that are compatible with their analytical methods. The principal analytical methods currently available are:

- Plate count/culture. Plate count is generally deemed the gold standard for determining microbial presence and viability (ASTM International 1998). Colonies are counted to estimate the number present in the original sample, and suspected colony isolates are subjected to further phenotypic or genotypic testing for definitive identification or strain determination. The process takes $48 \mathrm{hr}$ but can be automated to speed the plating process.

- Replicate Organism Detection and Counting (RODAC) plates. The RODAC procedure is both a surface-sampling and detection technique. Plates are specially constructed with dome-shaped agar medium to contact the surface being sampled (10-mm total sampled). After incubation, the plates are manually counted for the presence of viable bacteria. The test takes a minimum of $48 \mathrm{hr}$ (Angelotti et al. 1964; Bond and Sehulster 2004).

- Polymerase chain reaction (PCR). This technique is used by the BioWatch Program for air monitoring of pathogens in the environment. Currently, real-time PCR is performed where specific and unique DNA sequences representing biothreat agents are amplified from the liquid suspension of an air filter, swab, swipe, or vacuum sock. The analysis takes 4 to $8 \mathrm{hr}$. Viability is not determined; if an organism is detected, another technique must be used to determine viability.

- Rapid-viability polymerase chain reaction (RV-PCR). This method tests a liquid suspension of the extracted sample before and after a short growth period using a real-time PCR assay. If an increase in the amount of DNA is detected, then the spores have germinated and are viable. The test can detect 1 to 10 live spores in a high dead-spore background $\left(10^{8}\right.$ spores/ml). The process takes $17 \mathrm{hr}$ (Kane et al. 2007). This method could be used in parallel with standard LRN procedures if timeline to results is critical.

- Analysis in the Field. Handheld devices (i.e., HANAA; Koopman and Schmidt, 2001) or other methods (i.e., smart tickets) could be used by first responders along with standard LRN laboratory analyses. Results from handheld devices are not public health actionable.

The varied collection methods have different efficiencies that depend on several variables. For sample collection, the main variables are:

- $\quad$ Surface being sampled (e.g., porous versus nonporous).

- Material used for sampling (e.g., macrofoam versus cotton).

- Amount of background interference present.

- Target organism being sampled (spore versus vegetative cell).

- Recovery efficiency (effectiveness of the sampling medium to grab spores off the collection surface for subsequent detection). 


\section{Characterization}

For sample analysis, the main variables are:

- Extraction efficiency (effectiveness of spore transfer from sampling medium to liquid medium, and the agitation method used).

- Degree to which microbial degradation occurs on the surface sampled and during transport.

- DNA extraction efficiency, which is related to the ability to release DNA from spores.

- Amount of biological background present in the environmental sample.

- Presence of certain chemicals in the environmental sample.

The last two variables, above, can interfere with both PCR and culture-detection sensitivities.

Table 7-4 is a summary of laboratory experiments reporting limits of detection (LODs) for surface sampling methods. Whether or not field use of such methods will achieve similar LODs is unknown. For comprehensive details on the CDC's LRN environmental-sample-collection techniques, see <http://emergency.cdc.gov/agent/anthrax/environmental-sampling-apr2002.asp>.

Table 7-4. Estimated limits of detection for selected surface sampling methods.

\begin{tabular}{|c|c|c|c|}
\hline $\begin{array}{l}\text { Sampling } \\
\text { method }\end{array}$ & Details & Surface material & Limit of detection \\
\hline $\mathrm{Swab}^{\mathrm{a}}$ & $\begin{array}{l}\text { Polyester/rayon swabs pre- } \\
\text { moistened with sterile } \\
\text { deionized water }\end{array}$ & $\begin{array}{c}\text { Stainless steel, painted } \\
\text { wallboard }\end{array}$ & $25 \mathrm{CFU} / \mathrm{m}^{2}$ \\
\hline \multirow[t]{4}{*}{ Vacuum sock ${ }^{b}$} & - & Stainless steel & $500 \mathrm{CFU} / \mathrm{m}^{2}$ \\
\hline & - & Painted wallboard & $600 \mathrm{CFU} / \mathrm{m}^{2}$ \\
\hline & - & Carpet & $525 \mathrm{CFU} / \mathrm{m}^{2}$ \\
\hline & - & Bare concrete & $800 \mathrm{CFU} / \mathrm{m}^{2}$ \\
\hline \multirow[t]{2}{*}{ BiSKit sponge $^{c}$} & Dry & Metal & $42.5 \mathrm{CFU} / \mathrm{m}^{2}$ \\
\hline & Wet & Metal & $100.5 \mathrm{CFU} / \mathrm{m}^{2}$ \\
\hline
\end{tabular}

When planning sampling strategies and goals, laboratories responsible for sample processing should be consulted to estimate capacity and throughput for different sampling media. The 2001 anthrax response revealed many knowledge gaps in environmental sampling, and several Government Accountability Office (GAO) reports comment on the state of environmental sampling (Rhodes 2005, 2006). Although no standards are in place today specifying which collection methods are most appropriate for a given situation, if an event were to occur today, sampling procedures such as those in <http://www.bt.cdc.gov/Agent/Anthrax/environmentalsampling-apr2002.asp > or Emanuel et al. (2008) would likely be used. 


\section{Characterization}

\subsubsection{Determine Laboratory Analytical Capacities}

The EPA would likely lead the sampling teams during characterization. Estimating the total number of samples that could be collected per day is difficult. However, using Baseline Scenario \#1 (Section 1.6.1) as an example, it is estimated that 75 three-person teams would be able to collect surface samples at the rate of 4 samples per hr. Assuming a 4-hr work shift (taking into account the considerable logistics of a sampling program), 1,200 surface samples could be collected per day. The actual number could vary greatly depending on the number of teams, types of samples taken, proximity of sampling locations, and other logistical factors. The number of air samples would likely be fewer because air sampling units are usually placed in the field where they operate for a specified period before samples are retrieved.

Laboratory analysis of samples collected during characterization would be done, for the most part, by means of high-throughput PCR using protocols approved for the CDC Laboratory Response Network (LRN) public health laboratories. In a partnership of the CDC, FBI, and Association of Public Health Laboratories, the LRN fulfills the Federal responsibility of rapid sample testing and identification of biological (and other) threat agents through established protocols and reagents. About 160 LRN laboratories operate nationwide. Current mobile laboratory capability consists of one DHS BioWatch laboratory stationed at LLNL, with the capability for other units, if appropriate. The mobile BioWatch laboratory and other deployable assets can provide surge support during an emergency. Table 7-5 summarizes estimated analytical capacities, available through existing DHS resources, of the three types of analytical laboratory assets.

Table 7-5. Current environmental sample-processing capacities of analytical laboratories.

\begin{tabular}{|l|l|l|l|}
\hline Laboratory asset & \multicolumn{1}{|c|}{ Sample media } & \multicolumn{1}{c|}{ Available methods } & \multicolumn{1}{c|}{ Daily capacity } \\
\hline $\begin{array}{l}\text { Typical LRN } \\
\text { (the CDC LRN } \\
\text { network) }\end{array}$ & $\begin{array}{l}\text { Swab, wipe, air filter, } \\
\text { vacuum sock, 3M trace- } \\
\text { evidence filter, soil, } \\
\text { water, vegetation }\end{array}$ & Real-time PCR; culture & $\begin{array}{l}50 \text { to 100 samples wipe and swab } \\
\text { <10/day vacuum sock, 3M filter, } \\
\text { soil and vegetation } \\
\text { Varies by laboratory; some LRN } \\
\text { laboratories may not be equipped to } \\
\text { process environmental samples. }\end{array}$ \\
\hline $\begin{array}{l}\text { Mobile and fixed } \\
\text { high throughput } \\
\text { (HTP) assets for } \\
\text { rapid detection } \\
\text { (e.g., LLNL mobile } \\
\text { laboratory, CSTs) }\end{array}$ & $\begin{array}{l}\text { Swab, wipe, air filter, } \\
\text { vacuum sock, soil, 3M } \\
\text { trace-evidence filter, } \\
\text { water, vegetation }\end{array}$ & $\begin{array}{l}\text { Real-time PCR } \\
\text { (methods depend on asset) }\end{array}$ & $\begin{array}{l}\text { 10s to100s } \\
\text { Depends on sample type }\end{array}$ \\
\hline $\begin{array}{l}\text { Remote support } \\
\text { from fixed assets } \\
\text { (e.g., LLNL RV- } \\
\text { PCR laboratory) }\end{array}$ & $\begin{array}{l}\text { Swab, wipe, air filter, } \\
\text { vacuum sock, 3M trace } \\
\text { evidence filter, soil, } \\
\text { water, vegetation }\end{array}$ & $\begin{array}{l}\text { RV-PCR } \\
\text { (methods depend on asset) }\end{array}$ & $\begin{array}{l}\text { 100s } \\
\text { Depends on sample type }\end{array}$ \\
\hline
\end{tabular}

Sample analysis requirements for all remediation phases (characterization, decontamination, and clearance) for a wide-area event would likely be done through a coordinated approach involving 


\section{Characterization}

all available laboratory assets to manage the overall resources available, the diversity of sample types, and sample surge. To help deal with numerous samples, a rapid-detection asset (e.g., mobile laboratory) could be used to quickly screen thousands of samples for presence or absence of the targeted BWA, and a prioritized subset could then be sent to an LRN laboratory for culturing. The HTP mobile laboratory is currently transported to an incident by truck, so the delivery time would be approximately three to five days for a cross-country deployment in the continental U.S., depending on the number of scheduled drivers. Samples can also be sent to other locations, such as the CDC in Atlanta, GA, the National Bio-Forensic Analysis Center (NBFAC) in Frederick, MD, and the Naval Medical Research Center (NMRC) in Bethesda, MD. These three laboratories have knowledgeable staff and the instrumentation necessary to perform analyses. Because these three labs likely could take some samples, but probably not hundreds, they are not included in the following estimates.

Although the total LRN capacity is large (50 to 100 samples/day $\times 150$ labs $=7,500$ to 15,100 samples/day), it will be difficult to achieve such throughput. The logistics of delivering samples to many laboratories would be challenging. In addition, given a confirmed wide-area release somewhere in the nation, other regions might increase their sampling and use some of that capacity. LRN laboratories may also be sent many clinical samples, likely to have a higher priority, so their ability to support wide-area characterization may be limited and could impact environmental sampling capability. The EPA Environmental Response Laboratory Network (ERLN) may also provide primary or secondary laboratory analysis support for such an effort by utilizing interagency agreements to access biological sample analysis capacity from its Federal partners. The ERLN currently leverages the LRN for core laboratory capabilities related to biothreat response, and using all available assets should accommodate a minimum of 1,200 samples per day, per Table 7-5. Analytical capacity is expected to increase as additional laboratory resources come online. In any event, it is essential to discuss incident scenarios with local LRNs to better understand the sample throughput that could be anticipated during a widearea event.

\subsection{Address Health Measures, and Provide for Worker Decontamination}

A Health and Safety Plan (HASP) is a written plan required under the Occupational Health and Safety Administration's (OSHA's) Hazardous Waste Operations and Emergency Response (HAZWOPER) standard (29 CFR 1910.120) for characterization, decontamination, and clearance activities. The HASP describes physical, chemical, and biological hazards at a site and should include procedures for discovering unknown hazards. The plan describes the establishment of HazMat hot, warm, and cold zones; PPE requirements; personal decontamination procedures; and emergency procedures to be used by sampling and decontamination personnel. It can include prophylaxis requirements for workers. The IC or UC, through the Site Safety Officer, is responsible for ensuring the health and safety of responding entities. The ICS planning process includes HASP development to ensure that consistent and coordinated health and safety measures are in place for all responders. The Site Safety Officer coordinates with the Logistics Section's Medical Unit with regard to the HASP. More than one may be required for a wide-area response. One possible approach is to start with a HASP suitable for characterization activities and update it as necessary for subsequent activities. 


\section{Characterization}

A model HASP for $B$. anthracis response is provided by OSHA (January 2006) at: $<$ http://www.osha.gov/dep/anthrax/hasp $>$. Additional resources include:

- The EPA's Health and Safety Manual and Field Guide, available at: <http://epaosc.org/ HealthSafetyManual/specific.htm>.

- A Consolidated Site-Specific Health \& Safety Plan (HASP) template, which is available from EPA Region 9 staff.

- Rocky Mountain Arsenal, Procedures Manual to the Technical Plan, Volume 3: Project Health and Safety Plan, which is available for purchase at: <http://www.stormingmedia.us/09/0911/A091192.html>.

- Anthrax eTool (OSHA); <http://www.osha.gov/dep/etools/ehasp/index.html>.

- Technical Assistance for Anthrax Response (2005), Chapter 5: Health and Safety Considerations (NRT); available electronically at <http://www.nrt.org/production/NRT/ NRTWeb.nsf/PagesByLevelCat/Level2TA?Opendocument $>$.

- Interim Recommendations for the Selection and Use of Protective Clothing and Respirators Against Biological Agents, which is available at: <http://emergency.cdc.gov/documentsapp/Anthrax/Protective/10242001Protect.asp〉.

\subsection{Conduct Characterization Environmental Sampling, and Evaluate Results (Box 305-3)}

Once sampling locations and analytical methods have been selected, all characterization goals are identified, and the necessary supporting information developed, a draft Characterization Sampling and Analysis Plan (SAP) is prepared. Upon completing the draft of a Characterization SAP an internal review is initiated. Upon approval of the plan by the IC or UC, characterization commences for the designated area. The Sampling Group within the Operations Section of the ICS implements the Characterization SAP with the assistance of teams of trained samplers. Upon completion of characterization activities, first-round results are evaluated for completeness by the EU and the IC or UC, with input from the TWG. If necessary, the Characterization SAP is revised, and additional characterization activities are recommended and implemented as needed. The process is repeated for areas or facilities designated with the next-highest priority for remediation.

\subsection{Conduct Environmental Risk Assessment for Remediation (Box 306)}

As part of risk management described in Section 6, potential risks posed by a BWA must be assessed (Figure 7-9, Box 306-1) to help decision-makers set clearance goals, formulate a decontamination strategy, and develop a Remediation Action Plan (Section 8). Characterization supports risk assessment by collecting and evaluating as much information as possible about the biological agent, and then providing decision-makers with a scientifically reliable, quantitative or qualitative estimate of the potential level of risk to humans, animals, and the environment. After sufficient characterization data have been acquired, the risk assessment should be updated following procedures detailed in Section 6. 


\section{Characterization}

\section{CHARACTERIZATION (306 expanded)}
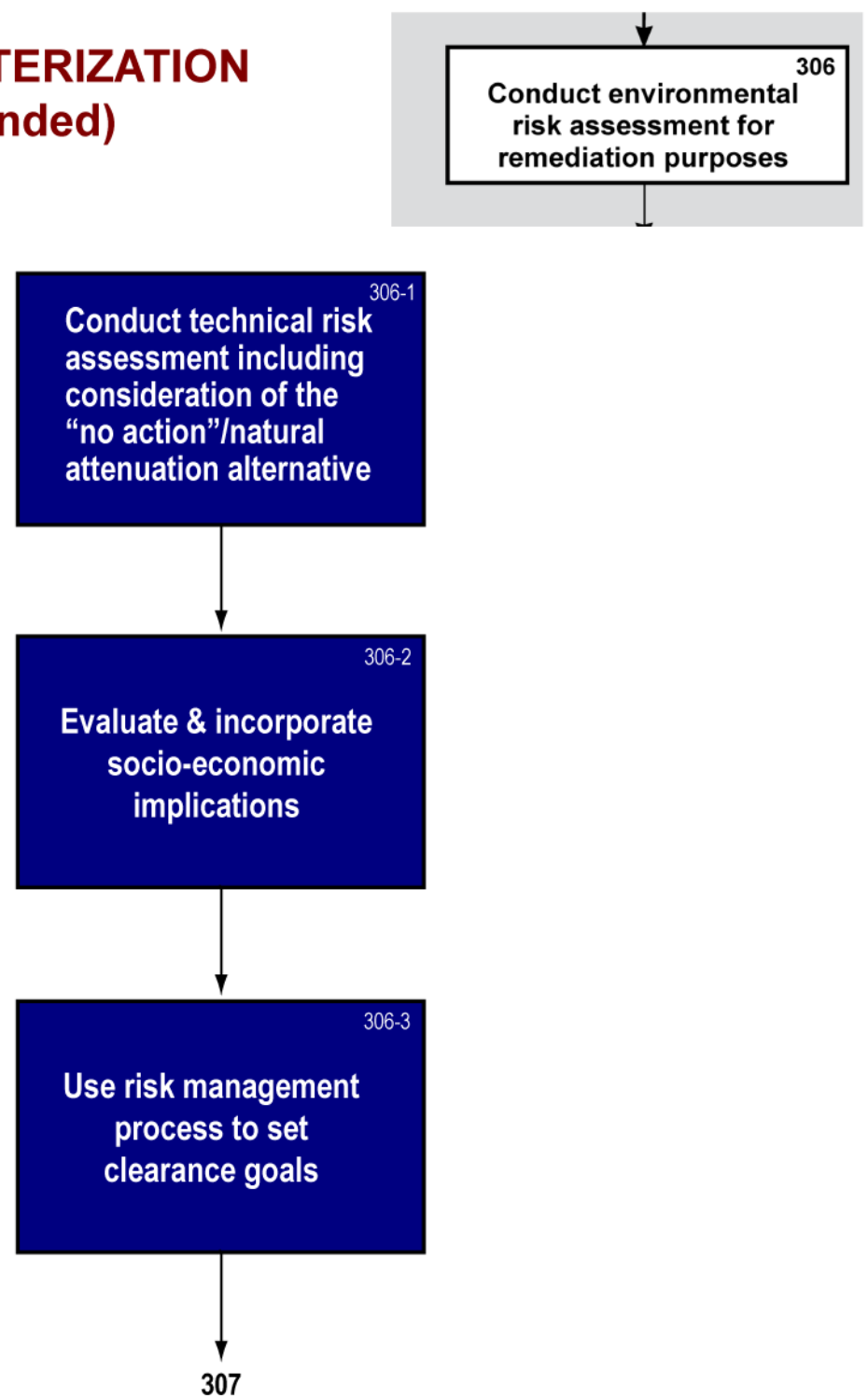

Figure 7-9. Expanded Box 306: conduct environmental risk assessment for remediation purposes.

\subsection{Establish Clearance Goals (Box 307)}

Issues pertinent to clearance goals and clearance criteria are discussed in Section 6 and earlier in Section 7. For a wide-area application the collective, professional judgment of technical experts, within the context of stakeholder concerns and socio-economic implications (Box 306-2), will be used to set clearance goals (Raber et al. 2001) appropriate to site-specific circumstances (Box 306-3). Currently, and on the bases of literature reviews and judgments made during the 2001 anthrax attacks, the best estimation for what an indoor clearance goal will be (Box 307) is no growth on any clearance sample (Canter 2005). Clearance goals are reviewed as characterization 


\section{Characterization}

progresses, and they could potentially change. The current default clearance goal just mentioned (see Section 6) would likely be used at the beginning of characterization and until such time as an incident-specific clearance goal is developed. Clearance goals for outdoor areas and waterdistribution systems subject to a wide-area attack are not presently codified; see Section 6.5.3 for more information.

\subsection{Reassess Public Health and Medical Options (Boxes 308-313, 315)}

Results from characterization activities are also used to re-evaluate public health decisions and determine any additional actions to minimize health risks. If BWA contamination is extensive and natural attenuation (Boxes 308-313) is inadequate to eliminate human health impacts, intermediate goals may be set, complemented by other interventions (Box 315), such as prophylaxis, vaccination, shelter-in-place advisories, medical monitoring, PPE, and other ESF \#6 and ESF \#8 mass-care considerations. At this point in remediation, medical treatment, patient care, and public health options would be re-evaluated and decisions implemented as necessary.

\subsection{Reassess Risk Management and Communication (Box 316)}

Risk-management considerations, including the potential use of public health interventions, the cost and feasibility of decontamination options, past experience in similar situations, public perception of acceptable risk, and regulatory and stakeholder needs, should be reassessed now in view of all characterization and other data. For example, if an epidemiological investigation suggests that an agent was present in a specific area, but none can be detected by characterization sampling and analysis, then a risk management decision could be made to use a decontaminant, providing some assurance to the public that health risk has been reduced as much as possible.

Ideally, a risk communication plan should be developed and ready for implementation before a biological incident occurs. However, because every crisis evolves in phases, targeted communication must evolve with the phases. Section 4.2.7 discusses risk communication strategies in more detail. Effective communication reduces the likelihood that scarce public health and safety resources might be misallocated (e.g., through pressures arising from incomplete information or misinformation), or that public health and safety recommendations are ignored or circumvented. Decision-makers should update and implement risk communication messages to the public in light of all new data arising from characterization results and other pertinent input. Additional information on risk communication is available from the CDC's Crisis and Emergency Risk Communication (Reynolds 2002) and in the NRT (2005).

\subsection{Section 7 Summary of Actions}

Although complete wide-area characterization protocols are not established at present, Table 7-6 lists recommended characterization actions if a wide-area BWA release were to occur today. 


\section{Characterization}

\section{Table 7-6. Summary of characterization actions in approximate order of unfolding events.}

\begin{tabular}{|c|c|}
\hline Responsible Personnel & Action \\
\hline $\begin{array}{l}\text { Planning Section: Situation } \\
\text { Unit }\end{array}$ & $\begin{array}{l}\text { Compile all analytical and observational data and reports created during first } \\
\text { response, and provide the information to the Environmental Unit. Using preliminary } \\
\text { sampling data and models, establish preliminary boundaries for "decontamination" } \\
\text { and "remediation" zones. Estimate source areas for reaerosolization or tracking. }\end{array}$ \\
\hline \multirow[t]{4}{*}{$\begin{array}{l}\text { IC or UC (or appropriate Unit } \\
\text { Leader in a large incident) }\end{array}$} & $\begin{array}{l}\text { Work with stakeholders to prioritize areas and facilities for detailed characterization } \\
\text { to better define zone boundaries, and to characterize MEI and other critical } \\
\text { infrastructure. Proceed in accordance with Section } 5 \text {. }\end{array}$ \\
\hline & $\begin{array}{l}\text { Mobilize as necessary all resources for characterization activities, including: } \\
\text { - Laboratory Response Network (LRN) laboratories. } \\
\text { - Environmental sampling teams, decontamination and disposal resources, and PPE. } \\
\text { - Data management and documentation specialists. } \\
\text { - Fate and transport modeling resources. }\end{array}$ \\
\hline & $\begin{array}{l}\text { Activate TWG and ECC if desired; establish lines of authority and responsibilities. } \\
\text { Establish perimeter and access control for remediation zones. }\end{array}$ \\
\hline & Begin notifying resources for remediation, clearance, and waste management. \\
\hline $\begin{array}{l}\text { Site Safety Officer and } \\
\text { Medical Unit }\end{array}$ & $\begin{array}{l}\text { Create Health and Safety Plan (HASP), and determine appropriate PPE. } \\
\text { Vaccinate or provide antibiotics to appropriate cleanup and response personnel. }\end{array}$ \\
\hline $\begin{array}{l}\text { Facilities, Public Works, and } \\
\text { other applicable agencies }\end{array}$ & $\begin{array}{l}\text { Provide maps or blueprints of areas and structures affected (including HVAC } \\
\text { systems, sewers, power, and water) to Planning Section, Documentation Unit. }\end{array}$ \\
\hline $\begin{array}{l}\text { Planning Section: } \\
\text { Environmental Unit }\end{array}$ & $\begin{array}{l}\text { - Consider and recommend to the IC or UC immediate agent containment and source } \\
\text { reduction, if needed. } \\
\text { - Implement recommended agent containment actions. } \\
\text { - Depending on actions completed during first response: (1) assess potential } \\
\text { contaminant transport, (2) evaluate the need for air monitoring, and (3) evaluate } \\
\text { the need for conceptual or mathematical modeling. } \\
\text { - Evaluate the need for fate and transport modeling to estimate initial extent of } \\
\text { contamination. } \\
\text { - Evaluate the need for geostatistical modeling to estimate initial extent of } \\
\text { contamination. } \\
\text { - Establish process for periodic or on-demand updating of models. }\end{array}$ \\
\hline Operations Section & $\begin{array}{l}\text { - Characterize source areas as soon as possible. } \\
\text { - Begin containment activities as soon as possible. } \\
\text { - Perform air monitoring to detect BWA spread and potential exposure. } \\
\text { - Reassess agent containment, and establish isolation for fumigation, if needed. }\end{array}$ \\
\hline $\begin{array}{l}\text { Planning Section: EU, with } \\
\text { input from Sampling Group } \\
\text { and TWG }\end{array}$ & $\begin{array}{l}\text { Develop risk-based clearance goals and a characterization sampling strategy to } \\
\text { support remediation activities. Identify resource limitations. } \\
\text { Write zone-specific Characterization Environmental SAP with all goals identified. }\end{array}$ \\
\hline Ops Section Chief and UC & Approve the Characterization Environmental Sampling and Analysis Plan. \\
\hline Ops Section: Sampling Group & Implement the Characterization Environmental Sampling and Analysis Plan. \\
\hline $\begin{array}{l}\text { LRN or other CDC-approved } \\
\text { laboratories }\end{array}$ & $\begin{array}{l}\text { Analyze samples to meet goals of Characterization SAP, including identifying } \\
\text { characteristics of bioagent (e.g., survivability, toxicity, and ability to reaerosolize). }\end{array}$ \\
\hline $\begin{array}{l}\text { IC or UC, with input from } \\
\text { Technical Working Group }\end{array}$ & $\begin{array}{l}\text { Evaluate results of characterization. Recommend additional characterization } \\
\text { activities to Planning Section, if needed. Work with decontamination and } \\
\text { prioritization units through the UC to update activities. }\end{array}$ \\
\hline
\end{tabular}




\subsection{Interim Recommendations for Characterization}

\section{Table 7-7. Summary of interim recommendations for characterization.}

\begin{tabular}{|c|c|}
\hline Recommended action or process & Comments and qualifications \\
\hline $\begin{array}{l}\text { Modeling: } \\
\text { - Consult with fate and transport modeling experts to } \\
\text { extrapolate the extent of contamination from surface } \\
\text { and air sampling results that are available. } \\
\text { - Obtain any initial dispersion modeling results, then } \\
\text { as part of an iterative process to determine the } \\
\text { extent of contamination, update assessments as new } \\
\text { sampling data become available. }\end{array}$ & $\begin{array}{l}\text { - Zone boundaries are determined by contaminant levels } \\
\text { and health-risk assessments (Section } 6 \text { ). } \\
\text { - Per the NRF, contact IMAAC to perform fate and } \\
\text { transport modeling. }\end{array}$ \\
\hline $\begin{array}{l}\text { Sampling strategies: } \\
\text { - Address the issue of whether or not to decontaminate } \\
\text { as the sole purpose of sampling. } \\
\text { - Determine appropriate characterization } \\
\text { environmental sampling strategies. Consider } \\
\text { judgmental, systematic, statistical, and geostatistical } \\
\text { approaches }\end{array}$ & $\begin{array}{l}\text { Evaluate sampling strategies appropriate to the spatial } \\
\text { scale and specifics of the incident. For example, obtain: } \\
\text { - Judgmental samples to target specific locations. } \\
\text { - Systematic samples based on grids or transects. } \\
\text { - Statistical samples to evaluate random locations. } \\
\text { - Geostatistical analyses to optimize sampling design. } \\
\text { Assemble sample-collection teams. }\end{array}$ \\
\hline $\begin{array}{l}\text { Sampling methods: } \\
\text { - Determine appropriate sampling methods for } \\
\text { potentially contaminated outdoor, indoor, semi- } \\
\text { enclosed, and water system locations. } \\
\text { - Aim sampling at determining whether or not a health } \\
\text { risk exists, with emphasis on inhalation risk for } \\
\text { B. anthracis. Understanding reaerosolization and } \\
\text { resuspension is the primary goal. }\end{array}$ & $\begin{array}{l}\text { Recommended methods are: } \\
\text { - Surface sampling to determine a contaminated zone(s) } \\
\text { and help define extent of contamination. } \\
\text { - HEPA vacuuming for porous surfaces, HVAC filters, } \\
\text { and all large-area samples, including those for } \\
\text { nonporous surfaces. } \\
\text { - Small numbers of wipes and swabs for nonporous } \\
\text { surfaces, as needed. } \\
\text { - High-volume air sampling to characterize inhalation } \\
\text { risk in the contaminated zones. } \\
\text { - Bulk samples for water distribution/treatment systems. }\end{array}$ \\
\hline $\begin{array}{l}\text { Laboratory analysis methods: } \\
\text { Use the best available sample analysis capabilities. } \\
\text { - Use PCR to test for the presence or absence of } \\
\text { biothreat agents, but not viability. RODAC agar } \\
\text { plates are recommended for detection on surfaces of } \\
\text { sanitary importance. } \\
\text { - Use RV-PCR when possible for rapid-viability } \\
\text { analysis. Plate count is the recommended "gold } \\
\text { standard" for determining the viability of B. } \\
\text { anthracis spores. }\end{array}$ & $\begin{array}{l}\text { - LRN laboratories can process } ~ 50 \text { to } 100 \text { samples/day } \\
\text { (daily throughput and types of samples that can be } \\
\text { analyzed vary across laboratories. } \\
\text { - LLNL mobile HTP lab can process } 100 \text { s to } 1000 \text { s of } \\
\text { most sample types per day; } 200 \text { soil or vacuum sock } \\
\text { samples/day. } \\
\text { - For more analysis support contact other labs, such as } \\
\text { - DHS LLNL/NCR BioWatch. } \\
\text { - DHS LLNL HTP BioWatch laboratory in } \\
\text { - Livermore, CA. } \\
\text { - CDC in Atlanta, GA. } \\
\text { - At least } 1200 \text { samples/day can be processed using } \\
\text { existing assets. }\end{array}$ \\
\hline
\end{tabular}




\section{Characterization}

\begin{tabular}{|c|c|}
\hline $\begin{array}{l}\text { Data Management methods: } \\
\text { - It is imperative to use a rapid data-collection, } \\
\text { processing, storage, and reporting system. } \\
\text { Recommend using systems with which local } \\
\text { responders are most familiar. } \\
\text { - Other tools would be used for statistical sampling } \\
\text { design, including VSP (offered by PNNL), } \\
\text { BROOM, and F/S Plus (EPA). }\end{array}$ & $\begin{array}{l}\text { Recommended methods today are: } \\
\text { Outdoors: } \\
\text { - SCRIBE - offered and used currently by EPA. } \\
\text { - Also consider the EPA Region } 6 \text { Response Manager } \\
\text { web-based system. } \\
\text { Indoors: } \\
\text { - BROOM - offered by SNL. }\end{array}$ \\
\hline $\begin{array}{l}\text { Iteration: } \\
\text { - Iteratively plan and perform sampling and modeling } \\
\text { to refine remediation zone and contamination zone } \\
\text { boundaries. } \\
\text { - Work to reassign indeterminate areas as either } \\
\text { needing or not needing remediation. } \\
\text { - Within remediation zones, categorize facilities or } \\
\text { functions according to the prioritization framework } \\
\text { (Section 5) and facility characteristics. }\end{array}$ & $\begin{array}{l}\text { - Characterization sampling and modeling must be } \\
\text { iterative processes because of acquisition of new data, } \\
\text { natural attenuation, tracking, reaerosolization, } \\
\text { resuspension, and other fate and transport mechanisms. } \\
\text { - The result of characterization is a list of areas and } \\
\text { facilities designated as needing remediation and } \\
\text { facilities or functions organized by remediation } \\
\text { priority. }\end{array}$ \\
\hline
\end{tabular}

\subsection{Section 7 References}

Abbott, M. L. (1999), Air Dispersion Modeling of Mine Waste In The Southeast Missouri Old Lead Belt, Idaho National Engineering and Environmental Laboratory, INEEL/EXT-99-00235 Revision 0.

Allwine, K. J., J. S. Shinn, G. E. Streit, K. L. Clawson, and M. Brown (2002), Bul. Amer. Meteor. Soc. 83, 521.

Angelotti, R., J. L. Wilson, W. Litsky, and W. G. Walter (1964), "Comparative Evaluation of the Cotton Swab and Rodac Methods for the Recovery of Bacillus subtilis Spore Contamination from Stainless Steel Surfaces.," Health Laboratory Sci. 1, 289-296.

ASTM International (1998), Standard Practice for Determining Microbial Colony Counts from Waters Analyzed by Plating Methods, ASTM Standard D5465-93.

ATSDR (1994), U.S. Department of Health and Human Services, Public Health Service, Agency for Toxic Substances and Disease Registry, Division of Health Assessment and Consultation, Environmental Data Needed for Public Health Assessments, A Guidance Manual; available at <http://www.atsdr.cdc.gov/ednpha.html\#ambient>, accessed May 4, 2009.

Bond, W. W. and L. Sehulster (2004), "Microbiological Assay of Environmental and MedicalDevice Surfaces," in Clinical Microbiology Procedures Handbook, $2^{\text {nd }}$ Edition, H. D. Isenberg, Ed., ASM Press, Washington, D.C.

Brown, G. S., R. G. Betty, J. E. Brockmann, et al. (2007a), "Evaluation of Rayon Swab Surface Sample Collection Method for Bacillus Spores from Non-Porous Surfaces," J Appl, Microbiol. DOI: 10.1111/j.1365-2672.2007.03331.x 


\section{Characterization}

Brown, G. S., R. G. Betty, J. E. Brockmann et al. (2007b), "Evaluation of Vacuum Sock Surface Sample Collection Method for Bacillus Spores from Porous and Non-Porous Surfaces," J. Environ. Monitoring 9, 666-671.

Buttner, M. P., P. Cruz, L. D. Stetzenbach, A. K. Klima-Comba, V. L. Stevens, and T. D. Cronin (2004a), "Determination of the Efficacy of Two Building Decontamination Strategies by Surface Sampling with Culture and Quantitative PCR Analysis," Appl. Environ. Microbiol. 70, 47404747.

Buttner, M. P., P. Cruz, L. D. Stetzenbach, A. K. Klima-Comba, V. L. Stevens, and P. A. Emanuel (2004b), "Evaluation of the Biological Sampling Kit (BiSKit) for Large-Area Surface Sampling," Appl. Environ. Microbiol. 70(12), 7040.

Canter, D. A. (2005), “Addressing Residual Risk Issues at Anthrax Cleanups: How Clean is Safe?” J. Toxicol. Environ. Health, Part A 68, 1017-1032.

CDC (2002), Centers for Disease Control and Prevention, Comprehensive Procedures for Collecting Environmental Samples for Culturing Bacillus anthracis; available at $<$ http://www.cdc.gov/niosh/unp-envsamp.html $>$.

Chan, S. T., and M. J. Leach (2007), “A Validation of FEM3MP with Joint Urban 2003 Data,” J. Appl. Meteor. Climatol. 46, 2127-2146.

Chan, W. R., W. W. Nazaroff, P. N. Price, and A. J. Gadgil (2007a), "Effectiveness of Urban Shelter-in-Place, I: Idealized Conditions," Atmospheric Env. 41, 4962-4976.

Chan, W. R., W. W. Nazaroff, P. N. Price, and A. J. Gadgil (2007b), "Effectiveness of Urban Shelter-in-Place, II: Residential Districts," Atmospheric Env. 41, 7082-7095.

Chow, F. K., B. Kosovism, and S. Chan (2008), "Source Inversion for Contaminant Plume Dispersion in Urban Environments Using Building-Resolving Simulation," J. Appl. Meteor. Climatol. 47, 1553-1572.

Crumbling, D. M., J. Griffith, and D.M. Powell (2003), “Improving Decision Quality: Making the Case for Adopting Next Generation Site Characterization Practice," Remediation: The Journal of Environmental Cleanup Costs, Technologies and Techniques 13(2), 91-111; available at <http://cluin.org/download/char/spring2003v13n2p91.pdf $>$.

DHHS (2002), Department of Health and Human Services, Guidance for Protecting Building Environments from Airborne Chemical, Biological, or Radiological Attacks, DHHS (NIOSH) Publication No. 2002-139.

DHS (2008), Department of Homeland Security, National Response Framework; documents available at <http://www.fema.gov/emergency/nrf/> .

Emanuel, P. et al. (2008), Sampling for Biological Agents in the Environment, ASM Press, Washington, D.C.

Englund, E. J. and N. Heravi (1994), "Phased Sampling for Soil Remediation," J. Environ. Ecol. Statistics 1, 247-263.

Fitch, J. P. et al. (2002), Proc. IEEE 90(11), 1708. 


\section{Characterization}

EPA (1992), U.S. Environmental Protection Agency, Geostatistical Environmental Assessment Software (Geo-EAS), by Evan Englund and Allen Sparks, Version 1.2.1, Environmental Monitoring Systems Laboratory, Las Vegas, NV.

EPA (2002), U.S. Environmental Protection Agency, Guidance on Choosing a Sampling Design for Environmental Data Collection, EPA QA/G-5S.

EPA (2003), United States Environmental Protection Agency, Guidance for Obtaining Representative Laboratory Analytical Subsamples from Particulate Laboratory Samples, EPA/600/R-03/027.

EPA (2005), United States Environmental Protection Agency, Decision Support ToolsDevelopment of a Screening Matrix for 20 Specific Software Tools U.S. Environmental Protection Agency Office of Superfund Remediation and Technology Innovation, Brownfields and Land Revitalization Technology Support Center, Washington, D.C.

EPA (2006), U.S. Environmental Protection Agency, Data Quality Objectives, EPA QA/G4.

EPA (2007), United States Environmental Protection Agency, Superfund Technical Assessment and Response Team (START III) Data Management Plan. Weston Solutions, Inc., July 2007, Revision 1.

IDQTF (2005), Intergovernmental Data Quality Task Force, Uniform Federal Policy for Quality Assurance Project Plans; EPA: EPA-505-B-04-990a and DOD: DTIC ADA 427785.

Kane, S., G. Murphy, and T. Alfaro (2007), "Development of Quantitative, High Throughput Rapid Viability PCR Protocols for the Detection of Bacillus anthracis on Surface Samples," Poster presentation, $107^{\text {th }}$ American Society for Microbiology General Meeting, Toronto, ON Canada May 21-25, 2007.

Koopman, R. P. and J. Schmidt (2001), HANAA: Putting DNA Identification in the Hands of First Responders, Lawrence Livermore National Laboratory, UCRL-JC-139443-Ext. ABS.

LBL (2004), Lawrence Berkeley National Laboratory, Indoor Environment Department, Advice for Safeguarding Buildings Against Chemical or Biological Attack; available at <http://securebuildings.lbl.gov>.

LLNL, SNL, and LBL (2008), Lawrence Livermore National Laboratory, Sandia National Laboratories, and Lawrence Berkeley National Laboratory, Technical Gap Analysis for Wide Area Biological Incidents, LLNL report UCRL-TR-401133.

Loosmore, G. A. (2003), "Evaluation and Development of Models for Resuspension of Aerosols at Short Times after Deposition," Atmospheric Environ. 37, 639-647.

Loosmore, G. A. and J. R. Hunt (1998), Dust Resuspension as a Contaminant Exposure Pathway: A Review, Lawrence Livermore National Laboratory, Livermore, CA, UCRL-JC132834.

Montgomery, D. (1997), Introduction to Statistical Quality Control, $3^{\text {rd }}$ Ed., John Wiley and Sons Inc.

Nicholson, K. W. (1988), “A Review of Particle Resuspension,” Atmospheric Environ. 22(12), 2639-2651. 


\section{Characterization}

Nie, D., T. E. Kleindienst, R. R. Arnts, and J. E. Sickles II (1995), The Design and Testing of a Relaxed Eddy Accumulation System, J. Geophys. Res. 100(D6), 11,415-11,423.

NRC (2005), National Research Council of the National Academies, Committee on Standards and Policies for Decontaminating Public Facilities Affected by Exposure to Harmful Biological Agents, How Clean is Safe? Reopening Public Facilities After a Biological Attack, National Academies Press, Washington, D.C.

NRC (2007), National Research Council of the National Academies, Committee on Models in the Regulatory Decision Process, Board on Environmental Studies and Toxicology, Division on Earth and Life Studies, Models in Environmental Regulatory Decision Making, National Academies Press, Washington, D.C.

NRT (updated July, 2005), National Response Team, Technical Assistance for Anthrax Response, Interim-Final Draft; available at $<$ http://www.nrt.org/production/NRT/NRTWeb.nsf/PagesByLevelCat/Level2TA?Opendocument $>$.

Raber, E., A. Jin, K. Noonan, R. McGuire, and R. D. Kirvel (2001), "Decontamination Issues for Chemical and Biological Warfare Agents: How Clean Is Clean Enough?" Internat. J. Environ. Health Res. 11, 128-148.

Raber, E., J. M. Hirabayashi, S. P. Mancieri, A. L. Jin, K. J. Folks, T. M. Carlsen, and P. Estacio (2002), "Chemical and Biological Agent Incident Response and Decision Process for Civilian and Public Sector Facilities," Risk Analysis 22(2), 195-202.

Reynolds, B. (2002), Crisis and Emergency Risk Communication, Centers for Disease Control and Prevention; available at <http://www.maxwell.af.mil/au/awc/awcgate/cdc/cerc_book.pdf $>$.

Rhodes, K. (2005), Agencies Need to Validate Sampling Activities in Order to Increase Confidence in Negative Results, Government Accountability Office, GAO-05-0493T.

Rhodes, K. (2006), Federal Agencies Have Taken Some Steps to Validate Sampling Methods and to Develop a Next Generation Anthrax Vaccine, Government Accountability Office, GAO-06$756 \mathrm{~T}$.

Rose, L., B. Jensen, A. Peterson, S. N. Banerjee, and M. J. Arduino (2004), "Swab Material and Bacillus anthracis Spore Recovery from Nonporous Surfaces," Emer. Infect. Dis. 10, 1023-29.

Sackschewsky, M. and J. Becker (2001), 200 West Area Dust Mitigation Strategies, Pacific Northwest National Laboratory, PNNL-13883.

Sego, L. H., J. E. Wilson, S.A. Shulman, B. A. Pulsipher, K. K. Anderson, and W. K. Sierber (2010), Acceptance Sampling Using Judgmental and Randomly Selected Samples, Pacific Northwest National Laboratory, PNNL-19315, Richland, WA; available at http://www.pnl.gov/main/publications/external/technical_reports/PNNL-19315.pdf.

Sehmel, G. A. (1980), "Particle Resuspension: A Review,” Environ. Internat. 4, 107-127. U.S. Army (2007), U.S. Army $20^{\text {th }}$ Support Command Information Sheet on CBRNE Analytical and Remediation Activity (CARA); available at 〈http://www.cbrne.army.mil/info/factsheets/cara.pdf $>$. 


\section{Characterization}

Weis, C. P., A. J. Intrepido, A. K. Miller, P. G. Cowin, M. A. Durno, J. S. Gebhardt, and R. Bull (2002), "Secondary Aerosolization of Viable Bacillus anthracis Spores in a Contaminated U.S. Senate Office," JAMA 288 (22), 2853.

Zhu, T., R. L. Desjardins, J. I. MacPherson, E. Pattey, and G. St. Amour (1998), Aircraft Measurements of the Concentration and Flux of Agrochemicals, Environ. Sci. Technol. 32, 1032-1038.

40 CFR Part 51, Revision to the Guideline on Air Quality Models: Adoption of a Preferred General Purpose (Flat and Complex Terrain) Dispersion Model and Other Revisions; Final Rule. 


\section{Decontamination}

Rapidly remediating and restoring operations throughout an area affected by a BWA release is critical to minimize economic and social impacts, and the principal technique for rapid remediation is decontamination. Whereas the primary objective of decontamination is reducing contamination to an acceptable level of health risk, an efficient process of decontamination requires vigilant attention to limit additional exposures and prevent the additional spread of contamination while decontamination is occurring. Decontamination activities themselves carry an inherent risk of possible adverse health effects because decontamination agents have demonstrated toxicity, and exposure of remediation workers to such agents must be prevented to the extent possible. Areas of gross contamination typically require immediate steps to minimize the spread of contamination. Once the overall extent and magnitude of contamination are determined for regions of lesser contamination, efforts to reduce wide-area contamination levels are initiated using engineered processes or monitored natural attenuation. Because few decontamination technologies have been developed for wide-area application, and even fewer have been demonstrated, decisions about selecting an appropriate decontamination technology should focus on identified best decontamination practices while taking into account the costbenefit and risk-benefit characteristics of the contaminant and site-specific environmental parameters that govern the effectiveness of various approaches.

Decontamination requires careful thought and preparation. A Remediation Action Plan (RAP) that is developed during the Decontamination Phase is a formal document used to guide operations by describing all the actions required to remove, reduce, or eliminate contaminants at a site. Preparation includes establishing the necessary infrastructure, organizing and staging engineered decontamination processes, ensuring safe working conditions, and preventing the spread of contamination. The choice of decontamination technologies (Hawley and Kozlovac 2004) depends primarily on the BWA, matrix to be decontaminated (e.g., outdoor, semienclosed, indoor, or water system), the extent and magnitude of contamination, effects of decontamination reagents on sensitive and other high-value equipment in the site to be treated, safety and health concerns, and stakeholder issues. Additional logistical factors that determine the feasibility of a particular approach include the adequacy and availability of a decontaminant delivery system, availability of qualified personnel, and accessibility to contaminated locations. For B. anthracis spores and other environmentally persistent BWAs, scenario- and site-specific decontamination technologies and delivery systems must be selected as part of the RAP. In addition, the RAP guides early decisions in assessing what items to decontaminate in place or remove for disposal or reuse after decontamination.

Because the RAP specifies how remediation activities will be carried out, the IC or UC, coordinating with appropriate state and local authorities, must approve the plan before it is implemented and must approve any changes as remediation progresses. The IC or UC takes into consideration any Federal or state authorities that may pertain to remediation and decides how to use or address those authorities. For example, the EPA has authority under the Federal Insecticide, Fungicide, and Rodenticide Act (FIFRA) for registering, or exempting from registration, the sale and use of pesticide products in the U.S. (7 U.S.C. 136-136y). Because only one product has been registered specifically for the inactivation of $B$. anthracis spores, the IC or 


\section{Decontamination}

UC must check with EPA about the possible need for obtaining one or more FIFRA exemptions for the use of unregistered pesticides at particular sites. Four types of FIFRA exemptions are available for different purposes: specific, quarantine, public health, and crisis (40 CFR Part 166).

Another EPA authority that that the IC or UC must consider in implementing the RAP is the Comprehensive Environmental Response, Compensation, and Liability Act (CERCLA) (see Section 1.5.1.). Pursuant to section 121(e) of CERCLA and section 300.400(e)(1) of the National Contingency Plan, Federal On-Scene Coordinators, under certain circumstances, are not required to obtain Federal, state, or local permits for onsite activities. "Onsite" actions are defined as "the areal extent" of contamination and all suitable areas located very close to the contamination necessary for the implementation of response actions. Accordingly, if a remediation is carried out under CERCLA, the IC or UC could treat FIFRA as an "applicable or relevant and appropriate requirement" (ARAR) waiver. Whereas FIFRA is intended to protect human health and the environment, CERCLA actions are also intended to do so. Accordingly, the substantive requirements of FIFRA would be addressed under CERCLA actions, and FIFRA exemptions may not be required in such circumstances. However, any additional actions taken outside of CERCLA would still be subject to FIFRA.

Waste disposal is a major consideration affecting any decontamination strategy because the expected quantities of waste generated after a wide-area incident may overwhelm traditional waste disposal procedures. Waste disposal begins during the First-Response Phase with the first entry of workers wearing PPE into known or potentially contaminated areas. It continues throughout remediation and is only completed after all contaminated areas are cleared for re-use. Wastes from areas contaminated with BWAs fall into three categories: site debris, disposable PPE, and decontamination liquids used to decontaminate workers and items leaving the hot zone. Without adequate waste disposal arrangements, the resumption of operations will almost certainly be delayed by the isolation and removal of contaminated wastes.

Once decontamination activities are complete, it is essential to demonstrate that clearance goals have been achieved (Section 9). Although demonstrating clearance follows decontamination, planning for clearance sampling should occur while decontamination plans are being generated and before decontamination begins. As explained in Sections 6.3 and 9.2, clearance goals must be established along with agreed-on processes (clearance criteria) for judging whether the goals are met to ensure that appropriate decontamination technique(s) are selected. Confidence in selected decontamination approach(es) and the clearance criteria must be defensible to regulatory agencies, relevant public-health agencies, and the public. The IC or UC may consider discussing with stakeholders any concerns regarding the decontamination technologies selected, clearance goals to be met, and clearance criteria to be applied to ensure the goals are met.

Because a wide-area attack is such a complex problem with numerous dependencies on incident details, an operationally specific RAP cannot be developed for a wide urban area in advance of an attack. Instead, this section addresses the overall steps to be taken and decision framework to be used in devising an optimal approach, rather than proposing a specific plan that cannot foresee details surrounding a real incident. Figure 8-1 summarizes the major activities that take place during the Decontamination Phase. Details on decontamination technologies, techniques (processes, such as fumigation), and applications (e.g., indoors versus outdoors versus water systems) are also discussed together with recommendations for consideration by decisionmakers. 


\section{Decontamination}

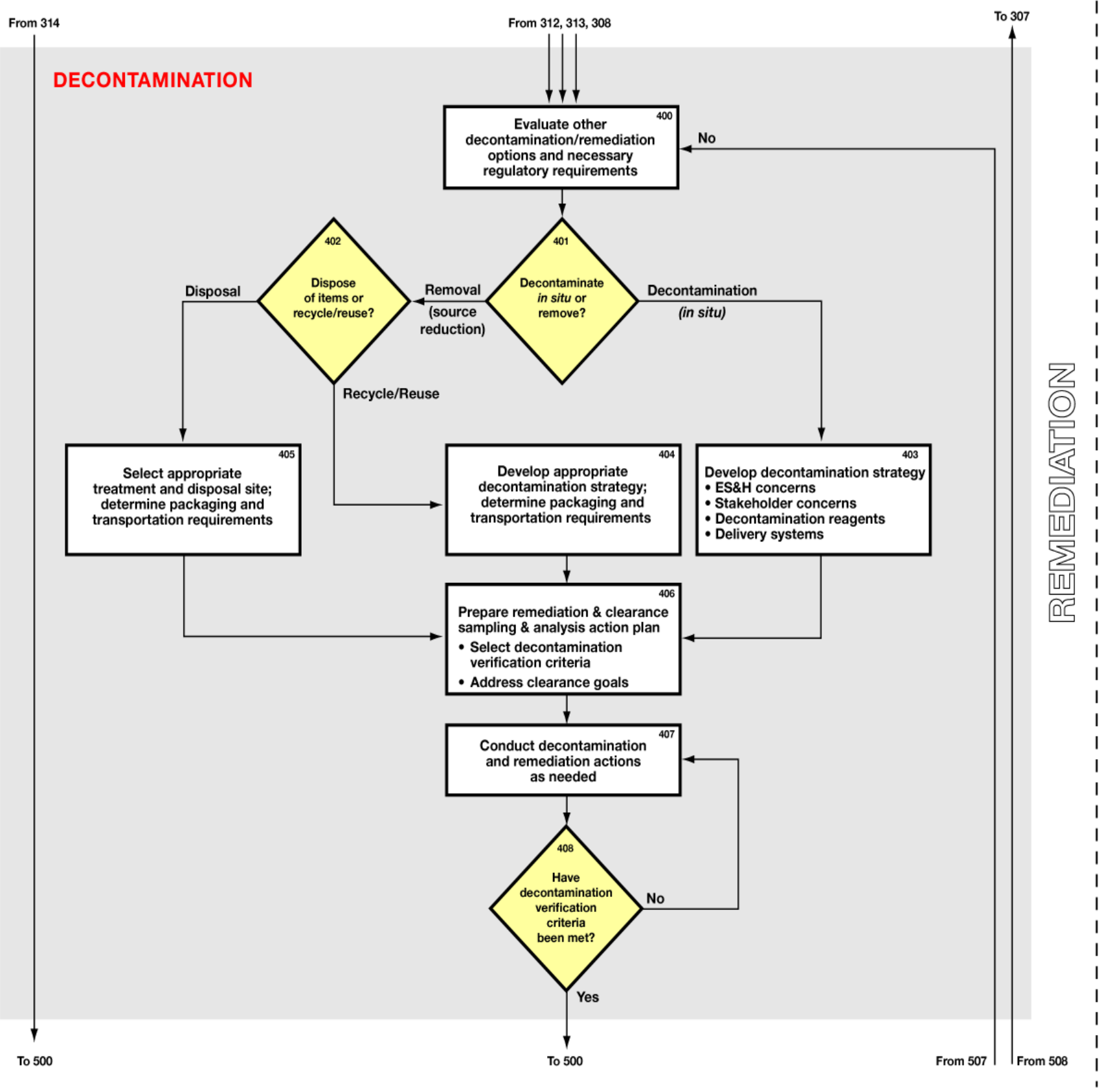

Figure 8-1. Principal activities associated with the Decontamination Phase. 


\section{Decontamination}

\subsection{Evaluate Options and Prioritize Decontamination Areas (Box 400)}

From the results of characterization (Section 7) and any additional data that may be integrated (such as updated plume models, outcomes of medical surveillance, and analytical laboratory results), decision-makers must evaluate their decontamination options within the context of applicable regulatory requirements, and reassess the prioritization framework developed at earlier stages of the recovery effort (Section 5). Decontamination approaches should be evaluated individually for each unique type of area that features a variation in either contamination magnitude or matrix characteristics (Figure 8-2, Box 400-1). Decontamination is also constrained by local prioritization decisions and the technical and logistics requirements of each decontamination process.

Prioritization options include decisions about the types of facilities or areas that are in need of decontamination and their rank order for remediation. Regional and local priorities are addressed in Section 5. Decisions to remediate areas with the highest probability of BWA depositions or areas that are essential to infrastructure operations are examples of priority options. Prioritization considerations may place critical lifeline activities and public health infrastructure high on the list for decontamination, requiring them to be decontaminated before outdoor decontamination occurs. If critical infrastructure is decontaminated while surrounding areas await decontamination, consideration should be given to mitigating the potential for crosscontamination into priority facilities from outdoor contamination by designing facility-entry protocols.

Decontamination approaches include natural measures, such as monitored natural attenuation, and engineered measures including both physical removal and biological or chemical destruction. Selecting among such approaches requires evaluating tradeoffs, including time, cost, complexity, efficacy of decontamination, and effects of reagents on sensitive and other highvalue equipment. In a wide-area scenario, it is likely that a range of approaches will be employed for the variety of contamination magnitudes and matrices likely to be encountered.

Decontamination using engineered biological or chemical destruction approaches involves processes that use a variety of delivery techniques to disseminate vapors or solutions. Thus, a wide-area scenario is likely to involve spraying surfaces, fumigating with gaseous reagents, or both. For example, gaseous fumigation typically requires tenting entire structures to contain toxic sterilant gases. Outdoor decontamination solutions may be applied by spray trucks or - in certain circumstances such as in large, contaminated open areas - by airborne drop. It is essential to evaluate the risk versus benefit of various dissemination approaches to ensure that those selected will improve the situation rather than spread contamination through resuspension and other means of secondary contamination. Logistical evaluations include consideration of the type of venue being remediated and the application of resources to that venue. Large-scale outdoor decontamination may be conducted as a massively parallel process with many spray trucks and numerous personnel or, alternatively, as a more serialized and slower process involving fewer trucks and personnel. Indoor decontamination can be approached in similar ways. Other logistical considerations could include the need to stockpile key assets that would speed up decontamination in the end, or to make provision for scaling up decontamination resources and personnel over time to achieve desired timelines. 


\section{Decontamination}

\section{DECONTAMINATION (expanded 400)}

\section{Evaluate other decontamination/remediation options and necessary regulatory requirements}

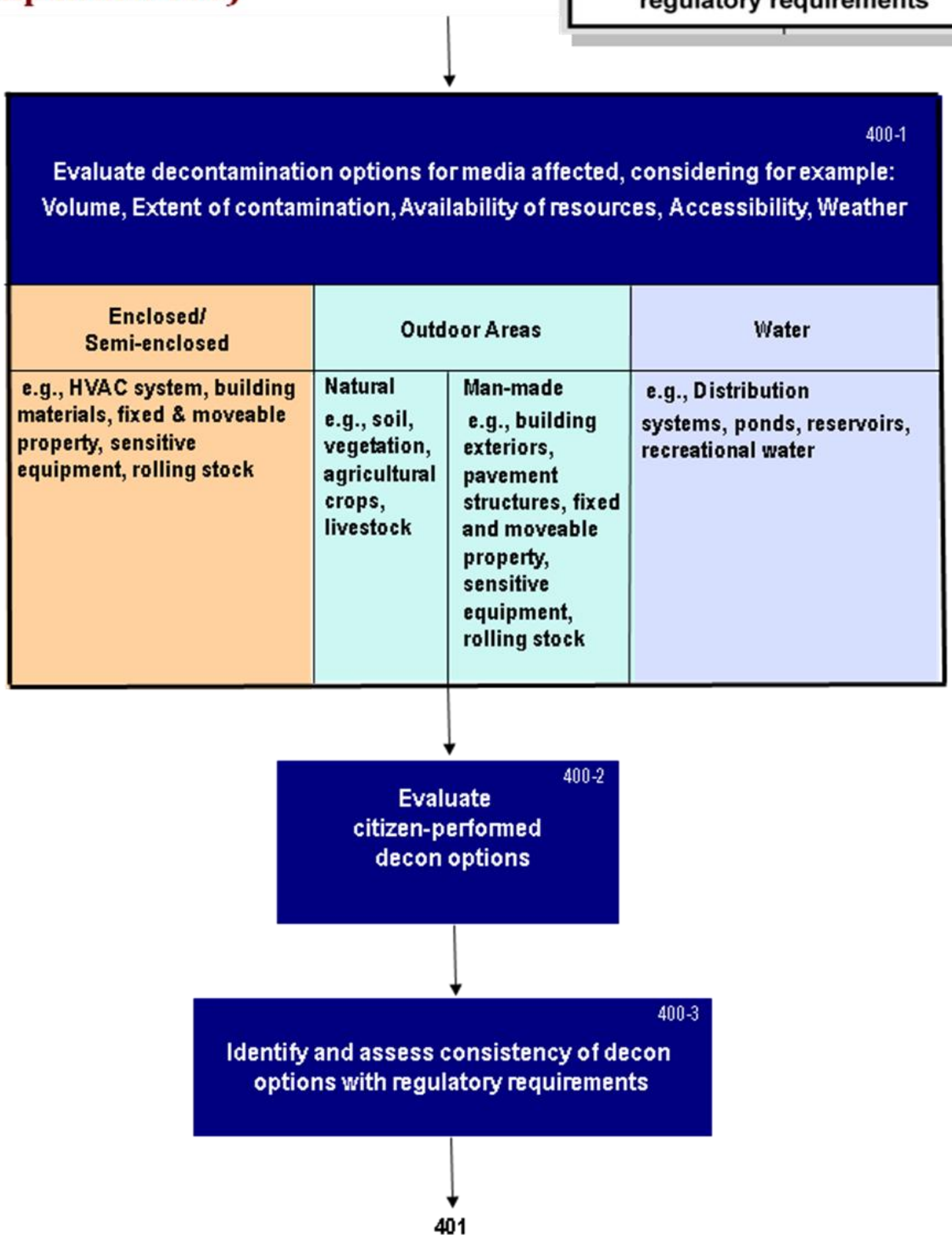

Figure 8-2. Expanded Box 400: Evaluate decontamination options. 


\section{Decontamination}

As previously stated, the overall goal of any decontamination strategy is to achieve defined clearance goal(s) while optimizing resources, costs, and time. Working from the prioritization framework, results of characterization, and factoring in available decontamination assets and capabilities, the IC or UC plans the overall decontamination strategy. The EPA provides and coordinates technical subject-matter experts. The TWG may also contribute relevant information that impacts the approaches adopted for decontamination. Other agent-, incident-, and mediaspecific considerations (see Figure 8-3, Box 403-1, later in this section) include the following:

- Identity-specific characteristics of the BWA (e.g., agent species and subspecies, environmental persistence, and ability to aerosolize).

- Mode of delivery of the BWA and nature and extent of its spread.

- Results of environmental sampling, including extent and magnitude of contamination.

- Epidemiological evidence (human disease cases) and what it shows (e.g., inhalational versus gastrointestinal versus dermal routes of exposure).

- Health risks posed by the BWA and its susceptibility to medical countermeasures.

- Nature of the site and items to be decontaminated (an entire facility or only one area within a facility; outdoor environment-rural or urban; an individual water tank or entire multi-jurisdictional metropolitan water-distribution system).

- Toxicities, potential effects on sensitive and high-value equipment, persistence of chemical(s) to be used during decontamination, and byproducts of the chemical(s) created during decontamination.

- Public perception, such as acceptance of a proposed decontamination technology.

- Environmental concerns, such as potential byproducts, air emissions, residues, and disinfection byproducts.

- Quantity of waste generated and ability to identify suitable staging and storage areas.

- Valid test data demonstrating the efficacy of the selected decontamination technology.

- Conditions required for effective application of a decontamination process (e.g., for fumigations, specified ranges of relative humidity, temperature, reagent concentration, and contact time as well as growth on all biological indicators used to measure the efficacy of fumigation; or $\mathrm{pH}$ for certain surface treatments and water).

- Timeframe of the decontamination process and associated costs.

- Potential collateral damage caused by decontamination (i.e., adverse effects on building infrastructure or equipment).

Considering all relevant information, an overall decontamination strategy and operational description of how to proceed is developed and articulated in the RAP (Section 8.8). It is anticipated that the RAP (more than one may be necessary) would be designed according to the zones used for characterization and would include individual facilities and areas. A key recommendation is to conduct any necessary outdoor decontamination first, before decontaminating indoor facilities within the hot zone. Such an approach is the best way to ensure that facilities within a hot zone remain free of contamination from an external source from which resuspension is likely to affect the surroundings. This recommendation must be factored into the overall decontamination strategy. However, if critical infrastructure or facilities 


\section{Decontamination}

are high on the priority list for re-opening, their decontamination may be required even before outdoor areas are addressed.

\subsection{Evaluate Monitored Natural Attenuation (Box 313) versus Engineered Decontamination in situ (Box 401) versus Removal, Reuse, or Disposal (Box 402)}

A complete evaluation of remediation alternatives should always consider monitored natural attenuation as an option. Natural attenuation of BWAs can be defined as the destruction or inactivation of a biological agent via natural environmental mechanisms such as heat, light, biochemical, or chemical reactions. Monitored natural attenuation (simply waiting, along with periodic sampling and analysis) should be considered within a risk-based framework since it may provide a simpler and more timely or less costly return to acceptable risk. However, in the case of spore-forming organisms, such as B. anthracis, caution is required because the spores are known to remain viable for long periods in the environment (Sinclair et al. 2008; USACHPPM 2008). Spore-forming organisms, such as B. anthracis, are resistant to environmental damage and decontamination chemicals, and therefore can be a persistent presence. The literature contains insufficient data to understand decay rates and other variables to determine the effectiveness of natural attenuation for B. anthracis spores (NRC 2005). It is possible that exposure to sunlight would eventually destroy the spores on light-exposed surfaces, but they can remain viable for decades within soil. Whether or not a biothreat agent deposited on or in the soil would be subjected to degradation by other environmental stressors and competing soil microflora, thus enhance natural attenuation, is unknown. Also unknown are the reaerosolization characteristics of spores from outdoor surfaces, such as vegetation, concrete, glass, and pavement. Therefore, if an incident were to happen today, high-volume air sampling would need to be done to determine whether or not an inhalation threat actually exists from airborne BWA. Air sampling results during the Characterization Phase will help inform decisions regarding the potential for reaerosolization during decontamination activities.

The EPA uses strategies that combine natural attenuation with long-term environmental monitoring for sites where soil and groundwater are contaminated by organic chemicals or radioactive tritium; however, the approach has not yet been applied to BWA contamination. Monitored natural attenuation may not be an option for spore-forming organisms, such as B. anthracis in certain settings, especially indoors where research shows that spores can remain viable for long periods (Sneath 1962; Block 2001; Pepper and Gentry 2002; Sinclair et al. 2008). Indoor remediation standards might also be different, and more stringent, than outdoor standards where some agents are indigenous in certain parts of the country. Little information is available on levels of BWA associated with no observable adverse effects for natural water resources.

For situations in which natural attenuation is not expected to be effective, the next step in developing a detailed decontamination strategy is the decision as to whether to decontaminate specific materials in situ (Box 401) or to remove contaminated items (source reduction) for recycling, reuse, or disposal (Box 402). Source reduction is discussed in Section 8.3. Waste guidelines, waste management, and disposal strategies are discussed in Section 8.5. 


\section{Decontamination}

\subsection{Source Reduction (Boxes 401 and 402)}

Source reduction is the process of removing certain items and/or materials from a contaminated site for further treatment and reuse or disposal, and of cleaning the remaining site and item surfaces prior to the main decontamination activity. The goals are to (1) reduce the number of items or materials present, (2) ensure that any matter that might inhibit decontamination is removed, and (3) generally reduce the levels of contaminant that may be present (DHS/EPA 2009). Source reduction is not only part of the decontamination activities, but it also can potentially reduce the cost of decontamination by mitigating the spread of contamination and decreasing the number of clearance environmental samples that need to be taken. Decisions need to be made on a case-by-case basis concerning (1) what materials and structural components are to be decontaminated for reuse or recycling, and (2) what is not to be reused, but rather appropriately packaged and transported for disposal as waste or for recycling. Nonessential items removed for disposal are treated very differently from essential items removed for offsite treatment and returned for reuse. Following a wide-area attack, it is recommended that no materials, other than items that are essential or of high value or may consume the decontamination reagent, be removed from contaminated facilities before decontamination because costs would otherwise be prohibitive, space and disposal options are expected to be limited, and time is of the essence. However, all perishable items, such as exposed food and contaminated medical supplies, should be disposed in an appropriate manner. A cost-benefit analysis should be incorporated into decisions concerning retention, disposal, and decontamination in situ options to optimize remediation activities. It might be easier in terms of the engineered decontamination step to remove easily strippable building materials and dispose of them as waste, but then more difficult during the waste-handling step of the overall decontamination phase. Decontamination decisions also depend on the reactivity of the materials under consideration. Some materials can consume a disproportionate amount of a decontamination solution or fumigant, or have incompatibilities that render the use of a specific decontamination technology undesirable. All such variables must be considered when optimizing the decontamination process.

During a wide-area incident, source reduction is likely to commence early and long before a RAP is developed and decontamination is underway. For the Decontamination Phase, the Operation Section's Decontamination Group plans source reduction activities. The goals are to:

- Reduce the number of items or materials present in view of disposal considerations.

- Ensure that any matter that might inhibit decontamination is removed.

- Generally reduce the levels of contaminant that may be present.

Although items or materials to be removed should be minimized, such items can be grouped into the following categories:

- Essential or sensitive items that must be protected, removed for decontamination elsewhere (e.g., at a regulated sterilization facility), and saved or restored for reuse. Examples include artwork, essential computer discs, expensive medical equipment, and valuable documents.

- Items or materials that must be removed, treated, and disposed or recycled. Examples include debris, items that might inhibit decontamination such as porous items, low-cost items that are more efficient to replace than decontaminate, exposed foodstuffs, other 


\section{Decontamination}

exposed perishables, and cleaning materials. The time and cost to the remediation process for removing and recycling any such items must be evaluated against the time and cost for disposal as waste.

\subsubsection{Staging and Storage}

Pre-decontamination work will depend on the decontamination technology chosen. It will include setting up secure areas for packaging and onsite treatment of essential and nonessential items prior to their being taken to designated onsite storage areas to await shipment to appropriate offsite facilities. Other staging areas will be needed for decontamination materials, supplies, and generation equipment; for scrubbing equipment used for the main decontamination activity, for negative air units (NAUs), and other relevant supplies, if fumigation is being used as the main decontamination activity; for tenting equipment and supplies used for containing the facility; for personnel decontamination tents near selected entrance and exit locations; for storing site debris, disposable PPE, and decontamination liquids prior to offsite shipment for treatment and waste disposal; and staging areas for remediation workers to park their cars and trucks. At large, complex facilities requiring fumigation(s), a large area will be needed for all the staging activities.

Equipment staging and material storage requirements depend on the requirements of a given technology and the size of the job. Staging locations should be chosen with an understanding of the workflow around the activity being staged and while making every effort to minimize the potential for the spread of contamination. Decontamination vendors will address issues such as power requirements according to equipment needs. Specific staging locations for equipment generation and decontamination supplies, and for tenting equipment and supplies, will also be determined by decontamination vendor(s). Treated waste should be segregated physically from untreated waste.

\subsubsection{Barriers and Tenting Technology}

Technologies that can be used as barriers in preparation for decontamination include sheeting materials used as isolation barriers inside a facility; building tents to seal structures; and sheeting to cover glass for ultraviolet protection. Sheeting materials and tarps can also cover and confine outdoor areas identified as hot spots or as physical barriers for fumigants applied outdoors. Other materials such as sealants and tapes (e.g., glues, foam, and caulking) are required to provide airtight seals and to cover joints and nails. Materials used as part of fumigations must have gasresistant properties and provide airtight installations.

Several vendors specialize in installing sealed, reinforced, polyethylene sheets to fumigate small and medium-size freestanding facilities for insect infestations. Such technology was successfully applied to cover homes and structures during chlorine dioxide fumigations for mold infestation in New Orleans. Vendors also offer sealed tents for large structures, such as apartment buildings and train stations, which could be applied to other large buildings. To cover structures and scaffoldings for environmental and rain protection, very large tarps have been installed on multistory buildings and bridge towers. Such technology could be applied for ultraviolet protection and modified during airtight installations for fumigation purposes.

Sheeting material applied for fumigation purposes must be light enough to be handled easily, strong and resistant to tears, impermeable to fumigation gases and water, resistant to ultraviolet 


\section{Decontamination}

light, stable at applicable temperatures, and fire retardant. Sheeting material for both tarp and fumigation tenting applications typically consists of multilayer, flexible, composite sheets with good strength-to-weight ratio and extremely low gas permeability. Sheets typically consist of two or three layers of strong, durable, lightweight polyethylene or polypropylene, sandwiching a woven film fabric for strength and durability. The nominal thickness of woven, reinforced polypropylene sheeting is 5 to 12 mil. Sheets can be made to any required size by joining panels with heat or high-frequency welding, as specified by the manufacturer. To prevent finished sheets from tearing, the edges are usually reinforced with seams.

\subsubsection{Outdoors}

When containment is a concern, initial actions taken to prevent the spread of contaminant may be critical. Application of surface fixatives or binders, or physical removal by a variety of methods, has the advantage of inhibiting potential resuspension and cross-contamination while allowing additional time for response personnel to consider prioritization, response planning, and actions for more thorough follow-on decontamination. Strategies previously used for alpha radioactive contamination, such as spraying oil or paint suspensions to bind the material to fixed surfaces (Fritz and Whitaker 2008), may also prove effective for reducing resuspension, but such strategies are untested for biological contamination. Targeted source reduction measures (e.g., removing contaminated vegetation or other easily removable contaminated objects) may be warranted. However, it is necessary to evaluate the risk-benefit ratio to ensure that such measures improve the situation through source reduction more than they spread contamination through resuspension and other means of secondary contamination. As with all mitigation measures, the effectiveness of containment should be evaluated before actions are taken. Small, but highly contaminated areas outdoors (or hot spots), when detected, would likely be cleaned up as a source-reduction measure by applying one of the reagents listed in Section 8.4 or by implementing removal and disposal options. Prompt source reduction outdoors is an excellent way to reduce contaminant load and the potential for spread early after an incident.

\subsubsection{Indoors}

Source reduction may be required at indoor facilities where fumigations or liquid decontamination treatments are employed. For materials that will remain onsite (such as equipment) and structural elements of a facility, prior HEPA vacuuming may be used, and surface treatment may be done with reagents such as amended sodium hypochlorite solution or other strong oxidants that are documented sporicidal chemicals. HEPA vacuuming is especially useful on porous materials (Nalipinski and Smith 2008). In addition to its ability to physically extract a BWA from matrices, it also removes dirt and other debris that can reduce the effectiveness of subsequent decontamination by surface reagents or fumigation. The technology can only be used to remove or reduce surface contamination and may not be appropriate for internal parts of sensitive equipment. An additional advantage of HEPA technology is that, when operated correctly, there is little potential for collateral damage, although it can readily spread contamination if vacuum exhaust stirs the air.

Any contaminated material that is removed will require transportation to an approved treatment and disposal facility. The Department of Transportation (DOT) and individual states have many requirements for pre-treating and packaging materials contaminated with infectious agents before leaving a contaminated facility, labeling such packages for transport, and transporting 


\section{Decontamination}

contaminated material to approved facilities (Section 8.5.2). The separate category of personal or valuable items that could be removed for offsite decontamination is discussed below.

\subsection{Select Decontamination Technologies (Box 403-1)}

Urban areas include a diverse range of environments (Figure 8-3), from parks that are more rural than urban in character, to semi-enclosed structures such as stadiums and subway systems, to enclosed high-rise buildings and single-family dwellings. Most commercial buildings have large, industrial air handling units (AHUs) that can facilitate the spread of spores and potentially complicate cleanup efforts. Commonplace today in most indoor settings are sophisticated electronics and computer systems that may need to be decontaminated. Because of the complex landscape, at least seven categories of decontamination technologies must be considered for contaminated outdoor areas, indoor facilities and their contents, as well as water systems:

- Large-scale liquid distribution systems (such as firefighting or crop-dusting equipment) with selected reagents or surfactants to decontaminate and stabilize outdoor surfaces.

- Liquid or semi-liquid reagents to decontaminate exposed nonporous and porous surfaces, respectively, for indoor use as well as potential small-scale outdoor applications.

- Gaseous or vaporized reagents to decontaminate difficult-to-reach porous and nonporous indoor surfaces, including HVAC or AHU systems.

- Technologies to decontaminate sensitive or expensive electronic equipment.

- Technologies to decontaminate small, personal, or valuable items, such as artwork.

- Approaches to decontaminate and minimize solid waste or wastewater.

- Approaches to decontaminate water resources and drinking water systems.

No single decontamination technology or strategy is effective in every situation.

Decontaminating an area or item contaminated by a BWA involves numerous issues specific to an individual location (see for example Hawley and Kozlovac 2004; OSHA anthrax etool, available at <http://www.osha.gov/SLTC/etools/anthrax/>; Canter et al. 2005; and <www.epa.gov/nhsrc/dcm.htm $>$ ). Regulatory requirements will guide decontamination activities, and the efforts will almost certainly be coordinated by the EPA OSC, with input from the CDC, under CERCLA regulations. Ultimate decisions will be those made at the scene by the IC or UC.

Physical decontamination either inactivates a BWA through physical means, such as heat or radiation, or removes the agent, such as by rinsing with soap and water. Biological or chemical decontamination inactivates a biological agent through the use of antimicrobial disinfectants or sterilants. However, only one chemical decontamination reagent (liquid peroxyacetic acid with hydrogen peroxide; specifically, Peridox with the Electrostatic Decontamination System, EPA Registration Number 81073-2, Conditional) is currently registered by the EPA specifically for inactivation of $B$. anthracis spores. Therefore, for each specific use of any other selected chemical reagent to decontaminate a location contaminated by $B$. anthracis spores, a FIFRA exemption may need to be obtained from the EPA for site- and incident-specific use. In the past, the EPA approved eight chemicals for indoor use only against $B$. anthracis spores, each to be used by authorized personnel following the specific requirements of its crisis exemption. 


\section{Decontamination}

\section{DECONTAMINATION (expanded 403)}

Develop decontamination strategy

- ES\&H concerns

- Stakeholder concerns

- Decontamination reagents

- Delivery systems

Select decontamination methods including specific reagents and reagent delivery

systems for media affected, considering for example:

Volume, Extent of contamination, Availability of resources, Accessibility, Weather

\begin{tabular}{|c|c|c|c|}
\hline $\begin{array}{c}\text { Enclosed/ } \\
\text { Semi-enclosed }\end{array}$ & \multicolumn{2}{|c|}{ Outdoor Areas } & Water \\
\hline \multirow[t]{2}{*}{$\begin{array}{l}\text { e.g., HVAC system, building } \\
\text { materials, fixed and moveable } \\
\text { property, sensitive equipment, } \\
\text { rolling stock }\end{array}$} & $\begin{array}{l}\text { Natural } \\
\text { e.g., soil, } \\
\text { vegetation, } \\
\text { agricultural } \\
\text { crops, } \\
\text { livestock }\end{array}$ & $\begin{array}{l}\text { Man-made } \\
\text { e.g., building } \\
\text { exteriors, } \\
\text { pavement } \\
\text { structures, fixed } \\
\text { and moveable } \\
\text { property, } \\
\text { sensitive } \\
\text { equipment, } \\
\text { rolling stock }\end{array}$ & \multirow[t]{2}{*}{$\begin{array}{l}\text { e.g., Distribution } \\
\text { systems, ponds, reservoirs, } \\
\text { recreational water } \\
\text { Considering: } \\
\text { - Treatment } \\
\text { - No treatment and } \\
\text { monitor }\end{array}$} \\
\hline & \multicolumn{2}{|c|}{$\begin{array}{l}\text { Considering: } \\
\text { - Localized treatment } \\
\text { - Wide area treatment } \\
\text { - Wash down and treat }\end{array}$} & \\
\hline
\end{tabular}

Develop emergency response plans to address potential uncontrolled reagent release(s)

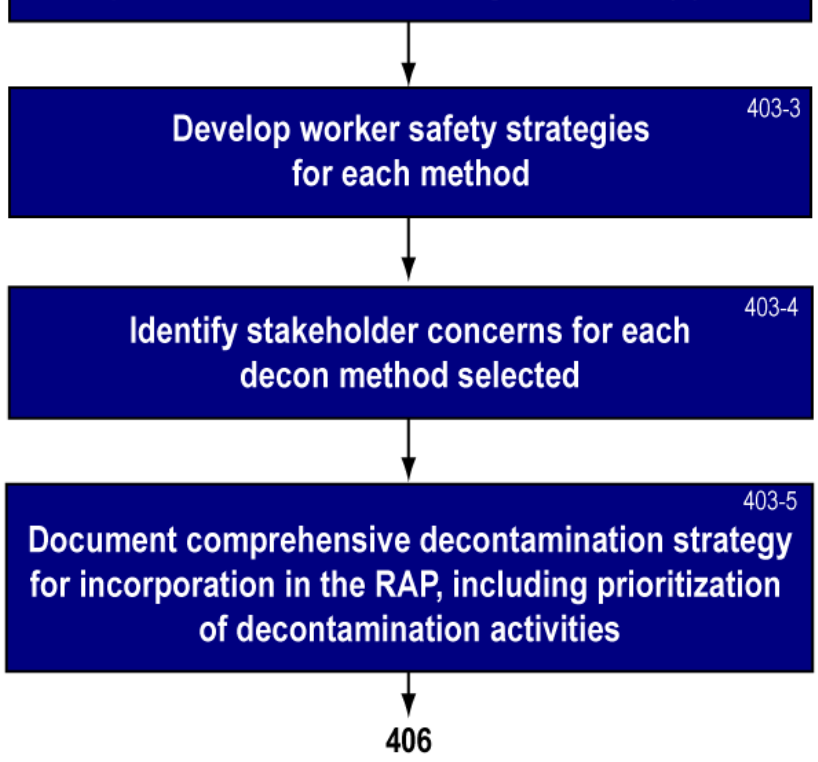

Figure 8-3. Expanded Box 403: develop decontamination strategy. 


\section{Decontamination}

The eight previously approved chemicals were vapor-phase hydrogen peroxide (VPHP), liquid and gaseous chlorine dioxide $\left(\mathrm{ClO}_{2}\right)$ created from sodium chlorite or sodium chlorate, liquid sodium hypochlorite (bleach, diluted 1:9 with water and neutralized with vinegar to $\mathrm{pH}$ 7), solid paraformaldehyde (heated to create formaldehyde gas), gaseous methyl bromide, liquid peroxyacetic acid with hydrogen peroxide, liquid hydrogen peroxide, and gaseous ethylene oxide (EtO). Although the liquid chemicals could potentially be effective outdoors, the IC or UC must consult with the EPA about the need for obtaining approval for each antimicrobial chemical (except Peridox) for use under a FIFRA exemption for each specific site. Another alternative that could be considered for outdoor (soil) uses would be fumigants such as methyl bromide, which is injected as a pre-plant agricultural soil fumigant and contained with a plastic tarp.

Decontamination methods that work solely through physical means, such as heat, rinsing, cleaning, washing, or vacuuming would not be subject to FIFRA and would not need a FIFRA exemption.

An additional biological decontamination option, which is at a less mature stage of development (Schuch et al. 2002; Walter 2003) compared to chemical decontamination of BWAs, may be highly desirable despite the lack of widespread experience. The use of bacteriophage or endolysins that attack specific BWA, such as vegetative $B$. anthracis cells, could be combined with germinants (Mah et al. 2008; Ireland and Hanna 2002) that initiate spore germination, if necessary. For cells in a vegetative form, their increased vulnerability to less aggressive but more specific forms of decontamination provides an option with fewer potential side effects compared to more aggressive oxidative approaches to decontamination. Although a promising technology, the amount of such biological materials, bacteriophage, or endolysins that would be effective in a wide-area outdoor scenario is not known, and site-specific pilot-scale testing and evaluation would be necessary before such an approach could be adopted with confidence for a wide-area application today. However, the advantages of using such an approach warrant its further consideration.

Deciding which decontamination method to apply at a given location requires a rigorous evaluation of available methods and at least the following considerations expanded from Planning Guidance for Recovery Following Biological Incidents (DHS and EPA 2009):

- Availability and capacity of specific decontamination technologies.

- Emergency-response plans to address potential uncontrolled reagent release (Box 403-2).

- Safety (e.g., toxicity, byproducts, persistence, and exposure limits) (Box 403-3).

- Efficacy (required contact times, penetration capability, efficacy data, and history of use).

- Generation, distribution, monitoring, and removal requirements.

- Cost (e.g., materials, equipment, and labor).

- Time (e.g., procurement, setup, testing, decontamination, removing equipment).

- Stakeholder concerns (Box 403-4), including site- and incident-specific considerations.

- Waste generation.

- Materials compatibility.

To provide adequate personnel in a major incident, the EPA will probably need to conduct training courses to educate personnel from additional service companies currently involved in hazardous cleanup about techniques needed to safely deal with $B$. anthracis spores or other 


\section{Decontamination}

BWAs. The following sections summarize current recommendations for consideration with respect to wide-area decontamination of $B$. anthracis spores, beginning with criteria listed in Table 8-1 for selecting a decontamination reagent, and extending to an evaluation of current technologies (Table 8-2).

\subsubsection{Hot-Spot Decontamination}

Depending on how a BWA is initially disseminated, it may be possible to find relatively large concentrations of biological agent constrained to surfaces near the point of release. For hard, nonporous surfaces, such areas can be treated effectively with a variety of decontamination approaches, although care should be taken to minimize reaerosolization. The availability and cost of technology and reagents will influence the selection of an approach (see Tables 8-1 and 8-2).

\section{Table 8-1. Criteria for selecting a decontamination reagent.}

\begin{tabular}{|c|c|c|}
\hline Critical factor & Corresponding questions & Performance measure \\
\hline $\begin{array}{l}\text { Efficacy and } \\
\text { practicality of the } \\
\text { process or reagent }\end{array}$ & $\begin{array}{l}\text { - Does reagent or process kill the BWA? } \\
\text { - Are reagent practical and applicable to intended } \\
\text { use(s)? } \\
\text { - What verification methods for effectiveness are } \\
\text { needed? } \\
\text { - Are process parameters (e.g., required contact times, } \\
\text { temperatures) practical and applicable for intended } \\
\text { use(s)? }\end{array}$ & $\begin{array}{l}\text { - Efficacy substantiated by EPA-sanctioned test } \\
\text { methods, peer-reviewed literature, or recent } \\
\text { unpublished research by highly reliable } \\
\text { investigator(s) that supports the decision } \\
\text { - Reagent and process use parameters are } \\
\text { considered for applicability and practicality, } \\
\text { including: surface types, contact time, } \\
\text { temperature, relative humidity, area or volume } \\
\text { limits, and penetration } \\
\text { - Types of verification needed to confirm onsite } \\
\text { efficacy of product may include recording } \\
\text { process parameters and biological indicators }\end{array}$ \\
\hline $\begin{array}{l}\text { Safety of the } \\
\text { process or reagent }\end{array}$ & $\begin{array}{l}\text { - Is reagent or process compatible with materials and } \\
\text { equipment for the times(s) required for } \\
\text { decontamination (e.g., } 30 \text { minutes or more)? } \\
\text { - Is reagent or process safe for emergency responders } \\
\text { and remediation personnel? } \\
\text { - Does reagent meet environmental acceptance criteria } \\
\text { or have byproducts that are more hazardous? }\end{array}$ & $\begin{array}{l}\text { - Analysis of materials compatibility test data } \\
\text { - Analysis of reagent breakdown products } \\
\text { - PPE requirements } \\
\text { - Acceptability of MSDSs } \\
\text { - Hazardous waste material generated, if any, } \\
\text { that must be collected for disposal }\end{array}$ \\
\hline $\begin{array}{l}\text { Impact on } \\
\text { schedule }\end{array}$ & $\begin{array}{l}\text { - Is reagent or process commercially or governmentally } \\
\text { available in sufficient quantities? } \\
\text { - Is a FIFRA exemption needed, or does remediation } \\
\text { process fall under CERCLA; how quickly can } \\
\text { approvals be granted using available efficacy data? } \\
\text { - Does reagent have DOT registration? }\end{array}$ & $\begin{array}{l}\text { - List suppliers and regional availability } \\
\text { - Review EPA registration for decontamination } \\
\text { liquids, foams, and gases against specific } \\
\text { BWA } \\
\text { - Estimate effort needed to obtain FIFRA } \\
\text { exemption or meet other EPA requirements } \\
\text { - Review DOT certification for ease of transport }\end{array}$ \\
\hline Cost & $\begin{array}{l}\text { - Is reagent or process cost effective? } \\
\text { - Is reagent or process multiuse (e.g., useful on } \\
\text { sensitive and nonsensitive equipment)? } \\
\text { - Is reagent or process harmful (i.e., corrosive) to } \\
\text { materials that would then need to be replaced? } \\
\text { - Does reagent or process generate large quantities of } \\
\text { waste? }\end{array}$ & $\begin{array}{l}\text { - Cost analysis of competitive reagents or } \\
\text { processes } \\
\text { - Analysis of materials-compatibility data and } \\
\text { reports } \\
\text { - Analysis of waste production }\end{array}$ \\
\hline
\end{tabular}




\section{Decontamination}

Specific recommendations for consideration on hard, nonporous surfaces include:

- Sodium hypochlorite (1:9 dilution of bleach to 5,250 to $6,000 \mathrm{ppm}$, corrected to $\mathrm{pH} 7$, with a 60 -minute contact time at $68^{\circ} \mathrm{F}$ or $20^{\circ} \mathrm{C}$ (see for example:

<http://www.epa.gov/pesticides/factsheets/chemicals/bleachfactsheet.htm> and Sagripanti and Bonifacino (1996).

- Liquid chlorine dioxide with a 30 -minute wet contact time at room temperature $\left(68^{\circ} \mathrm{F}\right.$ or $20^{\circ} \mathrm{C}$ ) (see for example:

<http://www.epa.gov/pesticides/factsheets/chemicals/chlorinedioxidefactsheet.htm >).

- Liquid hydrogen peroxide/peroxyacetic acid. Various brands known as peroxy compounds are marketed as ready-to-use solutions, generally with a 15- to 20-minute wet contact time and concentration as specified by the manufacturer. See NRT (2005).

- Other products such as hydrogen peroxide solution (3 to 25\%) and potassium peroxymonosulfate (see for example Young and Setlow (2004).

For BWAs, including spores, located outdoors on nonporous surfaces, many of the decontaminants listed above are expected to be effective. However, for outdoor surfaces that are highly porous or contain large amounts of organics (e.g., soil), careful evaluations must be done to determine effectiveness, including required residence time. Methyl bromide has been used as a soil fumigant, structural fumigant, and as a commodity (food) treatment to control agricultural pests, but because it depletes the ozone layer it was phased out in January 2005 pursuant to the Montreal Protocol on Substances that Deplete the Ozone Layer and Clean Air Act. However, certain critical uses - those for which there are no available alternatives - are exempted (EPA 2007), and methyl bromide could potentially be used to address some locations requiring decontamination (see Table 8-2).

For source reduction, spores located indoors can be vacuumed with a system that has a HEPA filter; however, care would be required to ensure that reaerosolization does not occur, and the captured and residual spores would still require decontamination. Specifically, additional decontamination with liquid or foam decontaminants would be necessary at a hot spot to ensure that residual spores not physically removed by vacuuming are decontaminated. Large pieces of critical but nonsensitive equipment, such as fire trucks and other emergency equipment, can be decontaminated using the same approach.

\subsubsection{Wide-Area Outdoor Surface Decontamination}

Both decontamination technology development and decontaminant validation testing are extremely limited with respect to a full range of outdoor decontamination scenarios of B. anthracis spores and other BWAs. The only wide-area experiences for addressing B. anthracis spores have been decontamination of former biological weapons testing facilities at Gruinard Island and Vozrozhdeniya Island. At Gruinard Island, 280 tons of formaldehyde solution diluted in seawater was sprayed over all 520 acres of the island, and the most-contaminated topsoil around the dispersal site was removed. Four years after decontamination and 48 years after the initial quarantine, the island was identified as safe. Other information on the effectiveness of decontaminants used in outdoor environments is sometimes conflicting. For example, the disinfectant VirkonS ${ }^{\circledR}\left(\right.$ Antec $^{\mathrm{TM}}$ International, Sudbury, Suffolk, UK), which is a stabilized blend of peroxygen compounds, surfactant, organic acids, and an inorganic buffer system, is 


\section{Decontamination}

currently used in the agricultural industry (specifically for Bacillus Anthracis) and in healthcare settings. However, the literature contains contradictory reports of its efficacy. Gasparini et al. (1999) reported that $1 \%$ and $2 \%$ concentrations of Virkon are effective on B. subtilis and B. stearotermophilus spores in distilled water and in physiologic solution, whereas and Hernández et al. (2000) were unable to demonstrate sporicidal activity with $1 \%$ Virkon® after 1 hr against bacterial spores (Bacillus cereus CIP 7.803).

The magnitude and variety of decontamination that would result from the wide-area nature of the problem addressed in this Interim Guidance makes it one of the most difficult aspects to address with confidence. Even though the simplest approach would be monitored natural attenuation, the cautionary statements in Section 8.2 regarding the use of such an approach outdoors for B. anthracis spores highlight its potential limitations.

Little is known about the application of wide-scale decontamination technologies, there is minimal experience in large-scale outdoor decontamination, decontamination reagents have not always been tested outdoors or have not been tested sufficiently to prove their efficacy, and data are sometimes contradictory. Therefore, any decontamination strategy will need to be evaluated first on a pilot scale or within a small zone and verified for the desired effectiveness before proceeding to larger, outdoor-scale applications. Decontamination effectiveness outdoors depends on the outdoor matrix, environmental conditions, and BWA concentration. For example, some decontamination reagents that may not be effective on high concentrations of spores may be effective on lower concentrations. Certain incident-specific factors can also influence the effectiveness of any given decontamination approach. Nevertheless, and in lieu of comprehensive published data on decontaminant efficacy, some decontaminant recommendations for consideration can be made on the basis of the documentation that is available and our best understanding of the technologies at hand.

Among the variables that must be considered are the effectiveness of any strategy or reagent on outdoor porous and nonporous surfaces, whether required contact times are possible to achieve, and the potentially large organic loading expected in soils, which affects the effectiveness of many current decontamination reagents. Key parameters that must be evaluated include surface orientation (e.g., vertical or horizontal), porosity, permeability, and overall ability to maintain adequate contact times. Furthermore, potential impacts on the environment must be understood and accepted before proceeding with many of the currently available options. Such decisions must be addressed by the IC or UC, with stakeholder agreement.

If outdoor decontamination is determined to be necessary in lieu of monitored natural attenuation, several different strategies could be applied to address the problem. Because none of the approaches have been comprehensively validated, outdoor field testing is strongly recommended before larger-scale application. If a wide-area attack were to occur today, the strategies for consideration (given in no order of priority along with pros and cons) are as follows:

Option 1 for Evaluation. Wash all contaminated buildings and surfaces with a liquid decontaminant reagent from the start using fire-fighting equipment and specialized aircraft that can distribute reagents in large quantities. It is essential to ensure that the necessary contact time(s) can be maintained. This could be very difficult on vertical surfaces or highly permeable materials for solution-based systems and may require multiple applications as contact times needed may be as much as 30-60 minutes. It is also critical with this option to ensure that the washing process is improving the situation more than it may be spreading contamination through 


\section{Decontamination}

resuspension, reaerosolization, and other means of secondary contamination. Additional spraying could be done with street-cleaning equipment augmented by sprinklers or hose distribution systems to the extent they are available in individual facilities. Localized testing of reagents is recommended to establish effectiveness as a function of concentration and time. For decontamination reagents to be effective, surfaces must be free of clutter and debris. Bleach solution is a widely available and low-cost disinfectant; however, bleach is not effective in soil because of its organic content and may require runoff containment. The EPA recently approved liquid peroxyacetic acid with hydrogen peroxide as a biocide, thus it should be one of the key oxidizers considered. Other peroxygen compounds have been shown to be effective in laboratory studies on small samples of surfaces and in solutions. Additional studies in outdoor environments are needed to verify the applicability of such chemicals to a wide-area release. Other potential reagents that might be effective are listed in Table 8-2. Option 1 would require more reagent than Option 2, below, but it is a one-step process and should be more effective. The potential for any long-term environmental impacts must be considered. Collection of runoff also needs to be evaluated on a site-specific basis and implemented with input from regulatory agencies.

Option 2 for Evaluation. Wash building exteriors and street surfaces with equipment such as fire trucks using a mild surfactant in water to mobilize and concentrate spores on the ground, then decontaminate the liquid runoff and ground using a decontaminant. As with Option 1, it would be essential to ensure that the washing process improves the situation more than it spreads contamination through resuspension or other means of secondary contamination. Such spread is of great concern because the washing solution does not decontaminate spores, and spores carried in reaerosolized droplets may create a secondary inhalation or gastrointestinal hazard and spread contamination. Little information is available on specific liquid application conditions (flow rate, drop-size distribution, impact velocity) that would effectively wash spores off buildings while minimizing reaerosolization, and ad hoc approaches could make the situation worse. The types of surfactants that could be used and their effectiveness have not been tested for such application and would need initial evaluation to ensure that adequate spore removal is possible. Once spores are on the ground, several liquid decontamination agents are available, as shown in Table 8-2 and discussed above in Option 1. Collection of runoff also needs to be evaluated on a sitespecific basis and implemented as appropriate with input from regulatory agencies.

Option 3 for Evaluation. To facilitate spore decontamination, spray an inexpensive nutrient solution or germinant to initiate desporulation (Mah et al. 2008; Ireland and Hanna 2002). Some desporulation is expected to occur naturally because of nutrients typically found in outdoors. However, Option 3 is intended to exploit the process. The resulting vegetative cells are more vulnerable than spores to both natural and engineered decontamination approaches. Once the BWA is in the vegetative form, any of the chemicals shown in Table 8-2 for wide-area outdoor use could be used to decontaminate, presumably at reduced concentrations. In theory, vegetative forms could also potentially be decontaminated with something as simple as salt distributed as a solid (e.g., rock salt) or a solution (e.g., seawater) that would cause cell rupture via osmosis. It must be emphasized that the efficacy of promoting desporulation on a wide-area scale has not been demonstrated and would require careful onsite validation before such an approach could be adopted for any wide-area application. Promoting the vegetative form of a BWA could also potentially make the situation worse if the environment contained enough nutrients to allow a BWA to replicate, thereby increasing the magnitude of contamination. Nevertheless, and given the absence of any fully validated approach for outdoor wide-area scenarios, a decontamination 


\section{Decontamination}

strategy using Option 3 warrants consideration in that it may result in fewer potential side effects compared to more aggressive chemical approaches to decontamination.

Table 8-2. Decontamination technology options for consideration.

\begin{tabular}{|c|c|c|}
\hline $\begin{array}{l}\text { Environment or type of } \\
\text { item }\end{array}$ & $\begin{array}{l}\text { Existing decontamination technologies } \\
\text { (crisis exemptions for reagents were } \\
\text { previously approved by the EPA, or some } \\
\text { peer-reviewed data are available) }\end{array}$ & Potential alternatives \\
\hline $\begin{array}{l}\text { Hot spots: interior } \\
\text { exposed surfaces; areas } \\
\text { such as doorways; } \\
\text { exterior areas such as } \\
\text { rooftops, walls, and } \\
\text { vehicles; and areas near } \\
\text { point(s) of release }\end{array}$ & $\begin{array}{l}\text { Sodium hypochlorite solution (1:9 dilution } \\
\text { of } 5.25 \text { to } 6.0 \% \text {, corrected to } \mathrm{pH} 7,5,250- \\
6,000 \mathrm{ppm})^{\mathrm{b}} \text { (e.g., pH-adjusted bleach) } \\
\text { Calcium hypochlorite (HTH) solution } \\
\text { Aqueous chlorine dioxide } \\
\text { Hydrogen peroxide/peracetic acid solution } \\
\text { (e.g., Peridox }{ }^{\circledR} \text { solution) } \\
\text { Hydrogen peroxide solution ( } 3 \text { to } 25 \%) \\
\text { Potassium peroxymonosulfate (Oxone }{ }^{\mathrm{e}} \text { ) }\end{array}$ & $\begin{array}{l}\text { CASCAD }^{\circledR} \text { foam or solution; active } \\
\text { ingredient: sodium dichoroisocyanurate } \\
\text { Decon Green } \\
\text { MDF-200 }{ }^{\circledR} / \text { EasyDECON }{ }^{\circledR}-200 \text { solution or }^{c} \\
\text { foam: peroxide-based formulation } \\
\text { VirkonS }^{\circledR d} \text { peroxygen-based solution }\end{array}$ \\
\hline $\begin{array}{l}\text { Wide-area outdoors, such } \\
\text { as building exteriors, } \\
\text { roads, walls, and vehicle } \\
\text { exteriors }\end{array}$ & $\begin{array}{l}\text { Monitored natural attenuation (UV light) } \\
\text { Hydrogen peroxide/peracetic acid solution } \\
\text { (e.g., Peridox }{ }^{\circledR} \text { solution) } \\
\text { Sodium hypochlorite spray (e.g., pH- } \\
\text { adjusted bleach; see above) } \\
\text { Calcium hypochlorite (HTH) solution } \\
\text { Hydrogen-peroxide-based sprays ( } 3 \text { to } 25 \% \text { ) } \\
\text { Potassium peroxymonosulfate (Oxone) }\end{array}$ & 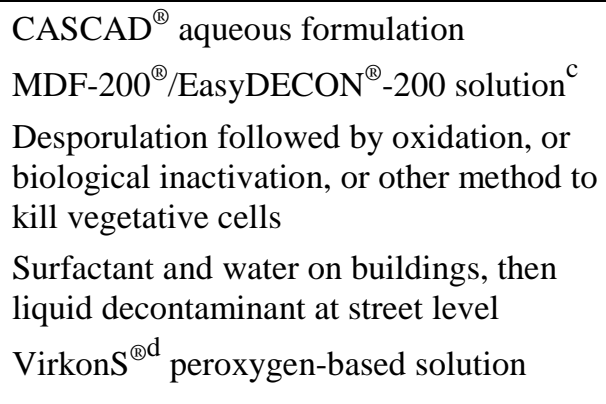 \\
\hline $\begin{array}{l}\text { Wide-area outdoors, } \\
\text { sensitive equipment, } \\
\text { such as power grids, } \\
\text { transformers, industrial } \\
\text { equipment }\end{array}$ & $\begin{array}{l}\text { Tenting followed by fumigation (e.g., } \\
\text { vapor-phase hydrogen peroxide, methyl } \\
\text { bromide) } \\
\text { For less-sensitive equipment, refer to hot } \\
\text { spot technologies listed above }\end{array}$ & $\begin{array}{l}\text { For less-sensitive equipment, refer to hot } \\
\text { spot technologies, listed above }\end{array}$ \\
\hline $\begin{array}{l}\text { Wide-area outdoors, soil } \\
\text { and foliage }\end{array}$ & $\begin{array}{l}\text { Formaldehyde }(5 \%) \text { in water }{ }^{\mathrm{f}} \text { (carcinogenic, } \\
\text { but the only verified technology) } \\
\text { Monitored natural attenuation }\end{array}$ & $\begin{array}{l}\text { Calcium hypochlorite }(\mathrm{HTH}) \text { solution } \\
\text { Other fumigants } \\
\text { Germination followed by biological } \\
\text { inactivation }\end{array}$ \\
\hline $\begin{array}{l}\text { Interior volumetric } \\
\text { spaces, such as buildings, } \\
\text { homes, and warehouses }\end{array}$ & $\begin{array}{l}\text { Chlorine dioxide fumigation } \\
\text { Vapor-phase hydrogen peroxide fumigation } \\
\text { Paraformaldehyde fumigation }\end{array}$ & Methyl bromide fumigation ${ }^{\mathrm{g}}$ \\
\hline $\begin{array}{l}\text { Indoor sensitive } \\
\text { equipment and valuable } \\
\text { items, such as artwork; } \\
\text { or indoor contents, such } \\
\text { as furniture or personal } \\
\text { items }\end{array}$ & $\begin{array}{l}\text { Ethylene oxide (gas) fumigation (requires } \\
\text { offsite chambers) } \\
\text { Vapor-phase hydrogen peroxide (for some } \\
\text { sensitive items) } \\
\text { X-ray or gamma ray irradiation (currently } \\
\text { used in mailroom facilities } \\
\text { Paraformaldehyde }\end{array}$ & Methyl bromide fumigation ${ }^{\mathrm{g}}$ \\
\hline
\end{tabular}




\section{Decontamination}

\begin{tabular}{|c|c|c|}
\hline $\begin{array}{l}\text { Wastes, including solids } \\
\text { and liquids }\end{array}$ & $\begin{array}{l}\text { Sodium hypochlorite (diluted and } \mathrm{pH} \\
\text { adjusted) } \\
\text { Aqueous chlorine dioxide }\end{array}$ & $\begin{array}{l}\text { Autoclave or incinerate solid waste, } \\
\text { depending on local requirements } \\
\text { For wastewater: calcium hypochlorite, } \\
\text { sodium hypochlorite, or chlorine dioxide }\end{array}$ \\
\hline $\begin{array}{l}\text { Water-distribution } \\
\text { systems and drinking } \\
\text { water sources }\end{array}$ & $\begin{array}{l}\text { Flocculants, settling, filtration followed } \\
\text { with sterile filtration }(<0.3 \text { micron })^{\mathrm{h}} \\
\text { Chlorination } \\
\text { Point-of-use membrane filtration systems }\end{array}$ & $\begin{array}{l}\text { Point-of-use chlorination treatment } \\
\text { alternatives }(>10 \text {-fold concentration } \\
\text { increase from standard practice })^{\mathrm{j}} \\
\text { Boiling at point of use ( }>10 \text { minutes in } \\
\text { covered vessel) }{ }^{\mathrm{k}}\end{array}$ \\
\hline $\begin{array}{l}\text { Personal (skin); mostly } \\
\text { for decon workers and } \\
\text { secondary exposures }\end{array}$ & $\begin{array}{l}\text { Soap and water using nonabrasive strokes } \\
\text { Bleach-containing towelettes for skin } \\
\text { See footnote }\end{array}$ & - \\
\hline \multicolumn{3}{|c|}{ a For details and additional references, see Krauter, Tucker, Miles, and Raber (2008). } \\
\hline \multicolumn{3}{|c|}{$\begin{array}{l}{ }^{c} \text { Mixed efficacy of Decon (MDF-200) is reported against wild-type B. subtilis spores by Young and Setlow (2004). } \\
\text { d Gasparini et al. (1999); Hernández et al. (2000). }\end{array}$} \\
\hline \multicolumn{3}{|c|}{ Raber and McGuire (2002); Young and Setlow (2004). } \\
\hline $\begin{array}{l}\mathrm{g} \text { EPA (2007). } \\
\text { h }{ }_{\text {Huertas et al. (2003). }}\end{array}$ & & \\
\hline \multicolumn{3}{|l|}{ i EPA (2006). } \\
\hline \multicolumn{3}{|c|}{ k Rice et al. (2004). } \\
\hline $\begin{array}{l}{ }^{1} \text { CDC }(2005,2006) . \\
{ }^{m} \text { For guidance, see Recom }\end{array}$ & . & us \\
\hline
\end{tabular}

If additional reagents or technological approaches are tested in the future and shown to be efficacious for outdoor use, they should be added to the list of potential options. Furthermore, decision-makers could consider an entirely new paradigm in which tested and approved decontamination product(s) are applied, but no environmental sampling is performed afterward. Then if anthrax disease were to occur subsequently in some location, additional cleanup would take place. Finally, weather variations should be used to advantage in outdoor settings. For example, many structures could be painted given suitable weather conditions.

In terms of dissemination methods for decontaminants, large-scale spraying will most likely be required for outdoor decontamination after a wide-area release, but the lack of dedicated equipment is an operational gap. Improvised dissemination options include aerial systems, such as large forest-firefighting aircraft, crop dusters, and helicopters; and ground-based systems, such as fire trucks and large military equipment. Spraying from fire trucks or similar truck-mounted, water-spraying systems is an efficient way to dispense liquids. Fire hoses can deliver about 1000 gallons per minute. SNL and LLNL (2008) estimated that spraying down a large building would require about $2 \mathrm{hr}$, and spray-washing a house about 30 minutes. It may be possible to locate on 


\section{Decontamination}

the order of 200 fire trucks in a large city. Large firefighting aircraft can distribute approximately 20,000 gallons of disinfectant in about 10 minutes and would need 1 to 5 days to decontaminate $\sim 0.7$ square miles. If aerial systems were used, cross-contamination of low-flying aircraft would need to be checked. Although numerous dissemination options exist for decontamination reagents, little information is available on specific liquid dissemination conditions (e.g., flow rate, drop-size distribution, and impact velocity) for each of the improvised dissemination platforms that could effectively distribute decontaminant while minimizing reaerosolization, and ad hoc approaches could make the situation worse. Thus, once again it is important to emphasize the need to evaluate the risk versus benefit of each dissemination platform to ensure that a given process improves the situation through effective decontamination more than it spreads contamination through resuspension and other means of secondary contamination.

\subsubsection{Indoor Surface Decontamination}

On hard nonporous surfaces, bleach solutions, other oxidants, and surface-wipe techniques may be acceptable for partial building decontamination and in circumstances in which the primary source of contamination is easily accessible, as might be the case for contaminant tracked into buildings or that collects around entryways and windows. Liquid decontamination reagents identified in Table 8-2 for interiors can be used to decontaminate both nonporous and porous exposed surfaces if the surface is permeable to the decontamination solution and has low organic content. Such solutions are also useful for localized surface areas that may be highly contaminated. The low-tech solutions have been shown to be effective when combined with scrubbing and HEPA vacuuming as an initial step, and should be considered as a first, low-cost option to evaluate. Several commercially available decontaminating solutions may be appropriate if they are readily available. A cost analysis should dictate the choice of aqueous reagent. Solutions can be applied with a clean mop, clean disposable wipes, or using a sprayer if application conditions do not cause reaerosolization. Any accumulated solution from such decontamination must be collected and properly disposed.

\subsubsection{Indoor Volumetric Decontamination}

Interior decontamination using gas and vapor technologies has been the subject of considerable research and development since the U.S. anthrax incidents in 2001. Although current knowledge is considerable, resources and manpower limitations would be problematic following a wide-area incident. Recommended disinfectants for indoor decontamination include gas-phase $\mathrm{ClO}_{2}$ and vapor-phase hydrogen peroxide (VPHP). Such methods could be used for entire buildings or portions of buildings in which air ducts are contaminated, although the logistics of gas or vaporphase decontamination of high-rise buildings (e.g., 20 or more stories) has not been demonstrated. For VPHP, materials such as carpet and ceiling tiles that are difficult to decontaminate have been typically removed and decontaminated with a liquid reagent before disposal. Buildings with exposed cinder blocks require isolation with plastic sheeting because of VPHP absorption. $\mathrm{ClO}_{2}$ gas can penetrate most materials other than paper; thus, carpet and ceiling tiles can remain in place. Dissemination techniques involve gas and vapor generators.

VPHP is useful for indoor areas containing sensitive equipment. Decontamination zones using VPHP are generally no larger than 200,000 to 250,000 $\mathrm{ft}^{3}$ each. A decontamination vendor determines the size and location of VPHP generators. During decontamination, areas within the 


\section{Decontamination}

VPHP fumigation zone should be subjected to a slight negative pressure by exhausting approximately 5000 cubic feet per minute (cfm) through a HEPA-filtered negative air machine. Some vendors add a catalytic scrubber to remove excess VPHP from the fumigation area before exhausting to air. After ceiling tiles are removed, gross accumulation in the plenum should be vacuumed, and the debris bleached then doubled-bagged prior to disposal by an offsite waste handler. The outside of each bag should be wiped with bleach solution. All sensitive equipment beneath overhead vacuuming sites should be protected with plastic drapes. Power to AHUs must be turned off to limit the spread of contamination, and each unit should be tagged with name, date, and time. Air-exhaust screens should be removed, vacuumed, and wet-wiped using bleach. Air filters on AHUs and air conditioning units should be removed, the insulation on the unit should be scraped and removed, and the insides should be HEPA-vacuumed and wet-wiped with a liquid decontamination solution. Ceilings, light fixtures, and walls should be vacuumed and wet-wiped using $\mathrm{pH}$-adjusted bleach or other liquid oxidizing solution. Carpeting and furniture should be removed for VPHP treatment because they can serve as sinks to the decontaminant, although such removal will create additional waste. Such waste items should be sprayed with a liquid decontamination reagent and doubled-bagged for removal and disposal. Equipment covers or doors should be opened or removed to allow maximum exposure during fumigation. A key to protecting critical equipment, such as mainframe computers, is thorough drying and returning the relative humidity to a normal value before turning on the power. In contrast, some experts recommend leaving fans running while fumigating to circulate fumigant in and around computers. The vendors of Vaprox ${ }^{\mathrm{TM}}$ Hydrogen Peroxide Sterilant cite successful experience using this technique. Vendors should be consulted for best practices.

Chlorine dioxide is an antimicrobial pesticide generated in gas or liquid form that is effective against $B$. anthracis on porous and nonporous surfaces. The EPA first registered $\mathrm{ClO}_{2}$ gas as an antimicrobial pesticide in the 1980s for use in sterilizing manufacturing and laboratory equipment, environmental surfaces, tools, and clean rooms. Fumigation of large volumes can be achieved without secondary barriers. Existing HVAC systems can be used to deliver $\mathrm{ClO}_{2}$ fumigant. Skill is required to maintain $\mathrm{pH}$ and $\mathrm{ClO}_{2}$ gas concentration in a safe range. New information suggests that careful temperature control inhibits the production of chlorine gas, which is the chemical component that causes corrosion (EPA Decon Workshop, June, 2007).

Remediation with $\mathrm{ClO}_{2}$ gas is recommended for large, enclosed areas. A gas decontamination cycle consists of four phases: humidification, conditioning, decontamination, and scrubbing and aeration. $\mathrm{ClO}_{2}$ gas is introduced into a tented or sealed building after the building is preconditioned to $75^{\circ} \mathrm{F}$ and a relative humidity greater than $75 \%$. Air within a building is monitored for $\mathrm{ClO}_{2}$ using gas-sampling devices, and temperature and relative humidity meters are colocated in several predetermined sample locations. The gas dissipates quickly, so tenting or other methods for sealing a building are required. The vendor calculates the time required for $\mathrm{ClO}_{2}$ to reach an appropriate concentration. After treatment is completed, $\mathrm{ClO}_{2}$ gas is neutralized with sodium bisulfite or exhausted through a bank of carbon filters.

A major issue associated with the two fumigation technologies for a wide-area scenario is that they are currently time and equipment limited. Each large building can take on the order of one to four weeks to remediate, depending on size and contents. If 10 percent of the buildings within a major city were contaminated, then nearly 500 buildings would need remediation. The supply 


\section{Decontamination}

of qualified personnel and equipment to perform indoor decontamination is limited to less than 10 units nationwide (a "unit" refers to all resources required to decontaminate a building).

If fumigation were chosen for an indoor facility, then a method to seal the building to prevent the release of fumigant would be required. Isolation refers to actions taken to seal a site (historically and typically indoors) to permit fumigation and prevent the release or inappropriate runoff of a fumigant, such as a gas- or vapor-phase decontamination reagent. (The term "isolation" has been defined differently by various agencies; see Glossary.) Any containment measures put in place during first response or characterization were probably not done with fumigation in mind. If the volume of an isolated space exceeds the volume capacity of a selected fumigation technology, then either another technology needs to be selected, or isolated areas must be subdivided into smaller volumes. Seals can be smoke tested for leak-tightness. Negative air units (NAUs), also known as negative air machines, are used for isolation because they subject an isolated area to a slightly negative pressure to ensure that the biological agent and fumigant remain in the contamination zone. Separate NAUs can be used in each of several different areas to be decontaminated.

Where fumigations are performed indoors, site preparation can be time-consuming, costly, resource-intensive, complex, and must be carefully planned and documented. Indoor site preparation before decontamination using fumigation includes:

- Identifying any power-generation requirements according to the vendors' equipment.

- Identifying specific staging locations for the supplies and equipment needed to generate the reagent and for tenting or sealing equipment.

- Assembling decontamination units for workers.

- Subdividing spaces with temporary walls or seals, as needed.

- Conducting source reduction and removing nonessential items destined for waste into areas that can be subsequently treated or fumigated.

- Sealing or tenting buildings.

- Testing for leaks, and sealing all leaks and openings.

- Constructing local waste-processing units.

- Installing and testing chemical-generation systems.

- Installing and testing chemical, temperature, and humidity monitoring systems.

- Installing and testing NAUs and air-scrubbing systems.

- Commissioning new equipment.

- Testing low-level fumigation.

- Placing fumigant sensors, chemical indicators, or biological indicators (BIs) properly.

A low-level performance test may be conducted before a large-scale fumigation, which includes the scrubbing system, to show that the system as a whole will work when run at full capacity.

\subsubsection{Sensitive Equipment and Valuable-Item Decontamination}

Sensitive equipment includes computers, fiber optics, electronic components, and surgical or medical equipment. Other items of high value, such as artwork and historical items, simply cannot be replaced. Valuable items, including documents, ledgers, receipts, and money, will 


\section{Decontamination}

require accountability (chain of custody) and decontamination. Such items need special handling and destructive decontamination methods. A conservative approach for selecting the decontamination reagent for sensitive items should consider efficacy, safety, schedule impact, and cost. Items may potentially be decontaminated by gas or vapor technologies, such as EtO fumigation or VPHP, or by irradiation sterilization with e-beam or gamma rays, but material compatibility with any such approach should be verified with experts in material compatibility, as appropriate.

Sterilants and irradiation chambers can be used to decontaminate personal or valuable items removed from a facility if there are no adverse material compatibility issues. Irradiation is now used to treat all Federal government mail. In addition, sterilants may be used for smaller pieces of sensitive electronic equipment. Chemicals such as paraformaldehyde, methyl bromide, EtO, VPHP, or $\mathrm{ClO}_{2}$ gas can be used to kill spores on discrete items placed in a sterilization chamber. Adequate aeration of items after treatment is required to remove residual sterilant and any toxic byproducts that may have formed.

The exteriors of items such as ATM equipment, cash registers, essential computers, security cameras, and other small but valuable items can first be thoroughly vacuumed using HEPA vacuums (with $99.97 \%$ or better efficiency) for source reduction, and then decontaminated with an aqueous-based reagent, such as a peroxygen foam or gel which would need to meet contact time requirements. Vacuum debris must be doubled bagged, bleached, and decontaminated before disposal in offsite waste handlers. As each electrical item is decontaminated, it should be locked and tagged as out of service until sampling is completed and results show no growth. Receipts, money, and sensitive documents can be collected, carefully accounted for, and entered onto a chain-of-custody document. Paper material can be removed and bagged for offsite EtO fumigation or gamma-ray irradiation, as appropriate.

EtO is a diffusion-controlled, chemical process that sterilizes products through an alkalization reaction, destroying an organism's ability to reproduce. To be effective, products must be placed in permeable packaging, and gas concentration, temperature, relative humidity, and time of exposure must be controlled. Under conditions for effective sterilization, EtO reacts with moisture and chloride ions to form ethylene glycol and 2-chlorethanol, a nonvolatile residue referred to as ethylene chlorohydrin $(\mathrm{ECH})$. Because this residue remains in place after processing, products must undergo an aeration period, allowing any residual gases to dissipate to levels that are safe for the handling of processed product. Decontamination problems could arise because EtO is absorbed by some polymer types (i.e., rubbers and polyvinyl chloride). One of the best packaging materials for EtO gas sterilization is Tyvek because it is porous but does not allow microorganisms to penetrate unless the packaging is dropped, damaged, or damp. EtO is reportedly safe for electronic equipment. With the exception of glass and metal, EtO can penetrate most materials to an effective level of sterilization, although stacks of paper, for example, must not be tightly packed. Refer to Lucas et al (2003) and AAMI (2008) for further information on EtO penetration and materials compatibility. Consideration should be given to sending important, removable electronic equipment offsite for decontamination. At present, mobile EtO units can hold thirteen 40-in. $\times 48$-in. $\times 72$-in. pallets. Run time for a full load is approximately $14 \mathrm{hr}$, which includes loading, preconditioning, and air purging.

Irradiation sterilization techniques include exposure to high-energy electrons from particle accelerators or high-energy electromagnetic radiation in the form of an e-beam, x rays, or gamma 


\section{Decontamination}

rays. Radioisotopes of cobalt and cesium are the principal sources of gamma rays. Given a sufficient absorbed dose, all organisms, including spores of $B$. anthracis, are rendered unable to reproduce as a result of DNA damage. However, irradiation can also destroy magnetic media, such as film or videotape, and it tends to be expensive. The EPA does not have regulatory authority over irradiation because it is governed under the Federal Drug Administration's medical instrument regulations.

\subsubsection{Water Resources and Water-Distribution Systems}

Although some work has been done on decontaminating water that contains biological agents, comprehensive studies are limited. In the event of BWA contamination of outdoor water resources such as lakes, streams, or river systems, no treatment is currently recommended. Rather, because it is expected that spores would eventually flocculate and be mixed into the sediment, there would be no inhalation risk. Furthermore, any type of in situ, large-scale treatment would have an ecological impact. Therefore, it is recommended that monitoring be done to determine if and when a water resource can be used for other purposes, such as a drinking water source or for recreation. If a large-scale water resource does not return to an acceptable condition, other options would need to be evaluated, including (a) continued treatment of removed water by conventional disinfection, (b) increasing the level of disinfection for all or part of the system, or (c) issuing end-of-pipe treatment devices [Planning Guidance for Recovery Following Biological Incidents (DHS and EPA 2009)].

Recent studies by the EPA (Szabo et al. 2007; Morrow et al. 2008) have shown that greater concentrations of free chlorine and monochloroamine than are normally associated with drinking water treatment will be required to kill spores associated with copper, iron, and PVC surfaces, which tend to deplete the amount of available oxidant. Absolute numbers are not known at present, but preliminary research indicates that a greater than 10-fold increase from current treatment practices may be effective as a starting point. Evaluations should take into account the construction and age of water distribution systems; biofilms could create a sink for disinfectants and provide a matrix as a long-term source for continued re-introduction of spores into the system. Therefore, if a wide-area biological attack were to occur today, it is recommended that point-of-use chlorination treatment and filtration systems be considered (see Section 9.2.3 for further discussion). Membrane filtration systems, although expensive, could also be used to physically remove spore contamination at the point of use.

Further illustrating the complexity of the problem is the possibility that some decontamination reagents used to address biocontamination might themselves become problematic during a widearea cleanup. Decontamination with powerful chemicals to decrease exposure to a given microbial pathogen could result in increased exposure to the decontaminant chemical used, particularly in drinking water (Macler and Regli 1993). The concern thus becomes health risk arising not from intentional contamination of drinking water, but from the treatment (decontamination) process rather than the microbes per se. This problem would be exacerbated in a wide-area scenario if high levels of treatment were applied over a wide area, and if the byproducts of treatment were disposed as untreated wastewater and found their way into water supplies. Clearly, risk trade-offs must be considered as part of the decision process whereby decontaminant chemicals and treatment methods are selected and applied to minimize microbial risks, but approaches to strictly limit or prevent secondary contamination of water systems should be incorporated into remediation planning. 
Decontamination

\subsubsection{Waste and Wastewater Decontamination}

For most scenarios involving the wide-area release of a BWA, unprecedented amounts of waste would be generated during remediation. Virtually all waste will be required to be decontaminated before transport to disposal facilities. Therefore, waste must be minimized, and decontamination strategies should incorporate in situ decontamination and reuse whenever possible. More specifically, it would be best to decontaminate items such as furniture and carpets as part of building fumigations if possible, for example, if chlorine dioxide gas were the decontamination reagent selected. There may be no alternative for contaminated food and other perishables.

If needed, inexpensive and abundant chemical oxidizers are the most appropriate technologies to decontaminate specific waste items. Such items can be placed in a bath of inexpensive decontaminant (such as amended bleach) long enough to kill all biological agents. Contact times on the order of 60 minutes should suffice (see <http://www.epa.gov/pesticides/factsheets/chemicals/bleachfactsheet.htm $>$. It is possible that 10,000 to 100,000 gallons of bleach would be required for each day of decontamination operations, at a cost of $<\$ 1$ per gallon.

Preventing contaminated wastewater from running off into uncontaminated areas is an important consideration. Vast networks of storm drainage systems must be understood to identify places prone to problems, such as overflow and interference with proper wastewater management. Compliance with regulatory restrictions on wastewater can pose substantial challenges to the management of contaminated liquids. Because decontamination decisions have a major impact on waste generation and associated disposal costs, having a wastewater plan in advance is a critical part of the RAP. Any discharge into the wastewater system that could interrupt sewagetreatment-plant operations needs to be discussed and resolved.

The former Soviet Union's Veterinary-Sanitary Measures Manual recommends a concentration of 200-mg chlorine per liter of wastewater and a contact time of $12 \mathrm{hr}$ for water contaminated with $B$. anthracis spores. Water retention systems can be decontaminated with calcium hypochlorite, sodium hypochlorite, chloramines, or chlorine dioxide. The use of liquid chlorine in contact settling tanks has been recommended $(500 \mathrm{mg}$ active chlorine per liter of wastewater with a chlorine concentration of $35 \mathrm{mg}$ per liter, $2 \mathrm{hr}$ after chlorination). Alternatives that meet U.S. regulatory standards, as with all other treatment strategies, need to be evaluated on a smaller scale before wide-area implementation. Depending on the destination, wastewater from decontamination technologies is regulated by Clean Water Act pretreatment requirements specified in 33 USCA 1317, 40 CFR 403, state regulations regarding pretreatment, and any local Publicly Owned Treatment Works (POTW) pretreatment requirements. 


\section{Decontamination}

\subsection{Select Waste-Management and Waste-Disposal Strategies (Boxes 404 and 405)}

Decontamination decisions have a major impact on disposal decisions, and vice versa. Decontamination should be implemented in a way that prevents the release of harmful substances to the environment. In summarizing the problem of waste management following a wide-area attack, SNL and LLNL (2008, p. 62) caution the following:

Handling the enormous amounts of contaminated waste from a wide-area biological incident will overwhelm normal medical waste processes. Although there are understood processes for treating and handling contaminated waste, if [they are] not addressed properly in a wide-area event [they] could bring remediation efforts to a halt.

Waste streams from a wide-area incident would originate from all phases of remediation and include contaminated indoor and outdoor materials, waste generated from personnel and equipment decontamination, and waste generated from packaging and transporting contaminated materials. The total could amount to hundreds of thousands of tons in a large urban area. The three major categories of wastes expected from B. anthracis remediation are: (1) PPE and other materials associated with decontamination, (2) debris intended for disposal, and (3) wastewater generated during decontamination and from possible flushing of water distribution systems.

Figure 8-4 identifies the steps associated with planning removal, packaging, transportation, and treatment for wastes to be recycled or reused (Boxes 404-1 through 404-5). Figure 8-5 identifies the steps associated with planning removal, packaging, transportation, and treatment for wastes to be disposed (Boxes 405-1 through 405-5). SNL and LLNL (2008) identified several gaps related to waste management and disposal. In general, the problem of waste disposal from a wide-area remediation is the lack of efficient processes for handling the vast amounts of contaminated waste in an environmentally acceptable way. The overall recommendation is to limit the amount of waste to be disposed, decontaminate in situ, and reuse items and materials whenever possible. This is a key theme for a wide-area biological incident. 


\section{Decontamination}

\section{DECONTAMINATION (expanded 404)}
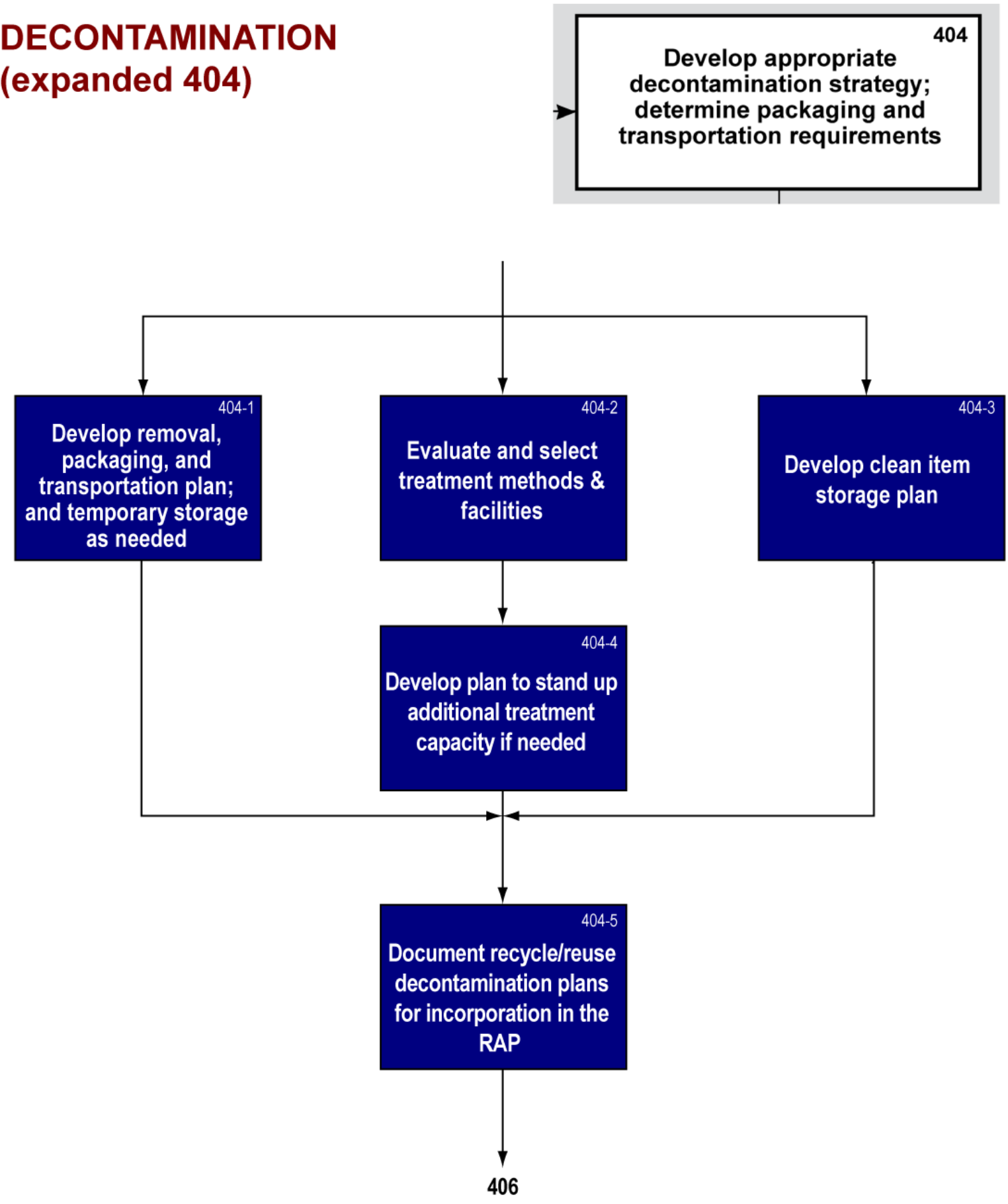

Figure 8-4. Box 404 expanded: determine strategy for waste to be recycled or reused. 


\section{Decontamination}

\section{DECONTAMINATION (expanded 405)}
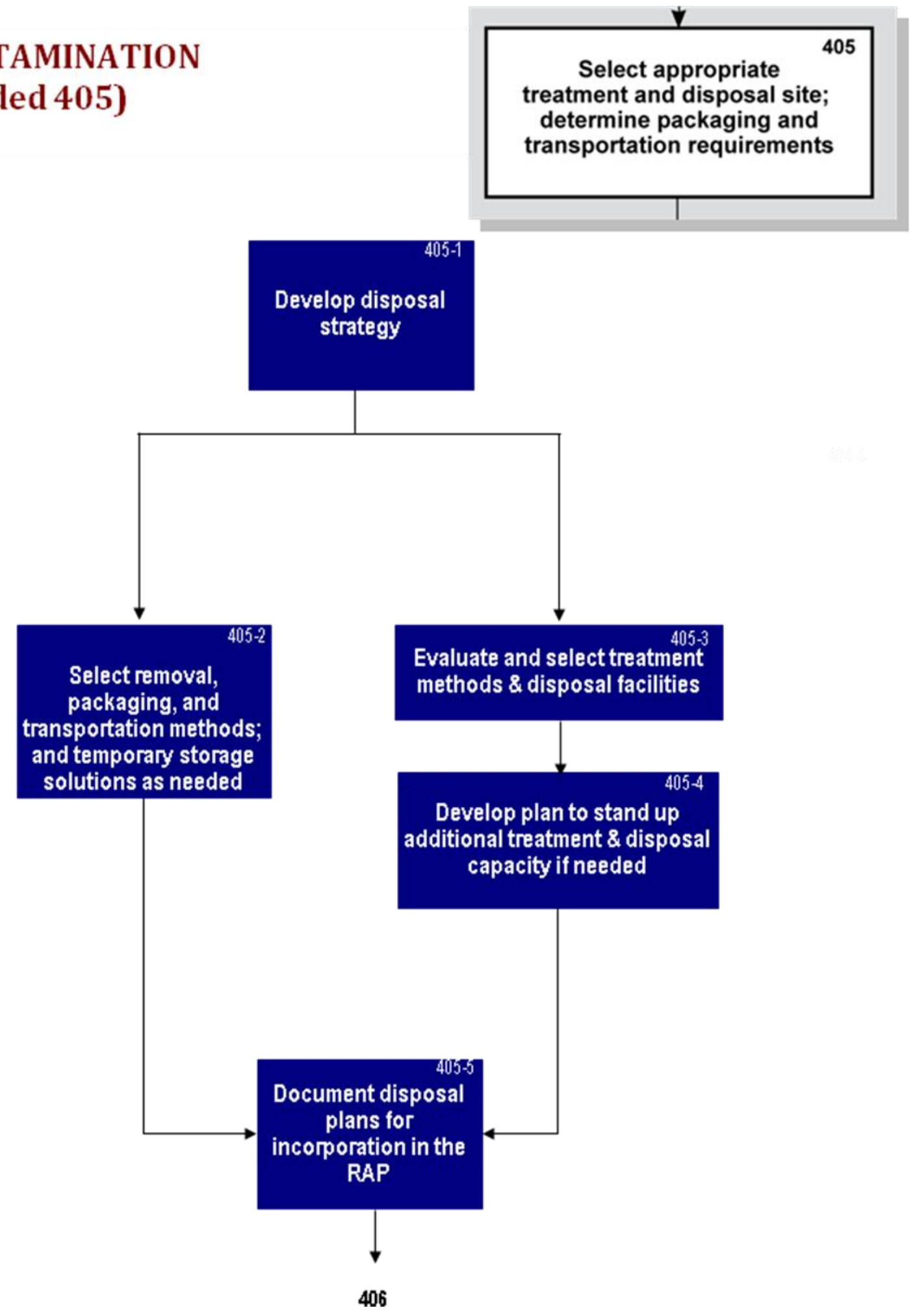

Figure 8-5. Box 405 expanded: determine strategy for waste to be disposed. 


\section{Decontamination}

\subsubsection{Waste Guidelines}

Solid waste disposal is typically regulated by the solid-waste management division of a state's environmental protection department. A waste disposal facility voluntarily accepts waste through contractual arrangement. Both entities are important stakeholders. It is generally easier to dispose of wastes in facilities within the same state in which contamination is located, as opposed to another state; however, optimal disposal facilities for certain waste streams may not be present or adequate in a particular state. B. anthracis-contaminated wastes are not regulated under Subtitle $\mathrm{C}$ of the Resource Conservation and Recovery Act (RCRA), but they should be handled with caution because of the potential for exposure to an infectious agent. In some states and localities, such contaminated wastes are considered medical waste or infectious substances with special requirements for handling and disposal. Therefore, it is essential to contact the state or local regulatory agency early to determine what requirements apply and what treatment and disposal options are available. State authorities have the primary responsibility to regulate and oversee management of wastes that may be contaminated with an infectious agent, such as B. anthracis. It is highly advisable to establish contact in advance of an incident or early in the remediation process with waste-disposal stakeholders, such as publicly owned wastewater treatment operators and landfill, incinerator, and sterilization facilities. Disposal contracts should be prenegotiated, if possible.

Before discussing waste disposal with potential disposal facilities, decision-makers need to have at least a rough idea of the quantities and characteristics of materials destined for disposal. An important aspect of the waste disposal process is the regulatory category into which waste falls. The categorization of types of wastes varies from state to state, but materials from a BWA remediation might be categorized as regulated medical waste or as a special waste. New York State, for example, has begun a process of defining bioterrorism waste from a regulatory perspective. For the Seattle Baseline Scenario \#1, a relevant local code related to waste is the Seattle Municipal Code (SMC, Title 21) on Infectious Waste Management. This policy provides the authority for city public health officials to manage issues surrounding infectious materials and waste, and it governs infectious waste generation, storage requirements, transfer, and disposal. Requirements for each phase of handling infectious waste are described in the SMC.

Municipal-waste site operators may be reluctant to take material from a BWA incident even after it has been decontaminated; thus, pre-established disposal plans are essential. A disposal plan should be developed at the same time as decontamination planning, if not before. The disposal plan should reflect any state, local, or facility requirements (e.g., decontamination actions, postdecontamination sampling, and PPE for transportation and disposal facility workers) for disposal of decontaminated material as municipal waste. The disposal plan should estimate types and amounts of wastes, transportation needs, and costs. It should also describe any clearance sampling to be done at disposal sites as well as long-term monitoring requirements, if necessary. The team(s) managing a remediation effort must characterize all wastes and manage each type according to applicable Federal, state, and local regulations.

\subsubsection{Waste Storage, Transport, and Disposal}

B. anthracis-contaminated waste may be stored for further treatment, or pending test results, in sealed containers that are appropriately labeled. If waste is temporarily stored before transport to offsite disposal, it must be in containers that meet the DOT Division 6.2 (Infectious Substances) 


\section{Decontamination}

packaging requirements. The storage area must provide weather protection and prevent access by unauthorized individuals or vermin. Items containing hazardous or radioactive materials contaminated by $B$. anthracis spores create additional considerations as more difficult waste to handle, and appropriate precautions are required for their disposal.

When possible, $B$. anthracis-contaminated wastes should be treated onsite to reduce or destroy spores, tested to confirm treatment effectiveness, and treated further, if necessary, until posttreatment sampling shows no indication of viable spores. If such a process is followed, treated wastes may possibly be disposed of as municipal solid waste or wastewater, given approval from appropriate state and local authorities. When total elimination of spores cannot be confirmed, wastes must be properly packaged and transported to a state or locally approved waste-treatment facility capable of destroying any remaining spores. Depending on the capacity of available facilities and the size and volume of wastes to be treated, medical or other equivalent types of waste-treatment facilities might need to be used.

B. anthracis is a select agent defined under Select Agent Regulations (9 CFR 121 and 42 CFR 73). The CDC administers the Select Agent Program for those select agents and toxins that pose a severe threat to public health and safety. Before transporting $B$. anthracis-contaminated waste to an offsite treatment facility, generators should contact the Select Agent Program (phone: 404718-2000; email 1rsat@ cdc.gov) for any special handling and transportation requirements that may apply. Information on the Select Agent Regulations is available at <http://www.selectagents.gov/>. B. anthracis-contaminated waste may not be transported as regulated medical waste, and currently there are no existing de minimis levels for residual biological agents in waste. Following a wide-area attack or disaster declaration, it is possible that some rules may be modified or suspended. When the DHHS Secretary declares a Public Health Emergency, exemptions may be granted for 30 days, subject to one 30-day renewal from Select Agents' requirements for entities to respond to a domestic or foreign public health emergency that involves the select agent or toxin.

B. anthracis-contaminated waste may not be transported as regulated medical waste. Commercial transportation of such waste must meet requirements in the DOT's Hazardous Materials Regulations (HMR 49 CFR Parts 171-180). The requirements do not apply to waste that has been treated so that the spores are destroyed. If appropriate state and local officials approve, ash or other residues from $B$. anthracis treatment via combustion, autoclaves, or other state-approved treatment technologies may be disposed as municipal solid waste.

\subsubsection{Liquid Waste}

Large quantities of liquid waste and wastewater (e.g., from decontamination processes and from washing down equipment, materials, and personnel) will present special problems that must be managed by collection and treatment when possible to prevent release into a drainage system and ultimately into nearby rivers or other surface water. All chemicals should be separated and contained according to standard environmental, health, and safety regulations.

Wastewater collection and treatment facilities are usually designed to accommodate pathogenic microorganisms. There are, however, circumstances under which a traditional wastewater treatment system may not be able to handle wastewater from a biological contamination incident. For example, a rapid influx of large volumes of water, particularly if contaminated with a large quantity of BWA, may challenge a wastewater system beyond its capacity. Options considered 


\section{Decontamination}

for disposal of sludge or wastewaters during previous B. anthracis cleanups included incineration, hazardous waste landfills, and treatment at the local wastewater treatment plant or POTW. The potential generation of large volumes of wastewater makes the POTW an important stakeholder that needs to be involved early during remediation when decontamination decisions are made.

Decontamination planners must identify the location of drains and other connections that would provide routes for materials to enter the environment. Measures should be taken to protect the exits, such as plugging storm drains before the start of surface decontamination activities or containing flows from a decontamination zone before discharge to the environment. The resultant waste materials can be removed using wet-dry vacuums, mops, or wiping down surfaces. If a centralized containment or staging area is established, materials can be rinsed into a containment area where wastewater may need to be treated, then characterized, pumped, and properly disposed. The need for treatment depends on local regulatory agencies, which should be contacted early in the remediation process.

Taking preventive measures before waste is released to the environment can potentially save money and spare resources that would otherwise be required to remediate contaminated or recontaminated areas. If a release does occur, stakeholder and regulatory requirements must be met to mitigate the damage. Guidelines for discharging B. anthracis-decontamination wastewater to POTWs can be found in Appendix E of the National Response Team's Technical Assistance for Anthrax Response (NRT 2005).

\subsubsection{Hazardous and Radioactive Wastes}

Items that contain hazardous or radioactive components at environmentally significant levels require special handling, even after viable microbial agents have been removed. Small waste items that are hazardous or radioactive, by DOT definition, must be packaged and transported pursuant to DOT regulations, as prescribed in 49 CFR Parts 100-185. Sterilized, small and large hazardous waste items that are normally recycled, and that contain interstitial spaces, should not be recycled, but managed as hazardous waste. Large DOT-regulated items may require placement in DOT-approved bulk containers.

\subsubsection{Support Tool For Disposal}

The EPA's National Homeland Security Research Center (NHSRC) has been developing a decision support tool for the disposal of items and debris from the decontamination of buildings and water systems (Lemieux et al. 2006). The tool can quickly estimate quantities and characteristics of residues produced during remediation, and it can provide information useful for selecting an appropriate disposal facility. This tool can assist in evaluating cost tradeoffs between decontamination and disposal, and it can be used either as a planning tool before an incident occurs or during remediation to develop a waste management plan. The web-based decision support tool called "EPA's Suite of Disaster Debris Management and Disposal Decision Support Tools," is available at $<$ http://www2.ergweb.com/bdrtool/home.asp $>$. Decision-makers will need to evaluate the relative efficiencies of onsite decontamination versus decontamination assemblyline processes, costs of packaging and transporting contaminated items offsite, and costs of waste disposal and replacement. 


\section{Decontamination}

\subsection{Verify Decontamination Processes (Boxes 406 and 408)}

Decontamination processes are monitored as they are carried out and then evaluated as to whether they have achieved the desired level of contamination reduction. The type of verification applied depends on whether the decontamination involves liquid versus gaseous or vaporized chemicals.

\subsubsection{Liquid Decontamination}

For decontamination reagents applied to hard, nonporous surfaces, effectiveness is evaluated in terms of whether the minimum product concentration and contact time specified on the product label — or specified in the FIFRA exemption issued by the EPA — have been attained. Records of relevant parameters must be kept to show that process criteria for a given decontamination action were met. In addition, sporicidal decontaminants intended to inactivate $B$. anthracis spores must be used in accordance with requirements of the applicable Remediation Action Plan, which would likely specify the collection and analysis of environmental clearance samples in a treated area to ensure that decontamination is successful.

\subsubsection{Fumigation}

The effectiveness of fumigation is evaluated using two factors. First, four key process variables are monitored throughout fumigation: temperature, relative humidity, fumigant concentration, and contact time. Each must be kept within a specified range. Temperature and relative humidity are recorded continuously during fumigation. Fumigant gas or vapor concentration is always monitored by real-time chemical sensors or chemical analysis of manually collected samples. Concentration is sometimes monitored with chemical-sensitive paper as well. Second, the effectiveness of fumigation is sometimes confirmed through use of biological indicators (BIs) that consist of nonpathogenic (surrogate) spores of a species related to B. anthracis.

Nonpathogenic spores used in BIs are intended to be more resistant to inactivation and possibly present in greater numbers than the virulent biological agent, so that if all spores on a BI are killed, then the implication is that all virulent spores present have also been killed. However, research from the EPA shows that paper BIs (bearing B. atrophaeus spores) exposed to chlorine dioxide gas or VPHP are inactivated before the concentration $\times$ time $(C T)$ requirement is met. Thus, BIs are only considered to be a general, but not definitive, indicator of the effectiveness that fumigation was effective.

BIs, if used, are placed in various locations and heights at a minimum frequency specified in the RAP. A density of one BI per $100 \mathrm{ft}^{2}$ of floor space was used in at least some of the $2001 \mathrm{~B}$. anthracis remediations, but this rate is unlikely to be practical for a wide-area incident. For example, a single 5,000,000 $\mathrm{ft}^{2}$ building would require 50,000 BIs, and there would likely be many such buildings. Placing BIs in locations of known or suspected contamination and in spaces hard to reach by a fumigant is standard practice. After fumigation is complete, both treated and control BIs are sent to an analytical laboratory with experience in analyzing BIs from biomedical sterilization and other relevant fumigation processes. They are then incubated to determine spore viability. When process parameters are met, and all spores on the BIs have been killed, the fumigation may be judged as likely to have been effective. However, the fact that all tested BIs are negative would not guarantee that all BWA spores have been inactivated. The overall criterion for success of a remediation is usually obtained through environmental 


\section{Decontamination}

clearance sampling showing no growth by culture in any sample, as described in Section 9. Because of problems identified with BIs, more extensive monitoring of process parameters is being evaluated as a replacement for the use of BIs.

\subsubsection{Wastewater and Water-Treatment Systems}

For decontamination of wastewater and water-treatment systems, decontaminant concentration, contact time, and temperature parameters must be met. The parameters may vary as a function of $\mathrm{pH}$ or other water-quality factors and must be monitored to ensure that all regulatory conditions are met. Numerous chemicals in a wastewater matrix can interact with disinfectants; thus, decontaminant concentration must be monitored during any wastewater decontamination process. Standard wastewater treatment methods, such as flocculation or settling, should also be considered as alternatives to the use of decontaminant chemicals.

\subsection{Identify Civilian and Military Assets Needed to Implement Decontamination}

The IC or UC will need to address other decisions and constraints (Figure 8-2) in advance of wide-area decontamination, which are likely to include:

- Availability of decontamination-related equipment that may be on hand within the urban area, or can be mobilized from surrounding areas, including military and national sources, to support specific types of decontamination objectives, such as surface decontamination.

- Availability and stockpiles of specific decontamination supplies, such as liquid and fumigation chemicals.

- Access to certain regions in the urban area if ports, airports, train routes, interstate highways, and other means of access are compromised by biological contamination.

- Availability of potential contractors.

- Physical or other practical limitations on locations (e.g., skyscrapers) and numbers and spatial extent of staging areas for equipment and supplies.

- Availability and siting of potential waste-disposal facilities as well as nontechnical (e.g., legal and regulatory) challenges at the time that disposal of waste takes place.

- The possibility of citizens performing their own decontamination (Boxes 400-2 and 406-8).

- Applicable local, state, or Federal regulatory requirements related to decontamination (Box 400-3).

Table 8-3 lists agencies, teams, and technical contacts that should be identified by decisionmakers in advance of an attack, or at a minimum, before proceeding with decontamination. Estimates of the resources and assets required for decontamination can be derived by decisionsupport tools, some of which have been developed and used for Superfund and CERCLA remediation programs. The recently developed Analyzer for Wide-Area Restoration Effectiveness (AWARE) should be evaluated for applicability if a wide-area biological incident were to occur (Einfeld 2008). 


\section{Decontamination}

\subsection{Prepare Site-Specific Remediation Action Plan(s) (Box 406)}

As shown in Figure 8-6, once an overall decontamination strategy is developed for a given site (Boxes 406-1 through 406-4), a RAP (Boxes 403-5 and 406-5) is assembled by the EU, Decontamination Group, or both, with advice from the TWG if one is assembled. The Operations Section Chief reviews, and the IC or UC approves the plan. Many such plans may be needed to address wide-area remediation. A RAP spells out the plan and methods for decontaminating a particular contaminated area or facility or water system and its contents, starting with the highest-priority areas and facilities. The RAP and Clearance SAP (Box 406-6; see also Section 9) are generally created concurrently because a remediation strategy can directly affect characterization and clearance sampling strategies.

Table 8-3. Decontamination resources. (Urban planners to fill in contact information.)

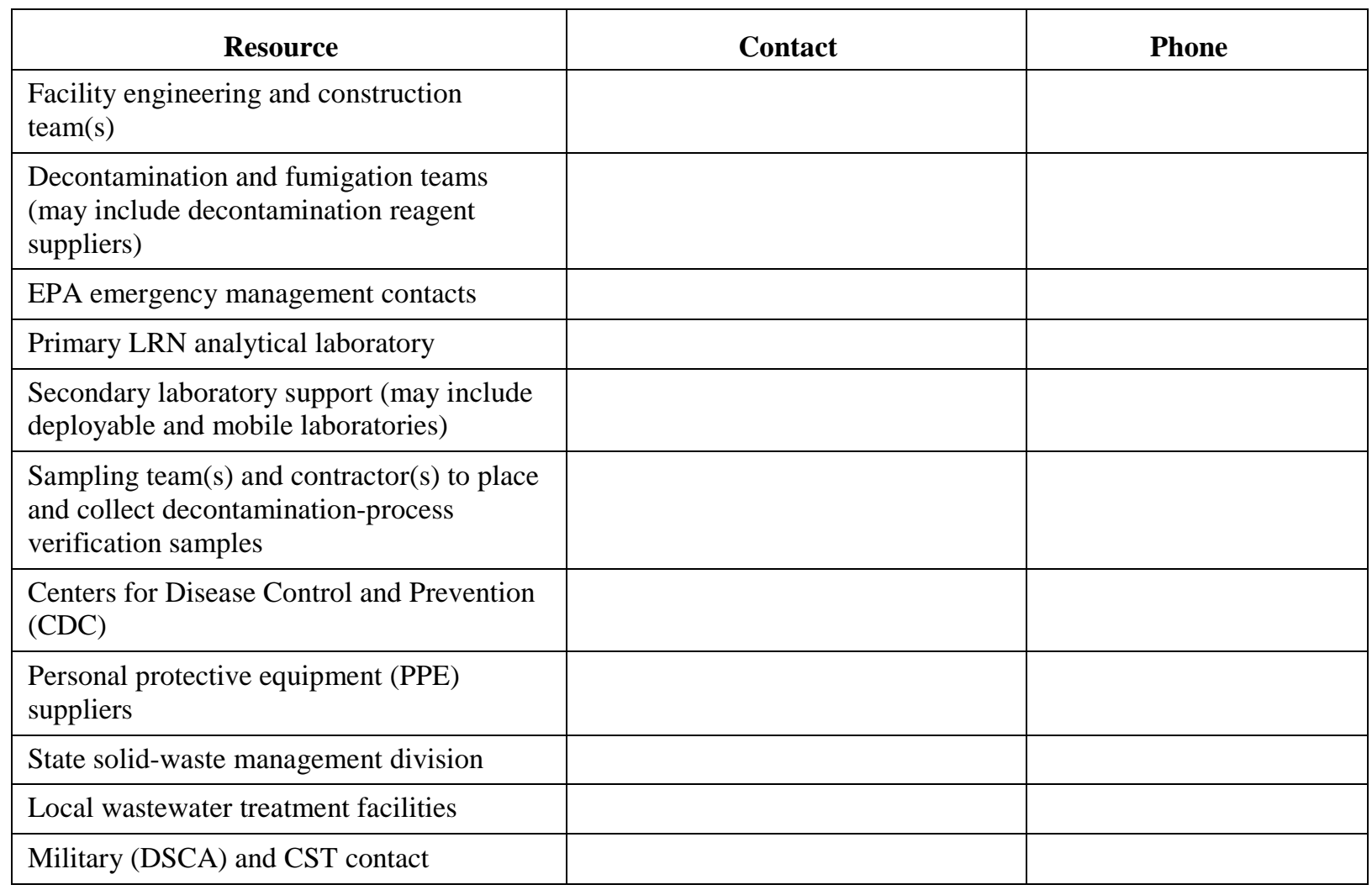

The RAP for a wide-area incident may differ from, and include topics not always contained in, a standard RAP for a localized incident. The RAP for a wide-area incident would likely include the following sections:

- Site Information.

- Background information, including site data, area use, and surrounding area.

- Description of area to be remediated.

- Contamination Information.

- Incident description, initial release, type of contaminant, initial actions, and relevant meteorological data. 


\section{Decontamination}

\section{DECONTAMINATION (expanded 406)}

\section{Update prioritization of targets for decontamination}

Prepare remediation \& clearance sampling \& analysis action plan

- Select decontamination

verification criteria

- Address clearance goals

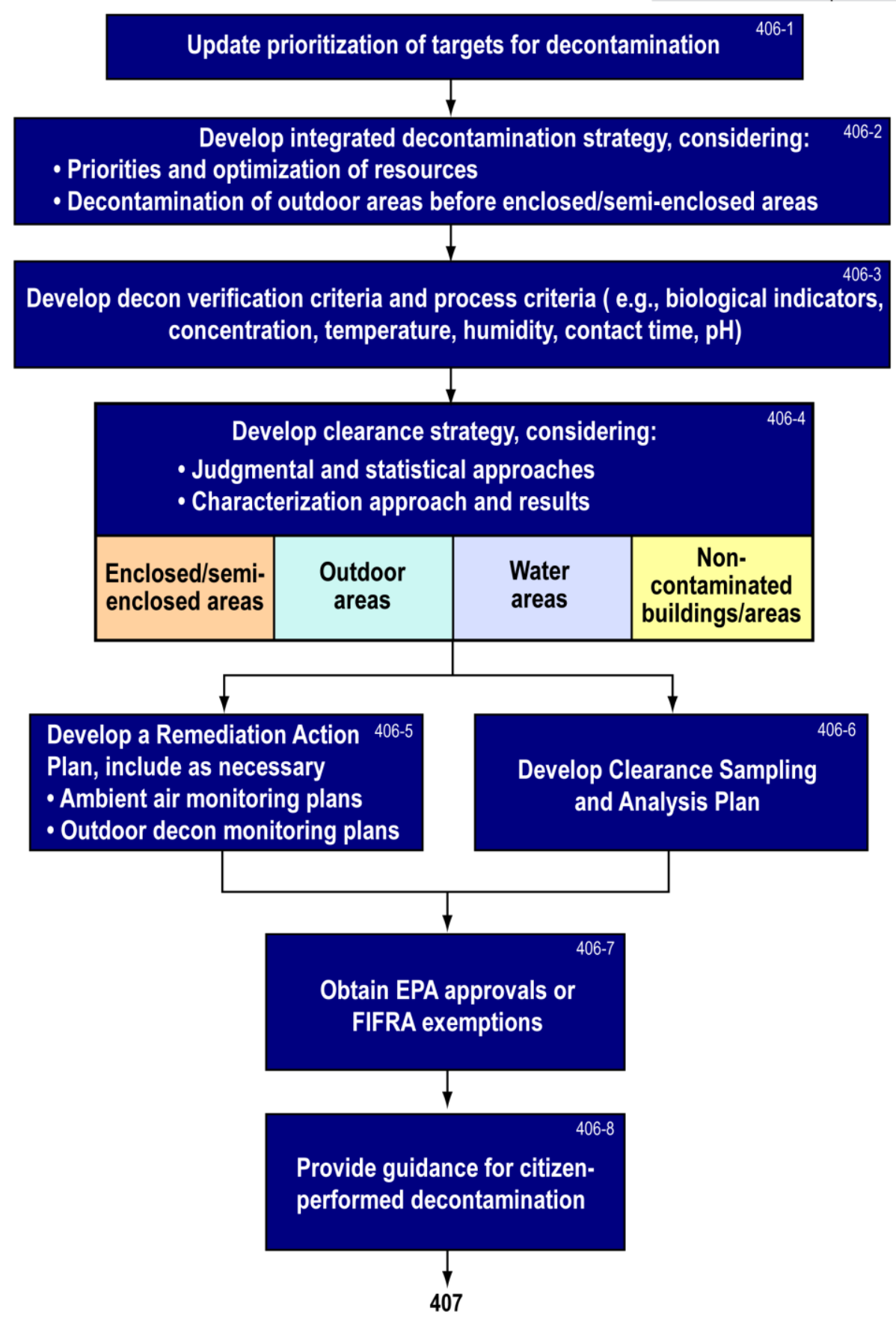

Figure 8-6. Box 406 expanded: develop RAP and clearance SAP. 


\section{Decontamination}

- Work to date including first-response data, characterization goals and results, air sampling results, and any initial decontamination related to first-response activities.

- Environmental risk assessment including exposure and dose-response assessments to produce the Characterization Environmental SAP.

- Clearance goals.

\section{- Administrative Information.}

- Organizational structure including team structure and IC or UC contacts.

- Communication structure and requirements including public relations and risk communication strategies.

- Justification for EPA approvals or FIFRA exemption(s) (Box 406-7; see also below).

- Zone Establishment, and Perimeter and Access Control.

- Perimeter control, developed with assistance from local law enforcement.

- Worker access portal with provisions for worker decontamination.

\section{- Proposed Cleanup Actions.}

- Site or area preparation.

- Prioritization of decontamination activities including source reduction, external versus internal areas, and the order of decontamination.

- List of items to be decontaminated in place versus removal for offsite decontamination (e.g., sensitive equipment) or disposal as waste.

- Technologies and techniques to be employed for decontamination, with documentation and justifications for the decisions, including tie-in to clearance goals.

- Procedures for minimizing reaerosolization or spreading of BWA from the decontamination effort (e.g., methods to catch spray from building wash-down with water or other liquid).

- Procedures or isolation measures required to seal a building during fumigation or to prevent inappropriate runoff.

- Specific resources, personnel, equipment, and chemical reagents to be used during decontamination.

- Schedule for decontamination resulting from prioritization scheme and resource allocation considerations.

- Verification of the decontamination processes.

- Post-operation cleanup and reallocation of resources to other sites.

- Waste Disposal.

- Determination of site(s) for disposal of different types of waste and access routes to disposal sites.

- $\quad$ Procedures for collecting waste for disposal, including solid wastes and liquid waste stream from decontamination processes.

- Waste storage, transport, and final disposition.

- Safety.

- Description of health and safety procedures. This section typically is a reference to the Health and Safety Plan.

- Self-Remediation (Emergency Exemption Approved) Procedures. 


\section{Decontamination}

- Guidance for use by facility owners.

- Guidance for the general public for personal and dwelling decontamination (Box 4068).

- Clearance Activities.

- $\quad$ Summary of the Clearance Environmental SAP (see Section 9).

- Clearance decision-making criteria.

- Activation of post-clearance, long-term monitoring plan.

- Schedule, consisting of the timeline of planned remediation activities.

The RAP contains appropriate tables, figures, drawings, references, and appendixes of key information from other documents, such as procedures and methods used during the remediation process and the characterization environmental sampling report. If decontamination capabilities are identified in advance of an incident, as recommended, then a RAP can be prepared more rapidly. In a wide-area release, sub-RAPs or multiple RAPs can be written to cover subsets of the larger remediation effort, such as individual buildings or sections of the release area.

Because the RAP specifies how remediation activities are to be carried out, the IC or UC needs to approve the plan before it is implemented. The IC or UC must also approve any changes to the RAP as remediation progresses. If any Federal or state agencies have jurisdiction over activities described, they should review and approve the RAP. The RAP must also be approved by the EPA if the BWA is $B$. anthracis spores and if a FIFRA exemption is required (Box 406-7). Only one antimicrobial product is currently registered under FIFRA to inactivate $B$. anthracis spores on inanimate surfaces (40 CFR 150-189 Subchapter E, Pesticide Programs). If no registered antimicrobial product is available or appropriate for a particular use or site, a FIFRA exemption may be needed, depending on whether the remediation is conducted solely under CERCLA or not.

The PR Notice 2008-2, issued on August 26, 2008, limits the sale and distribution of anthraxrelated products to the following personnel: (1) Federal OSCs; (2) other Federal, state, tribal, and local government workers authorized to perform biological decontamination; or (3) persons trained and certified as competent by registrants. In addition to the EPA's role in product registration, ultimate decisions on what decontaminants and methods are to be used for decontamination following a wide-area release would be made by the IC or UC.

\subsection{Prepare Related Documents}

If the RAP calls for fumigation, then it should be accompanied by a written ambient air monitoring plan (AAMP) and a Clearance Sampling and Analysis Plan (Clearance SAP; Box 406-6). Clearance sampling is also needed for decontamination that does not involve fumigation because areas and items treated with liquids and semi-liquids need to be sampled and cleared. It is expected that the EPA will require other documentation (e.g., Monitoring Plan) for the use of a wide-area decontaminant to minimize unnecessary impacts to the environment, such as runoff.

Use of $\mathrm{ClO}_{2}$ fumigant inside a facility requires air monitoring outside the facility to ensure that fumigant does not escape in concentrations that may pose a hazard to workers or the surrounding population. The RAP together with the AAMP and clearance SAP are used to obtain a FIFRA exemption from the EPA, if needed. Alternatively, the EU can submit drafts of the three documents to the EPA for a preliminary review to ensure the information is complete before 


\section{Decontamination}

final submission together with a formal exemption request. If certain pesticide products become registered for inactivation of $B$. anthracis in the future, the three plans will likely be required by the product's labeling, but the plans would no longer be submitted to the EPA for approval; instead, the IC or UC would approve them.

If fumigations are to be used, a sector-wide Emergency Response Plan is also recommended, although such a contingency plan is not required to obtain a FIFRA exemption. The Site Safety Officer develops an Emergency Response Plan to address potentially uncontrolled fumigation releases from unexpected events, such as explosion, fire, or severe storms (Box 403-2). An appropriate worker Health and Safety Plan (HASP) will also be required; see Section 7.6.

\subsection{Perform Decontamination (Box 407)}

Step-by-step remediation actions for a wide urban area cannot be suggested in advance of an attack because the details of remediation will be site- and incident-specific and governed by the details of a prioritization scheme (Box 406-2). In general, however, after site preparation is complete and the necessary documentation is approved, decontamination commences starting with the highest-priority area(s). The RAP is implemented in a series of Incident Action Plans (IAPs), as defined in the NRF.

Designated decontamination contractor(s) and trained decontamination personnel carry out the decontamination activities, with oversight by the Operations Section's Decontamination Group. Decontamination resources will be allocated according to the schedule developed in the RAP. Decontamination activities must be completed in accordance with procedures referenced in the RAP, and any deviations must be approved. Changes to the plan are likely to occur given the limited national experience in wide-area BWA releases and because of the magnitude and complexity of the effort. Therefore, good communication and operational flexibility must be maintained to quickly adjust to new priorities, evolving decontamination techniques, and the changing availability of resources.

Some essential urban operations or functions may need to be relocated during decontamination activities. The Logistics Section, working with applicable regional and city officials as well as stakeholders, would devise a plan to move essential functions and services to contamination-free (cold) zones until decontamination and clearance activities are complete. The relocation of operations might involve the physical relocation of some assets. If any physical items were moved from a contaminated area to an uncontaminated one, each would require decontamination and clearance before being relocated.

Following decontamination activities, the EU and Decontamination Group, with input from the TWG, evaluate results for completeness and to ensure that process criteria have been met (Section 8.6; Box 408). The EU, Decontamination Group, or both, may recommend additional decontamination activities, if warranted. Once the IC or UC concludes that decontamination has been effective, it submits relevant data from response and recovery activities to the ECC for an independent review of the effectiveness, and a recommendation whether the site is safe for re-use 


\section{Decontamination}

\subsection{Section 8 Summary of Actions}

\section{Table 8-4. Summary of decontamination actions in approximate order of unfolding events.}

\begin{tabular}{|c|c|}
\hline Responsible Personnel & Action \\
\hline Emergency planners & $\begin{array}{l}\text { For pre-planning purposes, inventory decontamination resources, such as equipment, } \\
\text { expendable materials, sources, and providers. Plan decontamination operations for various } \\
\text { scenarios using available tools. }\end{array}$ \\
\hline $\begin{array}{l}\text { Planning Section: EU, with input } \\
\text { from TWG }\end{array}$ & $\begin{array}{l}\text { Develop measurable clearance criteria, based on the results of characterization, to meet the } \\
\text { defined clearance goals. }\end{array}$ \\
\hline IC or UC & Approve clearance goals and clearance criteria. \\
\hline \multirow{7}{*}{$\begin{array}{l}\text { Planning Section: Environmental } \\
\text { Unit, with input from TWG }\end{array}$} & Review prioritization scheme from the results of characterization and any other new data. \\
\hline & $\begin{array}{l}\text { Develop decontamination zones and strategies, including assessment of potential } \\
\text { environmental impacts of decontamination choices. }\end{array}$ \\
\hline & $\begin{array}{l}\text { Prepare the Remediation Action Plan(s) (RAPs) for affected areas, including: } \\
\text { - Areas to decontaminate and types of media and surfaces involved. } \\
\text { - Materials, structures, and rolling stock to decontaminate in place or remove. } \\
\text { - Decontamination technologies to use (e.g., reagents and delivery systems). } \\
\text { - Where to station decontamination equipment, power requirements, and access points. } \\
\text { - Appropriate process parameters and analytical techniques. } \\
\text { - Constraints imposed by resource limitations and optimization. } \\
\text { - Risk management and disposal methods. }\end{array}$ \\
\hline & Include Ambient Air Monitoring Plan (AAMP) in RAP if fumigation is used. \\
\hline & Include Outdoor Decon Monitoring Plan in RAP if hazardous chemicals are used. \\
\hline & $\begin{array}{l}\text { Prepare Clearance Sampling and Analysis Plans (SAPs), including: } \\
\text { - Clearance zones. } \\
\text { - Sampling approaches for each zone (targeted, random, or probability sampling). } \\
\text { - Aggressive air sampling indoors and outdoors, as necessary. }\end{array}$ \\
\hline & $\begin{array}{l}\text { Prepare disposal plan, including estimated types and amounts of wastes; transportation needs } \\
\text { and costs; sampling at disposal sites; and long-term monitoring. }\end{array}$ \\
\hline $\begin{array}{l}\text { Operations Section: } \\
\text { Decontamination Group }\end{array}$ & $\begin{array}{l}\text { Perform source reduction, minimize waste to be removed from area and facilities. } \\
\text { Provide input to, and review and finalize draft RAPs and Clearance SAPs. }\end{array}$ \\
\hline IC or UC & Approve the RAPs and Clearance SAPs. \\
\hline EU & $\begin{array}{l}\text { Submit RAPs and clearance SAPs to EPA to obtain a FIFRA exemption if necessary and if } \\
\text { using unregistered product for decontamination (sterilant or pesticide not EPA-approved). }\end{array}$ \\
\hline $\begin{array}{l}\text { Safety Officer and Logistics } \\
\text { Section: Medical Unit }\end{array}$ & $\begin{array}{l}\text { If fumigating, develop Emergency Response Plans to address uncontrolled fumigation } \\
\text { releases (e.g., from explosion, fire, or severe storm) or release from a spill. }\end{array}$ \\
\hline Ops Section: Decon/Sampling & Perform all site preparations specified in the RAPs. \\
\hline $\begin{array}{l}\text { Operations Section: } \\
\text { Decontamination Group }\end{array}$ & $\begin{array}{l}\text { Conduct decontamination according to established priorities. Identify and communicate any } \\
\text { potential remediation actions the public can perform on their own. }\end{array}$ \\
\hline $\begin{array}{l}\text { EU with input from } \\
\text { Decontamination Group and } \\
\text { TWG; and with concurrence from } \\
\text { UC }\end{array}$ & $\begin{array}{l}\text { Evaluate whether decontamination process criteria are met: } \\
\text { - Fumigation (e.g., temp, RH, fumigant concentration, contact time, and BIs). } \\
\text { - Surface decontamination (e.g., limited surface sampling, contact time, pH). } \\
\text { - Wide-area outdoor decontamination (e.g., residence time, contact time). } \\
\text { - Water resources (e.g., monitoring, and pH). } \\
\text { Recommend additional decontamination activities, as necessary. }\end{array}$ \\
\hline Disposal Group & Develop disposal plan, and carry out disposal activities specified in the plan. \\
\hline
\end{tabular}




\section{Decontamination}

\subsection{Interim Recommendations for Decontamination}

At present (August 2009), the many key technology development and knowledge gaps related to decontamination include - but are not limited to - lack of validated methods for outdoor decontamination, lack of scientific guidance for citizen-conducted decontamination of small structures, and lack of validated methods for in situ decontamination of certain building contents, such as sensitive equipment. However, if a wide-area BWA release were to occur today, actions would have to be taken despite the absence of validated methods for large-area remediation. Table 8-5 is a list of interim recommendations for decontamination strategies associated with a wide-area BWA release.

Table 8-5. Summary of recommended strategies for decontamination.

\begin{tabular}{|c|c|}
\hline Recommended strategy & Comments or qualifications \\
\hline \multicolumn{2}{|c|}{ Decontamination Planning } \\
\hline $\begin{array}{l}\text { Determine if decontamination needs to be done, or consider } \\
\text { implementing medical countermeasures as the primary } \\
\text { protective measure, or proceed with a combination of both. } \\
\text { - If no inhalation hazard exists, decontamination may not be } \\
\text { necessary, but consider gastrointestinal and cutaneous risks. } \\
\text { - Surface contamination may represent a potential cutaneous } \\
\text { anthrax health hazard, which can be mitigated by medical } \\
\text { monitoring and treatment, and targeted surface } \\
\text { decontamination. }\end{array}$ & $\begin{array}{l}\text { The IC or UC, TWG, and Planning Section review } \\
\text { characterization data and determine incident- and } \\
\text { site-specific trade-offs. } \\
\text { - Use risk-based approach (Section 6) and cost } \\
\text { analysis. } \\
\text { - Use medical countermeasures, assuming antibiotics } \\
\text { and vaccines are available and effective. } \\
\text { - Implement risk communication (Section 4). } \\
\text { - Implement targeted surface decon (Table 8-2). }\end{array}$ \\
\hline $\begin{array}{l}\text { Identify areas and infrastructure to be decontaminated versus } \\
\text { implementing removal, reuse, or disposal options according to } \\
\text { characterization results and agreed-on clearance goals. } \\
\text { - See Section } 6 \text { and } 7 \text { recommendations for goals. } \\
\text { - See "EPA's Suite of Disaster Debris Management and } \\
\text { Disposal Decision Support Tools," available at } \\
\text { <http://www2.ergweb.com/bdrtool/home.asp > to assist with } \\
\text { assessments. }\end{array}$ & $\begin{array}{l}\text { - Minimize waste to focus remediation efforts per } \\
\text { characterization results. Only high-value items, } \\
\text { perishables, and reagent-consuming items should } \\
\text { be removed from contaminated areas to manage } \\
\text { costs, reduce time, and address limited space. } \\
\text { - Incorporate a cost-benefit analysis in decisions } \\
\text { concerning retention versus disposal versus } \\
\text { decontamination in situ of all other items. }\end{array}$ \\
\hline $\begin{array}{l}\text { - Establish decontamination zones, and control access and } \\
\text { egress, according to characterization results, updated data, } \\
\text { modeling results, and decontamination options. } \\
\text { - Identify key assets in each zone. } \\
\text { - Set decontamination priorities by coupling previous } \\
\text { infrastructure prioritization with remediation strategies to } \\
\text { optimize schedules and costs. }\end{array}$ & $\begin{array}{l}\text { - IC or UC works with Planning Section to rank key } \\
\text { assets by priority (Section 5). } \\
\text { - IC or UC works with Planning Section to create } \\
\text { protocols for entrance to and exit from key assets } \\
\text { to mitigate potential for cross-contamination. }\end{array}$ \\
\hline $\begin{array}{l}\text { Evaluate monitored natural attenuation versus engineered } \\
\text { in situ decontamination options. Use high-volume air } \\
\text { sampling in key areas to determine if inhalation threat exists } \\
\text { (should have been done during characterization and before } \\
\text { any decisions regarding decontamination). }\end{array}$ & $\begin{array}{l}\text { - Monitored natural attenuation (simply waiting with } \\
\text { periodic sampling and analysis) should be } \\
\text { considered as a decontamination option within a } \\
\text { risk-based framework. } \\
\text { - Use caution because } B \text {. anthracis spores can remain } \\
\text { viable for long periods in the environment. }\end{array}$ \\
\hline $\begin{array}{l}\text { Plan for decontamination activities, and plan to prepare } \\
\text { RAP(s). Choose the specific decontamination approach for } \\
\text { each environment. }\end{array}$ & $\begin{array}{l}\text { Emergency exemptions for reagents may be required } \\
\text { Those decontaminants given prior EPA approval } \\
\text { under crisis exemptions are: }\end{array}$ \\
\hline
\end{tabular}




\section{Decontamination}
- No single technology is effective in every situation.
- Tailor decontamination approach to available resources. Understanding available resources as early as possible in the planning process helps narrow the choices.
- Choose decontaminant appropriate for surface material.
- Choose reagent dispersal technique appropriate for spaces.
- Vaporous hydrogen peroxide
- Liquid and gaseous chlorine dioxide
- Liquid sodium hypochlorite (diluted 1:9)
- Solid paraformaldehyde heated to gas
- Gaseous methyl bromide
- Liquid peroxyacetic acid with hydrogen peroxide
- Liquid hydrogen peroxide
- Gaseous ethylene oxide (EtO).

\section{Decontamination Operations}

Initiate source control and agent stabilization methods, as needed.

For highly contaminated outdoor areas, perform hot spot decontamination, stabilization, or source removal early to prevent the further spread of contamination.

For high-source-term indoor areas, tailor treatment to porous versus nonporous surface types.
In high-source-term areas outdoors:

- Consider strategies used for alpha radioactive contamination (e.g., spraying oil or paint suspensions to bind material to fixed surfaces) or soil stabilization methods.

- Apply amended sodium hypochlorite solution or strong oxidants (documented sporicides per Table 8-2), or implement removal and disposal options.

For high-source-term areas indoors:

- Use HEPA vacuuming first on porous surfaces

- Then use surface treatment (e.g., amended sodium hypochlorite solution or other strong oxidants documented as sporicidal chemicals).

Conduct necessary outdoor decontamination first, before decontaminating facilities within the contaminated footprint.

For outdoor, wide-area, surface decontamination, select from three approaches (see Section 8.4.2):

Option 1: Wash down buildings, streets, and surfaces with liquid decontamination reagent. (e.g., bleach solution, peroxygen solutions) and evaluate alternatives in Table 8-2.

Option 2: Wash down buildings and streets with watersurfactant solution to mobilize spores, followed by liquid reagent to treat runoff, as described above in Option 1.

Option 3: Spray a germinant solution to initiate spore growth, making spores more vulnerable to natural and engineered decontamination approaches. Once in vegetative form, use a lower-concentration decontamination technology from Table 8-2, or use chemicals that can cause cell rupture via osmosis.

Note: Collection of runoff from Options 1 and 2 needs to be evaluated and implemented as appropriate.

For indoor facilities, first conduct HEPA vacuuming for physical removal before decontamination, then use liquid surface biocides or volumetric fumigant decontamination.

For highly sensitive and valuable equipment (electronics, artwork, medical), use less corrosive and nonliquid options to avoid damage. For less sensitive items, such as emergency vehicles, use hot spot decontamination methods.

For water resources and drinking water systems, use:
Ensure that facilities remain free of contamination from a continued source of spores or vegetative cells.

- Minimal knowledge and experience about applying wide-area decontamination technologies mandates caution. Any strategy must be tested on a smaller scale and evaluated for effectiveness before largescale application. Options 2 and 3 would require additional testing and evaluation before being used on a large scale.

- Lack of enough equipment for dissemination (e.g., large-scale spraying) is an operational gap. Options include aerial systems, as with forest firefighting aircraft, crop dusters, and helicopters; and groundbased systems, such as fire trucks and large military equipment. Spraying from fire trucks or similar truck-mounted, water-spraying systems is an efficient way to dispense liquids. Spraying could also entail street-cleaning equipment augmented by facility sprinklers or hose distribution systems.

- Fumigants: chlorine dioxide and VPHP.

- Liquid decontaminants: amended sodium hypochlorite solution or other strong oxidants documented as sporicidal chemicals (Table 8-2).

- EtO or VPHP in an offsite chamber (for valuables).

- X-ray or gamma ray irradiation (for documents). 


\section{Decontamination}

- Chlorination (at $10 \times$ the standard treatment level) or membrane filtration sized appropriately for spore size.

- Monitored natural attenuation to attain an acceptable usage condition, rather than treatment, is currently recommended for outdoor water resources such as streams, lakes, and rivers. The intent is to avoid longer-term ecological damage. treatment of water by conventional disinfection, (b) increasing disinfection levels for all or part of the system, (c) end-of-pipe treatment devices.

- Pipes in water-treatment facility systems impact the availability of free chlorine.

- B. anthracis spores are known to be trapped by biofilms, which make system-wide treatment less effective.

- Minimize waste and wastewater to reduce costs and address resource and capacity issues.

- Adhere to existing solid waste and wastewater regulations and requirements, or obtain exemptions when necessary.

- Apply tested and approved decontamination product(s), but perform no environmental sampling afterward.

- Consider exploiting seasonal advantages.

\section{Verification Operations}

Implement decontamination verification strategies

- Use BIs, process-control sensors, or both for fumigations.

- Use treatment-specific chemical (GC-MS) and biological monitoring for liquid treatments.

\subsection{Section 8 References}

AAMI (2008), Association for Advancement of Medical Instrumentation, TIR 17, Appendix B, EO Sterilization-Material Compatibility Fundamentals.

Block, S. (Ed.) (2001), Disinfection, Sterilization, and Preservation, 5th Edition, Lippincott, Williams, and Wilkins, Philadelphia, PA.

Canter, D. A., D. Gunning, P. Rodgers, L. O'Connor, C. Traunero, and C. J. Kempter (2005), "Remediation of Bacillus anthracis Contamination in the U.S. Department of Justice Mail Facility," Biosecurity and Bioterrorism: Biodefense Strategy, Practice, and Sci. 3(2), 119-27.

CDC (2005), Centers for Disease Control and Prevention, CDC Vessel Sanitation Program; available at $\langle$ www.cdc.gov/index.htm $>$; click on Publications and Products.

CDC (2006), Centers for Disease Control and Prevention, Infection Control in Health-Care Facilities; available at <www.cdc.gov/index.htm>; click on Publications and Products.

Einfeld, W., D. M. Edwards, D. O. Franco, J. Fruetel, and L. I. Yang (2008), “AWARE: A Planning and Response Tool for Wide-Area Military or Civilian Contamination Events," Chemical and Biological Defense Physical Sciences and Technology Conference Proceedings, November 2008, in press.

DHS and EPA (2009), Department of Homeland Security and Environmental Protection Agency, Planning Guidance for Recovery Following Biological Incidents, National Science and Technology Council, Biological Decontamination Standards Working Group. 


\section{Decontamination}

EPA (2006), U.S. Environmental Protection Agency, Office of Research and Development, National Homeland Security Research Center, Investigation of the Capability of Point-ofUse/Point-of-Entry Treatment devices as a Means of Providing Water Security, EPA/600/R06/012; available at <http://www.epa.gov/NHSRC/pubs/600r06012.pdf> .

EPA (2007), U.S. Environmental Protection Agency, Anthrax Spore Decontamination Using Methyl Bromide; available at <http://www.epa.gov/pesticides/factsheet/chemicals/methylbromide_factsheet.htm $>$, updated July 2007.

Gasparini, R., T. Pozzi, E. Montomoli, M. Gulino, C. M. Sansone, G. Poliseno, E. Losi, D. Panatto, G. Sigari, and P. Cuneo-Crovari (1999), "The Sporicidal Effects of a Biodegradable Peroxidic Disinfectant," J. Prevent. Med. Hygiene 40, 72-76.

Fritz, B., and J. D. Whitaker (2008), "Evaluation of Sprayable Fixatives on A Sandy Soil for Potential Use in A Dirty Bomb Response," Health Physics 94(6), 512-518.

Hawley, R. J. and J. P. Kozlovac (2004), "Decontamination,” in Biological Weapons Defense: Infections Disease and Counterbioterrorism (Humana Press, Totowa, NJ).

Hamilton, E. and T. Leighton (2008), Anthrax Catastrophe in New York City: Zero Hour Through Decontamination and Recovery, report prepared for DHS Homeland Security Institute, HSI publication number ITN08-018 (unreleased OUO draft).

Hernández, A., E. Martró, L. Matas, M. Martin, and V. Ausina (2000), “Assessment of In-Vitro Efficacy of 1\% Virkon ${ }^{\circledR}$ Against Bacteria, Fungi, Viruses and Spores by Means of AFNOR Guidelines," J. Hospital Infection 46, 203-209.

Huertas, A., B. Barbeau, C. Desjardins, A. Galarza, M. A. Figueroa, and G. A. Toranzos (2003), "Evaluation of Bacillus subtilis and Coliphage MS2 as Indicators of Advanced Water Treatment Efficiency," Water Sci. Technol. 47(3), 255-259.

Ireland, J. A. W. and P. C. Hanna (2002), "Amino Acid- and Purine Ribonucleoside-Induced Germination of Bacillus anthracis $\Delta$ Sterne Endospores," J. Bacteriol. 184(5), 1296-1303.

Krauter, P., M. Tucker, R. Miles, and E. Raber (2008), "Decontamination of Wide Urban Areas Following a Biological Agent Release," in Technical Gap Analysis for Wide Area Biological Incidents, Lawrence Livermore National Laboratory, Livermore, CA, report UCRL-TR-401133.

Krauter P. and A. Biermann (2007), "Reaerosolization of Fluidized Spores in Ventilation Systems," Appl. Environ. Microbiol. 73, 2165-2172.

Lemieux, L., S. Thorneloe, K. Nickel, and M. Rodgers (2006), A Decision Support Tool for Disposal of Residual Materials Resulting from National Emergencies, AWMA Annual Conference and Exhibition, New Orleans, LA, June 20-23, 2006.

Lucas, Merritt, Hitchins, Woods, McNamee, Lyle, and Brown. (2003), "Residual Ethylene Oxide in Medical Devices and Device Material," J. Biomed. Mater. Res. Part B: Appl. Biomater 66B, 548-552.

Macler, B. A. and S. Regli (1993), "Use of Microbial Risk Assessment in Setting United-States Drinking-Water Standards," Int. J. Food Microbiol. 18(4), 245-256. 


\section{Decontamination}

Mah, J. H., D. H. Kang, and J. Tang (2008), "Effects of Minerals on Sporulation and Heat Resistance of Clostridium sporogenes," Int. J. Food Microbiol. 128(2), 385-9.

Manchee, R. J. (1994), "Formaldehyde Solution Effectively Inactivates Spores of Bacillus anthracis on the Scottish Island of Gruinard," Appl. Env. Microbiol. 60(11), 4167-4171.

Morrow, J. B, J. L. Almeida, L. A. Fitzgerald, and J. D. Cole (2008), “Association and Decontamination of Bacillus Spores in a Simulated Drinking Water System," Water Res. 42(20), 5011-5012.

Nalipinski, M. and K. Smith (2008), After Action Report, Danbury Anthrax Incident, U.S. EPA National Decontamination Team.

NRC (2005), National Research Council of the National Academies, Committee on Standards and Policies for Decontaminating Public Facilities Affected by Exposure to Harmful Biological Agents, How Clean is Safe? Reopening Public Facilities After a Biological Attack, National Academies Press, Washington, D.C.

NRT (updated July, 2005), National Response Team, Technical Assistance for Anthrax Response, Interim-Final Draft; available at http://www.nrt.org/production/NRT/NRTWeb.nsf/PagesByLevelCat/Level2TA?Opendocument.

Pepper, I. L. and T. J. Gentry (2002), "Incidence of Bacillus anthracis in Soil,” Soil Sci. 167, 627-35.

Raber, E. and McGuire, R. (2002), "Oxidative Decontamination of Chemical and Biological Warfare Agents Using L-Gel,” J. Haz. Mater. B93, 339-352.

Rice E. W., L. J. Rose, C. H. Johnson, L. A. Boczek, M. J. Arduino, and D. J. Reasoner (2004), "Boiling and Bacillus Spores," Emerg. Infect. Dis. (serial on the Internet); available at <http://www.cdc.gov/ncidod/EID/vol10no10/04-0158.htm>.

Sagripanti, J.-L. and A. Bonifacino (1996), "Comparative Sporicidal Effects of Liquid Chemical Agents," Appl. Env. Micribiol. 62(2), 545-551.

Sinclair, R., S. A. Boone, D. Greenberg, P. Keim, and C. P. Gerba (2008), "Persistence of Category A Select Agents in the Environment," App Env. Microbiol. 74(3), 555-563.

SMC, Seattle Municipal Code. Title 21, Chapter 21.43, Sections 21.43.010 to 21.43.090. Utilities, Infectious Waste Management; available at $<$ http://clerk.ci.seattle.wa.us/ public/toc/table.htm>.

Sneath, P. H. A. (1962), “Longevity of Microorganisms,” Nature 195, 643-6.

SNL and LLNL (2008), Sandia National Laboratories and Lawrence Livermore National Laboratory, IBRD Task 1 Systems Analysis Report (same OUO document published separately at both laboratories as report SNL2008-1349 and report LLNL-AR-401510).

Schuch, R. D. Nelson, and V.V. Fischetti (2002), “A Bacteriolytic Agent that Detects and Kills Bacillus anthracis," Nature 418(6900, 825-6. 


\section{Decontamination}

Szabo, J. G., E. W. Rice, and P. L. Bishop (2007), "Persistence and Decontamination of Bacillus atrophaeus Subsp. globigii Spores on Corroded Iron in a Model Drinking Water System," Appl. Environ. Microbiol. 73(8), 2451-2457.

USACHPPM (2008), U.S. Army Center for Health Promotion and Preventive Medicine, Technical Guide 188: U.S. Army Food and Water Vulnerability Assessment Guide; July 2008 revision available for official use by contacting USACHPPM.

Walter, M. H (2003), "Efficacy and Durability of Bacillus anthracis Bacteriophages Used Against Spores," Environ. Health 66(1), 9-15.

Young, S. B. and P. Setlow (2004), "Mechanisms of Killing of Bacillus subtilis Spores by Decon and Oxone ${ }^{\mathrm{TM}}$, Two General Decontaminants for Biological Agents," J. Appl. Microbiol. 96, 289. 


\section{Clearance}

\section{Clearance}

To ensure that characterization and decontamination tasks are conducted appropriately, it is imperative that health-based clearance and reoccupancy exposure guidelines be incorporated into decision-making as soon as possible following a BWA release. Clearance goals need to be established for all potential populations that may be exposed after clearance is granted. Although the primary exposure pathway for all populations is expected to be inhalation, dermal and ingestion pathways may also need to be considered. Specifying acceptable levels of residual contamination for each exposure pathway and population is a pre-requisite for developing clearance sampling strategies. Levels should be specified in measureable units, which depend on characteristics of the specific exposure pathway selected (e.g., surfaces, air, or water). Most of the information in Section 6 was aimed at establishing a risk-based decision-making approach to establish clearance goals. The decision is necessary up front to determine whether or not cleanup or mitigation options are necessary, and if so, which option would result in attaining acceptable decontamination. Some clearance goals may be established that could require medical countermeasures as a risk-management option, as discussed in Section 6.

After decontamination is conducted and the processes are verified for a given area or facility, clearance environmental sampling is performed (DHS and EPA 2009, Section 4.18). The means by which decontamination processes are verified depend on the decontamination method, as discussed in Section 8.6.2 of this Interim Guidance.

The purpose of clearance is to verify the efficacy of decontamination, provide the best possible scientific evidence that a residual BWA is no longer present at a level that poses unacceptable risk to human health, and decide whether or not it is appropriate to release an outdoor area, semienclosed structure, indoor facility, or water system under consideration for reoccupancy or reuse. Clearance includes the following major components:

- Reviewing information from earlier phases of remediation, including characterization environmental sampling data; source-reduction activities, if any; and data from monitoring the decontamination processes, including BIs if used as part of indoor fumigation verification.

- Conducting clearance environmental surface sampling after decontamination, or water sampling after disinfection, where appropriate (for sampling methods, see Section 7).

- Performing aggressive air sampling outdoors for BWAs that can reaerosolize, to understand the remaining inhalation risks.

- Performing laboratory culture analysis of clearance environmental samples for the presence of viable spores (for analysis methods, see Section 7).

- Reviewing all the above information in light of clearance goal(s) that will have been established earlier (Section 6.3).

- Determining whether or not to release a given area, facility, or water system for Restoration Phase activities (Section 10), such as refurbishment if needed, or reoccupancy.

At most, but not all, indoor sites with fumigations following the 2001 B. anthracis attacks, ECCs were established. The ECCs reviewed data from all sampling phases, namely initial, characterization, and clearance environmental sampling, as well as relevant data on 


\section{Clearance}

decontamination activities, to arrive at a conclusion as to whether the remediation had been effective. If so, they made a recommendation that the facility was acceptable for reuse. The ECC for at least one site recommended that further clearance environmental sampling be conducted before it was convinced that sufficient evidence existed that the remediation had been effective. Although not mandated, formation of one or more ECCs is strongly recommended for a widearea remediation and is assumed in this Interim Guidance. ECC members should not be the same individuals as those who serve on the TWG and help design the characterization and decontamination approaches. They should represent their own fields of expertise rather than the views of any agency and should be recognized by stakeholders and the public as subject-matter experts in their respective fields. Members can include sterilization experts, environmental sampling experts, chemical engineers for remediations that include fumigations, analytical laboratory experts, toxicologists, industrial hygienists, epidemiologists, microbiologists, physicians and clinicians with expertise in infectious diseases and infection control, and experts from local departments of public health, with not more than one or two individuals drawn from any single field. The ECC is often chaired by a local public health official. The ECC should be created early and briefed on the proposed concept for the Clearance Environmental Sampling and Analysis Plan (SAP), including the types of sampling to be performed, and rationale for such sampling and analysis methods to be used. By having a concept review, the ECC can let the UC and EU know if it agrees with the approach so that appropriate mid-course corrections can be made in the sampling approach, if needed, and so that when the ECC performs the ultimate peer review of the overall remediation, it will not question the approach taken.

Resources and personnel necessary for clearance are similar to those already identified for characterization (see Table 7-1), and most should be on scene, depending on available resources. Figure 9-1 shows the major activities associated with the Clearance Phase.

\subsection{Identify Prioritized Clearance Actions to Be Taken}

As for characterization and decontamination activities, decision-makers will need to apply the results of the prioritization framework (Section 5) to allocate available, limited clearance resources according to the assigned importance or urgency associated with remediating a given area or facility. As previously discussed, high-priority facilities and areas will include national and regional MEI (e.g., top-priority freeway corridors, access corridors, and shipping ports outdoors, and indoor facilities such as power plants and hospitals).

Clearance, much like characterization, should be organized using a zone-by-zone approach, coordinated by regional or area commands, as appropriate. Zones should be defined in a flexible manner that makes sense to those performing the work. Large outdoor areas as well as very large semi-enclosed or indoor structures will need to be cleared in phases. If fumigation is performed within an indoor facility, each fumigation zone is a natural clearance zone. For outdoor areas, assessments of zones need to be area-specific and need to make sense from characterization, access, and prioritization points of view. 


\section{Clearance}

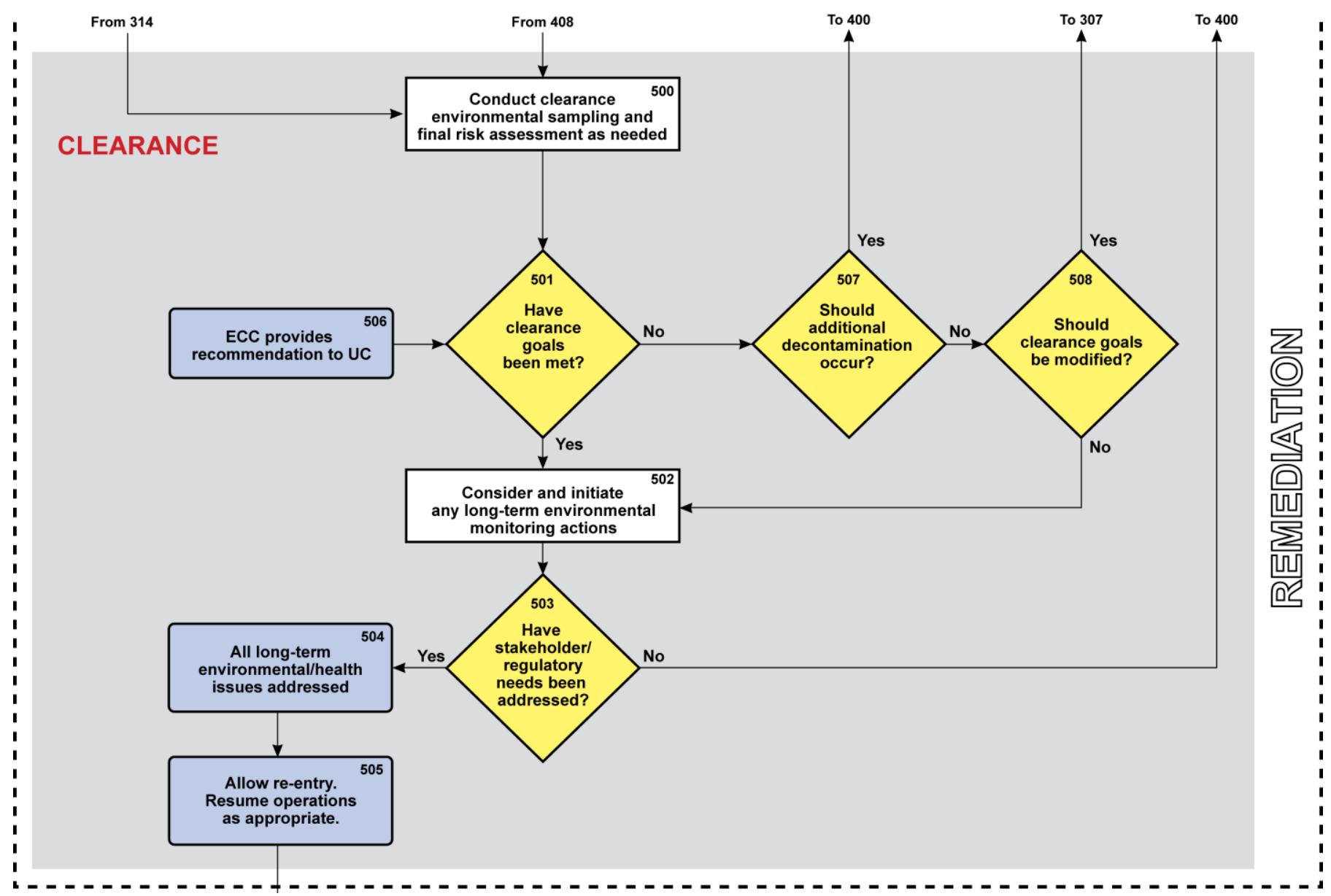

Figure 9-1. Principal activities associated with the Clearance Phase.

The remainder of Section 9 assumes that clearance evaluations are organized using the same zones as those established for characterization and decontamination, an approach that can be adopted regardless of the decontamination method. Such an approach helps relate clearance environmental sampling results with characterization sampling results, an important consideration given the mass of data from a wide-area incident. A decision to clear an outdoor area or an entire building is made only after a clearance decision has been reached for every clearance zone in the area or building. In Section 9, the terms "positive" and "positive result," when referring to a single sample, mean that growth of the BWA was detected on the sample (i.e., the biological agent is alive and infectious). "Negative" and "negative result" mean that growth was not detected on the sample.

\subsection{Review Clearance Goals}

Before selecting a decontamination technique, clearance goals must be established along with agreed-on processes (clearance criteria) for judging whether the goals are met. The criteria for success are developed for each site and the specific BWA involved. As to the question of how clean is safe, the Catastrophic Incident Supplement to the NRF (DHS 2008) states, "Due to the 


\section{Clearance}

site-specific nature of many cleanup issues, ... a determination of 'how clean is safe' for returning residences and resumption of business is a risk management decision based on the selection and site-specific application of such values. As such, cleanup goals will be determined on a site-by-site basis by local governments working in tandem with Federal and state technical experts in accordance with NRF/NIMS decision-making processes." As mentioned in Section 6, initial clearance goals may be revised as part of a risk-based remediation approach. Naturally, clearance will be determined by the revised goals.

\subsubsection{Outdoors}

As explained in Section 6, there are no codified clearance goals for outdoor BWA remediation at this time. It does not appear either practical or relevant at present for a risk assessment to use numbers associated with surface sampling for outdoor clearance goals. The emphasis for clearance needs to be on understanding whether any actual inhalation risk exists and to evaluate what the remaining risk is and whether additional mitigation or decontamination options would be effective in trying to reduce that risk. However, some limited surface sampling may be necessary in hot zones to better understand whether a public health risk for cutaneous anthrax is present and to gain stakeholder acceptance of such a risk, although the disease is treatable. (The case-fatality rate of cutaneous anthrax is reported to be in the range of 5 to $20 \%$ without antibiotic treatment and less than $1 \%$ with antibiotic treatment. See for example, <http://www.cdc.gov/vaccines/pubs/pinkbook/downloads/anthrax-508.pdf>. Whereas the goal, "no viable $B$. anthracis spores detected from any high-volume (aggressive) air sampling" is a highly conservative outdoor clearance goal, it may need to be used until data are available to make a better-informed decision (Turtletaub and Raber 2008, p. 60). Such a goal might be redefined as, "no viable B. anthracis spores detected above background levels from any highvolume (aggressive) air sampling," to account for endemic spores. To address that type of goal, local agencies might be able to identify regional ambient-air-monitoring programs with archived samples that could be accessed to understand baseline levels of $B$. anthracis spores in the affected area. In any case, additional evaluation of statistical sampling models and relevant technologies to implement such a goal are needed before a decision can be made. The current state of knowledge has led several expert panels to recommend a conservative no-threshold model, which holds that one spore would be capable of causing disease in some subgroups of the population, although other models and acceptance of more risk is an option for stakeholders and decision-makers. Nonetheless, it is the responsibility of the EU, with advice from the TWG, to review any standards in effect at the time and to decide what the goal should be. The ECC must concur with the clearance goal and agree that supporting clearance data show that the goal has indeed been met or else recommend additional steps to be taken (e.g., further decontamination or sampling in specific areas) if it concludes that the goal has not been met.

\subsubsection{Semi-Enclosed and Indoor Facilities}

The indoor clearance goal depends on factors including - but not limited to - the type of contaminant released (e.g., specific agent, its grade, and potential for aerosolization), location(s) of contamination within a facility, public perception of risk, scientific information on infectious dose and potential risk, and applicable environmental regulations. As previously explained, the goal used following distribution of the anthrax letters in the U.S. was no growth of $B$. anthracis spores on any clearance environmental sample (either surface or air samples) collected. There is no indication that this goal will change in the foreseeable future (NRC 2005). Nonetheless, it is 


\section{Clearance}

the responsibility of the EU, with advice from the TWG, to review any standards in effect at the time and to decide what the goal should be. The ECC reports to the EU on whether or not clearance data show that the goal has been met. If not, the ECC recommends additional steps to be taken (e.g., further decontamination or sampling in specific areas).

\subsubsection{Drinking Water}

See Section 6 for a discussion of possible clearance goals in drinking water. Most spores are in the range of 1 micron in size, and commercially available microspore filtration systems can filter out particles larger than 0.2 microns. Although only limited historical information is available on the performance of point-of-use treatment devices for biological agents or their surrogates in water, if drinking water were known to have spores after a wide-area incident, a discussion of point-of-use water filtration for homes and other locations might be appropriate. Refer to EPA (2006), available at 〈http://www.epa.gov/NHSRC/pubs/600r06012.pdf $>$, for further discussion of point-of-use treatment devices, such as solid block activated carbon (SBAC) filters, as a possible means of providing water security. Any clearance goal(s) for water, especially drinking water, would need buy-in from area decision-makers and stakeholders. In essence, a watersampling strategy is devised as described in Section 9.3.5, and the results of sampling are reviewed for conformance to drinking water clearance goals as discussed in Section 9.5.3.

\subsection{Plan for Clearance Environmental Sampling}

The clearance environmental sampling strategy (Figure 9-2) is documented in a Clearance SAP for a given outdoor, semi-enclosed, indoor, or water facility. More than one Clearance SAP will be needed during a wide-area incident. It is essential to have high confidence in a decision to reoccupy or reuse an area or facility. Unfortunately, it is not possible to prove by sampling that absolutely no viable or infectious BWA is present after decontamination. Even if every square inch of an area or facility could be sampled, the following limitations apply:

- Sampling methods have less than $100 \%$ collection efficiency, meaning that an agent may be present in the environment, but not enough is collected in the sample to be detectable.

- Analytical methods have less than $100 \%$ extraction efficiency, meaning that an agent may be present in the sample, but the analytical method does not extract enough of it from the sample medium to be detectable.

- Even if both sampling and extraction had $100 \%$ efficiency, analytical methods still have detection limits, meaning that an agent could be present in the environment but not be detectable by the analytical method. However, relatively few spores can be detected if gold-plated culturing or advanced rapid-viability methods are used.

- Some errors in collecting, analyzing, and documenting samples are inevitable. 


\section{Clearance}

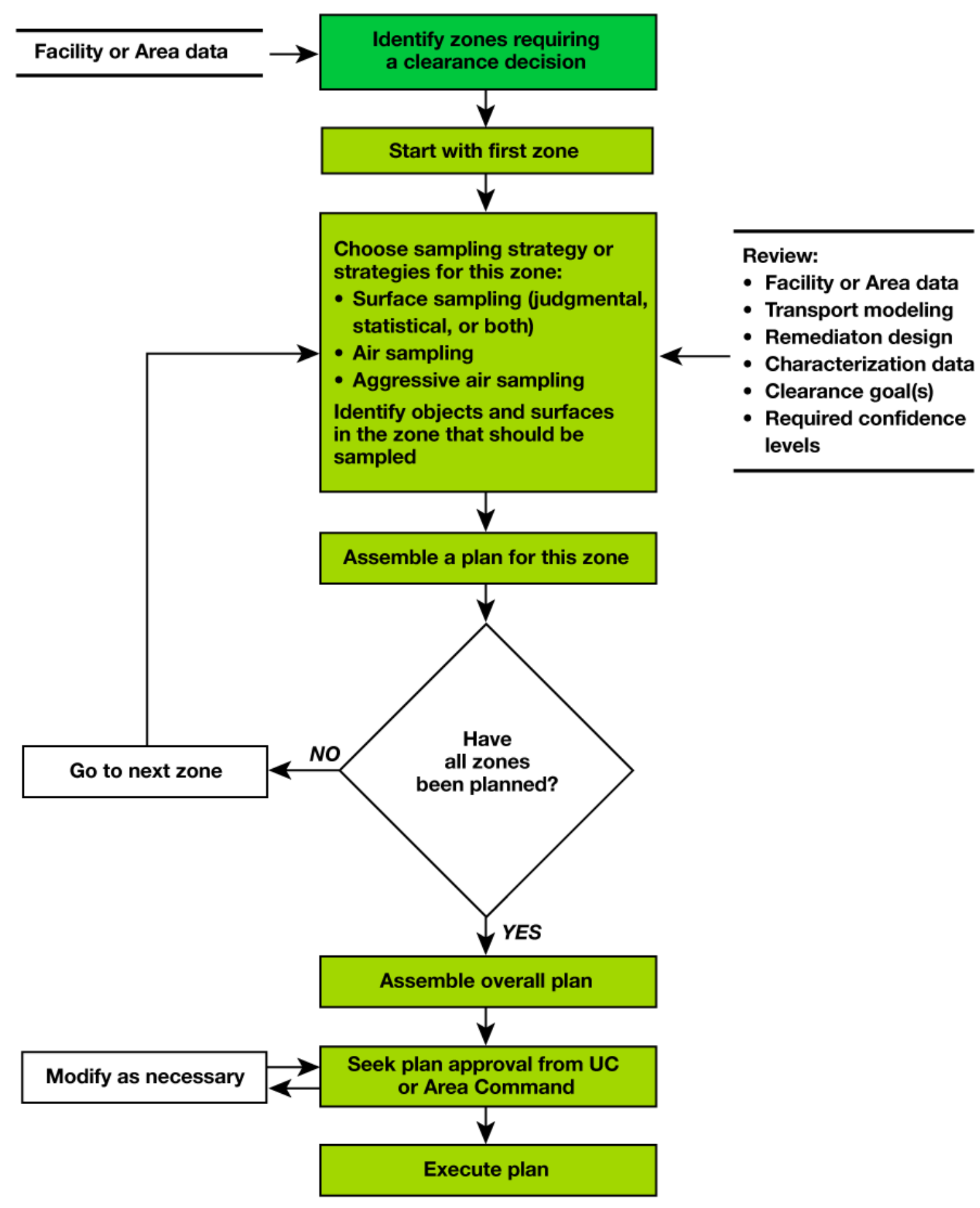

Figure 9-2. Developing a strategy for clearance. 


\section{Clearance}

Thus, even if all clearance sample results were negative, it would not be certain that absolutely no viable or infectious agent remains in the environment. It is necessary to infer from a set of negative results that, at most, a negligible quantity of agent remains. That is, the locations or levels of remaining agent, if any, are sufficiently rare or sufficiently low that they present no unacceptable threat to human health. The important question that must be answered is: How much sampling is necessary to make that inference with confidence?

Areas that were decontaminated (i.e., within decontamination zone boundaries) should undergo a clearance process during the Clearance Phase. Areas that were not decontaminated need not undergo a clearance process during the Clearance Phase, provided there is sufficient confidence that the decision not to decontaminate was correct. Such confidence should have been developed during characterization (Section 7.5.1). Although decision-makers may wish to revisit decisions and consider clearance activities outside the boundaries, it is more efficient from a time and cost perspective to have continuously monitored the correctness of the boundaries during characterization and decontamination (e.g., for changes arising from variations in winds and weather) and modified them, as appropriate.

\subsubsection{Select Clearance Sampling Methods}

For purposes of clearance, sampling methods should be appropriate for assessing whether residual contamination, if any, presents an unacceptable health risk (i.e., whether residual contamination is above or below clearance goals.) As mentioned in Section 6, clearance goals may be established for indoor or outdoor surfaces, items such as equipment or personal belongings, the air in rooms or open spaces, or water, and clearance goals are defined for each potential exposure pathway.

If an incident were to happen today, the likely indoor clearance goal would be "no growth on all post-remediation environmental samples," hence sampling methods should be those with the best ability to discover a decontamination failure by collecting viable spores. Thus, sampling and analytical methods should be as efficient as possible. Options include high-volume air sampling, aggressive air sampling, vacuum sampling, and large-area wipe sampling (Section 7.5.5).

As also mentioned in Section 6, outdoor clearance goals do not exist at present. However, because inhalation represents the major health risk associated with a wide-area release, sampling methods should be able to provide data with which to assess the inhalation risk from resuspended residual contamination. Therefore, high-volume air sampling, including aggressive air sampling, would likely be the primary outdoor clearance sampling method if an incident were to happen today.

Regardless of the uncertainties associated with setting clearance goals, any sampling method used for clearance purposes should not kill viable agent because the clearance goal will necessarily be expressed in terms of viable agent. See Section 7.5.5 for a summary of sampling methods recommended for outdoor areas (both localized and wide areas), indoor and semienclosed facilities, and water facilities or sources. Many LRN labs can support the analysis of environmental samples collected for the purpose of clearance. 


\section{Clearance}

\subsubsection{Select Sampling Locations}

The two principal methods for selecting sampling locations are judgmental and statistical. For example, judgmental methods were used for indoor clearance surface sampling during the $2001 B$. anthracis decontaminations. Following those efforts, a review by the U.S. Government Accountability Office (GAO 2005) strongly suggested that statistically designed sampling should be used to increase confidence in the clearance decision when all results are negative. In addition, statistical sampling is included as an option in the interim-final Technical Assistance for Anthrax Response (NRT 2005). Since 2001, mathematical (Bayesian) methods for combining judgmental and statistical sampling have been developed (Axelrod 2005; Grieve 1994; Sego et al. 2010; Wright 1992). These methods have the potential to reduce the number of required samples, provided that decision-makers have confidence in certain inputs to the methods. Clearance sampling locations may be chosen using any or all of these approaches. If an incident were to happen today, it is likely that both judgmental and statistical approaches would be used because both have a long history of acceptance in the field of environmental remediation. The newer, combined judgmental and statistical sampling would likely be used, provided there is decisionmaker and stakeholder acceptance.

Confidence that surface clearance goals have been met requires inference from sampled locations to nonsampled locations. Judgmental and statistical sampling strategies use different approaches to developing such confidence. If a specified (i.e., numeric, such as "95\%") confidence level is desired, statistical methods are necessary.

Inference from judgmental sampling incorporates the idea that the number and placement of samples provide high confidence that the biological agent, if present anywhere, will be detected somewhere in a judgmental sample. That is, sampling planners have knowledge that indicates the most likely locations for residual contamination. Although the 2001 decontamination actions were for indoor contamination, the concept of inference also applies to outdoor sampling of all types because exhaustive sampling of an entire outdoor area potentially affected is not possible.

Inference from judgmental sampling also uses the following reasoning: If the responsible organization is confident that all areas of significant contamination were found during characterization, and the same areas are re-sampled during clearance and found to be below clearance goals, then there is confidence that decontamination was successful. Such reasoning requires a belief that, because decontamination was successful in known areas of significant contamination (i.e., areas selected for judgmental sampling), it was also successful in areas with less contamination and areas of significant contamination that might have been missed during characterization. For example, assume that characterization sampling immediately inside the entrance to a building found viable spores, and the building was fumigated on that basis. Let us also assume it was believed that the entrance area was the location of the highest concentrations within the building, and clearance sampling in the same location found no viable spores. Such a result could be interpreted as evidence that the entire building had been adequately fumigated (provided there was also evidence that the fumigant achieved its design parameters throughout the building).

Inference from statistical sampling depends, in part, on the planned statistical analysis of the results, and there are too many options to list here. A simple example for the "no-growth" goal for surfaces would be to specify a high probability of discovering the presence of residual contamination, even if it is present in only a very small percentage of the available surface area. 


\section{Clearance}

In general, statistical inference is based on the idea that statistical sampling results are both representative and reproducible. Representative means that the results will rarely be much different than the underlying reality; reproducible means that if the statistical sampling were to be repeated, the results would rarely be much different.

Confidence that the agent will be detected at a particular location, if it is present at that location, depends on the sampling method. A sampling method with lower collection efficiency is less likely to detect the presence of an agent. Detection is more likely if the sampling method covers a large area (see Section 7.5.3). When a statistical level of confidence is specified for random sampling, it is "statistically designed" as well as "random," and a required confidence level is set. The criterion is the same: all results must be negative. For example, the UC could require that there be $95 \%$ confidence of detecting the presence of an agent if more than $5 \%$ of the sampled volume or area has the agent at detectable levels. Such specification will determine how many samples must be collected and with what coverage.

Random or statistically designed sampling makes sense for large surfaces or volumetric areaseither indoors or outdoors - where inference to nonsampled locations is necessary or where human contact occurs in a somewhat random or haphazard manner. Examples include walls and ceilings indoors, streets or large fields outdoors, or areas where relatively little is known about contaminant distribution.

Statistically designed sampling can be used with the goal of no growth of viable spores on any clearance sample whether using air or surface samples. It can also be used with criteria that permit low, but nonzero, levels after decontamination, in the event that such criteria are used in the future. Statistical methods applicable to environmental clearance decisions can be found in many references, including, Gilbert (1987); Gilbert et al. (1996); Hardin and Gilbert (1993); Mulhausen and Damiano (1998); and EPA $(1996,1997)$. Experts in the field of sampling and statistics should be consulted and be a part of the TWG if statistical sampling is used.

The number of samples taken and the actual area sampled within a zone are a function of the desired likelihood of detecting viable spores, the desired confidence in a "clean" decision (when all results are negative), as well as consideration of limited sampling resources. For example, in the case of surface sampling, SNL and LLNL (2008, p. 46) estimated that 10 to 300 clearance samples per floor might be taken in a building sampled during a wide-area response. Decisionmakers are advised to accept confidence levels using the lower end of this range because, for example, a zone consisting of ten 10-story buildings would require 30,000 samples if 300 samples per floor were taken. The other option is to use a mix of surface and air sampling to lower the total number of samples required. Approaches for using aggressive air sampling are described below.

\subsubsection{Plan Aggressive Air Sampling Indoors}

Aggressive air sampling for aerosolizable BWAs is intended to maximize the likelihood of finding viable agent. Fans are used to create turbulence, lifting particles such as $B$. anthracis spores from surfaces and into the air where air samplers can collect them. This method is described in the interim-final NRT (2005) Technical Assistance for Anthrax Response as follows: "While the area is under negative pressure, all surfaces are aggressively agitated and air is continuously disturbed while samples are collected. An air sampling method that maximizes the likelihood of detecting contamination should be used." The method augments, and thereby 


\section{Clearance}

reduces, the number of clearance surface samples needed. All samples should meet the requirement of no growth of $B$. anthracis spores. The method requires that indoor areas be isolated and sealed, as they would be to prevent the release of fumigant. Basic air sampling principles indicate that the lower the air concentration, the larger the volume of air that must be sampled to collect enough spores to reach analytical detection limits (Hess-Kosa 2002; ACGIH 1999). If decontamination has nearly but not quite succeeded, the concentration of viable spores is likely to be low, possibly extremely low, so planners should anticipate sampling a large volume of air. In extremely large and open areas indoors, aggressive air sampling may not be feasible because it may not be possible to sample the amount of air needed to produce meaningful results. Fate and transport models for certain indoor facilities (i.e., those with BioWatch collectors) may be available through the BioWatch Program, which may provide assistance in selecting sampling locations.

In each zone, sufficient numbers of air samplers should be spaced closely enough and at various heights so that particles are unlikely to be moved around without encountering a sampler. Fans are placed in the zone and turned on immediately after the air samplers are turned on. Sampling technicians wearing appropriate PPE carry hand-held fans and blow air across all accessible surfaces while the air samplers operate. The process should be done in a planned and systematic manner to ensure thorough coverage. Air samples are collected during the agitation, and workers in the area can wear personal sampling devices during the process.

After the process is complete, any suspended particles will re-settle in new locations. Therefore, comparisons of particulate concentrations at specific locations before (e.g., from characterization) and after aggressive air sampling are not meaningful. The expected effect of turbulence, if done thoroughly and for long enough, is to mix particles from all areas. The result is a physical averaging of particle concentrations (similar to compositing samples). Comparisons of averages before and after would be meaningful, but any comparisons involving variabilitysuch as minimum, maximum, standard deviation, or range - are not.

There is ongoing debate over the pros and cons of operating negative air units (NAUs) during aggressive air sampling; however, NAUs were used during previous anthrax cleanups. The issue should be addressed on a case-by-case basis.

\subsubsection{Plan Outdoor Air Sampling for Clearance}

Clearance sampling outdoors after decontamination should be directed at estimating the potential for individuals to be exposed to viable $B$. anthracis after remediation. The methods to be used were described in Section 7. For clearance, high-volume and aggressive air sampling should be done (e.g., with commercial leaf or snow blowers) to determine if there is any remaining risk from resuspension of spores following decontamination. Aggressive air sampling should increase the confidence of clearance by increasing the shear forces on settled spores, thus making their capture in a sampling medium more likely. Such blowing of air across surfaces could, for example, act as a surrogate for unusually high winds that occur rarely. Air samplers should also be placed in locations that could be sources of resuspension of respirable and viable spores and in locations with high exposure potential, such as areas with a high volume of pedestrian traffic. Examples include outdoor plazas in downtown areas that host special events (e.g., outdoor concerts), where people congregate during lunch hour, entrances to heavily used public transportation facilities, and the like. 


\section{Clearance}

Depending on available resources, such judgmental locations should be backed up with additional systematically placed samplers to ensure thorough coverage of an entire outdoor decontamination area. The spatial density of such sampling should be somewhat greater in the areas that were most heavily contaminated. Fate and transport modeling available through the IMAAC can assist in the placement of air samplers for this purpose.

If seasonal changes in environmental parameters can potentially affect resuspension, and thus health risk, the option of sampling for at least a full seasonal cycle before granting unconditional clearance should be considered. However, such a decision could delay clearance by as much as a full year. All samples taken and analyzed should meet the requirement of no growth of B. anthracis spores from any clearance samples taken, unless anthrax is known to be indigenous to the area and preexisting background levels are known or can be established. Section 10 discusses the option of longer-term environmental monitoring to ensure public safety.

\subsubsection{Plan Sampling Strategy for Water-Distribution Systems}

Key locations for sampling of water-distribution systems are pre-determined as part of normal water-quality-control checks. Additional locations such as point-of-use filters and water softeners may act as concentration devices for clearance sampling of smaller amounts of water over time. Locations susceptible to build-up of biofilms should also be considered for sampling because spores can be trapped in such areas. It should be possible to develop a sampling plan that contains elements of targeted and biased sampling by coupling an understanding of the epidemiology of a disease outbreak with knowledge of the hydrologic functioning of a waterdistribution system. Such an approach should enhance the probability of detecting any residual contaminant beyond a simple, randomized sampling strategy.

\subsubsection{Allocate Resources}

As frequently stated in this Interim Guidance, sampling resources will be limited following a wide-area attack. Therefore, it will be necessary to allocate resources according to the prioritized methodology developed and implemented earlier (Section 5) and assets that are actually available.

\subsection{Review Data Management, Visualization, and Analysis}

The data-management systems used during characterization (Section 7.5.2) should be adequate for clearance. Specific features that are useful during clearance include an easy way to distinguish clearance samples from characterization samples, and an easy way to view co-located characterization and clearance samples side-by-side.

\subsection{Conduct Clearance (Box 500)}

Applying the concepts in Figures 9-1 and 9-2, the EU prepares the Clearance SAPs, which are approved by the IC or UC. The Operations Section then performs the actions specified in the Clearance SAPs in priority order (Figure 9-3). As clearance gets underway, if not before, decision-makers should reassess the need for clearance in uncontaminated areas that are located within potentially impacted areas (Box 500-1) and proceed on the basis of established priorities as well as the potential for recontamination of a given area or facility (Boxes 500-2 and 500-3). Such a reassessment would ideally be done during planning for the Clearance Phase. 


\section{Clearance}

\subsubsection{Prepare Clearance Environmental Sampling and Analysis Plans}

Separate Clearance SAPs will likely be needed for:

- Outdoor areas treated as a unit for purposes of decontamination and clearance.

- Each indoor and semi-enclosed facility treated as a unit for decontamination and clearance.

- Water sources and facilities treated as a unit for decontamination (if any) and clearance.

Most environmental sampling plans, including post-decontamination Clearance SAPs, share some basic elements. They need to include descriptions of the circumstances, statements of the authority under which the operation takes place, summaries of applicable environmental laws and regulations, summaries of the kinds of decisions to be made, the rationale supporting various decisions, technical information about the sampling and analysis methods used, information about the kind of quality controls applied, and types of PPE the sampling teams use. Clearance plan templates have been developed for indoor transportation facilities and could be adapted for application to a wide-area incident (Carlsen et al. 2005). Much of the necessary background information for a Clearance SAP will be available from the Characterization Phase, including a set of sampling unit definitions, estimates of locations of maximum contaminant levels, possibly a contaminant map, sample-naming conventions, a database for analytical results, and other elements.

A Clearance SAP must be specific and include information about exactly where to take each sample or how to determine where to take each sample. The plan must include information on what sampling method(s) to use, how sampling locations will be determined in units where random sampling is used, how to package and transport each sample, how to document each sample, who instructs the necessary personnel, who collects the necessary supplies, and so on. Sampling plans must include adequate attention to quality assurance, and should meet requirements in the Uniform Federal Policy for Quality Assurance Project Plans (UFP-QAPP; IDQTF 2005). EPA regional offices can be expected to have sampling plan templates that conform to the UFP-QAPP and that might be used, although they may need to be adapted for sampling plans that are intended to coordinate with dispersion modeling. It is important to ensure that the sampling staff can understand and follow the sampling plan exactly. The ECC should review the clearance sampling strategy and concept for the Clearance SAP before the actual Clearance SAP is developed. Upon approval of the plan by the Operations Section Chief and the IC or UC, clearance sampling commences. An appropriate worker HASP will also be required; see Section 7.6. 


\section{Clearance}

CLEARANCE (expanded 500)

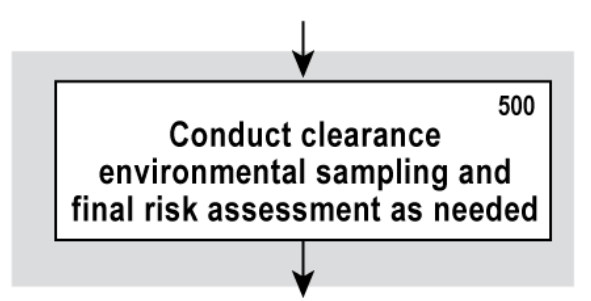

500-1

Reassess need for clearance

in non-contaminated

potentially impacted areas

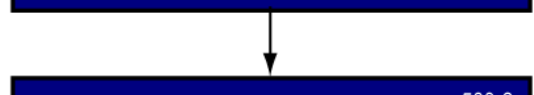

$500-2$

Reassess Clearance Sampling and

Analysis Plan based on priorities,

dependencies, and potential for

recontamination

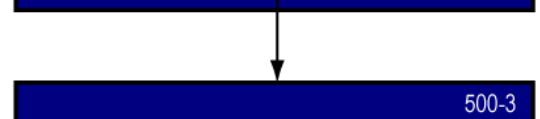

Execute Clearance Sampling and Analysis Plan

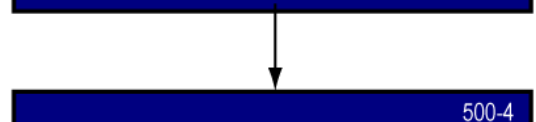

Conduct final technical risk

assessment, considering results

from clearance sampling

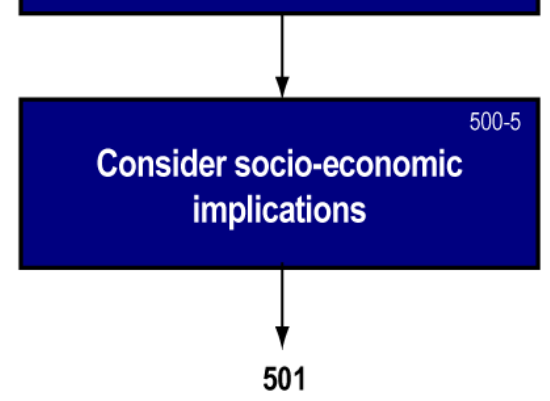

Figure 9-3. Box 500 expanded: conduct clearance environmental sampling. 


\section{Clearance}

\subsubsection{Commence Clearance for Each Operational Period (Box 500)}

The Clearance Environmental SAP for a designated area or facility is attached to the IAP for approval by the IC or UC for the next operational period. IAPs are a series of Action Plans, as defined in the NRF. As clearance sampling commences (Figure 9-3), the IC or UC staff, especially the EU, works closely with clearance environmental sampling contractor(s) to ensure that all guidance in the Clearance SAP is followed.

\subsubsection{Review Results, and Make Clearance Decisions (Boxes 501-508)}

The IC or UC ultimately makes a clearance decision for each area or facility by exercising judgment as to whether the criteria for decontamination verification and clearance have been met. The judgment considers (1) the clearance goal (Box 501); (2) a thorough analysis of all sampling, process, and other data pertinent to criteria for success, as outlined in the RAP and Clearance SAP; (3) the potential need for long-term environmental monitoring (Box 502; see Section 10.3); and (4) stakeholder concerns and regulatory requirements (Box 503). A key component in the decision is a final, technical risk assessment from the results of clearance sampling (Box 500-4) and consideration of the socio-economic implications of the decision (Box 500-5). The assessment needs to be done using the approach and information discussed in Section 6.

The clearance decision process unfolds as follows. After decontamination activities and clearance environmental sampling and analysis are completed, the Planning Section's EU, with input from the Decontamination Group and TWG, reviews all pertinent data, such as fumigation parameters, if used, characterization and clearance sampling data, and results from culture of BIs or other controls, if used. The EU determines whether clearance criteria are met for a given area or facility being considered as a unit and writes a report for the IC or UC as to whether remediation has been successful, all long-term environmental and health issues have been addressed (Box 504), and people may re-enter the site (Box 505) without using PPE. Each report summarizes all relevant information on remediation actions, including decontamination and clearance results. Stakeholders must be involved in the process, and their needs and concerns addressed. For additional certainty and credibility, the ECC provides a separate analysis of all pertinent data and makes an independent recommendation to the IC or UC (Box 506).

The IC or UC reviews the clearance recommendations and confirms whether or not, for a specific area or facility, regulatory and stakeholder needs are met so that the area or facility, or parts of it (with complete contents other than perishables or expendables), can be reoccupied or reused. The IC or UC makes a clearance decision either alone (if on Federal or tribal land) or in coordination with the responsible local or state public health agency. In the latter case, the public health agency typically makes the final clearance decision, but with input from the IC or UC. A facility authority (e.g., private owner) determines whether to reopen all or parts of a given privately owned facility, whether to initiate restoration activities, or both.

If the data indicate that an unacceptable level of residual contamination remains, further decontamination and clearance sampling may be necessary (Box 507). If additional decontamination is deemed necessary, other decontamination options could be evaluated and possibly implemented, or the same decontamination technology could be repeated, and the clearance decision process repeated. It is also possible that decision-makers might opt to modify the originally specified clearance goal(s) (Box 508), in which case the decision process would be 


\section{Clearance}

repeated and could be supplemented with medical countermeasures to allow for faster recovery. Clearly, modified clearance goals would require buy-in by stakeholders and regulators along with assurance that long-term environmental and health issues have been addressed.

\subsection{Pre-Incident Planning}

Table 9-1 identifies essential pre-incident planning activities related to clearance.

Table 9-1. Summary of clearance actions to be taken prior to a biological attack.

\begin{tabular}{|l|l|}
\hline \multicolumn{1}{|c|}{ Responsible Personnel } & \multicolumn{1}{c|}{ Pre-Incident Actions } \\
\hline Urban area decision-makers & $\begin{array}{c}\text { - Identify members of an Environmental Clearance Committee. ECC } \\
\text { members should review this Interim Guidance and convene early, } \\
\text { before characterization, if possible. }\end{array}$ \\
\hline Emergency Planners & $\begin{array}{c}\text { Identify available laboratory facilities and specific capacities locally } \\
\text { and national for viability clearance analysis. }\end{array}$ \\
\hline Emergency Planners & $\begin{array}{l}\text { Identify and become familiar with appropriate high-volume air- } \\
\text { sampling equipment and equipment for outdoor aggressive air } \\
\text { sampling. }\end{array}$ \\
\hline
\end{tabular}

\subsection{Section 9 Summary}

Table 9-2 identifies the principal actions that take place during the Clearance Phase, including those entities responsible for executing those actions.

Table 9-2. Summary of clearance actions in approximate order of unfolding events.

\begin{tabular}{|c|c|}
\hline Personnel & Action \\
\hline \multirow{2}{*}{$\begin{array}{l}\text { Planning Section: } \\
\text { Environmental Unit, with } \\
\text { input from the TWG }\end{array}$} & $\begin{array}{l}\text { Review and revise, as necessary, the area- and facility-specific Clearance } \\
\text { Environmental SAPs from results of decontamination activities. }\end{array}$ \\
\hline & Review prioritization scheme and methodology according to remediation status. \\
\hline $\begin{array}{l}\text { IC or UC, with input from the } \\
\text { TWG }\end{array}$ & Approve the Clearance Environmental SAPs, if revised. \\
\hline $\begin{array}{l}\text { Operations Section: Sampling } \\
\text { Group }\end{array}$ & $\begin{array}{l}\text { Perform clearance sampling with assistance of contractors or other support that may } \\
\text { be available. }\end{array}$ \\
\hline $\begin{array}{l}\text { Planning Section: } \\
\text { Environmental Unit, with } \\
\text { input from Decontamination } \\
\text { Group and TWG }\end{array}$ & $\begin{array}{l}\text { Evaluate Clearance Environmental SAP results. } \\
\text { Determine whether cleanup criteria are met. } \\
\text { Recommend additional decontamination if necessary. }\end{array}$ \\
\hline Environmental Unit & $\begin{array}{l}\text { Document clearance results. Write final clearance reports, and submit reports to the } \\
\text { IC or UC. }\end{array}$ \\
\hline $\begin{array}{l}\text { EU and ECC, or ECC } \\
\text { independently }\end{array}$ & $\begin{array}{l}\text { Recommend whether the areas or facilities and associated items have been effectively } \\
\text { decontaminated. }\end{array}$ \\
\hline IC or UC & $\begin{array}{l}\text { Conduct reviews, and confirm that area, facility, regulatory, and stakeholder needs } \\
\text { are met. }\end{array}$ \\
\hline $\begin{array}{l}\text { IC or UC, or area authority } \\
\text { (such as health department), or } \\
\text { facility owners }\end{array}$ & $\begin{array}{l}\text { Determine whether to clear all or parts of a facility or area, and to initiate Restoration } \\
\text { Phase activities. If none of the above, further decontamination may be warranted. }\end{array}$ \\
\hline
\end{tabular}




\section{Clearance}

\subsection{Interim Recommendations for Clearance}

At present (January 2009), key knowledge gaps related to clearance include the absence of a consensus-based outdoor clearance policy or an indoor clearance policy appropriate for a widearea attack; relatively poor understanding of the risks associated with long-term indoor contamination; insufficient outdoor clearance sampling capabilities to address a wide-area incident; and the absence of scientifically based criteria for declaring remediation complete. Nevertheless, if a wide-area BWA release were to occur today, certain actions would have to be taken despite the lack of consensus for large-area clearance. Table 9-3 is a list of interim recommendations related to clearance following a wide-area BWA release. 


\section{Clearance}

\section{Table 9-3. Summary of interim recommendations for clearance.}

\begin{tabular}{|c|c|}
\hline $\begin{array}{c}\text { Item, action, or process recommended for } \\
\text { consideration }\end{array}$ & $\begin{array}{c}\text { Comments, qualifications, or responsible } \\
\text { entity }\end{array}$ \\
\hline Order the clearance activities as a function of prioritization. & $\begin{array}{l}\text { Priorities should have been established before } \\
\text { decontamination. See Sections } 5 \text { and } 9.1 \text {. }\end{array}$ \\
\hline $\begin{array}{l}\text { Establish clearance sampling plans, decision criteria, and risk- } \\
\text { assessment parameters early (e.g., before decontamination). }\end{array}$ & $\begin{array}{l}\text { See Section 9.2. See Section } 6 \text { for risk-assessment } \\
\text { details, background information, and references. }\end{array}$ \\
\hline $\begin{array}{l}\text { Consider current clearance goal for building interiors: No } \\
\text { growth of spores from any clearance samples taken. }\end{array}$ & $\begin{array}{l}\text { Based on EPA cleanup clearance values used for } \\
\text { anthrax-contaminated buildings; see Section } 6 .\end{array}$ \\
\hline $\begin{array}{l}\text { Consider recommended clearance goal for outdoor } \\
\text { contamination: No growth on any high-volume air samples } \\
\text { taken. }\end{array}$ & $\begin{array}{l}\text { - Goal is based on eliminating inhalation risk only. } \\
\text { Assumes some surface samples can be positive and } \\
\text { that monitoring for cutaneous anthrax will be done } \\
\text { and additional actions taken as appropriate. See } \\
\text { Section } 6 \text { for other risk-based decision options. } \\
\text { - Value may change given indigenous anthrax. }\end{array}$ \\
\hline $\begin{array}{l}\text { Use clearance sampling and detection methods that can } \\
\text { distinguish the presence of any viable spores. }\end{array}$ & $\begin{array}{l}\text { - Nonviable spores are not a concern. } \\
\text { - Rapid viability detection methods need to be used } \\
\text { for overall efficiency and augmented with the } \\
\text { current "gold standard," CDC culturing protocols. } \\
\text { - Sampling methods must be carefully evaluated to } \\
\text { ensure that viability is not affected. }\end{array}$ \\
\hline $\begin{array}{l}\text { Apply sampling strategies, including any or all of targeted, } \\
\text { biased, and random. Statistical analysis should be used for } \\
\text { quantitative confidence in having met clearance goals. }\end{array}$ & See Section 9.3.2. \\
\hline $\begin{array}{l}\text { Apply aggressive air sampling supplemented by a reduced set } \\
\text { of targeted surface samples for indoor clearance. }\end{array}$ & See Section 9.3.3. \\
\hline $\begin{array}{l}\text { Use high-volume aggressive air sampling, which is } \\
\text { recommended as the primary assessment tool for outdoor } \\
\text { clearance because it targets inhalation exposure potential. }\end{array}$ & $\begin{array}{l}\text { - Include locations with high resuspension potential, } \\
\text { and areas with high population density (including } \\
\text { both "fixed" and transient populations). See } \\
\text { Section 9.3.4. } \\
\text { - Depending on site-specific use, limited surface } \\
\text { sampling may be needed in previously high- } \\
\text { contamination areas to meet stakeholder needs. }\end{array}$ \\
\hline $\begin{array}{l}\text { Plan water-distribution system sampling according to system } \\
\text { hydrology and locations currently used for water-quality } \\
\text { assessments. }\end{array}$ & See Section 9.3.5. \\
\hline $\begin{array}{l}\text { Organize clearance activities using the same zones for areas } \\
\text { and facilities as for characterization and decontamination. }\end{array}$ & See Section 9.1. \\
\hline $\begin{array}{l}\text { Obtain ECC input for clearance decisions. If clearance goals } \\
\text { are not met, consider additional decontamination (first), or } \\
\text { modifying clearance goals (second). }\end{array}$ & $\begin{array}{l}\text { Evaluate whether clearance decision criteria have } \\
\text { been met, or consider an additional risk assessment } \\
\text { to modify clearance goals, if appropriate. Modifying } \\
\text { clearance goals implies changes to risk-management } \\
\text { decisions. See Section } 9 \text { introduction and } \\
\text { Sections } 9.2,9.3 \text {, and } 9.5 \text {. }\end{array}$ \\
\hline
\end{tabular}




\section{Clearance}

\subsection{Section 9 References}

ACGIH (1999), Bioaerosols: Assessment and Control, American Conference of Governmental Industrial Hygienists, Cincinnati, $\mathrm{OH}$.

Axelrod, M. (2005), Using Ancillary Information to Reduce Sample Size in Discovery Sampling and the Effects of Measurement Error, Lawrence Livermore National Laboratory, Livermore CA, UCRL-TR-216206.

Carlsen, T., L. Berg, D. MacQueen, W. Wilson, G. Brown, S. Mancieri, R. Bishop, K. Folks, R. Kirvel, and V. Vyas (September, 2005), Restoration Plan for Major International Airports After a Bioterrorist Attack, Lawrence Livermore National Laboratory, Livermore, CA, UCRL-TR210178.

DHS (2008), Department of Homeland Security, National Response Framework; documents available at $<$ http://www.fema.gov/emergency/nrf/> .

DHS and EPA (2009), Department of Homeland Security and Environmental Protection Agency, Planning Guidance for Recovery Following Biological Incidents, National Science and

Technology Council, Biological Decontamination Standards Working Group.

EPA (1986) U.S. Environmental Protection Agency, Bacteriological Ambient Waste Quality Criteria for Marine and Fresh Recreational Water.

EPA (1996), U.S. Environmental Protection Agency, Geostatistical Sampling and Evaluation Guidance for Soils and Solid Media (review draft), EPA, Office of Solid Waste.

EPA (1997), U.S. Environmental Protection Agency, Multi-Agency Radiation Survey and Site Investigation Manual (MARSSIM), Washington, D.C., EPA, DOE, NRC, and DOD, NUREG1575, EPA 402-R-97-016.

EPA (2006), U.S. Environmental Protection Agency, Office of Research and Development, National Homeland Security Research Center, Investigation of the Capability of Point-ofUse/Point-of-Entry Treatment devices as a Means of Providing Water Security, EPA/600/R06/012, available at 〈http://www.epa.gov/NHSRC/pubs/600r06012.pdf > .

GAO (2005), U.S. Government Accountability Office, Anthrax Detection: Agencies Need to Validate Sampling Activities in Order to Increase Confidence in Negative Results, Testimony before the Chairman, Subcommittee on National Security, Emerging Threats, and International Relations, House Committee on Government Reform, House of Representatives, statement of Keith A. Rhodes, Applied Research and Methods, GAO-05-493T, April 2005.

Gilbert, R. O. (1987), Statistical Methods for Environmental Pollution Monitoring, (New York, NY, Van Nostrand Reinhold).

Gilbert, R. O., T. LeGor, et al. (1996), An Overview of Methods for Evaluating the Attainment of Cleanup Standards for Soils, Solid Media, and Groundwater, PNNL, PNL-10908, EC-502.

Grieve, A. P. (1994), “A Further Note on Sampling to Locate Rare Defectives with Strong Prior Evidence," Biometrika 81, 787-789.

Hardin, J. W., and R. O. Gilbert (1993). Comparing Statistical Tests for Detecting Soil Contamination Greater than Background (Pacific Northwest Laboratory, Richland, WA), PNL-8989, UC-630. 


\section{Clearance}

Hess-Kosa (2002), Indoor Air Quality: Sampling Methodologies, Lewis Publishers CRC Press Ltd, Boca Raton, Florida.

IDQTF (2005), Intergovernmental Data Quality Task Force, Uniform Federal Policy for Quality Assurance Project Plans, Environmental Protection Agency, EPA-505-B-04-990a and DOD DTIC ADA 427785.

Mulhausen, J. R. and J. Damiano, (1998), A Strategy for Assessing and Managing Occupational Exposures (AIHA Press, American Industrial Hygiene Association, Fairfax, VA).

NRC (2005), National Research Council of the National Academies, Committee on Standards and Policies for Decontaminating Public Facilities Affected by Exposure to Harmful Biological Agents, Reopening Public Facilities After a Biological Attack, National Academies Press, Washington, D.C.

NRT (updated July, 2005), National Response Team, Technical Assistance for Anthrax Response, Interim-Final Draft; available at http://www.nrt.org/production/NRT/NRTWeb.nsf/PagesByLevelCat/Level2TA?Opendocument.

SA-32 Environmental Clearance Sampling Plan (2003), Attachment 10.9 to the report, Remedial Action Plan for Fumigation of SA-32 Diplomatic Pouch and Mail Facility, Sterling VA.

Sego, L. H., J. E. Wilson, S.A. Shulman, B. A. Pulsipher, K. K. Anderson, and W. K. Sierber (2010), Acceptance Sampling Using Judgmental and Randomly Selected Samples, Pacific Northwest National Laboratory, PNNL-19315, Richland, WA; available at http://www.pnl.gov/main/publications/external/technical_reports/PNNL-19315.pdf.

SNL and LLNL (2008), Sandia National Laboratories and Lawrence Livermore National Laboratory, IBRD Task 1 Systems Analysis Report (same OUO document published separately at both laboratories as report SNL2008-1349 and report LLNL-AR-401510).

Turtletaub K., and E. Raber (2008), "Outdoor Biological Agent Risk Analysis and Assessment," in Technical Gap Analysis for Wide Area Biological Incidents, Lawrence Livermore National Laboratory, UCRL-TR 401133.

Wright, T. (1992), “A Note on Sampling to Locate Rare Defectives with Strong Prior Evidence," Biometrika 79(4), 685-691. 


\section{Restoration/Reoccupancy}

After characterization, decontamination, and clearance activities are complete, the focus shifts to assisting individuals, businesses, and critical infrastructure in meeting basic needs and returning to self-sufficiency. Section 10 briefly reviews some considerations that must be addressed by decision-makers. Considerations include public perception of the condition of the affected area, mental health and wellbeing of the residential population, and community resiliency. To address such issues, specific efforts can be implemented during the long-term recovery and maintenance period. Examples of the efforts include long-term medical monitoring, sustained environmental monitoring, and public reassurance programs. The remainder of Section 10 outlines the efforts that are expected to be community-specific. The JFO, which is the primary Federal incidentmanagement field structure, remains the central coordination point for all entities providing restoration and reoccupancy assistance. In the event of a wide-area attack, such as that described by this Interim Guidance, many of the longer-term and area-specific needs cannot be fully evaluated in advance of an actual incident.

\subsection{Review Reoccupancy Considerations (Boxes 600-603)}

Site-specific restoration/reoccupancy plans (Figure 10-1; Box 600) vary widely depending on the extent of potential residual contamination, necessary refurbishment, the amount of renovation required to meet local safety codes, or any enhancements deemed appropriate (Box 601). The Bio-Detection System (Noller 2005) is an example of an "enhancement" or upgrade that has been implemented in U.S. Postal Service Processing and Distribution Centers.

Before reopening an area or facility to the general public, all reoccupancy and reuse criteria must be defined by key stakeholders and addressed (Box 602). Remediation is judged successful when no significant risk exists, even with no "control" action taken on the part of individuals (e.g., PPE, training, standard operating procedures, or medical surveillance). However, following a wide-area release, reoccupancy and reuse may require some continued mitigation actions to ensure general population safety in cases where absolute risk cannot be fully addressed because of the catastrophic nature of the incident and the lack of supporting scientific data. Risk communication continues as part of the recovery process (Box 600). It is also possible that a phased restart of business operations might have been planned in parallel with other response and recovery activities (Box 603). Such a phased approach is often specified in Continuity-ofOperations Plans (COOPs).

Restoration for water - that is, the reuse of water in a distribution system - might involve a phased approach as well. For example, water service might first be re-established for certain lifeessential services, such as fire fighting, then the appropriate authorities might approve certain nonconsumption uses, such as washing and sanitation. Finally, the water distribution system would be certified as sanitary for drinking water. Authority to make decisions on the reuse of previously contaminated water systems varies from state to state and may be overseen by a Department of Natural Resources. 


\section{Restoration/Reoccupancy}

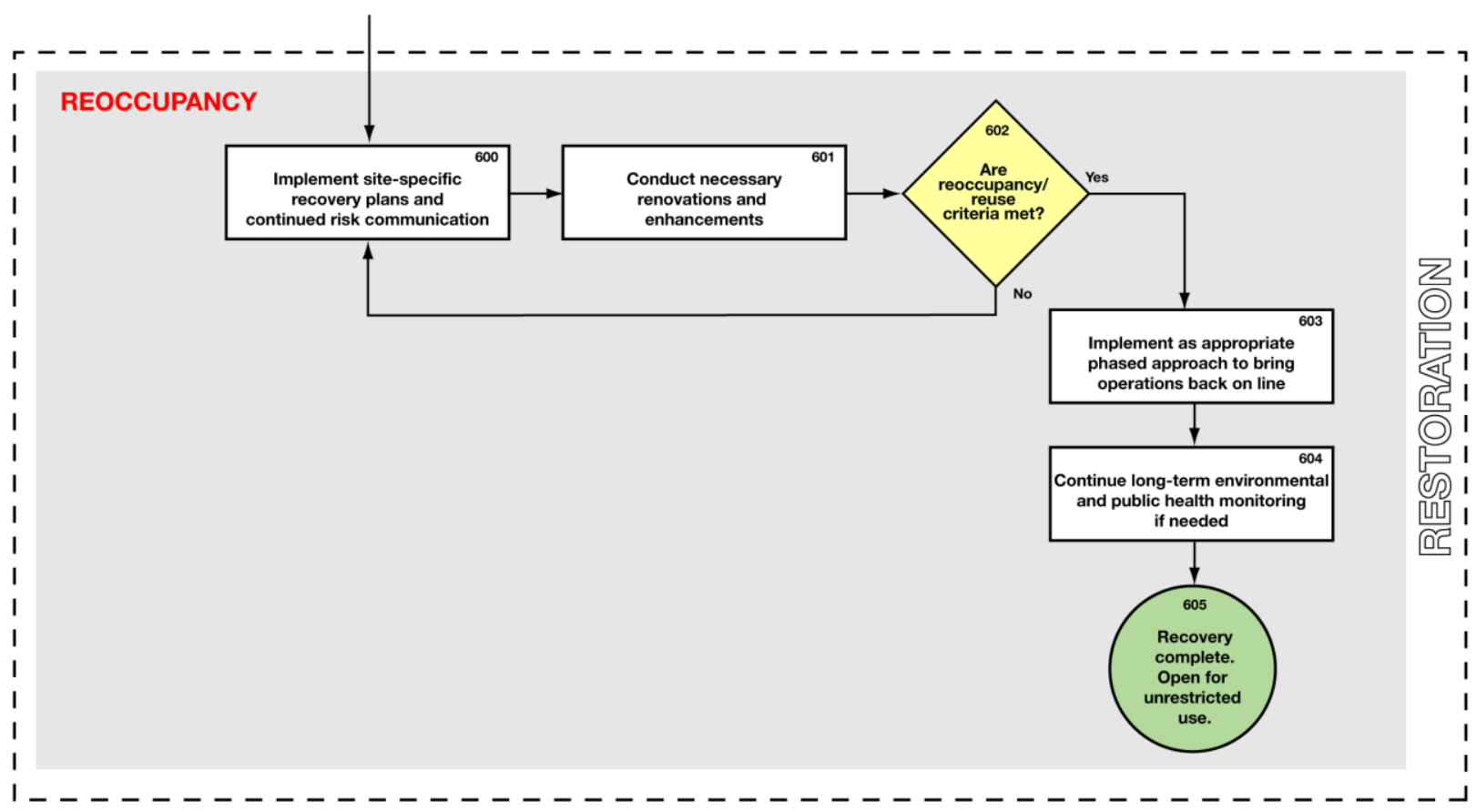

Figure 10-1. Principal activities associated with the Restoration/Reoccupancy Phase.

\subsection{Evaluate Long-Term Medical Monitoring (Box 604)}

A long-term medical follow-up (monitoring) and treatment program may be implemented (Figure 10-2; Box 604-1) to ensure that area residents and workers receive appropriate medication or other treatment deemed appropriate. This type of activity is expected to be overseen by local public health, although Federal oversight and coordination may be needed. Components of a medical program could include, but are not limited to:

- Health monitoring of workers and establishment of controls (Box 604-2) for any individuals determined to be at risk (such as work reassignment, PPE, and prophylactic medication).

- Follow-ups on absenteeism.

- Epidemiological monitoring of the entire urban-area population.

- Selection and administration of prophylactic or other medication, as appropriate.

- Recommended personal medical checkup and hygiene programs.

- Animal health monitoring over an extended region (Box 604-3).

Some sites (e.g., occupational as opposed to residential) will have more flexibility than others in implementing engineering or administrative controls (Box 604-2) to provide health protection, as required in a site-specific HASP (Section 7.4). 


\section{Restoration/Reoccupancy}

\section{REOCCUPANCY \\ (expanded 604)}

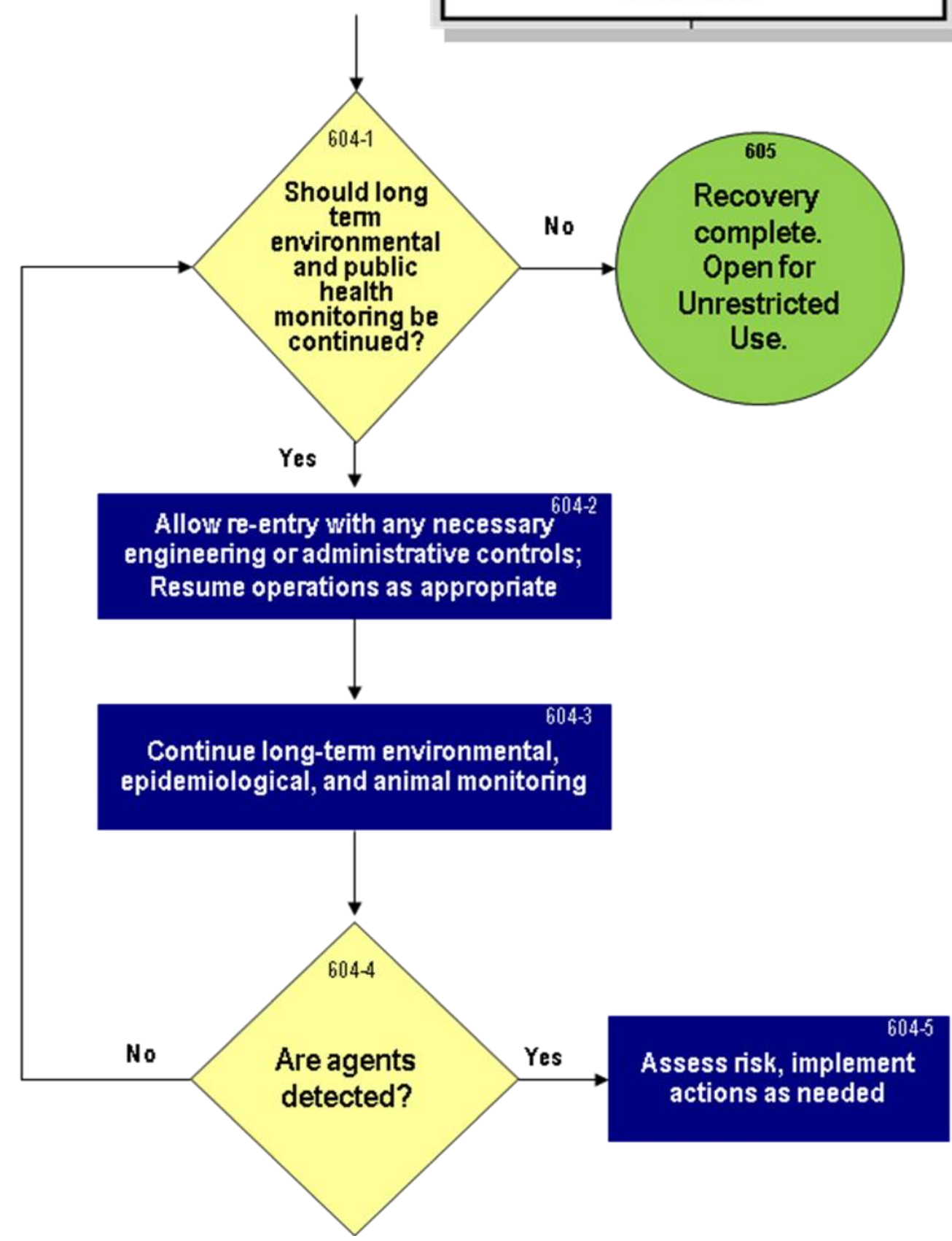

Figure 10-2. Box 604 expanded: consider long-term environmental monitoring.

\subsection{Initiate Post-Clearance Environmental Monitoring (Box 604)}

Other types of post-clearance environmental monitoring may be implemented (Box 604-1) to gain regulatory approval, maintain public confidence, provide ongoing assurance and consistency, and ensure public health and safety, especially for long-lived BWAs, such as 
B. anthracis. Options and durations for conducting long-term, high-volume air monitoring are site and incident specific. If reoccupancy and reuse criteria described in the recovery plans require the continuous collection of high-volume air samples, the extent and duration of such monitoring will be determined by guidance from local public health officials and buy-in by stakeholders. To ensure that inhalation health risk remains acceptable, additional long-term monitoring may be needed. If so, it is recommended that any affected jurisdiction take advantage to the extent possible of pre-existing programs. For example, BioWatch or Guardian cities should ensure continuation of existing programs, which may be considered an adequate postclearance program for outdoor areas. Other cities should augment or take advantage of preexisting ambient-air-monitoring programs.

Ideally, it would be best to use one type of air-monitoring system for consistency and to avoid different types of data. BioWatch cities could also consider using their existing BioWatch monitors and adding more locations to expand a long-term monitoring program. Another advantage is that is it possible to capture spores on BioWatch filters and then test for viability.

The post-incident duration of air monitoring would likely be influenced by results of periodically repeated site sampling, original source strength, and degree of dispersion of contaminant throughout an area or facility. Additional HEPA-vacuum surface sampling, bulk sampling, and surface sampling are not recommended except in areas that yield positive results from air sampling and represent a potential inhalation threat or can be linked to potential cutaneous anthrax outbreaks. Sampling would continue until repeated results demonstrate that contamination remains insignificant (Box 604-4).

\subsection{Repopulate through Public Reassurance and Incentives}

To facilitate the repopulation of a previously contaminated area, a multi-faceted effort may be needed to reassure the public that the region is not only fit for human use, but also fit for their own personal use. Such an effort could include:

- A large-scale media campaign to manage public perception.

- Public information about points of contact for environmental and public health monitoring in case of an emergency.

- Public demonstration of land and asset use.

- Federal incentives for repopulating homes and businesses.

Proper use of the mass media can help avoid public misunderstandings and manage public perception. Adverse psychological effects from a bioterrorist attack, distrust or insufficient understanding of government cleanup practices, and health and safety concerns, to name a few, may contribute to the skepticism or reluctance of a dislocated population. Enlisting the mass media to address such concerns can be the central feature of a successful public reassurance campaign.

In addition to a media campaign, public demonstrations that remediated areas now have acceptable levels of health risk can reassure those who desire to return and reoccupy the area. Such demonstrations may have particularly strong application to commercial assets. Demonstrating the safety of an alternative workforce in a remediated area or facility may be the fastest and easiest way to persuade an original workforce to return. Alternative workforces might include Title 32 and Title 10 military forces under DSCA. For such a tactic to be effective, an 


\section{Restoration/Reoccupancy}

alternative workforce that over time has shown no illness from $B$. anthracis must have the same level of immunization as the general public. When public officials in charge of remediation, along with their families, demonstrate they are willing to live in previously contaminated areas, then the public may be further convinced to return.

A population may be further convinced to return to and reoccupy a previously contaminated area through incentives. Property and business owners may be more highly motivated to return quickly than those with less at stake, and the number and value of incentives needed may also be correlated with the amount of time a given population is displaced. One recent estimate by SNL and LLNL (2008) of the time to repopulate a remediated urban area suggests a duration on the order of years, but the many unknowns make predictions of time difficult. If businesses or populations were displaced for lengthy periods, significant incentives might be required to bring them back. As a result, providing financial, medical, and social incentives to organizations and individuals could play a large part in the success of a repopulation effort.

\subsection{Address Remaining Stakeholder Issues, Concerns (Box 605)}

If additional stakeholder issues arise during reoccupancy, they must be addressed. Several options are available. Discussions would potentially include concerned stakeholders, facility authorities (owners and representatives), public health officials, and other government agencies such as the EPA and CDC, coordinated through the JFO. Principal decisions would focus on establishing mechanisms to ensure that no significant health effects are likely from reentry and reoccupation of an area or facility. For example, additional samples may be taken from multiple environmental media or by using different collection and analytical techniques to continue to confirm the reoccupancy decision, especially after major site alterations, such as earth movement, construction, or grading. Increases in cases from epi-survelliance or unusual ambient conditions may raise public concerns that could be addressed by sampling and continued reassurance derived from good analytical data. Availability of lifeline services and economic concerns can be addressed through government funding to restore the flow of goods and services throughout the region. Free medical monitoring and subsidized or free health care would also be motivational tools. Actions following chemical releases (e.g., chlorine vapor in Graniteville, South Carolina, in 2005) illustrate the collaborative processes used by multiple agencies in meeting technical challenges associated with reentry decisions following release of a hazardous substance. Once recovery is deemed complete, an area or facility is opened for unrestricted use (Box 605). 


\section{Restoration/Reoccupancy}

\subsection{Section 10 Summary of Actions}

\section{Table 10-1. Summary of restoration actions in approximate order of unfolding events.}

\begin{tabular}{|l|l|}
\hline \multicolumn{1}{|c|}{ Personnel } & \multicolumn{1}{c|}{ Action } \\
\hline $\begin{array}{l}\text { IC or UC in collaboration with } \\
\text { facility or regional emergency } \\
\text { managers }\end{array}$ & $\begin{array}{l}\text { Prepare and implement site-specific recovery plans by: } \\
\text { Implementing renovation, including refurbishment of removed and damaged items, } \\
\text { system testing, and any other required actions. } \\
\text { - Determining whether phased-in reuse of areas and facilities is needed to support } \\
\text { recovery operations. } \\
\text { • Upgrading or enhancing areas or facilities (e.g., mitigating biological vulnerability. } \\
\text { - Implementing risk-communication strategies. }\end{array}$ \\
\cline { 2 - 3 } & $\begin{array}{l}\text { Address special work activities, as necessary, under the reoccupancy (transitional) } \\
\text { program, such as safety-based maintenance and housekeeping. }\end{array}$ \\
\hline $\begin{array}{l}\text { IC or UC in collaboration with } \\
\text { local public health and OSHA, } \\
\text { where appropriate }\end{array}$ & $\begin{array}{l}\text { Continue long-term environmental and public health monitoring, if deemed } \\
\text { appropriate. }\end{array}$ \\
\cline { 2 - 3 } & $\begin{array}{l}\text { Determine whether to permit tenants and employees to return for normal business. } \\
\text { Address general industrial and residential safety issues. }\end{array}$ \\
\hline IC or UC & Advise the public to resume full operations and normal activities. \\
\hline
\end{tabular}




\subsection{Interim Recommendations for Restoration}

\section{Table 10-2. Summary of interim recommendations.}

\begin{tabular}{|l|l|}
\hline \multicolumn{1}{|c|}{ Recommended action or process } & \multicolumn{1}{c|}{ Comments or responsible entity } \\
\hline $\begin{array}{l}\text { Ensure that reoccupancy and reuse criteria are met before } \\
\text { releasing areas or facilities for reoccupancy or reuse. }\end{array}$ & $\begin{array}{l}\text { Site-specific reoccupancy plans (Section 9.5.1) with } \\
\text { specific reoccupancy criteria (9.5.3) for indoor and } \\
\text { outdoor locations should be developed and } \\
\text { implemented }\end{array}$ \\
\hline $\begin{array}{l}\text { Provide government incentives to businesses and individuals } \\
\text { willing to reoccupy areas or facilities. }\end{array}$ & $\begin{array}{l}\text { - Free long-term medical monitoring and care should } \\
\text { be a high priority. } \\
\text { Consider tax advantages and incentives for both } \\
\text { individuals and businesses. }\end{array}$ \\
\hline $\begin{array}{l}\text { Implement long-term medical monitoring plans. } \\
\text { - Ambient-air-monitoring programs to ensure no inhalation } \\
\text { risk. }\end{array}$ & $\begin{array}{l}\text { Local public health agencies should implement the } \\
\text { plans with Federal oversight if medication or other } \\
\text { treatment is deemed appropriate (Section 10.2). }\end{array}$ \\
\hline $\begin{array}{l}\text { Plan and initiate post-clearance environmental monitoring } \\
\text { plans. Include: }\end{array}$ & $\begin{array}{l}\text { Focus should be on long-lived BWAs (Section 10.3). } \\
\text { Determine whether existing programs (BioWatch) } \\
\text { existing ambient, particulate, air-monitoring } \\
\text { programs for incorporation, or implement new } \\
\text { programs to address stakeholder needs. }\end{array}$ \\
\hline $\begin{array}{l}\text { Implement long-term public information and communication } \\
\text { programs to address remaining stakeholder concerns. }\end{array}$ & \begin{tabular}{l} 
Any actions should have stakeholder involvement. \\
\hline
\end{tabular} \\
\hline
\end{tabular}

\subsection{Section 10 References}

DHS (2008), Department of Homeland Security, National Response Framework; documents available at <http://www.fema.gov/emergency/nrf/> .

Noller, A. (2005), "US Postal Service Bio-Detection System," National Homeland Security Consortium Meeting, Monterey, CA, May 24-25, 2005 (National Emergency Management Association, Lexington, KY); available at $<\underline{\mathrm{http}}$ ://www.nemaweb.org/?1381 $>$; see also National Association of Letter Carriers (2005), USPS Biohazard Detection System (BDS); available at $<$ http://www.nalc.org/depart/safety/USPSBDS.html $>$, accessed 9/30/2005.

SNL and LLNL (2008), Sandia National Laboratories and Lawrence Livermore National Laboratory, IBRD Task 1 Systems Analysis Report (same OUO document published separately at both laboratories as report SNL2008-1349 and report LLNL-AR-401510, respectively). 


\section{Checklist}

\section{Part V: Appendixes}

\section{Recommended Checklist for Planning Wide-Area Remediation}

Following a wide-area BWA attack, members of the IC or UC would benefit from some overall scheme for anticipating and tracking issues as they are likely to arise during the various phases of response and recovery. This section provides a checklist identifying the types of information required for planning activities starting with notification and first response, progressing through remediation, and ending with restoration.

\begin{tabular}{|c|c|c|}
\hline Responsible Personnel & & Action \\
\hline \multicolumn{3}{|r|}{ Notification Phase } \\
\hline \multirow[t]{4}{*}{$\begin{array}{l}\text { Emergency management } \\
\text { organization and law } \\
\text { enforcement or other } \\
\text { response and public } \\
\text { health organizations }\end{array}$} & $\square$ & $\begin{array}{l}\text { Emergency manager or public health receives notification that: } \\
\circ \text { A biological incident has been detected, or } \\
\circ \text { A biological incident is suspected, or } \\
\circ \text { Information about a developing threat is received from an agency or } \\
\text { responsible person as the result of an active detection system (e.g., } \\
\text { BioWatch), medical surveillance, or epidemiologic investigation. }\end{array}$ \\
\hline & $\square$ & $\begin{array}{l}\text { Gather information and continue to assess incident credibility, incident status, } \\
\text { potential effects on facilities or areas, and the degree to which a response is } \\
\text { needed. }\end{array}$ \\
\hline & $\square$ & $\begin{array}{l}\text { Emergency manager and/or public health makes notifications, as appropriate, by: } \\
\text { Following previously established notification protocols, tailored to specific } \\
\text { triggers at each stage of a developing incident, and either alerting responders } \\
\text { and agencies (Federal, state, and local) or acting on direction from them. } \\
\text { Disseminating information, including preliminary risk communication and } \\
\text { public health directives. }\end{array}$ \\
\hline & $\square$ & Alert and consider standing up additional resources, such as a JIC. \\
\hline
\end{tabular}




\section{Checklist}

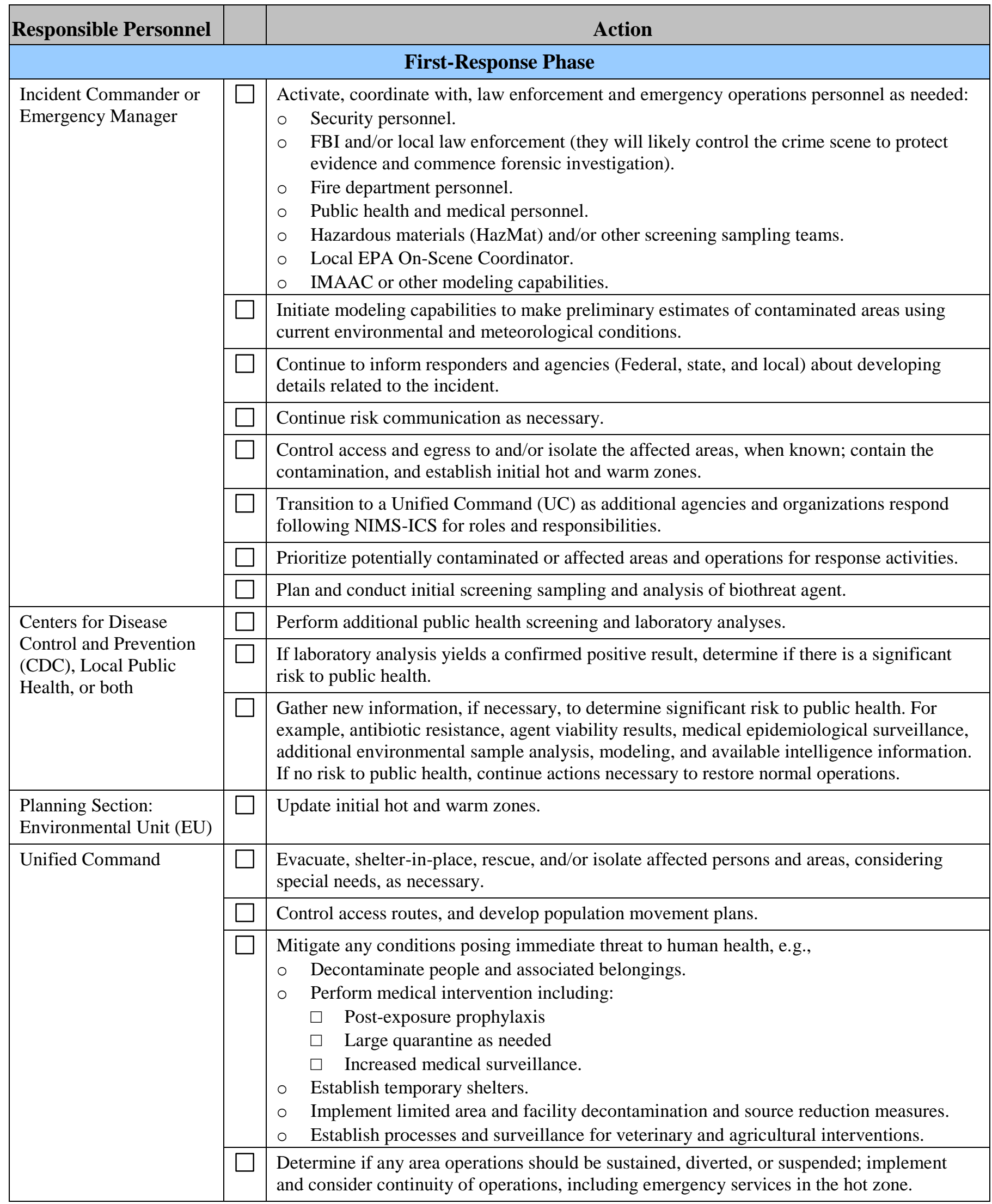


Checklist

\begin{tabular}{|c|c|c|}
\hline Responsible Personnel & & Action \\
\hline \multicolumn{3}{|r|}{ Characterization Phase } \\
\hline $\begin{array}{l}\text { Planning Section: } \\
\text { Situation Unit }\end{array}$ & $\square$ & $\begin{array}{l}\text { Compile all analytical and observational data and reports that were created during the First- } \\
\text { Response Phase, and provide results to the Environmental Unit. }\end{array}$ \\
\hline \multirow[t]{4}{*}{ Unified Command } & $\square$ & $\begin{array}{l}\text { Identify and prioritize areas, facilities, and functions for detailed characterization and } \\
\text { remediation by considering: } \\
\circ \text { Critical infrastructure and facilities. } \\
\circ \text { Minimum essential infrastructure. } \\
\circ \quad \text { Population distribution. } \\
\circ \quad \text { Lifelines. }\end{array}$ \\
\hline & $\square$ & $\begin{array}{l}\text { Mobilize or activate, as necessary, pre-identified resources for characterization activities, } \\
\text { including: } \\
\circ \text { Laboratory Response Network (LRN) and other CDC-approved laboratories. } \\
\circ \text { Environmental sampling teams, decontamination and disposal resources, and personal } \\
\text { protective equipment (PPE). } \\
\circ \text { Data management and documentation specialists. } \\
\circ \text { Air-dispersion modeling resources. }\end{array}$ \\
\hline & $\square$ & $\begin{array}{l}\text { Create or activate a Technical Working Group (TWG) and Environmental Clearance } \\
\text { Committee (ECC) if desired, and establish lines of authority and responsibilities. }\end{array}$ \\
\hline & $\square$ & $\begin{array}{l}\text { Begin notifying and deploying pre-identified resources for decontamination, clearance, and } \\
\text { waste management, as needed. }\end{array}$ \\
\hline \multirow{2}{*}{$\begin{array}{l}\text { Safety Officer and } \\
\text { Logistics Section: } \\
\text { Medical Unit }\end{array}$} & $\square$ & Create and implement a Health and Safety Plan (HASP) for response personnel. \\
\hline & $\square$ & $\begin{array}{l}\text { Vaccinate or provide antibiotics to appropriate response personnel, as needed, per } \\
\text { HHS/CDC guidance. }\end{array}$ \\
\hline \multirow{2}{*}{$\begin{array}{l}\text { Facility/Public Works } \\
\text { and other applicable } \\
\text { agencies }\end{array}$} & $\square$ & Provide detailed plans (e.g., HVAC systems) for affected facilities. \\
\hline & $\square$ & $\begin{array}{l}\text { Provide detailed maps and infrastructure information (e.g., sewer, power, water, natural } \\
\text { resource maps) for the affected region. }\end{array}$ \\
\hline \multirow{2}{*}{$\begin{array}{l}\text { Planning Section: } \\
\text { Environmental Unit }\end{array}$} & $\square$ & Recommend any additional agent containment and source reduction deemed necessary. \\
\hline & $\square$ & $\begin{array}{l}\text { Depending on actions completed during first response: } \\
\circ \quad \text { Assess potential contaminant transport outside the contained areas and facilities. (e.g., } \\
\text { through tracking and re-aerosolization): } \\
\square \quad \text { Evaluate the need for pre-characterization sampling. } \\
\square \quad \text { Evaluate the need for air monitoring. } \\
\square \quad \text { Evaluate the need for additional refinement of outdoor and/or indoor modeling. } \\
\circ \quad \text { Develop the necessary implementation strategy. }\end{array}$ \\
\hline \multirow[t]{2}{*}{ Operations Section } & $\square$ & $\begin{array}{l}\text { Perform recommended actions to assess potential contaminant transport from above } \\
\text { assessments. }\end{array}$ \\
\hline & $\square$ & Implement any recommended agent containment and isolation actions. \\
\hline
\end{tabular}




\section{Checklist}

\begin{tabular}{|c|c|c|}
\hline Responsible Personnel & & Action \\
\hline \multicolumn{3}{|r|}{$\begin{array}{l}\text { Characterization Phase } \\
\text { (continued) }\end{array}$} \\
\hline \multirow[t]{2}{*}{$\begin{array}{l}\text { Planning Section: } \\
\text { Environmental Unit with } \\
\text { input from TWG }\end{array}$} & $\square$ & $\begin{array}{l}\text { Develop a characterization strategy to support remediation activities, including identifying } \\
\text { current characteristics of the confirmed biothreat agent (e.g., has it remained viable, is it still } \\
\text { toxic, can it reaerosolize?). } \\
\circ \text { Consider statistical and judgmental criteria. } \\
\circ \text { Employ iterative modeling approach to optimize sampling. }\end{array}$ \\
\hline & $\square$ & $\begin{array}{l}\text { Write incident-specific characterization sampling and analysis plan(s) (SAPs) in which all } \\
\text { objectives are identified. } \\
\circ \text { Organize the affected areas and facilities into characterization zones. } \\
\circ \text { Select sampling locations and methods. } \\
\circ \quad \text { Identify resource limitations, and optimize their use. }\end{array}$ \\
\hline Unified Command & $\square$ & Approve the characterization SAP(s). \\
\hline \multirow{2}{*}{$\begin{array}{l}\text { Operations Section: } \\
\text { Sampling Group }\end{array}$} & $\square$ & Implement the characterization SAP(s) according to area-specific priorities. \\
\hline & $\square$ & $\begin{array}{l}\text { Track implementation of characterization SAP(s), and make adjustments as needed as data } \\
\text { become available. }\end{array}$ \\
\hline \multirow{3}{*}{$\begin{array}{l}\text { Planning Section: } \\
\text { Environmental Unit with } \\
\text { input from TWG }\end{array}$} & $\square$ & $\begin{array}{l}\text { Evaluate results of characterization activities, and consult with the ECC, as appropriate. } \\
\text { Recommend additional characterization activities, as needed, to the Operations Section. }\end{array}$ \\
\hline & $\square$ & Conduct risk assessment. \\
\hline & $\square$ & Develop clearance goals for the affected area(s). \\
\hline $\begin{array}{l}\text { Local, State, or Federal } \\
\text { Public Health } \\
\text { (HHS/CDC) }\end{array}$ & $\square$ & Recommend any additional public health or medical options. \\
\hline \multirow{2}{*}{$\begin{array}{l}\text { Unified Command with } \\
\text { input from TWG }\end{array}$} & $\square$ & Approve clearance goals. \\
\hline & $\square$ & Approve any HHS/CDC public health recommendations. \\
\hline
\end{tabular}




\section{Checklist}

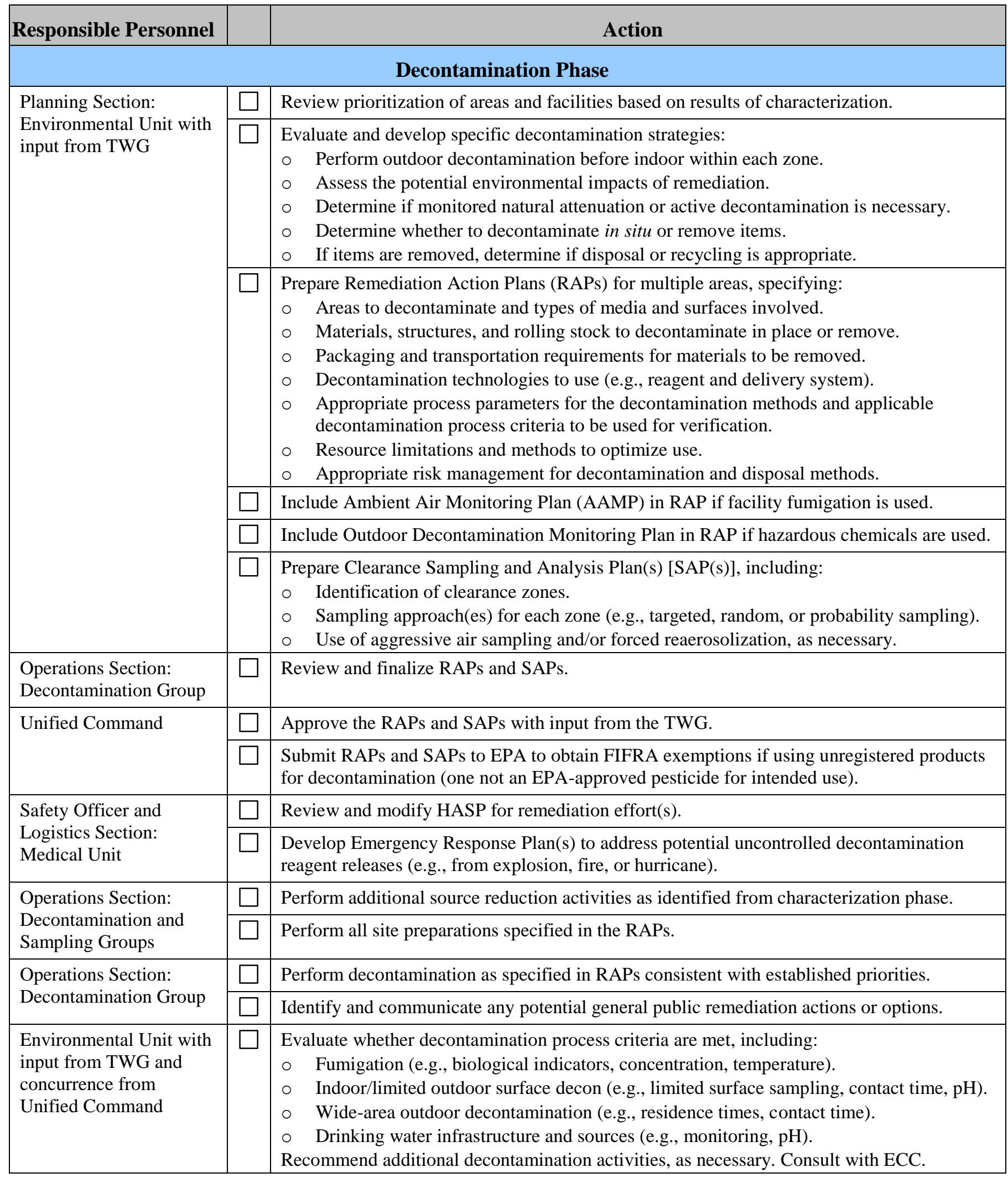




\section{Checklist}

\begin{tabular}{|c|c|c|}
\hline Responsible Personnel & & Action \\
\hline \multicolumn{3}{|r|}{ Clearance Phase } \\
\hline \multirow{2}{*}{$\begin{array}{l}\text { Planning Section: } \\
\text { Environmental Unit with } \\
\text { input from the TWG }\end{array}$} & $\square$ & $\begin{array}{l}\text { Review, and revise as appropriate, the incident-specific clearance SAPs using results of } \\
\text { decontamination activities. }\end{array}$ \\
\hline & $\square$ & Review prioritization of areas, facilities, and functions based on remediation status. \\
\hline $\begin{array}{l}\text { Unified Command with } \\
\text { input from the TWG }\end{array}$ & $\square$ & Approve the incident-specific clearance SAPs, if revised. \\
\hline $\begin{array}{l}\text { Operations Section: } \\
\text { Sampling Group }\end{array}$ & $\square$ & Perform clearance sampling as specified in the SAPs. \\
\hline $\begin{array}{l}\text { Planning Section: } \\
\text { Environmental Unit with } \\
\text { input from TWG }\end{array}$ & $\square$ & $\begin{array}{l}\text { Evaluate the clearance SAP results. Determine if cleanup goals have are met. Recommend } \\
\text { additional remediation if necessary. }\end{array}$ \\
\hline $\begin{array}{l}\text { Planning Section: } \\
\text { Environmental Unit }\end{array}$ & $\square$ & $\begin{array}{l}\text { Document final clearance results for each SAP: } \\
\circ \quad \text { Conduct final technical risk assessment. } \\
\circ \quad \text { Consider socioeconomic implications. }\end{array}$ \\
\hline $\begin{array}{l}\text { Unified Command with } \\
\text { input from ECC }\end{array}$ & $\square$ & $\begin{array}{l}\text { Review final clearance results including final risk assessment. Make recommendations on } \\
\text { whether zones (e.g., facilities, outdoor areas, items) are effectively decontaminated. }\end{array}$ \\
\hline \multirow[t]{2}{*}{ Unified Command } & $\square$ & $\begin{array}{l}\text { Make clearance decision: } \\
\text { Conduct reviews, and confirm that regulatory and stakeholder needs are addressed. } \\
\text { Determine whether to reopen all or parts of an area or facility; or to initiate recovery } \\
\text { and refurbishment activities. If not, further decontamination may be warranted. }\end{array}$ \\
\hline & $\square$ & Determine any long-term environmental monitoring needs, and implement as necessary. \\
\hline \multicolumn{3}{|r|}{ Restoration Phase } \\
\hline \multirow[t]{2}{*}{$\begin{array}{l}\text { Unified Command in } \\
\text { collaboration with } \\
\text { facility and regional } \\
\text { emergency managers }\end{array}$} & $\square$ & $\begin{array}{l}\text { Prepare and implement site-specific recovery plans: } \\
\text { Implement renovation, including refurbishment of removed and damaged items, system } \\
\text { testing, and other required actions. } \\
\text { Determine whether phased-in reuse of areas and facilities is needed to support recovery } \\
\text { operations. } \\
\text { Upgrade or enhance areas or facilities, as appropriate (e.g., mitigate biological } \\
\text { vulnerability). } \\
\text { Implement risk communication strategy and plans. }\end{array}$ \\
\hline & $\square$ & $\begin{array}{l}\text { Address special work activities as necessary under the reoccupancy (transitional) program, } \\
\text { such as safety-based maintenance and housekeeping. }\end{array}$ \\
\hline \multirow{2}{*}{$\begin{array}{l}\text { Unified Command in } \\
\text { collaboration with local } \\
\text { public health and OSHA, } \\
\text { where appropriate }\end{array}$} & $\square$ & Continue long-term environmental and public health monitoring, if deemed appropriate. \\
\hline & $\square$ & $\begin{array}{l}\text { Determine whether to permit tenants and employees to return for normal business. Address } \\
\text { general industrial and residential safety issues. }\end{array}$ \\
\hline Unified Command & $\square$ & Resume full operations for the public. \\
\hline
\end{tabular}




\section{Expanded Framework}

\section{Expanded Operational Decision Framework}

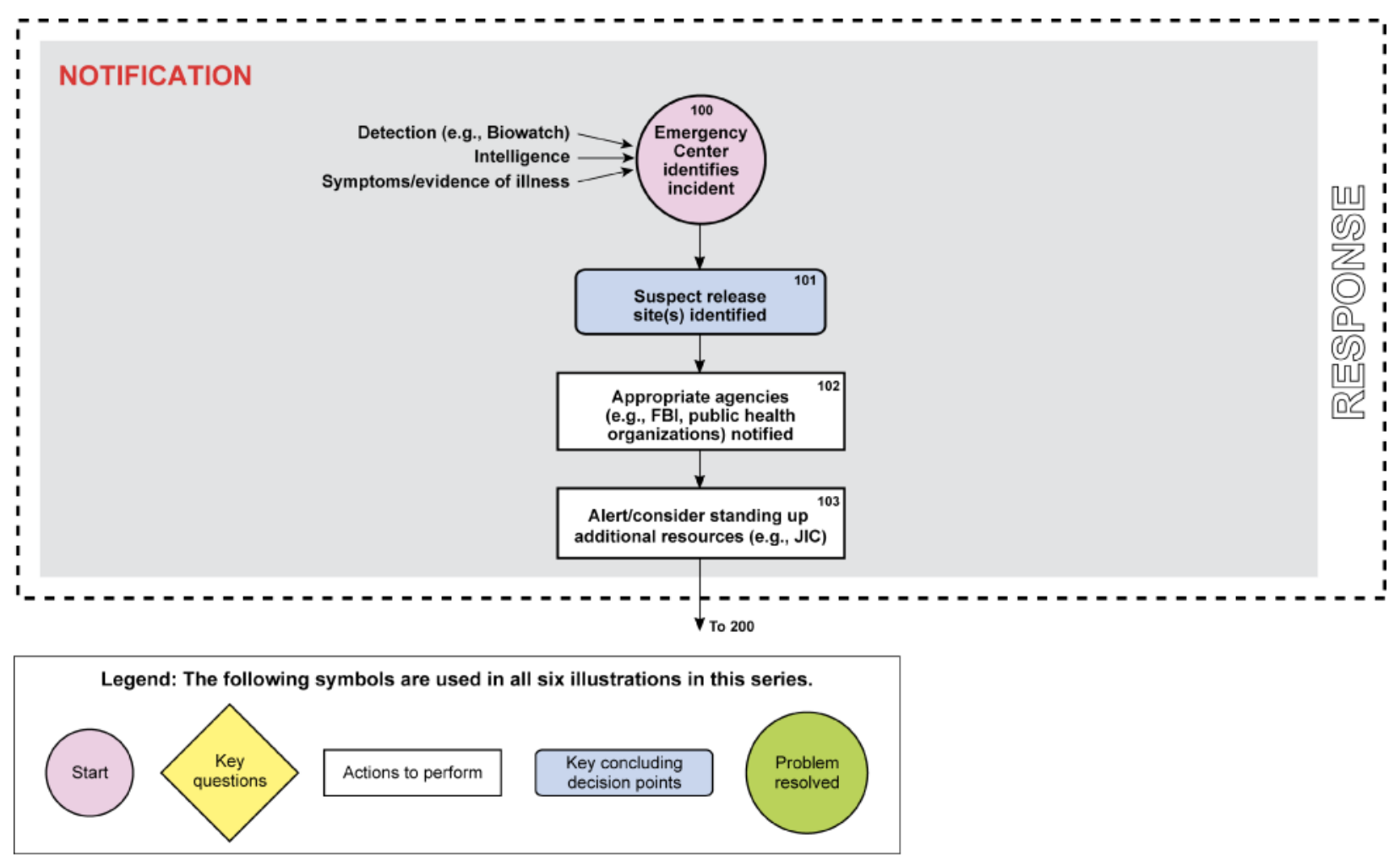




\section{Expanded Framework}

\section{NOTIFICATION (100 Expanded)}
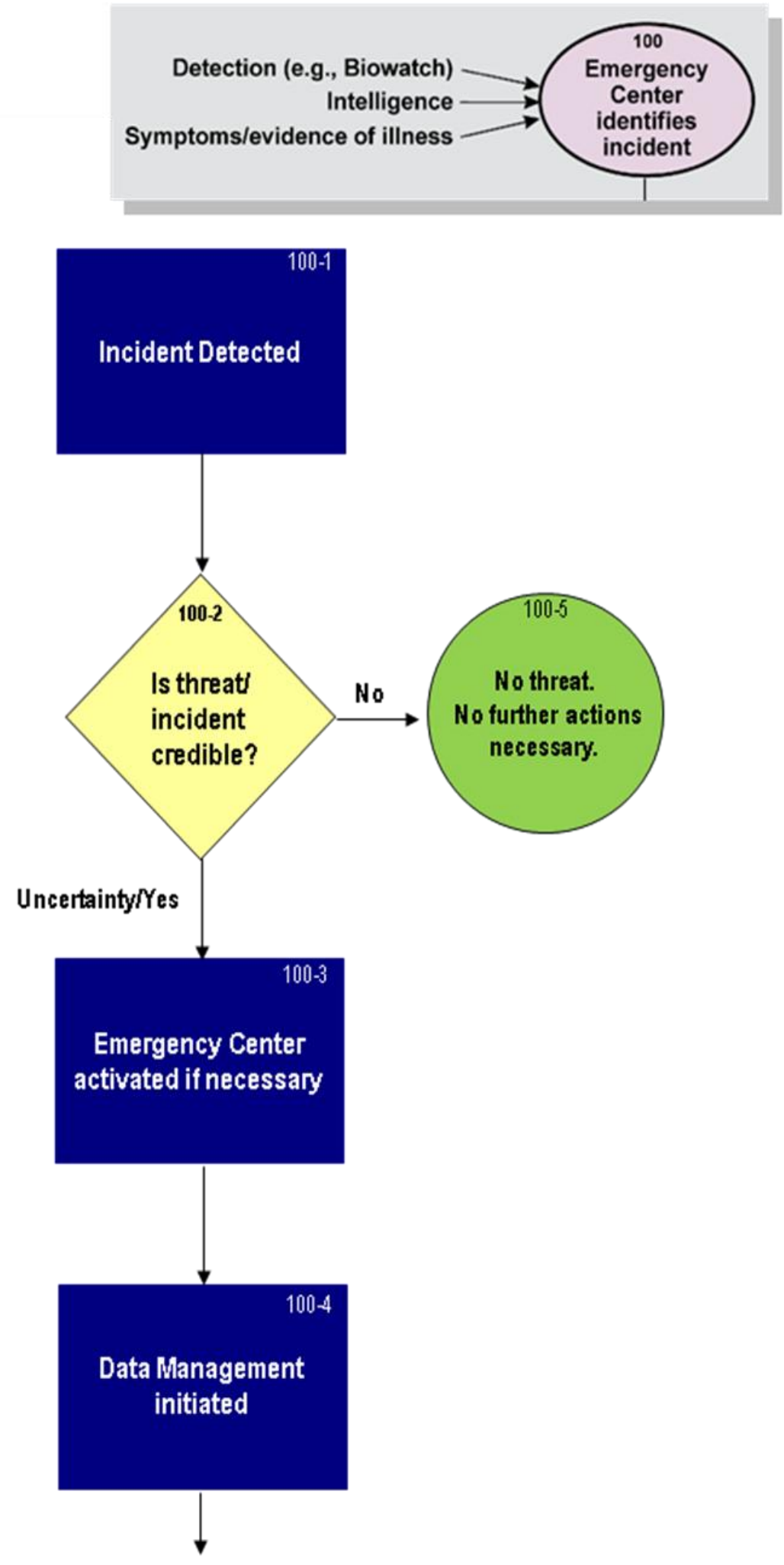

101 


\section{Expanded Framework}

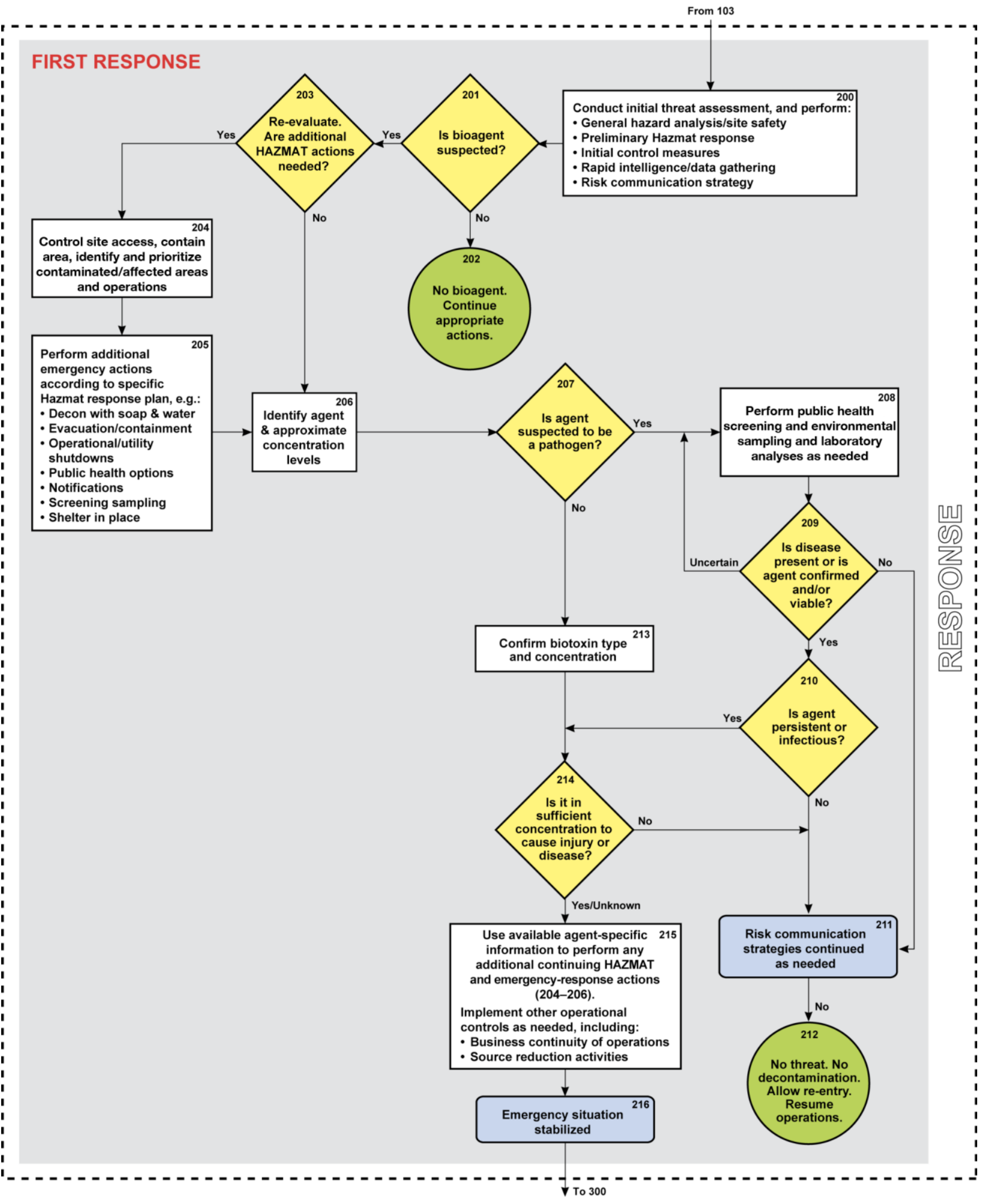




\section{Expanded Framework}

\section{FIRST RESPONSE (204 Expanded)}

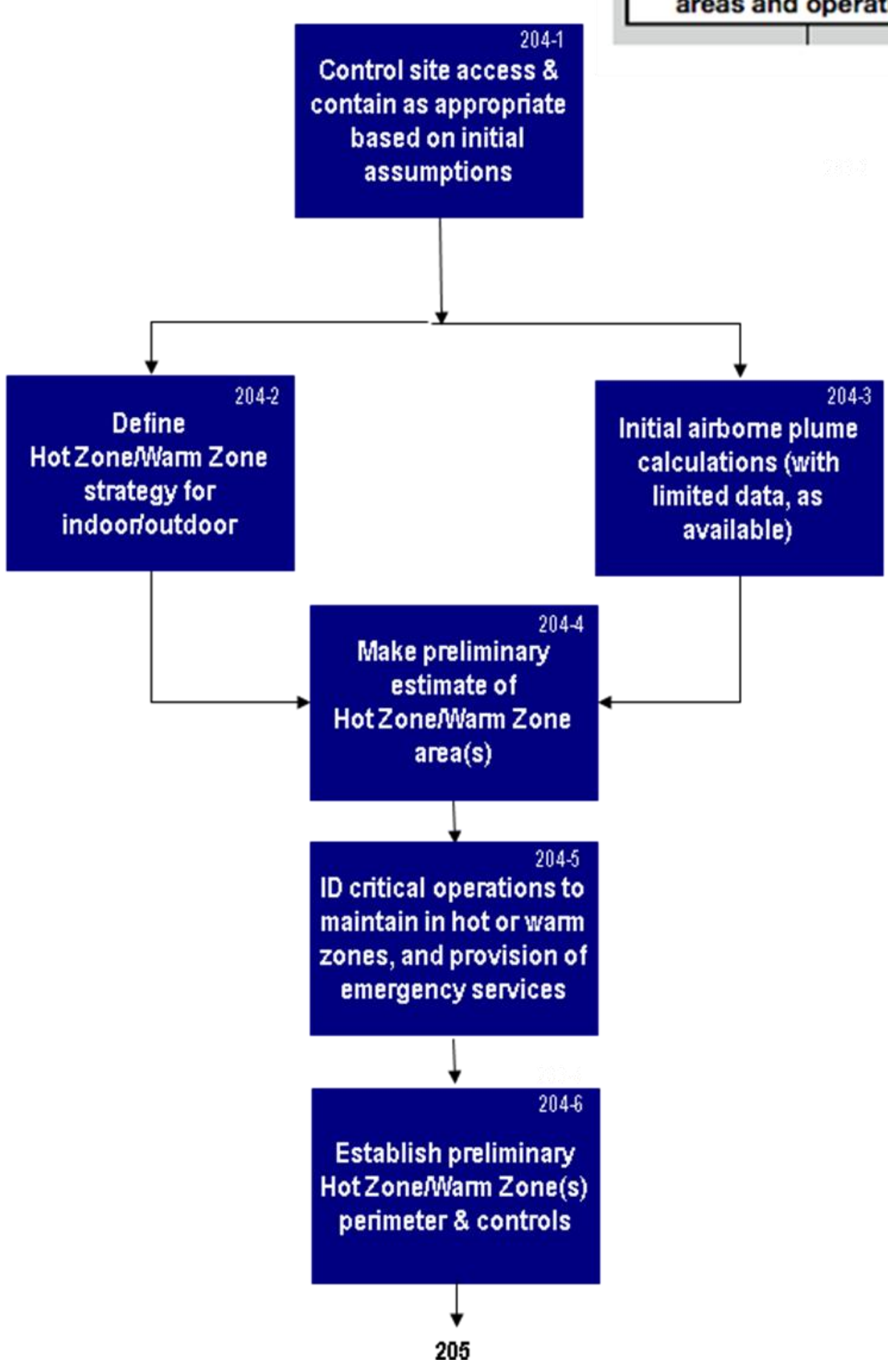




\section{Expanded Framework}

\section{FIRST RESPONSE (208 Expanded)}

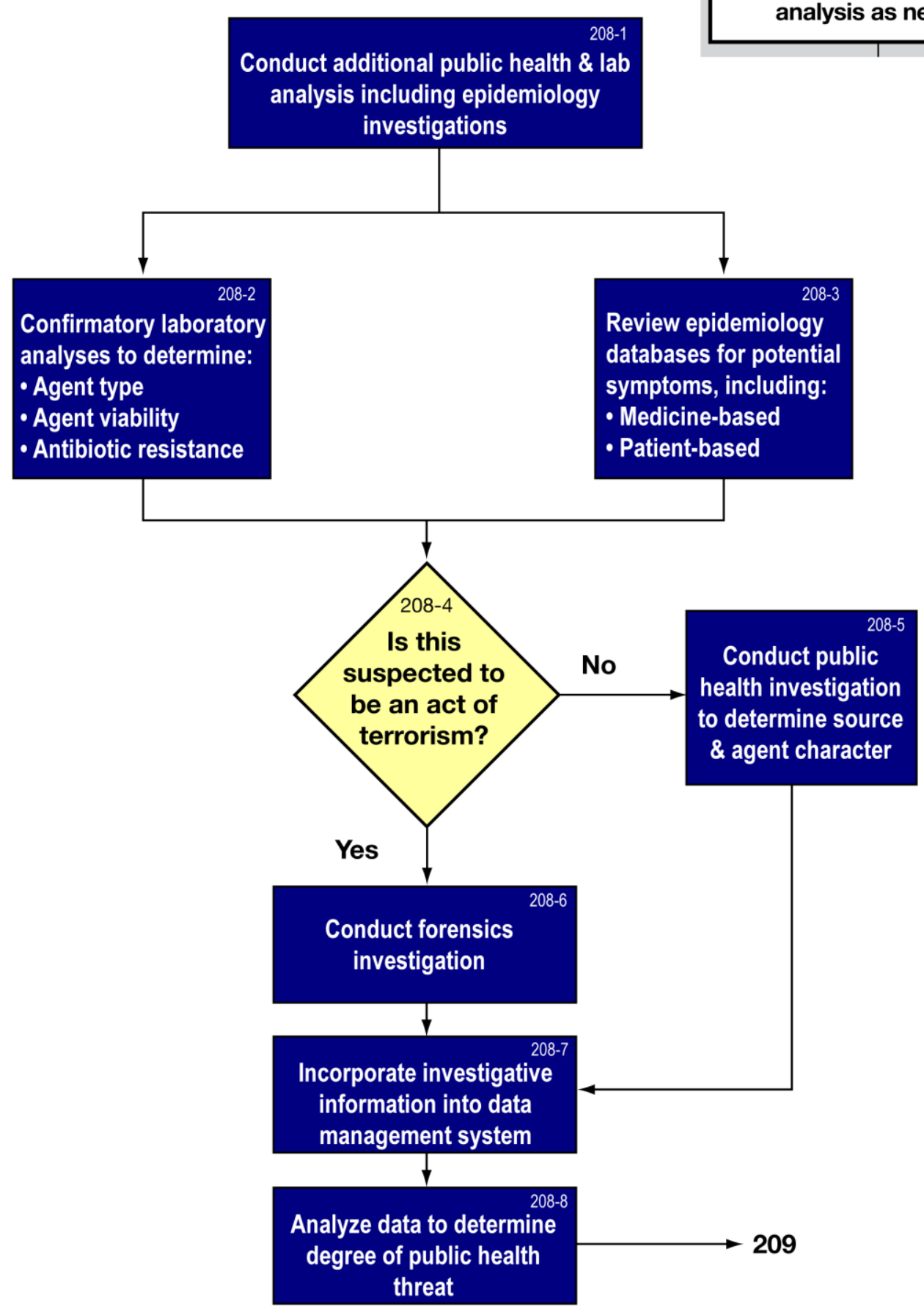

Perform public health screening and environmental sampling and laboratory analysis as needed 


\section{Expanded Framework}

\section{FIRST RESPONSE (215 Expanded)}

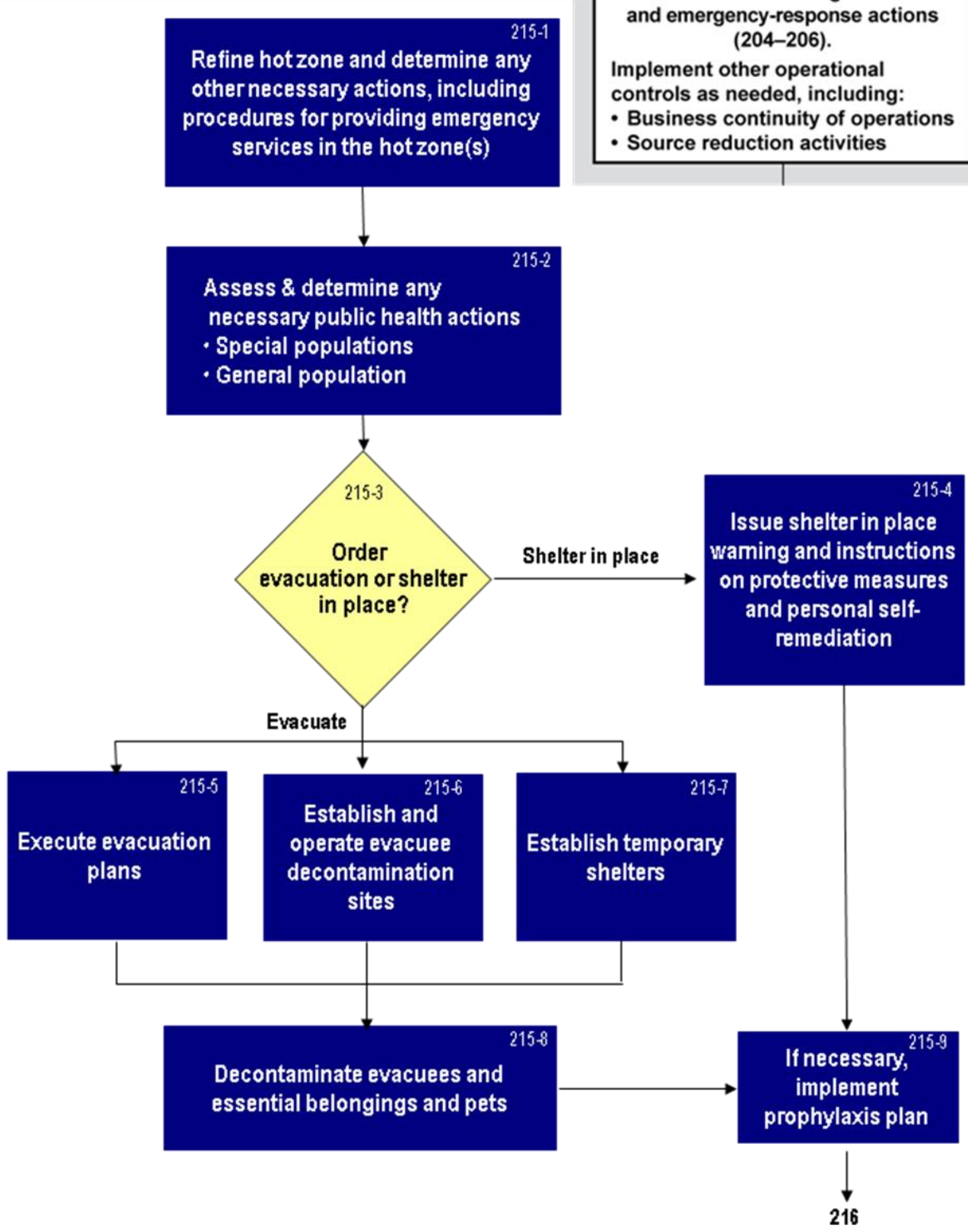
information to perform any additional continuing HAZMAT and emergency-response actions (204-206). controls as needed, including:

Business continuity of operations

Source reduction activities
Use available agent-specific 215

Implement other operational

15




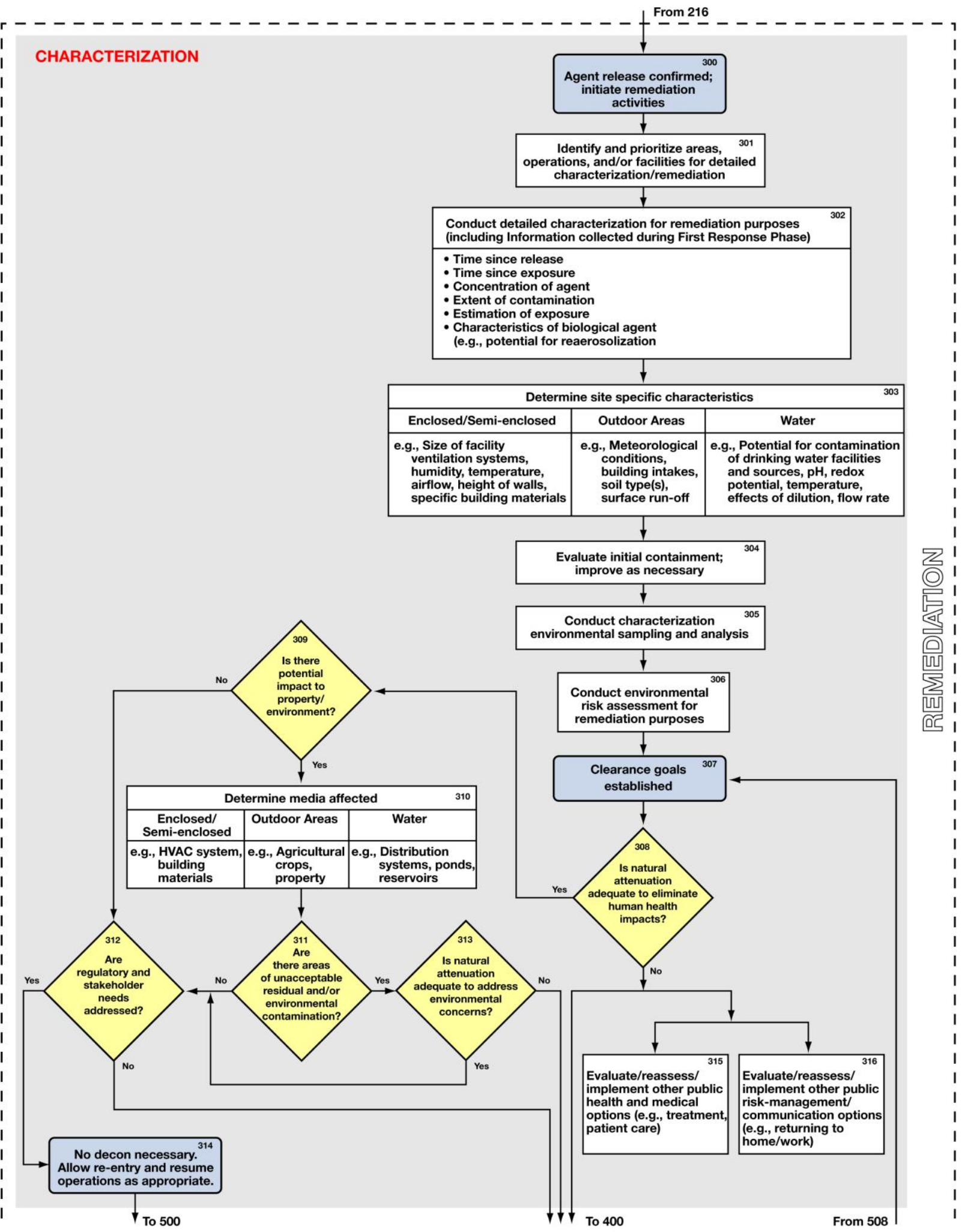




\section{Expanded Framework}

\section{CHARACTERIZATION (301 expanded)}

Identify and prioritize areas,

301

operations, and/or facilities for detailed characterization/remediation

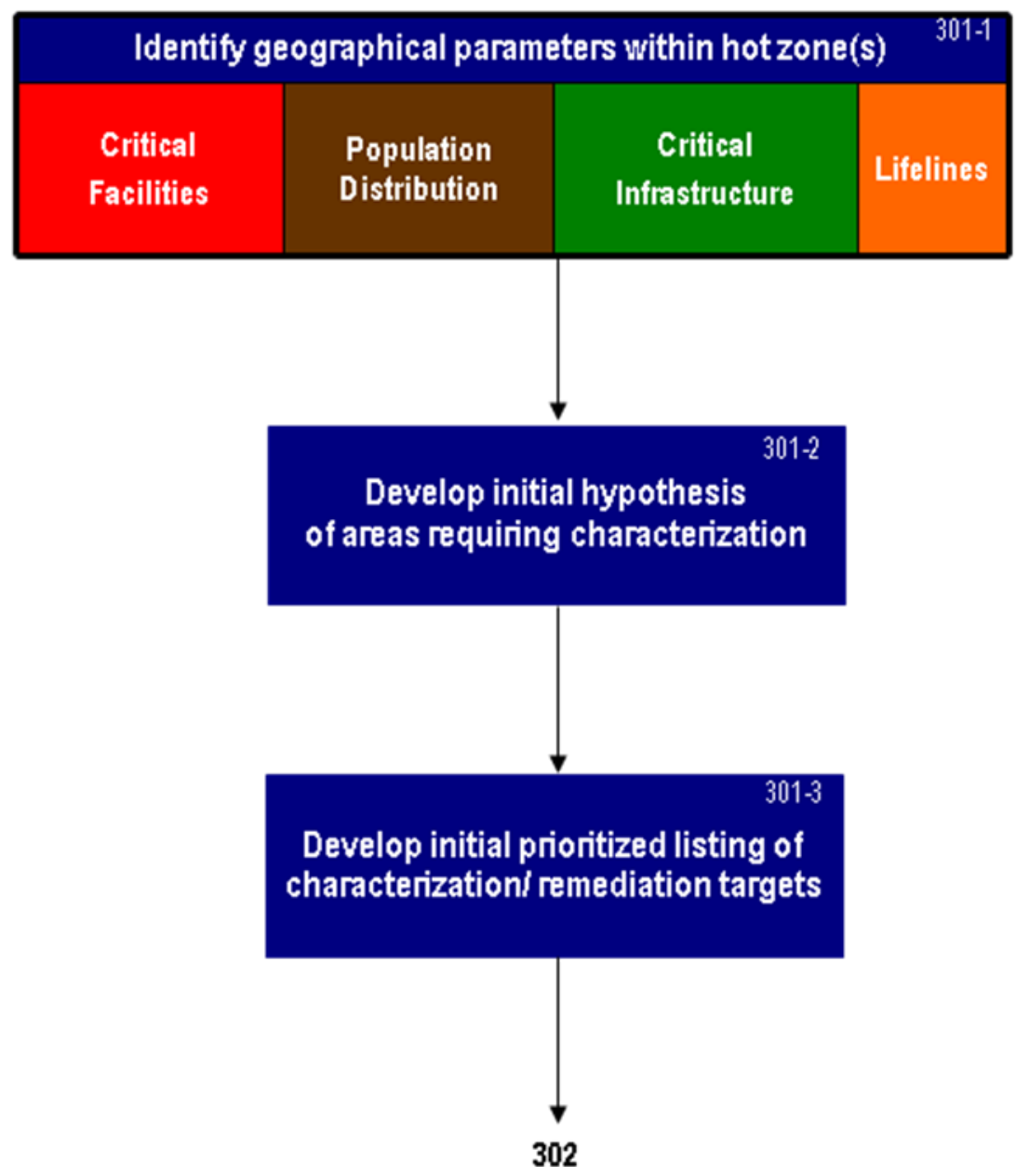




\section{Expanded Framework}

\section{CHARACTERIZATION (302 expanded)}

Conduct detailed characterization for remediation purposes (including Information collected during First Response Phase)

- Time since release

- Time since exposure

- Concentration of agent

- Extent of contamination

- Estimation of exposure

- Characteristics of biological agent

(e.g., potential for reaerosolization)

Gathericollect information from

first response (e.g., time since release, concentration maps, characteristics of agent)

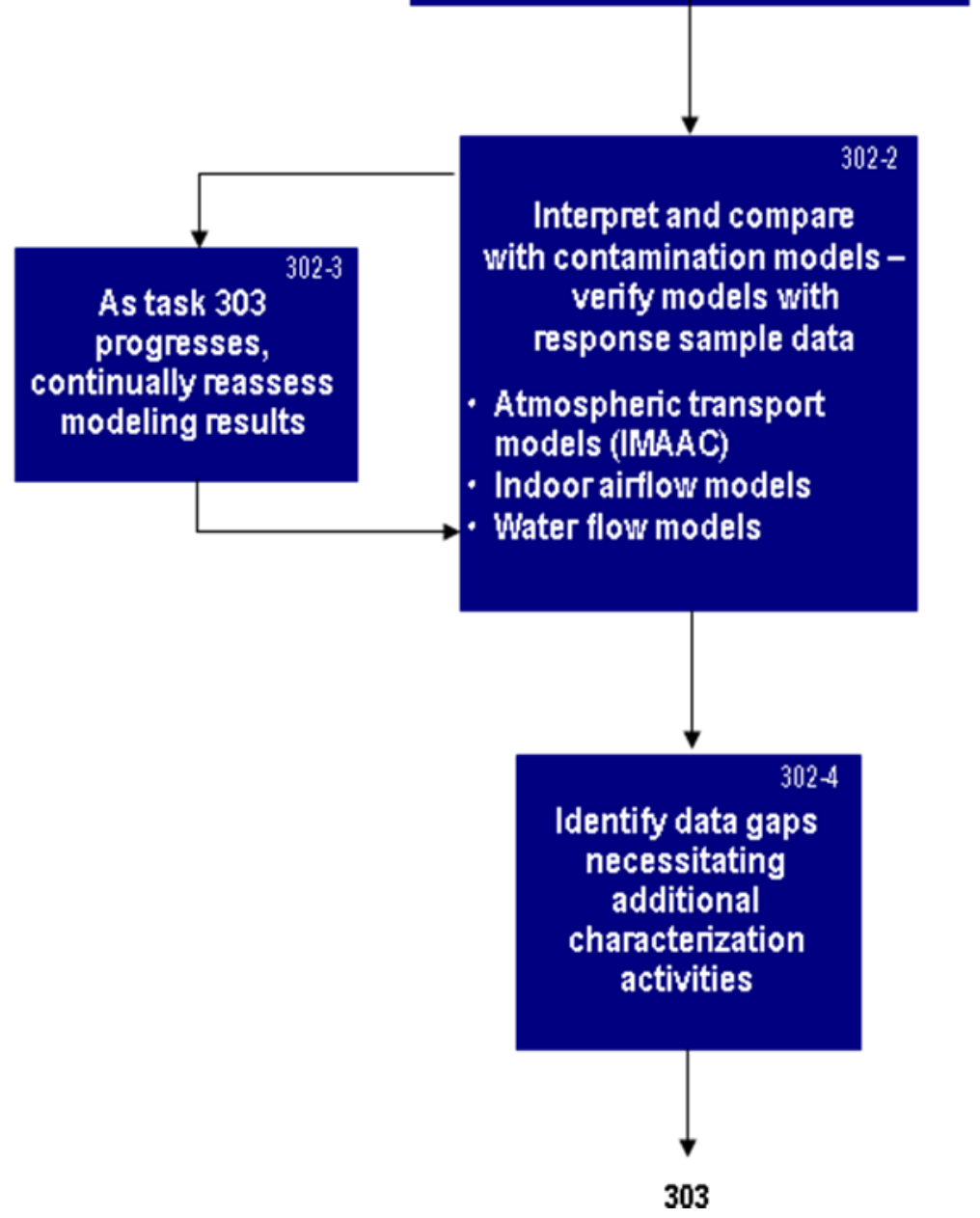




\section{Expanded Framework}

\section{CHARACTERIZATION (303 expanded)}

\begin{tabular}{|c|c|c|}
\hline \multicolumn{3}{|c|}{ Determine site specific characteristics } \\
\hline Enclosed/Semi-enclosed & Outdoor Areas & Water \\
\hline $\begin{array}{c}\text { e.g., Size of facility } \\
\text { ventilation systems, } \\
\text { humidity, temperature, } \\
\text { airflow, height of walls, } \\
\text { specific building materials }\end{array}$ & $\begin{array}{c}\text { e.g., Meteorological } \\
\text { conditions, } \\
\text { building intakes, } \\
\text { soil type(s), } \\
\text { surface run-off }\end{array}$ & $\begin{array}{c}\text { e.g., Potential for contamination } \\
\text { of drinking water facilities } \\
\text { and sources, pH, redox } \\
\text { potential, temperature, } \\
\text { effects of dilution, flow rate }\end{array}$ \\
\hline
\end{tabular}

Determine contamination vulnerabilities and characteristics for all components within affected areas based on understanding of transport mechanisms

\begin{tabular}{|c|c|c|}
\hline $\begin{array}{l}\text { Enclosed/Semi-enclosed } \\
\text { structures }\end{array}$ & Outdoor Areas & Water \\
\hline $\begin{array}{l}\text { - Exposure pathways } \\
\text { - Facility transport systems } \\
\text { - Porousinonporous } \\
\text { surface areas } \\
\text { - Characteristics of } \\
\text { materials } \\
\text { - Soil presence } \\
\text { - Potential contamination } \\
\text { reservoirs }\end{array}$ & $\begin{array}{l}\text { - Soil types } \\
\text { - Surfaces } \\
\text { - Vegetation } \\
\text { - Environmental } \\
\text { conditions } \\
\text { - Transport } \\
\text { mechanisms } \\
\text { - Reaerosolization } \\
\text { potential }\end{array}$ & $\begin{array}{l}\text { - All connections and components of the } \\
\text { drinking water system } \\
\text { - All connections and components of the } \\
\text { surface water handling system, to include } \\
\text { runoff maps and flow rates } \\
\text { - Physico-chemical characteristics of water in } \\
\text { both drinking water and runoff systems } \\
\text { - All connections and components of the } \\
\text { waste water system }\end{array}$ \\
\hline
\end{tabular}

$303-2$

Compile a list of geographically located potential contamination sites

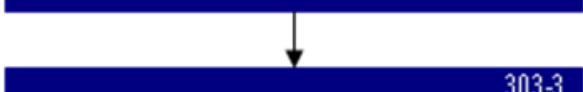

Map potential contamination sites, lifelines, and residual population

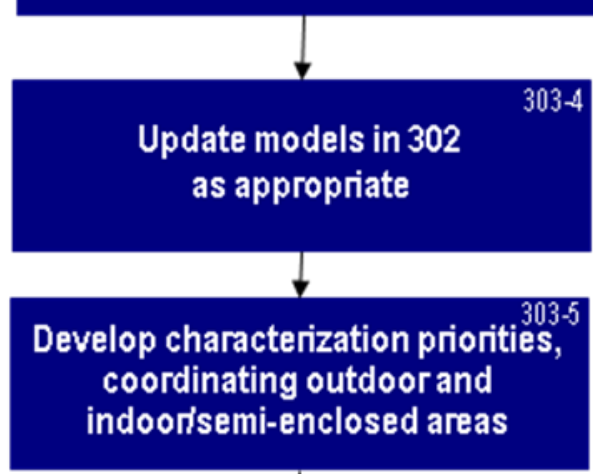

coordinating outdoor and

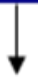

304 


\section{Expanded Framework}

\section{CHARACTERIZATION (304 expanded)}
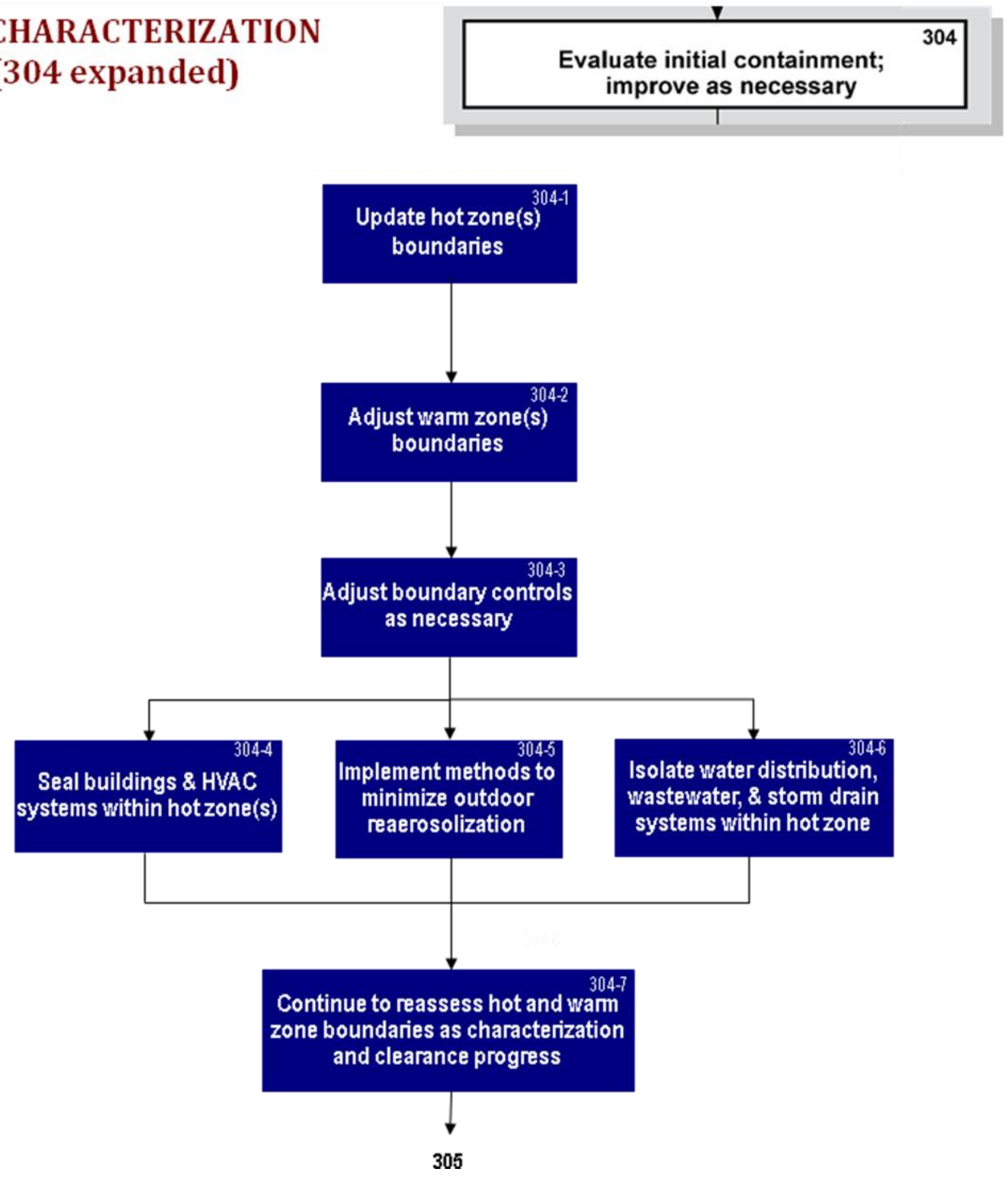


\section{Expanded Framework}

\section{CHARACTERIZATION (305 expanded)}

Conduct characterization environmental sampling and analysis

Develop comprehensive characterization sampling strategies

- Consider a phased approach to rapidly refine the limits of contamination

- Develop data quality objectives

- Consider statistical and judgmental criteria

- Employ iterative modeling approach to optimize sampling

- Establish minimum characterization sampling requirements

- Consider employing a zonal approach for sampling

- Consider surface, ari, and forced air sampling

- Address all necessary information requirements for risk assessment (including inhalationalçutaneous, or gastrointestinal risks)

$\downarrow$

\section{Write incident specific}

Characterization Sampling andAnalysis Plan(s) (SAP)

- Select sampling methods

- Select sampling locations

- Select analytical methods

- Identify resource limitations and optimize implementation
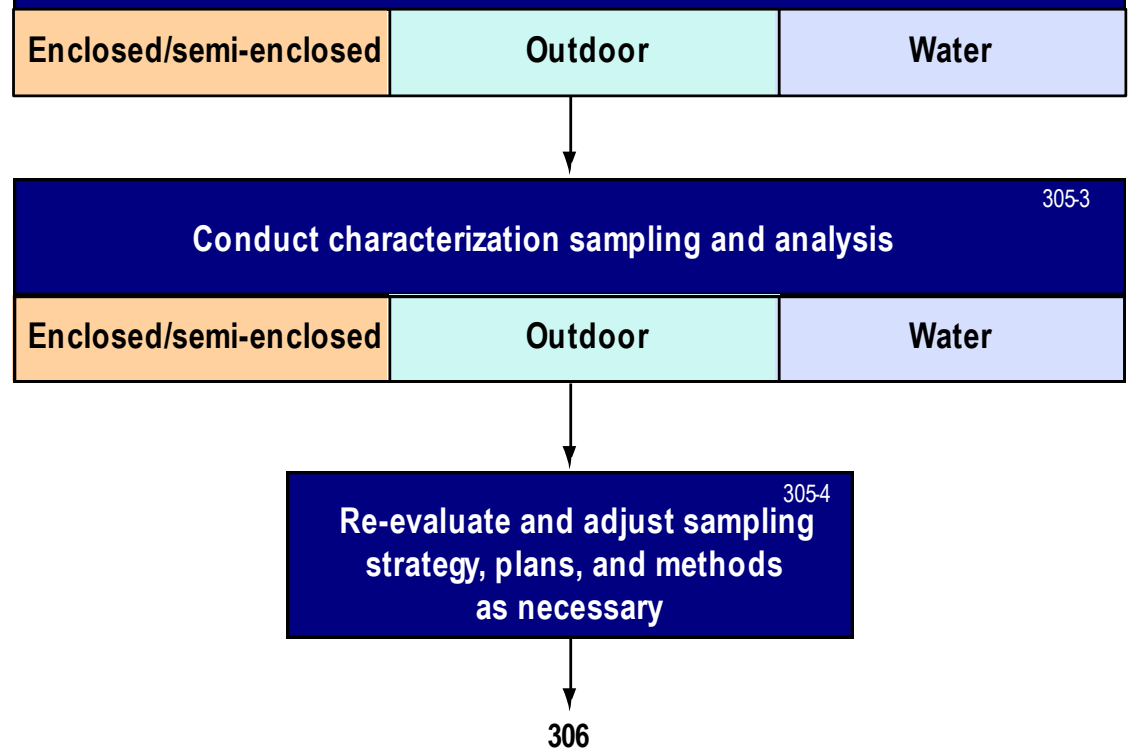


\section{Expanded Framework}

\section{CHARACTERIZATION (306 expanded)}
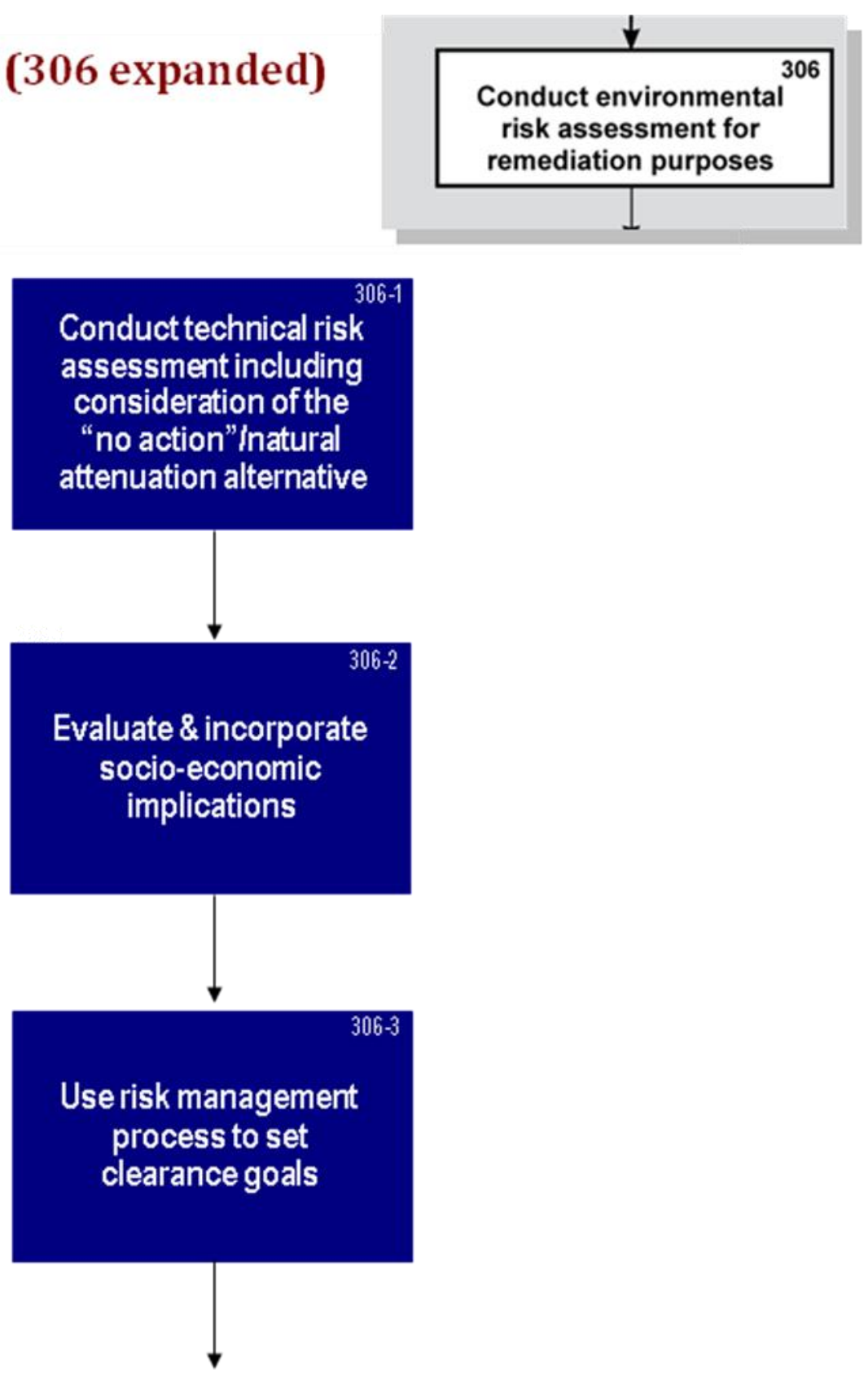

307 


\section{Expanded Framework}

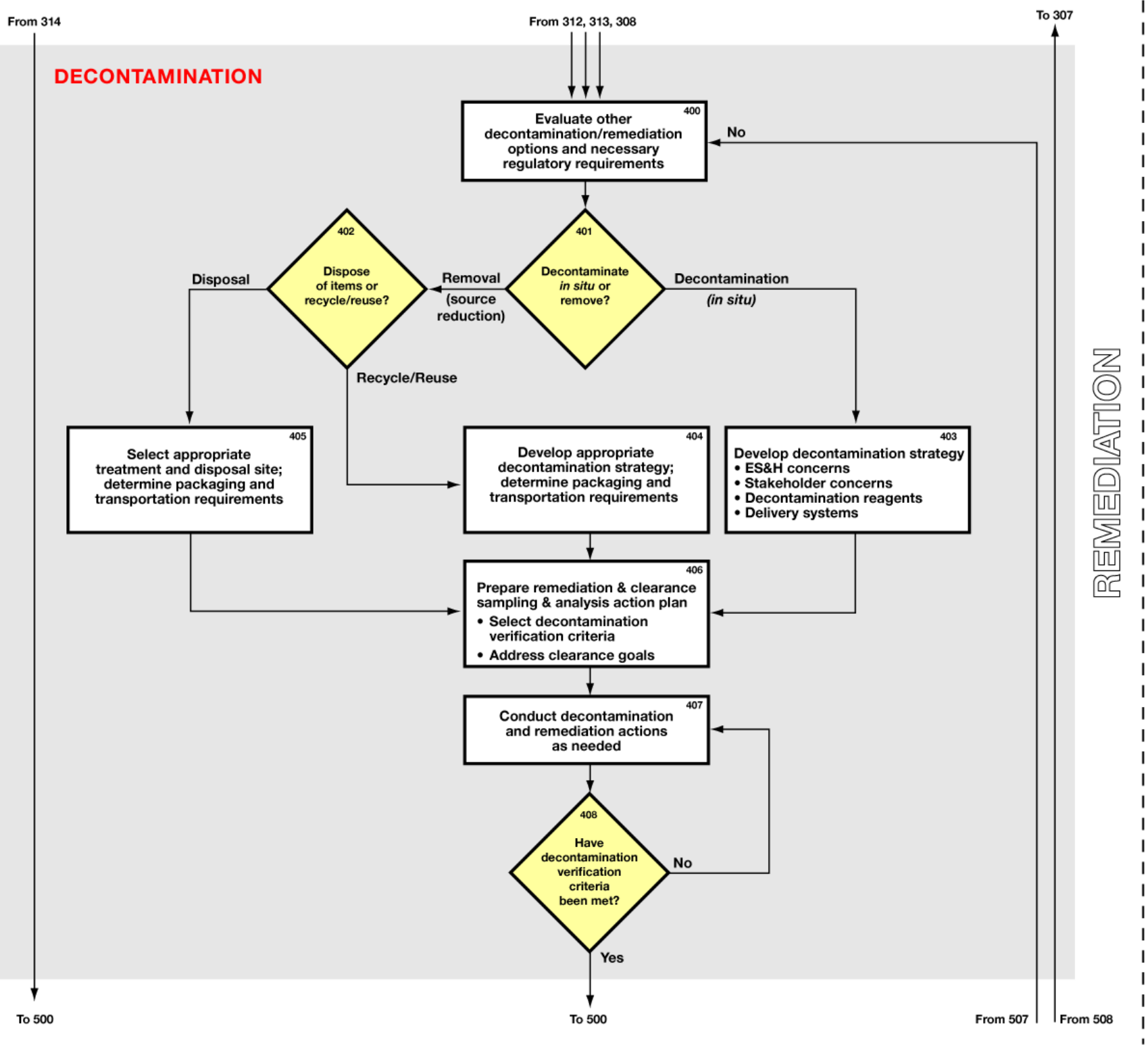




\section{Expanded Framework}

\section{DECONTAMINATION (expanded 400)}

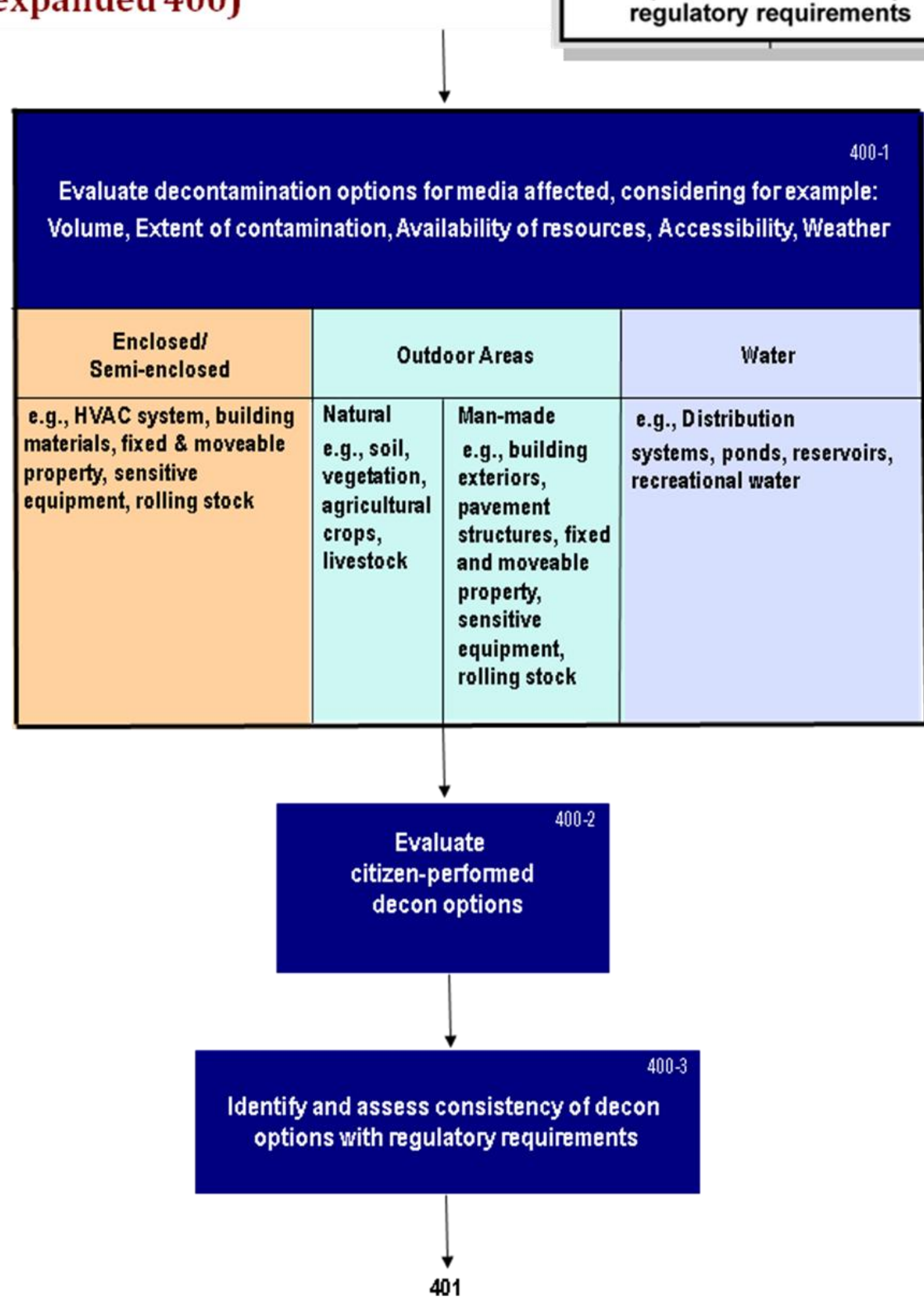




\section{Expanded Framework}

\section{DECONTAMINATION (expanded 403)}

Develop decontamination strategy

- ES\&H concerns

- Stakeholder concerns

- Decontamination reagents

- Delivery systems

Select decontamination methods including specific reagents and reagent delivery

systems for media affected, considering for example:

Volume, Extent of contamination, Availability of resources, Accessibility, Weather

\begin{tabular}{|c|c|c|c|}
\hline $\begin{array}{c}\text { Enclosed/ } \\
\text { Semi-enclosed }\end{array}$ & \multicolumn{2}{|c|}{ Outdoor Areas } & Water \\
\hline \multirow[t]{2}{*}{$\begin{array}{l}\text { e.g., HUAC system, building } \\
\text { materials, fixed and moveable } \\
\text { property, sensitive equipment, } \\
\text { rolling stock } \\
\text { Considering: } \\
\text { - Surface treatment } \\
\text { - Volumetric methods }\end{array}$} & $\begin{array}{l}\text { Natural } \\
\text { e.g., soil, } \\
\text { vegetation, } \\
\text { agricultural } \\
\text { crops, } \\
\text { livestock }\end{array}$ & $\begin{array}{l}\text { Man-made } \\
\text { e.g., building } \\
\text { exteriors, } \\
\text { paventent } \\
\text { structures, fixed } \\
\text { and moveable } \\
\text { property, } \\
\text { sensitive } \\
\text { equipment, } \\
\text { rolling stock }\end{array}$ & \multirow{2}{*}{$\begin{array}{l}\text { e.g., Distribution } \\
\text { systems, ponds, reservoirs, } \\
\text { recreationalwater } \\
\text { Considering: } \\
\text { - Treatment } \\
\text { - No treatment and } \\
\text { monitor }\end{array}$} \\
\hline & \multicolumn{2}{|c|}{$\begin{array}{l}\text { Considering: } \\
\text { - Localized treatment } \\
\text { - Wide area treatment } \\
\text { - Wash down and treat }\end{array}$} & \\
\hline
\end{tabular}

Develop emergency response plans to address potential uncontrolled reagent release(s)

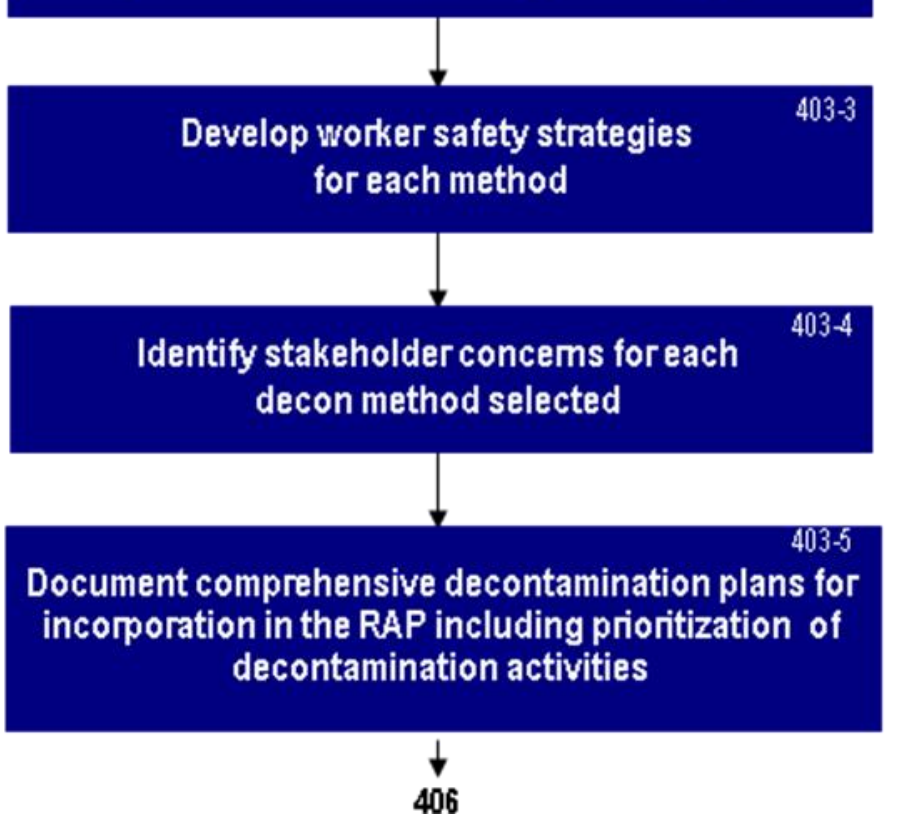




\section{Expanded Framework}

DECONTAMINATION (expanded 404)
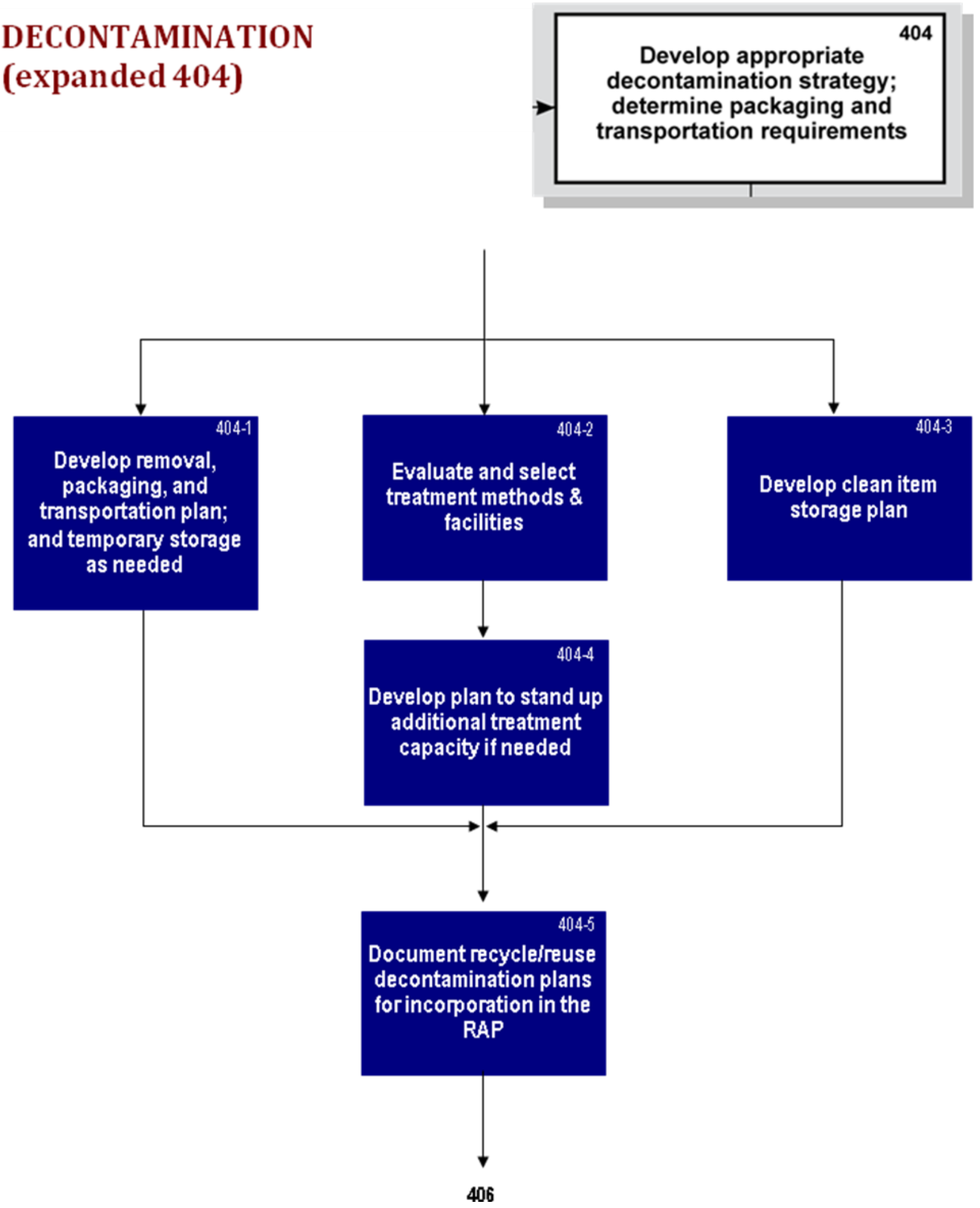


\section{Expanded Framework}

\section{DECONTAMINATION (expanded 405)}
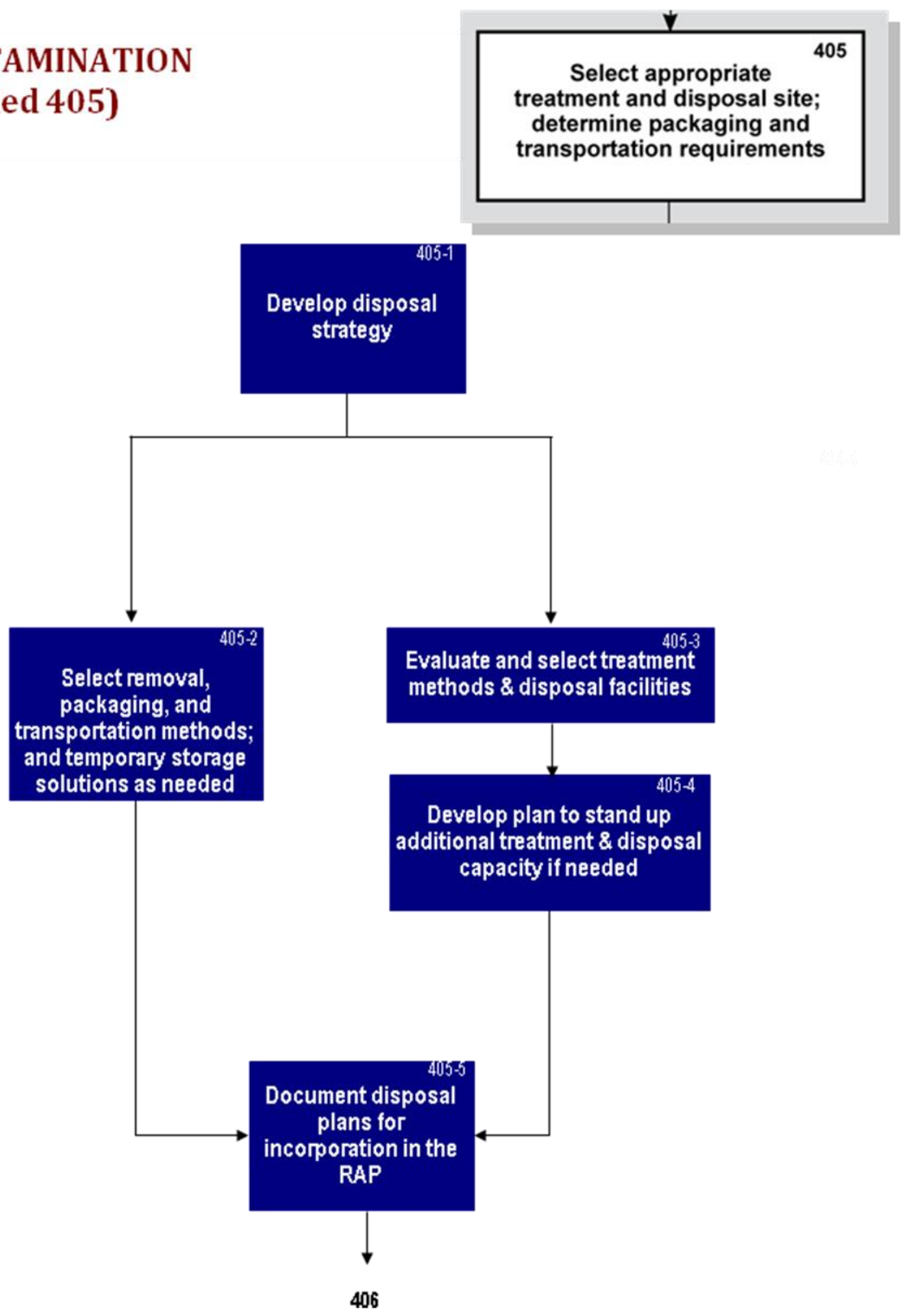


\section{Expanded Framework}

\section{DECONTAMINATION (expanded 406)}
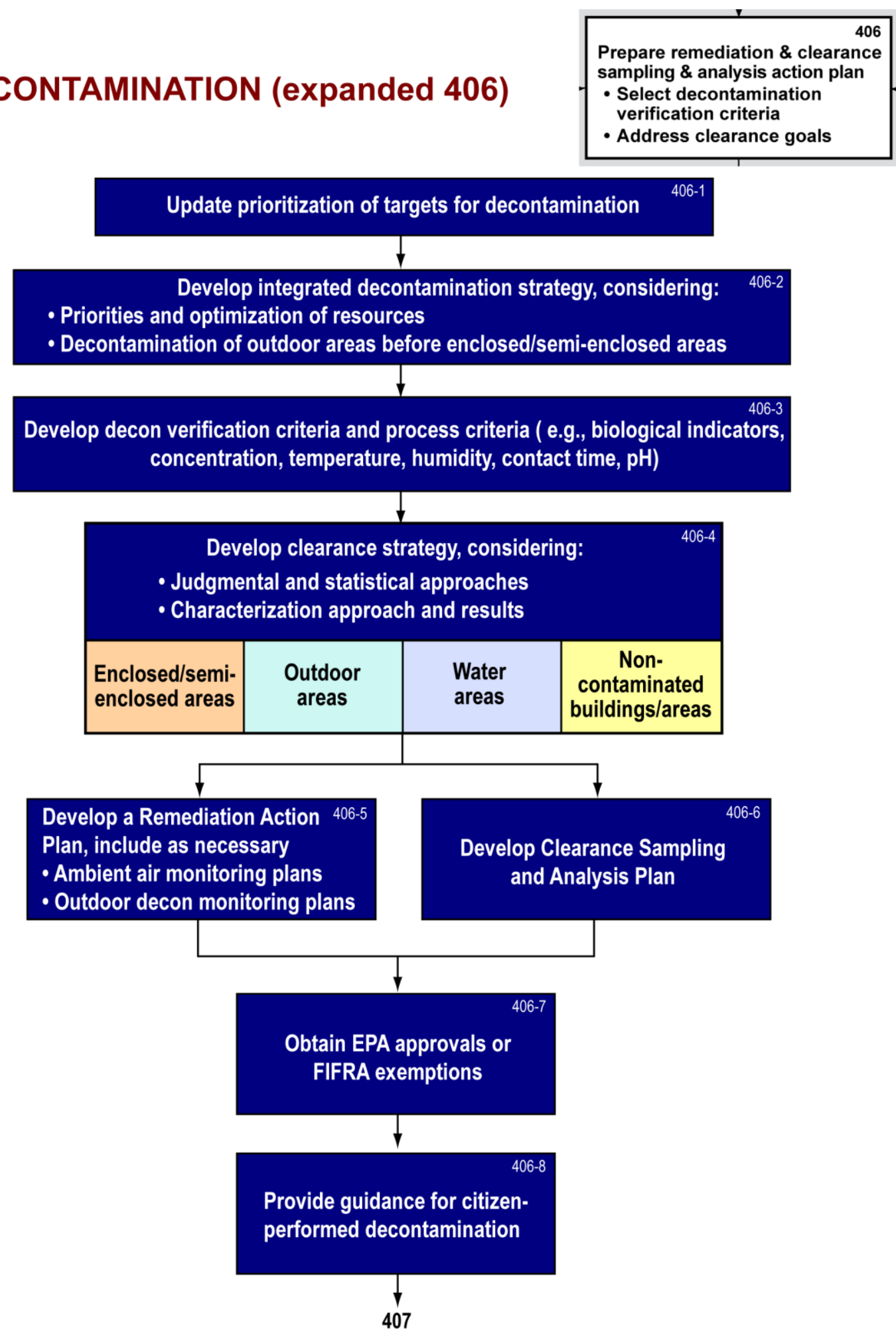


\section{Expanded Framework}

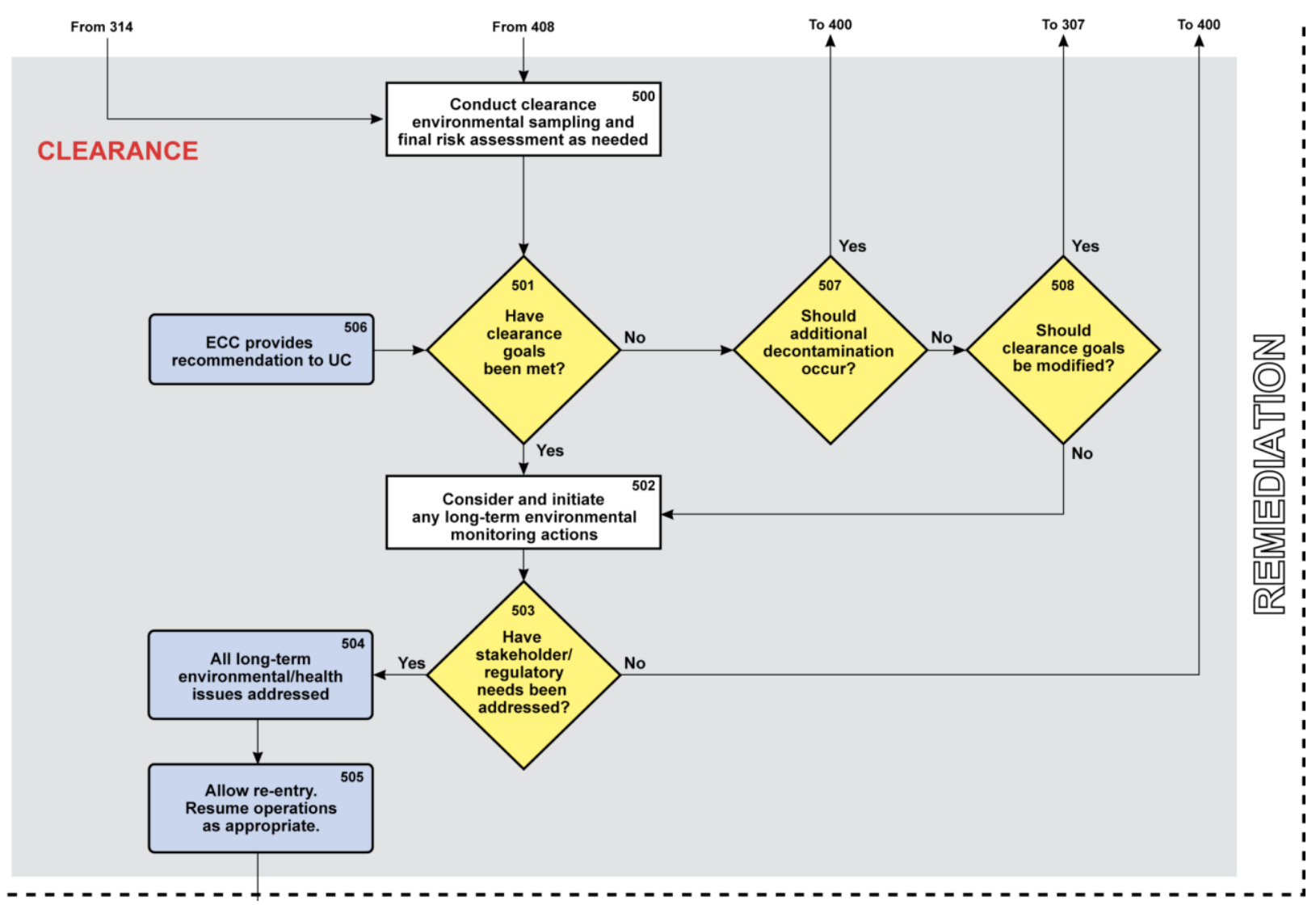




\section{Expanded Framework}

\section{CLEARANCE (expanded 500)}

Conduct clearance environmental sampling and final risk assessment as needed
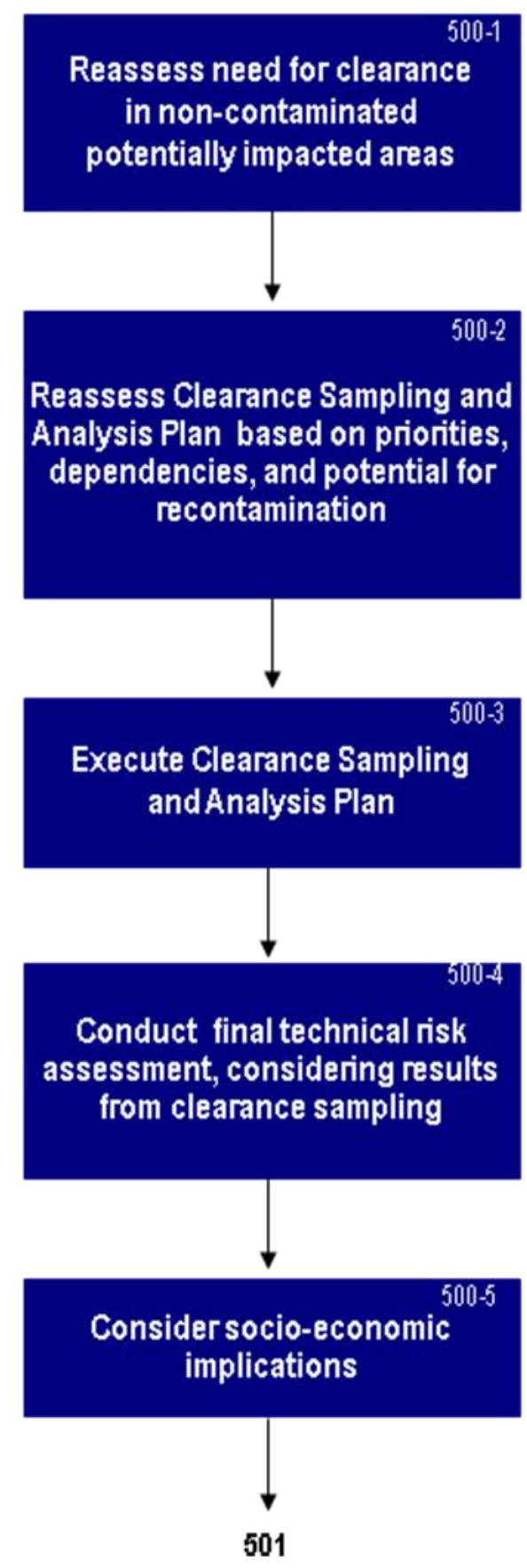


\section{Expanded Framework}

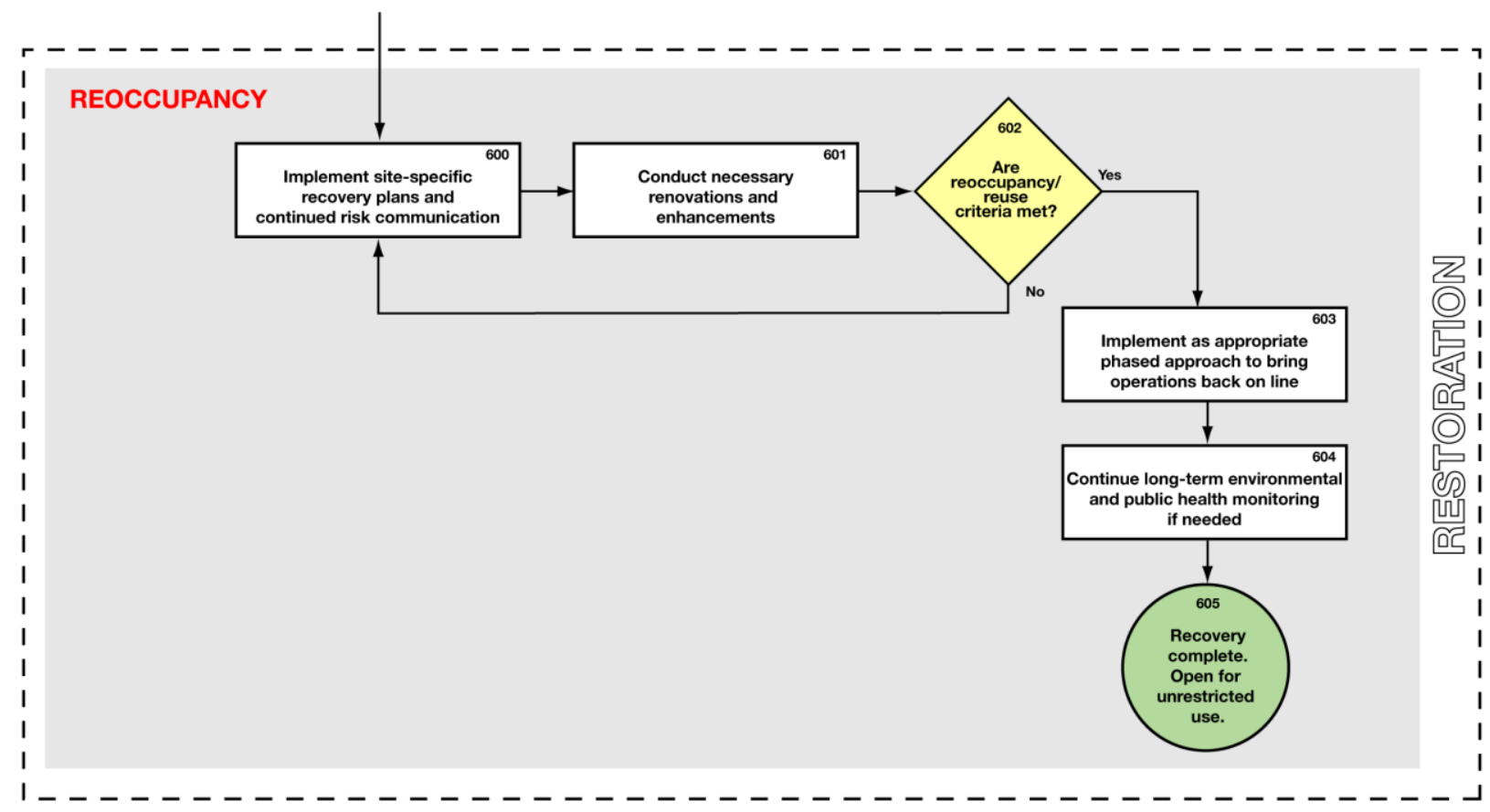




\section{Expanded Framework}

REOCCUPANCY

(expanded 604)
604

Continue long-term environmental and public health monitoring if needed

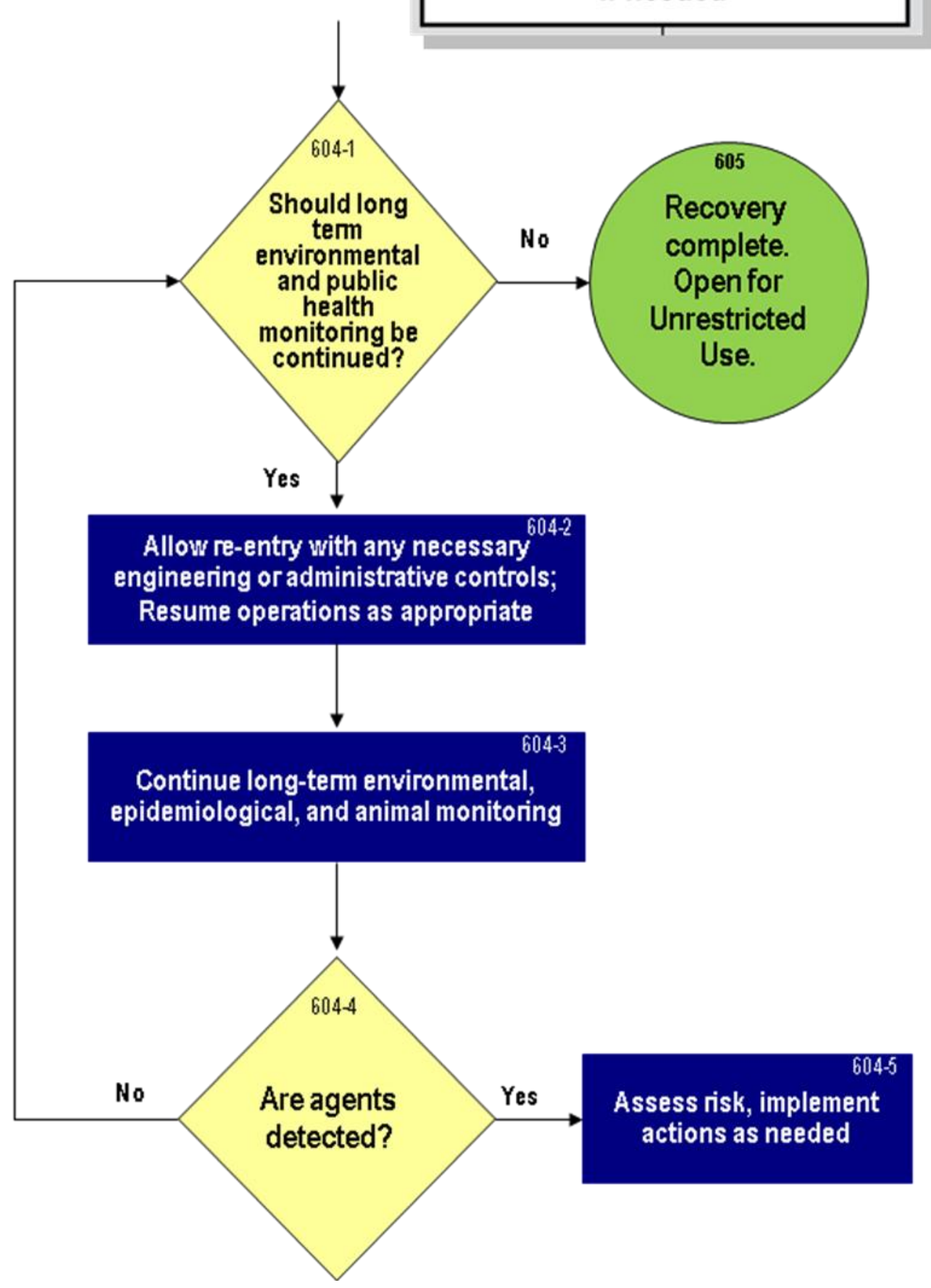




\section{Glossary}

Aggressive air sampling. Any method used to agitate particulates or fibers that may have settled out of the air or that could easily become airborne because of human activity (usually the use of high-powered fans or leaf blowers). The air should be agitated either during the entire time that an air sample is being collected or at regular intervals during the sampling period. Aggressive air sampling gives the most conservative of worst-case results of a given contaminant in indoor air. The Agency for Toxic Substances and Disease Registry (ATSDR) recommends that such sampling be performed because it is difficult to interpret surface-wipe sampling data for health purposes (DHHS 1994).

Ambient Air Monitoring Plan (AAMP). A written plan required by the U.S. Environmental Protection Agency as part of the crisis exemption process for using an unregistered sterilant or pesticide, such as a gaseous fumigant. The plan for monitoring ambient air is designed to ensure that the fumigant does not escape a facility in concentrations that may be a hazard to the surrounding population. (See also FIFRA exemption.)

Antimicrobial agent. An agent that kills or suppresses the growth of microorganisms. (Block 2001; DHS/EPA 2009.)

Area Command (Unified Area Command). An organization established (1) to oversee the management of multiple incidents that are each being handled by an Incident Command System (ICS) organization or (2) to oversee the management of large or multiple incidents to which several Incident Management Teams have been assigned.

Area Command becomes Unified Area Command when incidents are multi-jurisdictional. Area Command may be established at an Emergency Operations Center (see EOC) facility or at some location other than an Incident Command Post (see ICP). (DHS, December 2007.)

Anthrax. A non-contagious, infectious, often fatal, naturally occurring disease caused by the bacterium Bacillus anthracis that may be contracted by humans or animals via exposure through inhalation, the skin, or the gastrointestinal tract. (DHS/EPA 2009.)

Bacillus anthracis (B. anthracis). A spore-forming bacterium that causes anthrax. The spore form is about 1 by 2 microns in size and can easily be inhaled. In a warm, moist environment (such as the lungs), spores grow into vegetative, rod-shaped cells that multiply and cause hemorrhage, edema, and necrosis in humans and animals. (DHS/EPA 2009.)

BASIS Program. An environmental monitoring system originally designed for use at the 2002 Winter Olympics. Biological Aerosol Sentry and Information System (BASIS) is a joint project of two U.S. national laboratories, with participation of law enforcement and public health organizations. It uses a network of inexpensive sampling stations to collect and store aerosol samples. Couriers regularly bring samples to a central laboratory where they are analyzed for selected pathogens. Similar monitoring systems have been developed and deployed by the U.S. Department of Defense. (Fitch et al. 2003.)

Biohazard Safety Level (BSL). Different biosafety levels developed for microbiological and biomedical laboratories provide increasing levels of personnel and environmental protection from pathogenic microorganisms and hazardous subcellular entities (e.g., prions). Accordingly, laboratories may be classified as BSL-1, BSL-2, BSL3 or BSL-4, ranked from lowest to highest in degree of safety level. (DHS/EPA 2009.)

Biological incident. A natural or human-caused incident involving microbiological organisms (bacteria, fungi, and viruses) or biologically derived toxins that pose a hazard to humans, animals, or plants. (DHS/EPA 2009.)

Biological indicator (BI). A standardized preparation of bacterial spores on or in a carrier serving to demonstrate whether sterilizing conditions have been met. Spores of different organisms are used for different methods of sterilization. (Block, 2001)

Biological warfare agent (BWA). A microorganism (bacteria, fungi, and viruses) or biologically derived toxin that is intentionally introduced to cause disease or harm in humans, animal, or plants. Per Title 18 USC $\S 178$, any biological material capable of causing death, disease, or other biological malfunction in a human, animal, plant, or another living organism; or causing deterioration of food, water, equipment, supplies, or material of any kind; or causing harmful alteration of the environment.

BioWatch Program. BioWatch is an early-warning system that can rapidly detect trace amounts of biological materials in the air whether arising from intentional release or minute quantities that are naturally in the air. The 
system is patterned after the Biological Aerosol Sentry and Information System (BASIS) environmental monitoring system. It operates nationwide and focuses on major urban centers. See also BASIS. (DHS BioWatch website and Fitch et al. 2003.)

Bulk sampling. Environmental sampling done by collecting a volume (or mass) of material such as soil, water, rubber, acoustic tile, or concrete.

CERCLA. The Comprehensive Environmental Response, Compensation, and Liability Act (42 USC 9601 et seq.), as amended by the Superfund Amendments and Reauthorization Act of 1986. CERCLA authorizes the President and EPA (by delegation from the President) to respond to releases or substantial threats of releases of pollutants or contaminants that may present an imminent and substantial danger to the public health or welfare.

Characterization. The process of obtaining specific information about a biological agent, such as its identity, genetic composition, formulation, physical properties, toxicological properties, ability to aerosolize, and persistence in the environment as a viable form, and about the nature and extent of contamination of the agent, such as locations or items contaminated and the amount of contamination. Characterization of the agent and of the contamination at an affected site generally occurs after First Response and before Decontamination. (DHS/EPA 2009.)

Characterization environmental sampling. Environmental sampling intended to assess the nature (identity and properties) and extent (location and quantity) of contamination of an area or items. Generally occurs after First Response and before Decontamination. (DHS/EPA 2009.)

Characterization zone. A discrete section of a contaminated site that is examined for the purpose of determining the potential for exposure to the contaminant in that area. (DHS/EPA 2009.)

Cleanup. The process of characterizing, decontaminating, and clearing a contaminated site or items, including disposal of wastes. Cleanup is a synonym for remediation. Generally occurs after characterization and before clearance. (DHS/EPA 2009.)

Clearance. The process of determining that a clearance goal has been met for a specific contaminant at a specific site or on an item. Clearance generally occurs after decontamination and before reoccupancy. Clearance typically includes environmental sampling together with analysis of data by subject-matter experts (such as an Environmental Clearance Committee) and stakeholders to ensure that all long-term health and environmental issues are addressed.

Clearance criteria or clearance decision criteria. A defined process for determining whether clearance goals have been met. The process should ensure that exposure guidelines are met with a level of confidence that is acceptable to stakeholders. (DHS/EPA 2009.)

Clearance/Cleanup goal. An amount of residual contamination for a specific contaminant in or on an area or item that, once achieved following decontamination, provides acceptable protection to human health and the environment. A clearance goal specifies criteria for determining the success of decontamination that are measurable and for permitting unprotected reentry. (DHS/EPA 2009.)

Clearance environmental sampling. Environmental sampling that is conducted after the decontamination process is completed for a specific contaminant in an area or on items, and is intended to provide a basis for determining whether the clearance goal has been met. (DHS/EPA 2009.)

Clearance Environmental Sampling and Analysis Plan (Clearance SAP). A formal, written plan that describes how clearance sampling will be done, including the rationale for the clearance sampling design. It specifies the clearance decision criteria, that is, how the clearance sampling results will be used to determine whether clearance goals have been met. The Clearance SAP is a companion to the Remediation Action Plan (RAP), and is required before the RAP is executed.

Clearance zone. A section or subsection of a contaminated site for which a clearance decision is made.

Cold zone. See staging area. Also called the clean zone, per Hazardous Waste Operations and Emergency Response (HAZWOPER).

Concept of Operations (ConOps). A formal plan that describes the roles, responsibilities, and relationships of organizations involved in a response to a contaminated area or items. Typically, a CONOPS addresses Federal, State, local and Tribal agencies and how they should interact when responding to a potential or actual terrorist threat or incident. (DHS/EPA 2009.)

Consequence Management. Predominantly an emergency management function that includes measures to protect public health and safety; restore essential government services; and provide emergency relief to governments, businesses, and individuals affected by the consequences of terrorism (DHS, December 2008). Includes Remediation (i.e., Characterization, Decontamination, Clearance) and Restoration and Reoccupancy activities (see 
six-phase Figure 1-3). (See also DHS/EPA 2009.) The requirements of consequence management and crisis management are combined in the National Response Framework (DHS 2008). See also Crisis Management.

Containment. In the context of this document, includes actions or measures taken to prevent the spread of a contaminant (biological warfare agent) from a particular zone or to prevent the movement of a contaminant within a zone. Compare with Isolation. This term is defined differently by different agencies. (DHS/EPA 2009.)

Contaminant reduction zone. The transition area between the exclusion and support zones where responders enter and exit the exclusion zone and where decontamination activities take place. Also called the Warm Zone. (EPA 2004.)

Covert release. In the context of this document, includes the intentional release of a biological warfare agent that is not reported or openly acknowledged by terrorists, or observed by surveillance systems, or witnessed by potential victims at the scene of release, and typically requiring epidemiological or medical observations to lead to the discovery of an agent's release.

Crisis Management. Predominantly a first-responder and law-enforcement function that includes measures to identify, acquire, and plan the use of resources needed to anticipate, prevent, and resolve a threat or act of terrorism. In the context of this document, includes measures that are predominantly first-responder and law-enforcement functions to resolve the immediate threat or act of terrorism. The requirements of consequence management and crisis management are combined in the National Response Framework (DHS 2007). See Consequence Management.

Culturing. In this document, growing microorganisms in a controlled, artificial environment. The CDC bacterial culture method is the definitive confirmatory test on environmental samples for positive identification of Bacillus anthracis spores upon which public health decisions are made.

Decision maker. A person charged with determining and directing appropriate actions in response to a potential or actual biological incident at a particular site. (DHS/EPA 2009.)

Decontamination. The process of inactivating or reducing a contaminant in or on humans, animals, plants, food, water, soil, air, areas, or items through physical, chemical, or other methods to meet a cleanup goal.

Decontamination applies to both disinfection and sterilization processes. Generally occurs as part of Remediation. (Note: Decontamination has been defined in different ways by different Federal agencies and other entities.) (DHS/EPA 2009.)

Decontamination area or zone. A section of a contaminated site that can be isolated from other areas and is decontaminated as a unit. (DHS/EPA 2009.)

Decontamination agent. A substance that is used to inactivate or reduce a contaminant on humans, animals, plants, or inanimate surfaces or in other media. If the contaminant is a microorganism, the chemical is an antimicrobial pesticide. (DHS/EPA 2009.)

Disinfectant. A chemical or physical agent that destroys pathogenic or other harmful microorganisms, but not bacterial spores on inanimate surfaces. (DHS/EPA 2009.)

Disinfection. The destruction of pathogenic and other kinds of microorganisms by physical (e.g., heat, desiccation, freezing, radiation) or chemical means. Disinfection is a less-lethal process than sterilization because it destroys most recognized pathogenic microorganisms, but not necessarily all microbial forms, such as bacterial spores.

Disinfection processes do not ensure the margin of safety associated with sterilization processes. (AAMI, 1995)

Disposal. The deposition or placement of any solid or hazardous waste on or in the land or water. Disposal of wastes from the remediation of a wide urban area will likely be accomplished through the use of permitted and licensed landfills meeting certain criteria (i.e., if the material being disposed is a hazardous waste, it would be sent to a hazardous waste landfill) or through appropriate treatment technologies, such as steam autoclaving or incineration. Treatment technologies such as incineration may generate residues that must be tested and then appropriately disposed, most often in a hazardous-waste or a municipal solid-waste landfill.

Emergency Operations Center (EOC). The physical location at which the coordination of information and resources to support domestic incident management activities normally takes place. An EOC may be a temporary facility or may be located in a more central or permanently established facility, perhaps at a higher level of organization within a jurisdiction. EOCs may be organized by major functional disciplines (e.g., fire, law enforcement, and medical services), by jurisdiction (e.g., Federal, State, regional, county, city, or tribal), or by some combination thereof. (DHS 2008.)

Environmental Clearance Committee (ECC). An independent group of scientific experts from a variety of Federal, State, and local agencies that provides advice, data and process analysis, and recommendations related to 
decontamination of a facility. An ECC provides a final recommendation on whether the cleanup was adequate to justify reopening an area or facility for normal operations and use. Although not required, the use of an ECC to evaluate the adequacy of cleanup through highly qualified professional debate is recommended to ensure adequate protection of public health. (Modified from Proceedings from the 2nd Civilian-Military Anthrax Response Technical Workshop, 2004.)

Environmental sampling. Sampling conducted on inanimate surfaces or in air, water, or soil for the purpose of detecting the presence of a specific biological agent. (DHS/EPA 2009.)

Environmental Unit. An Incident Command System unit responsible for environmental matters associated with a response, including strategic assessment, modeling, and environmental monitoring and permitting.

Exclusion zone. An area with actual or potential contamination and the highest potential for exposure to the contaminant. Entry to this area is permitted only for persons wearing appropriate personal protective equipment (PPE). Equivalent to Hot Zone, Red Zone, Isolation Zone, or Restricted Zone. (DHS/EPA 2009.)

FIFRA exemption. Under the authority of Section 18 of the Federal Insecticide, Fungicide, and Rodenticide Act (FIFRA), the Administrator of EPA may exempt any Federal or state agency from the pesticide registration requirements of FIFRA, if the Administrator determines that emergency conditions exist that require such exemption. As described in EPA's regulations (40 CFR Part 166), four types of exemptions - specific, quarantine, public health, and crisis - may be issued under different circumstances. Other types of emergency exemptions require a state or Federal agency to submit an application to EPA for review and approval.

First responders. Primarily local and nongovernmental police, fire, and emergency personnel who in the early stages of an incident are responsible for the protection and preservation of life, property, evidence, and the environment, including emergency response providers as defined in Section 2 of the Homeland Security Act of 2002 (6 U.S.C. 101), as well as emergency management, public health, clinical care, public works, and other skilled personnel who provide immediate support services.

First response. Actions taken immediately following notification of a biological incident or release. In addition to search and rescue, perimeter control, site security, and law enforcement activities, first response includes initial site containment, environmental sampling and analysis, and public health activities, such as treatment of potentially exposed persons. (DHS/EPA 2009.)

Federal On-Scene Coordinator (FOSC OR OSC). The Federal official predesignated by the U.S. Environmental Protection Agency or the U.S. Coast Guard to coordinate responses under subpart D of the National Contingency Plan (NCP), or the government official designated to coordinate and direct removal actions under subpart $\mathrm{E}$ of the NCP. (DHS 2008.)

Fumigant. In the context of this document, a fumigant is a gaseous or vaporized decontamination reagent, such as vaporous hydrogen peroxide, chlorine dioxide, ethylene oxide, methyl bromide, or paraformaldehyde, which is known to be effective in killing Bacillus anthracis spores and used during cleanup.

Fumigation. Use of a chemical gas or vapor in a contained space to inactivate biological contaminants (primarily pathogenic bacteria, fungi, and viruses). (DHS/EPA 2009.)

Fumigation zone. A discrete section or subsection of a building or facility that is isolated with respect to other areas of the building or facility for the purposes of fumigation. See Isolation.

Hazardous material. A substance or material, including a hazardous substance, that has been determined by the Secretary of Transportation to be capable of posing an unreasonable risk to health, safety, and property when transported in commerce, and which has been so designated (49 CFR 171.8).

Health and Safety Plan (HASP). A written plan required under the Occupational Health and Safety Administration's (OSHA's) Hazardous Waste Operations and Emergency Response (HAZWOPER) standard (29 CFR 1910.120). This standard requires a written HASP, which identifies site hazards and appropriate controls to protect employee health and safety. (National Response Team, NRT 2005.) The HASP describes known physical, chemical, and biological hazards at a site; the establishment of hot (contaminated), cold (uncontaminated), and warm (intermediate) zones; personal protective equipment (PPE); personal decontamination procedures; and emergency procedures to be used by sampling and decontamination personnel.

Hotline. The outer boundary of the Exclusion Zone (Hot Zone) that separates the area of contamination from the Contamination Reduction Zone (Warm Zone). (DHS/EPA 2009.)

Hot zone. See Exclusion zone. 
Inactivation. Removing the activity of microorganisms by killing or inhibiting reproductive or enzyme activity. When referring to an antimicrobial agent, inactivation means neutralizing the activity of microorganisms by any means. (Block 2001.)

Incident. An occurrence or event, natural or human-caused, which requires an emergency response to protect life or property. Incidents can include major disasters, emergencies, terrorist attacks, terrorist threats, wild land and urban fires, floods, hazardous materials spills, nuclear accidents, aircraft accidents, earthquakes, hurricanes, tornadoes, tropical storms, war-related disasters, public health and medical emergencies, and other occurrences requiring an emergency response. (DHS 2008.)

Incident Action Plan (IAP). An oral or written plan containing general objectives reflecting the overall strategy for managing an incident. It may identify operational resources and assignments. It may also include attachments that provide direction and important information for managing the incident during one or more operational periods. In the context of this document, the Remediation Action Plan (RAP) is implemented through a series of IAPs.

Incident Command (IC). The unit responsible for all incident activities, including the development of strategies and tactics and the ordering and release of resources. The IC has overall authority and responsibility for conducting incident operations and is responsible for managing all incident operations at the incident site. (NIMS 2008; DHS 2008)

Incident Commander (IC). The individual responsible for all incident activities, including the development of strategies and tactics and the ordering and the release of resources. The IC has overall authority and responsibility for conducting incident operations and is responsible for the management of all incident operations at the incident site. (NIMS 2008; DHS 2008.)

Incident Command Post (ICP). As defined in the NRF, the ICP is the field location at which the primary tacticallevel, on-scene incident command functions are performed. The ICP may be co-located with the incident base or other incident facilities and is normally identified by a green rotating or flashing light. Compare with EOC.

Incident Command System (ICS). A standardized, on-scene, emergency management construct specifically designated to provide for the adoption of an integrated organizational structure that reflects the complexity and demands of single or multiple incidents, without being hindered by jurisdictional boundaries. ICS is the combination of facilities, equipment, personnel, procedures, and communications operating with a common organizational structure, designed to aid in managing resources during incidents.

Infectious dose (ID). A dose at which an organism can reproduce in the host and produce a measurable effect. (Johnson 2003.)

Isolation. For the purposes of this document, action taken to seal a site, or portions of a site, to permit gas- or vaporphase decontamination and prevent release of fumigant. Compare with containment. This term has been used differently by various agencies.

Isolation Zone. A contaminated area for which entry is permitted only for persons wearing appropriate personal protective equipment (PPE). Equivalent to Hot Zone, Red Zone, Exclusion Zone, and Restricted Zone. (DHS/EPA 2009.)

Judgmental sampling. Environmental sampling in which the locations are determined by professional judgment. Generally based on incident-specific information, such as a known release location, obvious presence of contamination, or facility-specific information including air-flow patterns.

Laboratory Response Network (LRN). The organization of public health laboratories established by the Department of Health and Human Services, Centers for Disease Control and Prevention (CDC) in accordance with Presidential Decision Directive 39. The LRN and its partners maintain an integrated national and international network of laboratories that are equipped to respond quickly to acts of chemical or biological terrorism, emerging infectious diseases, and other public health threats and emergencies. (CDC, 2005.) In a partnership of the CDC, FBI, and Association of Public Health Laboratories, the LRN fulfills the Federal responsibility of rapid sample testing and identification of biological and chemical threat agents through established protocols and reagents. The LRN also serves as a sentinel warning system for covert biological incidents.

Life safety zones. Zones established at a contaminated site that are intended to reduce the accidental spread of hazardous substances by workers or equipment from contaminated areas to clean areas. Safety zones specify the type of operations that occur in each zone, the degree of hazard at different locations within the release site, and the areas at the site that should be avoided by unauthorized or unprotected employees. (DHS/EPA 2009.) 
Lifelines. The underlying infrastructure necessary to sustain human activity. Lifelines include information and communications; electrical power systems; gas and oil production, storage, and transportation; banking and finance; transportation; water-supply systems; emergency services; and continuity of essential government services.

Monitored natural attenuation. The destruction or inactivation of a microorganism or products of a microorganism, such as a toxin, via natural, environmental mechanisms such as heat, light, biochemical, or chemical reactions. (DHS/EPA 2009.)

National Incident Management System (NIMS). A nationwide template enabling Federal, State, local, and tribal governments and private-sector and nongovernmental organizations to work together effectively and efficiently to prevent, prepare for, respond to, and recover from domestic incidents regardless of cause, size, or complexity. The NIMS provides a core set of doctrine, concepts, terminology, and organizational processes to enable collaborative incident management at all levels.

National Response Framework (NRF). An all-discipline, all-hazards plan that establishes a single, comprehensive framework for managing domestic incidents. The NRF provides the structure and mechanisms for coordinating Federal support to, and exercising direct Federal authorities and responsibilities for, such incidents.

Native air samples. "Found samples" yielding data on possible contaminants in the air, which might be collected over a wide area with greater expediency than collecting environmental surface samples from devices placed in the field after an incident. Examples include samples taken from air filters already in the field (such as building HVAC filters and selected vehicle air filters), or the data gathered by data-collection systems, such as from environmental aerosol monitoring stations operated by the EPA, state and local agencies, or others.

Negative air unit (NAU). A system that subjects an area to a slightly negative pressure to ensure that a contaminant (and decontamination reagent) remains in the contamination zone. NAUs consist of a HEPA filter, chemical scrubber, demister, carbon bed, fan, and stack. Air within a contamination zone is exhausted through HEPA filters at a rate sufficient to pull a slightly negative pressure in the zone. (Carlsen et al., 2005.)

Notification. The process of communicating the occurrence or potential occurrence of a biological incident through and to designated authorities who initiate First Response actions. Generally occurs as the first step in a response to a suspected or actual biological incident. (DHS/EPA 2009.)

Operations Section. The ICS section responsible for all tactical incident operations.

Optimization. A flexible decision process that addresses multiple aspects of the problem and seeks to analyze, consider, and balance these factors in decontamination and recovery activities. (DHS/EPA 2009.)

Overt release. In the context of this document, the intentional release of a biological warfare agent that is reported or openly acknowledged by terrorists, or observed by surveillance systems or witnesses at the scene of the release, or otherwise made known at the time of release.

Pathogen. Any disease-producing microorganism. (Block 2001.)

Planning Section. The Incident Command System section responsible for collecting, evaluating, and disseminating operational information related to an incident and for preparing the Incident Action Plan. The Planning Section maintains information on the current and forecasted situation and on the status of resources assigned to the incident.

Polymerase chain reaction (PCR). A method, sometimes referred to as "molecular photocopying," for generating copies of a fragment of DNA. PCR can characterize and synthesize any specific piece of DNA and identify genetic material from specimens, including microbes, such as Bacillus anthracis. As a field test described in this document, the rapid, automated, and quantitative PCR technique involves a portable piece of equipment using a reaction tube, reagents, and a heat source to obtain presumptive evidence of the presence of Bacillus anthracis spores.

Confirmation of the presence of such spores must be obtained through the laboratory culture of sampled material, a more lengthy process.

Principal Federal Official (PFO). The Federal official designated by the Secretary of Homeland Security to act as his/her representative locally to oversee, coordinate, and execute the Secretary's incident management responsibilities under HSPD-5 for major incidents. (DHS 2008.)

Process monitoring. Measuring and recording the key variables of a decontamination process as they occur. For example, during fumigation, the key variables are gas concentration, temperature, contact time, and relative humidity. (DHS/EPA 2009.)

Quality Assurance. An integrated system of activities involving planning, quality control, quality assessment, reporting, and quality improvement to ensure that a product or service meets defined standards of quality with a stated level of confidence. (EPA 2002.) For the purposes of this document, the term refers to the quality of data. 
Quality Control. The overall system of technical activities the purpose of which is to measure and control the quality of a product or service so that it meets the needs of its users. The aim is to provide quality that is satisfactory, adequate, dependable, and economical. (EPA 2002.) For the purposes of this document, the term refers to the quality of data.

Random sampling. Environmental sampling in which sampling locations are chosen with some degree of randomness. Such sampling is based on the idea that choosing locations at random ensures both representative and reproducible results.

Recommissioning. The process of testing and verifying that equipment is fully functional and may be returned to normal use. (DHS/EPA 2009.)

Recovery. In the short term, recovery is an extension of the response phase in which basic services and functions are restored. In the long term, recovery is a restoration of both the personal lives of individuals and the livelihood of the community. Recovery can include the development, coordination, and execution of service- and site-restoration plans; the reconstitution of government operations and services; programs to provide housing and to promote restoration; long-term care and treatment of affected individuals; and additional measures for social, environmental, and economic restoration. (DHS, 2008) Recovery generally includes actions taken after Notification and First Response activities have been initiated (see six-phase of response and recovery Figure 1-3). (DHS/EPA 2009.)

Remediation. The processes of characterizing, decontaminating, and clearing a contaminated site or items, including disposal of wastes. Generally occurs after the First-Response Phase and before the Restoration Phase (see six-phase Figure 1-3). A synonym for cleanup. Remediation is not the same as "remedial action," which is defined below. (DHS/EPA 2009.)

Remedial action. Long-term response actions that permanently and significantly reduce the dangers associated with releases or threats of releases of hazardous substances that are serious, but not immediately life threatening. If applicable and with available resources, remedial action may be performed in accordance with the National Oil and Hazardous Substances Pollution Contingency Plan and under the authority of CERCLA. See 40 CFR 300.430 and .435 .

Remediation Action Plan (RAP). A formal plan developed for the Unified Command that describes actions to remove, reduce, or eliminate contaminants at a site. The RAP is developed at the beginning of the Decontamination Phase. In the context of this document, the RAP is a written, incident-specific plan that includes details on (1) what facilities and areas need to be decontaminated; (2) what materials and structural components are to be decontaminated in situ, or removed for treatment and either reuse or disposed; (3) to what extent removed items will be decontaminated prior to disposal, and how and where such items will be decontaminated and disposed; (4) the decontamination technologies to be used; (5) the personnel and teams responsible for decontamination tasks; and (6) the types of wastes that will be produced and how they will be treated or disposed.

Removal action. Response actions taken to address releases or threatened releases of hazardous substances, pollutants, or contaminants that require a prompt response. If applicable and with available resources, removal action may be performed in accordance with the National Oil and Hazardous Substances Pollution Contingency Plan and under the authority of CERCLA. See 40 CFR 300.415.

Renovation. The process of reconstructing or refurbishing a facility subsequent to clearance but before allowing occupants to return. (DHS/EPA 2009.)

Reoccupancy. The process of renovating a facility, monitoring the workers performing the renovation, and deciding when to permit reoccupation. Generally occurs after a facility has been cleared but before occupants are allowed to return. (See six-phase Figure 1-3.) (DHS/EPA 2009.)

Residual contamination. The detectable amount of contaminant remaining, if any, after an area has been decontaminated. (DHS/EPA 2009.)

Response. Includes immediate actions to save lives, protect property and the environment, and meet basic human needs. Response also includes the execution of emergency plans and actions to support short-term recovery. (DHS, 2008)

Restoration. The process of renovating or refurbishing a facility, bringing it back to an unimpaired or improved condition, and making a decision to allow the occupants to return. Generally occurs after the Clearance Phase but before occupants are allowed to return. (See six-phase Figure 1-3.) (DHS/EPA 2009.)

Risk. The probability that a substance or situation will produce harm under specified conditions. Risk is a combination of two factors: (1) the probability that an adverse event will occur (such as a specific disease or type of 
injury), and (2) the consequences of the adverse event. (Presidential and Congressional Commission on Risk Assessment and Risk Management, 1997.)

Risk communication. A field in the area of environmental health through which a communicator hopes to provide the receiver with information about the expected type and magnitude of an outcome. Typically, risk communication is a discussion about an adverse outcome and the probability of that outcome occurring (Reynolds 2002).

Risk assessment. Gathering and analyzing information on what potential harm a situation poses and the likelihood that people or the environment will be harmed. (The Presidential and Congressional Commission on Risk Assessment and Risk Management, 1997.) A methodological approach to estimate the potential human or environmental risk of a substance that uses hazard identification, dose-response, exposure assessment, and risk characterization. (DHS/EPA 2009.)

Risk management. The process of identifying, evaluating, selecting, and implementing actions to reduce risk to human health and to ecosystems. The goal of risk management is scientifically sound, cost-effective, integrated actions that reduce or prevent risk while taking into account social, cultural, ethical, and legal considerations. (Presidential and Congressional Commission on Risk Assessment and Risk Management, 1997)

Robert T. Stafford Disaster Relief and Emergency Assistance Act (Stafford Act 2007). This Act (Public Law 100-707), which was signed into law on November 23, 1988, amends the Disaster Relief Act of 1974, PL 93-288. It created the system in place today by which a Presidential disaster declaration of an emergency triggers financial and physical assistance through the Federal Emergency Management Agency (FEMA). The Act gives FEMA the responsibility for coordinating government-wide relief efforts. The Federal response plan it implements includes the contributions of 28 Federal agencies and nongovernmental organizations (such as the Red Cross). Thus, the Act constitutes the statutory authority for most Federal disaster response activities especially as they pertain to FEMA and FEMA programs. Its purpose is to "provide an orderly and continuing means of assistance by the Federal Government to State and local governments in carrying out responsibilities to alleviate the suffering and damage which result from ... disasters."

Sampling and Analysis Plan (SAP). A plan that describes the methods, strategies, and analyses for characterization sampling, verification sampling (if applicable), and clearance sampling for a contaminated site. (DHS/EPA 2009.)

Sampling unit. A sub-section of a sampling zone, such as walls, floors, and furniture surfaces, which can be sampled and evaluated collectively. (DHS/EPA 2009.)

Sampling zone. A discrete section of a contaminated site in which environmental sampling is conducted. (DHS/EPA 2009.)

Screening analysis. The process of analyzing environmental samples by non-laboratory personnel, equipment, or facilities is considered to constitute "first-pass," "screening," or "field" testing. There is no recognized, definitive, reliable field test for biological agents. Compare with Laboratory Response Network and Culturing, above.

Screening environmental sampling. The initial collection of a limited number of environmental samples for the purpose of determining the identity, concentration, viability, and approximate location of contamination by a purported biological agent, and for informing the IC/UC for decision-making on appropriate public health and subsequent remediation actions. (DHS/EPA 2009.)

Source reduction. The process of removing certain items and/or materials from a contaminated site for further treatment and reuse or disposal, and of cleaning the remaining site and item surfaces prior to the main decontamination activity. The goals of this process are to (1) reduce the number of items and/or materials present, (2) ensure that any matter that might inhibit decontamination is removed, and (3) generally reduce the levels of contaminant that may be present. (DHS/EPA 2009.)

Spores. The thick-walled, resting cells produced by some bacteria and fungi that are capable of surviving in unfavorable environments and are more resistant to antimicrobial agents than vegetative cells. (Block 2001.)

Staging area. A safety zone established at a hazardous-substance release site that is designated as the support zone (or cold zone). It is the area of the site that is free from contamination and that may be safely used as a planning and staging area. (EPA 2004.)

Sterilant. A substance that destroys all microorganisms on inanimate surfaces, including vegetative and spore forms of bacteria and fungi, as well as viruses. Sterilants registered by the EPA must be effective on both porous and nonporous surfaces. (DHS/EPA 2009.)

Sterilization. A process intended to remove or destroy all viable forms of microbial life, including bacterial spores, to achieve an acceptable sterility assurance level. (AAMI 1995.) 
Subject-matter expert (SME). An individual who is a technical expert in a specific area or in performing a specialized job, task, or skill.

Support zone. Area of a site that is free from contamination and that may be safely used as a planning and staging area. Also called the Cold Zone. (DHS/EPA 2009.)

Swab sampling. Collecting environmental samples from nonporous surfaces by rubbing a small area with a wet, absorptive material attached to the end of a wood or plastic stick. (DHS/EPA 2009.)

Targeted sampling. Sampling during clearance at specific locations that were found to be contaminated during the Characterization Phase. A special case of judgmental sampling. The term has been used differently in different reports.

Technical Working Group (TWG). A group of technical experts assembled by the Incident or Unified Command to provide guidance during the planning and implementation of cleanup operations. (Carlsen et al., 2005.)

Unified Command. An application of the Incident Command System used when there is more than one agency with incident jurisdiction or when incidents cross jurisdictions. Agencies work together through the designated members of the Unified Command to establish their designated Incident Commander at a single Incident Command Post and to establish a common set of objectives and strategies and a single Incident Action Plan. (DHS, 2008)

Vacuum sampling. Collecting environmental samples by suctioning porous or nonporous surfaces with a vacuum cleaner that contains a high-efficiency particulate air (HEPA) filter. (DHS/EPA 2009.)

Vapor-phase hydrogen peroxide (VPHP). A decontamination technology that involves flash vaporization of an aqueous peroxide mixture.

Vegetative cells. Microbial cells in the growth and reproductive phase of a growth cycle. (Block 2001.)

Verification sampling. Use of chemical indicators, biological indicators, or both to document that fumigation has been successful. (DHS/EPA 2009.)

Warm zone. The transition area between the Exclusion and Support Zones. This area is where responders enter and exit the Exclusion Zone and where decontamination activities take place. (EPA, 2004) Also called the contamination reduction zone per HAZWOPER.

Weapon of mass destruction (WMD). As defined in Title 18, U.S.C. § 2332a: (1) any explosive, incendiary, or poison gas, bomb, grenade, rocket having a propellant charge of more than 4 ounces, or missile having an explosive or incendiary charge of more the one-quarter ounce, or mine or similar device; (2) any weapon that is designed or intended to cause death or serious bodily injury through the release, dissemination, or impact of toxic or poisonous chemicals or the precursors; (3) any weapon involving a disease organism; or (4) any weapon that is designed to release radiation or radioactivity at a level dangerous to human life.

Wipe sampling. Collecting environmental surface samples by rubbing a thin, flat piece of wet, absorptive material on a small area of a non-porous surface. (DHS/EPA 2009.) 


\section{Glossary References}

AAMI (1995), Association for Advancement of Medical Instrumentation, Standards and Recommended Practices. Sterilization, Part I. Sterilization of Health Care Facilities;

Sterilization, Part 2. Hospital Equipment and Industrial Process Control, Arlington, VA.

Block, S. (Ed.) (2001), Disinfection, Sterilization, and Preservation, $5^{\text {th }}$ Edition (Lippincott, Williams, and Wilkins, Philadelphia, PA).

Carlsen, T., L. Berg, D. MacQueen, W. Wilson, G. Brown, S. Mancieri, R. Bishop, K. Folks, R. Kirvel, and V. Vyas (September, 2005), Restoration Plan for Major International Airports After a Bioterrorist Attack, Lawrence Livermore National Laboratory, Livermore, CA, UCRL-TR210178.

CDC (2005), Centers for Disease Control and Prevention, The Laboratory Response Network; available at $<\underline{\text { http: } / / \text { www.bt.cdc.gov/lrn/ }>\text {. }}$

DHHS (1994), U.S. Department of Health and Human Services, Agency for Toxic Substances and Disease Registry, Environmental Data Needed for Public Health Assessments; A Guidance Manual; available at <http://www.atsdr.cdc.gov/ednpha.html\#ambient>.

DHS (December, 2008), Department of Homeland Security, National Response Framework; available at $<\underline{\text { http: } / / \text { www.fema.gov/emergency/nrf/ }>\text {. }}$

DHS/EPA (2009), U. S. Department of Homeland Security and U.S. Environmental Protection Agency, Remediation Guidance for Major Airports after a Bioterrorist Attack.

EPA (2002), U.S. Environmental Protection Agency, Health Effects Notebook, Health Effects Glossary; available at $<$ http://www.epa.gov/ttnatw01/hlthef/hapsec1.html $>$.

EPA (2002), U.S. Environmental Protection Agency, Health Effects Glossary, Air Toxics; available at $<\underline{\mathrm{http}}: / / \mathrm{www}$.epa.gov/ttn/atw/hapsec1.html $>$.

EPA (2004), U.S. Environmental Protection Agency, Safety Zones, Emergency Response

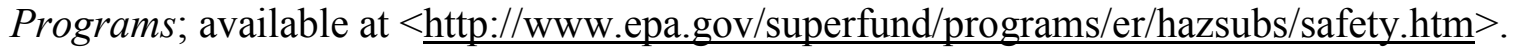

EPA/IRIS (2005), U.S. Environmental Protection Agency, Integrated Risk Information System, Integrated Risk Information System (IRIS) Glossary, revised December 2005, accessed December 2006; available at $<$ http://www.epa.gov/iris/gloss8.htm $>$.

Fitch, J. P., Raber, E., and D. R. Imbro (2003), "Technology Challenges in Responding to Biological or Chemical Attacks in the Civilian Sector," Science 302(5649), 1350-54; see also Fitch, J. P. et al., Proc. IEEE 90(11), 1708 (2002).

Johnson, B. (2003), "OSHA Infectious Dose White Paper," App. Biosafety 8(4), 160-165.

NIMS (2008), National Incident Management System, document available at: <http://www.fema.gov/pdf/emergency/nims/NIMS_core.pdf>.

NRT (updated July, 2005), National Response Team, Technical Assistance for Anthrax Response, Interim-Final Draft; available at http://www.nrt.org/production/NRT/NRTWeb.nsf/PagesByLevelCat/Level2TA?Opendocument. 
Presidential/Congressional Commission on Risk Assessment and Risk Management (1997), Final Report, Volume 1, Framework for Environmental Health Risk Management; Volume 2, Risk Assessment and Risk Management in Regulatory Decision-Making, Presidential/Congressional Commission on Risk Assessment and Risk Management, Washington, D.C.; available at $<$ http://www.riskworld.com/Nreports/nr7me001.htm $>$.

Proceedings from the 2nd Civilian-Military Anthrax Response Technical Workshop (April 1314, 2004), Current State of Federal Governmental Capabilities and Positions; available at $<$ http://www.wetp.org/wetp/public/hasl_get blob.cfm?ID=741>.

Reynolds, B. (2002), Crisis and Emergency Risk Communication, Centers for Disease Control and Prevention; available at $<$ http://www.maxwell.af.mil/au/awc/awcgate/cdc/cerc book.pdf $>$. 


\section{Checklist}

\section{Part V: Appendixes}

\section{Recommended Checklist for Planning Wide-Area Remediation}

Following a wide-area BWA attack, members of the IC or UC would benefit from some overall scheme for anticipating and tracking issues as they are likely to arise during the various phases of response and recovery. This section provides a checklist identifying the types of information required for planning activities starting with notification and first response, progressing through remediation, and ending with restoration.

\begin{tabular}{|c|c|c|}
\hline Responsible Personnel & & Action \\
\hline \multicolumn{3}{|r|}{ Notification Phase } \\
\hline \multirow[t]{4}{*}{$\begin{array}{l}\text { Emergency management } \\
\text { organization and law } \\
\text { enforcement or other } \\
\text { response and public } \\
\text { health organizations }\end{array}$} & $\square$ & $\begin{array}{l}\text { Emergency manager or public health receives notification that: } \\
\circ \text { A biological incident has been detected, or } \\
\circ \text { A biological incident is suspected, or } \\
\circ \text { Information about a developing threat is received from an agency or } \\
\text { responsible person as the result of an active detection system (e.g., } \\
\text { BioWatch), medical surveillance, or epidemiologic investigation. }\end{array}$ \\
\hline & $\square$ & $\begin{array}{l}\text { Gather information and continue to assess incident credibility, incident status, } \\
\text { potential effects on facilities or areas, and the degree to which a response is } \\
\text { needed. }\end{array}$ \\
\hline & $\square$ & $\begin{array}{l}\text { Emergency manager and/or public health makes notifications, as appropriate, by: } \\
\text { Following previously established notification protocols, tailored to specific } \\
\text { triggers at each stage of a developing incident, and either alerting responders } \\
\text { and agencies (Federal, state, and local) or acting on direction from them. } \\
\text { Disseminating information, including preliminary risk communication and } \\
\text { public health directives. }\end{array}$ \\
\hline & $\square$ & Alert and consider standing up additional resources, such as a JIC. \\
\hline
\end{tabular}




\section{Checklist}

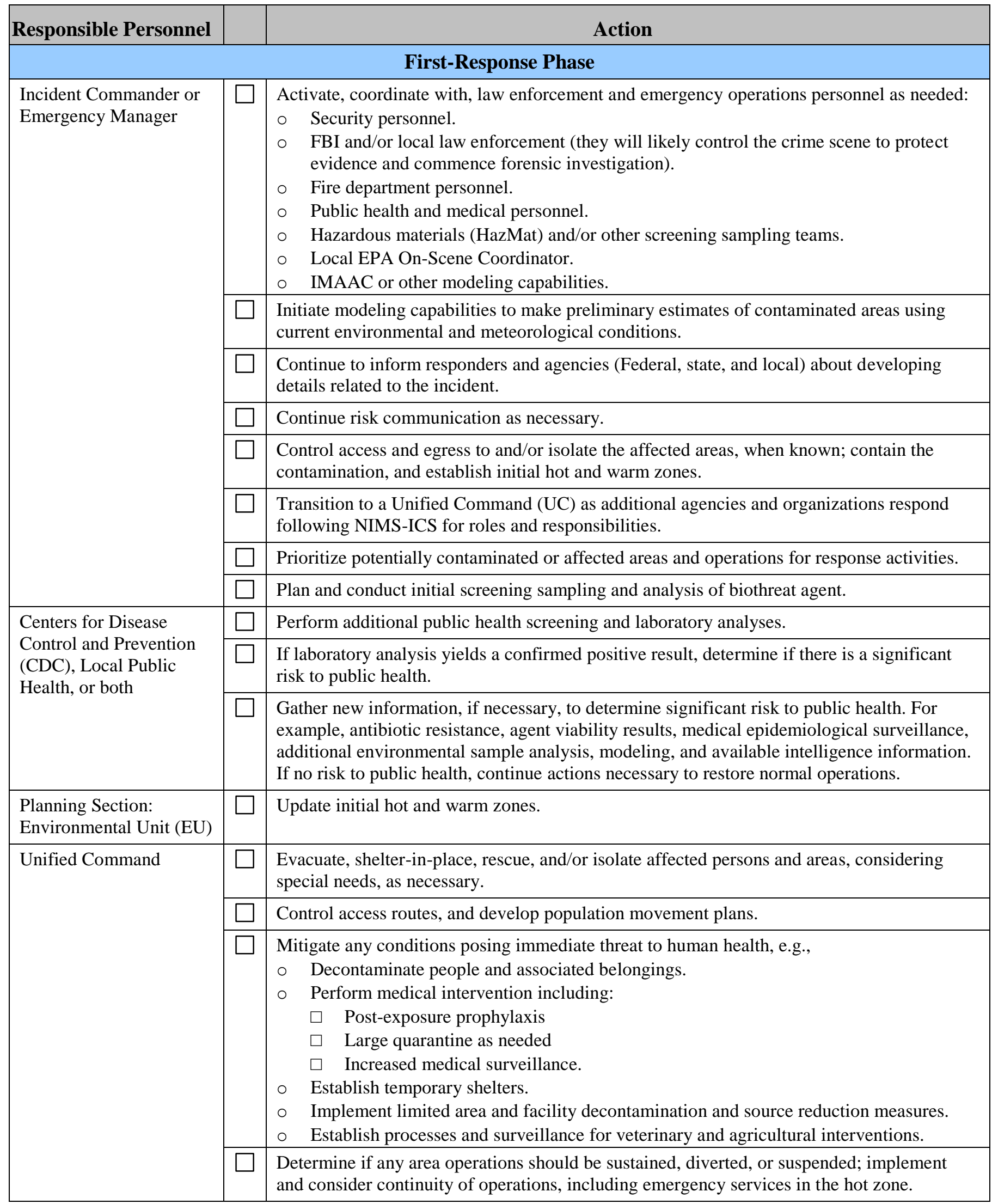


Checklist

\begin{tabular}{|c|c|c|}
\hline Responsible Personnel & & Action \\
\hline \multicolumn{3}{|r|}{ Characterization Phase } \\
\hline $\begin{array}{l}\text { Planning Section: } \\
\text { Situation Unit }\end{array}$ & $\square$ & $\begin{array}{l}\text { Compile all analytical and observational data and reports that were created during the First- } \\
\text { Response Phase, and provide results to the Environmental Unit. }\end{array}$ \\
\hline \multirow[t]{4}{*}{ Unified Command } & $\square$ & $\begin{array}{l}\text { Identify and prioritize areas, facilities, and functions for detailed characterization and } \\
\text { remediation by considering: } \\
\circ \text { Critical infrastructure and facilities. } \\
\circ \text { Minimum essential infrastructure. } \\
\circ \quad \text { Population distribution. } \\
\circ \quad \text { Lifelines. }\end{array}$ \\
\hline & $\square$ & $\begin{array}{l}\text { Mobilize or activate, as necessary, pre-identified resources for characterization activities, } \\
\text { including: } \\
\circ \text { Laboratory Response Network (LRN) and other CDC-approved laboratories. } \\
\circ \text { Environmental sampling teams, decontamination and disposal resources, and personal } \\
\text { protective equipment (PPE). } \\
\circ \text { Data management and documentation specialists. } \\
\circ \text { Air-dispersion modeling resources. }\end{array}$ \\
\hline & $\square$ & $\begin{array}{l}\text { Create or activate a Technical Working Group (TWG) and Environmental Clearance } \\
\text { Committee (ECC) if desired, and establish lines of authority and responsibilities. }\end{array}$ \\
\hline & $\square$ & $\begin{array}{l}\text { Begin notifying and deploying pre-identified resources for decontamination, clearance, and } \\
\text { waste management, as needed. }\end{array}$ \\
\hline \multirow{2}{*}{$\begin{array}{l}\text { Safety Officer and } \\
\text { Logistics Section: } \\
\text { Medical Unit }\end{array}$} & $\square$ & Create and implement a Health and Safety Plan (HASP) for response personnel. \\
\hline & $\square$ & $\begin{array}{l}\text { Vaccinate or provide antibiotics to appropriate response personnel, as needed, per } \\
\text { HHS/CDC guidance. }\end{array}$ \\
\hline \multirow{2}{*}{$\begin{array}{l}\text { Facility/Public Works } \\
\text { and other applicable } \\
\text { agencies }\end{array}$} & $\square$ & Provide detailed plans (e.g., HVAC systems) for affected facilities. \\
\hline & $\square$ & $\begin{array}{l}\text { Provide detailed maps and infrastructure information (e.g., sewer, power, water, natural } \\
\text { resource maps) for the affected region. }\end{array}$ \\
\hline \multirow{2}{*}{$\begin{array}{l}\text { Planning Section: } \\
\text { Environmental Unit }\end{array}$} & $\square$ & Recommend any additional agent containment and source reduction deemed necessary. \\
\hline & $\square$ & $\begin{array}{l}\text { Depending on actions completed during first response: } \\
\circ \quad \text { Assess potential contaminant transport outside the contained areas and facilities. (e.g., } \\
\text { through tracking and re-aerosolization): } \\
\square \quad \text { Evaluate the need for pre-characterization sampling. } \\
\square \quad \text { Evaluate the need for air monitoring. } \\
\square \quad \text { Evaluate the need for additional refinement of outdoor and/or indoor modeling. } \\
\circ \quad \text { Develop the necessary implementation strategy. }\end{array}$ \\
\hline \multirow[t]{2}{*}{ Operations Section } & $\square$ & $\begin{array}{l}\text { Perform recommended actions to assess potential contaminant transport from above } \\
\text { assessments. }\end{array}$ \\
\hline & $\square$ & Implement any recommended agent containment and isolation actions. \\
\hline
\end{tabular}




\section{Checklist}

\begin{tabular}{|c|c|c|}
\hline Responsible Personnel & & Action \\
\hline \multicolumn{3}{|r|}{$\begin{array}{l}\text { Characterization Phase } \\
\text { (continued) }\end{array}$} \\
\hline \multirow[t]{2}{*}{$\begin{array}{l}\text { Planning Section: } \\
\text { Environmental Unit with } \\
\text { input from TWG }\end{array}$} & $\square$ & $\begin{array}{l}\text { Develop a characterization strategy to support remediation activities, including identifying } \\
\text { current characteristics of the confirmed biothreat agent (e.g., has it remained viable, is it still } \\
\text { toxic, can it reaerosolize?). } \\
\circ \text { Consider statistical and judgmental criteria. } \\
\circ \text { Employ iterative modeling approach to optimize sampling. }\end{array}$ \\
\hline & $\square$ & $\begin{array}{l}\text { Write incident-specific characterization sampling and analysis plan(s) (SAPs) in which all } \\
\text { objectives are identified. } \\
\circ \text { Organize the affected areas and facilities into characterization zones. } \\
\circ \text { Select sampling locations and methods. } \\
\circ \text { Identify resource limitations, and optimize their use. }\end{array}$ \\
\hline Unified Command & $\square$ & Approve the characterization SAP(s). \\
\hline \multirow{2}{*}{$\begin{array}{l}\text { Operations Section: } \\
\text { Sampling Group }\end{array}$} & $\square$ & Implement the characterization SAP(s) according to area-specific priorities. \\
\hline & $\square$ & $\begin{array}{l}\text { Track implementation of characterization SAP(s), and make adjustments as needed as data } \\
\text { become available. }\end{array}$ \\
\hline \multirow{3}{*}{$\begin{array}{l}\text { Planning Section: } \\
\text { Environmental Unit with } \\
\text { input from TWG }\end{array}$} & $\square$ & $\begin{array}{l}\text { Evaluate results of characterization activities, and consult with the ECC, as appropriate. } \\
\text { Recommend additional characterization activities, as needed, to the Operations Section. }\end{array}$ \\
\hline & $\square$ & Conduct risk assessment. \\
\hline & $\square$ & Develop clearance goals for the affected area(s). \\
\hline $\begin{array}{l}\text { Local, State, or Federal } \\
\text { Public Health } \\
\text { (HHS/CDC) }\end{array}$ & $\square$ & Recommend any additional public health or medical options. \\
\hline \multirow{2}{*}{$\begin{array}{l}\text { Unified Command with } \\
\text { input from TWG }\end{array}$} & $\square$ & Approve clearance goals. \\
\hline & $\square$ & Approve any HHS/CDC public health recommendations. \\
\hline
\end{tabular}




\section{Checklist}

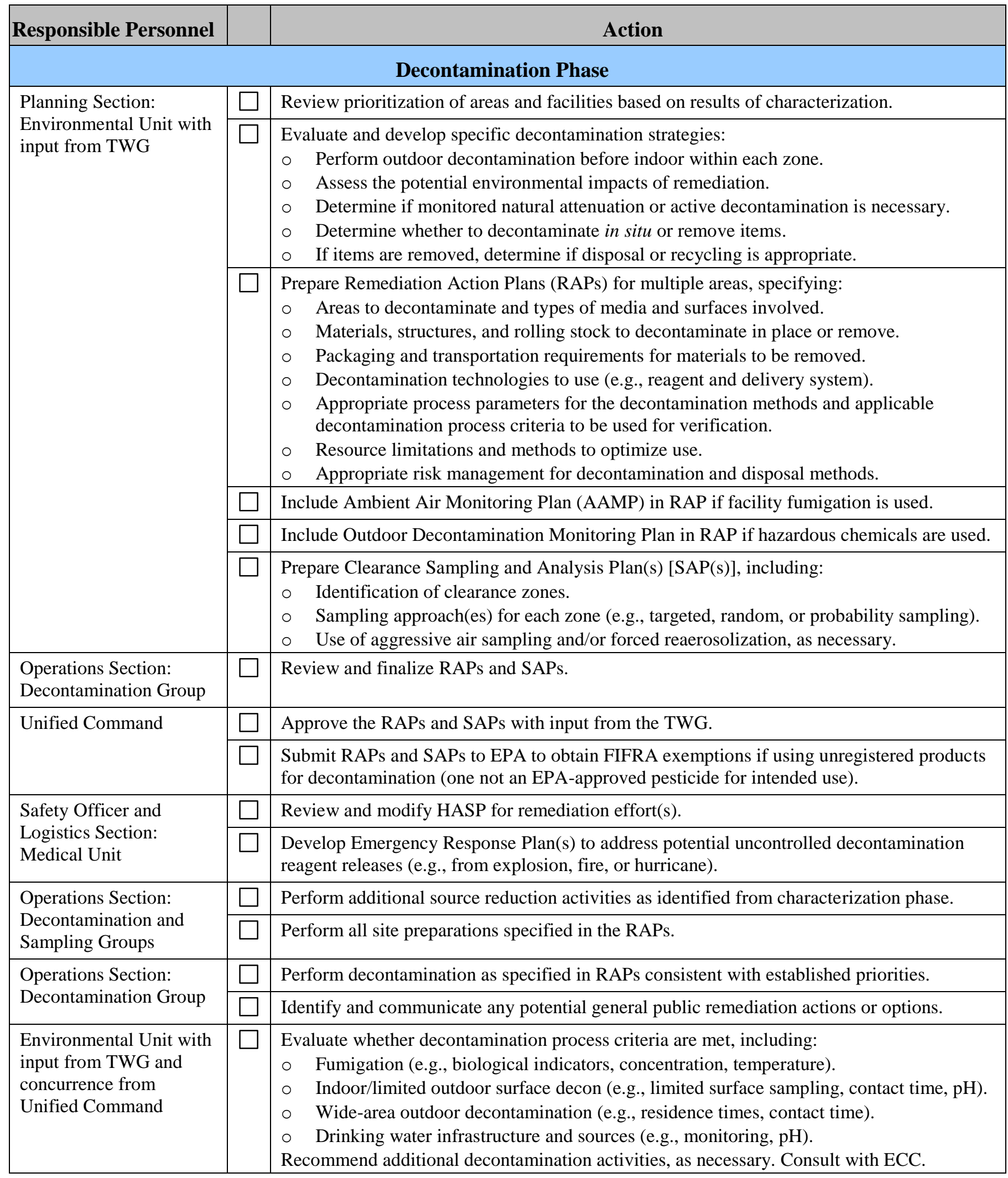




\section{Checklist}

\begin{tabular}{|c|c|c|}
\hline Responsible Personnel & & Action \\
\hline \multicolumn{3}{|r|}{ Clearance Phase } \\
\hline \multirow{2}{*}{$\begin{array}{l}\text { Planning Section: } \\
\text { Environmental Unit with } \\
\text { input from the TWG }\end{array}$} & $\square$ & $\begin{array}{l}\text { Review, and revise as appropriate, the incident-specific clearance SAPs using results of } \\
\text { decontamination activities. }\end{array}$ \\
\hline & $\square$ & Review prioritization of areas, facilities, and functions based on remediation status. \\
\hline $\begin{array}{l}\text { Unified Command with } \\
\text { input from the TWG }\end{array}$ & $\square$ & Approve the incident-specific clearance SAPs, if revised. \\
\hline $\begin{array}{l}\text { Operations Section: } \\
\text { Sampling Group }\end{array}$ & $\square$ & Perform clearance sampling as specified in the SAPs. \\
\hline $\begin{array}{l}\text { Planning Section: } \\
\text { Environmental Unit with } \\
\text { input from TWG }\end{array}$ & $\square$ & $\begin{array}{l}\text { Evaluate the clearance SAP results. Determine if cleanup goals have are met. Recommend } \\
\text { additional remediation if necessary. }\end{array}$ \\
\hline $\begin{array}{l}\text { Planning Section: } \\
\text { Environmental Unit }\end{array}$ & $\square$ & $\begin{array}{l}\text { Document final clearance results for each SAP: } \\
\circ \quad \text { Conduct final technical risk assessment. } \\
\circ \quad \text { Consider socioeconomic implications. }\end{array}$ \\
\hline $\begin{array}{l}\text { Unified Command with } \\
\text { input from ECC }\end{array}$ & $\square$ & $\begin{array}{l}\text { Review final clearance results including final risk assessment. Make recommendations on } \\
\text { whether zones (e.g., facilities, outdoor areas, items) are effectively decontaminated. }\end{array}$ \\
\hline \multirow[t]{2}{*}{ Unified Command } & $\square$ & $\begin{array}{l}\text { Make clearance decision: } \\
\text { Conduct reviews, and confirm that regulatory and stakeholder needs are addressed. } \\
\text { Determine whether to reopen all or parts of an area or facility; or to initiate recovery } \\
\text { and refurbishment activities. If not, further decontamination may be warranted. }\end{array}$ \\
\hline & $\square$ & Determine any long-term environmental monitoring needs, and implement as necessary. \\
\hline \multicolumn{3}{|r|}{ Restoration Phase } \\
\hline \multirow[t]{2}{*}{$\begin{array}{l}\text { Unified Command in } \\
\text { collaboration with } \\
\text { facility and regional } \\
\text { emergency managers }\end{array}$} & $\square$ & $\begin{array}{l}\text { Prepare and implement site-specific recovery plans: } \\
\text { Implement renovation, including refurbishment of removed and damaged items, system } \\
\text { testing, and other required actions. } \\
\text { Determine whether phased-in reuse of areas and facilities is needed to support recovery } \\
\text { operations. } \\
\text { Upgrade or enhance areas or facilities, as appropriate (e.g., mitigate biological } \\
\text { vulnerability). } \\
\text { Implement risk communication strategy and plans. }\end{array}$ \\
\hline & $\square$ & $\begin{array}{l}\text { Address special work activities as necessary under the reoccupancy (transitional) program, } \\
\text { such as safety-based maintenance and housekeeping. }\end{array}$ \\
\hline \multirow{2}{*}{$\begin{array}{l}\text { Unified Command in } \\
\text { collaboration with local } \\
\text { public health and OSHA, } \\
\text { where appropriate }\end{array}$} & $\square$ & Continue long-term environmental and public health monitoring, if deemed appropriate. \\
\hline & $\square$ & $\begin{array}{l}\text { Determine whether to permit tenants and employees to return for normal business. Address } \\
\text { general industrial and residential safety issues. }\end{array}$ \\
\hline Unified Command & $\square$ & Resume full operations for the public. \\
\hline
\end{tabular}




\section{Expanded Framework}

\section{Expanded Operational Decision Framework}

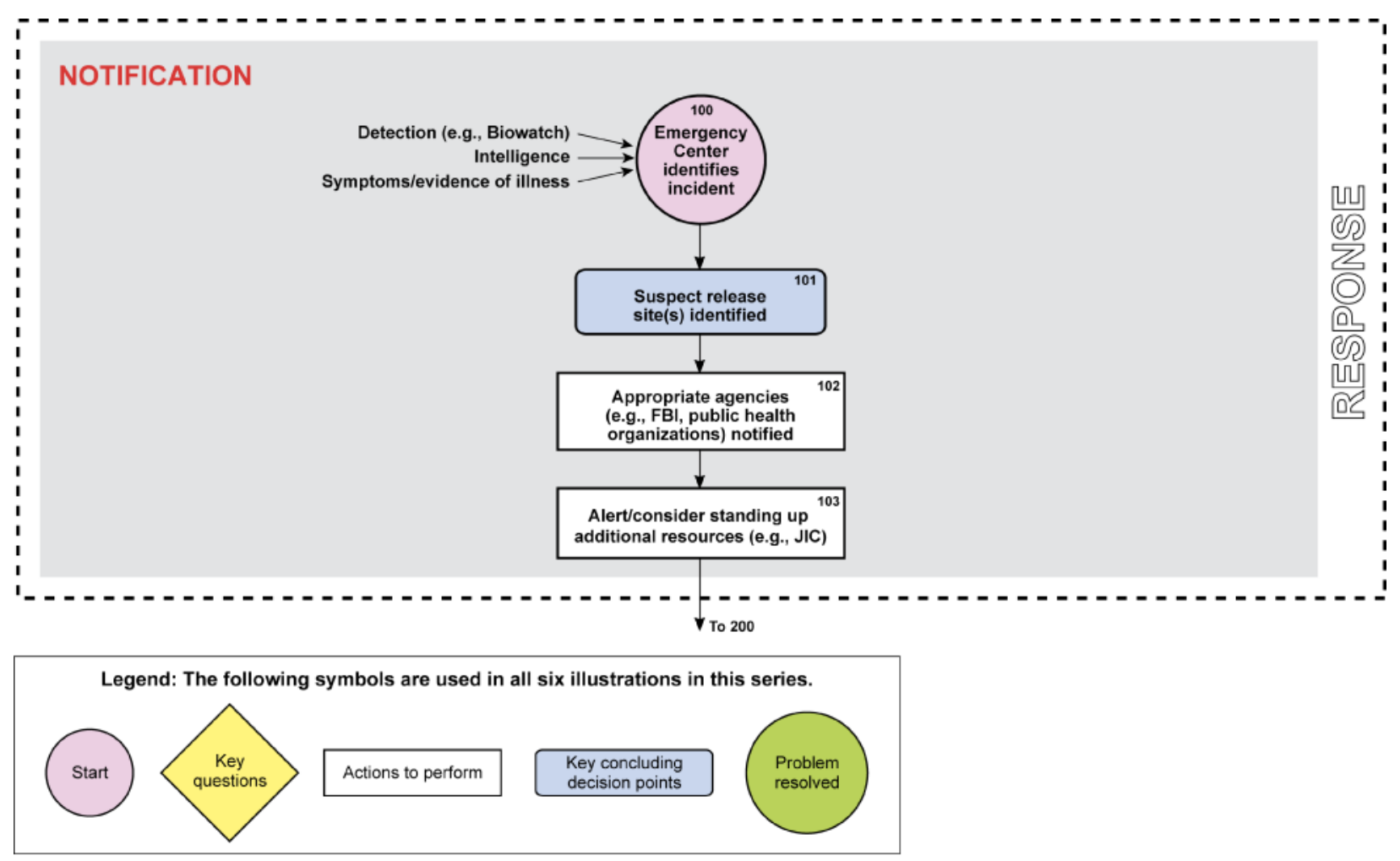




\section{Expanded Framework}

\section{NOTIFICATION (100 Expanded)}
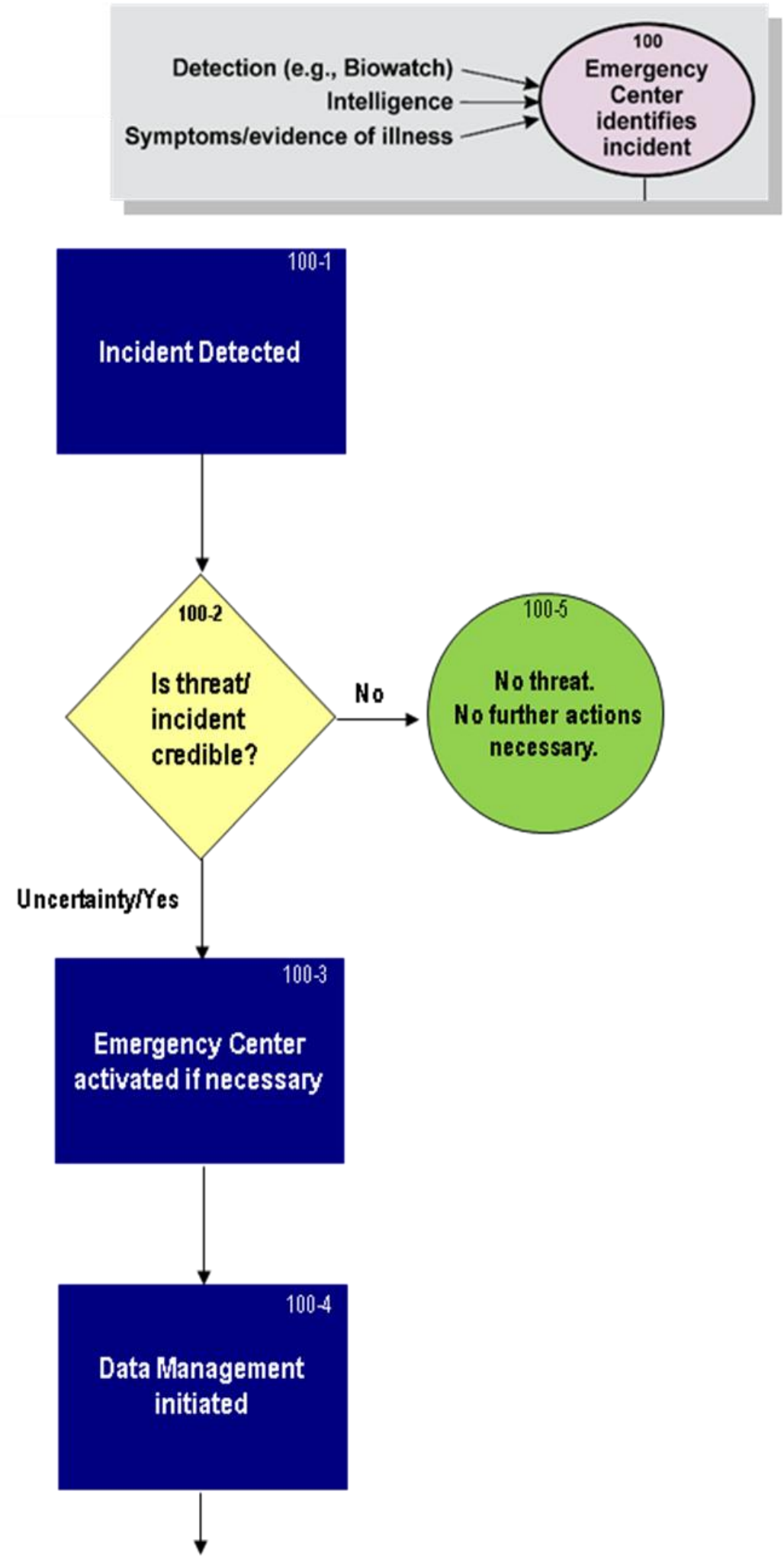

101 


\section{Expanded Framework}

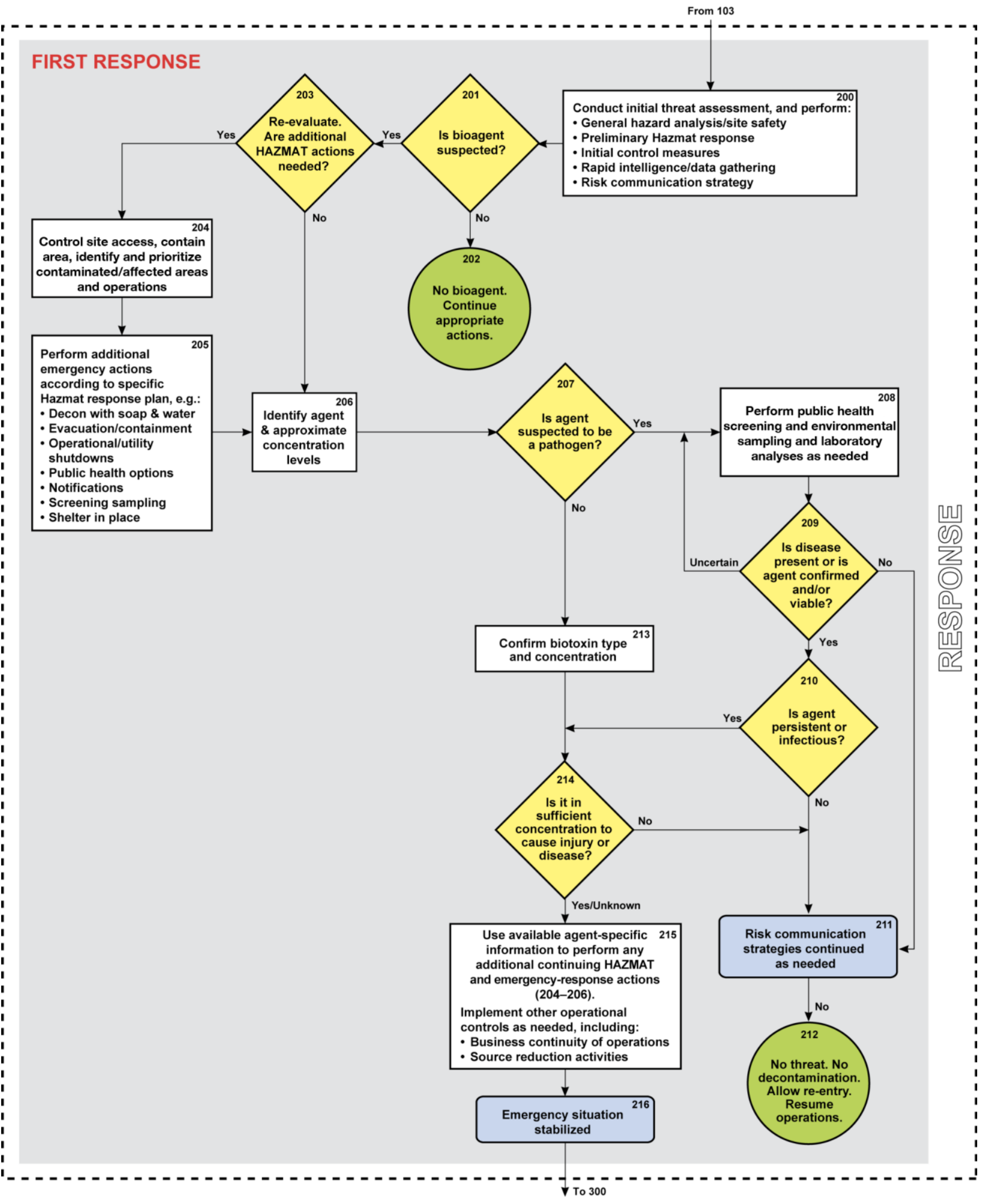




\section{Expanded Framework}

\section{FIRST RESPONSE (204 Expanded)}

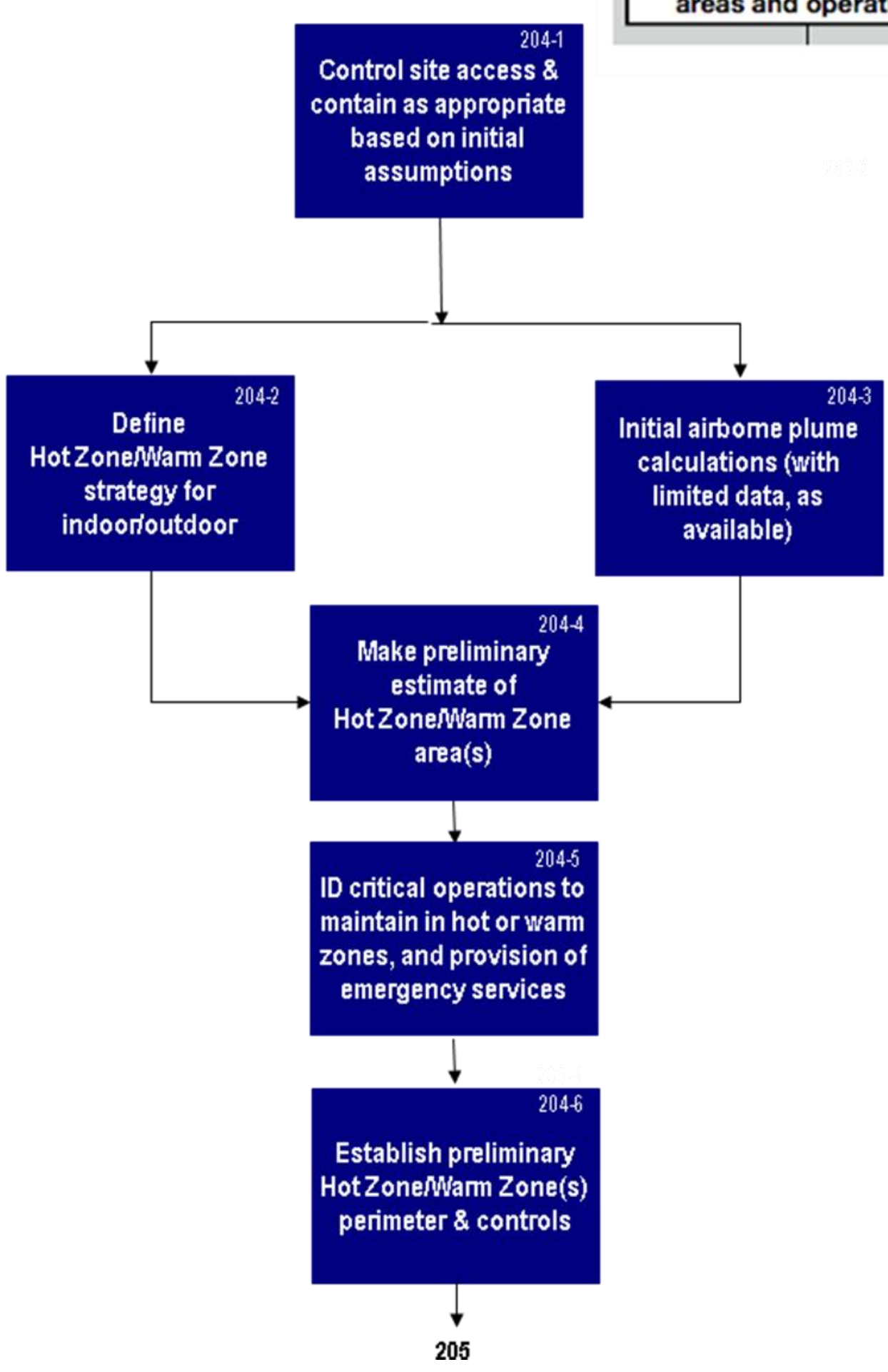




\section{Expanded Framework}

\section{FIRST RESPONSE (208 Expanded)}

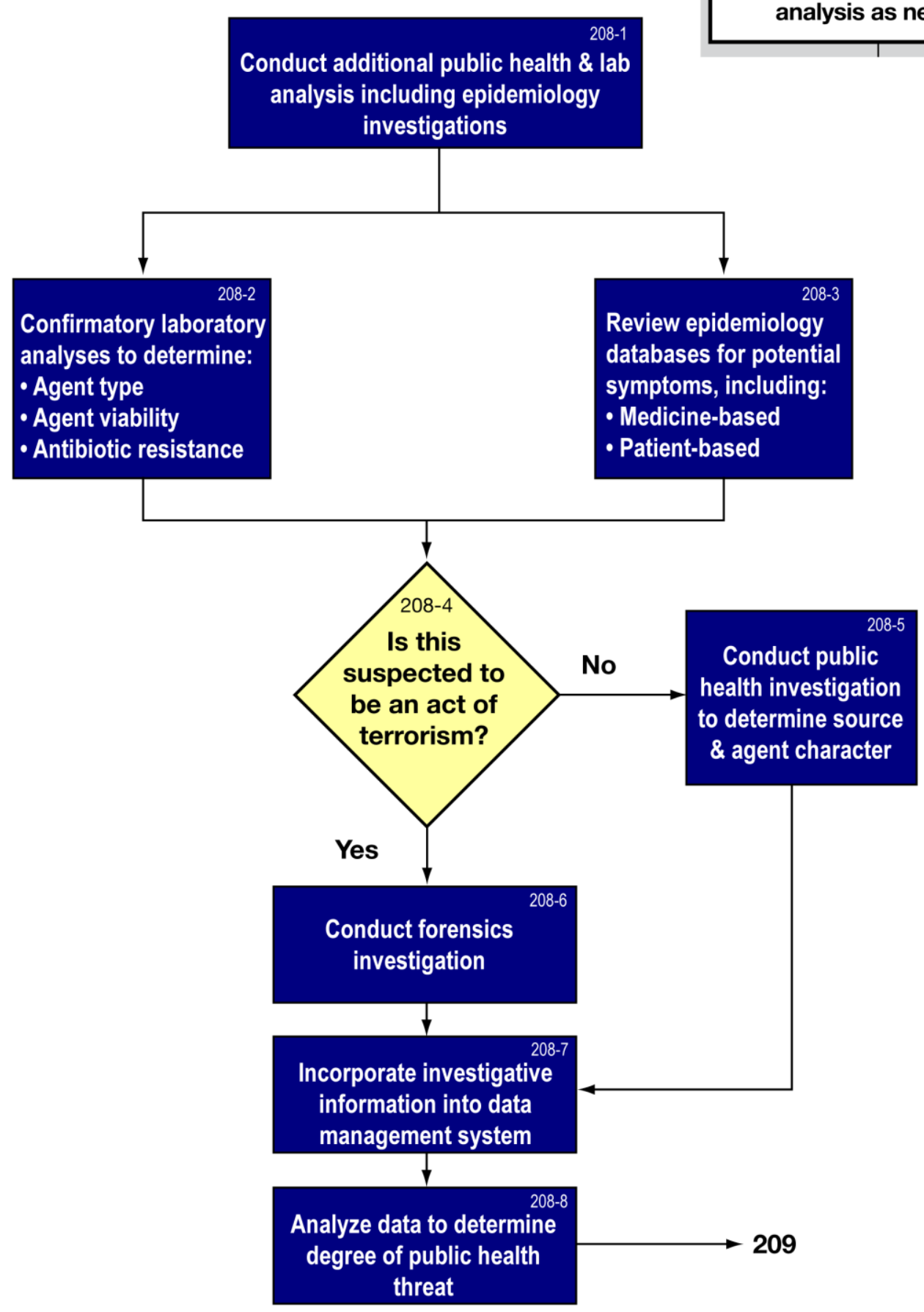

Perform public health screening and environmental sampling and laboratory analysis as needed 


\section{Expanded Framework}

\section{FIRST RESPONSE (215 Expanded)}

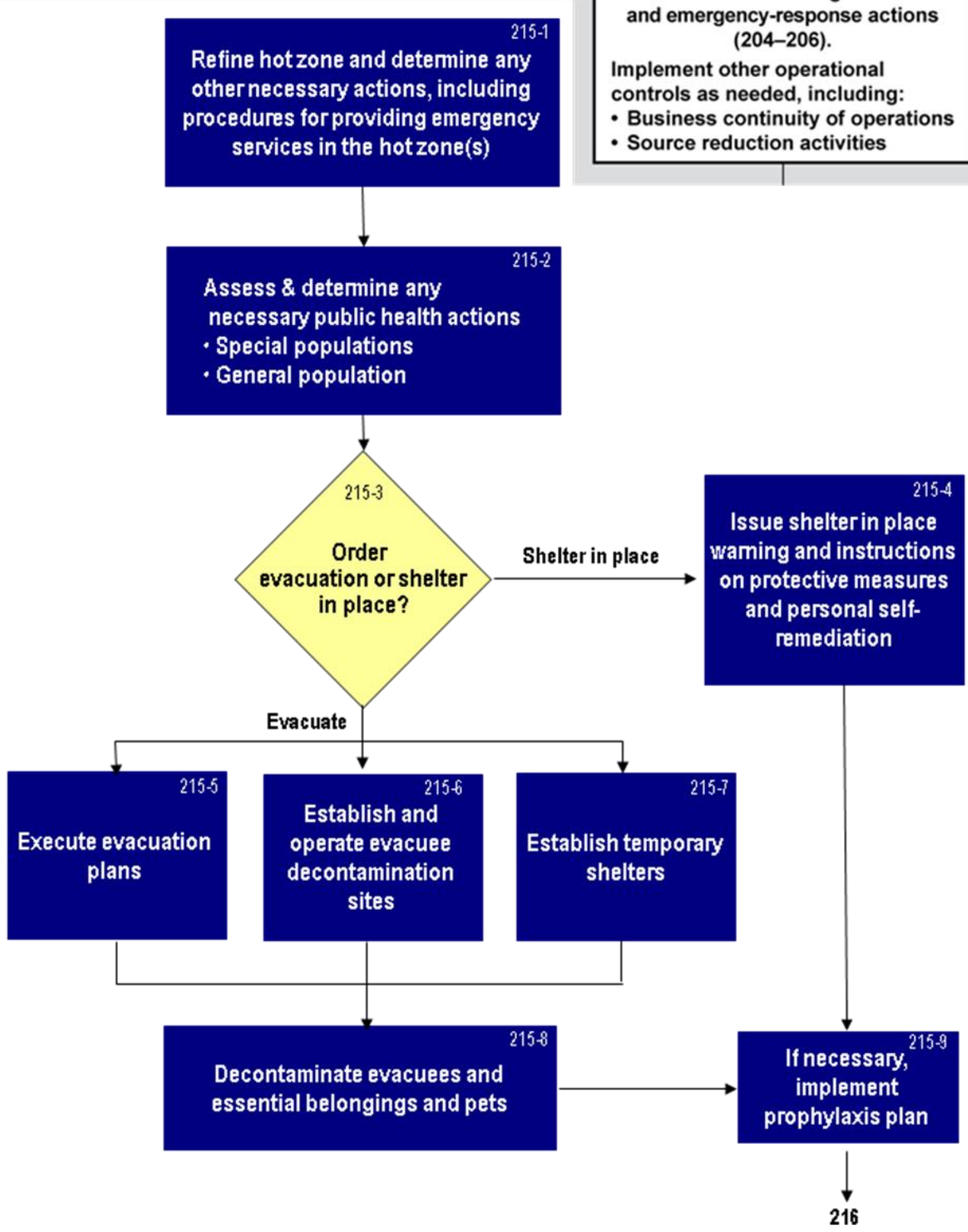
information to perform any additional continuing HAZMAT and emergency-response actions (204-206). controls as needed, including:

Business continuity of operations

Source reduction activities
Use available agent-specific 215

Implement other operational

15




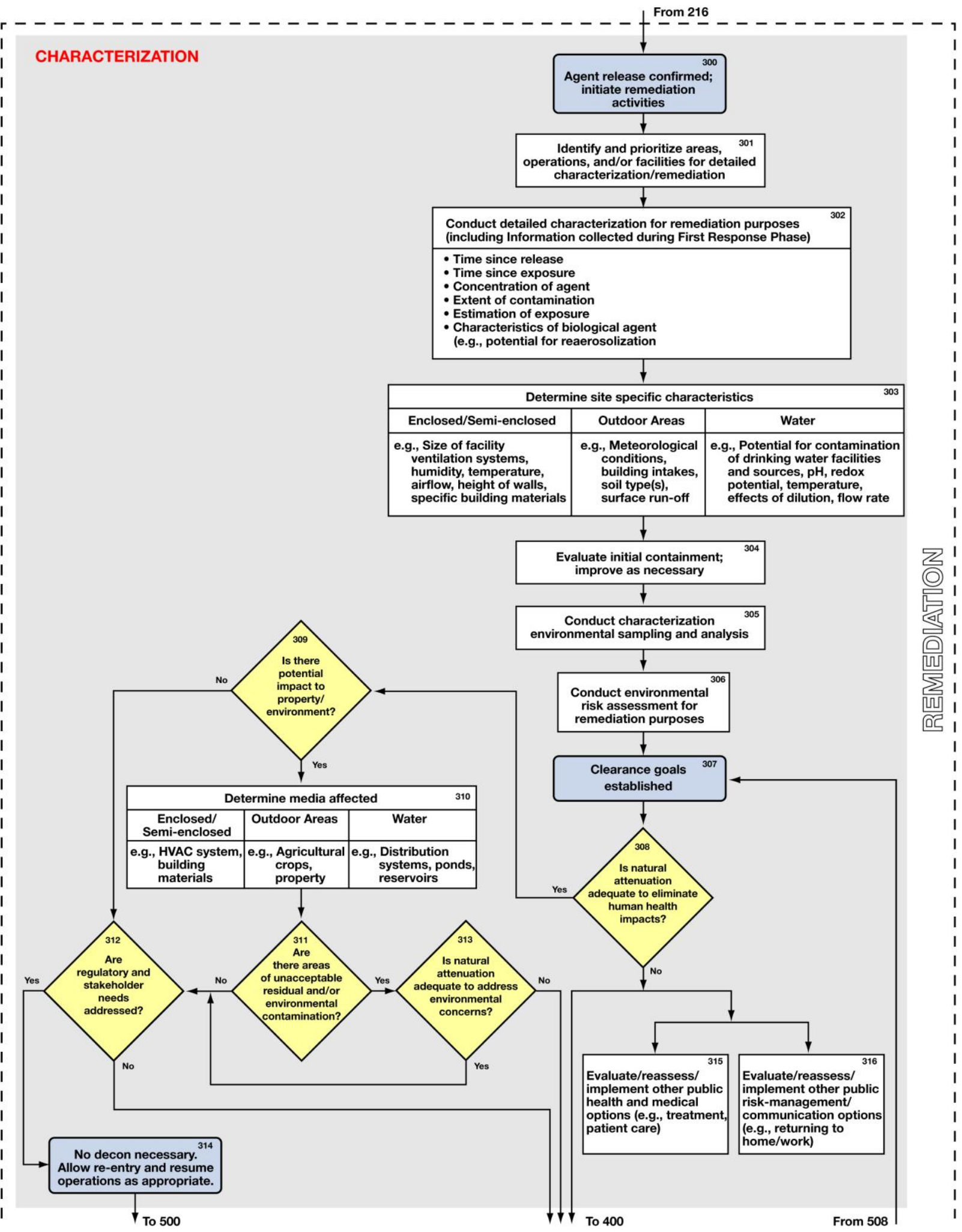




\section{Expanded Framework}

\section{CHARACTERIZATION (301 expanded)}

Identify and prioritize areas,

301

operations, and/or facilities for detailed characterization/remediation

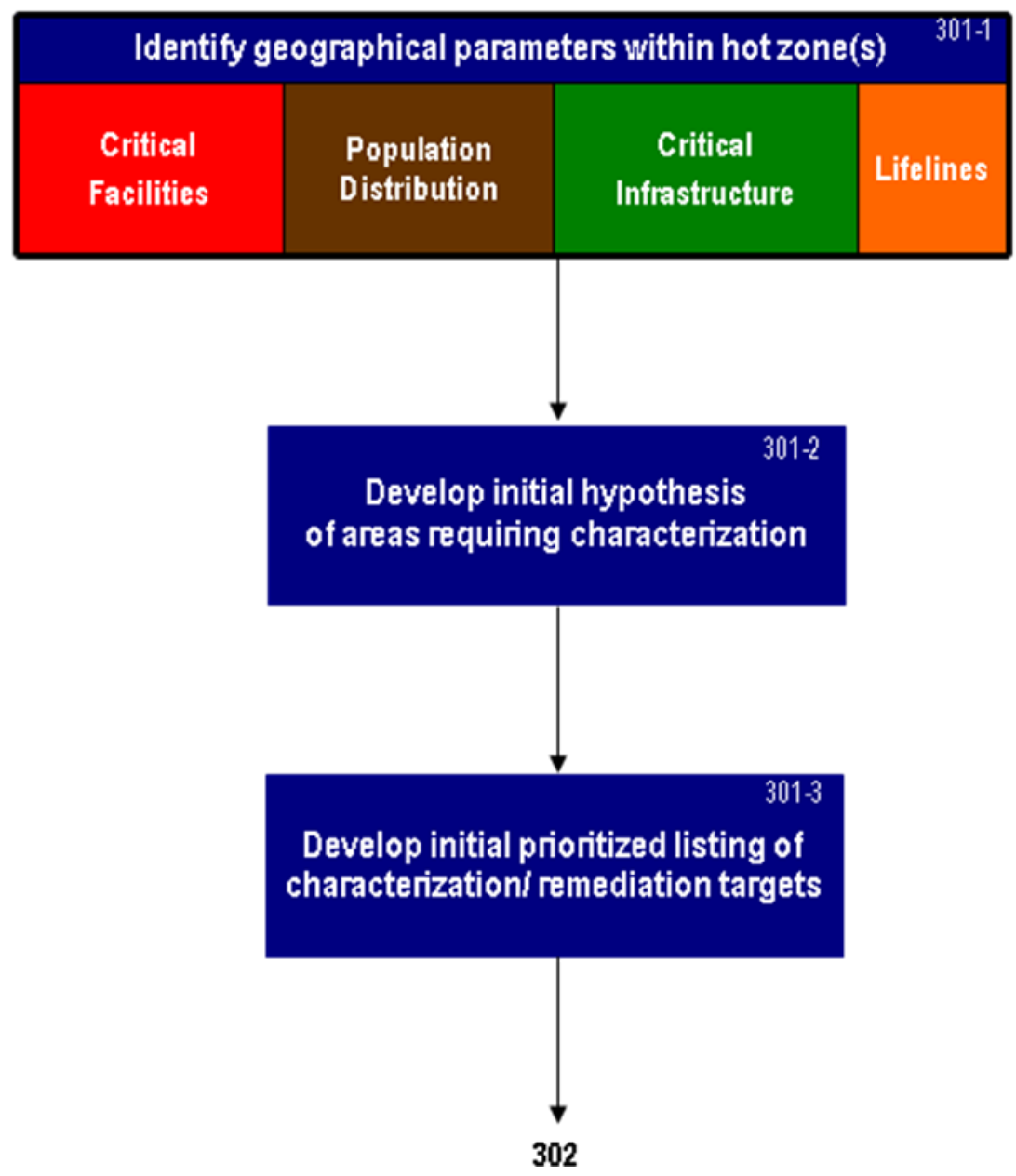




\section{Expanded Framework}

\section{CHARACTERIZATION (302 expanded)}

Conduct detailed characterization for remediation purposes (including Information collected during First Response Phase)

- Time since release

- Time since exposure

- Concentration of agent

- Extent of contamination

- Estimation of exposure

- Characteristics of biological agent

(e.g., potential for reaerosolization)

Gathericollect information from

first response (e.g., time since release, concentration maps, characteristics of agent)

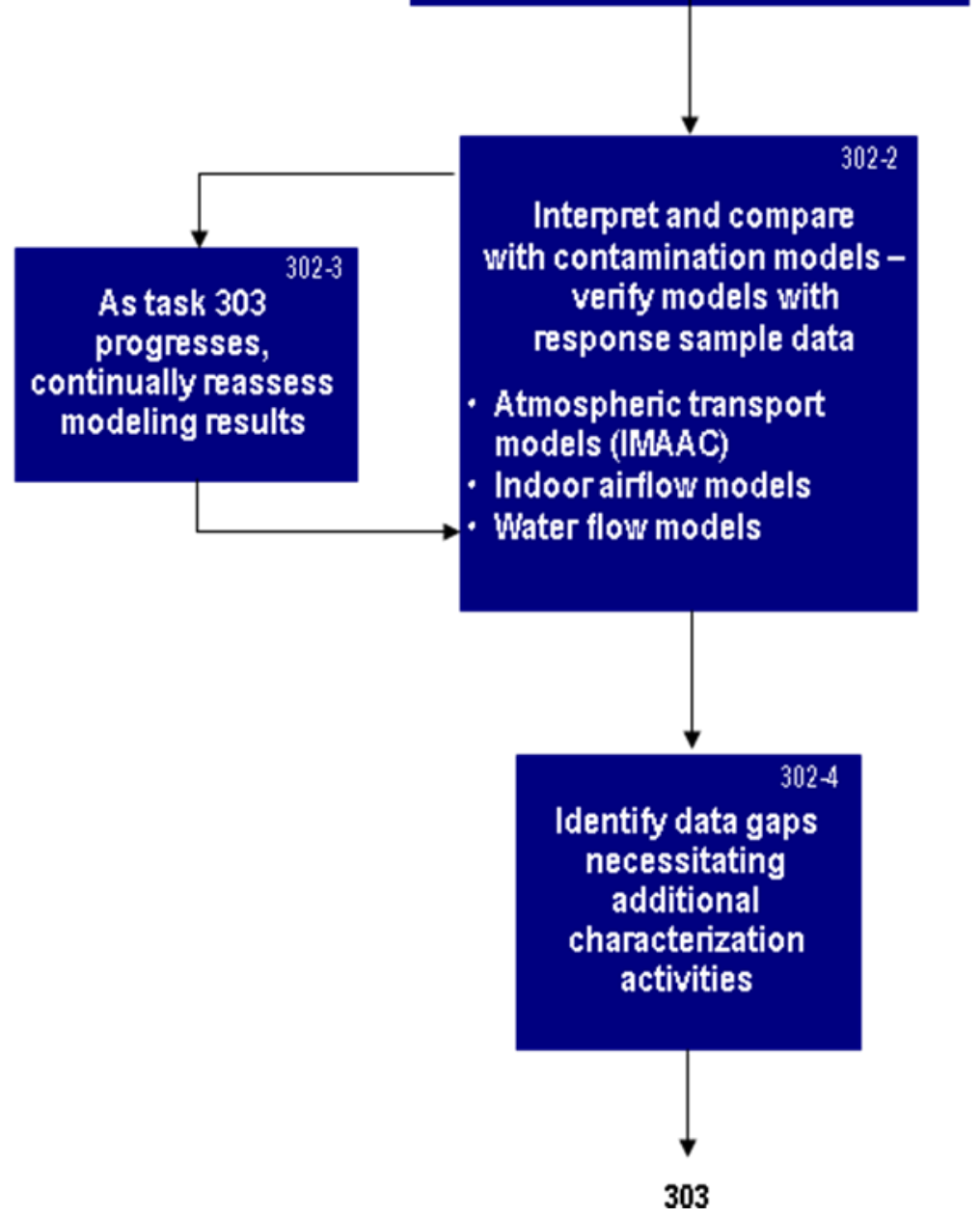




\section{Expanded Framework}

\section{CHARACTERIZATION (303 expanded)}

\begin{tabular}{|c|c|c|}
\hline \multicolumn{3}{|c|}{ Determine site specific characteristics } \\
\hline Enclosed/Semi-enclosed & Outdoor Areas & Water \\
\hline $\begin{array}{c}\text { e.g., Size of facility } \\
\text { ventilation systems, } \\
\text { humidity, temperature, } \\
\text { airflow, height of walls, } \\
\text { specific building materials }\end{array}$ & $\begin{array}{c}\text { e.g., Meteorological } \\
\text { conditions, } \\
\text { building intakes, } \\
\text { soil type(s), } \\
\text { surface run-off }\end{array}$ & $\begin{array}{c}\text { e.g., Potential for contamination } \\
\text { of drinking water facilities } \\
\text { and sources, pH, redox } \\
\text { potential, temperature, } \\
\text { effects of dilution, flow rate }\end{array}$ \\
\hline
\end{tabular}

Determine contamination vulnerabilities and characteristics for all components within affected areas based on understanding of transport mechanisms

\begin{tabular}{|c|c|c|}
\hline $\begin{array}{l}\text { Enclosed/Semi-enclosed } \\
\text { structures }\end{array}$ & Outdoor Areas & Water \\
\hline $\begin{array}{l}\text { - Exposure pathways } \\
\text { - Facility transport systems } \\
\text { - Porousinonporous } \\
\text { surface areas } \\
\text { - Characteristics of } \\
\text { materials } \\
\text { - Soil presence } \\
\text { - Potential contamination } \\
\text { reservoirs }\end{array}$ & $\begin{array}{l}\text { - Soil types } \\
\text { - Surfaces } \\
\text { - Vegetation } \\
\text { - Environmental } \\
\text { conditions } \\
\text { - Transport } \\
\text { mechanisms } \\
\text { - Reaerosolization } \\
\text { potential }\end{array}$ & $\begin{array}{l}\text { - All connections and components of the } \\
\text { drinking water system } \\
\text { - All connections and components of the } \\
\text { surface water handling system, to include } \\
\text { runoff maps and flow rates } \\
\text { - Physico-chemical characteristics of water in } \\
\text { both drinking water and runoff systems } \\
\text { - All connections and components of the } \\
\text { waste water system }\end{array}$ \\
\hline
\end{tabular}

$303-2$

Compile a list of geographically located potential contamination sites

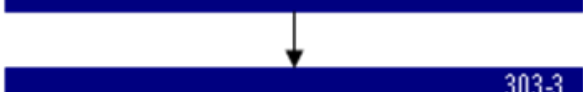

Map potential contamination sites, lifelines, and residual population

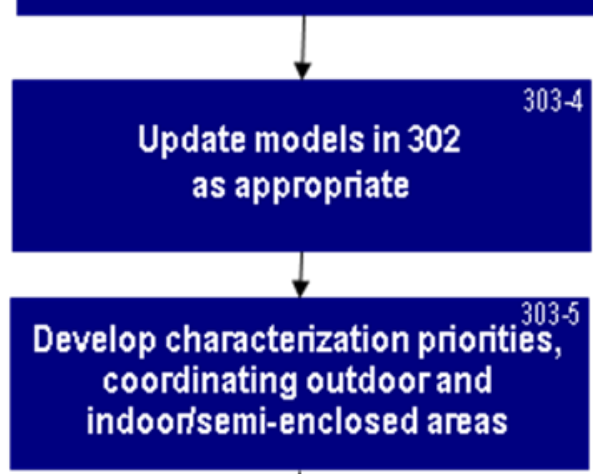

coordinating outdoor and

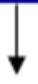

304 


\section{Expanded Framework}

\section{CHARACTERIZATION (304 expanded)}
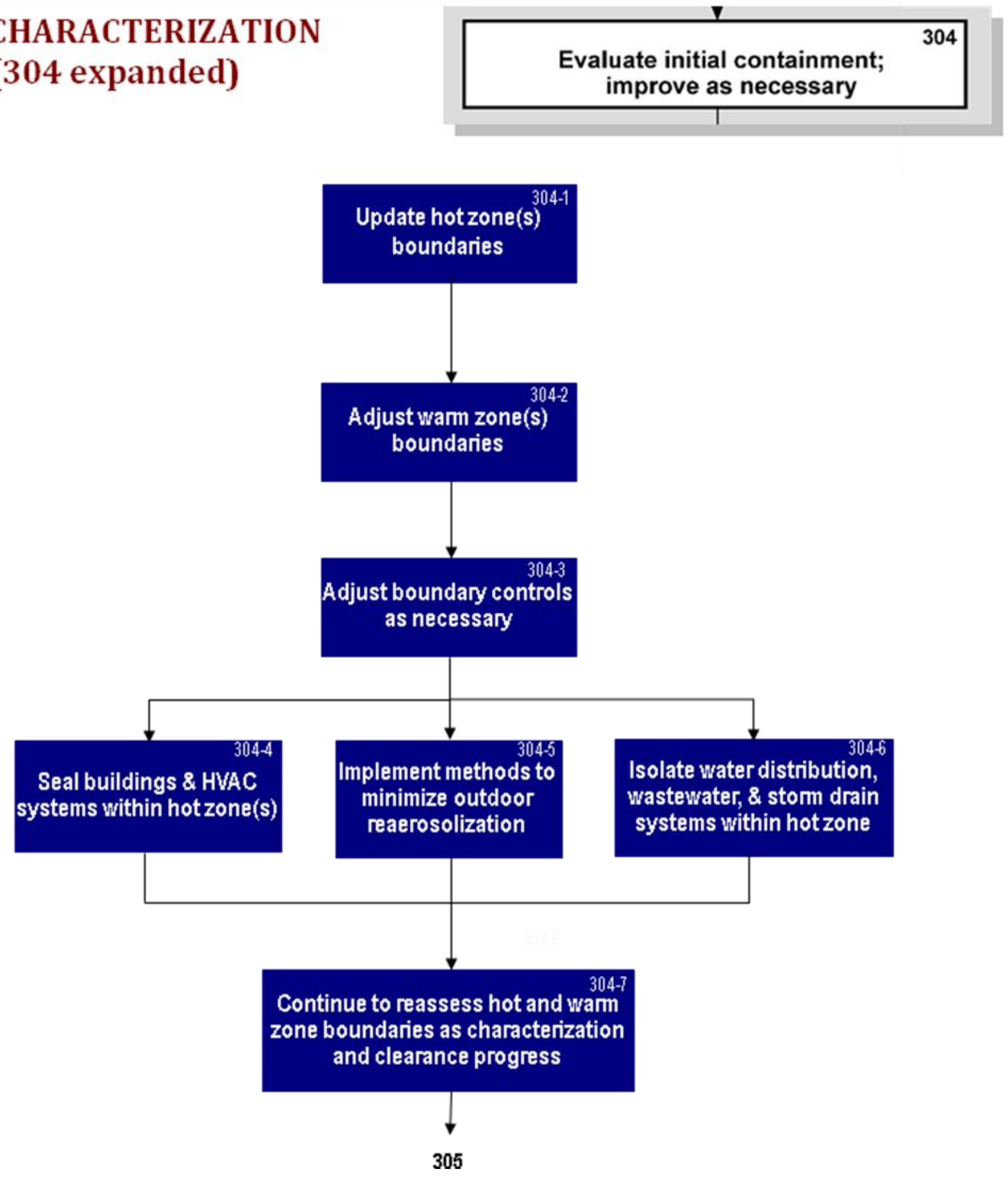


\section{Expanded Framework}

\section{CHARACTERIZATION (305 expanded)}

Conduct characterization environmental sampling and analysis

Develop comprehensive characterization sampling strategies

- Consider a phased approach to rapidly refine the limits of contamination

- Develop data quality objectives

- Consider statistical and judgmental criteria

- Employ iterative modeling approach to optimize sampling

- Establish minimum characterization sampling requirements

- Consider employing a zonal approach for sampling

- Consider surface, ari, and forced air sampling

- Address all necessary information requirements for risk assessment (including inhalationalçutaneous, or gastrointestinal risks)

$\downarrow$

\section{Write incident specific}

Characterization Sampling andAnalysis Plan(s) (SAP)

- Select sampling methods

- Select sampling locations

- Select analytical methods

- Identify resource limitations and optimize implementation
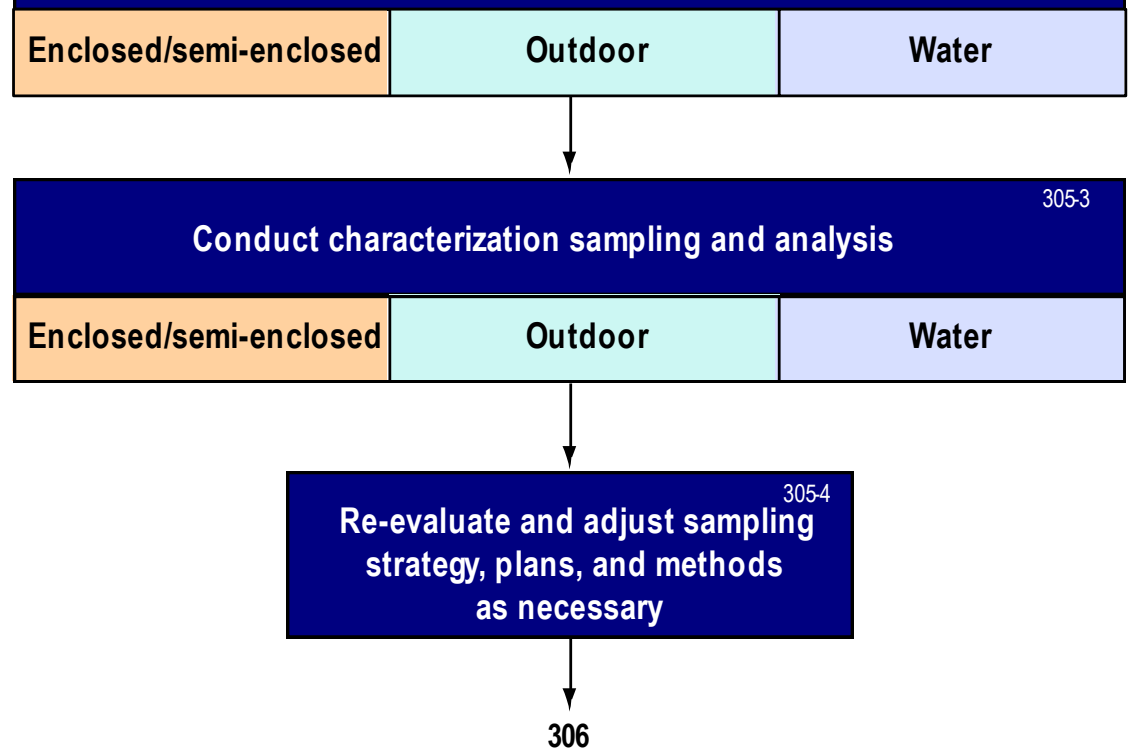


\section{Expanded Framework}

\section{CHARACTERIZATION (306 expanded)}
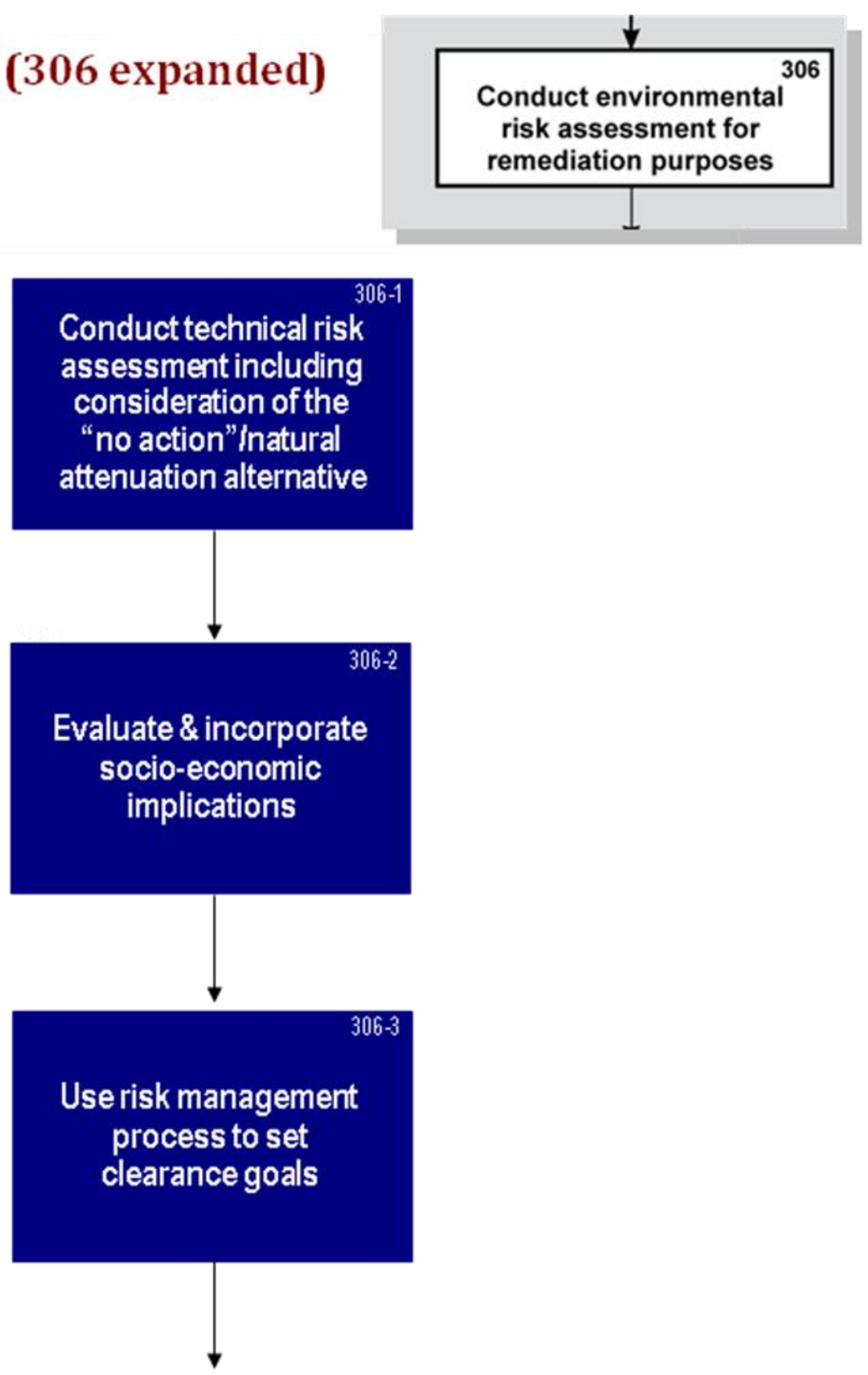

307 


\section{Expanded Framework}

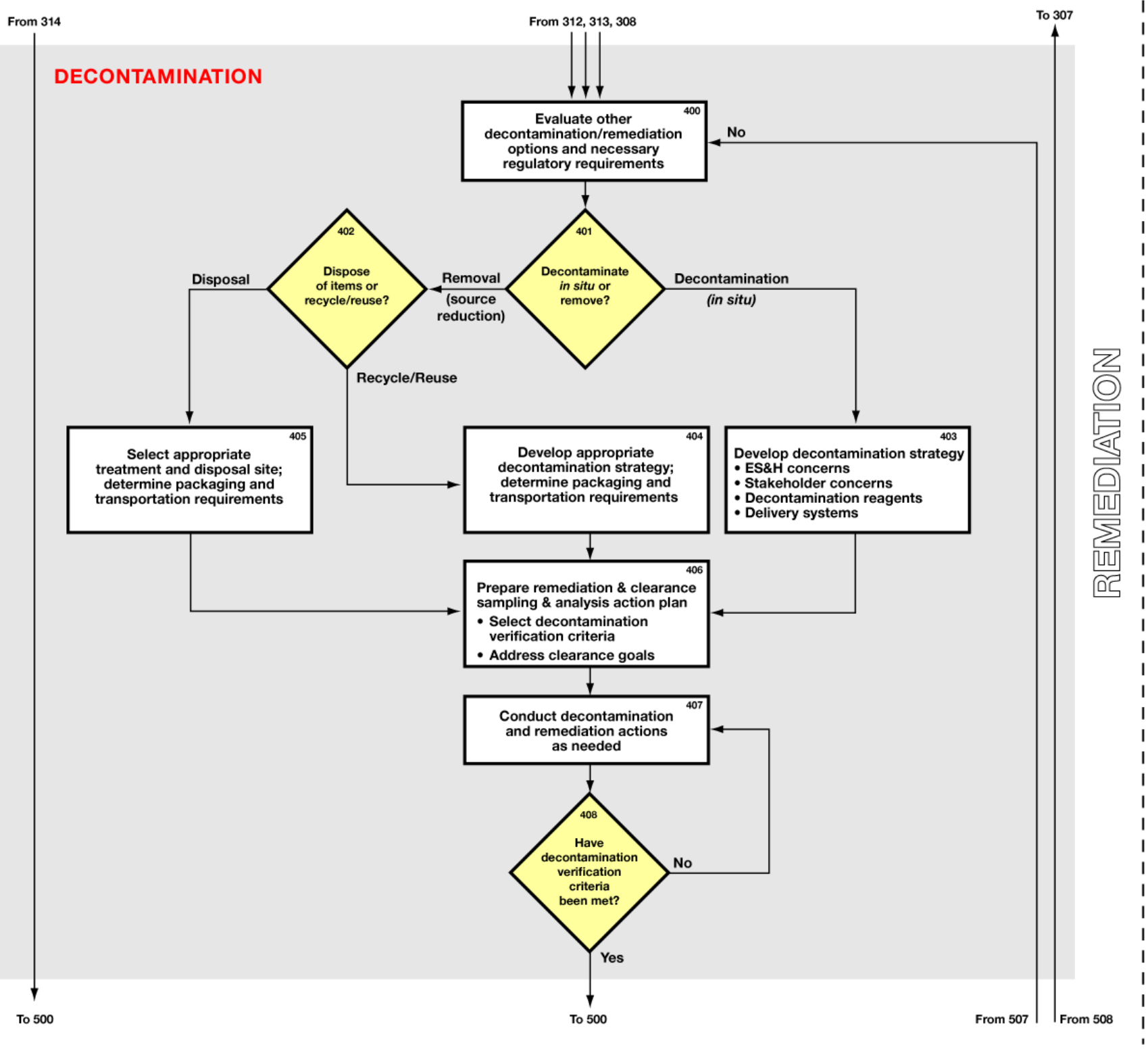




\section{Expanded Framework}

\section{DECONTAMINATION (expanded 400)}

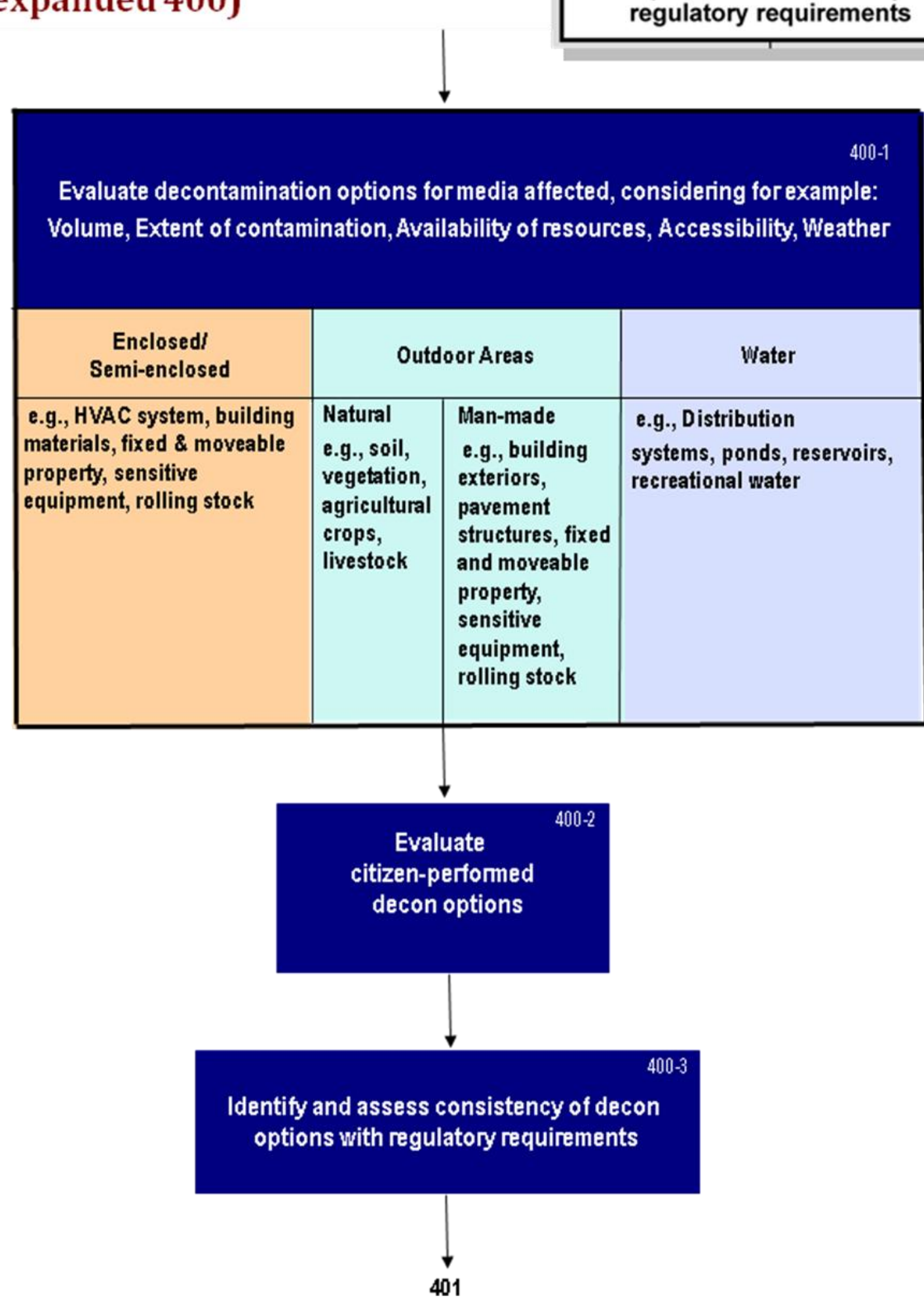




\section{Expanded Framework}

\section{DECONTAMINATION (expanded 403)}

Develop decontamination strategy

- ES\&H concerns

- Stakeholder concerns

- Decontamination reagents

- Delivery systems

Select decontamination methods including specific reagents and reagent delivery

systems for media affected, considering for example:

Volume, Extent of contamination, Availability of resources, Accessibility, Weather

\begin{tabular}{|c|c|c|c|}
\hline $\begin{array}{c}\text { Enclosed/ } \\
\text { Semi-enclosed }\end{array}$ & \multicolumn{2}{|c|}{ Outdoor Areas } & Water \\
\hline \multirow[t]{2}{*}{$\begin{array}{l}\text { e.g., HUAC system, building } \\
\text { materials, fixed and moveable } \\
\text { property, sensitive equipment, } \\
\text { rolling stock } \\
\text { Considering: } \\
\text { - Surface treatment } \\
\text { - Volumetric methods }\end{array}$} & $\begin{array}{l}\text { Natural } \\
\text { e.g., soil, } \\
\text { vegetation, } \\
\text { agricultural } \\
\text { crops, } \\
\text { livestock }\end{array}$ & $\begin{array}{l}\text { Man-made } \\
\text { e.g., building } \\
\text { exteriors, } \\
\text { paventent } \\
\text { structures, fixed } \\
\text { and moveable } \\
\text { property, } \\
\text { sensitive } \\
\text { equipment, } \\
\text { rolling stock }\end{array}$ & \multirow{2}{*}{$\begin{array}{l}\text { e.g., Distribution } \\
\text { systems, ponds, reservoirs, } \\
\text { recreationalwater } \\
\text { Considering: } \\
\text { - Treatment } \\
\text { - No treatment and } \\
\text { monitor }\end{array}$} \\
\hline & \multicolumn{2}{|c|}{$\begin{array}{l}\text { Considering: } \\
\text { - Localized treatment } \\
\text { - Wide area treatment } \\
\text { - Wash down and treat }\end{array}$} & \\
\hline
\end{tabular}

Develop emergency response plans to address potential uncontrolled reagent release(s)

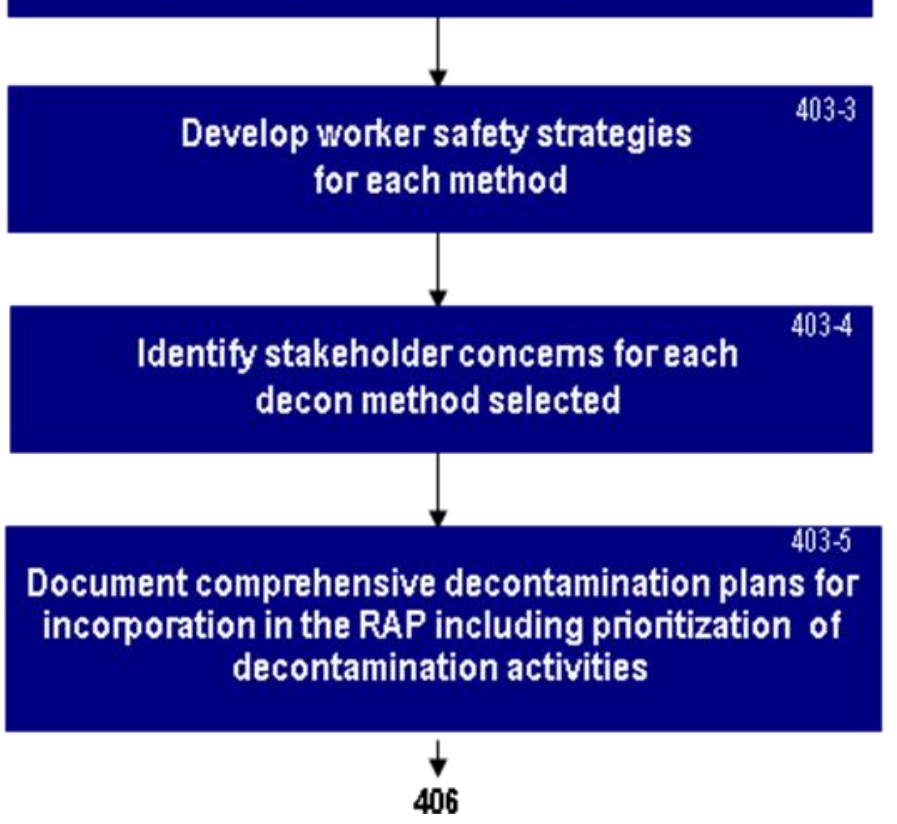




\section{Expanded Framework}

DECONTAMINATION (expanded 404)
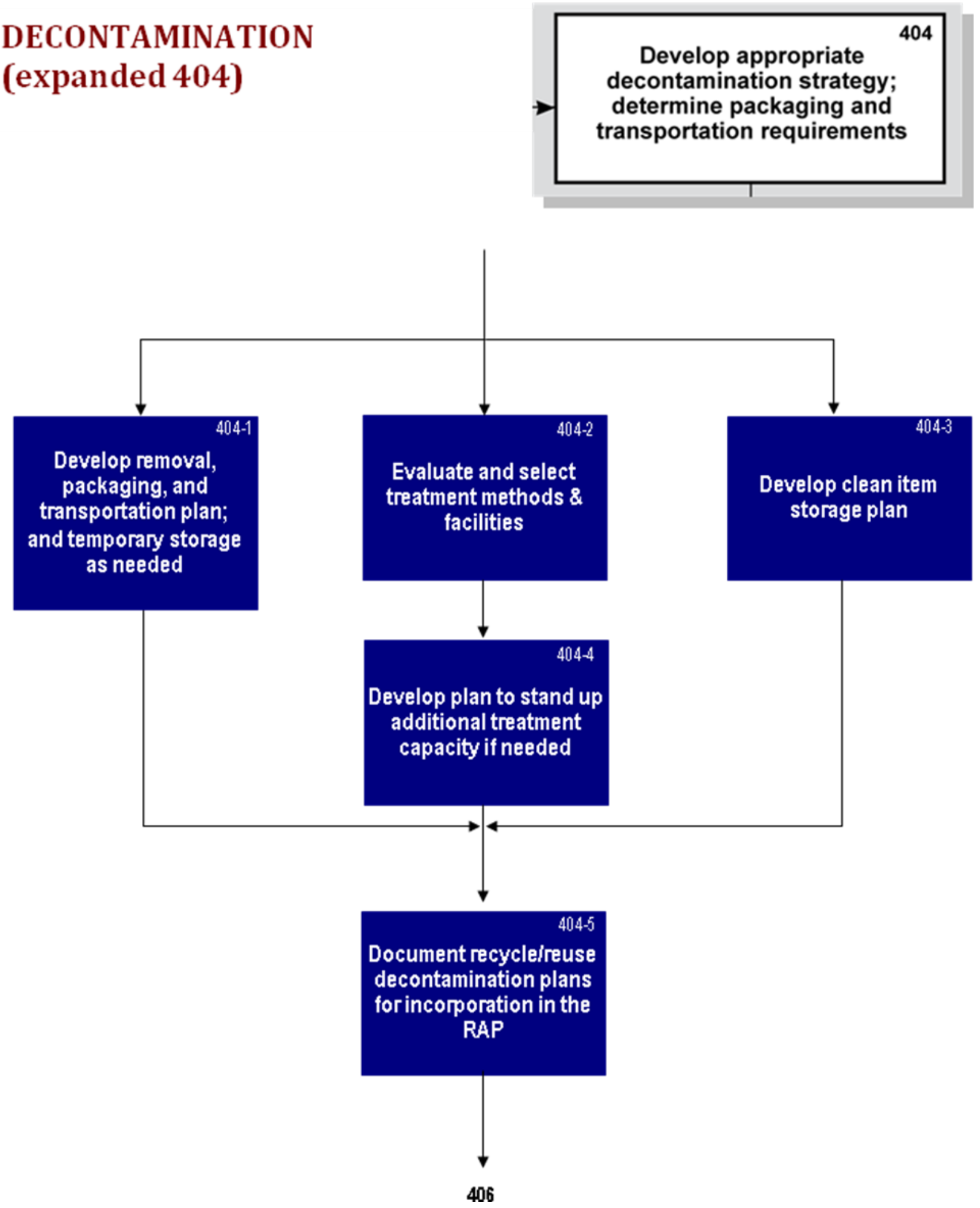


\section{Expanded Framework}

\section{DECONTAMINATION (expanded 405)}
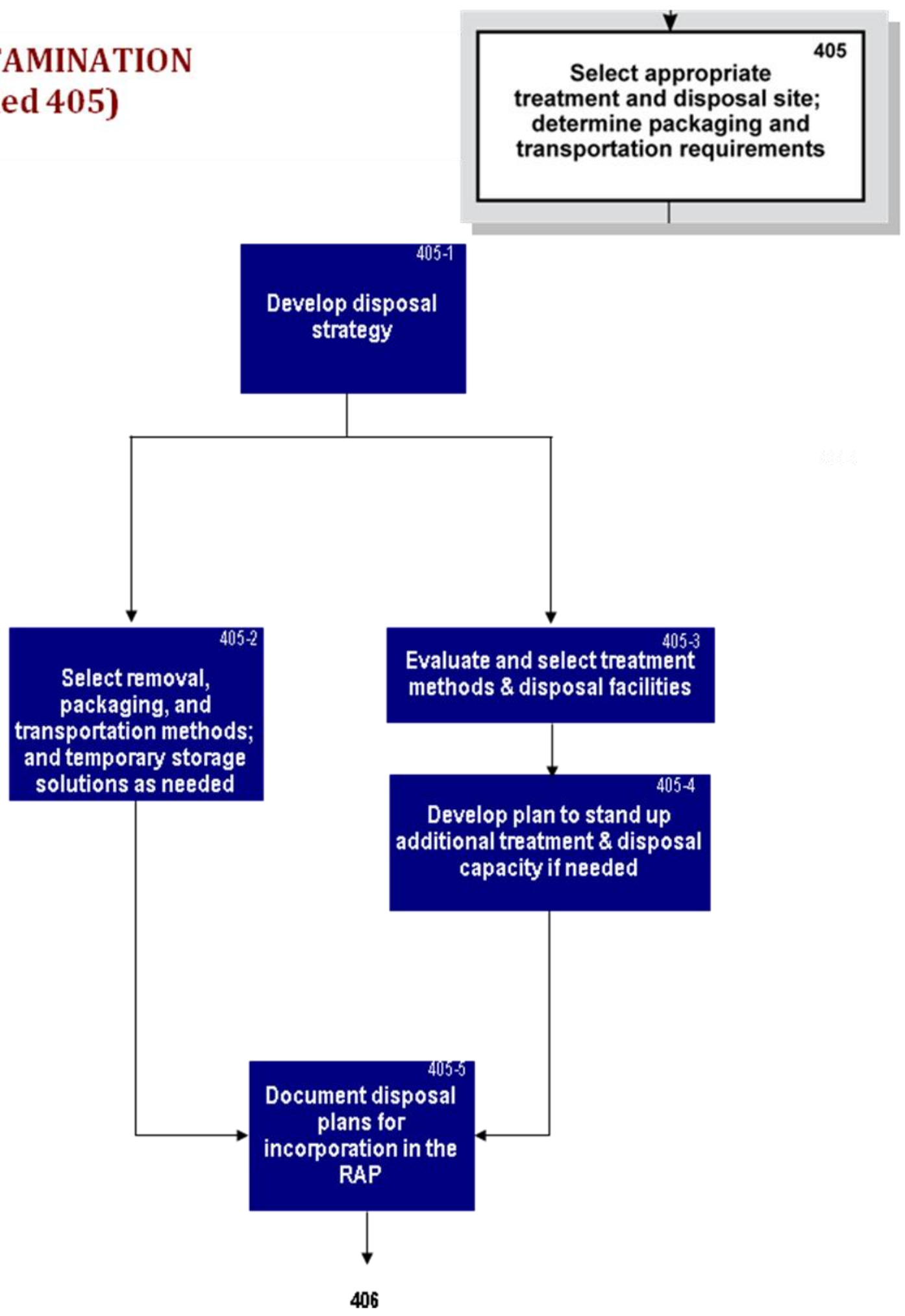


\section{Expanded Framework}

\section{DECONTAMINATION (expanded 406)}
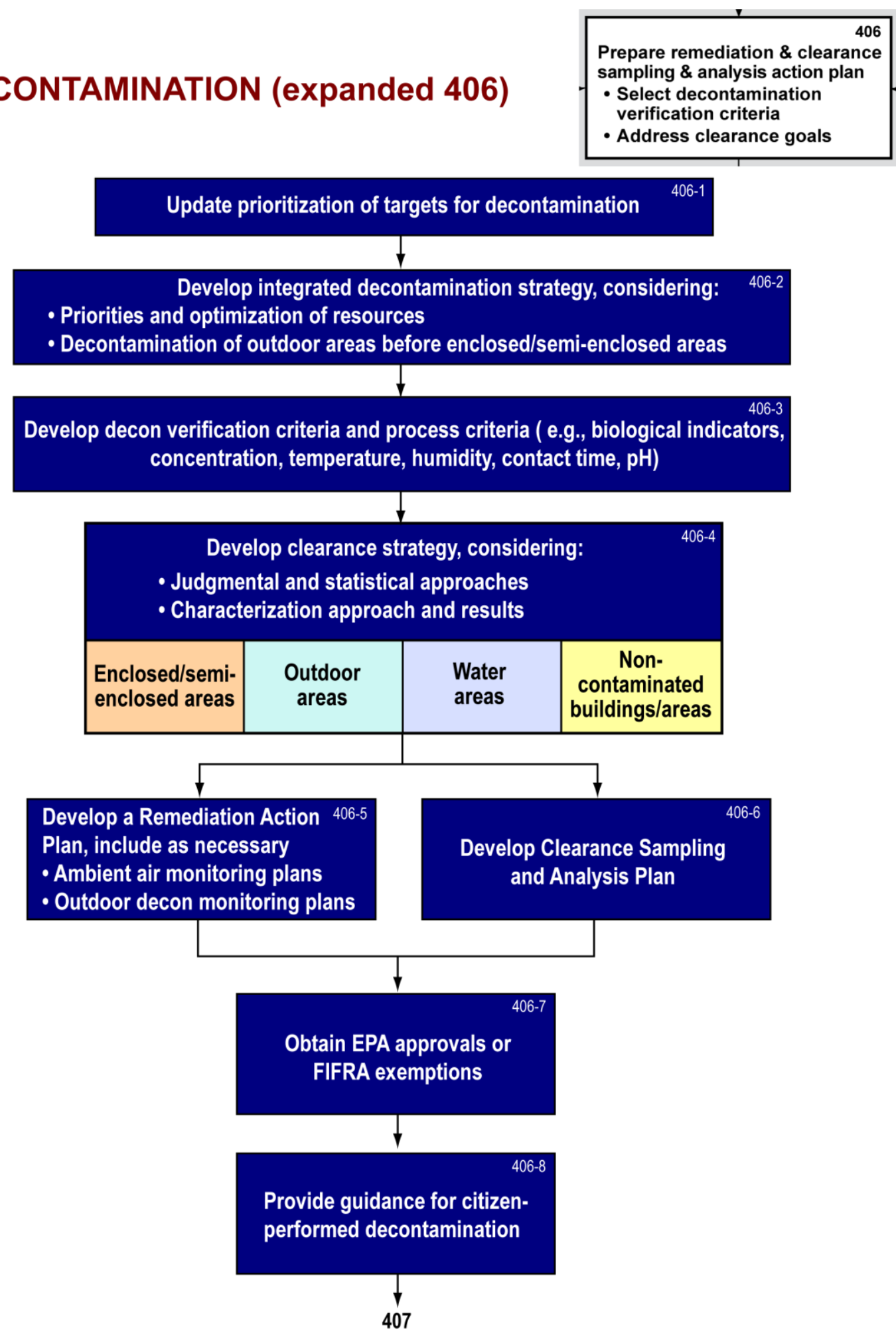


\section{Expanded Framework}

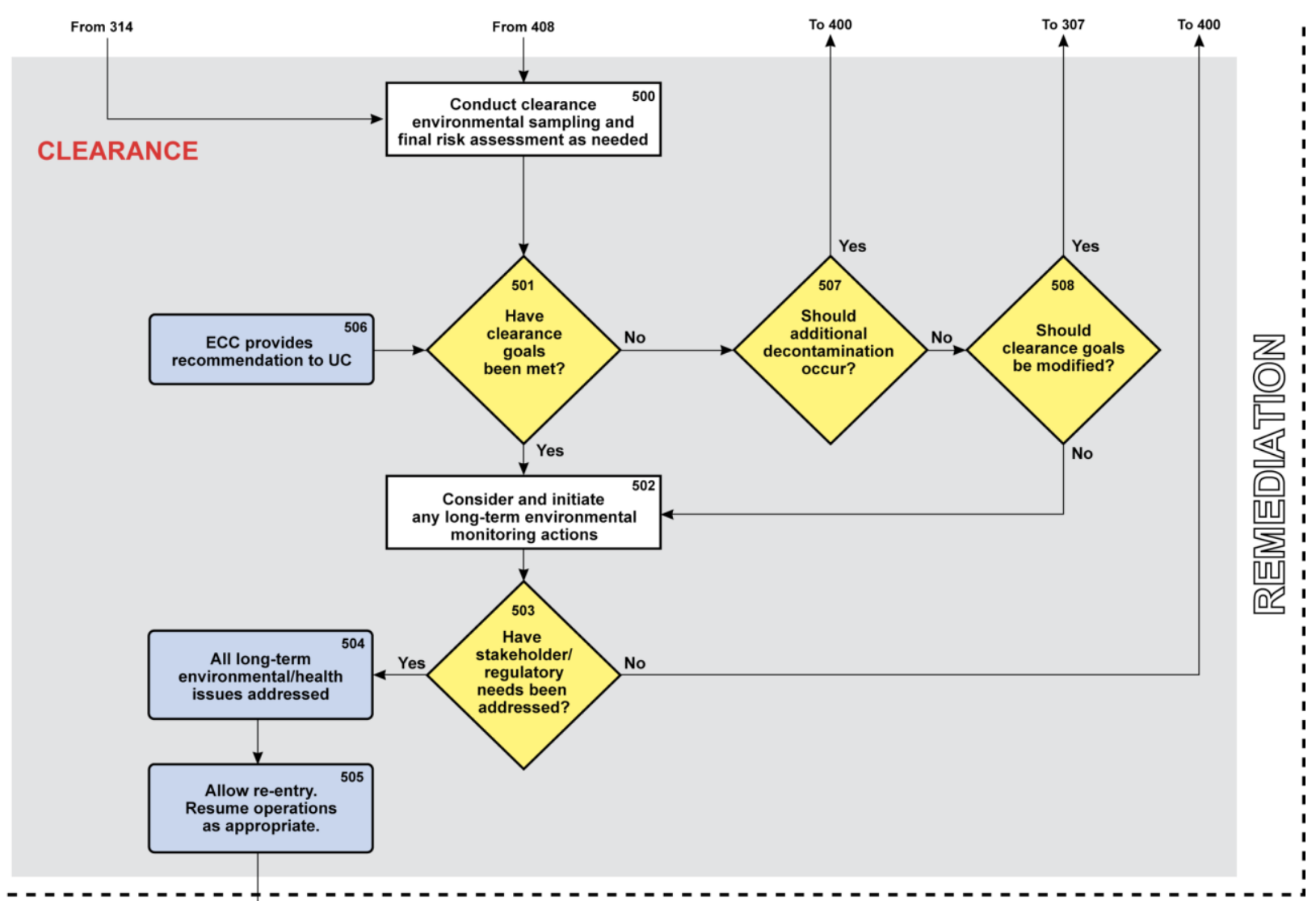




\section{Expanded Framework}

\section{CLEARANCE (expanded 500)}

Conduct clearance environmental sampling and final risk assessment as needed
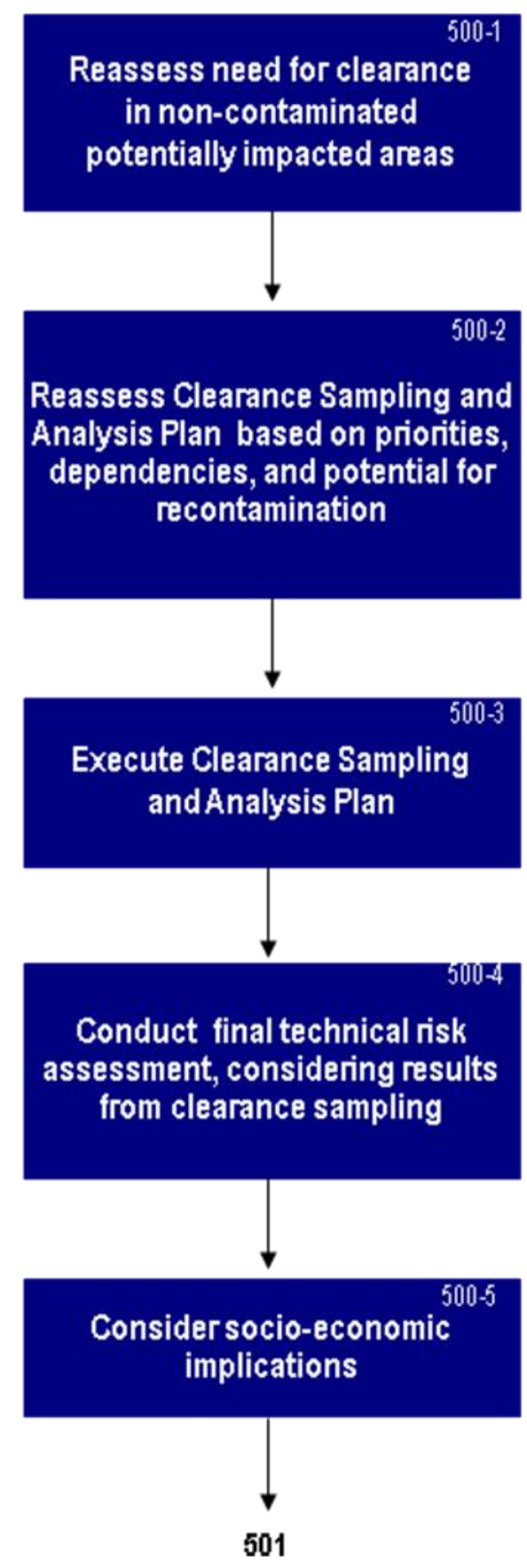


\section{Expanded Framework}

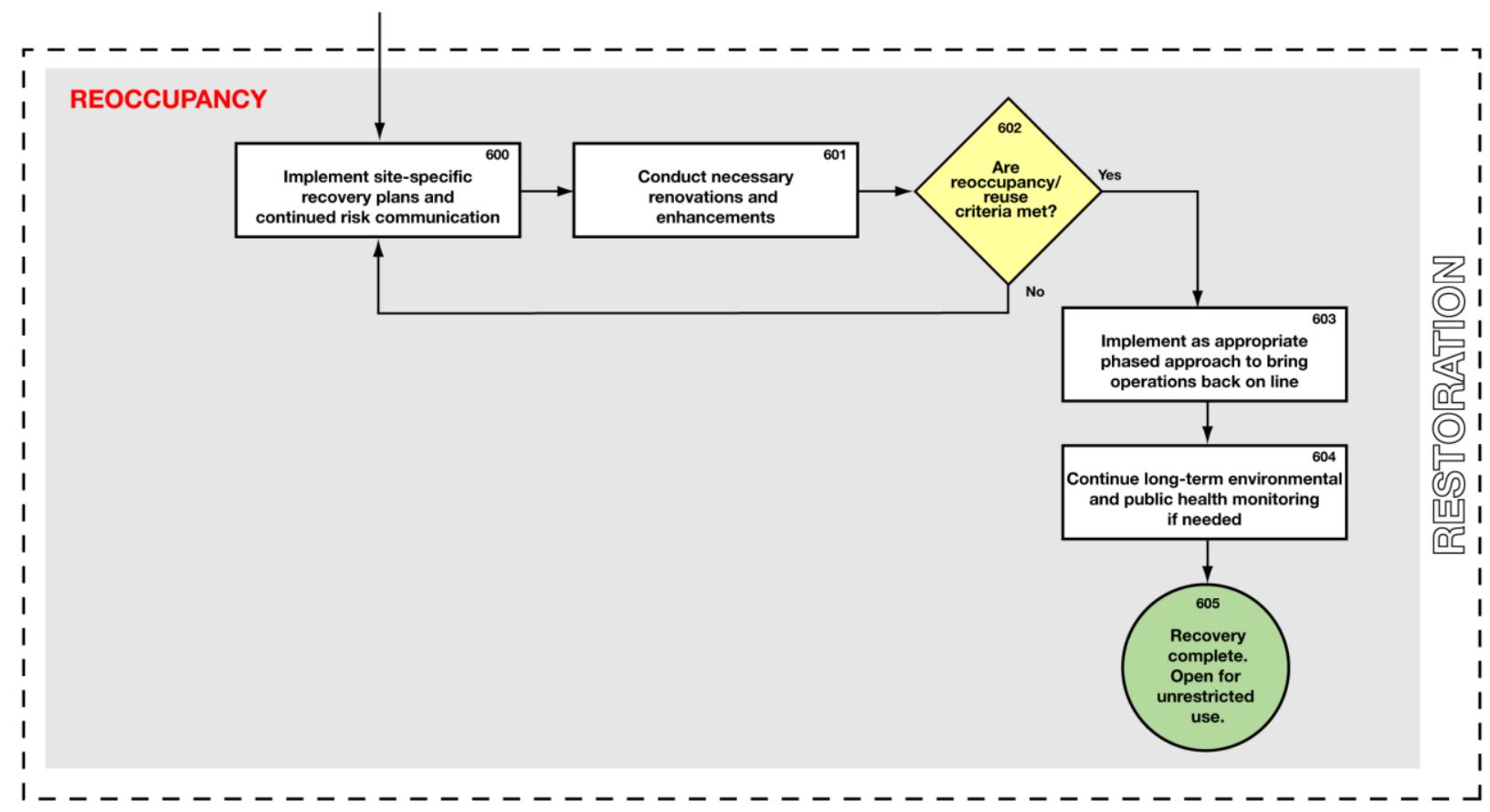




\section{Expanded Framework}

REOCCUPANCY

(expanded 604)
604

Continue long-term environmental and public health monitoring if needed

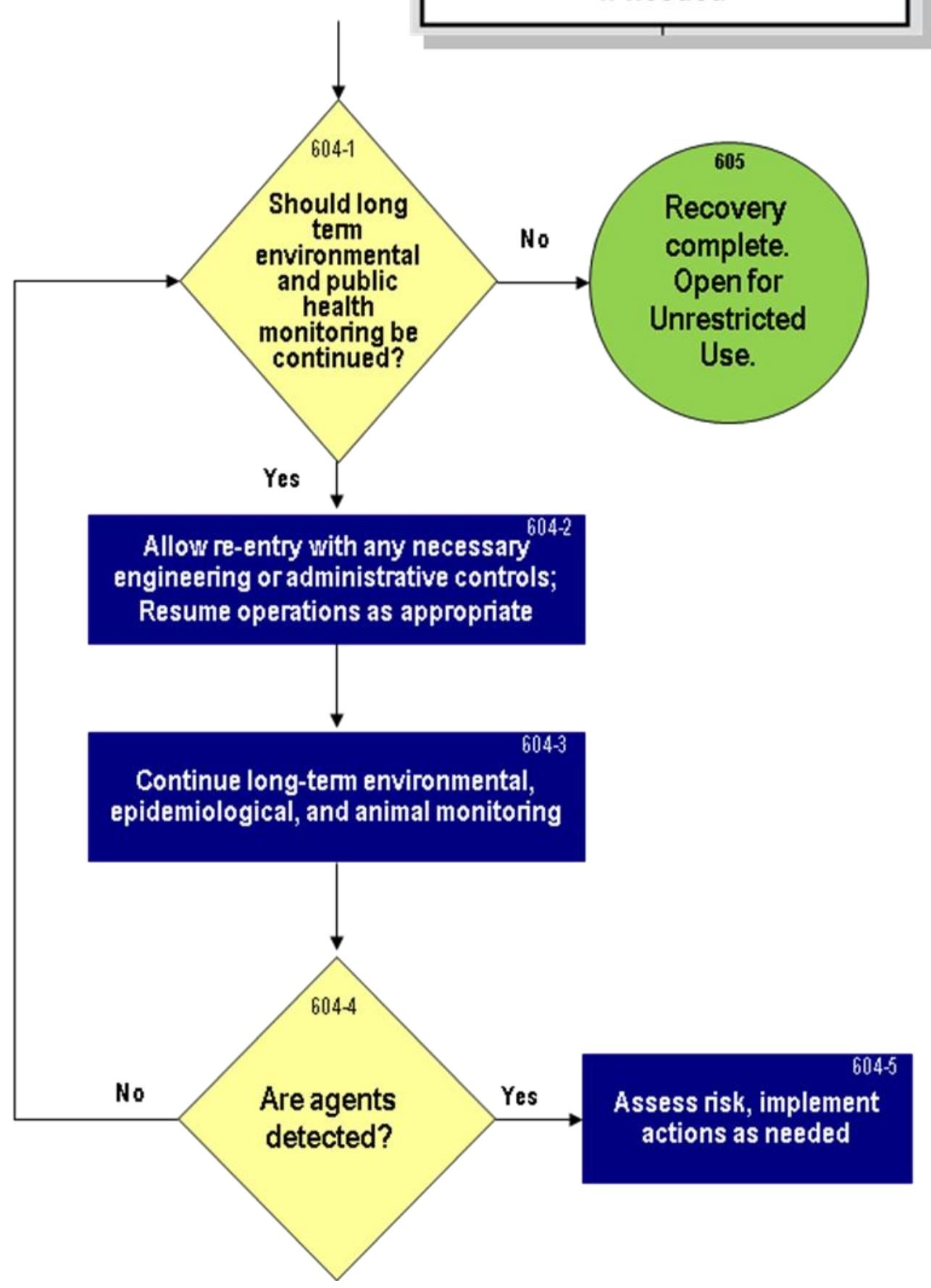




\section{Glossary}

Aggressive air sampling. Any method used to agitate particulates or fibers that may have settled out of the air or that could easily become airborne because of human activity (usually the use of high-powered fans or leaf blowers). The air should be agitated either during the entire time that an air sample is being collected or at regular intervals during the sampling period. Aggressive air sampling gives the most conservative of worst-case results of a given contaminant in indoor air. The Agency for Toxic Substances and Disease Registry (ATSDR) recommends that such sampling be performed because it is difficult to interpret surface-wipe sampling data for health purposes (DHHS 1994).

Ambient Air Monitoring Plan (AAMP). A written plan required by the U.S. Environmental Protection Agency as part of the crisis exemption process for using an unregistered sterilant or pesticide, such as a gaseous fumigant. The plan for monitoring ambient air is designed to ensure that the fumigant does not escape a facility in concentrations that may be a hazard to the surrounding population. (See also FIFRA exemption.)

Antimicrobial agent. An agent that kills or suppresses the growth of microorganisms. (Block 2001; DHS/EPA 2009.)

Area Command (Unified Area Command). An organization established (1) to oversee the management of multiple incidents that are each being handled by an Incident Command System (ICS) organization or (2) to oversee the management of large or multiple incidents to which several Incident Management Teams have been assigned.

Area Command becomes Unified Area Command when incidents are multi-jurisdictional. Area Command may be established at an Emergency Operations Center (see EOC) facility or at some location other than an Incident Command Post (see ICP). (DHS, December 2007.)

Anthrax. A non-contagious, infectious, often fatal, naturally occurring disease caused by the bacterium Bacillus anthracis that may be contracted by humans or animals via exposure through inhalation, the skin, or the gastrointestinal tract. (DHS/EPA 2009.)

Bacillus anthracis (B. anthracis). A spore-forming bacterium that causes anthrax. The spore form is about 1 by 2 microns in size and can easily be inhaled. In a warm, moist environment (such as the lungs), spores grow into vegetative, rod-shaped cells that multiply and cause hemorrhage, edema, and necrosis in humans and animals. (DHS/EPA 2009.)

BASIS Program. An environmental monitoring system originally designed for use at the 2002 Winter Olympics. Biological Aerosol Sentry and Information System (BASIS) is a joint project of two U.S. national laboratories, with participation of law enforcement and public health organizations. It uses a network of inexpensive sampling stations to collect and store aerosol samples. Couriers regularly bring samples to a central laboratory where they are analyzed for selected pathogens. Similar monitoring systems have been developed and deployed by the U.S. Department of Defense. (Fitch et al. 2003.)

Biohazard Safety Level (BSL). Different biosafety levels developed for microbiological and biomedical laboratories provide increasing levels of personnel and environmental protection from pathogenic microorganisms and hazardous subcellular entities (e.g., prions). Accordingly, laboratories may be classified as BSL-1, BSL-2, BSL3 or BSL-4, ranked from lowest to highest in degree of safety level. (DHS/EPA 2009.)

Biological incident. A natural or human-caused incident involving microbiological organisms (bacteria, fungi, and viruses) or biologically derived toxins that pose a hazard to humans, animals, or plants. (DHS/EPA 2009.)

Biological indicator (BI). A standardized preparation of bacterial spores on or in a carrier serving to demonstrate whether sterilizing conditions have been met. Spores of different organisms are used for different methods of sterilization. (Block, 2001)

Biological warfare agent (BWA). A microorganism (bacteria, fungi, and viruses) or biologically derived toxin that is intentionally introduced to cause disease or harm in humans, animal, or plants. Per Title 18 USC $\S 178$, any biological material capable of causing death, disease, or other biological malfunction in a human, animal, plant, or another living organism; or causing deterioration of food, water, equipment, supplies, or material of any kind; or causing harmful alteration of the environment.

BioWatch Program. BioWatch is an early-warning system that can rapidly detect trace amounts of biological materials in the air whether arising from intentional release or minute quantities that are naturally in the air. The 
system is patterned after the Biological Aerosol Sentry and Information System (BASIS) environmental monitoring system. It operates nationwide and focuses on major urban centers. See also BASIS. (DHS BioWatch website and Fitch et al. 2003.)

Bulk sampling. Environmental sampling done by collecting a volume (or mass) of material such as soil, water, rubber, acoustic tile, or concrete.

CERCLA. The Comprehensive Environmental Response, Compensation, and Liability Act (42 USC 9601 et seq.), as amended by the Superfund Amendments and Reauthorization Act of 1986. CERCLA authorizes the President and EPA (by delegation from the President) to respond to releases or substantial threats of releases of pollutants or contaminants that may present an imminent and substantial danger to the public health or welfare.

Characterization. The process of obtaining specific information about a biological agent, such as its identity, genetic composition, formulation, physical properties, toxicological properties, ability to aerosolize, and persistence in the environment as a viable form, and about the nature and extent of contamination of the agent, such as locations or items contaminated and the amount of contamination. Characterization of the agent and of the contamination at an affected site generally occurs after First Response and before Decontamination. (DHS/EPA 2009.)

Characterization environmental sampling. Environmental sampling intended to assess the nature (identity and properties) and extent (location and quantity) of contamination of an area or items. Generally occurs after First Response and before Decontamination. (DHS/EPA 2009.)

Characterization zone. A discrete section of a contaminated site that is examined for the purpose of determining the potential for exposure to the contaminant in that area. (DHS/EPA 2009.)

Cleanup. The process of characterizing, decontaminating, and clearing a contaminated site or items, including disposal of wastes. Cleanup is a synonym for remediation. Generally occurs after characterization and before clearance. (DHS/EPA 2009.)

Clearance. The process of determining that a clearance goal has been met for a specific contaminant at a specific site or on an item. Clearance generally occurs after decontamination and before reoccupancy. Clearance typically includes environmental sampling together with analysis of data by subject-matter experts (such as an Environmental Clearance Committee) and stakeholders to ensure that all long-term health and environmental issues are addressed.

Clearance criteria or clearance decision criteria. A defined process for determining whether clearance goals have been met. The process should ensure that exposure guidelines are met with a level of confidence that is acceptable to stakeholders. (DHS/EPA 2009.)

Clearance/Cleanup goal. An amount of residual contamination for a specific contaminant in or on an area or item that, once achieved following decontamination, provides acceptable protection to human health and the environment. A clearance goal specifies criteria for determining the success of decontamination that are measurable and for permitting unprotected reentry. (DHS/EPA 2009.)

Clearance environmental sampling. Environmental sampling that is conducted after the decontamination process is completed for a specific contaminant in an area or on items, and is intended to provide a basis for determining whether the clearance goal has been met. (DHS/EPA 2009.)

Clearance Environmental Sampling and Analysis Plan (Clearance SAP). A formal, written plan that describes how clearance sampling will be done, including the rationale for the clearance sampling design. It specifies the clearance decision criteria, that is, how the clearance sampling results will be used to determine whether clearance goals have been met. The Clearance SAP is a companion to the Remediation Action Plan (RAP), and is required before the RAP is executed.

Clearance zone. A section or subsection of a contaminated site for which a clearance decision is made.

Cold zone. See staging area. Also called the clean zone, per Hazardous Waste Operations and Emergency Response (HAZWOPER).

Concept of Operations (ConOps). A formal plan that describes the roles, responsibilities, and relationships of organizations involved in a response to a contaminated area or items. Typically, a CONOPS addresses Federal, State, local and Tribal agencies and how they should interact when responding to a potential or actual terrorist threat or incident. (DHS/EPA 2009.)

Consequence Management. Predominantly an emergency management function that includes measures to protect public health and safety; restore essential government services; and provide emergency relief to governments, businesses, and individuals affected by the consequences of terrorism (DHS, December 2008). Includes Remediation (i.e., Characterization, Decontamination, Clearance) and Restoration and Reoccupancy activities (see 
six-phase Figure 1-3). (See also DHS/EPA 2009.) The requirements of consequence management and crisis management are combined in the National Response Framework (DHS 2008). See also Crisis Management.

Containment. In the context of this document, includes actions or measures taken to prevent the spread of a contaminant (biological warfare agent) from a particular zone or to prevent the movement of a contaminant within a zone. Compare with Isolation. This term is defined differently by different agencies. (DHS/EPA 2009.)

Contaminant reduction zone. The transition area between the exclusion and support zones where responders enter and exit the exclusion zone and where decontamination activities take place. Also called the Warm Zone. (EPA 2004.)

Covert release. In the context of this document, includes the intentional release of a biological warfare agent that is not reported or openly acknowledged by terrorists, or observed by surveillance systems, or witnessed by potential victims at the scene of release, and typically requiring epidemiological or medical observations to lead to the discovery of an agent's release.

Crisis Management. Predominantly a first-responder and law-enforcement function that includes measures to identify, acquire, and plan the use of resources needed to anticipate, prevent, and resolve a threat or act of terrorism. In the context of this document, includes measures that are predominantly first-responder and law-enforcement functions to resolve the immediate threat or act of terrorism. The requirements of consequence management and crisis management are combined in the National Response Framework (DHS 2007). See Consequence Management.

Culturing. In this document, growing microorganisms in a controlled, artificial environment. The CDC bacterial culture method is the definitive confirmatory test on environmental samples for positive identification of Bacillus anthracis spores upon which public health decisions are made.

Decision maker. A person charged with determining and directing appropriate actions in response to a potential or actual biological incident at a particular site. (DHS/EPA 2009.)

Decontamination. The process of inactivating or reducing a contaminant in or on humans, animals, plants, food, water, soil, air, areas, or items through physical, chemical, or other methods to meet a cleanup goal.

Decontamination applies to both disinfection and sterilization processes. Generally occurs as part of Remediation. (Note: Decontamination has been defined in different ways by different Federal agencies and other entities.) (DHS/EPA 2009.)

Decontamination area or zone. A section of a contaminated site that can be isolated from other areas and is decontaminated as a unit. (DHS/EPA 2009.)

Decontamination agent. A substance that is used to inactivate or reduce a contaminant on humans, animals, plants, or inanimate surfaces or in other media. If the contaminant is a microorganism, the chemical is an antimicrobial pesticide. (DHS/EPA 2009.)

Disinfectant. A chemical or physical agent that destroys pathogenic or other harmful microorganisms, but not bacterial spores on inanimate surfaces. (DHS/EPA 2009.)

Disinfection. The destruction of pathogenic and other kinds of microorganisms by physical (e.g., heat, desiccation, freezing, radiation) or chemical means. Disinfection is a less-lethal process than sterilization because it destroys most recognized pathogenic microorganisms, but not necessarily all microbial forms, such as bacterial spores. Disinfection processes do not ensure the margin of safety associated with sterilization processes. (AAMI, 1995)

Disposal. The deposition or placement of any solid or hazardous waste on or in the land or water. Disposal of wastes from the remediation of a wide urban area will likely be accomplished through the use of permitted and licensed landfills meeting certain criteria (i.e., if the material being disposed is a hazardous waste, it would be sent to a hazardous waste landfill) or through appropriate treatment technologies, such as steam autoclaving or incineration. Treatment technologies such as incineration may generate residues that must be tested and then appropriately disposed, most often in a hazardous-waste or a municipal solid-waste landfill.

Emergency Operations Center (EOC). The physical location at which the coordination of information and resources to support domestic incident management activities normally takes place. An EOC may be a temporary facility or may be located in a more central or permanently established facility, perhaps at a higher level of organization within a jurisdiction. EOCs may be organized by major functional disciplines (e.g., fire, law enforcement, and medical services), by jurisdiction (e.g., Federal, State, regional, county, city, or tribal), or by some combination thereof. (DHS 2008.)

Environmental Clearance Committee (ECC). An independent group of scientific experts from a variety of Federal, State, and local agencies that provides advice, data and process analysis, and recommendations related to 
decontamination of a facility. An ECC provides a final recommendation on whether the cleanup was adequate to justify reopening an area or facility for normal operations and use. Although not required, the use of an ECC to evaluate the adequacy of cleanup through highly qualified professional debate is recommended to ensure adequate protection of public health. (Modified from Proceedings from the 2nd Civilian-Military Anthrax Response Technical Workshop, 2004.)

Environmental sampling. Sampling conducted on inanimate surfaces or in air, water, or soil for the purpose of detecting the presence of a specific biological agent. (DHS/EPA 2009.)

Environmental Unit. An Incident Command System unit responsible for environmental matters associated with a response, including strategic assessment, modeling, and environmental monitoring and permitting.

Exclusion zone. An area with actual or potential contamination and the highest potential for exposure to the contaminant. Entry to this area is permitted only for persons wearing appropriate personal protective equipment (PPE). Equivalent to Hot Zone, Red Zone, Isolation Zone, or Restricted Zone. (DHS/EPA 2009.)

FIFRA exemption. Under the authority of Section 18 of the Federal Insecticide, Fungicide, and Rodenticide Act (FIFRA), the Administrator of EPA may exempt any Federal or state agency from the pesticide registration requirements of FIFRA, if the Administrator determines that emergency conditions exist that require such exemption. As described in EPA's regulations (40 CFR Part 166), four types of exemptions - specific, quarantine, public health, and crisis - may be issued under different circumstances. Other types of emergency exemptions require a state or Federal agency to submit an application to EPA for review and approval.

First responders. Primarily local and nongovernmental police, fire, and emergency personnel who in the early stages of an incident are responsible for the protection and preservation of life, property, evidence, and the environment, including emergency response providers as defined in Section 2 of the Homeland Security Act of 2002 (6 U.S.C. 101), as well as emergency management, public health, clinical care, public works, and other skilled personnel who provide immediate support services.

First response. Actions taken immediately following notification of a biological incident or release. In addition to search and rescue, perimeter control, site security, and law enforcement activities, first response includes initial site containment, environmental sampling and analysis, and public health activities, such as treatment of potentially exposed persons. (DHS/EPA 2009.)

Federal On-Scene Coordinator (FOSC OR OSC). The Federal official predesignated by the U.S. Environmental Protection Agency or the U.S. Coast Guard to coordinate responses under subpart D of the National Contingency Plan (NCP), or the government official designated to coordinate and direct removal actions under subpart $\mathrm{E}$ of the NCP. (DHS 2008.)

Fumigant. In the context of this document, a fumigant is a gaseous or vaporized decontamination reagent, such as vaporous hydrogen peroxide, chlorine dioxide, ethylene oxide, methyl bromide, or paraformaldehyde, which is known to be effective in killing Bacillus anthracis spores and used during cleanup.

Fumigation. Use of a chemical gas or vapor in a contained space to inactivate biological contaminants (primarily pathogenic bacteria, fungi, and viruses). (DHS/EPA 2009.)

Fumigation zone. A discrete section or subsection of a building or facility that is isolated with respect to other areas of the building or facility for the purposes of fumigation. See Isolation.

Hazardous material. A substance or material, including a hazardous substance, that has been determined by the Secretary of Transportation to be capable of posing an unreasonable risk to health, safety, and property when transported in commerce, and which has been so designated (49 CFR 171.8).

Health and Safety Plan (HASP). A written plan required under the Occupational Health and Safety Administration's (OSHA's) Hazardous Waste Operations and Emergency Response (HAZWOPER) standard (29 CFR 1910.120). This standard requires a written HASP, which identifies site hazards and appropriate controls to protect employee health and safety. (National Response Team, NRT 2005.) The HASP describes known physical, chemical, and biological hazards at a site; the establishment of hot (contaminated), cold (uncontaminated), and warm (intermediate) zones; personal protective equipment (PPE); personal decontamination procedures; and emergency procedures to be used by sampling and decontamination personnel.

Hotline. The outer boundary of the Exclusion Zone (Hot Zone) that separates the area of contamination from the Contamination Reduction Zone (Warm Zone). (DHS/EPA 2009.)

Hot zone. See Exclusion zone. 
Inactivation. Removing the activity of microorganisms by killing or inhibiting reproductive or enzyme activity. When referring to an antimicrobial agent, inactivation means neutralizing the activity of microorganisms by any means. (Block 2001.)

Incident. An occurrence or event, natural or human-caused, which requires an emergency response to protect life or property. Incidents can include major disasters, emergencies, terrorist attacks, terrorist threats, wild land and urban fires, floods, hazardous materials spills, nuclear accidents, aircraft accidents, earthquakes, hurricanes, tornadoes, tropical storms, war-related disasters, public health and medical emergencies, and other occurrences requiring an emergency response. (DHS 2008.)

Incident Action Plan (IAP). An oral or written plan containing general objectives reflecting the overall strategy for managing an incident. It may identify operational resources and assignments. It may also include attachments that provide direction and important information for managing the incident during one or more operational periods. In the context of this document, the Remediation Action Plan (RAP) is implemented through a series of IAPs.

Incident Command (IC). The unit responsible for all incident activities, including the development of strategies and tactics and the ordering and release of resources. The IC has overall authority and responsibility for conducting incident operations and is responsible for managing all incident operations at the incident site. (NIMS 2008; DHS 2008)

Incident Commander (IC). The individual responsible for all incident activities, including the development of strategies and tactics and the ordering and the release of resources. The IC has overall authority and responsibility for conducting incident operations and is responsible for the management of all incident operations at the incident site. (NIMS 2008; DHS 2008.)

Incident Command Post (ICP). As defined in the NRF, the ICP is the field location at which the primary tacticallevel, on-scene incident command functions are performed. The ICP may be co-located with the incident base or other incident facilities and is normally identified by a green rotating or flashing light. Compare with EOC.

Incident Command System (ICS). A standardized, on-scene, emergency management construct specifically designated to provide for the adoption of an integrated organizational structure that reflects the complexity and demands of single or multiple incidents, without being hindered by jurisdictional boundaries. ICS is the combination of facilities, equipment, personnel, procedures, and communications operating with a common organizational structure, designed to aid in managing resources during incidents.

Infectious dose (ID). A dose at which an organism can reproduce in the host and produce a measurable effect. (Johnson 2003.)

Isolation. For the purposes of this document, action taken to seal a site, or portions of a site, to permit gas- or vaporphase decontamination and prevent release of fumigant. Compare with containment. This term has been used differently by various agencies.

Isolation Zone. A contaminated area for which entry is permitted only for persons wearing appropriate personal protective equipment (PPE). Equivalent to Hot Zone, Red Zone, Exclusion Zone, and Restricted Zone. (DHS/EPA 2009.)

Judgmental sampling. Environmental sampling in which the locations are determined by professional judgment. Generally based on incident-specific information, such as a known release location, obvious presence of contamination, or facility-specific information including air-flow patterns.

Laboratory Response Network (LRN). The organization of public health laboratories established by the Department of Health and Human Services, Centers for Disease Control and Prevention (CDC) in accordance with Presidential Decision Directive 39. The LRN and its partners maintain an integrated national and international network of laboratories that are equipped to respond quickly to acts of chemical or biological terrorism, emerging infectious diseases, and other public health threats and emergencies. (CDC, 2005.) In a partnership of the CDC, FBI, and Association of Public Health Laboratories, the LRN fulfills the Federal responsibility of rapid sample testing and identification of biological and chemical threat agents through established protocols and reagents. The LRN also serves as a sentinel warning system for covert biological incidents.

Life safety zones. Zones established at a contaminated site that are intended to reduce the accidental spread of hazardous substances by workers or equipment from contaminated areas to clean areas. Safety zones specify the type of operations that occur in each zone, the degree of hazard at different locations within the release site, and the areas at the site that should be avoided by unauthorized or unprotected employees. (DHS/EPA 2009.) 
Lifelines. The underlying infrastructure necessary to sustain human activity. Lifelines include information and communications; electrical power systems; gas and oil production, storage, and transportation; banking and finance; transportation; water-supply systems; emergency services; and continuity of essential government services.

Monitored natural attenuation. The destruction or inactivation of a microorganism or products of a microorganism, such as a toxin, via natural, environmental mechanisms such as heat, light, biochemical, or chemical reactions. (DHS/EPA 2009.)

National Incident Management System (NIMS). A nationwide template enabling Federal, State, local, and tribal governments and private-sector and nongovernmental organizations to work together effectively and efficiently to prevent, prepare for, respond to, and recover from domestic incidents regardless of cause, size, or complexity. The NIMS provides a core set of doctrine, concepts, terminology, and organizational processes to enable collaborative incident management at all levels.

National Response Framework (NRF). An all-discipline, all-hazards plan that establishes a single, comprehensive framework for managing domestic incidents. The NRF provides the structure and mechanisms for coordinating Federal support to, and exercising direct Federal authorities and responsibilities for, such incidents.

Native air samples. "Found samples" yielding data on possible contaminants in the air, which might be collected over a wide area with greater expediency than collecting environmental surface samples from devices placed in the field after an incident. Examples include samples taken from air filters already in the field (such as building HVAC filters and selected vehicle air filters), or the data gathered by data-collection systems, such as from environmental aerosol monitoring stations operated by the EPA, state and local agencies, or others.

Negative air unit (NAU). A system that subjects an area to a slightly negative pressure to ensure that a contaminant (and decontamination reagent) remains in the contamination zone. NAUs consist of a HEPA filter, chemical scrubber, demister, carbon bed, fan, and stack. Air within a contamination zone is exhausted through HEPA filters at a rate sufficient to pull a slightly negative pressure in the zone. (Carlsen et al., 2005.)

Notification. The process of communicating the occurrence or potential occurrence of a biological incident through and to designated authorities who initiate First Response actions. Generally occurs as the first step in a response to a suspected or actual biological incident. (DHS/EPA 2009.)

Operations Section. The ICS section responsible for all tactical incident operations.

Optimization. A flexible decision process that addresses multiple aspects of the problem and seeks to analyze, consider, and balance these factors in decontamination and recovery activities. (DHS/EPA 2009.)

Overt release. In the context of this document, the intentional release of a biological warfare agent that is reported or openly acknowledged by terrorists, or observed by surveillance systems or witnesses at the scene of the release, or otherwise made known at the time of release.

Pathogen. Any disease-producing microorganism. (Block 2001.)

Planning Section. The Incident Command System section responsible for collecting, evaluating, and disseminating operational information related to an incident and for preparing the Incident Action Plan. The Planning Section maintains information on the current and forecasted situation and on the status of resources assigned to the incident.

Polymerase chain reaction (PCR). A method, sometimes referred to as "molecular photocopying," for generating copies of a fragment of DNA. PCR can characterize and synthesize any specific piece of DNA and identify genetic material from specimens, including microbes, such as Bacillus anthracis. As a field test described in this document, the rapid, automated, and quantitative PCR technique involves a portable piece of equipment using a reaction tube, reagents, and a heat source to obtain presumptive evidence of the presence of Bacillus anthracis spores.

Confirmation of the presence of such spores must be obtained through the laboratory culture of sampled material, a more lengthy process.

Principal Federal Official (PFO). The Federal official designated by the Secretary of Homeland Security to act as his/her representative locally to oversee, coordinate, and execute the Secretary's incident management responsibilities under HSPD-5 for major incidents. (DHS 2008.)

Process monitoring. Measuring and recording the key variables of a decontamination process as they occur. For example, during fumigation, the key variables are gas concentration, temperature, contact time, and relative humidity. (DHS/EPA 2009.)

Quality Assurance. An integrated system of activities involving planning, quality control, quality assessment, reporting, and quality improvement to ensure that a product or service meets defined standards of quality with a stated level of confidence. (EPA 2002.) For the purposes of this document, the term refers to the quality of data. 
Quality Control. The overall system of technical activities the purpose of which is to measure and control the quality of a product or service so that it meets the needs of its users. The aim is to provide quality that is satisfactory, adequate, dependable, and economical. (EPA 2002.) For the purposes of this document, the term refers to the quality of data.

Random sampling. Environmental sampling in which sampling locations are chosen with some degree of randomness. Such sampling is based on the idea that choosing locations at random ensures both representative and reproducible results.

Recommissioning. The process of testing and verifying that equipment is fully functional and may be returned to normal use. (DHS/EPA 2009.)

Recovery. In the short term, recovery is an extension of the response phase in which basic services and functions are restored. In the long term, recovery is a restoration of both the personal lives of individuals and the livelihood of the community. Recovery can include the development, coordination, and execution of service- and site-restoration plans; the reconstitution of government operations and services; programs to provide housing and to promote restoration; long-term care and treatment of affected individuals; and additional measures for social, environmental, and economic restoration. (DHS, 2008) Recovery generally includes actions taken after Notification and First Response activities have been initiated (see six-phase of response and recovery Figure 1-3). (DHS/EPA 2009.)

Remediation. The processes of characterizing, decontaminating, and clearing a contaminated site or items, including disposal of wastes. Generally occurs after the First-Response Phase and before the Restoration Phase (see six-phase Figure 1-3). A synonym for cleanup. Remediation is not the same as "remedial action," which is defined below. (DHS/EPA 2009.)

Remedial action. Long-term response actions that permanently and significantly reduce the dangers associated with releases or threats of releases of hazardous substances that are serious, but not immediately life threatening. If applicable and with available resources, remedial action may be performed in accordance with the National Oil and Hazardous Substances Pollution Contingency Plan and under the authority of CERCLA. See 40 CFR 300.430 and .435 .

Remediation Action Plan (RAP). A formal plan developed for the Unified Command that describes actions to remove, reduce, or eliminate contaminants at a site. The RAP is developed at the beginning of the Decontamination Phase. In the context of this document, the RAP is a written, incident-specific plan that includes details on (1) what facilities and areas need to be decontaminated; (2) what materials and structural components are to be decontaminated in situ, or removed for treatment and either reuse or disposed; (3) to what extent removed items will be decontaminated prior to disposal, and how and where such items will be decontaminated and disposed; (4) the decontamination technologies to be used; (5) the personnel and teams responsible for decontamination tasks; and (6) the types of wastes that will be produced and how they will be treated or disposed.

Removal action. Response actions taken to address releases or threatened releases of hazardous substances, pollutants, or contaminants that require a prompt response. If applicable and with available resources, removal action may be performed in accordance with the National Oil and Hazardous Substances Pollution Contingency Plan and under the authority of CERCLA. See 40 CFR 300.415.

Renovation. The process of reconstructing or refurbishing a facility subsequent to clearance but before allowing occupants to return. (DHS/EPA 2009.)

Reoccupancy. The process of renovating a facility, monitoring the workers performing the renovation, and deciding when to permit reoccupation. Generally occurs after a facility has been cleared but before occupants are allowed to return. (See six-phase Figure 1-3.) (DHS/EPA 2009.)

Residual contamination. The detectable amount of contaminant remaining, if any, after an area has been decontaminated. (DHS/EPA 2009.)

Response. Includes immediate actions to save lives, protect property and the environment, and meet basic human needs. Response also includes the execution of emergency plans and actions to support short-term recovery. (DHS, 2008)

Restoration. The process of renovating or refurbishing a facility, bringing it back to an unimpaired or improved condition, and making a decision to allow the occupants to return. Generally occurs after the Clearance Phase but before occupants are allowed to return. (See six-phase Figure 1-3.) (DHS/EPA 2009.)

Risk. The probability that a substance or situation will produce harm under specified conditions. Risk is a combination of two factors: (1) the probability that an adverse event will occur (such as a specific disease or type of 
injury), and (2) the consequences of the adverse event. (Presidential and Congressional Commission on Risk Assessment and Risk Management, 1997.)

Risk communication. A field in the area of environmental health through which a communicator hopes to provide the receiver with information about the expected type and magnitude of an outcome. Typically, risk communication is a discussion about an adverse outcome and the probability of that outcome occurring (Reynolds 2002).

Risk assessment. Gathering and analyzing information on what potential harm a situation poses and the likelihood that people or the environment will be harmed. (The Presidential and Congressional Commission on Risk Assessment and Risk Management, 1997.) A methodological approach to estimate the potential human or environmental risk of a substance that uses hazard identification, dose-response, exposure assessment, and risk characterization. (DHS/EPA 2009.)

Risk management. The process of identifying, evaluating, selecting, and implementing actions to reduce risk to human health and to ecosystems. The goal of risk management is scientifically sound, cost-effective, integrated actions that reduce or prevent risk while taking into account social, cultural, ethical, and legal considerations. (Presidential and Congressional Commission on Risk Assessment and Risk Management, 1997)

Robert T. Stafford Disaster Relief and Emergency Assistance Act (Stafford Act 2007). This Act (Public Law 100-707), which was signed into law on November 23, 1988, amends the Disaster Relief Act of 1974, PL 93-288. It created the system in place today by which a Presidential disaster declaration of an emergency triggers financial and physical assistance through the Federal Emergency Management Agency (FEMA). The Act gives FEMA the responsibility for coordinating government-wide relief efforts. The Federal response plan it implements includes the contributions of 28 Federal agencies and nongovernmental organizations (such as the Red Cross). Thus, the Act constitutes the statutory authority for most Federal disaster response activities especially as they pertain to FEMA and FEMA programs. Its purpose is to "provide an orderly and continuing means of assistance by the Federal Government to State and local governments in carrying out responsibilities to alleviate the suffering and damage which result from ... disasters."

Sampling and Analysis Plan (SAP). A plan that describes the methods, strategies, and analyses for characterization sampling, verification sampling (if applicable), and clearance sampling for a contaminated site. (DHS/EPA 2009.)

Sampling unit. A sub-section of a sampling zone, such as walls, floors, and furniture surfaces, which can be sampled and evaluated collectively. (DHS/EPA 2009.)

Sampling zone. A discrete section of a contaminated site in which environmental sampling is conducted. (DHS/EPA 2009.)

Screening analysis. The process of analyzing environmental samples by non-laboratory personnel, equipment, or facilities is considered to constitute "first-pass," "screening," or "field" testing. There is no recognized, definitive, reliable field test for biological agents. Compare with Laboratory Response Network and Culturing, above.

Screening environmental sampling. The initial collection of a limited number of environmental samples for the purpose of determining the identity, concentration, viability, and approximate location of contamination by a purported biological agent, and for informing the IC/UC for decision-making on appropriate public health and subsequent remediation actions. (DHS/EPA 2009.)

Source reduction. The process of removing certain items and/or materials from a contaminated site for further treatment and reuse or disposal, and of cleaning the remaining site and item surfaces prior to the main decontamination activity. The goals of this process are to (1) reduce the number of items and/or materials present, (2) ensure that any matter that might inhibit decontamination is removed, and (3) generally reduce the levels of contaminant that may be present. (DHS/EPA 2009.)

Spores. The thick-walled, resting cells produced by some bacteria and fungi that are capable of surviving in unfavorable environments and are more resistant to antimicrobial agents than vegetative cells. (Block 2001.)

Staging area. A safety zone established at a hazardous-substance release site that is designated as the support zone (or cold zone). It is the area of the site that is free from contamination and that may be safely used as a planning and staging area. (EPA 2004.)

Sterilant. A substance that destroys all microorganisms on inanimate surfaces, including vegetative and spore forms of bacteria and fungi, as well as viruses. Sterilants registered by the EPA must be effective on both porous and nonporous surfaces. (DHS/EPA 2009.)

Sterilization. A process intended to remove or destroy all viable forms of microbial life, including bacterial spores, to achieve an acceptable sterility assurance level. (AAMI 1995.) 
Subject-matter expert (SME). An individual who is a technical expert in a specific area or in performing a specialized job, task, or skill.

Support zone. Area of a site that is free from contamination and that may be safely used as a planning and staging area. Also called the Cold Zone. (DHS/EPA 2009.)

Swab sampling. Collecting environmental samples from nonporous surfaces by rubbing a small area with a wet, absorptive material attached to the end of a wood or plastic stick. (DHS/EPA 2009.)

Targeted sampling. Sampling during clearance at specific locations that were found to be contaminated during the Characterization Phase. A special case of judgmental sampling. The term has been used differently in different reports.

Technical Working Group (TWG). A group of technical experts assembled by the Incident or Unified Command to provide guidance during the planning and implementation of cleanup operations. (Carlsen et al., 2005.)

Unified Command. An application of the Incident Command System used when there is more than one agency with incident jurisdiction or when incidents cross jurisdictions. Agencies work together through the designated members of the Unified Command to establish their designated Incident Commander at a single Incident Command Post and to establish a common set of objectives and strategies and a single Incident Action Plan. (DHS, 2008)

Vacuum sampling. Collecting environmental samples by suctioning porous or nonporous surfaces with a vacuum cleaner that contains a high-efficiency particulate air (HEPA) filter. (DHS/EPA 2009.)

Vapor-phase hydrogen peroxide (VPHP). A decontamination technology that involves flash vaporization of an aqueous peroxide mixture.

Vegetative cells. Microbial cells in the growth and reproductive phase of a growth cycle. (Block 2001.)

Verification sampling. Use of chemical indicators, biological indicators, or both to document that fumigation has been successful. (DHS/EPA 2009.)

Warm zone. The transition area between the Exclusion and Support Zones. This area is where responders enter and exit the Exclusion Zone and where decontamination activities take place. (EPA, 2004) Also called the contamination reduction zone per HAZWOPER.

Weapon of mass destruction (WMD). As defined in Title 18, U.S.C. $§ 2332 \mathrm{a}$ : (1) any explosive, incendiary, or poison gas, bomb, grenade, rocket having a propellant charge of more than 4 ounces, or missile having an explosive or incendiary charge of more the one-quarter ounce, or mine or similar device; (2) any weapon that is designed or intended to cause death or serious bodily injury through the release, dissemination, or impact of toxic or poisonous chemicals or the precursors; (3) any weapon involving a disease organism; or (4) any weapon that is designed to release radiation or radioactivity at a level dangerous to human life.

Wipe sampling. Collecting environmental surface samples by rubbing a thin, flat piece of wet, absorptive material on a small area of a non-porous surface. (DHS/EPA 2009.) 


\section{Glossary References}

AAMI (1995), Association for Advancement of Medical Instrumentation, Standards and Recommended Practices. Sterilization, Part I. Sterilization of Health Care Facilities;

Sterilization, Part 2. Hospital Equipment and Industrial Process Control, Arlington, VA.

Block, S. (Ed.) (2001), Disinfection, Sterilization, and Preservation, $5^{\text {th }}$ Edition (Lippincott, Williams, and Wilkins, Philadelphia, PA).

Carlsen, T., L. Berg, D. MacQueen, W. Wilson, G. Brown, S. Mancieri, R. Bishop, K. Folks, R. Kirvel, and V. Vyas (September, 2005), Restoration Plan for Major International Airports After a Bioterrorist Attack, Lawrence Livermore National Laboratory, Livermore, CA, UCRL-TR210178.

CDC (2005), Centers for Disease Control and Prevention, The Laboratory Response Network; available at $<\underline{\mathrm{http}}: / /$ www.bt.cdc.gov/lrn/ $>$.

DHHS (1994), U.S. Department of Health and Human Services, Agency for Toxic Substances and Disease Registry, Environmental Data Needed for Public Health Assessments; A Guidance Manual; available at <http://www.atsdr.cdc.gov/ednpha.html\#ambient>.

DHS (December, 2008), Department of Homeland Security, National Response Framework; available at $<$ http://www.fema.gov/emergency/nrf/ $>$.

DHS/EPA (2009), U. S. Department of Homeland Security and U.S. Environmental Protection Agency, Remediation Guidance for Major Airports after a Bioterrorist Attack.

EPA (2002), U.S. Environmental Protection Agency, Health Effects Notebook, Health Effects Glossary; available at $<$ http://www.epa.gov/ttnatw01/hlthef/hapsec1.html $>$.

EPA (2002), U.S. Environmental Protection Agency, Health Effects Glossary, Air Toxics; available at $<\underline{\text { http: } / / \text { www.epa.gov/ttn/atw/hapsec1.html }>\text {. }}$

EPA (2004), U.S. Environmental Protection Agency, Safety Zones, Emergency Response

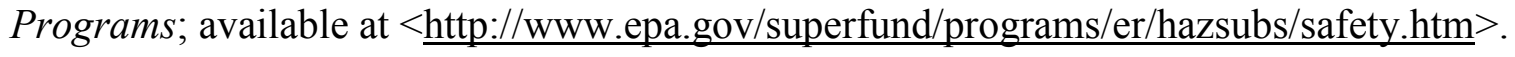

EPA/IRIS (2005), U.S. Environmental Protection Agency, Integrated Risk Information System, Integrated Risk Information System (IRIS) Glossary, revised December 2005, accessed

December 2006; available at $<$ http://www.epa.gov/iris/gloss8.htm $>$.

Fitch, J. P., Raber, E., and D. R. Imbro (2003), “Technology Challenges in Responding to Biological or Chemical Attacks in the Civilian Sector," Science 302(5649), 1350-54; see also Fitch, J. P. et al., Proc. IEEE 90(11), 1708 (2002).

Johnson, B. (2003), "OSHA Infectious Dose White Paper," App. Biosafety 8(4), 160-165.

NIMS (2008), National Incident Management System, document available at: <http://www.fema.gov/pdf/emergency/nims/NIMS_core.pdf>.

NRT (updated July, 2005), National Response Team, Technical Assistance for Anthrax Response, Interim-Final Draft; available at http://www.nrt.org/production/NRT/NRTWeb.nsf/PagesByLevelCat/Level2TA?Opendocument. 


\section{Glossary}

Presidential/Congressional Commission on Risk Assessment and Risk Management (1997), Final Report, Volume 1, Framework for Environmental Health Risk Management; Volume 2, Risk Assessment and Risk Management in Regulatory Decision-Making, Presidential/Congressional Commission on Risk Assessment and Risk Management, Washington, D.C.; available at $<$ http://www.riskworld.com/Nreports/nr7me001.htm $>$.

Proceedings from the 2nd Civilian-Military Anthrax Response Technical Workshop (April 1314, 2004), Current State of Federal Governmental Capabilities and Positions; available at $<$ http://www.wetp.org/wetp/public/hasl_get_blob.cfm?ID=741>.

Reynolds, B. (2002), Crisis and Emergency Risk Communication, Centers for Disease Control and Prevention; available at $<$ http://www.maxwell.af.mil/au/awc/awcgate/cdc/cerc book.pdf $>$. 